Memoria presentada por Teresa Ros Dosdá para optar al grado de doctora

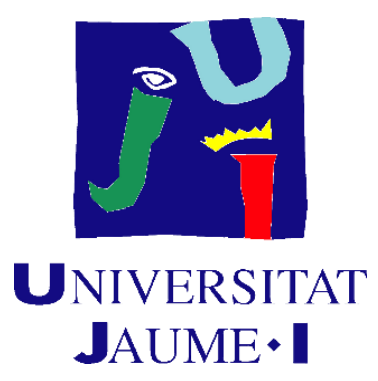

Programa de Doctorado en Tecnologías Industriales y Materiales

Escuela de Doctorado de la Universitat Jaume I

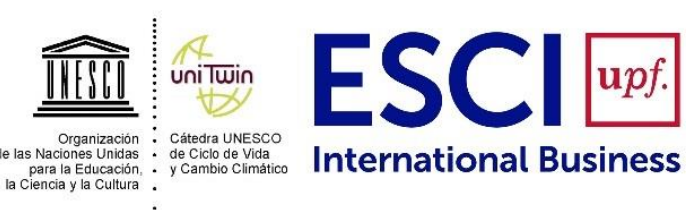

Cátedra UNESCO de Ciclo de Vida y Cambio Climático

Escuela Superior de Comercio Internacional - Universitat Pompeu Fabra

Doctoranda:

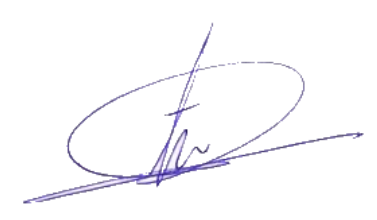

Teresa Ros Dosdá

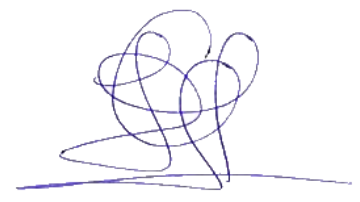

Dr. Eliseo Monfort Gimeno
PERE

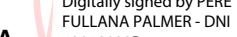 43018038B
DN: $C=E S$, Sn=FULLANA $\mathrm{DN}: \mathrm{C}=\mathrm{ES}, \mathrm{Sn}=\mathrm{FULLANA}$
PALMER, givenName $=P E R E$ PALMER, givenName $=$ PERE,
serialNumber $=$ IDCES-43018 038B, $\mathrm{Cn}=$ PERE FULLANA PALMER - DNI 43018038B
Date: 2019.11.04 13:01:19
DN 43018038B $+01^{\prime} 00^{\prime}$

Dr. Pere Fullana i

Palmer

Castelló de la Plana, Noviembre 2019 



\section{Este estudio ha sido financiado a por:}

- El Instituto de la Pequeña y Mediana Empresa de la Región de Valencia (IMPIVA), España, a través de los II Planes de Competitividad Sectorial 2011 Acción 4: Desarrollo de Mercados (Fondo Europeo de Desarrollo Regional (FEDER). Referencia del proyecto: IMPCDB/2011/28.

- $\quad$ El Instituto de Valencia para la Competitividad Empresarial (IVACE) y el Fondo Europeo de Desarrollo Regional (FEDER). Referencias de los proyectos: IMDEEA/2014/12, IMAMCA/2015/1, IMDEEA/2015/11 e IMDEEA/2018/12.

- La Comisión Europea a través del programa LIFE + Política Ambiental y Gobernanza. Referencia del proyecto: LIFE12 ENV/ES/230-LIFE CERAM.

- Climate KIC a través del Programa Pioneer into Practice. Referencia del proyecto: AREP0047_2014-3.4-174_P062-01

- Diputación de Castellón 

A mis padres, Mayte y Alberto,

y a mi hijo Alberto 



\section{AGRADECIMIENTOS}

¡Qué bonito es rodearse de gente buena!

Me siento muy afortunada por haber estado, y seguir estando, rodeada de personas buenas que han sido fundamentales para que, de forma directa o indirecta, este trabajo saliera adelante; buenas en todos los sentidos, científico-técnico y de corazón.

Las principales personas responsables de empujarme a la piscina con este "proyectito" han sido Eliseo, Pere e Irina. A ellos tres quiero darles mi agradecimiento especial por la ayuda, entusiasmo y apoyo recibido en todo el proceso.

Eliseo: gracias por haber confiado en mí y por haberme guiado con cercanía en todo el trabajo, por la dedicación prestada, seguimiento, tus sabios consejos, por llevarme "por el buen camino" y por motivarme en cada reunión con las palabras que necesitaba oír. Ya me conoces como si fueras mi "padre tecnológico". Gracias por las discusiones, reflexiones, paciencia y por mostrarme perspectivas diferentes.

Pere: gracias por haberme metido el "gusanillo de la tesis", aunque a veces, durante estos últimos meses, no te voy a engañar, pensé que ese gusanillo se había convertido en una Taenia ipor lo menos!; pero te lo agradezco de todo corazón. No sólo por animarme a hacer la tesis, también por tus consejos, asesoramiento, visión, ayuda en este trabajo, y en otros, y además, por haberme acogido en tu equipo en Barcelona para enseñarme la base de lo que sé en este campo.

Irina: gracias por haberme dado la oportunidad de formar parte de la Colla Ecologista, por haber creído en mí, haberme dado siempre libertad, respaldarme y ayudarme siempre en todo. Todo empezó con "els potets", ¿te acuerdas? Bueno, pues al final, no lo hicimos nada mal!! Y de ahí, surgió una bonita y larga amistad con los Análisis de Ciclo de Vida. Gracias por acompañarme en todo el camino; has sido mi pilar, modelo de trabajo, esfuerzo y dedicación.

Muchas gracias al ITC por brindarme la posibilidad de realizar y presentar este trabajo de tesis y sobre todo por todas las facilidades y medios sin los que, sin duda, la realización de un trabajo así no hubiera sido posible.

Asimismo, deseo agradecer a ASCER el haber impulsado una parte importante de los estudios incluidos en esta tesis y en especial a Victoria Zaera y a todas aquellas empresas que nos cedido sus datos para realizar la parte experimental de esta tesis, y sin cuya colaboración, hubiera resultado imposible. Esta tesis pretende tener una aplicación industrial, así que espero sea de utilidad.

Por supuesto, gracias a la Colla Ecologista, quienes han sustentado mi moral con su apoyo y me han dado ímpetu para seguir adelante. Salva, Tica y Raúl, por estar siempre dispuestos a ayudarme, darme apoyo y buenos consejos técnicos y mucha serenidad: "tranquila, eso nos ha pasado a todos", "tranquila, es normal", "tranquila, luego ya no te acordarás". A Alicia por las risas, cariño y por acompañarme de cerca en estos últimos meses. Y por supuesto, al resto del equipo del área, por sus ánimos y disposición cuando los he necesitado: Filipe, Clara, Fernando, Ana M., Ana L., Salva F., Ma Jesús, Aroa e Iván. Además, no me puedo olvidar de David Lores, por su infinita paciencia y ayuda en la maquetación de este trabajo. También al resto de personas del ITC 
que, de alguna manera, han estado involucrados directa o indirectamente en parte de este trabajo: Laura, Jorge, Javier, Alfredo, Dori...

Como he dicho antes, mi estancia en Barcelona fue clave para llegar hasta aquí. Especialmente quiero darle las gracias a Cristina, quien me ha acompañado directa e indirectamente todo este tiempo, y siempre le estaré agradecida. A Gabriela y a Alba, por su colaboración, dedicación y generosidad con sus conocimientos y a Marina, Marta y Pilar por hacerme sentir como en casa.

Y aunque mi estancia en ENEA fue corta, también me acuerdo de los que me ayudaron a focalizar parte del trabajo y a sentirme como una más: Caterina, Paolo, Christian y Piero.

Y por último a los míos, las personas más importantes de mi vida. A mi hijo Alberto, quien vino al mundo durante este proceso y se ha convertido en el centro de mi vida. Sus risas y sonrisas han trivializado los problemas y me han dado la fuerza necesaria para seguir adelante. Álex, esto no lo podría haber hecho sin ti. Muchas gracias por tu apoyo incondicional, por tu paciencia, por tus ánimos y por tu ayuda diaria.

Y por supuesto, los otros responsables de esta tesis son mis padres Mayte y Alberto: millones de gracias por todo el esfuerzo y confianza depositada en mí, por haberme dado la educación que tengo para haber podido llegar hasta aquí y por haberme hecho sentir siempre capaz en todo. A mi hermana Claudia, por estar ahí, ayudarme y comprenderme. Me siento muy afortunada de tener en casa un ejemplo de entusiasmo por las cosas, de buen sentido del humor, carácter crítico, de trabajo, de esfuerzo y de superación.

Y como esto ya se va pareciendo a una carta de agradecimientos por mi vida mientras espero en el corredor de la muerte, sólo me queda disculparme y mostrar mi agradecimiento a aquellas personas que hayan colaborado en la realización del presente trabajo y que haya olvidado nombrar. 


\section{RESUMEN}

La fabricación de baldosas cerámicas es una actividad regulada e incluida en la Directiva de Emisiones Industriales (Directiva 2010/75/UE) y en la Directiva del régimen de comercio de derechos de emisión de gases con efecto invernadero (Directiva 2003/87/CE). El sector español de fabricación de baldosas cerámicas es líder en Europa, tanto en los niveles de producción como de exportación. No obstante, en los próximos años deberá enfentarse a importantes retos para poder mantener su posición de liderazgo.

En este trabajo, se han identificado tres retos ambientales que, a juicio de la doctoranda, serán determinantes para la estabilidad, e incluso supervivencia, del sector de las baldosas cerámicas en Europa, si no se abordan estrategias adecuadas. Concretamente, los retos identificados son: i) comunicar de forma eficiente las características ambientales de las baldosas; ii) obtener argumentos ambientales para aumentar su competitividad; iii) establecer medidas para mitigar el cambio climático.

El presente documento se ha estructurado en base a estos tres retos identificados. En el mismo, se han definido estrategias y desarrollado herramientas relacionadas el ciclo de vida de las baldosas cerámicos con el fin de acometer cada uno de estos retos.

En la figura R1 se muestra un resumen gráfico del planteamiento general de esta tesis doctoral.

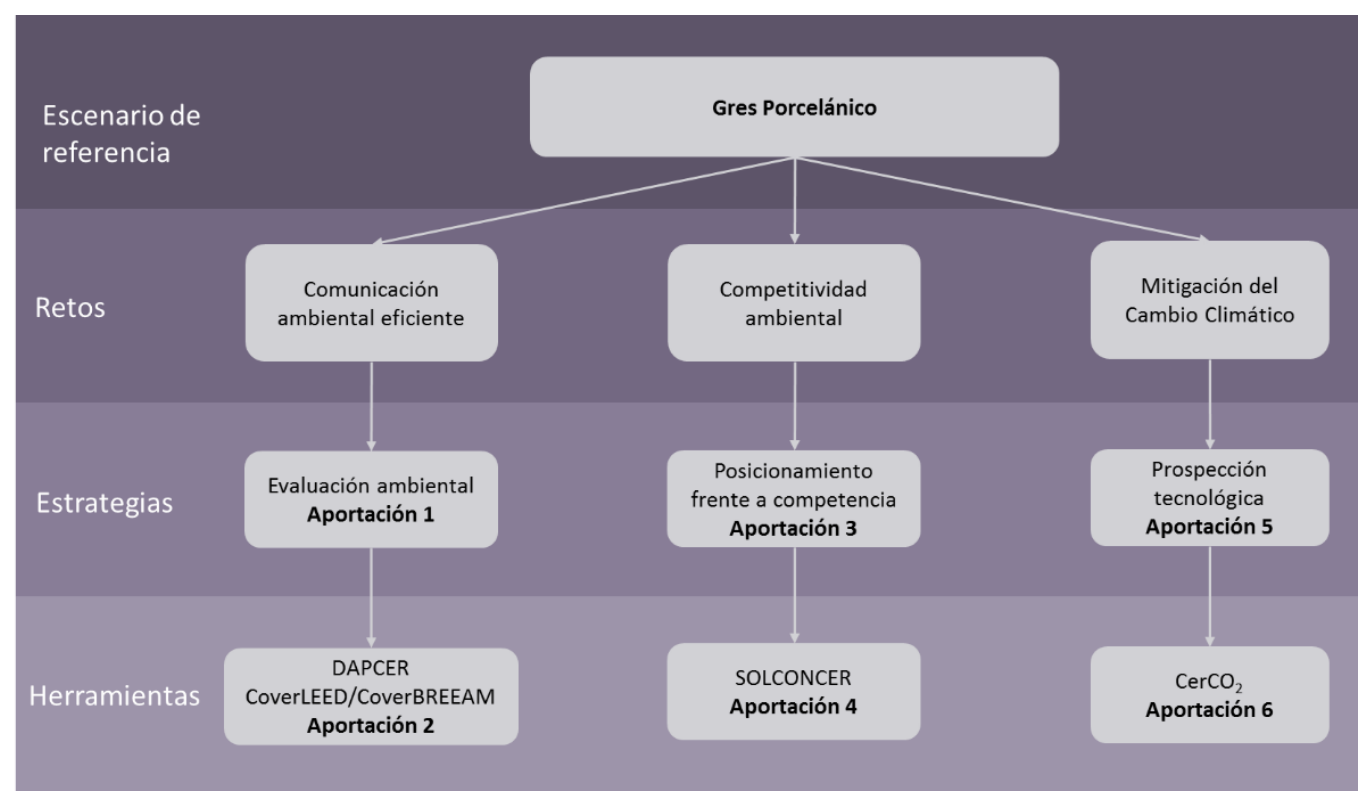

Figura R1. Planteamiento global del trabajo de tesis

La metodología utilizada en el presente trabajo se ha basado en establecer un escenario de referencia como punto de partida, concretamente el ciclo de vida de las baldosas de gres porcelánico, a partir del cual, se han identificado parámetros que han resultado clave para determinar los escenarios legislativos, tecnológicos y de innovación explorados en cada una de 
las estrategias y herramientas del ciclo de vida. Este escenario de referencia se ha simulado mediante un modelo de Análisis de Ciclo de Vida (ACV) en el software GaBi, al cual se le ha dotado de la flexibilidad necesaria para contemplar todas las casuísticas consideradas en los análisis de escenarios de forma consistente a lo largo del proyecto.

El enfoque global e integrado que ofrece la perspectiva del ciclo de vida es fundamental para encontrar soluciones de compromiso y consenso científico, que ayuden en la toma de decisiones para el desarrollo de políticas y estrategias ambientales verdaderamente efectivas, tanto a nivel sectorial como individual.

Como resultado, se ha encontrado que la etapa de fabricación de las baldosas es la que contiene mayor número de parámetros clave, siendo los más significativos la cantidad de materias primas del soporte (parámetro directamente relacionada con el espesor), el consumo de energía y la cantidad y tipo de esmalte.

Las estrategias y las herramientas desarrolladas para afrontar cada reto han sido:

Reto de comunicación eficiente:

Se han planteado las Declaraciones Ambientales de Producto (DAP) como medio para responder a las peticiones de información ambiental, debido a la cantidad y tipo de información objetiva que contienen, además, son instrumentos de comunicación reconocidos y estandarizados (ISO 14020, 2000; ISO 14025, 2006). El desarrollo de un ACV del gres porcelánico y de sus variantes (en base al espesor, cantidad de esmalte y tratamientos mecánicos superficiales) ha permitido cuantificar la significancia ambiental de las variaciones de baldosas cerámicas fabricadas por un productor, así como estimar el número de DAPs necesarias para cubrir todas las variantes de un mismo tipo de producto, dependiendo del programa de DAPs aplicado.

Se ha desarrollado, testeado y aplicado diferentes herramientas: DAPCER, que permite obtener informes de ACV y DAPs disminuyendo plazos de ejecución y costes económicos, y las herramientas CoverLEED y CoverBREEAM by ITC, orientadas al uso de las baldosas cerámicas en construcciones sostenibles certificadas por LEED $^{\circledR}$ y BREEAM $^{\circledR}$, respectivamente.

Reto de competitividad

Se han tratado mediante un estudio de ACV comparativo, con un alcance de cuna a cuna, seis sistemas de suelos con distintos recubrimientos de interiores, a partir de la información contenida en las DAPs y modelizando el resto de las etapas, bajo los mismos escenarios en la etapa de uso y aplicando una transición progresiva hacia la Economía Circular. Este análisis ha permitido posicionar a las baldosas cerámicas desde el punto de vista ambiental, así como obtener argumentos que puedan ser utilizados con fines comerciales. Los resultados han demostrado que, los sistemas de suelos con recubrimientos inorgánicos (gres porcelánico y piedra natural) son los que presentan mejor desempeño ambiental, pues aunque los impactos son elevados durante la etapa de fabricación, se compensan por la elevada vida útil y fácil mantenimiento. Por el contrario, los sistemas de suelos con moqueta sintética son los que 
presentan los impactos más elevados, tanto por los impactos generados durante la fabricación, como por las consecuencias de su corta vida útil y elevados requerimientos para su mantenimiento.

Para este reto, se ha puesto a disposición de empresas y prescriptores la herramienta SolconCer, que permite la caracterización de soluciones constructivas con diferentes recubrimientos mediante su aplicación online con acceso gratuito.

\section{Reto de cambio climático}

Se han evaluado diecisiete alternativas y veinticinco escenarios tecnológicos orientados a reducir las emisiones de $\mathrm{CO}_{2}$ en el ciclo de vida de las baldosas cerámicas, de acuerdo con los objetivos establecidos por la UE para 2020 y 2050 (COM(2011)112 final). Este estudio ha permitido: i) estimar el grado de innovación tecnológica requerido; ii) definir y focalizar estrategias y iii) diseñar las líneas de desarrollo tecnológico que se deben implementar en el sector de fabricación de baldosas cerámicas en los próximos años. Los resultados han demostrado que, a mayor alcance del ciclo de vida considerado, mayores innovaciones se requieren para reducir las emisiones de gases de efecto invernadero (GEI) del sector. Estas innovaciones deben contemplar la implementación conjunta de medidas de vanguardia, tanto endógenas como exógenas, en el sector cerámico. Concretamente, se ha determinado que para 2050 se requerirán cambios en el diseño del producto (reducción a la mitad del espesor del soporte, de la cantidad de esmalte y/o del contenido en frita), así como la implantación de tecnologías de elevada eficiencia energética en secaderos y hornos que funcionen, al menos, con la mitad de la energía procedente de fuentes renovables.

Se ha desarrollado la herramienta $\mathrm{CerCO}_{2}$ que permite a las empresas del sector hacer ejercicios de prospección de las emisiones de GEl de diferentes escenarios tecnológicos a partir de su situación actual.

En definitiva, se confirma que es posible aplicar el ACV en el sector de las baldosas cerámicas para abordar los retos de comunicación ambiental, competitividad y cambio climático mediante la evaluación de tendencias y prospecciones legislativas, tecnológicas y de innovación de una forma rigurosa, representativa y consistente. No obstante, la aplicación de la metodología de ACV y la interpretación de los resultados requieren un alto grado de especialización, por lo que es importante dotar a las empresas del sector cerámico de herramientas de fácil uso y acceso, para poder posicionarse y autoevaluarse frente a los diferentes retos expuestos. 



\section{RESUM}

La fabricació de taulells ceràmics és una activitat regulada i inclosa en la Directiva d'Emissions Industrials (Directiva 2010/75/UE) i en la Directiva del règim de comerç de drets d'emissió de gasos amb efecte hivernacle (Directiva 2003/87/CE). El sector espanyol de fabricació de taulells ceràmics és capdavantera a Europa, tant en els nivells de producció com d'exportació. No obstant això, en els pròxims anys caldrà enfrontar-se a importants reptes per a poder mantenir la seua posició de lideratge.

En aquest treball, s'han identificat tres reptes ambientals que, segons el parer de la doctoranda, seran determinants per a l'estabilitat, i fins i tot supervivencia, del sector dels taulells ceràmics a Europa, si no s'aborden estratègies adequades. Concretament, els reptes identificats són: i) comunicar de forma eficient les característiques ambientals dels taulells; ii) obtenir arguments ambientals per a augmentar la seua competitivitat; iii) establir mesures per a mitigar el canvi climàtic.

El present document s'ha estructurat sobre la base d'aquests tres reptes identificats. En el mateix, $s^{\prime}$ han definit estratègies $i$ desenvolupat eines relacionades el cicle de vida dels taulells ceràmics amb la finalitat de dur a terme cadascun d'aquests reptes.

En la figura R1 es mostra un resum gràfic del plantejament general d'aquesta tesi doctoral.

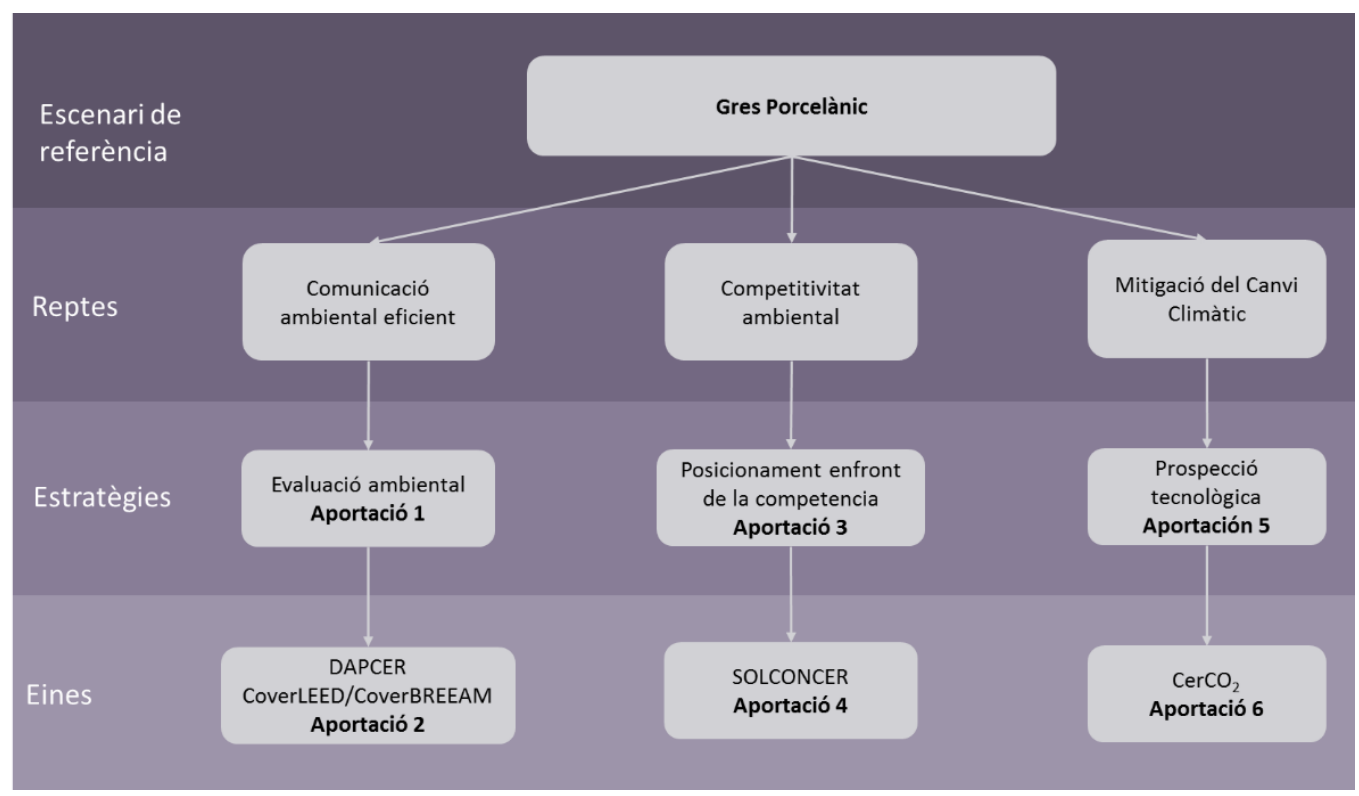

Figura R1. Plantejament global del treball de tesi

La metodologia utilitzada en el present treball s'ha basat en establir un escenari de referència com a punt de partida, concretament el cicle de vida dels taulells de gres porcelànic, a partir del qual, $s^{\prime}$ han identificat paràmetres que han resultat clau per a determinar els escenaris legislatius, tecnològics i d'innovació explorats en cadascuna de les estratègies i eines del cicle de vida. Aquest escenari de referència s'ha simulat mitjançant un model d'Anàlisi de Cicle de Vida (ACV) en el 
programari $\mathrm{GaBi}$, al qual se li ha dotat de la flexibilitat necessària per a contemplar totes les casuístiques considerades en les anàlisis d'escenaris de forma consistent al llarg del projecte.

L'enfocament global i integrat que ofereix la perspectiva del cicle de vida és fonamental per a trobar solucions de compromís i consens científic, que ajuden en la presa de decisions per al desenvolupament de polítiques i estratègies ambientals efectives, tant a nivell sectorial com a individual.

Com a resultat, s'ha trobat que l'etapa de fabricació dels taulells és la que conté major nombre de paràmetres clau, sent els més significatius la quantitat de matèries primeres del suport (paràmetre directament relacionada amb l'espessor), el consum d'energia i la quantitat i tipus d'esmalt.

Les estratègies i les eines desenvolupades per a afrontar cada repte han sigut:

Repte de comunicació eficient:

S'han plantejat les Declaracions Ambientals de Producte (DAP) com a mitjà per a respondre a les peticions d'informació ambiental, per la quantitat i tipus d'informació objectiva que contenen, a més, són instruments de comunicació reconeguts i estandarditzats (ISO 14020, 2000; ISO 14025, 2006). El desenvolupament d'un ACV del gres porcelànic i de les seues variants (definides per l'espessor, quantitat d'esmalt i tractaments mecànics superficials) ha permés quantificar la significança ambiental de estes variacions de taulells ceràmics fabricats per un productor, així com estimar el nombre de DAPs necessàries per a cobrir totes les variants d'un mateix tipus de producte, depenent del programa de DAPs aplicat.

S'ha desenvolupat, comprovat i aplicat diferents eines: DAPCER, que permet obtindre informes d'ACV i DAPs disminuint terminis d'execució i costos economics; i les eines CoverLEED i CoverBREEAM by ITC, orientades a l'ús dels taulells ceràmics en construccions sostenibles certificades per LEED $\circledast$ i BREEAM $尺$, respectivament.

\section{Repte de competitivitat}

S'han tractat mitjançant un estudi d'ACV comparatiu, amb un abast de bressol a bressol, sis sistemes de sòls amb diferents recobriments d'interiors, a partir de la informació continguda en les DAPs, i modelitzant la resta de les etapes sota els mateixos escenaris en l'etapa d'ús i aplicant una transició progressiva cap a l'Economia Circular. Aquesta anàlisi ha permés posicionar als taulells ceràmics des del punt de vista ambiental, així com obtenir arguments que puguen ser utilitzats amb finalitats comercials. Els resultats han demostrat que, els sistemes de sòls amb recobriments inorgànics (gres porcelànic i pedra natural) són els que presenten millor comportament ambiental, doncs encara que els impactes són elevats durant l'etapa de fabricació, es compensen per l'elevada vida útil i fàcil manteniment. Per contra, els sistemes de sòls amb moqueta sintètica són els que presenten els impactes més elevats, tant pels impactes generats durant la fabricació, com per les conseqüències de la seua curta vida útil i elevats requeriments per al seu manteniment.

Per a aquest repte, s'ha posat a disposició d'empreses i prescriptors l'eina SolconCer, que permet la caracterització de solucions constructives amb diferents recobriments mitjançant la seua aplicació en línea amb accés gratuiit. 
Repte de canvi climàtic

S'han avaluat disset alternatives i vint-i-cinc escenaris tecnològics orientats a reduir les emissions de $\mathrm{CO}_{2}$ en el cicle de vida dels taulells ceràmics d'acord amb els objectius establits per la UE per a 2020 i 2050 (COM(2011)112 final). Aquest estudi ha permès: i) estimar el grau d'innovació tecnològica requerit; ii) definir i focalitzar estratègies i iii) dissenyar les línies de desenvolupament tecnològic que s'han d'implementar en el sector de fabricació de taulells ceràmics en els pròxims anys. Els resultats han demostrat que, a major abast del cicle de vida considerat, majors innovacions es requereixen per a reduir les emissions de gasos d'efecte d'hivernacle (GEH) del sector. Aquestes innovacions han de contemplar la implementació conjunta de mesures d'avantguarda, tant endògenes com a exògenes, en el sector ceràmic. Concretament, s'ha determinat que per al 2050 es requeriran canvis en el disseny del producte (reducció a la meitat de l'espessor del suport, de la quantitat d'esmalt i/o del contingut en frites), així com la implantació de tecnologies d'elevada eficiència energètica en assecadors i forns que funcionen, almenys, amb la meitat de l'energia procedent de fonts renovables.

S'ha desenvolupat l'eina $\mathrm{CerCO}_{2}$ que permet a les empreses del sector fer exercicis de prospecció de les emissions de GEH de diferents escenaris tecnològics a partir de la seua situació actual.

En definitiva, es confirma que és possible aplicar I'ACV en el sector dels taulells ceràmics per a abordar els reptes de comunicació ambiental, competitivitat i canvi climàtic mitjançant l'avaluació de tendències i prospeccions legislatives, tecnològiques i d'innovació d'una forma rigorosa, representativa i consistent. No obstant això, l'aplicació de la metodologia d'ACV i la interpretació dels resultats requereixen un alt grau d'especialització, per la qual cosa és important dotar a les empreses del sector ceràmic d'eines de fàcil ús i accés, per a poder posicionar-se i autoevaluarse enfront dels diferents reptes exposats. 



\section{ABSTRACT}

The manufacturing of ceramic tiles is an activity regulated and included in the Industrial Emissions Directive (Directive 2010/75/EU) and in the Directive on the greenhouse gas emission allowance trading scheme (Directive 2003/87/EC). The Spanish ceramic tile manufacturing sector is the leader in Europe, both in terms of production levels and exports. However, in the coming years, it will have to face major challenges in order to maintain its leadership position.

In this work, three environmental challenges have been identified which, in the doctoral candidate's opinion, will be decisive for the stability, and even survival, of the ceramic tile sector in Europe if adequate strategies are not addressed. Specifically, the challenges identified are: i) to efficiently communicate the environmental characteristics of tiles; ii) to gather some environmental arguments to increase their competitiveness; iii) to establish measures to mitigate climate change.

The present document has been structured on the basis of these three identified challenges. Here, strategies have been defined and tools have been developed relating to the life cycle of ceramic tiles in order to address each of these challenges.

Figure R.1 shows a graphic abstract of the general approach of this $\mathrm{PhD}$ thesis

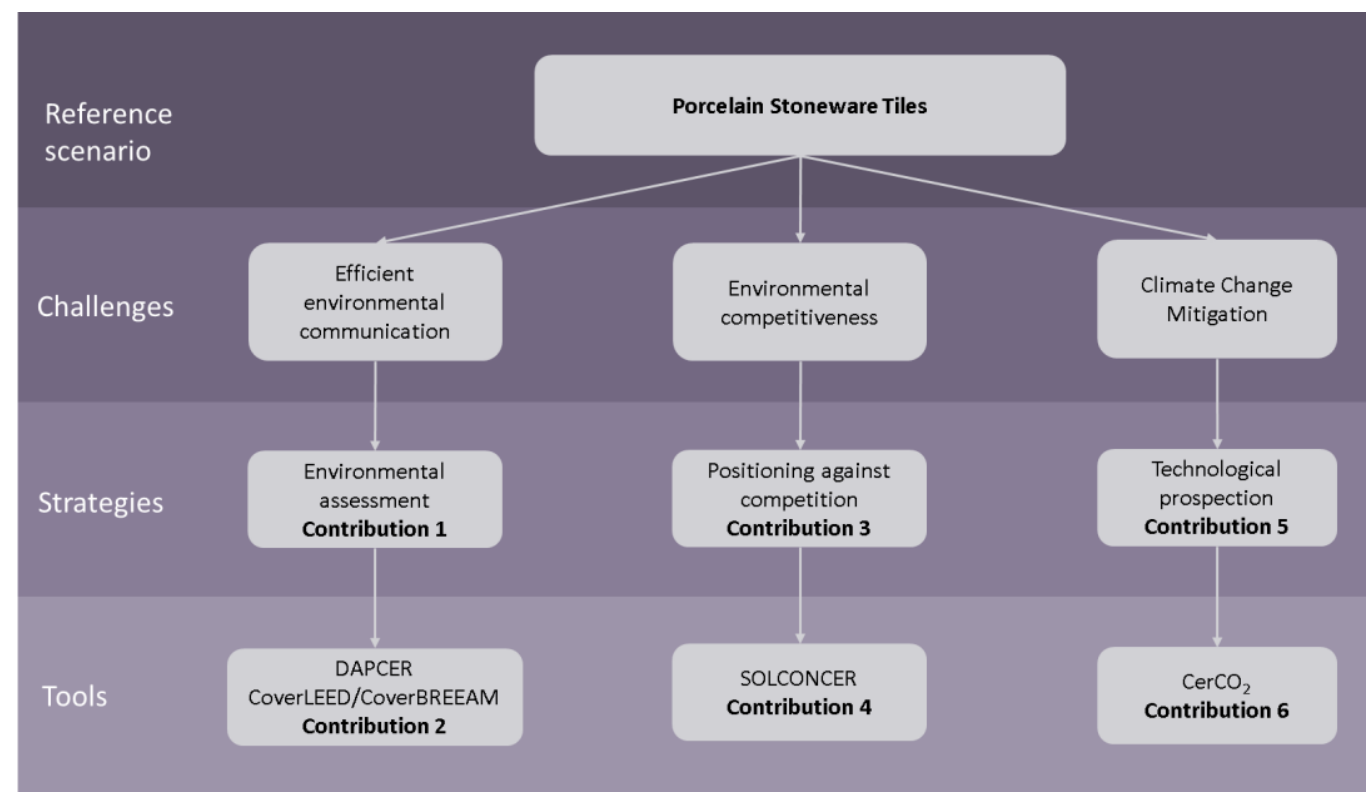

Figure R1. Global approach to thesis work

The methodology used in this work has been based on establishing a reference scenario as the starting point, specifically the life cycle of porcelain stoneware tiles, from which key parameters have been identified to determine the legislative, technological and innovation scenarios explored in each of the life cycle strategies and tools. This reference scenario has been simulated using a Life Cycle Analysis (LCA) model in GaBi software, which has been given the necessary flexibility to contemplate all the cases considered in the scenario analyses consistently throughout the project. 
The global and integrated approach offered by the life cycle perspective is fundamental in order to find compromise solutions and scientific consensus, which help in making decisions for the development of truly effective environmental policies and strategies, both at a sectorial and individual level.

As a result, it has been found that the tile manufacturing stage contains the greatest number of key parameters, the most significant being the amount of raw materials on the substrate (parameter directly related to thickness), energy consumption and the quantity and type of glaze.

The strategies and tools developed to face each of the challenges have been:

\section{Efficient communication challenge:}

The Environmental Product Declarations (EPD) have been proposed as a means of responding to requests for environmental information, due to the quantity and type of objective information they contain, as well as being widely recognized and standardized communication instruments (ISO 14020, 2000; ISO 14025, 2006). The development of an LCA of porcelain stoneware tile and its variants (based on thickness, quantity of glaze and mechanical surface treatments) has made it possible to quantify the environmental significance of the variations of ceramic tiles manufactured by a producer, as well as to estimate the number of EPDs required to cover all the variants of the same type of product, depending on the EPD program applied.

Different tools have been developed, tested and applied: DAPCER, which enables Life Cycle Assessment Studies and Environmental Product Declarations to be rapidly and economically obtained, and CoverLEED and CoverBREEAM by ITC, aiming at calculating and demonstrating compliance with credits/criteria demanded for materials in the LEED $^{\circledR}$ and BREEAM ${ }^{\circledR}$ certification systems for sustainable buildings, respectively.

\section{Competitiveness challenge}

A comparative LCA study of flooring systems with a cradle-to-cradle scope was performed. To do so, the relevant EPDs were used to assess the product stage (A1-A3), modelling the other life cycle stages under the same building context, and applying a progressive transition towards a circular economy. This analysis has allowed to position ceramic tiles from an environmental point of view, as well as to obtain arguments that can be used for commercial purposes. The results have shown that floor systems with inorganic coverings (porcelain stoneware tiles and natural stone) present the best environmental performance. Although the impacts are high during the manufacturing stage, they are compensated by long lifespan and easy maintenance. On the other hand, synthetic carpet flooring systems have the highest impacts, because of those generated during the manufacturing stage and because of a short lifespan and high maintenance requirements.

For this challenge, the SolconCer tool has been made available to companies and prescriptors. It aims at characterizing constructive solutions with different construction systems through online and free access. 


\section{Climate change challenge}

Seventeen alternatives and twenty-five technological scenarios aimed at reducing $\mathrm{CO}_{2}$ emissions in the life cycle of ceramic tiles have been evaluated, in accordance with the objectives established by the EU for 2020 and 2050 (COM (2011)112 final). This study has allowed: i) to estimate the degree of technological innovation required; ii) to define and to outline strategies and iii) to devise the lines of technological development which need to be implemented in the ceramic tile manufacturing sector in the coming years. The results have shown that the greater the scope of the life cycle under consideration, the greater the innovations required to reduce the sector's greenhouse gases (GHG) emissions. These innovations must contemplate the simultaneous implementation of endogenous and exogenous breakthrough technologies in the ceramic sector. Specifically, it has been determined that, by 2050 , changes in product design will be required (halving the thickness of the ceramic body, the amount of glaze and/or frit content), together with the implementation of highly energy-efficient technologies in dryers and kilns that run on, at least, half the energy from renewable sources.

The $\mathrm{CerCO}_{2}$ tool has been developed to assist the ceramic sector to carry out prospecting exercises on GHG emissions from different technological scenarios based on their current situation.

In short, it is confirmed that it is possible to apply LCA in the ceramic tile sector to tackle the challenges of environmental communication, competitiveness and climate change through the evaluation of legislative, technological and innovation trends and prospects in a rigorous, representative and consistent manner. However, the application of the LCA methodology and the interpretation of the results require a high degree of specialization. That is why it is important to provide companies in the ceramic sector with tools that are easy to use and access, in order to be able to position and to assess their products in the face of the different challenges exposed. 



\section{Tabla de contenido}

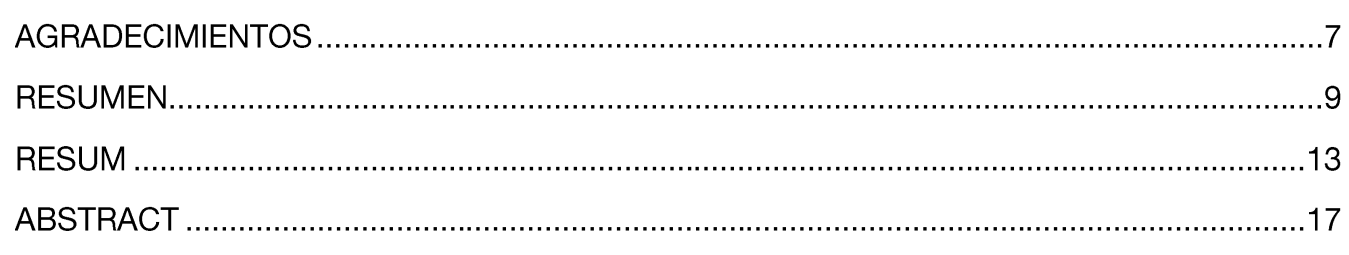

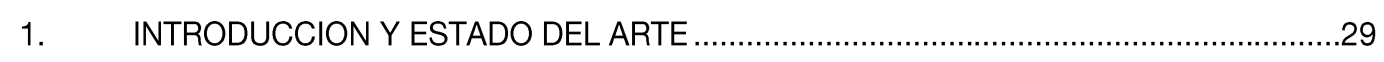

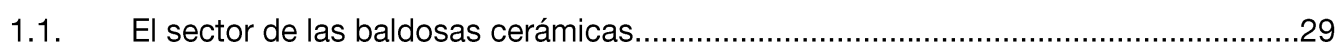

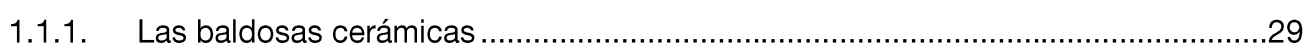

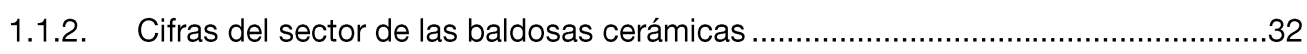

1.1.3. Procesos de fabricación de las baldosas cerámicas y esmaltes..............................33

1.2. Principales aspectos ambientales de la fabricación de las baldosas y esmaltes

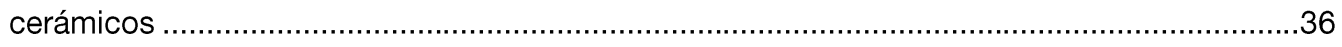

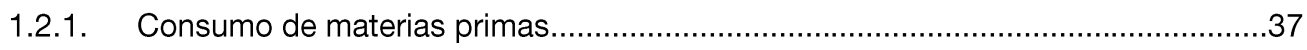

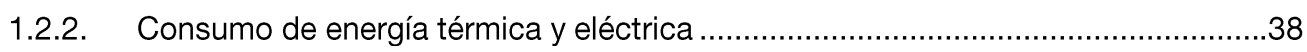

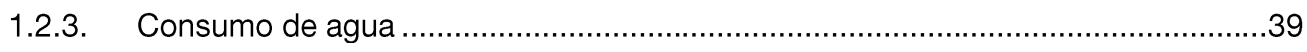

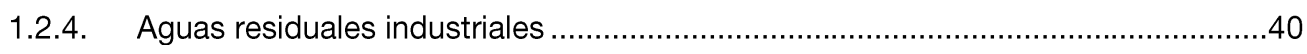

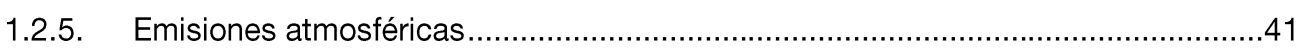

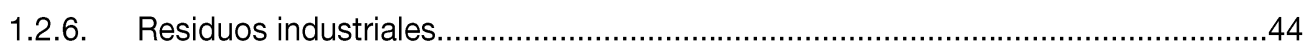

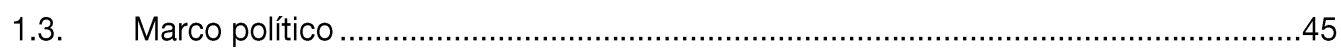

1.3.1. Organización Mundial de las Naciones Unidas ...................................................45

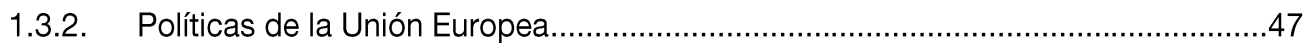

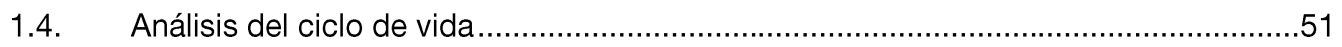

1.4.1. Importancia de la perspectiva del ciclo de vida ..................................................51

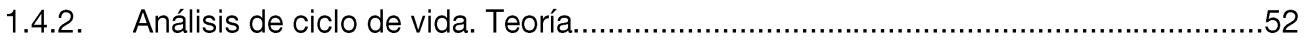

1.4.3. Revisión de las aplicaciones de ACV en recubrimientos.........................................54

1.5. Comunicación ambiental del ciclo de vida en el sector cerámico ...............................64

1.5.1. Instrumentos de comunicación ambiental de la gestión de las empresas ...............65

1.5.2. Instrumentos de comunicación ambiental de productos ........................................66

1.5.3. Instrumentos de comunicación ambiental de edificios...............................................71

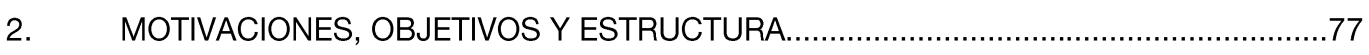

2.1. Motivaciones del presente estudio ..................................................................... 77 


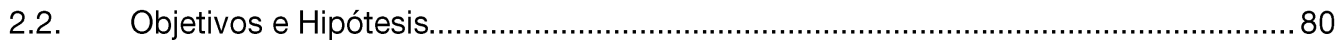

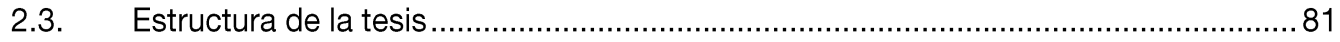

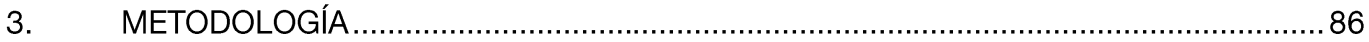

3.1. Metodología para la elaboración del ACV. Escenario de referencia............................. 87

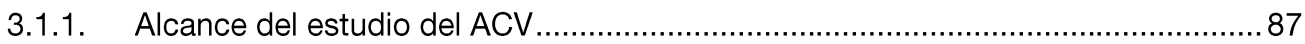

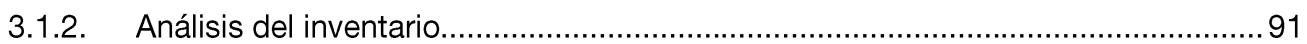

3.1.3. Evaluación e interpretación de los impactos ambientales ...................................... 95

3.2. Metodología para el desarrollo de estrategias y herramientas del ciclo de vida.........96

3.2.1. Reto de una comunicación ambiental eficiente .................................................... 97

3.2.1.2. Herramientas estratégicas de comunicación ambiental: DAPCER, CoverLEED y

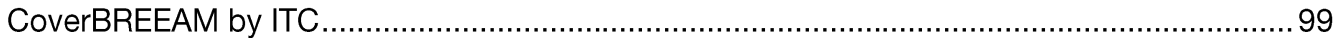

3.2.2. Reto de aumentar la competitividad .............................................................. 102

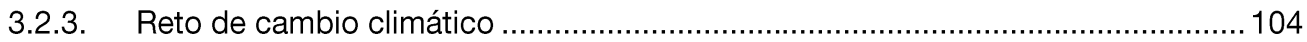

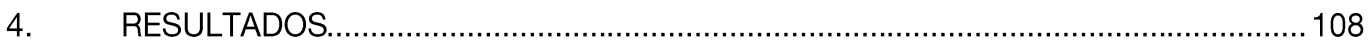

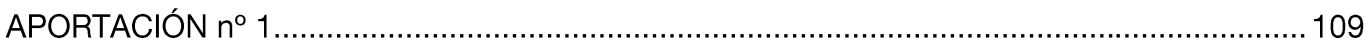

ENVIRONMENTAL PROFILE OF SPANISH PORCELAIN STONEWARE TILES ..........................111

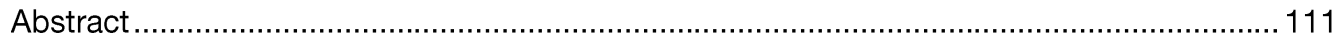

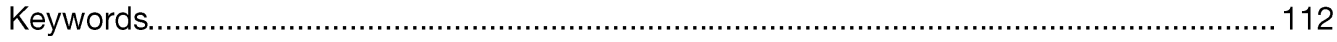

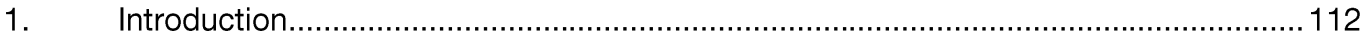

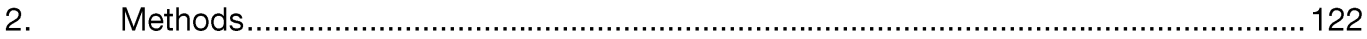

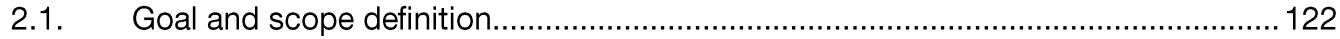

2.1.1. System boundaries and Functional Unit ......................................................... 123

2.1.2. Selected environmental impact categories .................................................... 125

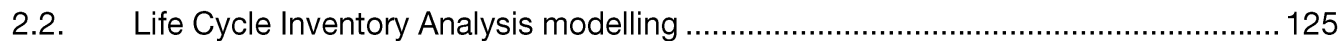

2.2.1. Description of the PST life cycle ................................................................... 132

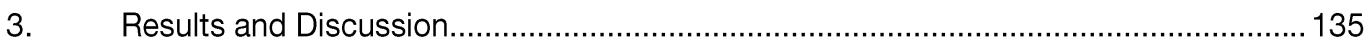

3.1. Life Cycle Environmental Impact Assessment of PST AAA .................................... 135

3.2. Environmental impact assessment of PST varieties.............................................. 139

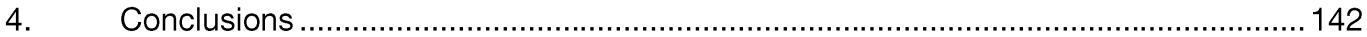

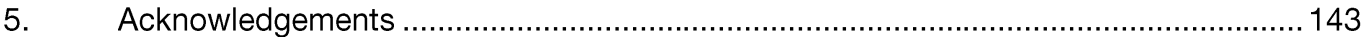

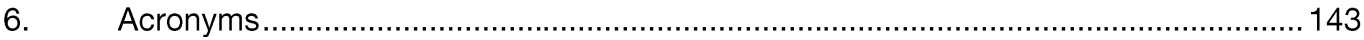

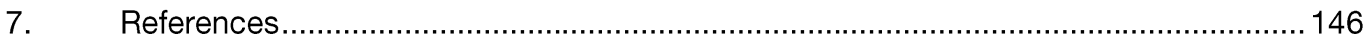

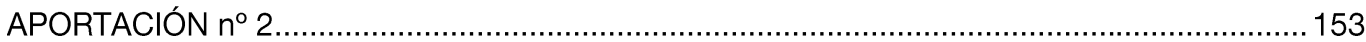


Abstract .155

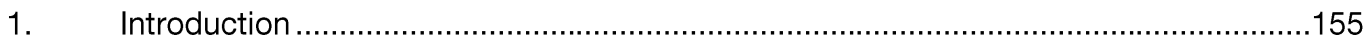

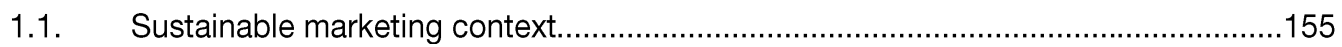

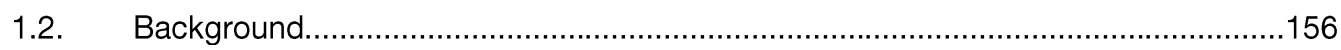

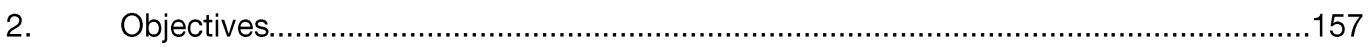

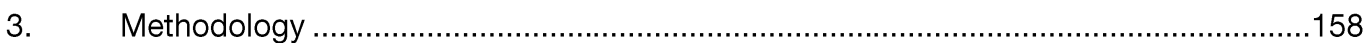

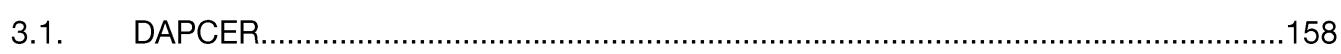

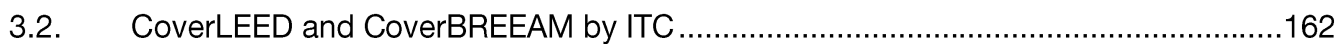

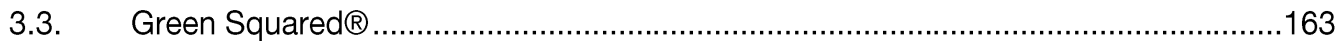

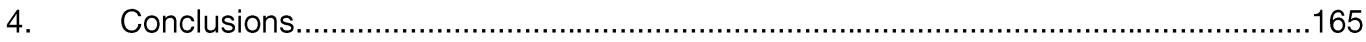

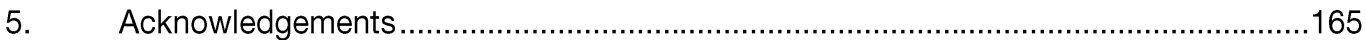

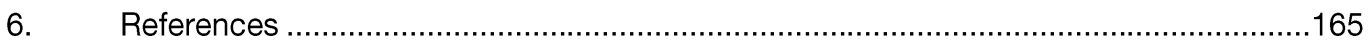

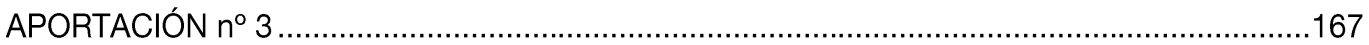

ENVIRONMENTAL COMPARISON OF INDOOR FLOOR COVERINGS....................................169

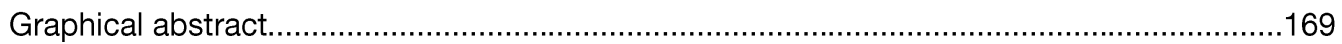

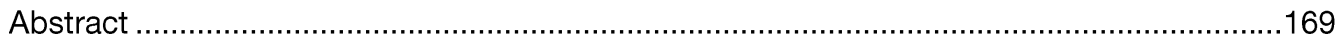

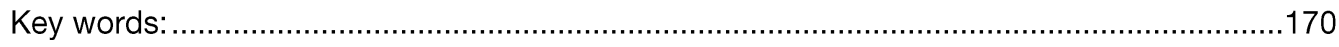

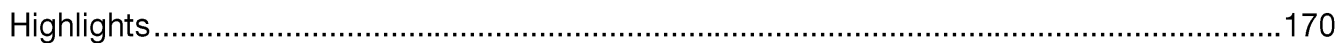

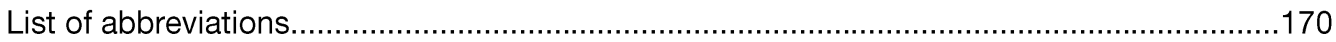

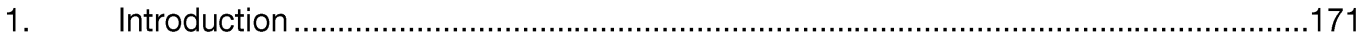

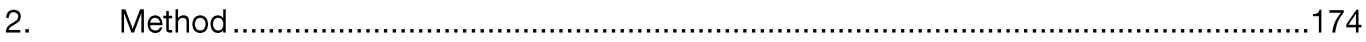

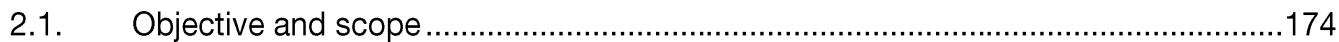

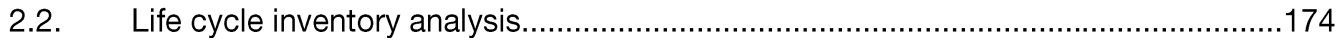

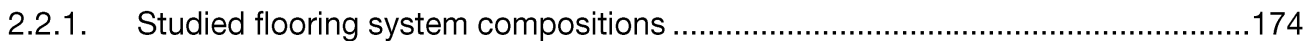

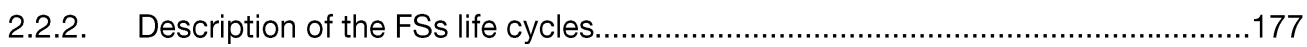

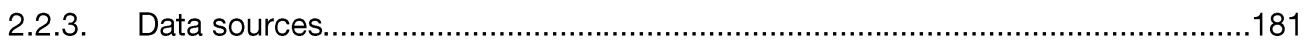

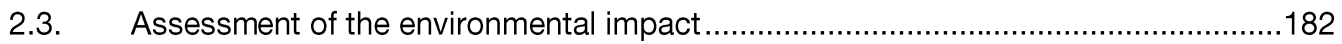

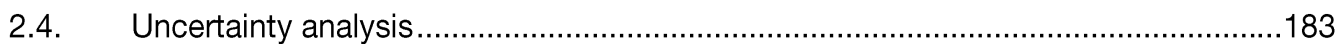

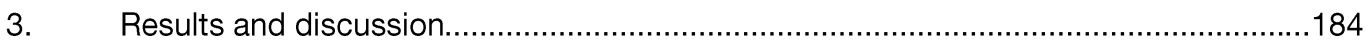

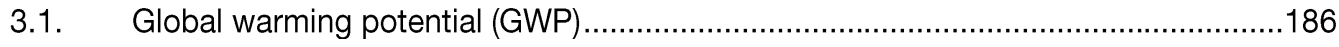

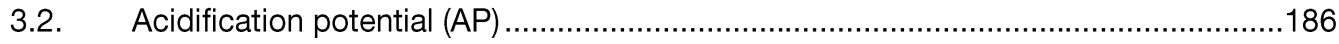

3.3. Eutrophication potential (EP)..................................................................... 187 


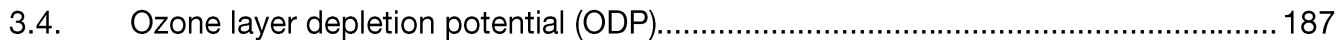

3.5. Photochemical ozone creation potential (POCP)..................................................... 188

3.6. Depletion potential for non-fossil resources (ADPE) ............................................ 188

3.7. Depletion potential for fossil resources (ADPF) ................................................. 188

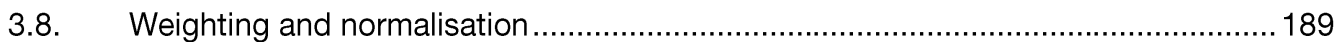

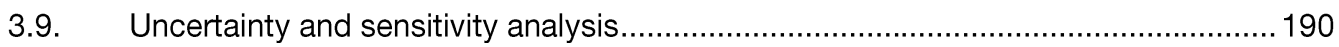

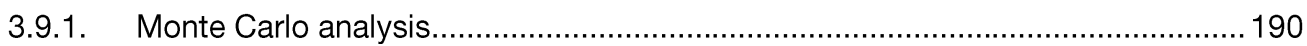

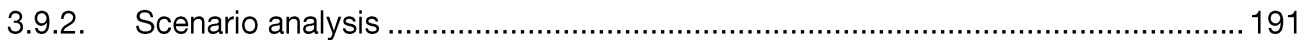

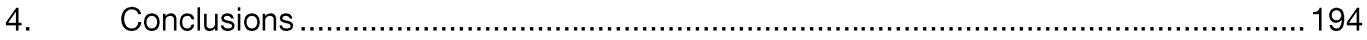

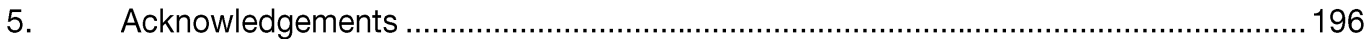

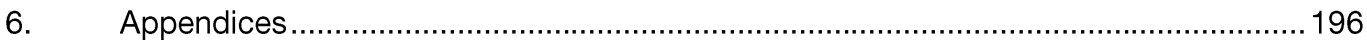

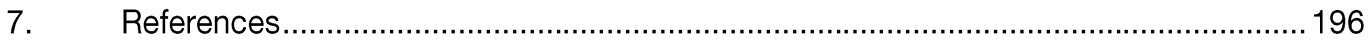

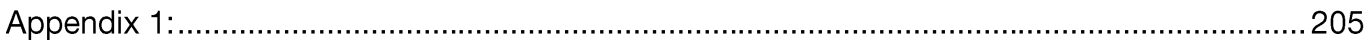

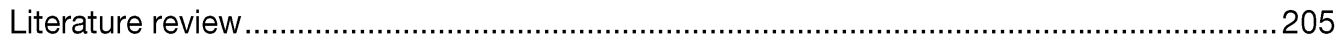

Appendix 2:

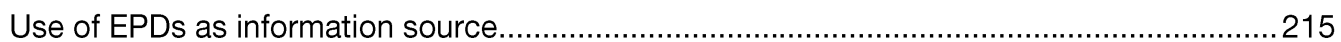

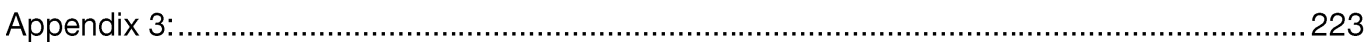

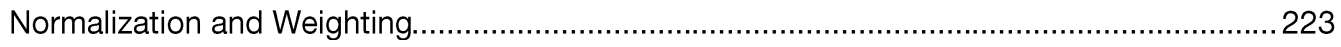

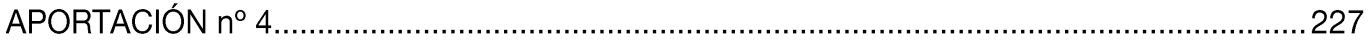

SOLCONCER, A HELPFUL TOOL FOR CHARACTERISING CONSTRUCTION SOLUTIONS ....229

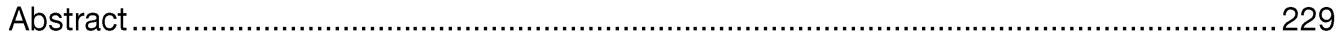

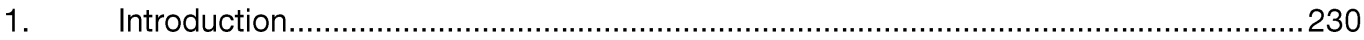

2. Considerations affecting all construction solutions ................................................2 232

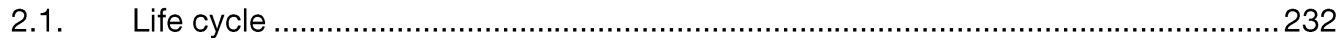

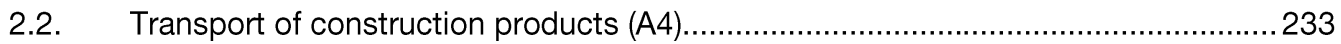

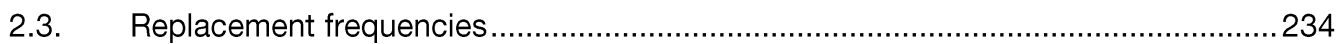

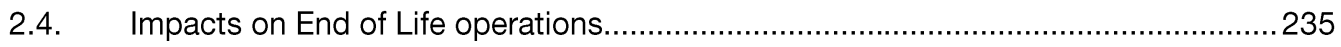

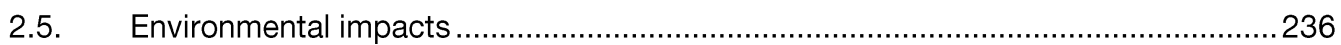

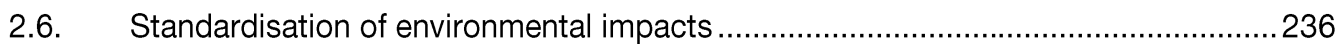

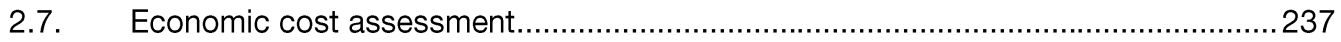

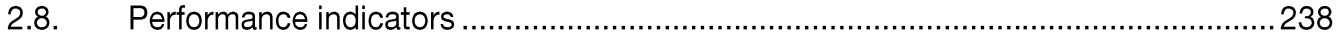

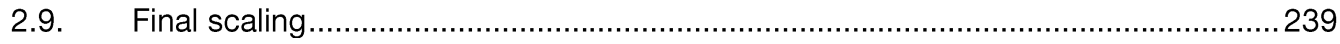




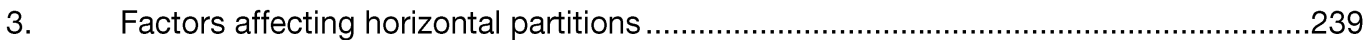

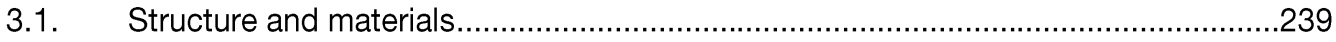

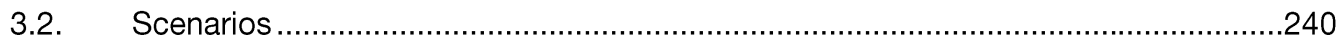

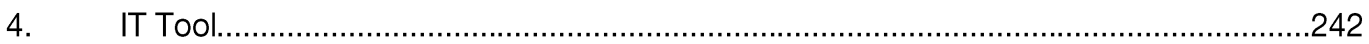

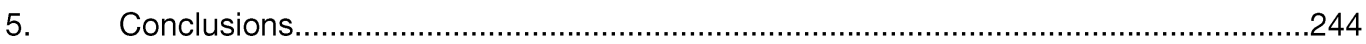

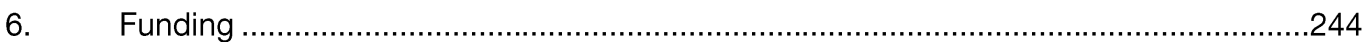

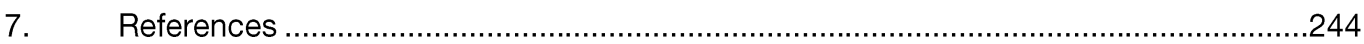

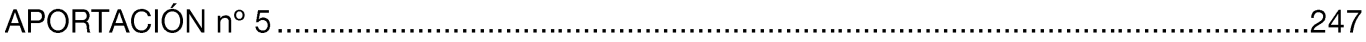

HOW CAN THE EUROPEAN CERAMIC TILE INDUSTRY MEET THE EU'S LOW-CARBON

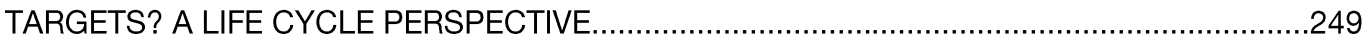

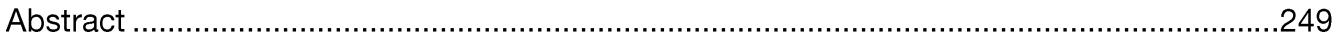

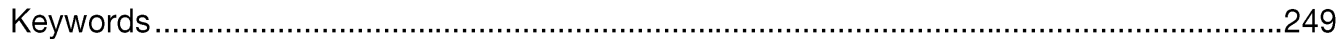

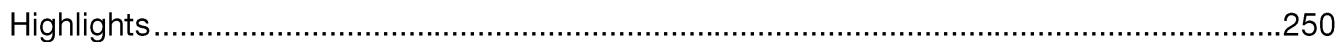

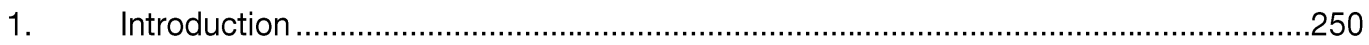

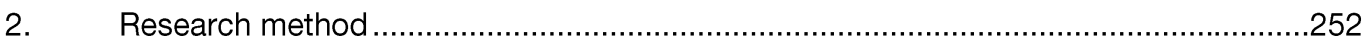

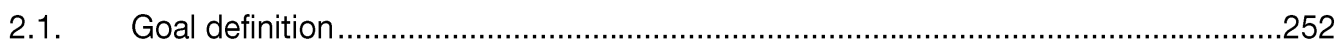

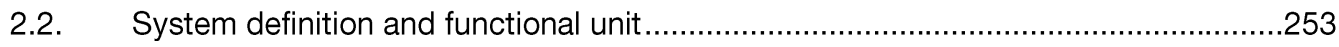

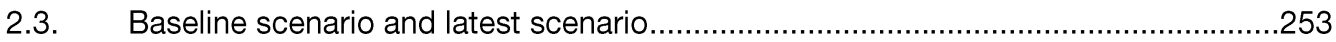

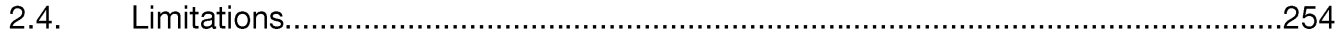

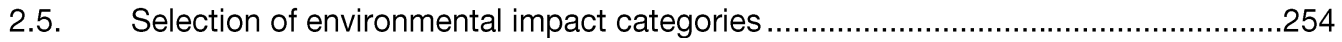

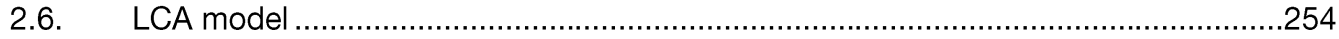

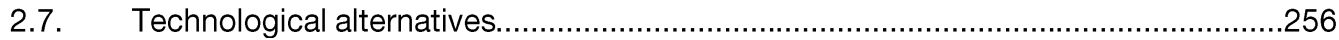

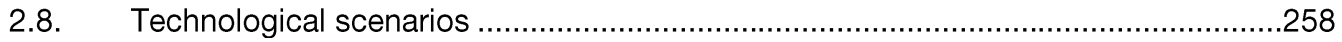

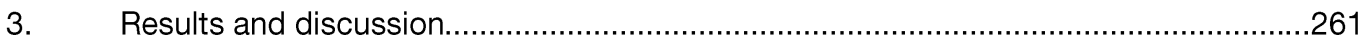

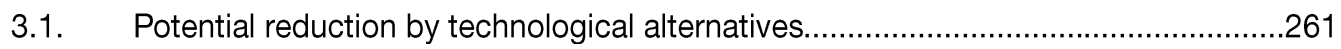

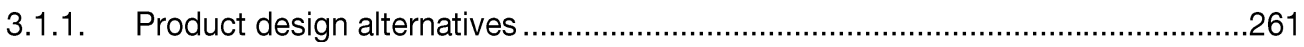

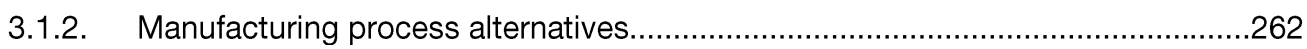

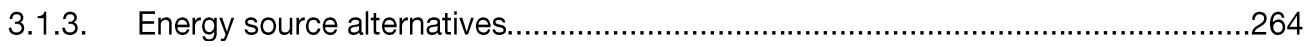

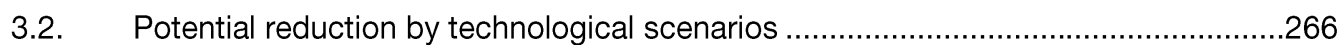

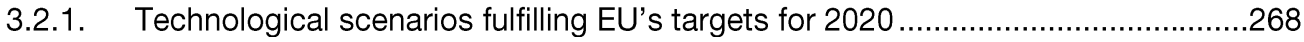

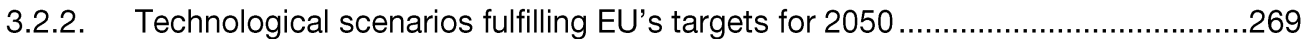

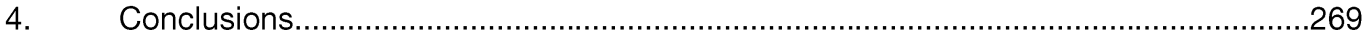

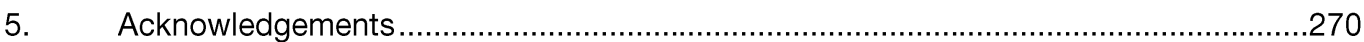




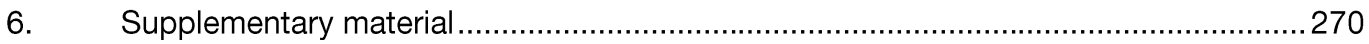

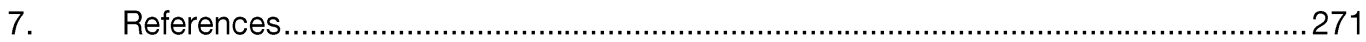

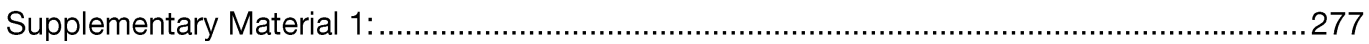

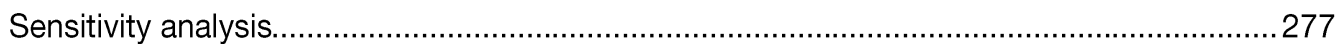

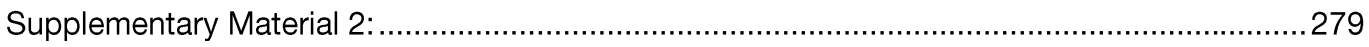

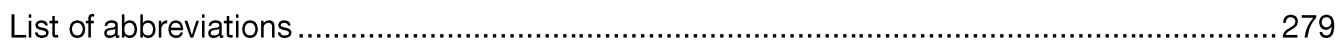

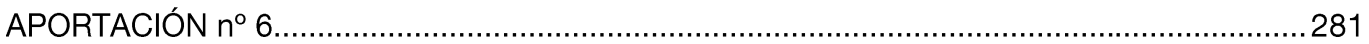

$\mathrm{CerCO}_{2}, \mathrm{CO}_{2}$ EMISSION SIMULATION TOOL FOR THE CERAMIC INDUSTRY ........................283

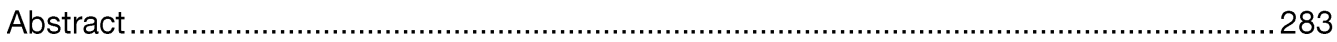

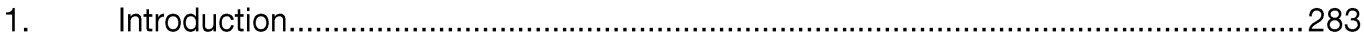

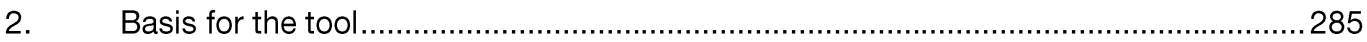

2.1. Technologies associated with the current process …...........................................28

2.2. Low-carbon technologies to be evaluated .......................................................... 287

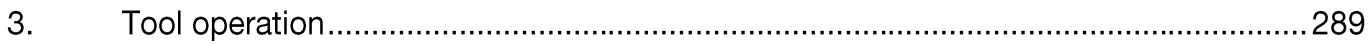

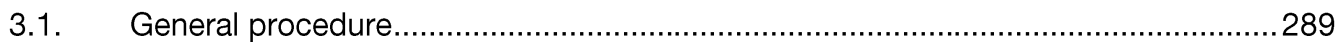

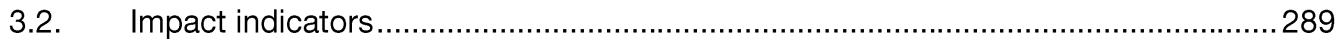

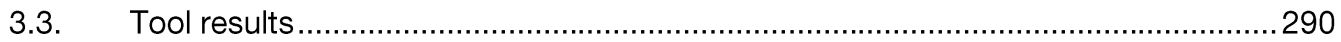

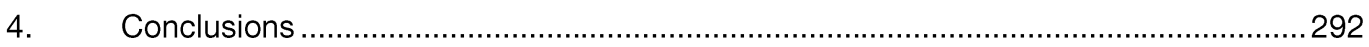

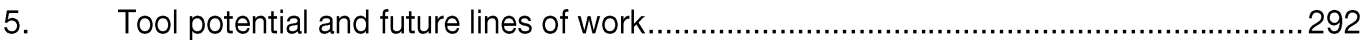

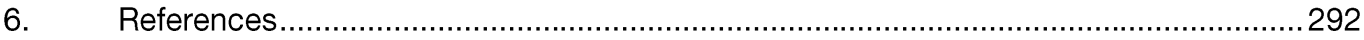

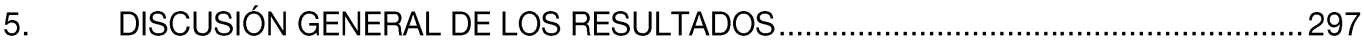

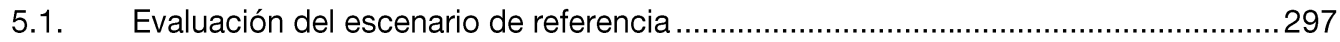

5.1.1. Cuantificación de las contribuciones a las categorías de impacto ambiental.......298

5.1.2. Identificación de parámetros clave ...................................................................29

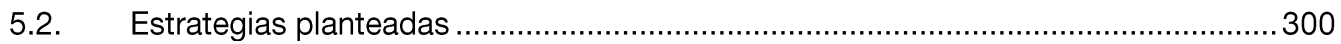

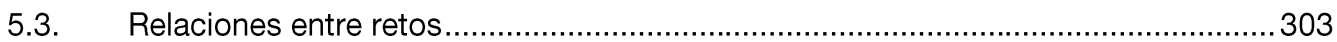

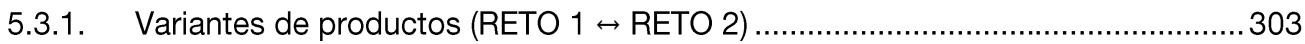

5.3.2. Parámetros ambientales clave (RETO $1 \leftrightarrow$ RETO 3) ............................................306

5.3.3. Competitividad en una economía hipocarbónica (RETO $2 \leftrightarrow$ RETO 3) ...................313

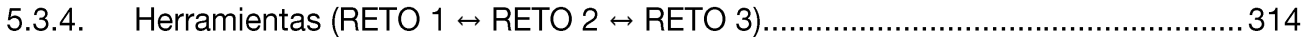

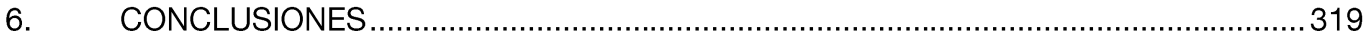

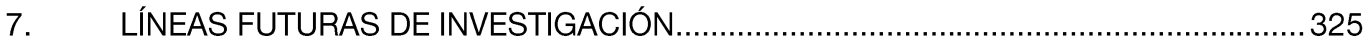




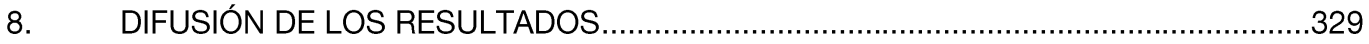

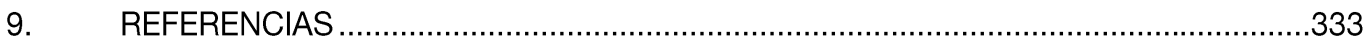

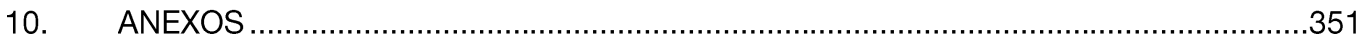

10.1. Anexo 1. Cuestionarios para la recogida de la información ambiental de las empresas 351

10.1.1. Cuestionario asociado a la fabricación de baldosas cerámicas .......................351

10.1.2. Cuestionario asociado a la preparación de las materias primas........................359

10.1.3. Cuestionario asociado a la fabricación de fritas, esmaltes, engobes, tintas y otros

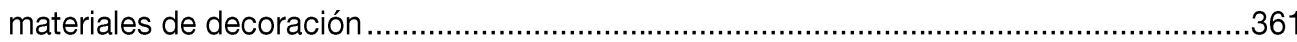

10.2. Anexo 2. Datos de inventario del ciclo de vida del escenario de referencia de gres

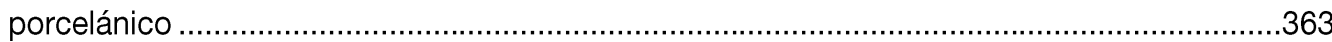

10.3. Anexo 3. Descripción del modelo de ACV de baldosas cerámicas ............................377

10.4. Anexo 4. Permiso de los coautores y coautoras.........................................................391

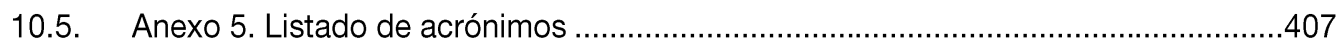

10.5.1. Acrónimos de los capítulos 1, 2, 3, 5, 6 y 7 ...................................................407

10.5.2. Acrónimos del capítulo 4.............................................................................. 409 


\section{INTRODUCCIÓN Y ESTADO DEL ARTE}




\section{INTRODUCCION Y ESTADO DEL ARTE}

\subsection{El sector de las baldosas cerámicas}

\subsubsection{Las baldosas cerámicas}

Las baldosas cerámicas son placas de poco grosor, generalmente utilizadas para el recubrimiento de superficies en el sector de la construcción, fabricadas a partir de una mezcla de materiales inorgánicos de naturaleza plástica y no plástica que se someten a molienda y/o amasado, se conforman y, seguidamente, son secadas y cocidas a temperatura suficiente para que adquieran, establemente, las propiedades requeridas para su uso (EN 14411, 2016). Dependiendo del tipo de baldosa y del aspecto final deseado, éstas pueden estar constituidas sólo por el soporte (baldosas no esmaltadas) o estar recubiertas por una fina capa de esmalte (baldosas esmaltadas). En la Figura 1.1 se muestran baldosas cerámicas con diferentes espesores y con diferentes diseños y acabados.

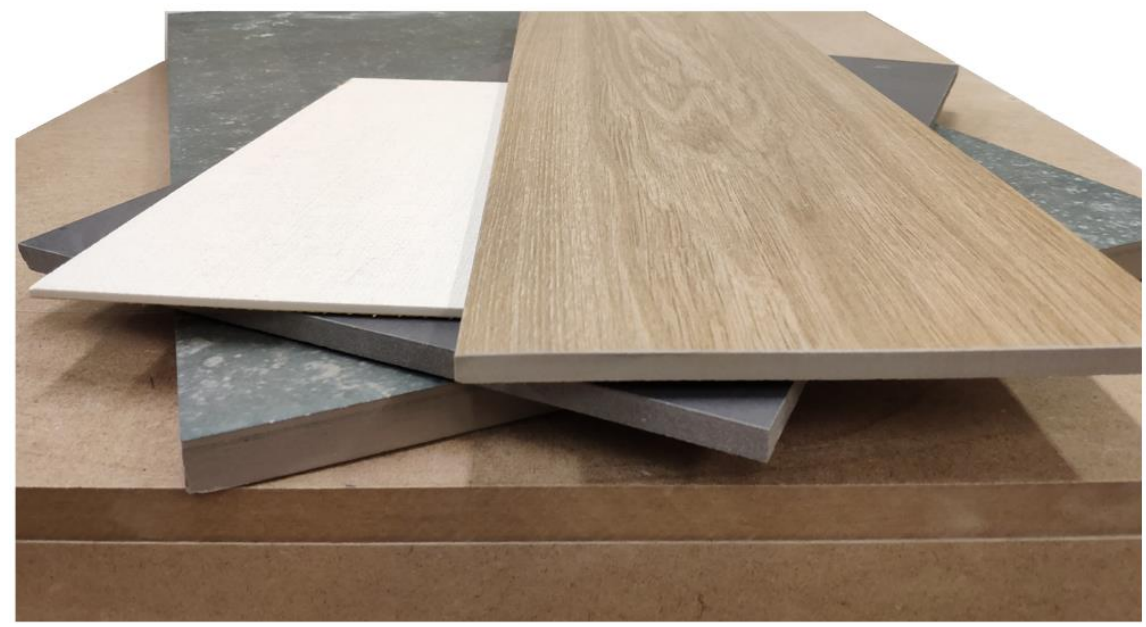

Figura 1.1 Imagen de baldosas cerámicas

Las cualidades estéticas, funcionales y prestacionales de las baldosas cerámicas han ampliado notablemente su uso. Tradicionalmente se han utilizado como revestimientos de suelos y paredes interiores pero, gracias a la innovación en diseño y a los avances tecnológicos, se ha conseguido extender su uso en muy diversas soluciones arquitectónicas como en fachadas, cubiertas, techos, o como pavimentos urbanos, entre otras (ASCER, 2011).

La clasificación de las baldosas cerámicas, según la norma EN 14411, 2016, se basa en dos variables: el método utilizado para su conformado (prensado o extrudido) y en la absorción de agua (de $<0,5 \%$ a $>10 \%$ ). En la Tabla 1.1, se muestra esta clasificación, acompañada de la nomenclatura utilizada en el argot sectorial, por la que se conocen a los distintos tipos de baldosas cerámicas. Cabe decir que el nombre común de las baldosas no está normalizado y puede variar en función de las regiones. 
Tabla 1.1 Principales tipologías de baldosas cerámicas fabricadas en España

\begin{tabular}{|c|c|c|c|}
\hline Moldeo & Absorción de agua (E) & Grupo(1) & Nombre común ${ }^{(2)}$ \\
\hline \multirow{5}{*}{$\stackrel{\text { A }}{\text { Extrudido }}$} & $\leq 0,5 \%$ & Ala & Gres porcelánico \\
\hline & $0,5 \%<\mathrm{E}<3 \%$ & Alb & \multirow{2}{*}{ Gres rústico } \\
\hline & $3 \%<\mathrm{E}<6 \%$ & Alla & \\
\hline & $6 \%<E \leq 10 \%$ & Allb & \multirow{2}{*}{ Barro cocido } \\
\hline & $>10 \%$ & Alll & \\
\hline \multirow{5}{*}{$\begin{array}{c}\text { B } \\
\text { Prensado }\end{array}$} & $\leq 0,5 \%$ & Bla & Gres porcelánico \\
\hline & $0,5 \%<\mathrm{E}<3 \%$ & Blb & \multirow{3}{*}{ Gres esmaltado } \\
\hline & $3 \%<\mathrm{E}<6 \%$ & Blla & \\
\hline & $6 \%<E \leq 10 \%$ & Bllb & \\
\hline & $>10 \%$ & BIII & Azulejo \\
\hline \multicolumn{4}{|c|}{ (1) Según EN 14411, 2016} \\
\hline
\end{tabular}

En los últimos 15 años, el volumen de producción del gres porcelánico en España ha crecido, en valor relativo, alrededor de un $20 \%$, la producción del gres esmaltado ha disminuido un $15 \%$, mientras que la producción del azulejo se ha mantenido prácticamente estable (ASCER, 2015).

Las baldosas cerámicas deben tener diferentes propiedades según su uso final. Las especificaciones requeridas son particulares para cada tipo de baldosa e incluyen: dureza, resistencia al desgaste, larga vida útil, inercia química y no toxicidad, resistencia al calor y al fuego, gran resistencia a la erosión que causan los agentes atmosféricos, resistencia eléctrica, y porosidad específica, entre otros (EIPPCB, 2007a). En la Tabla 1.2 se resumen las características técnicas de las baldosas cerámicas y las normas bajo las cuales deben caracterizarse (EN 14411, 2016). 
Tabla 1.2 Características técnicas de las baldosas cerámicas

\begin{tabular}{|c|c|c|c|c|}
\hline \multicolumn{3}{|c|}{ Características } & \multicolumn{2}{|c|}{ Método de ensayo } \\
\hline \multirow{8}{*}{$\begin{array}{c}\text { Dimensiones } \\
\text { y aspecto } \\
\text { superficial }\end{array}$} & \multicolumn{2}{|l|}{ Longitud } & \multirow{20}{*}{ ISO 10545} & \multirow{8}{*}{ Parte 2} \\
\hline & \multicolumn{2}{|l|}{ Espesor } & & \\
\hline & \multicolumn{2}{|c|}{ Rectitud de lados } & & \\
\hline & \multicolumn{2}{|c|}{ Ortogonalidad } & & \\
\hline & \multirow{3}{*}{ Curvatura } & Central & & \\
\hline & & Lateral & & \\
\hline & & Alabeo & & \\
\hline & \multicolumn{2}{|c|}{ Aspecto superficial } & & \\
\hline \multirow{16}{*}{$\begin{array}{l}\text { Propiedades } \\
\text { físicas }\end{array}$} & \multicolumn{2}{|c|}{ Absorción de agua } & & Parte 3 \\
\hline & \multicolumn{2}{|c|}{ Fuerza de rotura } & & \\
\hline & \multicolumn{2}{|c|}{ Resistencia a la flexión } & & rarte 4 \\
\hline & \multicolumn{2}{|c|}{ Resistencia al impacto } & & Parte 5 \\
\hline & \multicolumn{2}{|c|}{ Abrasión profunda } & & Parte 6 \\
\hline & \multicolumn{2}{|c|}{ Abrasión superficial PEI } & & Parte 7 \\
\hline & \multicolumn{2}{|c|}{ Dilatación térmica } & & Parte 8 \\
\hline & \multicolumn{2}{|c|}{ Choque térmico } & & Parte 9 \\
\hline & \multicolumn{2}{|c|}{ Expansión por humedad } & & Parte 10 \\
\hline & \multicolumn{2}{|l|}{ Cuarteo } & & Parte 11 \\
\hline & \multicolumn{2}{|l|}{ Helada } & & Parte 12 \\
\hline & \multicolumn{2}{|c|}{ Pequeñas diferencias de color } & & Parte 16 \\
\hline & \multicolumn{2}{|c|}{ Deslizamiento } & \multicolumn{2}{|c|}{ CEN/TS 16165} \\
\hline & \multicolumn{2}{|c|}{ Reacción al fuego } & \multicolumn{2}{|c|}{ EN 14411} \\
\hline & \multicolumn{2}{|l|}{ Adhesión } & \multicolumn{2}{|c|}{ EN 12004} \\
\hline & \multicolumn{2}{|c|}{ Propiedades táctiles } & & \\
\hline & Ácidnc v & Baja concentración & & \\
\hline & Acicus y & Alta concentración & & Parte 13 \\
\hline Propiedades & Producto & sticos y de piscinas & 10010515 & \\
\hline químicas & & Esmaltada & (10040 & \\
\hline & miviturias & Sin esmaltar & & ralle 14 \\
\hline & Extracció & mo y cadmio & & Parte 15 \\
\hline
\end{tabular}




\subsubsection{Cifras del sector de las baldosas cerámicas}

El sector de las baldosas cerámicas es el subsector cerámico con mayor importancia económica en Europa (Cerame Unie, 2019). La producción mundial en 2017 fue de $13.552 \mathrm{Mm}^{2}$ y la europea (EU-28 + Turquía) de $1.977 \mathrm{Mm}^{2}$, siendo España e Italia los principales países fabricantes. España se posicionó como quinto productor mundial, con un volumen total de negocio de $3.510 \mathrm{M}$ y 530 $\mathrm{Mm}^{2}$ fabricados, siguiendo a China, India, Brasil y Vietnam. España fue el mayor exportador europeo y segundo a nivel mundial, con un volumen exportado de $407 \mathrm{Mm}^{2}$. Los principales países importadores de baldosas cerámicas españolas en 2017 fueron Francia $\left(40,3 \mathrm{Mm}^{2} ; 278 \mathrm{M} €\right)$, EEUU (27 Mm²; $234 \mathrm{M} €$ ), Arabia Saudí (21 Mm²; $118 \mathrm{M} €$ ) y Reino Unido (20,7 Mm²; 168,6 M€) (ASCER, 2019; Baraldi, 2018; Cerame Unie, 2019). En la Figura 1.2, se presenta de forma gráfica la evolución de la producción española de baldosas cerámicas desde 1977 hasta 2018 (ASCER, 2019).

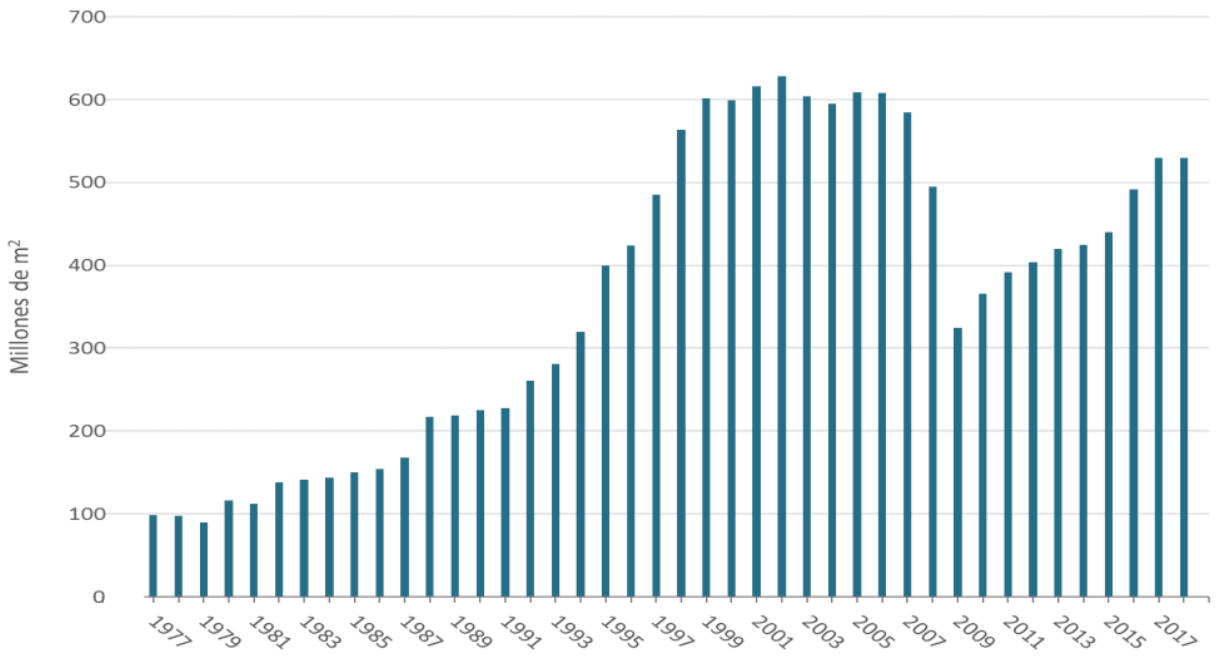

Figura 1.2 Evolución de la producción de baldosas cerámicas en España

Una de las principales características del sector de la fabricación de baldosas ceramicas en España es la alta concentración industrial existente en la provincia de Castellón, en especial en el área delimitada al Norte por Villafamés, al Oeste por l'Alcora, Ribesalbes y Onda, al Sur por Nules, y al Este por Castellón de la Plana y Almassora (véase la Figura 1.3). Esta área es conocida en términos económicos como "clúster cerámico" (Minguillón, 2007). En esta zona, se ubica el 83\% de las empresas directamente relacionadas con la fabricación de baldosas cerámicas, más otras actividades asociadas a dicho sector de forma indirecta, tales como talleres, ingenierías, empresas de servicios, proveedores de materias primas minoritarias, entre otras (véase la Figura 1.3), permitiendo su interrelación y, en consecuencia, la acumulación y desarrollo de conocimiento y apoyo común (Gabaldón-Estevan et al., 2014; Gabaldón Estevan and Hekkert, 2013). En 2017, la industria de baldosas cerámicas contaba con 128 empresas fabricantes de baldosas cerámicas, 
15 empresas dedicadas a la fabricación de gránulo atomizado, y 3 empresas a la fabricación de soporte cerámico para un esmaltado posterior; además, el sector también incluía 29 empresas de fabricación de piezas especiales. Adicionalmente, esta zona alberga 23 empresas dedicadas a la fabricación fritas, esmaltes y pigmentos cerámicos. (ANFFECC, 2019; ASCER, 2019). La Figura 1.3 presenta la distribución de las industrias más relevantes en el clúster industrial de Castellón.

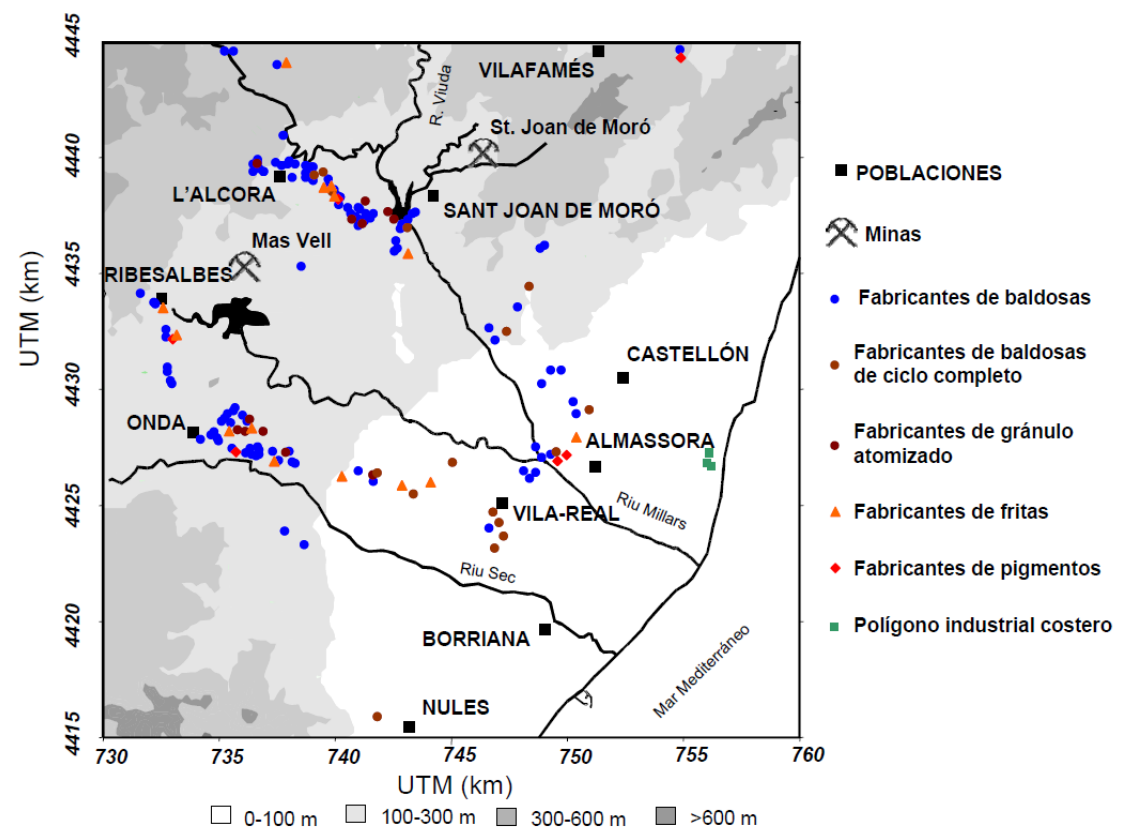

Figura 1.3 Mapa del clúster cerámico con indicación de las industrias más relevantes (Minguillón, 2007)

\subsubsection{Procesos de fabricación de las baldosas cerámicas y esmaltes}

\subsubsection{Fabricación de las baldosas cerámicas}

Los principales procesos de fabricación de baldosas carámicas son los siguientes: extracción de materias primas y transporte hasta la planta cerámica, trituración, molienda de las materias primas, conformado, secado, esmaltado y decoración, cocción, tratamiento mecánico (opcional), clasificación, envasado y embalado (EIPPCB, 2007a).

Algunos de estos procesos pueden llevarse a cabo mediante diferentes rutas: la preparación de las materias primas puede seguir una vía seca o vía húmeda; el conformado puede hacerse por prensado o extrudido; la cocción puede llevarse a cabo por monococción o por bicocción. De estos procesos, los más extendidos en España son: la preparación de materias primas por vía húmeda, el conformado por prensado y la cocción por monococción (Monfort et al., 2011b). En la Figura 1.4, se representa, de forma ilustrada, el proceso de fabricación de las baldosas cerámicas, reflejando las rutas alternativas (no simultáneas) de procesos. 


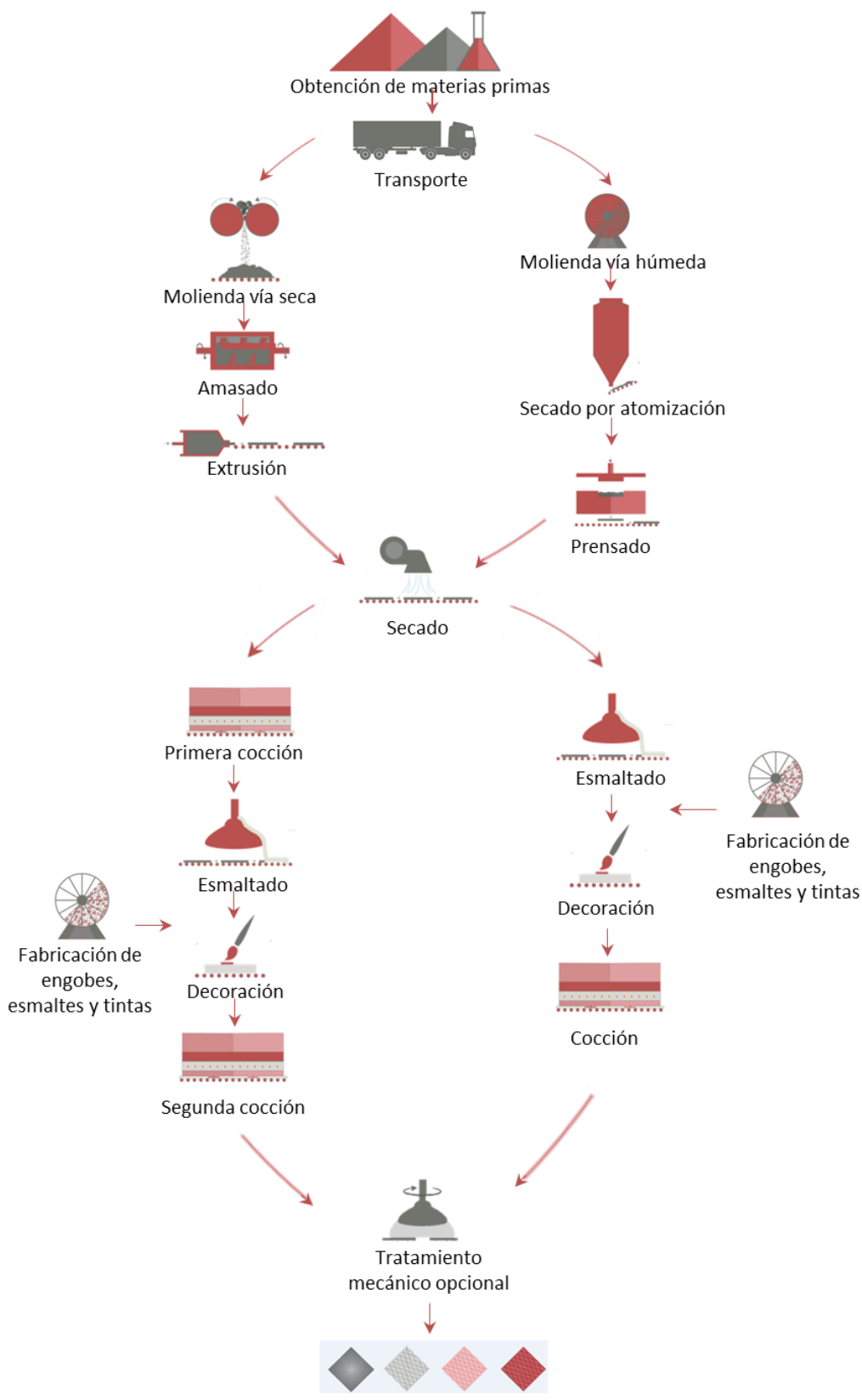

Figura 1.4 Esquema del proceso de fabricación de las baldosas cerámicas con diferentes rutas 


\subsubsection{Fabricación de los esmaltes cerámicos}

Los esmaltes cerámicos están compuestos fundamentalmente por materias primas inorgánicas, incluyendo sílice como componente fundamental formadora de vidrio, así como otros elementos que actúan como fundentes (alcalinos, alcalinotérreos, boro, cinc, etc.), opacificantes (circonio, titanio, etc.), y colorantes (hierro, cromo, cobalto, manganeso, etc.) (Bou, 2006). La composición de los esmaltes varía según el tipo de baldosa sobre la que se va a aplicar, así como de los efectos y propiedades requeridas. Los esmaltes cerámicos destinados a las baldosas contienen un porcentaje variable de fritas, materias primas cristalinas y pigmentos cerámicos.

Las fritas cerámicas son vidrios insolubles, de composición química compleja, preparados mediante la fusión completa a elevadas temperaturas $\left(1400-1500^{\circ} \mathrm{C}\right)$ de sus materias primas originales cristalinas, y posterior enfriamiento brusco. El proceso de fabricación de las fritas comienza con la dosificación de las materias primas, previamente seleccionadas y controladas en la proporción establecida. Mediante transporte neumático, se traslada a una mezcladora y posteriormente al horno donde tiene lugar el fritado propiamente dicho, el cual puede llevarse a cabo en hornos continuos o intermitentes. En cualquier caso, a la salida del horno, el material fundido se enfría bien con agua (proceso mayoritario) o con aire (Blasco et al., 1992).

Una vez obtenida la frita, ésta puede aplicarse en seco, a modo de granilla previa molturación en seco, o bien formar parte de la composición de esmaltes. Para este último propósito, las fritas, junto con otras materias primas cristalinas y pigmentos cerámicos, se molturan por vía húmeda, obteniendo una suspensión. Esta suspensión puede aplicarse directamente sobre el soporte cerámico mediante diversas técnicas como pueden ser la cortina (vela o campana), la pulverización (discos o aerógrafos), o la inyección. También puede someterse a procesos de secado con secaderos tipo flash o por atomización para poder aplicarse o suministrarse en seco. En la Figura 1.5, se representa de forma ilustrada el proceso de fabricación de los esmaltes cerámicos. Los pigmentos o colorantes cerámicos se basan en compuestos inorgánicos y se utilizan en pequeñas proporciones para conferir color a los esmaltes o a los soportes de las baldosas.

El proceso de fabricación de pigmentos cerámicos consta de varias etapas (Mestre, 1997; Singer and Singer, 1971). En primer lugar, se hace una selección de las materias primas apropiadas, y se mezclan en seco o se molturan por vía seca o vía húmeda. La mezcla resultante se calcina a elevada temperatura en hornos discontinuos, en los que el material se coloca dentro de crisoles refractarios, o en hornos continuos rotativos. En este último caso, los hornos en continuo pueden ser de contacto de llama directo o indirecto, en relación al contacto de los gases con las materias primas. Como resultado de esta calcinación, se obtiene un producto sinterizado. Dicho producto se moltura en seco o en húmedo, secando en el segundo caso la suspensión resultante, y se mezcla, o no, con otros componentes para obtener el pigmento final. 


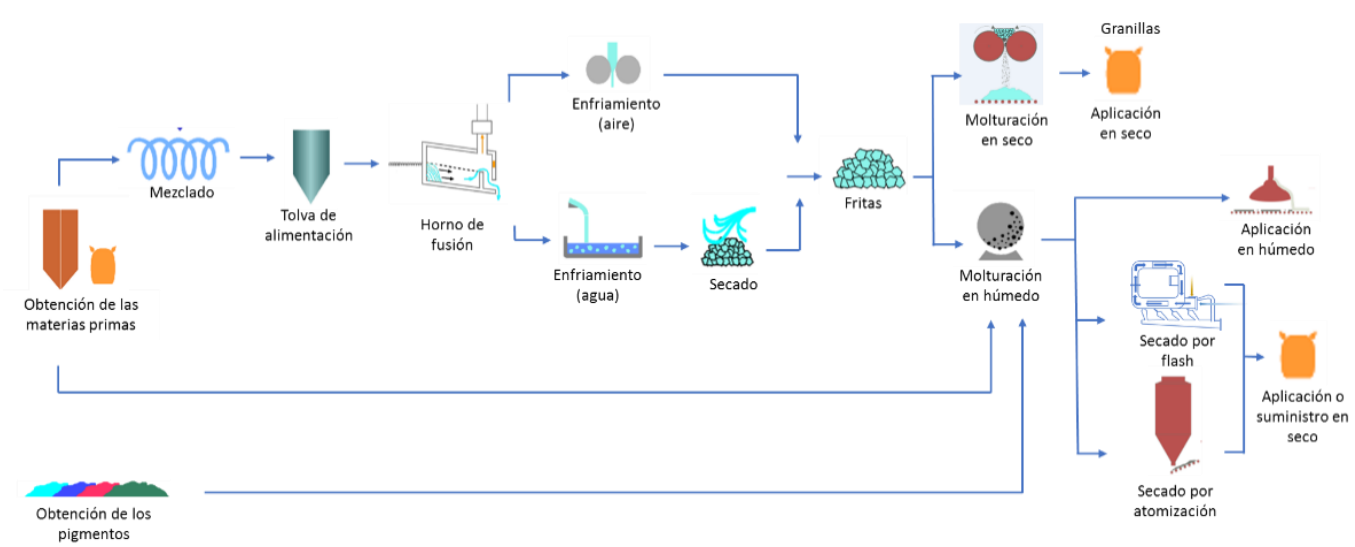

Figura 1.5 Fabricación de esmaltes cerámicos

\subsection{Principales aspectos ambientales de la fabricación de las baldosas y esmaltes cerámicos}

Entendemos por aspecto ambiental a un elemento derivado de las actividades, productos o servicios que pueda interactuar con el medio ambiente (ISO 14001, 2015).

Los principales aspectos ambientales en la industria cerámica son los siguientes (Instituto de Tecnología Cerámica y Comisión de Trabajo, 2010):

- Consumo de materias primas inorgánicas, las cuales suelen utilizarse, por lo general, tal y como se extraen de la mina o cantera o después de someterlas a un tratamiento físico relativamente sencillo (trituración, molienda, cribado, etc.)

- Consumo de energía térmica, procedente de la combustión del gas natural. Se emplea en la preparación de materias primas para el soporte, secado y cocción principalmente. También puede emplearse gas natural u otro tipo de combustible para secar las piezas porosas tras los procesos (opcionales) de mecanizado por vía húmeda. En la fabricación de esmaltes, se utiliza energía térmica para la fusión de fritas y en la etapa de calcinación para la obtención de los pigmentos cerámicos.

- Consumo de energía eléctrica, se da en todas las etapas de proceso, aunque los procesos de molienda de materias primas son los de mayor demanda.

- Consumo de agua, como materia prima en la preparación de las materias primas del soporte por vía húmeda, en el enfriamiento de las fritas con agua, en la preparación de esmaltes que son aplicados en húmedo y en la limpieza de equipamientos e instalaciones generales. 
- Emisiones a la atmósfera de partículas y compuestos gaseosos, tales como óxidos de carbono, óxidos de nitrógeno, óxidos de azufre, compuestos inorgánicos de flúor y cloro, compuestos orgánicos y metales pesados, que se generan tanto en la fabricación de las baldosas como en la fabricación de fritas, esmaltes y pigmentos.

- Aguas residuales de proceso, generadas en la limpieza de equipos e instalaciones y en los procesos de mecanizado. Estas aguas contienen principalmente componentes minerales y otros materiales inorgánicos, además de pequeñas cantidades de numerosos materiales orgánicos y metales pesados.

- Generación de residuos de proceso y asociados, compuestos principalmente por diferentes tipos de lodos, piezas rotas generadas antes y después de la cocción, agentes de adsorción usados, material pulverulento recogido por los sistemas de depuración, etc.

- Residuos no cerámicos, la mayoría derivados de las labores de mantenimiento de la maquinaria e instalaciones como aceites usados, envases de papel, plástico o metálicos, residuos de envases y embalajes (plástico, madera, cartón), chatarra, etc.

- Ruido y vibraciones, siendo los principales focos generadores hacia el exterior: las turbinas de cogeneración, motores ubicados en el exterior de la planta, actividades de carga y descarga de materias primas y producto acabado.

\subsubsection{Consumo de materias primas}

El soporte cerámico supone alrededor de un $95-97 \%$ en peso de la baldosa, mientras que la fina capa (opcional) de esmalte cerámico, supone sobre un 3-5\% (BenchTile, 2017; DAP sectorial, 2018).

Las materias primas necesarias para la fabricación de los soportes cerámicos se clasifican como: materias primas plásticas y materias primas no plásticas o desgrasantes. En general, se puede aceptar que la proporción entre estos dos tipos de materiales debe ser tal, que la mezcla obtenida sea tan plástica como para poder realizar un correcto moldeo de la pieza, y a la vez, conferir a ésta la suficiente resistencia en crudo como para permitir procesarla; además, su composición depende de las especificaciones requeridas para el producto acabado, es decir, que depende del tipo de baldosa cerámica.

- Las materias primas plásticas por excelencia son: las arcillas y los caolines.

- Las materias primas no plásticas o desgrasantes más habituales son: arenas silíceas, feldespatos alcalinos, carbonato cálcico, talco y silicato de circonio o circón.

- Otras materias primas que considerar son: los residuos de la propia fábrica, que pueden ser lodos o piezas de tiesto crudo o cocido, introduciéndose en la etapa de molturación de las materias primas. 
En cuanto a las materias primas de los esmaltes, las más habituales utilizadas en la formulación son: cuarzo, caolín, feldespatos alcalinos, nefelina, carbonato cálcico, dolomita, circón, wollastonita, alúmina calcinada y fritas cerámicas. También se añaden aditivos (suspensivantes, desfloculantes, ligantes) y pigmentos cerámicos preparados "ex proceso", generalmente por calcinación de óxidos (BenchTile, 2017; DAP sectorial, 2018). La proporción de estas materias primas varía en función de las características del vidriado a obtener (transparentes o cristalinas, opacas y mate) y del tipo de baldosas sobre las que se va a aplicar.

\subsubsection{Consumo de energía térmica y eléctrica}

La fabricación de baldosas cerámicas requiere un gran aporte de energía (30-40 kWh/m² para un peso específico medio de $22 \pm 1 \mathrm{~kg} / \mathrm{m}^{2}$ ) (Ibáñez-Forés et al., 2011; Mezquita et al., 2017; Monfort et al., 2010), sobre todo térmica, que supone el $90 \%$ del consumo directo total (Monfort et al., 2010). La energía térmica se consume principalmente en la etapa de secado de las suspensiones cerámicas (secado por atomización), el secado de los soportes recién conformados y, sobre todo, en la cocción de las baldosas cerámicas. El combustible mayormente empleado en la actualidad es el gas natural. La distribución porcentual media del consumo directo en estas tres etapas se refleja en la Figura 1.6.

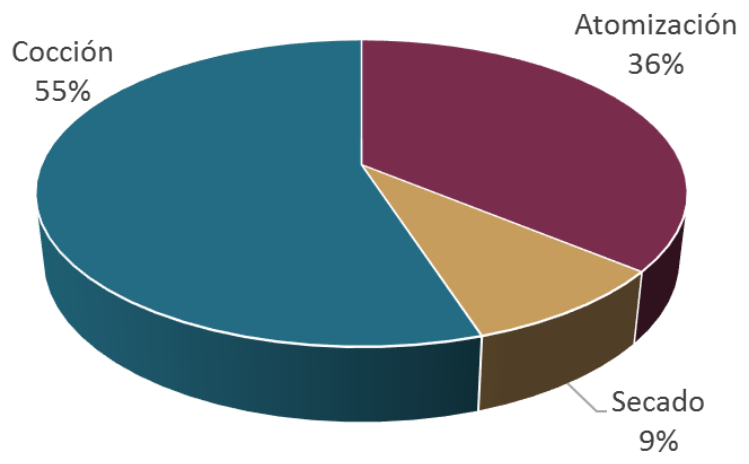

Figura 1.6 Distribución porcentual del consumo de energía térmica por etapas

En la fabricación de esmaltes, el consumo de energía térmica se da principalmente en la etapa de fusión de fritas (2,5-3,6 kWh/kg de frita) (EIPPCB, 2012).

La energía eléctrica se consume en todas las etapas de los procesos de fabricación de baldosas y esmaltes, siendo las etapas de mayor demanda de energía eléctrica, la molienda de las materias primas y el conformado de las piezas; no obstante, su consumo global es muy inferior al de energía térmica (Instituto de Tecnología Cerámica y Comisión de Trabajo, 2010) (3,3-4.4kWh/m², (Monfort et al., 2011b)). 


\subsubsection{Consumo de agua}

El agua desarrolla un papel muy importante en la industria cerámica, pues es un elemento indispensable para una serie de procesos, tanto en la fabricación de las baldosas como del esmalte. El agua consumida en el sector español se extrae mayoritariamente de pozos (Celades et al., 2012; Moliner, 2017), y en menor medida, de la red de distribución (que también procede en su mayoría de aguas subterráneas). El agua utilizada se puede clasificar en cuatro grandes grupos según la función que cumple en el proceso, que, a su vez, determina su destino final.

Los usos principales del agua son (Blasco et al., 1992; Instituto de Tecnología Cerámica y Comisión de Trabajo, 2010; Moliner, 2017):

- En la preparación de las materias primas para soportes cerámicos (molienda vía húmeda, humectación/granulación en la vía seca), preparación de esmaltes y humectación de piezas para la posterior aplicación de esmaltes.

- Como agente reductor de emisiones de partículas difusas (riego) y canalizadas (sistemas de depuración vía húmeda).

- Como agente de lavado de las instalaciones de preparación de las materias primas y preparación del esmalte y líneas de esmaltado.

- Como vehículo de intercambio de calor en la fabricación de fritas y en los tratamientos mecánicos, como pulido, lapatto, corte y biselado.

- Otros usos. En la industria cerámica, también se emplea agua en el lavado de colorantes calcinados, refrigeración y sellado de bombas, enfriamiento de compresores, enfriamiento de prensas hidráulicas, etc.

Parte del agua consumida en la preparación de las materias primas del soporte por vía húmeda es agua residual, generada en la misma planta o en centros productivos de baldosas cerámicas. Por otro lado, el agua empleada como vehículo de intercambio de calor en el enfriamiento de las fritas y en los procesos de mecanizado, se recircula en circuitos cerrados para su reutilización. No obstante, la evaporación de gran cantidad de agua, hace que los sólidos en suspensión y la conductividad de este agua aumente considerablemente, por lo que se somete a un tratamiento de decantación para la eliminación de sólidos y filtroprensado de los lodos obtenidos. Para compensar la pérdida de agua por evaporación y por purga del circuito para reducir la conductividad, se debe incorporar agua nueva.

El consumo de agua nueva en la fabricación de baldosas y esmaltes se especifica en la Tabla 1.3, diferenciando por etapa de proceso, y especificando por consumo medio por $\mathrm{kg}$ o por $\mathrm{m}^{2}$, según proceda en cada caso (BenchTile, 2017; DAP sectorial, 2018). 
Tabla 1.3 Consumos medios de agua nueva por etapas de proceso

\begin{tabular}{|c|c|}
\hline Etapa de proceso & Consumo medio \\
\hline Preparación de materias primas por vía húmeda ${ }^{(1)}$ & $0,46 \mathrm{l} / \mathrm{kg}$ de atomizado \\
\hline Preparación de fritas ${ }^{(2)}$ & $0,5-3 \mathrm{l} / \mathrm{kg}$ de fritas \\
\hline Preparación de esmaltes ${ }^{(1)}$ & $\begin{array}{c}2,1 \mathrm{l} / \mathrm{kg} \text { de esmalte } \\
1,7 \mathrm{I} / \mathrm{m}^{2}\end{array}$ \\
\hline Limpieza de las líneas de esmaltado(1) & $\begin{array}{c}8 \mathrm{l} / \mathrm{kg} \text { de esmalte } \\
6,3 \mathrm{l} / \mathrm{m}^{2}\end{array}$ \\
\hline Tratamientos mecánicos (opcionales) ${ }^{(1)}$ & $1,8 \mathrm{l} / \mathrm{m}^{2}$ \\
\hline $\begin{array}{l}\text { Fuentes: } \\
\text { (1): BenchTile, 2017; DAP sectorial, } 2018 \\
\text { (2): EIPPCB, } 2012\end{array}$ & \\
\hline
\end{tabular}

\subsubsection{Aguas residuales industriales}

En la fabricación de baldosas, se generan aguas residuales industriales en las operaciones de limpieza y en la preparación y aplicación de esmaltes. En el resto de etapas, el agua consumida o bien se evapora, como son los casos del secado por atomización y humectación de las piezas antes de la aplicación de los esmaltes, o bien se trata y recircula en un circuito cerrado, como son los casos de los procesos de tratamiento superficial de pulido, lapatto, corte y biselado, así como del agua empleada para el enfriamiento en la fabricación de fritas (Blasco et al., 1992; Moliner, 2017), como se ha indicado en el apartado 1.2.3.

Estas aguas residuales suelen presentar turbidez y color debido a las finísimas partículas de esmalte y mineral arcilloso en suspensión (Instituto de Tecnología Cerámica y Comisión de Trabajo, 2010). Desde el punto de vista químico, se caracterizan por la presencia de:

- Sólidos en suspensión: arcillas, restos de frita, silicatos insolubles en general.

- Aniones en solución: sulfatos, cloruros, fluoruros, etc.

- Metales pesados en solución y/o suspensión: principalmente plomo y zinc.

- Boro.

- Materia orgánica: vehículos y colas utilizadas en las operaciones de esmaltado.

La concentración de estos elementos dependerá de la operación que las genera, del tipo y composición de los esmaltes utilizados y del volumen de agua empleado.

Cabe decir que, la mayoría de las empresas del sector español tiene vertido cero de aguas residuales industriales, ya que las recicla como materia prima en la fabricación de gránulo por vía húmeda. 


\subsubsection{Emisiones atmosféricas}

Las emisiones atmosféricas tienen unas características u otras dependiendo de la etapa de proceso donde se generen. En la Tabla 1.4, se describen las principales emisiones atmosféricas originadas directamente de la fabricación de baldosas cerámicas y proceso de fritado.

Tabla 1.4 Características de las principales emisiones atmosféricas de la fabricación de baldosas cerámicas y fritas (Blasco et al., 1992)

\begin{tabular}{|c|c|c|c|c|}
\hline \multirow{2}{*}{ Etapa de proceso } & \multicolumn{4}{|c|}{ Emisión } \\
\hline & Concentración & Caudal & Foco $^{(1)}$ & $\begin{array}{c}\text { Contaminante } \\
\text { emitido }\end{array}$ \\
\hline $\begin{array}{c}\text { Almacenamiento y } \\
\text { manipulación de materias } \\
\text { primas (arcillas) }\end{array}$ & Variable & $\begin{array}{l}\text { Continuo/ } \\
\text { Discontinuo }\end{array}$ & $\begin{array}{c}\text { Difuso/ } \\
\text { Canalizado }\end{array}$ & Partículas \\
\hline Molienda en seco & Variable & $\begin{array}{c}\text { Continuo/ } \\
\text { Discontinuo }\end{array}$ & Canalizado & Partículas \\
\hline Molienda en húmedo & Variable & $\begin{array}{c}\text { Continuo/ } \\
\text { Discontinuo }\end{array}$ & Canalizado & Partículas \\
\hline Secado por atomización & Constante & Continuo & Canalizado & Partículas y gases ${ }^{(2)}$ \\
\hline Conformado & Variable & Continuo & Canalizado & Partículas \\
\hline Secado & Constante & Continuo & Canalizado & Partículas y gases ${ }^{(2)}$ \\
\hline Fusión de fritas & Constante & $\begin{array}{l}\text { Continuo/ } \\
\text { Discontinuo }\end{array}$ & Canalizado & Partículas y gases ${ }^{(2)(3)}$ \\
\hline Preparación de esmaltes & Variable & Discontinuo & Canalizado & Partículas \\
\hline Esmaltado & Variable & Continuo & Canalizado & Partículas \\
\hline Cocción & Constante & Continuo & Canalizado & Partículas y gases ${ }^{(2)(3)}$ \\
\hline $\begin{array}{l}\text { (1) Emisión canalizada: emisión } \\
\text { a la atmósfera sin haber sido c } \\
\text { (2) Gases: } \mathrm{CO}_{2}, \mathrm{CO}, \mathrm{NO}_{x}, \mathrm{SO}_{x} \text {, } \\
\text { (3) Otros contaminantes gaseo }\end{array}$ & $\begin{array}{l}\text { a través de focos c } \\
\text { analizadas a través } \\
\text { etc. } \\
\text { sos }\end{array}$ & $\begin{array}{l}\text { halizados (chime } \\
\text { conducciones. }\end{array}$ & eas). Emisión di & usa: emisiones que llegan \\
\hline
\end{tabular}

\section{Emisiones de partículas}

La emisión de material particulado está considerada uno de los aspectos ambientales más significativos en la fabricación de baldosas cerámicas, ya que se trata de una actividad industrial que procesa materiales de naturaleza pulverulenta.

Este material particulado se emite a partir de focos canalizados y difusos, dependiendo del canal de emisión. Su naturaleza, composición química y concentración viene determinada por las materias primas empleadas y por las características de la etapa de proceso que las origina (Celades, 2013; Sanfélix, 2017). 


\section{Emisiones de contaminantes gaseosos}

Las emisiones gaseosas se originan en procesos industriales de alta temperatura y/o donde tienen lugar los procesos de combustión, es decir, en el secado de las suspensiones en secaderos por atomización, secado de las piezas conformadas, cocción de las baldosas cerámicas y fusión de fritas. Los contaminantes gaseosos se pueden agrupar según los procesos que los generan en:

- Gases generados en los procesos de combustión: $\mathrm{CO}_{2}, \mathrm{CO}, \mathrm{NO}_{x}, \mathrm{SO}_{x}$, etc.

- Gases producidos por la descomposición de las materias primas en los procesos de alta temperatura en los que se producen transformaciones físico-químicas importantes de los materiales procesados: $\mathrm{CO}_{2}, \mathrm{HF}, \mathrm{HCl}, \mathrm{SO}_{\times}$, metales pesados, compuestos orgánicos volátiles (COVs), etc.

Es posible encontrar más información al respecto recogida por Gomar, 2016 y Monfort et al., $2011 a$.

Desde la Figura 1.7 hasta la Figura 1.10, se detallan las concentraciones medias y los intervalos entre los que se encuentran, así como las etapas de proceso donde se generan los citados contaminantes. Estos valores han sido facilitados por las empresas del sector en 2018 a través del proyecto "Benchmarking Sectorial-Elaboración de un Benchmarking ambiental y energético para la elaboración de una DAP sectorial" (BenchTile, 2017) y del proyecto "Elaboración de una DAP sectorial del proceso de fabricación de baldosas cerámicas" (DAP sectorial, 2018). Además, en las gráficas también se reflejan los valores límite asociados a las Autorizaciones Ambientales Integradas (AAl) concedidas a las empresas del sector cerámico de la Comunitat Valenciana.

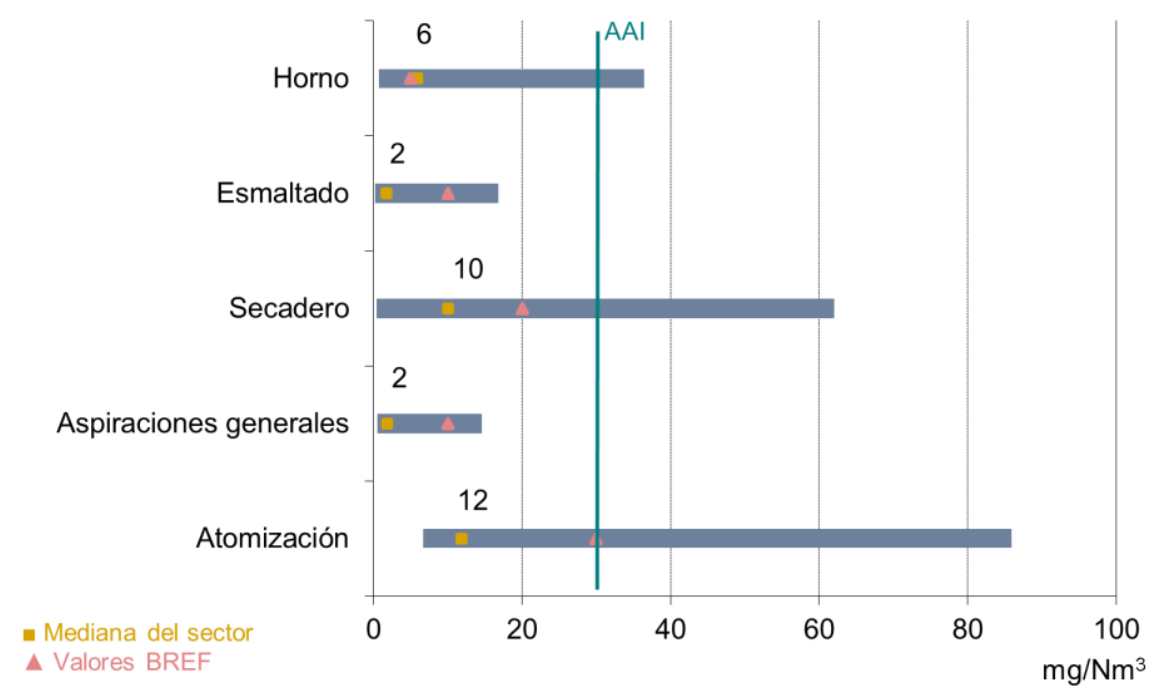

Figura 1.7 Concentración de partículas en emisiones atmosféricas (en $\mathrm{mg} / \mathrm{Nm}^{3}$, referidas al $18 \%$ de $\mathrm{O}_{2}$ ) 


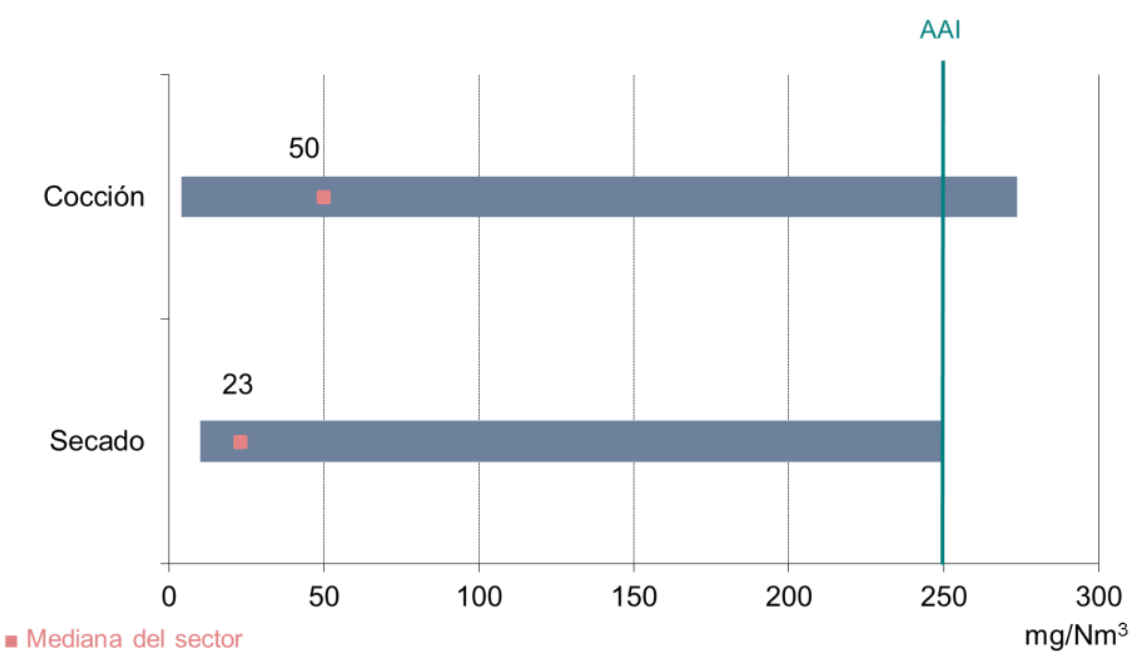

Figura 1.8 Concentración de $\mathrm{NO}_{x}$ en emisiones atmosféricas (en $\mathrm{mg} / \mathrm{Nm}^{3}$ referidas al $18 \%$ de $\mathrm{O}_{2}$ )

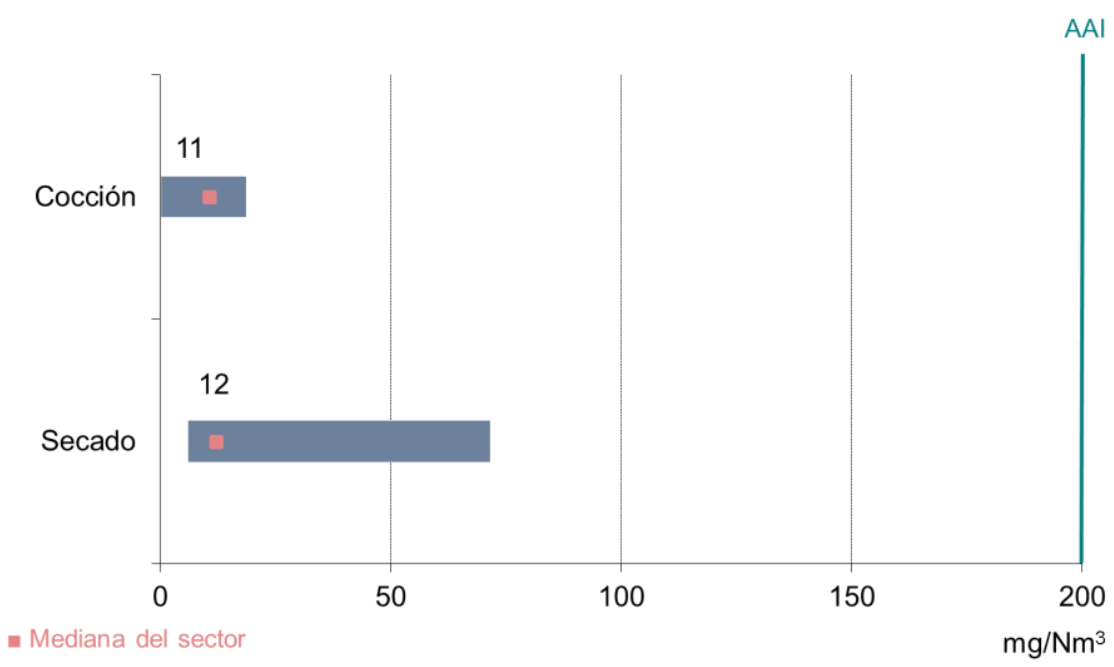

Figura 1.9 Concentración de $\mathrm{SO}_{2}$ en emisiones atmosféricas (en $\mathrm{mg} / \mathrm{Nm}^{3}$ referidas al $18 \%$ de $\mathrm{O}_{2}$ ) 


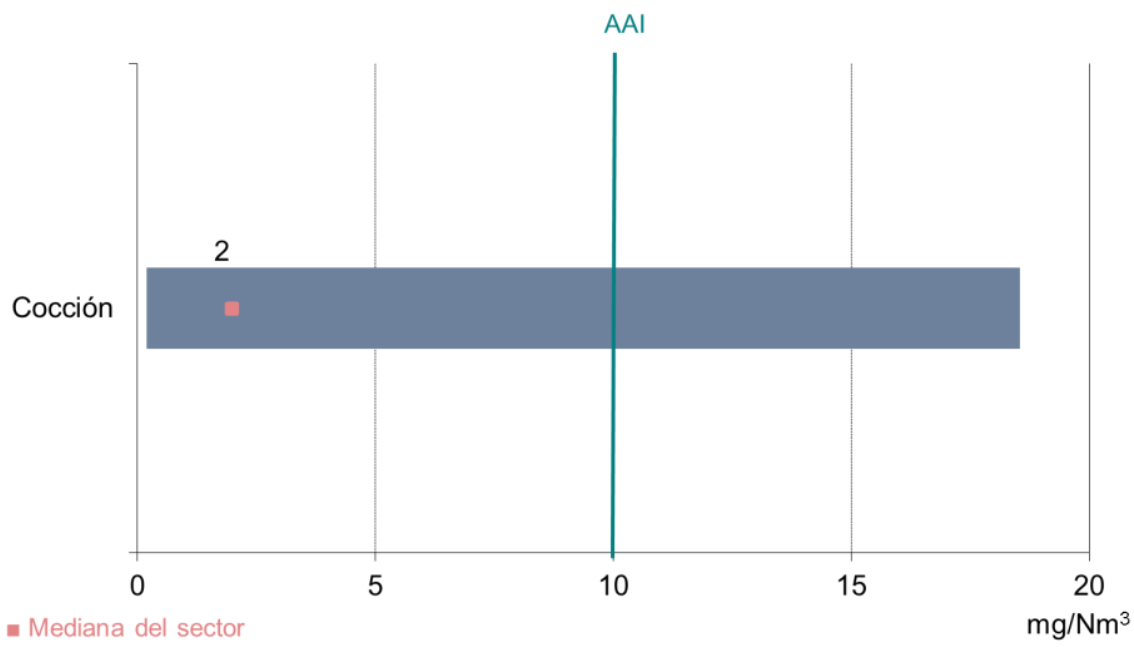

Figura 1.10 Concentración de HF en emisiones atmosféricas (en mg/ $\mathrm{Nm}^{3}$, referidas al $18 \%$ de $\mathrm{O}_{2}$ )

\subsubsection{Residuos industriales}

Como ocurre en el resto de los sectores industriales, los residuos que se generan en los procesos de la industria cerámica pueden agruparse básicamente en residuos peligrosos y no peligrosos, con arreglo a la lista de residuos establecida por última vez mediante la Decisión 2014/955/UE.

Los residuos industriales no peligrosos son los que se generan en mayor volumen y proceden de todas las etapas del proceso productivo. Los más numerosos son: residuos de piezas cerámicas generadas antes y después del proceso de cocción, restos de materias primas y aditivos, polvo retenido por los sistemas de depuración de emisiones atmosféricas canalizadas, lodos y suspensiones acuosas que contienen materiales cerámicos, residuos de envases y embalajes, y residuos derivados de los servicios auxiliares de proceso y mantenimiento, tales como envases, chatarra, rodillos, elementos refractarios, abrasivos, etc.

Los residuos peligrosos se producen en los procesos que utilizan materias primas que, por su composición, les pueden conferir ese carácter. Son destacables los restos de materias primas contaminadas y aditivos, fangos y otros materiales procedentes de la depuración de aguas de proceso que contengan sustancias peligrosas, derivados de los servicios auxiliares de proceso y mantenimiento, como residuos de envases contaminados, aceites usados, baterías, filtros, etc.

La Tabla 1.5, recoge las cantidades promedio de los residuos generados en la fabricación de baldosas, indicando el código LER (Decisión 2014/955/UE). En cuanto a los residuos generados por las empresas atomizadoras, se ha considerado que no se ha obtenido suficiente representatividad, por lo que no se han incluido. 
Tabla 1.5 Cantidades medias de residuos generados en la fabricación de baldosas cerámicas (BenchTile, 2017; DAP sectorial, 2018)

\begin{tabular}{|l|c|c|}
\hline \multicolumn{1}{|c|}{ Residuos específicos } & Código LER & Cantidad de residuo generado $\left(\mathbf{g} / \mathbf{m}^{2}\right)$ \\
\hline Aceites prensas & $130100^{*}$ & 0,4 \\
\hline Tierra contaminada & $170106^{*}$ & 0,1 \\
\hline Residuos de piezas cocidas & 101208 & 374.1 \\
\hline $\begin{array}{l}\text { Residuos de piezas crudas y } \\
\text { partículas de polvo }\end{array}$ & 101201 & 651,73 \\
\hline Esmaltes antes de la cocción & 101203 & 9,8 \\
\hline Suspensiones acuosas & $101109^{*}$ & 1500,0 \\
\hline Lodos no peligrosos & 80203 & 139,0 \\
\hline Plásticos de embalaje & 80202 & 2,4 \\
\hline Cartón y papel & 150102 & 9,4 \\
\hline Envases de madera & 150101 & 2,7 \\
\hline Envases contaminados & 150103 & 0,6 \\
\hline Trapos y absorbentes & $150110^{*}$ & 0,2 \\
\hline * Indican que el residuo está clasificado como peligroso & \\
\hline
\end{tabular}

\subsection{Marco político}

El presente trabajo de investigación está alineado con una serie de políticas que promueven la sostenibilidad ambiental mediante el uso eficiente de energía y recursos naturales. En esta sección, se presenta un resumen de la Agenda 2030 de la Organización Mundial de las Naciones Unidas (ONU) sobre Desarrollo Sostenible a nivel internacional y los objetivos de la Unión Europea sobre Energía, Cambio Climático y Medio Ambiente.

\subsubsection{Organización Mundial de las Naciones Unidas}

En 2015, la ONU aprobó la Agenda 2030 sobre el Desarrollo Sostenible, en la que se desarrollan 17 Objetivos (véase la Figura 1.11), que incluyen entre otros, la lucha contra el cambio climático, la defensa del medio ambiente o el diseño de las ciudades. Cada uno de estos objetivos comprende diferentes metas, con diferentes alcances y destinatarios (ONU, 2015). 

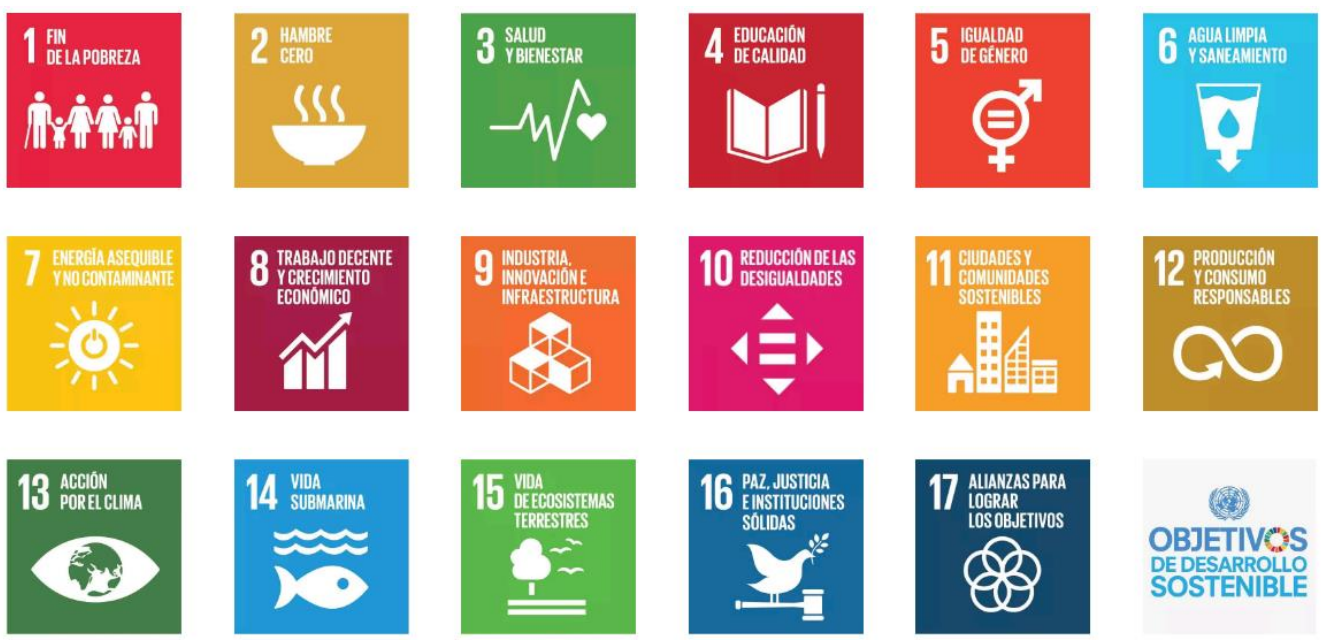

OBJETIVOS

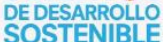

Figura 1.11 Pictograma de los objetivos de desarrollo sostenible de la ONU (ONU, 2015).

A continuación, se resumen los objetivos que, a juicio de la autora, están directamente relacionados con el sector español de las baldosas cerámicas:

Objetivo 6: Garantizar la disponibilidad de agua y su gestión sostenible y el saneamiento para todos

Metas 6.3 y 6.4: para el 2030, mejorar el uso eficiente del agua y mejorar la calidad de las aguas residuales

Objetivo 7: Garantizar el acceso a una energía asequible, segura, sostenible y moderna para todos Metas 7.2 y 7.3: aumentar la proporción de energía renovable y mejorar la eficiencia energética.

Objetivo 9: Industria, Innovación e Infraestructuras

Metas 9.1 y 9.4: aumentar la sostenibilidad de las industrias, optimizando los residuos y promoviendo la adopción de tecnologías y procesos industriales limpios y ambientalmente racionales.

\section{Objetivo 11: Ciudades y Comunidades Sostenibles}

Meta 11.6: reducir el impacto ambiental negativo de las ciudades, prestando especial atención a la calidad del aire y la gestión de los desechos municipales y de otro tipo.

Objetivo 12: Garantizar modalidades de consumo y producción sostenibles

Metas 12.2, 12.4-12.7: lograr la gestión sostenible y el uso eficiente de los recursos naturales, reducción de desechos y gestión racional de los mismos a lo largo de su ciclo de vida, adopción de medidas sostenibles por parte de las empresas e incorporación de información sobre la sostenibilidad en su ciclo de vida y promoción de prácticas de adquisición pública sostenibles. 
Objetivo 13: Adoptar medidas urgentes para combatir el cambio climático y sus efectos Meta 13.2: incorporar medidas relativas al cambio climático en las políticas, estrategias y planes nacionales.

\subsubsection{Políticas de la Unión Europea}

La política ambiental europea se basa en los principios de cautela, prevención, corrección de la contaminación en su fuente y "quien contamina paga". Desde 1973, la Comisión Europe establece las acciones futuras en todos los ámbitos de la política ambiental (propuestas legislativas y objetivos para la política ambiental) a través de los Programas de Acción plurianuales.

\section{Programas de Acción plurianuales}

En Junio 2002, se aprobó el Sexto Programa de Acción en materia de Medio Ambiente (Decisión 1600/2002/CE) que determinó la política ambiental de la Unión Europea (en adelante EU) a lo largo de la década 2002-2012.

Durante este periodo, se aprobó la Directiva 2010/75/EU, sobre las emisiones industriales, cuyo objeto es simplificar el marco jurídico y las cargas administrativas, y lograr un alto nivel de protección del medio ambiente en su conjunto. Para ello, se aplica un enfoque integrado y armonizado a nivel europeo sobre la prevención y el control de las emisiones a la atmósfera, el agua y el suelo, a la gestión de residuos, a la eficiencia energética y a la prevención de accidentes.

El enfoque integrado significa que, las instalaciones donde se lleven a cabo las actividades enumeradas en el Anexo I de la Directiva 2010/75/EU, deben cumplir con ciertos principios:

- Implementar medidas preventivas contra la contaminación.

- Aplicar las Mejores Técnicas Disponibles.

- Asegurar que no se produce ninguna contaminación importante.

- Evitar la generación de los residuos, en primer lugar, y gestionar los residuos generados priorizando la reutilización, reciclaje, recuperación, de acuerdo a la Directiva 2008/98/CE.

- Maximizar la eficiencia energética.

- $\quad$ Prevenir posibles accidentes y limitar su impacto.

- Rehabilitar los lugares de la explotación cuando las actividades llegan a su fin.

Las condiciones de los permisos a estas instalaciones, incluidos los valores límite de emisión, deben basarse en el contenido de las conclusiones sobre las mejores técnicas disponibles (en adelante MTD) que se recogen en los documentos de referencia sobre las MTDs denominados BREF por sus siglas del inglés Best available techniques Reference Documents.

A continuación, se lista los documentos BREF que afectan al sector de las baldosas cerámicas: 
- $\quad$ BREF in the Ceramic Manufacturing Industry (EIPPCB, 2007a).

- $\quad$ BREF in the Glass Manufacturing Industry (EIPPCB, 2012).

- $\quad$ BREF in Production of Speciality Inorganic Chemicals (EIPPCB, 2007b).

- $\quad$ BREF in Emissions from Storage (EIPPCB, 2006).

En 2013 se aprobó el Séptimo Programa de Acción en materia de Medio Ambiente (en adelante $7^{\circ} \mathrm{PMA}$ ) mediante la Decisión 1386/2013/EU, es el marco general que guia la política ambiental europea hasta 2020. Este programa incluye la iniciativa de "vivir bien dentro de los límites del planeta", la cual enfatiza la necesidad de "convertir a la Unión en una economía eficiente en recursos, ecológica y competitiva con bajas emisiones de carbono" para 2050.

El programa identifica tres ámbitos prioritarios:

- Proteger la naturaleza y fortalecer la resiliencia ecológica.

- Promover un crecimiento hipocarbónico que utilice los recursos de forma eficiente.

- Reducir las amenazas para la salud y el bienestar humanos asociadas a la contaminación, las sustancias químicas y el impacto del cambio climático.

En lo que respecta al segundo ámbito incluye: la Estrategia Europa 2020, con acuerdos para alcanzar metas más ambiciosas a más largo plazo; la mejora significativa del comportamiento ambiental de los productos a lo largo de su ciclo de vida; y la disminución del impacto ambiental del consumo, con especial preocupación por transformar los residuos en recursos

La Estrategia Europa 2020 es el programa marco de la UE para "un crecimiento inteligente, sostenible e integrador" (COM(2010)2020 final). Su enfoque se basa en la idea de que se requieren soluciones innovadoras para movilizar inversiones en energía, transporte, industria y tecnologías de la información y la comunicación, y en la necesidad de utilizar eficazmente los recursos.

Dentro de esta estrategia, se establecen una serie de políticas (planes, programas, paquetes y hojas de ruta). A continuación, se resumen aquellas con mayor incidencia desde el punto de vista de la presente tesis para el sector cerámico.

\section{Paquete de Medidas sobre Clima y Energía para 2020}

El paquete establece tres objetivos clave:

- Reducción del 20\% de las emisiones de gases de efecto invernadero (en adelante GEI), con respecto a los niveles de 1990, de las grandes instalaciones, de los sectores de la energía y la industria, así como del sector de la aviación.

- El $20 \%$ de la energía de la UE debe proceder de fuentes renovables. Además, se incluyen objetivos nacionales (Directiva 2009/28/CE) según los diferentes puntos de partida de los Estados miembros. España tiene un $20 \%$ como objetivo nacional. 
- El 20\% de mejora de la eficiencia energética, mediante las medidas establecidas en el Plan de Eficiencia Energética y en la Directiva 2012/27/EU. Posteriormente, han habido dos nuevas actualizaciones para ampliar este objetivo de eficiencia energética. En Noviembre 2016 se propuso ampliar la eficiencia energética al $30 \%$ y reducir las emisiones asociadas de $\mathrm{CO}_{2}$ en al menos un $40 \%$ para 2030.

Asimismo, se aprueba la estrategia energética 2020 para una energía competitiva, sostenible y segura mediante COM(2010)639 final y SEC(2010)1436 final.

\section{Hoja de Ruta hacia una Economía Hipocarbónica Competitiva en 2050}

La Comisión Europea mira más allá de los objetivos para 2020, y establece un plan con objetivos y medidas económicas para alcanzar el objetivo, a largo plazo, de reducir las emisiones para avanzar hacia una economía competitiva con bajas emisiones de carbono en 2050 (COM(2011)112 final).

Esta hoja de ruta marca como objetivo una reducción global del $79-82 \%$ de las emisiones de GEI de la UE para 2050 (en comparación con 1990) para los sectores económicos clave, considerando los ritmos de innovación tecnológica y los precios de los combustibles fósiles. Además, insta a los diferentes sectores a trazar su propia hoja de ruta, considerando los costes, los compromisos y las incertidumbres. En la Tabla 1.6, se especifican los objetivos de reducción de emisiones de GEl, con respecto 1990.

Tabla 1.6 Objetivos de reducción de gases de efecto invernadero, con respecto 1990

\begin{tabular}{|l|c|c|c|}
\hline \multicolumn{1}{|c|}{ Sectores } & 2005 & 2030 & 2050 \\
\hline Electricidad $\left(\mathrm{CO}_{2}\right)$ & $-7 \%$ & $-54 \mathrm{a}-68 \%$ & $-93 \mathrm{a}-99 \%$ \\
\hline Industria $\left(\mathrm{CO}_{2}\right)$ & $-20 \%$ & $-34 \mathrm{a}-40 \%$ & $-83 \mathrm{a}-87 \%$ \\
\hline $\begin{array}{l}\text { Transporte }\left(\mathrm{CO}_{2}\right) \text { (incluido la aviación, } \\
\text { excluido el transporte marítimo) }\end{array}$ & $+30 \%$ & $+20 \mathrm{a}-9 \%$ & $-54 \mathrm{a}-67 \%$ \\
\hline Residencial y servicios $\left(\mathrm{CO}_{2}\right)$ & $-12 \%$ & $-37 \mathrm{a}-53 \%$ & $-88 \mathrm{a}-91 \%$ \\
\hline Agricultura $\left(\mathrm{no} \mathrm{CO}_{2}\right)$ & $-20 \%$ & $-36 \mathrm{a}-37 \%$ & $-42 \mathrm{a}-49 \%$ \\
\hline Otros distintos de $\mathrm{CO}_{2}$ & $-30 \%$ & $-72 \mathrm{a}-73 \%$ & $-70 \mathrm{a}-78 \%$ \\
\hline
\end{tabular}

El sector de la fabricación de las baldosas cerámicas tiene como objetivo reducir sus emisiones para el 2030 en un 34-40\%, y para el 2050 en un 83-87\%. En este sentido, Cerame Unie (Asociación Europea de las Industrias Cerámicas) ha publicado una hoja de ruta (Cerame Unie, 2012), donde identifica, de forma general, aquellas medidas potenciales encaminadas a estos objetivos, citando expresamente, la necesidad de abordar el problema desde una perspectiva de ciclo de vida, dada la longevidad de los materiales cerámicos. La Figura 1.12 presenta un análisis de algunas de las tecnologías clave que podrían aplicarse en toda la industria cerámica, matizando su disponibilidad actual y futura según la rentabilidad y la probabilidad de que tengan éxito en la reducción de emisiones de GEl (Cerame Unie, 2012). 


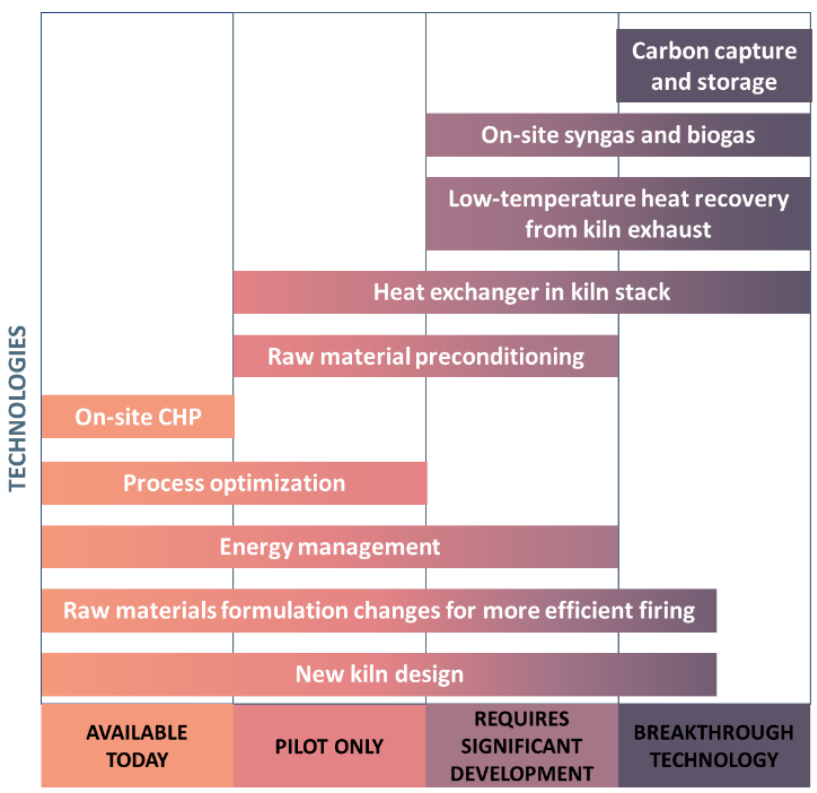

Figura 1.12 Análisis de tecnologías clave potenciales en toda la industria cerámica (Cerame Unie, 2012)

\section{Paquete de Economía Circular}

En 2015, la Comisión Europea adoptó el Plan de Acción de la Economía Circular (COM(2015)0614 final), donde se incluye medidas para estimular la transición de Europa hacia una Economía Circular, impulsar la competitividad mundial, fomentar el crecimiento económico sostenible y generar nuevos puestos de trabajo. Las acciones propuestas pretenden contribuir a "cerrar el círculo" de los ciclos de vida de los productos mediante un mayor reciclado y reutilización, y así, aportar beneficios, tanto para el medio ambiente, como para la economía.

En este Plan de Acción se determinan cinco sectores prioritarios para acelerar la transición a lo largo de sus cadenas de valor: plásticos, residuos alimentarios, materias primas críticas, construcción y demolición, biomasa y biomateriales.

\section{Hoja de Ruta para la Eficiencia de Recursos}

El Plan de trabajo para una Europa eficiente en el uso de los recursos (COM(2011)0571 final) describe cómo poder transformar la economía de Europa en una economía sostenible para 2050. Esta hoja de ruta propone formas de aumentar la productividad de los recursos, y desvincular el crecimiento económico del uso de los recursos y su impacto ambiental. Además, ilustra la forma en que las políticas asociadas se interrelacionan y se basan unas en otras.

En esta hoja de ruta, se hace especial mención a la necesidad de analizar los recursos clave desde la perspectiva del ciclo de vida y de la cadena de valor. Se citan los sectores de la nutrición, la 
vivienda, y la movilidad, como los sectores responsables de la mayoría de los impactos ambientales, y se proponen acciones en estos ámbitos para complementar las medidas existentes.

Concretamente, en lo que respecta al sector de la construcción, se publicaron las oportunidades de eficiencia de recursos específicas de este sector (COM(2014)445 final).

\section{El Plan de Acción de Ecoinnovación}

Para alcanzar los objetivos del $7^{\circ}$ PMA se necesitarán nuevas tecnologías y nuevos planteamientos empresariales con ideas innovadoras que favorecerán que las empresas europeas sean más competitivas y puedan contribuir a impulsar su crecimiento.

Este plan refuerza iniciativas como el sistema de gestión y auditorías ambientales (EMAS), la etiqueta ecológica de la UE, el sistema de verificación de tecnologías ambientales (ETV), la huella ambiental de los productos (PEF), y la Economía Circular.

\section{Nueva agenda estratégica 2019-2024}

En Junio de 2019 se aprueba la Agenda Estratégica 2019-2024 de la UE que se centra en cuatro prioridades principales:

- Proteger a los ciudadanos y las libertades;

- Desarrollar una base económica sólida y dinámica;

- Construir una europa climáticamente neutra, ecológica, justa y social;

- Promover los intereses y valores europeos en la escena mundial.

Por último, expone la manera de alcanzar dichos objetivos prioritarios.

\subsection{Análisis del ciclo de vida}

\subsubsection{Importancia de la perspectiva del ciclo de vida}

Se define ciclo de vida de un producto al conjunto de etapas consecutivas e interrelacionadas del sistema desde la adquisición de materias primas o generación de recursos naturales hasta su eliminación final (ISO 14040, 2006).

El objetivo clave del enfoque del ciclo de vida es obtener una visión global del conjunto del sistema a estudiar. Este enfoque permite tratar los aspectos ambientales más allá de los límites locales de los sistemas analizados pudiendo detectar puntos críticos no evidentes desde enfoques más sesgados; además, permite identificar posibles transferencias de cargas ambientales a lo largo de la cadena de fabricación, o de un medio a otro, transferencia geográfica, o bien transferencia entre impactos, al tiempo que se intenta minimizar los impactos ambientales en otros lugares (Baumann 
and Tillman, 2004; Fullana-i-Palmer and Puig, 1997). Por tanto, ayuda a la toma de decisiones, con rigor científico, a la hora de escoger las mejores tecnologías disponibles, y minimizar desde su diseño, el impacto ambiental de los productos (Benveniste et al., 2011; Ibáñez-Forés et al., 2013).

De forma tradicional, la gestión o control de los impactos ambientales se ha limitado a la etapa de fabricación del producto o a las principales salidas de materia y energía, prestando menor atención al consumo de materias primas y a los recursos indirectos. Por otro lado, muchas de las medidas correctoras secundarias conllevan una transferencia de carga ambiental de un medio a otro, ello confirma la necesidad de evaluar y analizar todas las consecuencias a lo largo del ciclo de vida del producto o servicio a estudiar.

Desde el punto de vista del fabricante, el enfoque del ciclo de vida facilita la identificación de oportunidades para mejorar el comportamiento ambiental del producto, y para obtener argumentos que aumenten la competitividad, mejoren la imagen de la empresa y reduzcan los costes económicos. Desde el punto de vista gubernamental, el enfoque del ciclo de vida ayuda a ver más allá de la frontera política, evaluando la situación y las consecuencias de las decisiones de manera global.

Esta perspectiva del ciclo de vida conlleva implicaciones especiales sobre los impactos ambientales de un sistema de producto ${ }^{1}$. La mayoría de los impactos ambientales considerados son globales y agregados en espacio y tiempo, no pudiendo trazar, en detalle, el momento o la zona geográfica afectada. La diferenciación geográfica y efectos sobre el entorno causada por las emisiones (residuos, vertidos o emisiones atmosféricas) depende de la cantidad de sustancias emitidas, las propiedades de la sustancia, las características de la fuente emisora y del medio receptor. Los impactos ambientales pueden ser calculados con arreglo a las condiciones del entorno, representando la suma de las emisiones y sus consecuencias durante años a partir de las emisiones liberadas en el momento del estudio.

\subsubsection{Análisis de ciclo de vida. Teoría}

El análisis de Ciclo de Vida (en adelante ACV) es una metodología para la evaluación de las cargas ambientales asociadas al ciclo de vida de un producto, proceso o actividad mediante la identificación y cuantificación del consumo de los recursos y de los residuos emitidos al entorno, con el fin de analizar el impacto de éstos sobre el medio ambiente y evaluar e implementar posibles mejoras (ISO 14040, 2006).

\footnotetext{
${ }^{1}$ Conjunto de procesos unitarios con flujos elementales y flujos de producto, que desempeña una o más funciones definidas, y que sirve de modelo para el ciclo de vida de un producto (ISO 14040, 2006)
} 
La primera definición formal del ACV fue formulada por SETAC (Society of Environmental Toxicology and Chemistry) en su publicación "Guidelines for Life Cycle Assessment: a code of practice" en 1993, como "un procedimiento objetivo de evaluación de cargas energéticas y ambientales correspondientes a un proceso o a una actividad, que se efectúa identificando los materiales y la energía utilizada y los residuos liberados en el ambiente natural. La evaluación se realiza en el ciclo de vida completo del proceso o actividad, incluyendo la extracción y tratamiento de la materia prima, la fabricación, el transporte, la distribución, el uso, el reciclado, la reutilización, y la retirada final".

El ACV es una técnica de soporte en la gestión ambiental pero puede no ser siempre la técnica más apropiada a usar en todas las situaciones. Normalmente, los ACV no incluyen aspectos económicos abordados por el Análisis de Costes del Ciclo de Vida (LCC, por sus siglas del inglés) o aspectos sociales abordados por el Análisis Social del Ciclo de Vida (SLCA, por sus siglas del inglés) relacionados con el producto o el proceso. El ACV no reemplaza el proceso de toma de decisiones, sino que aporta elementos para facilitarlo.

Los principios fundamentales en todo ACV son: apreciación general, enfoque ambiental, unidad funcional, enfoque iterativo, transparencia, integridad, y enfoque científico.

Los estudios de ACV se componen de 4 fases de trabajo interrelacionadas, tal y como se expone en la Figura 1.13.

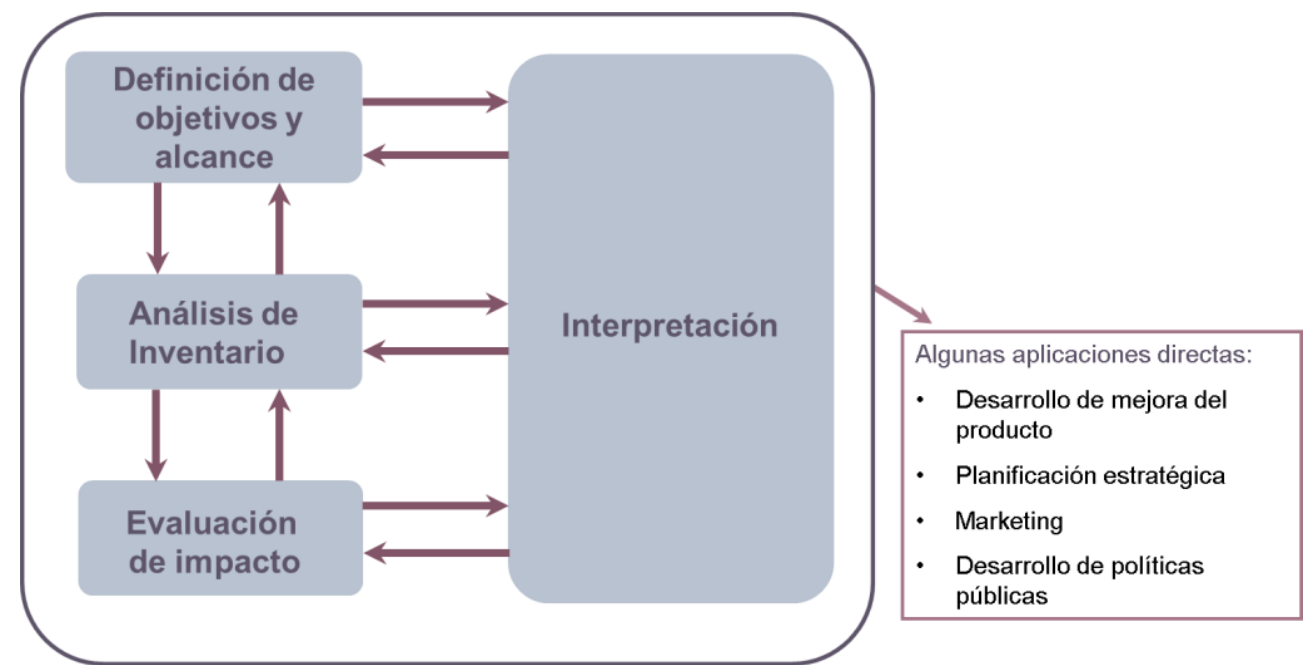

Figura 1.13 Etapas de un ACV (ISO 14020, 2000)

La definición de objetivos y alcance del estudio es una etapa crucial en los estudios de ACV, ya que los objetivos determinan la metodología a seguir, amplitud, o el grado de detalle de los datos a utilizar. El alcance del estudio debe ser el adecuado para la consecución de los objetivos del 
estudio. Deben especificarse aspectos como la función del sistema del producto bajo estudio, la unidad funcional, los límites del sistema, los requisitos de calidad de datos, etc.

La fase del inventario del ciclo de vida consiste en la recopilación de las entradas y salidas de materia y energía del sistema a estudiar, refiriéndolas a la unidad funcional definida en la fase anterior. Es la más costosa de un estudio de ACV. El grado de detalle, tanto de los procesos unitarios, como las entradas y salidas, dependerán del objetivo y alcance marcado.

La finalidad de la fase de evaluación del impacto ambiental del ciclo de vida es la de interpretar los datos compilados en la fase del inventario, analizando y evaluando los impactos ambientales producidos por las cargas ambientales cuantificadas en éste. Aquí, se transforman los centenares de datos de entradas y salidas del inventario, en un número reducido de impactos ambientales con el fin de comprender mejor su importancia ambiental.

La interpretación del ciclo de vida es la fase final de un ACV, en la cual, se resumen y se discuten los resultados del inventario y de la evaluación del impacto ambiental, asumiendo las hipótesis y limitaciones asociadas a los resultados y a la metodología aplicada, modo de obtención de datos, análisis de calidad de datos, etc.

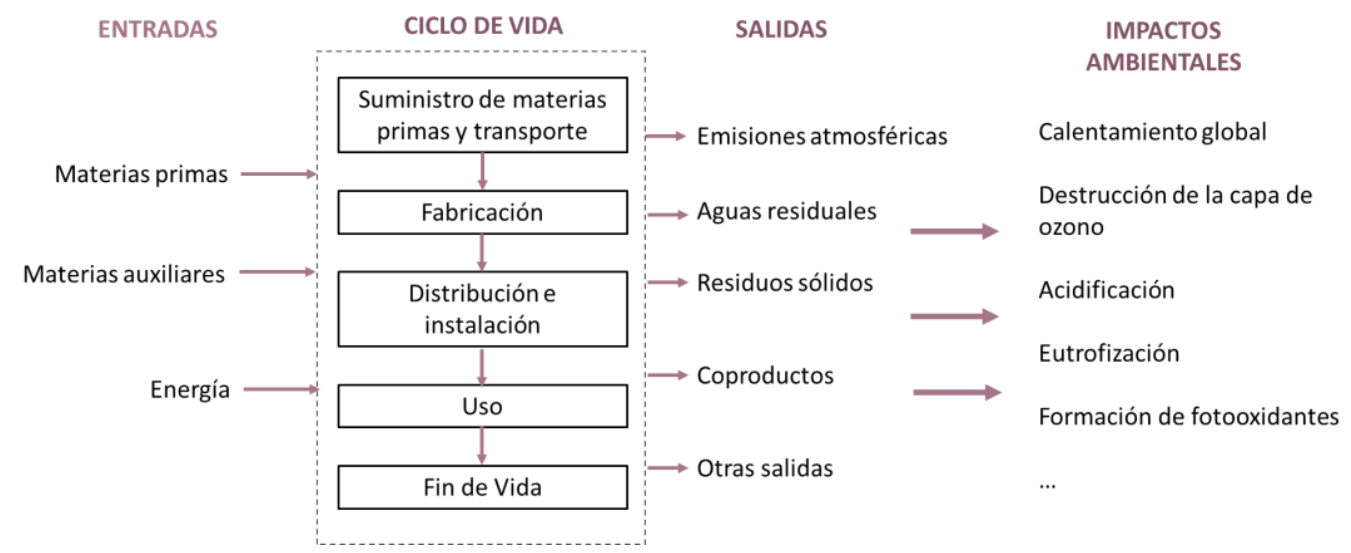

Figura 1.14 Esquema metodológico del ACV

\subsubsection{Revisión de las aplicaciones de ACV en recubrimientos}

\subsubsection{Baldosas cerámicas}

El ACV es, sin duda, la metodología más reconocida y extendida para la evaluación de los impactos ambientales de productos, especialmente los de la construcción (Basbagill et al., 2013; Iribarren et al., 2015; Zabalza Bribián et al., 2009). Entre las aplicaciones del ACV en este sector está: la evaluación de la sostenibilidad de materiales (Balaguera et al., 2018), sistemas constructivos (Albertí et al., 2019), proyectos edificatorios (Assiego de Larriva et al., 2014; Häfliger et al., 2017; Khasreen et al., 2009; Zabalza Bribián et al., 2009), hasta ciudades (Albertí et al., 2017); innovación y ecodiseño (Chang et al., 2014; Fazeni et al., 2014; Ortiz et al., 2009; Puig et al., 2017); 
y marketing, por ejemplo, a través de Declaraciones Ambientales de Producto (en adelante, DAP) (Gazulla, 2012; Ibáñez-Forés et al., 2016).

Para el caso particular de las baldosas cerámicas, se ha elaborado una recopilación de estudios de ACV, cuyos objetivos se recopilan en la Tabla 1.7.

De ésta, se puede concluir que, la aplicación de ACV en el sector de las baldosas cerámicas se centra sobre todo en la identificación de puntos críticos para la definición de medidas de mejora ambiental (Almeida et al., 2016; Asif et al., 2007; Belussi et al., 2015; Benveniste et al., 2011; Bovea et al., 2010, 2007; Han et al., 2015; Ibáñez-Forés et al., 2013, 2011; Nicoletti et al., 2002; Pini et al., 2014; Tikul, 2014; Tikul and Srichandr, 2010); para ser utilizada en instrumentos de comunicación ambiental, generalmente para ecoetiquetas tipo I o declaraciones tipo III (Almeida et al., 2013, 2016; Benveniste et al., 2011; Ruschi Mendes Saade et al., 2014) y para comparar la cerámica con otros tipos de recubrimientos (Abeysundara et al., 2009; Asif et al., 2007; Belussi et al., 2015; Han et al., 2015; Islam et al., 2015a, 2015b; Minne and Crittenden, 2015; Nicoletti et al., 2002; Rydh and Sun, 2005; Souza et al., 2015).

Estos estudios, a pesar de coincidir en el producto de estudio y en la Unidad Funcional (únicamente Tikul and Srichandr, 2010 define la unidad funcional como $1 \mathrm{t}$, en vez de $1 \mathrm{~m}^{2}$ ) difieren en la antigüedad de los datos, ubicación geográfica, variedad de producto, procesado y método de cálculo de los datos, hipótesis planteadas y, en muchos casos, metodologías de evaluación de impacto, entre otros. Esta heterogeneidad obstaculiza la comparación de los resultados obtenidos en estos estudios. No obstante, en el caso de las baldosas cerámicas, no hay disparidad en afirmar que, es la etapa de fabricación la que contribuye en mayor medida a los impactos ambientales en la mayoría de las categorías de impacto ambiental, independientemente del método de evaluación empleado, y más concretamente, la etapa de cocción debido a la elevada demanda térmica del proceso y a las emisiones gaseosas que en este proceso se generan. 


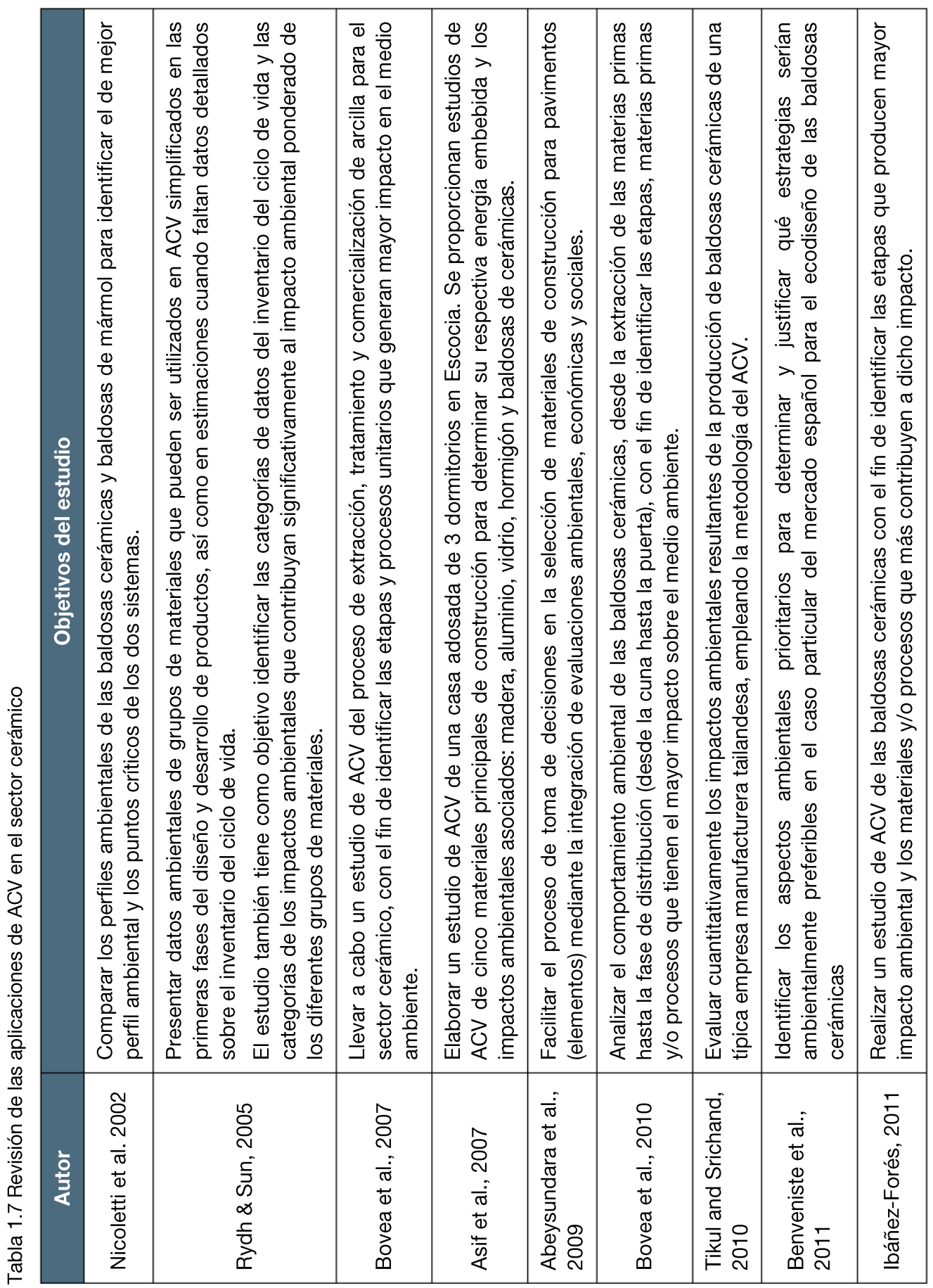




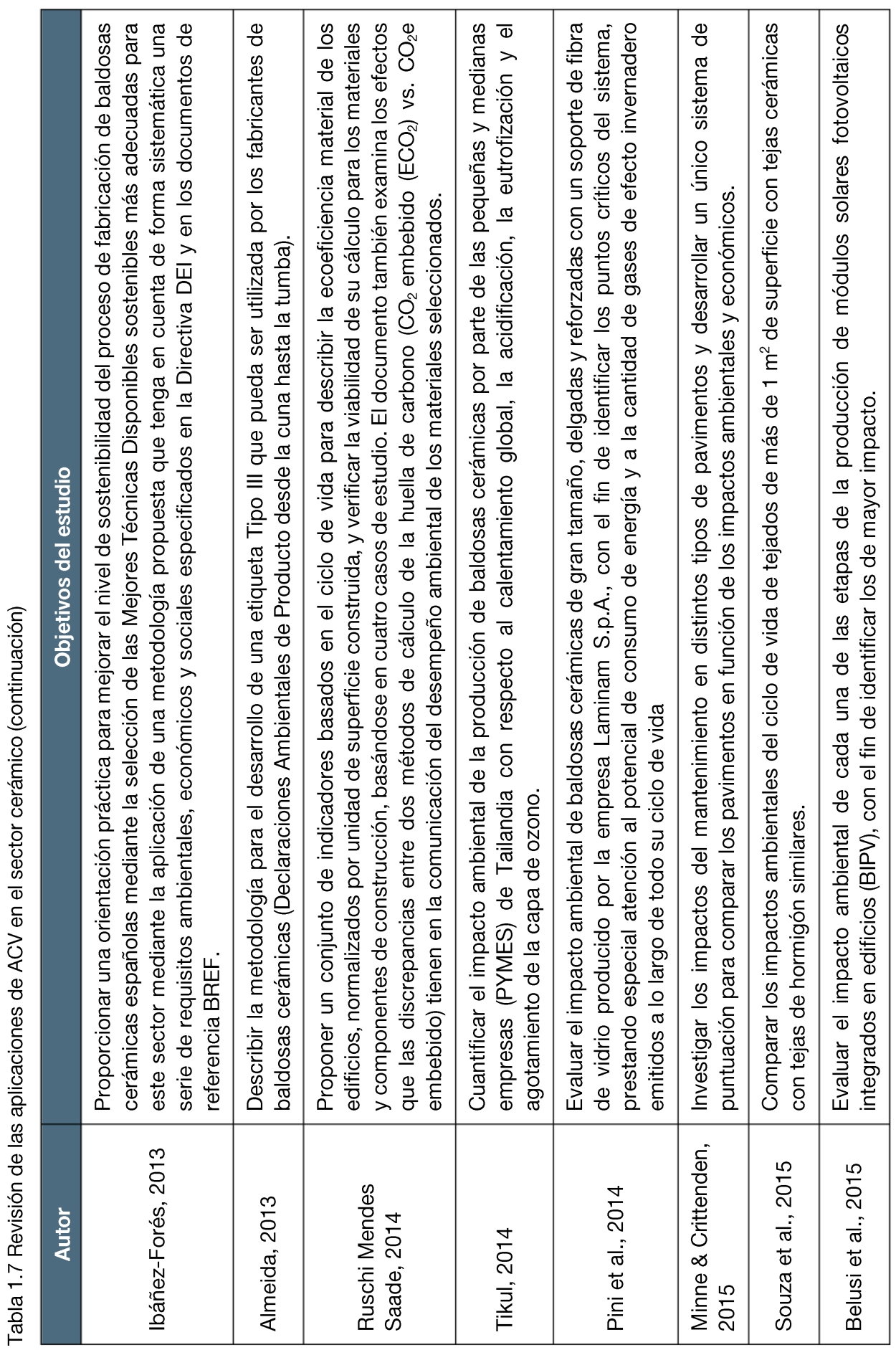




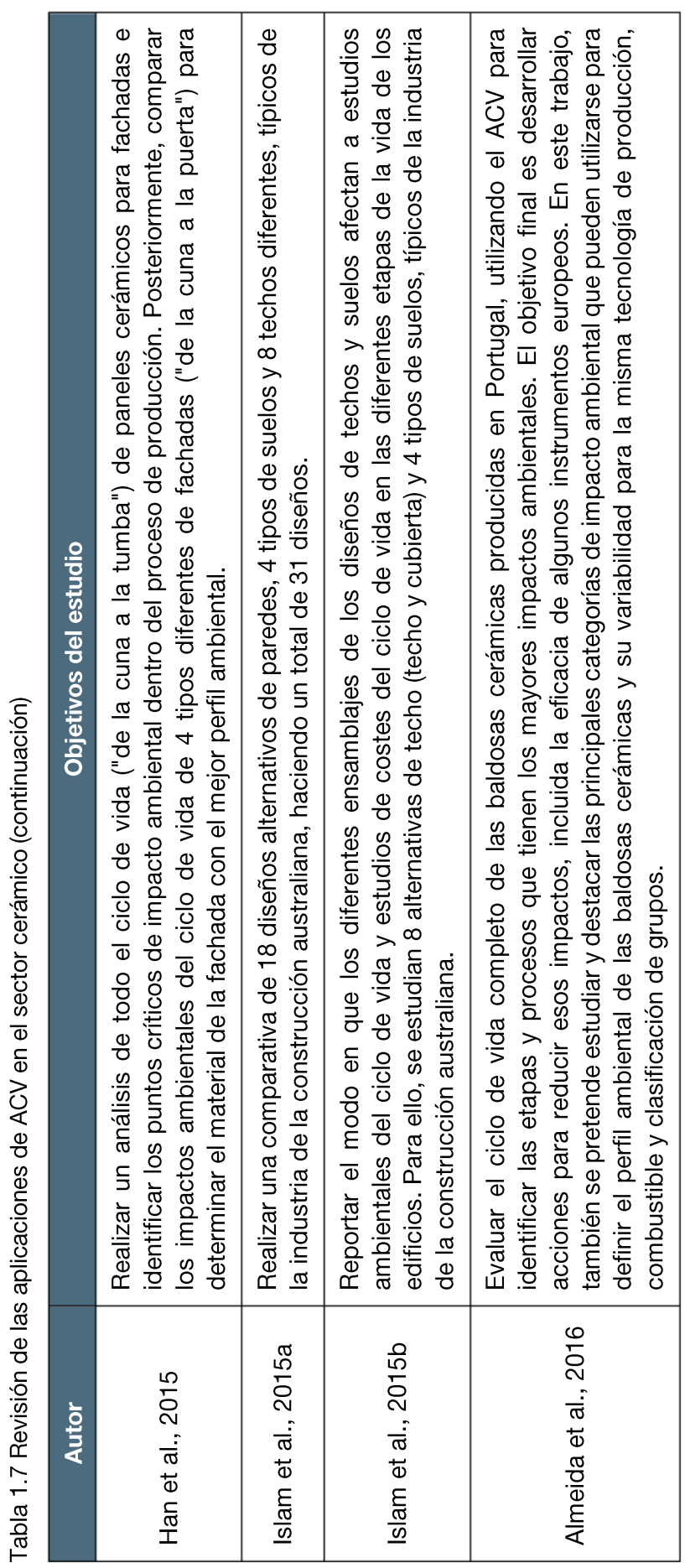




\subsubsection{Otros recubrimientos de suelos}

Uno de los grandes retos a los que se enfrenta el sector cerámico es la fuerte competitividad de productos alternativos. Los principales competidores son: la moqueta, la piedra natural, el suelo laminado, el recubrimiento de policloruro de vinilo (PVC) y el parquet. Las producciones mundiales, europeas y estadounidenses de estos productos se incluyen en la Tabla 1.8.

Tabla 1.8 Producción de los principales recubrimientos de suelos (en 2016)

\begin{tabular}{|c|c|c|c|}
\hline \multicolumn{4}{|c|}{ Producción (Millones de m²) } \\
\hline Recubrimientos & Mundial & Europa & EE.UU. ${ }^{(6)}$ \\
\hline Baldosas cerámicas $^{(1)}$ & 13056.0 & 1304.0 & 321 \\
\hline Moquetas $^{(2)}$ & 12095,0 & 848,0 & 1150 \\
\hline Piedra natural(3) & 514,3 & 87,4 & 33.5 \\
\hline Laminados $^{(4)}$ & 477,0 & 371,0 & 104 \\
\hline Parquet ${ }^{(5)}$ & n.d. & 80,4 & 163 \\
\hline PVC & n.d. & n.d. & 447 \\
\hline \multicolumn{4}{|c|}{$\begin{array}{l}\text { n.d.: No disponible Fuentes de información: } \\
\text { Datos mundiales y europeos: Baraldi, 2017; European Carpet and Rug Association (ECRA), 2018; Carlo Montani, 2018; } \\
\text { European Producers of Laminate Flooring (EPLF), 2018; European Federation of the Parquet Industry (FEP), } 2017 \\
\text { Datos estadounidenses: Floor covering weekly, } 2018\end{array}$} \\
\hline
\end{tabular}

La aplicación del ACV en otros materiales de recubrimiento de suelos ha sido un tema de interés constante en la bibliografía. En total, se han encontrado y analizado 24 referencias de estudios de ACV de recubrimientos de suelos de distinta naturaleza a la cerámica, los cuales pueden encontrarse en la Tabla 1.9. 


\begin{tabular}{|c|c|c|c|c|c|}
\hline $\begin{array}{l}\text { : } \\
\text { ㅎ̆ }\end{array}$ & & & 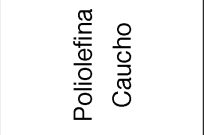 & & \\
\hline 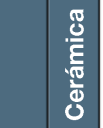 & & & & $\times$ & \\
\hline 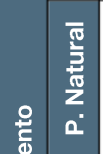 & & & & $\times$ & \\
\hline 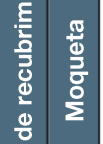 & & 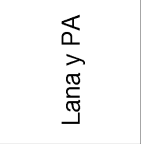 & $\times$ & & \\
\hline 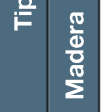 & $\times$ & & $\times$ & & $\times$ \\
\hline$\frac{\circ}{\bar{T}}$ & $\times$ & $\stackrel{\frac{0}{0}}{\frac{\pi}{\bar{Z}}}$ & 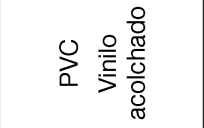 & & \\
\hline $\begin{array}{l}\frac{0}{\circ} \\
\frac{0}{0} \\
\frac{9}{3}\end{array}$ & $\times$ & $\times$ & $\times$ & & \\
\hline $\begin{array}{l}\frac{g}{0} \\
\frac{\sum_{0}^{\circ}}{0} \\
\frac{0}{0}\end{array}$ & 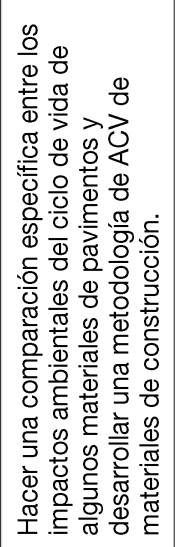 & 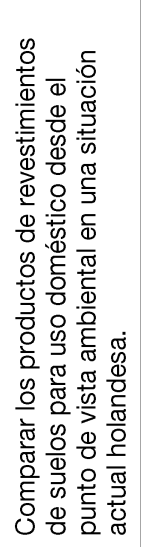 & 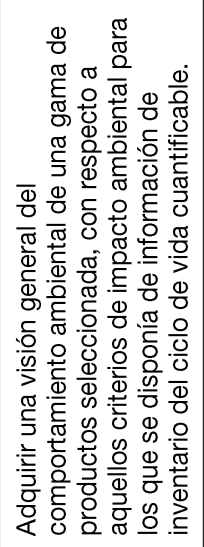 & 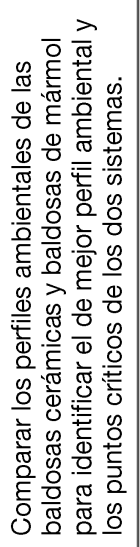 & 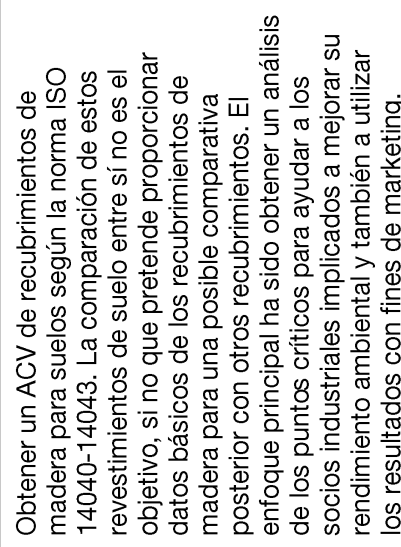 \\
\hline 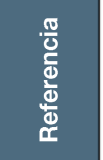 & 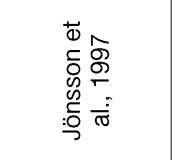 & 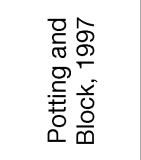 & 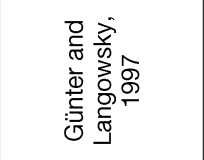 & 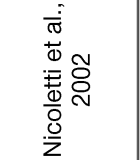 & 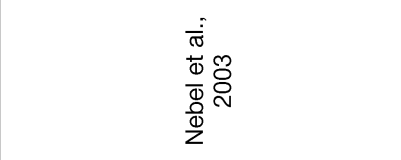 \\
\hline
\end{tabular}




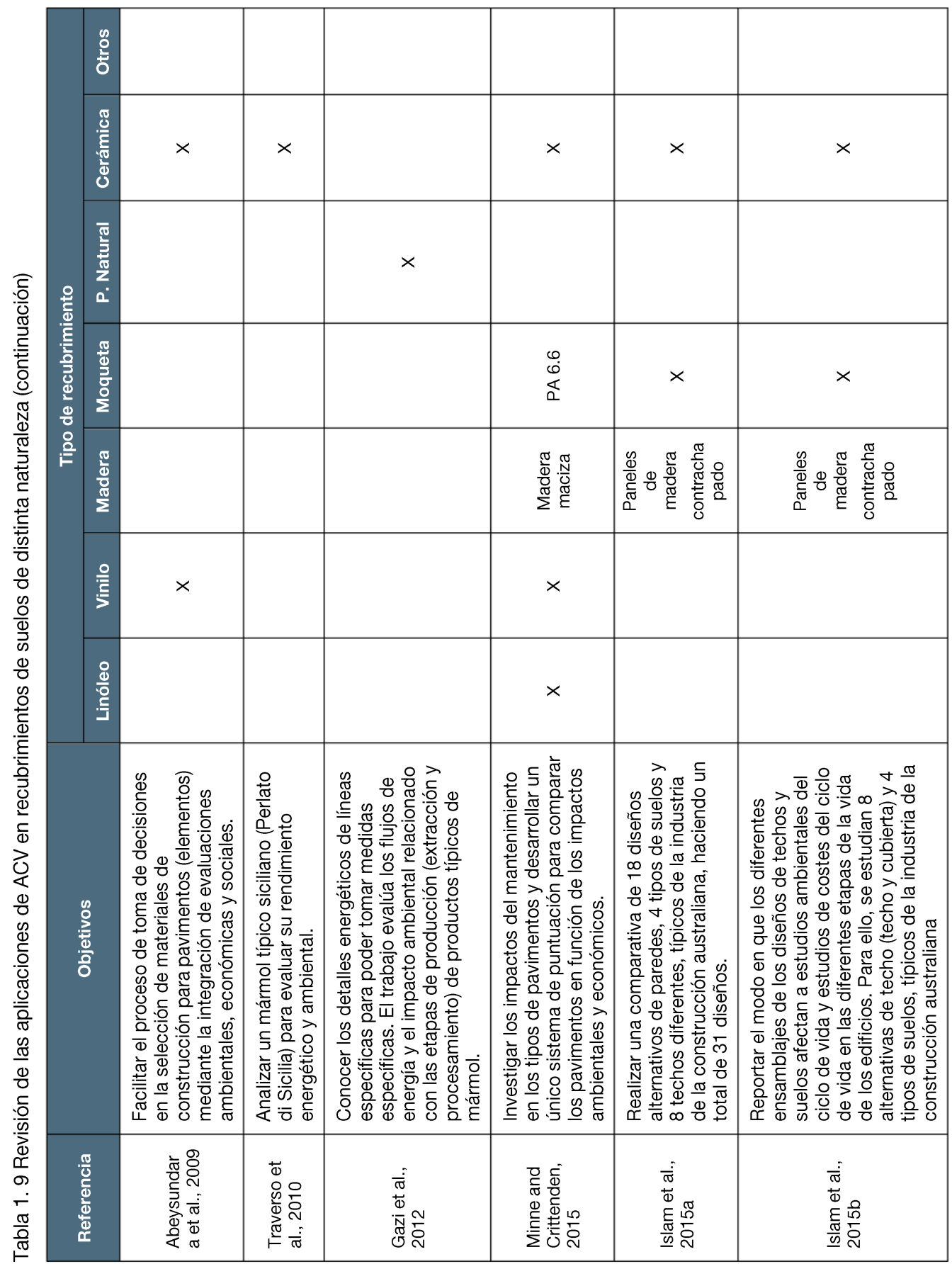




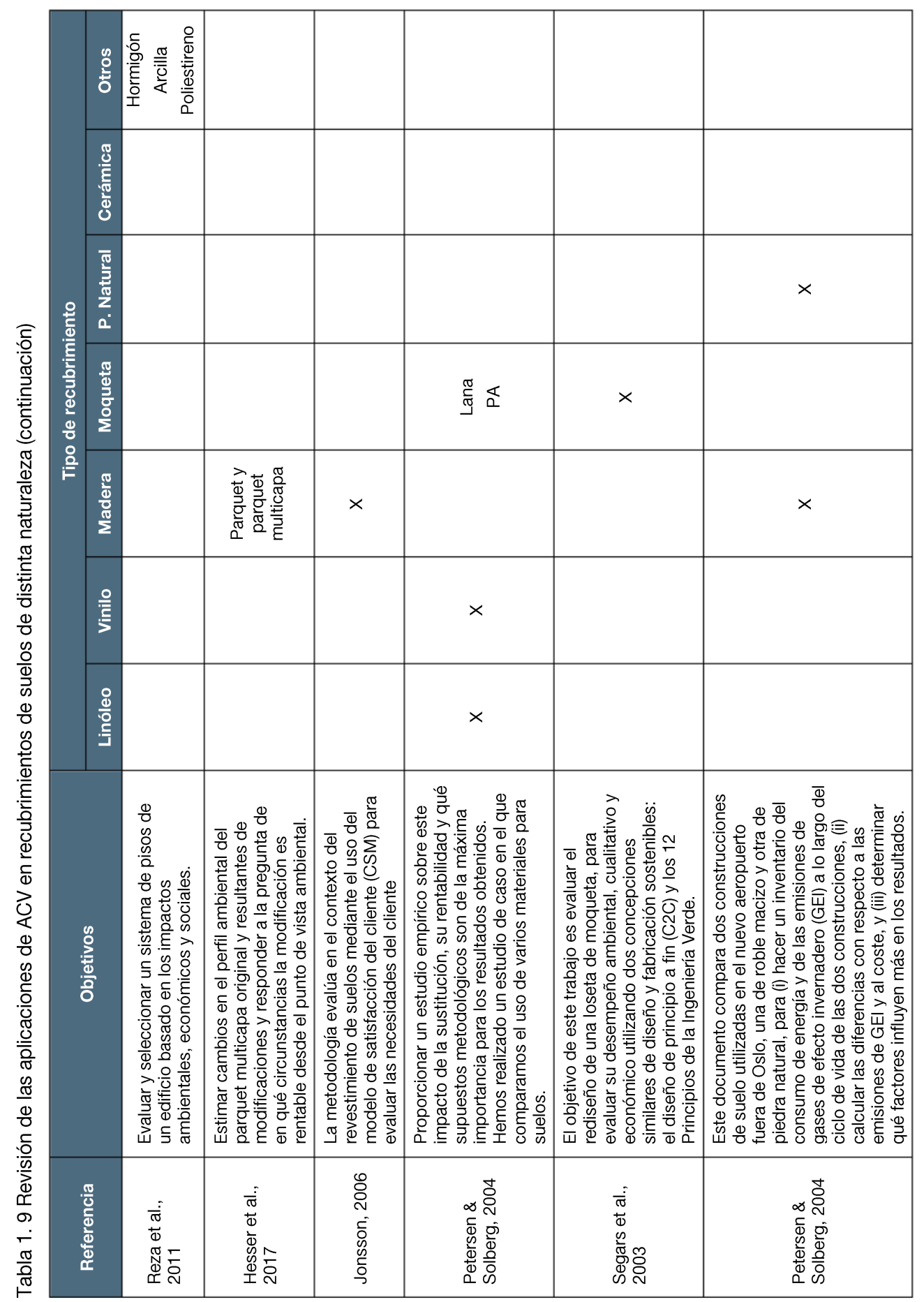




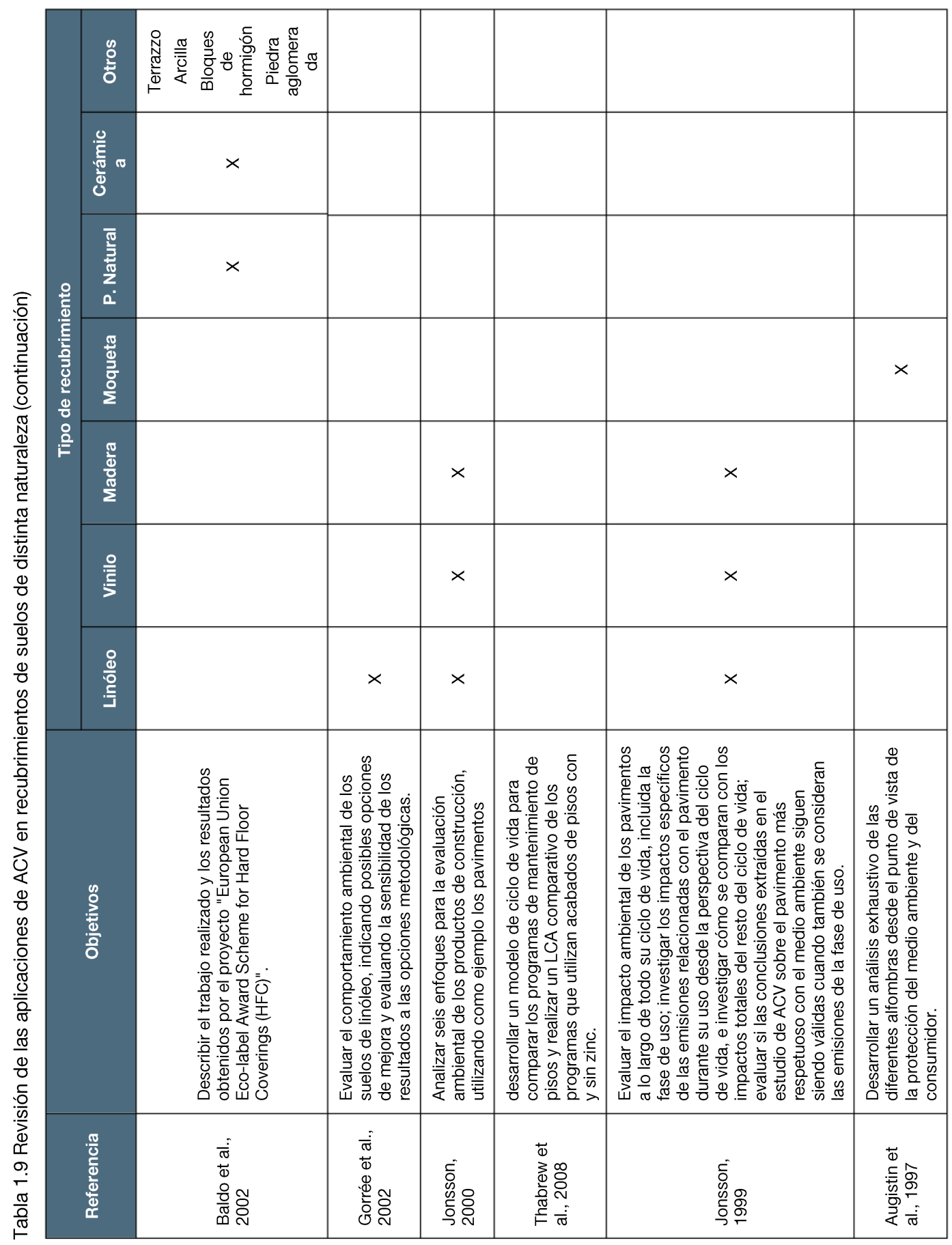


Del análisis de esta información, cabe destacar que las diferencias metodológicas, alcance, límites del sistema, métodos de evaluación de impacto, reglas de cálculo, etc. impiden que los resultados obtenidos en los estudios de ACV anteriores sean directamente comparables (Rivela et al., 2006), no pudiendo extraer conclusiones firmes acerca de la preferencia de los recubrimientos de suelos desde el punto de vista ambiental. De forma generalista, ha sido posible identificar ciertas coincidencias, en las que se concluye que el linóleo es el pavimento más interesante ambientalmente, seguido por el vinilo siempre que se comparen con suelos "blandos" y/o resilientes (Jönsson et al., 1997; Minne and Crittenden, 2015; Potting and Blok, 1995). Por el contrario, apenas se han encontrado estudios comparativos sobre recubrimientos rígidos (hard floor coverings) (Nicoletti et al., 2002).

\subsection{Comunicación ambiental del ciclo de vida en el sector cerámico}

Actualmente, el aumento de la concienciación ambiental, tanto por parte de los consumidores finales, como de la Administración y de las empresas, ha repercutido en un aumento de la oferta y la demanda de productos y/o servicios más respetuosos con el medio ambiente.

Por ello, cada vez son más, las empresas que utilizan herramientas para la evaluación y mejora del comportamiento ambiental de sus servicios: como el ACV, ecodiseño o los sistemas de gestión ambiental empresarial, así como las que emplean instrumentos de comunicación o distintivos ambientales para divulgar las características y ventajas ambientales de sus productos.

Es posible clasificar los instrumentos de comunicación ambiental en tres grandes categorías según su alcance:

a) Sobre la gestión de las empresas o certificados ambientales de empresa: EMAS, ISO 14001, memorias de responsabilidad social corporativa, etc.

b) Sobre las características ambientales de los productos: certificados ambientales de producto, etiquetado ecológico, declaraciones ambientales, etc.

c) Sobre el comportamiento ambiental del producto en sistemas más complejos, como son los edificios para el caso de las baldosas cerámicas: certificados de construcción sostenible, por ejemplo, LEED, BREEAM, VERDE, etc. 


\subsubsection{Instrumentos de comunicación ambiental de la gestión de las empresas}

Los sistemas de gestión ambiental (en adelante SGA) más reconocidos son:

- El SGA basado en la serie de normas ISO 14000 es el sistema más conocido internacionalmente $y$, probablemente, por el que más se ha optado. El conjunto de normas por las que se regula fue aprobado por la Organización Internacional de Normalización (ISO) en septiembre de 1996. Se destaca la norma ISO 14001:2015 que contiene los requisitos para su implantación y uso. Ésta ayuda a identificar, evaluar, priorizar y gestionar los aspectos ambientales de la organización de forma integrada y sistemática con sus prácticas operacionales habituales para una mejora continua (ISO 14001, 2015). En la actualidad, muchos fabricantes de baldosas cerámicas de todo el mundo lo han introducido y cuentan con esta certificación ISO (Monfort, 2012).

- El Sistema Comunitario de Gestión y Auditoría Ambiental (EMAS) es un sistema regulador y voluntario de la UE para la gestión, comunicación y mejora del comportamiento ambiental de las empresas. Está a disposición de las empresas de los sectores industriales desde 1995 y, posteriormente, de todos los sectores económicos, incluidos los servicios públicos y privados. Está regulado por el Reglamento (CE) no 1221/2009 ("EMAS III") con las posteriores modificaciones de sus anexos mediante el Reglamento de la Comisión (UE) 2017/1505 y el Reglamento de la Comisión (UE) 2018/2026. En la práctica, este sistema ha tenido menos éxito entre los fabricantes europeos de baldosas cerámicas que el sistema ISO 14001, quizás porque es menos conocido internacionalmente y sus criterios son más estrictos (Monfort, 2012). Sin embargo, el sistema EMAS es ampliamente reconocido a nivel europeo y está siendo utilizado como criterio de referencia por muchos gobiernos europeos en los procesos de compra pública verde.

- En julio de 2011, el comité ISO aprobó la norma ISO 14006, 2011 de Ecodiseño. Se trata de un sistema de gestión certificable, que puede complementarse con la serie ISO 14001, que regula la integración sistemática de los aspectos ambientales en el diseño y desarrollo del producto.

- La norma internacional sobre Responsabilidad Social (ISO 26000, 2010) fue lanzada con la intención de avanzar en términos de un entendimiento común de lo que es la responsabilidad social y armonizar la terminología afín. No es un sistema de gestión estándar y no es certificable, pero varias empresas y otras organizaciones lo utilizan para gestionar los aspectos sociales y ambientales de sus actividades, productos y servicios. Además, el desarrollo de la norma ISO 26000 ha llevado a la aparición de normas nacionales y documentos técnicos sobre la Responsabilidad Social, compatibles con ella, como el Sistema de Gestión de la Responsabilidad Social y certificables, como (IQNet SR10, 2011). 


\subsubsection{Instrumentos de comunicación ambiental de productos}

En lo que respecta a la comunicación ambiental de productos, durante los últimos años han surgido numerosos mecanismos e instrumentos de información ambiental, que bien pueden encontrarse de forma cuantitativa, o bien mediante afirmaciones cualitativas, símbolos o gráficos, etc. (Gazulla, 2012). Estos instrumentos de información ambiental pueden ser obligatorios o voluntarios.

Los sistemas obligatorios vienen regulados por la legislación y están verificados por terceras partes independientes. Estos marcados pueden contener una valoración ambiental o no, dependiendo de si expresan un beneficio ambiental respecto a otros equivalentes o si únicamente aportan información ambiental de interés. Ejemplos de marcados obligatorios sin valoración ambiental son las declaraciones de la composición del producto, sistemas de gestión integrados de residuos de envases y embalajes como el Punto Verde o los Sistemas de Depósito, Devolución y Retorno (SDDR). Ejemplos de marcados obligatorios con valoración ambiental son la etiqueta de eficiencia energética de aparatos de uso doméstico o la etiqueta de eficiencia energética de edificios. En la Figura 1.15 se muestra como ejemplo algunos de estos marcados.
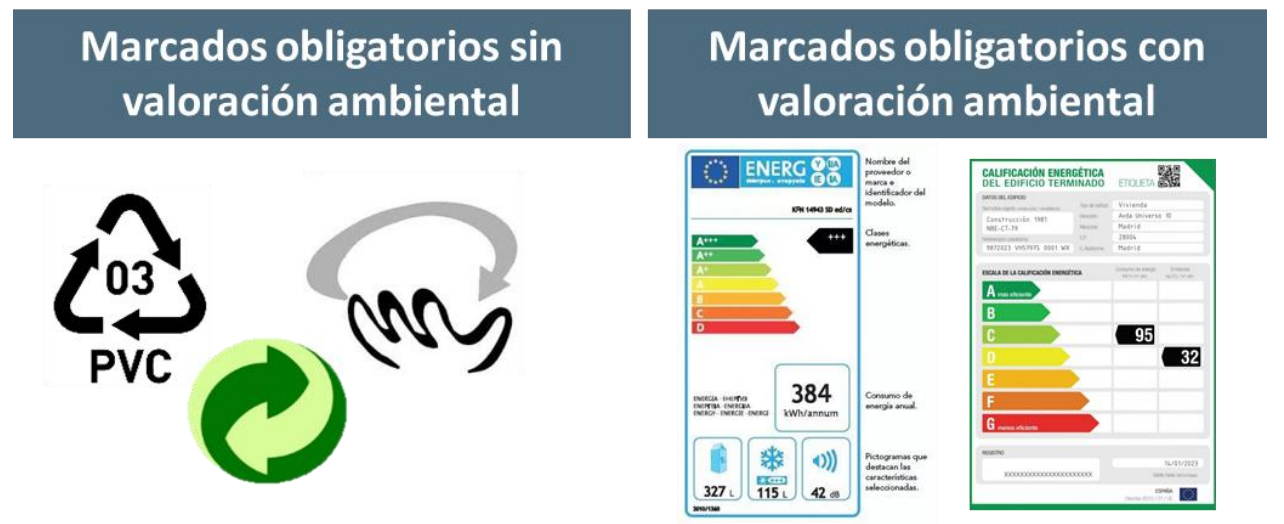

Figura 1.15 Ejemplos de marcados obligatorios. Izquierda: ejemplos de marcados obligatorios sin valoración ambienta para envases y embalajes: PVC; punto verde y sistema de depósito, devolución y retorno. Derecha: ejemplos de marcados obligatorios con valoración ambiental: calificación energética de edificios y de electrodomésticos

En lo que respecta a los sistemas voluntarios, existen normas internacionales (familia de normas ISO 14020) que tienen por objeto regular su desarrollo, aunque en el mercado es posible encontrar instrumentos de comunicación ambiental de producto que no cumplen el principio general ni los requisitos específicos de la familia ISO 14020.

En esta familia de normas se definen las etiquetas ecológicas y declaraciones ambientales como una manifestación que indica los aspectos ambientales de un producto o servicio. Una etiqueta o una declaración ambiental puede tomar la forma de un enunciado, símbolo o gráfico impreso en 
la etiqueta de un envase de un producto, en la documentación que acompaña al producto, en los boletines técnicos y en los medios de publicidad o divulgación, entre otros (ISO 14020, 2000).

El comité de la ISO ha clasificado las ecoetiquetas y declaraciones en tres tipos: tipo I o ecoetiquetas certificadas; tipo II o autodeclaraciones de productos ambientales; y tipo III o declaraciones ambientales de productos (ISO 14020, 2000).

Etiquetas ecológicas certificadas (Tipo I). Se conceden sobre la base de múltiples criterios basados en su ciclo de vida, que han sido establecidos por instituciones públicas o privadas a nivel regional, nacional o internacional. Tienen por objetivo principal distinguir a los productos que tienen un menor impacto ambiental que los de su misma categoría. Son etiquetas certificadas por una tercera parte independiente y están normalizadas por las normas ISO 14020, 2000; ISO 14024, 2018.

En el caso de las baldosas cerámicas, la Comisión Europea ha establecido los criterios ecológicos necesarios para optar a la Etiqueta Ecológica Europea, conocida como EU Ecolabel (European Commission, 2019), dentro de la categoría de revestimientos rígidos para suelos a través de la Decisión de la Comisión 2009/607/CE. Esta ecoetiqueta es válida en todo el espacio Económico Europeo y es concedida por organismos competentes de cada Estado miembro. En el caso de España, esta competencia se traslada a las Comunidades Autónomas y, en el caso de la Comunitat Valenciana, es el Servicio de Protección y Control Integrado de la Contaminación, Dirección General de Calidad Ambiental, Conselleria de Infraestructuras, Territorio y Medio Ambiente de la Generalitat Valenciana. En Marzo 2019, se contabilizaron 9 empresas europeas de baldosas cerámicas con un total de 2175 de productos con EU Ecolabel, cuyo reparto se sintetiza en la Tabla 1.10 (European Commission, 2019). Cabe decir que las licencias de la EU Ecolabel se otorgan a productos candidatos, es decir, a referencias comerciales individuales y no a un grupo de productos similares.

Tabla 1.10 Baldosas cerámicas certificadas con EU Ecolabel

\begin{tabular}{|l|c|c|}
\hline \multicolumn{1}{|c|}{ Países } & Baldosas certificadas & Número de empresas \\
\hline Italia & 2145 & 6 \\
\hline España & 14 & 1 \\
\hline Reino Unido & 14 & 1 \\
\hline República Checa & 2 & 1 \\
\hline
\end{tabular}

Por otro lado, existen otras ecoetiquetas de tipo I para baldosas cerámicas (por ejemplo, en Hong Kong, Japón, Nueva Zelanda, etc.). En general, no son tan específicas como las utilizadas en Europa, con la excepción de Australia, que ha establecido una ecoetiqueta para baldosas cerámicas con criterios similares a los de sus homólogos europeos (Monfort, 2012).

Cabe citar en este contexto el marcado Green Squared ${ }^{\circledR}$, etiqueta certificada de sostenibilidad específica de recubrimientos cerámicos y materiales de instalación (ANSI A138.1, 2012). Desarrollada por el Consejo Cerámico de Norte América (conocido por sus siglas en inglés por 
TCNA), la asociación de fabricantes y por miembros del Consejo de Edificios verdes de EE.UU. (United States Green Building Council, USGBC) (Griese, 2012). Se trata de una etiqueta multiatributo, que contempla criterios ambientales, sociales y económicos a lo largo de todo el ciclo de vida del producto y, que recoge los principios y exigencias actuales del certificado LEED (véase el apartado 1.5.3), para construcción sostenible. La distribución de los criterios contemplados se agrupa en áreas, cuya representatividad, en porcentaje, se presenta en la Figura 1.16 .

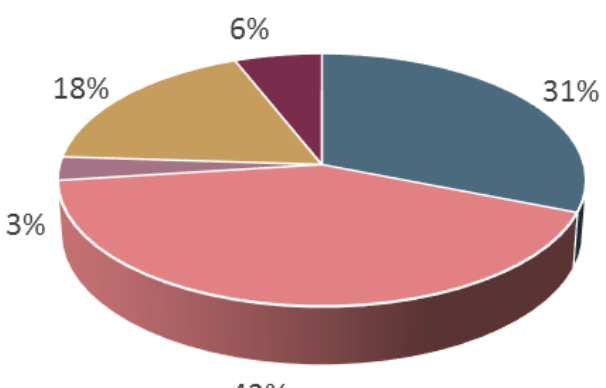

$42 \%$

\author{
- Características de \\ producto \\ - Extracción de materias \\ primas y fabricación \\ - Gestión del fin de vida \\ del producto \\ - Progreso del Gobierno \\ Corporativo
}

- Innovación

Figura 1.16 Áreas que abarca Green Squared ${ }^{\circledR}$, indicando los porcentajes de cada uno con respecto al total de los criterios sostenibles contemplados por este distintivo.

Autodeclaraciones ambientales de producto (Tipo II). Son declaraciones libres en las cuales se comunica uno o varios aspectos ambientales de un producto mediante una afirmación, gráfica o símbolo, que puede ser elaborada por los fabricantes, importadores, comerciantes al por mayor, detallistas y empresas de servicios, siempre y cuando, se cumplan los requisitos ambientales establecidos por las normas que las regulan (ISO 14020, 2000; ISO 14021, 2016). Estas etiquetas no son certificables por una tercera parte independiente, aunque su verificación aumenta su credibilidad. Algunos ejemplos comunes de este tipo de etiquetado son: compostable, biodegradable, contenido en reciclado, reciclable, reutilizable, consumo reducido de energía, producto de vida prolongada, etc. (véase la Figura 1.17). Una autodeclaración ambiental de producto puede ser válida para una o varias referencias comerciales. En este caso, es la empresa la que escoge el alcance y número de productos a los que hacer referencia, siempre y cuando, la declaración sea válida para todos ellos y se especifique claramente.

Las empresas fabricantes de baldosas cerámicas optan por este tipo de etiquetado especialmente para demostrar el cumplimiento de criterios solicitados a edificios o construcciones que son certificados como verdes o sostenibles, tales como LEED o BREEAM (véase el apartado 1.5.3), siendo, probablemente, el contenido en reciclado, la autodeclaración ambiental de producto más común. Como ejemplo de la importancia en la comercialización de producto, cabe indicar que, en los últimos 10 años, el Instituto de Tecnología Cerámica ha recibido la petición de calcular el contenido en reciclado de más de 30 referencias comerciales de baldosas cerámicas y composiciones de gránulo atomizado. 


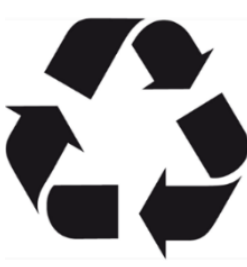

Productoreciclable

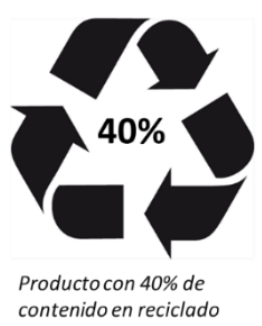

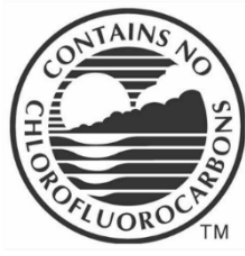

Productosin CFC

Figura 1.17 Ejemplos de símbolos utilizados como Autodeclaraciones Ambientales de Producto (tipo II)

Declaraciones Ambientales de Producto (tipo III). Presentan información ambiental cuantificada, obtenida a partir de estudios de ACV. Están normalizadas según las normas ISO 14020, 2000 e ISO 14025, 2006. Los estudios de ACV deben realizarse de acuerdo con las directrices específicas, acordadas para cada categoría de producto, conocidas como Reglas de Categoría de Producto (en adelante RCP) y desarrolladas por los programas que administran este tipo de declaraciones ambientales, junto con un panel sectorial. Este tipo de declaración ambiental no emite juicio de valor y no comunican un mejor comportamiento ambiental. Son declaraciones verificables por auditores acreditados por los programas que las administran, la mayoría de éstos son organismos privados. En teoría, ofrecen la ventaja de permitir la comparación entre productos que cumplen la misma función, siempre que estos estudios se realicen con los mismos criterios y bajo una serie de condiciones definidas en la norma ISO 14025, 2006, a pesar de que, en la práctica, se encuentran algunas dificultades debido a discrepancias en el contenido de las RCP y en los procesos de verificación. En el caso de los materiales de la construcción, la norma EN 15804+A1, 2013 de Reglas de Categoría de Producto Básicas para Productos de Construcción, tiene por objeto establecer un marco armonizado para el desarrollo de RCP específicas de productos, servicios y procesos de construcción, reduciendo (que no eliminando), las posibles discrepancias entre DAPs desarrolladas bajo diferentes programas.

El sector español de las baldosas cerámicas ha sido pionero en este tipo de etiquetado en España. Hasta la fecha se han identificado 57 DAPs europeas registradas en 4 programas diferentes. En la Tabla 1.11 se muestra una distribución de DAPs de recubrimientos cerámicos dadas de alta en programas europeos (GlobalEPD; EPDItaly; IBU-EPD; Inies; International EPD $®$ System; Programa DAPconstrucción $\left.{ }^{\circledR}\right)$.

Cabe decir que, en el caso de las DAPs, el registro puede hacer referencia a un producto o a un grupo de productos; y ser propiedad de un único o a varios fabricantes. El criterio y requisitos de agrupamiento viene definido por cada uno de los programas, tal y como se sintetiza en la Tabla 1.12 . 
1. Introducción y estado del arte

Tabla 1.11 DAPs de baldosas cerámicas registradas en programas europeos

\begin{tabular}{|l|c|c|c|c|c|}
\hline \multicolumn{1}{|c|}{ Programas europeos de DAPs } & Turquía & España & Italia & Alemania & Francia \\
\hline IBU-EPD & -- & -- & 4 & 1 & -- \\
\hline GlobalEPD & -- & 37 & -- & -- & -- \\
\hline The International EPD ${ }^{\circledR}$ System & 7 & 3 & -- & -- & -- \\
\hline EPD Italy $^{\text {EAPcons }}{ }^{\circledR}$ & -- & -- & 14 & -- & -- \\
\hline DAIES $^{\text {INI }}$ & -- & 11 & -- & -- & - \\
\hline
\end{tabular}

Tabla 1.12 Resumen de los criterios de agrupamiento de varios productos bajo una misma DAP

\begin{tabular}{|c|c|}
\hline $\begin{array}{l}\text { Programa/Norma } \\
\text { (categoría de producto) }\end{array}$ & $\begin{array}{c}\text { Consideraciones cuando se declara más de un producto bajo una } \\
\text { misma DAP }\end{array}$ \\
\hline $\begin{array}{l}\text { EN 15804:2012+A1:2013 } \\
\text { (Productos de la construcción) }\end{array}$ & $\begin{array}{l}\text { Debe especificarse el criterio de agrupamiento y el rango/variabilidad } \\
\text { de los resultados de la evaluación de impacto (LCIA) si es significante. }\end{array}$ \\
\hline $\begin{array}{l}\text { International EPD }{ }^{\circledR} \text { System } \\
\text { (Productos y servicios de la } \\
\text { construcción) }\end{array}$ & $\begin{array}{l}\text { Cuando las diferencias en los resultados de LCIA están por debajo de } \\
\pm 10 \% \text { (en relación con A1-A3) podrán declararse conjuntamente, } \\
\text { declarando los valores de un producto representativo del grupo. En la } \\
\text { declaración deberá presentarse una descripción del intervalo de } \\
\text { variación. } \\
\text { Cuando las diferencias son superiores al } \pm 10 \% \text {, pueden presentarse en } \\
\text { la misma DAP, pero utilizando columnas o tablas separadas. Una } \\
\text { alternativa es seleccionar un producto dentro del grupo de productos, } \\
\text { pero indicando que el intervalo supera el } 10 \% \text { o la cifra exacta válida } \\
\text { para el producto. }\end{array}$ \\
\hline $\begin{array}{l}\text { CET } 2014 \text { and Thurning et al. } \\
2013 \text { (Productos de arcilla para } \\
\text { la construcción) }\end{array}$ & $\begin{array}{l}\text { Pueden declararse valores promedio, pero siempre ponderados. } \\
\text { Además, cuando la declaración incluye varios centros productivos o } \\
\text { varios productores, deberán declararse los valores de mayor y menor } \\
\text { impacto. }\end{array}$ \\
\hline $\begin{array}{l}\text { INIES database } \\
\text { (Productos de la construcción) }\end{array}$ & $\begin{array}{l}\text { No podrán declararse en una misma FDES, varios productos cuya } \\
\text { diferencia en los valores de impacto ambiental sea superior a } \pm 10 \% \text { (en } \\
\text { relación con } A 1-A 3 \text { ) y en tal caso, se declarará el producto con mayor } \\
\text { impacto ambiental. }\end{array}$ \\
\hline $\begin{array}{l}\text { IBU EPD programme } \\
\text { (Baldosas y paneles cerámicos) }\end{array}$ & Podrá declararse un promedio indicando la distribución. \\
\hline $\begin{array}{l}\text { DAPcons }{ }^{\circledR} \\
\text { (Recubrimientos cerámicos) }\end{array}$ & $\begin{array}{l}\text { Pueden agruparse si pertenecen al mismo grupo de clasificación de la } \\
\text { norma EN } 14411 \text { (ISO 13006) y cuando las diferencias, en los resultados } \\
\text { de LCIA) están por debajo de } \pm 10 \% \text { (en relación con A1-A3), indicando } \\
\text { el grado de desviación. }\end{array}$ \\
\hline $\begin{array}{l}\text { GlobalEPD } \\
\text { (Recubrimientos cerámicos) }\end{array}$ & $\begin{array}{l}\text { Pueden agruparse si pertenecen al mismo grupo de clasificación de la } \\
\text { norma EN } 14411 \text { (ISO 13006) declarando un promedio ponderado, } \\
\text { incluyendo además, los valores de impacto de los productos que } \\
\text { presentan un menor y mayor impacto ambiental para acotar el } \\
\text { promedio declarado. }\end{array}$ \\
\hline
\end{tabular}


1. Introducción y estado del arte

Tabla 1.12 Resumen de los criterios de agrupamiento de varios productos bajo una misma DAP (continuación)

\begin{tabular}{|l|l|}
\hline \multicolumn{1}{|c|}{$\begin{array}{c}\text { Programa/Norma } \\
\text { (categoría de producto) }\end{array}$} & $\begin{array}{c}\text { Consideraciones cuando se declara más de un producto bajo una } \\
\text { misma DAP }\end{array}$ \\
\hline $\begin{array}{l}\text { NSF USA } \\
\text { (Suelo: moquetas, resilientes, } \\
\text { laminados, cerámica, parquet) }\end{array}$ & $\begin{array}{l}\text { Se describirá la variación y se indicarán los niveles mínimo y máximo } \\
\text { del comportamiento ambiental de la categoría de productos. }\end{array}$ \\
\hline
\end{tabular}

\subsubsection{Instrumentos de comunicación ambiental de edificios}

La construcción sostenible o verde puede definirse como la aplicación de los principios del desarrollo sostenible al ciclo de vida de los edificios, desde la planificación de la construcción, elección de las materias primas, proceso de construcción, uso, demolición y gestión de los residuos (Yılmaz and Bakış, 2015). Se trata de un proceso global y con enfoque del ciclo de vida que, a partir de la confluencia de varios parámetros, qie pretenden conseguir proyectos urbanos eficientes y respetuosos con el medio ambiente, al tiempo que se adaptan a las necesidades humanas y apoyan la igualdad económica (Kibert, 1994; Stamure et al., 2015; Yılmaz and Bakış, 2015).

Desde principios de los años 90, la construcción ecológica o sostenible ha atraído la atención mundial tanto de investigadores como de profesionales (Kibert, 2012; Li et al., 2013; Yudelson, 2007) y el número de certificaciones ha sufrido un aumento exponencial en la última década, lo que revela la importancia de esta industria (Darko and Chan, 2016). Desde entonces, se han desarrollado varias metodologías para definir los objetivos de sostenibilidad y para guiar los procesos de planificación y diseño de los "edificios verdes". El primer método de evaluación de la sostenibilidad de edificios fue BREEAM en Reino Unido (BREEAM, 2019). Actualmente, hay numerosos métodos de evaluación con posibilidad de certificación. El Consejo Mundial de Edificios Verdes (World Green Building Council) (WGBC, 2019) tiene pública una recopilación de los esquemas de calificación miembros de esta organización.

En esta línea, el Joint Research Centre de la Comisión Europea ha desarrollado un marco común de indicadores básicos de la Unión Europea para la evaluación de la sostenibilidad a lo largo de del ciclo de vida de edificios de oficinas y residenciales denominado Level(s) (Dodd et al., 2017).

Los certificados de construcción sostenible con mayor interés para las baldosas cerámicas españolas, según las peticiones recibidas en el Instituto de Tecnología Cerámica para desarrollar información ambiental son:

LEED (Leadership in Energy and Environmental Design), es un sistema de calificación para edificios y viviendas verdes (USGBC, 2019). Se ha convertido en un próspero paradigma empresarial en la promoción de la sostenibilidad en la industria de la construcción gracias a la aprobación gubernamental y a los esfuerzos del Consejo de Edificios Verdes de EE.UU (USGBC, 2019). El esquema LEED v4.1. incluye las siguientes áreas clave: (1) sitios sostenibles; (2) eficiencia del agua; (3) energía y atmósfera; (4) selección de materiales; (5) calidad del ambiente interior; y (6) proceso de innovación y diseño. LEED es un sistema flexible, que puede aplicarse a diferentes 
tipos de edificios, tal y como se muestra en la Figura 1.18. Las certificaciones se puntúan en relación con un conjunto de pre-requisitos de obligatorio cumplimiento y a la cantidad de los puntos adicionales conseguidos para determinar el nivel de certificación: Certificado, Plata, Oro, Platino, cuya puntuación es específica para cada tipo de edificación.

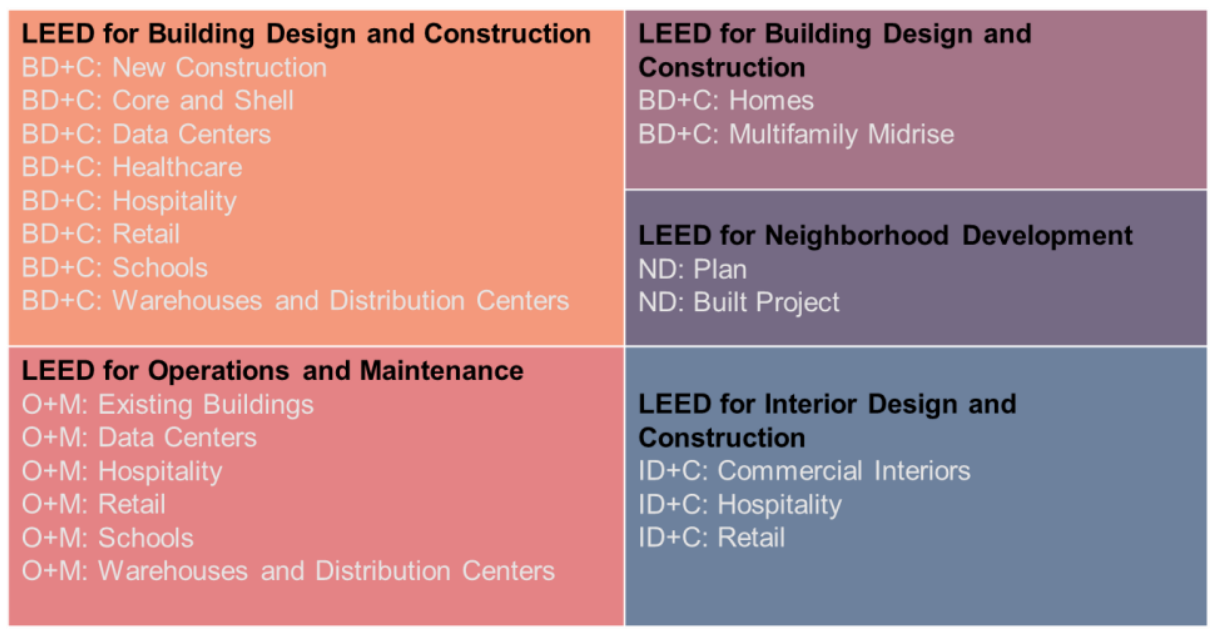

Figura 1.18 Esquemas de puntuación LEED.

BREEAM (Building Research Establishment Environmental Assessment Method) es un sistema de evaluación de la sostenibilidad en proyectos de construcción desarrollado por BRE (Building Research Establishment) a principios de los 90 en el Reino Unido (BREEAM, 2019). BREEAM se basa en un sistema de puntuación de 10 categorías ponderadas (véase la Tabla 1.13) para producir una única puntuación global del edificio a partir de la cual se califica según una escala de cinco rangos, que da el grado de cumplimiento BREEAM (BREEAM, 2019).

Tabla 1.13 Ponderación de las categorías ambientales de BREEAM

\begin{tabular}{|c|c|}
\hline Categoría & Ponderación ambiental (\%) \\
\hline Gestión & 11,50 \\
\hline Salud y bienestar & 14,00 \\
\hline Energía & 18,00 \\
\hline Transporte & 8,00 \\
\hline Agua & 10,50 \\
\hline Materiales & 12,00 \\
\hline Residuos & 7,00 \\
\hline Uso del suelo y ecología & 9,50 \\
\hline Contaminación & 9,50 \\
\hline Innovación & 10,00 \\
\hline
\end{tabular}


VERDE, es una metodología para la evaluación y certificación ambiental de edificios desarrollada por la Asociación GBC España (GBCe, 2019) y que está dotada de una serie de herramientas y manuales para su implementación y certificación. Esta certificación tiene una serie de criterios y reglas de acuerdo con el Código Técnico de la Edificación y Directivas Europeas para definir los límites y requisitos. Está orientada para nueva edificación, rehabilitación y edificios existentes, dedicados a uso residencial, unifamiliar y urbanizaciones, y también a equipamiento y polígonos (GBCe, 2019). La metodología VERDE, para la valoración del comportamiento sostenible del edificio, está basada en una aproximación al Análisis de Ciclo de Vida y consiste en evaluar la reducción de los impactos del edificio y su parcela mediante criterios de diseño y rendimiento. Los impactos analizados incluyen parámetros ambientales, sociales y económicos. Las certificaciones se puntúan en relación con un conjunto de resultados que se traducen en una puntuación global del siguiente modo: 0 hojas ( $<30 \%$ de los puntos); 1 hoja ( $>30-40 \%$ de los puntos); 2 hojas ( $>40-$ $50 \%$ de los puntos); 3 hojas ( $>50-60 \%$ de los puntos); 4 hojas ( $>60-80 \%$ de los puntos); 5 hojas (>80-100\% de los puntos). 

2. MOTIVACIONES, OBJETIVOS Y ESTRUCTURA 



\section{MOTIVACIONES, OBJETIVOS Y ESTRUCTURA}

\subsection{Motivaciones del presente estudio}

Considerando el estado del arte y el marco normativo expuesto en el capítulo anterior de esta tesis, se puede afirmar que, en los próximos años, el sector de baldosas cerámicas se va a enfrentar inevitablemente a una serie de retos ambientales que serán determinantes para la estabilidad del sector de las baldosas cerámicas en Europa, si no se abordan estrategias adecuadas.

Por ello, las principales motivaciones que se plantearon al realizar este estudio fueron:

1. Seleccionar y aplicar metodologías que ofrezcan una visión holística de los desafíos del sector a corto, medio y largo plazo.

2. Identificar, evaluar y desarrollar estrategias y herramientas pragmáticas que permitan abordar los retos ambientales en el sector de baldosas cerámicas

3. Definir un escenario de referencia adecuado en el sector de baldosas cerámicas para los próximos años, que permita realizar evaluaciones de tendencias legislativas, tecnológicas y de innovación de una forma consistente, rigurosa y representativa del sector español y europeo.

A continuación, se detallan estas motivaciones con mayor detalle.

1. Seleccionar y aplicar metodologías que ofrezcan una visión holística a los gestores ambientales

El enfoque global e integrado que ofrece la perspectiva del ciclo de vida es fundamental en ejercicios de prospectiva para poder identificar posibles desplazamientos de cargas ambientales a entidades exógenas, a otras etapas o procesos del ciclo de vida, o de un medio a otro, al mismo tiempo que se intenta minimizar los impactos en otros lugares (Baumann and Tillman, 2004; Fullana-i-Palmer and Puig, 1997).

Por tanto, se trata de un enfoque necesario para encontrar una solución de compromiso y consenso científico, que ayude en la toma de decisiones para el desarrollo de políticas y estrategias ambientales verdaderamente efectivas (Kørnøv and Thissen, 2000), tanto a nivel sectorial como individual.

\section{Identificar los grandes retos ambientales del sector de baldosas cerámicas}

Aunque los retos ambientales a escala local son numerosos (control de emisiones atmosféricas, consumo de agua, consumo de materiales, etc.), en este trabajo se han identificado tres grandes retos globales que, a juicio de la doctoranda, van a ser clave para la sostenibilidad del sector de baldosas cerámicas en las próximas décadas: 


\section{Reto 1. Desarrollar una comunicación ambiental eficiente}

Existen una serie de factores que favorecen, de forma coercitiva y no coercitiva, a aquellos productos que, o bien presentan un mejor comportamiento ambiental, o bien facilitan información ambiental cuantificada y objetiva (Gazulla, 2012). Algunos de estos factores son políticas que promueven el uso sostenible de los recursos, como por ejemplo, el Reglamento de materiales de la construcción (Regulation (EU) 305/2011) o el Plan de Acción de Economía Circular (COM(2015)0614 final). Además, el mantenimiento de unos niveles aceptables de calidad ambiental, la aparición en el mercado de certificaciones que exigen determinadas características ambientales de los productos de la construcción (Gelowitz and McArthur, 2017; Monfort, 2012), así como el aumento de criterios ambientales en los pliegos para licitaciones de obra o compra pública (Bratt et al., 2013; Ganassali et al., 2018; Monfort, 2012) son motores importantes para la comunicación ambiental.

Este incremento de demanda de información ambiental ha impulsado la aparición de numerosas etiquetas y marcados ambientales. De hecho, la web ecolabelindex (www.ecolabelindex.com), posiblemente el mayor directorio de ecoetiquetas del mundo (Gazulla, 2012), en Abril de 2019 tenía identificadas un total de 463 ecoetiquetas en 199 países correspondientes a 25 sectores industriales. Esta enorme cantidad de distintivos brinda numerosas oportunidades, pero también crea cierto desconcierto, confusión y escepticismo entre fabricantes y consumidores (lbáñezForés et al., 2016), además de establecer obstáculos para el libre comercio, especialmente en sectores, como el de las baldosas cerámicas, con un importante carácter exportador.

Por lo tanto, disponer de instrumentos de comunicación ambiental efectivos, eficientes especialmente, en lo relativo a tiempo y recursos- y reconocidos internacionalmente, -o al menos, en la mayor parte de las zonas geográficas donde se comercializan las baldosas cerámicas españolas-, es fundamental para los fabricantes y empresas comercializadoras. En este sentido, las DAPs, y los estudios de ACV que las sustentan, manejan datos ambientales suficientes (en el análisis del inventario y en la evaluación de los impactos del ciclo de vida), para responder a la mayoría de las peticiones de información ambiental. Además, son instrumentos de comunicación estandarizados mediante normas internacionales (ISO 14020, 2000; ISO 14025, 2006). No obstante, existen ligeras discrepancias entre programas en relación a los criterios para incluir varios productos bajo una misma DAP, lo que se traduce en diferencias en cuanto al número de DAPs necesarias para declarar la información ambiental de todos los productos de un fabricante (véase la Tabla 1.12).

Por ello, se considera necesario conocer: i) la magnitud y naturaleza de los impactos ambientales generados por las baldosas cerámicas a lo largo de todo su ciclo de vida, ii) la significancia ambiental de las distintas variantes que puede tener un determinado tipo de baldosas y, iii) los parámetros clave que permiten identificar las ventajas ambientales del producto y las oportunidades de mejora. 


\section{Reto 2. Competitividad ambiental con productos alternativos}

En 2017, el sector español de las baldosas cerámicas se posicionó como primer país exportador europeo y segundo exportador mundial (Baraldi, 2018). No obstante, las baldosas cerámicas están sometidas a una fuerte competencia por otros mercados y por recubrimientos alternativos (véase la Tabla 1.8), lo que crea una necesidad irrefutable de superar barreras comerciales y/o mantener la cuota en determinados mercados a través de la búsqueda de argumentos orientados a una diferenciación, especialmente, en situaciones con distintas condiciones legislativas, ambientales y sociales.

En este sentido, la variable ambiental es uno de los criterios más reconocidos para lograr esta diferenciación (Banerjee, 2017; Chen et al., 2015). Sin embargo, para definir estos argumentos de diferenciación y conocer el posicionamiento ambiental de las baldosas cerámicas frente a otros recubrimientos competitivos, se requieren procedimientos de evaluación exhaustivos, rigurosos e imparciales, y que además, tengan en consideración el resto de los elementos que conforman las soluciones constructivas a lo largo de todo su ciclo de vida para tener una visión integrada.

En la revisión de la bibliografía realizada en el marco de la presente tesis, se han identificado escasos estudios ambientales comparativos del ciclo de vida de los recubrimientos más habituales de España y Europa que cumplan las siguientes características: aplicación de una metodología común, inclusión de todo el sistema constructivo, consideración de varios escenarios en la etapa de uso y, que prevean tendencias políticas a medio y largo plazo, como puede ser la transición hacia una Economía Circular.

\section{Reto 3. Contribución a la mitigación del Cambio Climático}

El sector cerámico es un sector de consumo intensivo de energía y está sujeto a políticas y fuertes controles de las emisiones de GEl, responsables del cambio climático (Directiva 2003/87/EC; Directiva 2009/29/EC), además, está considerado como uno de los sectores industriales objetivo para alcanzar los objetivos para el 2020, 2030 y 2050 en materia de Energía, Cambio Climático y Medio Ambiente de la Unión Europea (Comisión Europea). Concretamente, la aprobación del "Roadmap for moving to a competitive low-carbon economy in 2050" (COM(2011)112 final) establece, como objetivo a los sectores industriales, reducir las emisiones de gases de efecto invernadero ente un $83 \%$ y un $87 \%$ para 2050 , con respecto a los valores de 1990 , y traslada a los diferentes sectores industriales trazar su propia hoja de ruta (Cerame Unie, 2012). Por tanto, la supervivencia del sector en una economía hipocarbónica, va a depender de la implementación simultánea de varias alternativas tecnológicas de vanguardia (breakthrough) en los procesos del ciclo de vida con mayor repercusión en el calentamiento global, ya que con las tecnologías implementadas actualmente no es posible el cumplimiento de dichos objetivos (Cerame Unie, 2012; Gabaldón-Estevan et al., 2016, 2014). Por ello, se hace necesario hacer un ejercicio de prospección con el fin de determinar y cuantificar los escenarios tecnológicos más adecuados para alcanzar dichos objetivos de reducción. 


\section{Definir un escenario de referencia apropiado para el sector de baldosas cerámicas}

En la presente tesis, se considera necesario asumir, como base de estudio, un escenario de referencia para poder definir y evaluar las estrategias ambientales planteadas para abordar los grandes retos ambientales identificados para el sector cerámico. Este escenario de referencia se ha determinado a partir de un estudio del ciclo de vida del gres porcelánico. Este tipo de baldosas cerámicas son las que presentan mayor interés comercial y de innovación (da Silva et al., 2014a, 2014b; Gabaldón Estevan and Hekkert, 2013; Martín-Márquez et al., 2010) gracias a su versatilidad técnica y funcional (ASCER, 2011; ISO 13006, 2012; Sánchez et al., 2010), además, su producción y demanda ha sido la que más ha aumentado en los últimos 15 años (ASCER, 2015) y es el tipo de baldosas que dispone de mayor número de distintivos ambientales, como la EU Ecolabel (European Commission, 2019) y DAPs (GlobalEPD; IBU-EPD; International EPD ${ }^{\circledR}$ System; Programa DAPconstrucción ${ }^{\circledR}$.

\subsection{Objetivos e Hipótesis}

El objetivo general es determinar y evaluar diferentes estrategias y herramientas para afrontar los retos identificados en esta tesis: comunicar de forma eficiente las características ambientales de las baldosas, obtener argumentos ambientales para aumentar su competitividad y, establecer medidas para mitigar su contribución y adaptarse al cambio climático mediante aplicaciones innovadoras de Análisis de Ciclo de Vida en el sector de las baldosas cerámicas.

Para su consecución, se han propuesto los siguientes objetivos específicos:

- Obtener datos actualizados, válidos y objetivos sobre el perfil ambiental de las baldosas de gres porcelánico a lo largo de su ciclo de vida.

- Verificar la magnitud y mejorar la comprensión de los efectos ambientales derivados de los diferentes formatos, patrones, diseños y acabados de las baldosas de gres porcelánico.

- Identificar los aspectos técnicos del producto o proceso que permitirían a las empresas influir y/o mejorar el comportamiento ambiental del producto.

- Cuantificar el impacto ambiental derivado de sistemas de suelos de distinta naturaleza instalados en interiores a lo largo de su ciclo de vida, tomando como punto de partida, la información contenida en DAPs de recubrimientos.

- Determinar las potenciales opciones tecnológicas que satisfagan los objetivos de emisiones de GEI de la UE 2020 y 2050, aplicando Análisis de Ciclo de Vida.

- Poner a disposición de los fabricantes de baldosas cerámicas una serie de herramientas para competir en un mercado globalizado, empleando argumentos ambientales como elemento diferenciador, al tiempo que se ofrece apoyo para adaptarse a una economía baja en carbono. 
En este contexto, la hipótesis con la que se presenta esta tesis es la siguiente:

"Es posible aplicar el Análisis de Ciclo de Vida en el sector de las baldosas cerámicas para abordar los retos de comunicación ambiental, competitividad y cambio climático mediante la evaluación de tendencias y prospecciones legislativas, tecnológicas y de innovación de una forma rigurosa, representativa y consistente".

\subsection{Estructura de la tesis}

El presente trabajo se estructura en cinco bloques, tal y como se expone a continuación:

\section{Bloque I: Introducción y estado del arte}

\section{Capítulo 1: Introducción y estado del arte}

El primer capítulo introduce información general correspondientes al sector de las baldosas cerámicas, los procesos de fabricación de baldosas y esmaltes cerámicos y sus principales aspectos ambientales. Asimismo, se presenta un resumen del marco político en materia de energía, cambio climático y medio ambiente de la Unión Europea relacionados con la temática del estudio. Por otro lado, se realiza una breve introducción sobre estudios de ACV, destacando la importancia de la perspectiva del ciclo de vida, fases que componen este tipo de estudios y finalizando con una revisión y análisis de la bibliografía publicada sobre ACV de recubrimientos cerámicos y recubrimientos alternativos de distinta naturaleza. Por último, se recogen los principales instrumentos de comunicación ambiental que emplean las empresas del sector de las baldosas cerámicas, tanto para destacar el comportamiento ambiental de sus organizaciones, como de los productos que fabrican y comercializan.

\section{Bloque II: Motivaciones, objetivos, estructura y metodología}

\section{Capítulo 2: Motivaciones, objetivos y estructura}

En el segundo capítulo, se exponen los principales factores motivantes que llevan a la realización del presente trabajo, donde se describen los retos que se abordan en la presente tesis, los objetivos a alcanzar, la hipótesis de partida y finalmente, la estructura de la memoria presentada.

\section{Capítulo 3: Metodología}

El tercer capítulo muestra la metodología seguida en el desarrollo del trabajo de investigación, que incluye una descripción del planteamiento del trabajo de tesis y las consideraciones metodológicas seguidas para la obtención de los resultados. Las metodologías seguidas para cada uno de las estrategias y herramientas desarrolladas se detallan en cada una de las publicaciones (Aportaciones). 


\section{Bloque III: Resultados y discusión}

\section{Capítulo 4: Resultados y discusión}

El cuarto capítulo recoge los resultados obtenidos en la presente tesis, así como la discusión de los mismos. Los resultados se han dividido en tres secciones correspondientes a cada uno de los retos abordados. Para cada reto, se plantea una estrategia y se desarrolla una herramienta para transferir y aplicar dicha estrategia al sector cerámico. Los resultados obtenidos se han publicado mediante artículos en revistas científicas y en ponencias en congresos internacionales y serán expuestos de la siguiente forma:

\section{Reto 1: Comunicación Ambiental Eficiente}

Aportación n¹: Environmental profile of Spanish porcelain stoneware tiles

Aportación n²: Strategic environmental communication tools

Reto 2: Competitividad Ambiental

Aportación n³: Environmental comparison of indoor floor coverings

Aportación $n^{\circ} 4$ : SolconCer, a helpful tool for characterising construction solutions

Reto 3: Mitigación del Cambio Climático

Aportación n5: How can the European ceramic tile industry meet the EU's low-carbon target? A life cycle perspective

Aportación n ${ }^{\circ}$ : $\mathrm{CerCO}_{2}$ - the $\mathrm{CO}_{2}$ Emission Simulation Tool for the Ceramic Industry

Capítulo 5: Discusión general de los resultados

En el quinto capítulo se lleva a cabo una discusión general entorno a la hipótesis planeada y los resultados obtenidos.

\section{Bloque IV: Conclusiones, líneas futuras de investigación y difusión de resultados}

\section{Capítulo 6: Conclusiones}

El sexto capítulo resume las principales conclusiones a las que se ha llegado tras la realización de esta investigación y en torno a los tres retos abordados. Las conclusiones específicas de cada aportación se recogen en cada uno de los artículos publicados.

\section{Capítulo 7: Líneas futuras de investigación}

En el séptimo capítulo se plantean posibles líneas de investigación para continuar y complementar el presente trabajo. 


\section{Capítulo 8: Difusión de resultados}

En el octavo capítulo se enumeran las publicaciones a congresos adicionales a las presentadas en el capítulo 4, en las que se ha llevado a cabo la difusión de los resultados obtenidos en el presente trabajo de investigación.

\section{Bloque V: Información complementaria y referencias}

\section{Capítulo 9: Referencias bibliográficas}

El noveno capítulo recopila la bibliografía citada en los capítulos de introducción y estado del arte, motivaciones, metodología y discusión general de los resultados. Las referencias bibliográficas de las aportaciones presentadas como resultados se recogen en las propias publicaciones.

\section{Capítulo 10: Anexos}

En el décimo capítulo se incluyen tres secciones adicionales anexadas con el fin de complementar la información incluida en la metodología y en los resultados. También se incluyen en este capítulo, la autorización de los coautores y coautoras para que la doctoranda pueda utilizar las publicaciones como parte de esta tesis y renuncian a incluirlas en otra tesis doctoral. 



\section{METODOLOGÍA}

En este apartado, se expone la metodología seguida para la consecución de los objetivos definidos y para hacer frente a los retos identificados y descritos en el capítulo de motivaciones. El planteamiento para acometer con éxito estos retos es mediante la aplicación de estrategias basadas en el ciclo de vida y en el desarrollo de herramientas asociadas a cada uno de los retos identificados. En la Figura 3.1 se representa la estructura general del trabajo de forma gráfica.

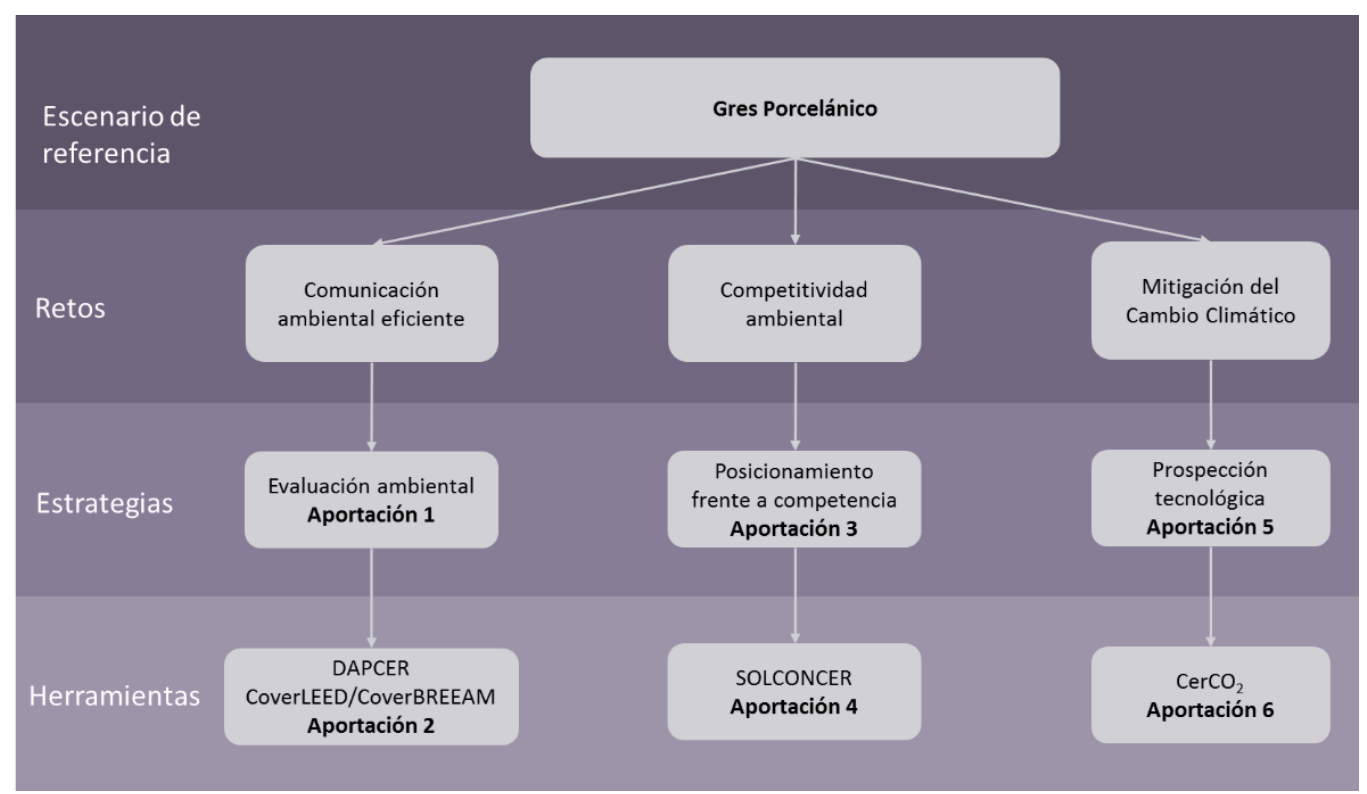

Figura 3.1 Planteamiento del trabajo de tesis

Tal y como se ha comentado en el apartado 1.4, el ACV es la metodología más aceptada para cuantificar los impactos ambientales de los productos de la construcción. En este apartado, se sintetiza la sistemática aplicada para el desarrollo de las aportaciones anteriormente citadas, en la que se ha seguido la metodología recogida por la ISO 14040:2006, tomando en consideración las normas de construcción sostenible (EN 15804+A1, 2013; EN 15978, 2011; ISO 21930, 2017) y las recomendaciones del ILCD handbook (Wolf et al., 2010).

Para desarrollar dichas estrategias y herramientas, se ha considerado necesario comenzar con la evaluación ambiental del escenario de referencia. A partir de la metodología aplicada y de los parámetros clave obtenidos como resultados de la evaluación de este escenario de referencia, se han llevado a cabo diversos análisis de escenarios. Estos escenarios permiten evaluar los parámetros clave para obtener y gestionar, de un modo eficiente, los instrumentos de comunicación ambiental de producto más adecuados, tomando como caso de estudio el uso de DAPs (Aportación $\mathbf{n}^{\circ} \mathbf{1}$ y $\mathbf{n}^{\mathbf{0}} \mathbf{2}$ ). Asimismo, permite posicionar y obtener argumentos ambientales para defender a las baldosas cerámicas en entornos competitivos (Aportación $\mathbf{n}^{\circ} \mathbf{3} \mathbf{y} \mathbf{n}^{\circ} \mathbf{4}$ ) y por último, permiten determinar los escenarios tecnológicos hipocarbónicos capaces de dar 
cumplimiento a los objetivos de reducción de $\mathrm{CO}_{2}$ establecidos por la Unión Europea en 2020 y 2050 para los sectores industriales (COM(2011)112 final) (Aportación n5 y n6).

Cabe decir que las Aportaciones $n^{\circ} 1,3$ y 5 tienen un carácter técnico-académico y por ello se han publicado en revistas científicas, mientras que las Aportaciones $n^{\circ} 2,4$ y 6 , tienen un enfoque aplicado a empresa, por ello se han publicado en congresos internacionales y en revistas de divulgación específicas del sector. De este modo, se asegura su transferencia y diseminación efectiva a ambos niveles.

\subsection{Metodología para la elaboración del ACV. Escenario de referencia}

\subsubsection{Alcance del estudio del ACV}

El escenario de referencia se ha obtenido mediante un estudio de ACV del gres porcelánico, con alcance de cuna a tumba, que emplea datos del sector cerámico español actualizados, representativos y verificados por terceras partes independientes, para obtener 14 DAPs específicas de gres porcelánico, y durante el periodo 2010-2015.

\subsubsection{Función y unidad funcional}

La función principal de las baldosas cerámicas es la de recubrir superficies. En este estudio de referencia se ha evaluado el del gres porcelánico como recubrimiento de suelos en el interior de una vivienda, a pesar de que la versatilidad de este tipo de baldosas, permite su instalación en otros lugares, como oficinas, comercios, hospitales, etc., en ambientes interiores y exteriores, así como también recubriendo paredes, fachadas $u$ otras superficies.

La unidad funcional se ha definido como "pavimento de $1 \mathrm{~m}^{2}$ del suelo interior de una vivienda durante 50 años".

\subsubsection{Límites del sistema}

El sistema estudiado incluye las siguientes etapas y procesos:

Suministro de materias primas:

- Extracción, y tratamiento de las materias primas del soporte

- Extracción, tratamiento y transporte de materias primas y producción de fritas y esmaltes cerámicos 


\section{Transporte:}

- Transporte de las materias primas del soporte, desde el lugar de extracción hasta la planta de preparación de las materias primas

Fabricación del gres porcelánico:

- Fabricación del gres porcelánico

- Producción del embalaje

- Recogida de residuos y gestión de los residuos

Distribución e instalación:

- Transportes desde la puerta de la fábrica hasta el punto de colocación

- Desembalaje de las baldosas y gestión de los residuos de embalajes y de construcción

- Proceso de instalación, inlcuyendo fabricación y transporte del material de agarre

\section{$\underline{\text { Uso/mantenimiento }}$}

- Operaciones de mantenimiento y limpieza

- Fabricación y transporte de productos utilizados como agentes de limpieza

Fin de vida:

- Deconstrucción y derribo

- Transporte de los residuos

- Reutilización y reciclaje

- Eliminación final

\section{Beneficios y cargas ambientales potenciales}

- Créditos ambientales derivados de actividades de reutilización, recuperación y reciclaje.

\subsubsection{Criterios de exclusión de entradas y salidas}

En este estudio de ACV con alcance de la cuna a tumba, se ha aplicado un criterio de corte de exclusión del $1 \%$ para el uso de energía (renovable y no renovable) y del $1 \%$ de la masa total en aquellos procesos unitarios cuyos datos son insuficientes. En total, se han incluido más del $95 \%$ de todas las entradas y salidas de materia y energía del sistema, excluyendo aquellos datos no disponibles o no cuantificados. Los datos excluidos son los siguientes: 
- Emisiones atmosféricas para los cuales no se establecen Valores Límite de Emisión en las Autorizaciones Ambientales Integradas.

- El proceso de reciclaje y reutilización de los residuos generados a lo largo del ciclo de vida de los recubrimientos cerámicos, tal y como se explica con mayor grado de detalle en el apartado 3.1.2.2. No obstante, el proceso de reciclaje de los residuos y los beneficios obtenidos por este reciclaje se han contabilizado como un módulo del ciclo de vida aparte.

- La producción de maquinaria y equipamiento industrial, debido a la dificultad que supone inventariar todos los bienes implicados (BSI PAS 2050, 2011), y también porque la comunidad de ACV considera que el impacto ambiental por unidad de producto es bajo en relación con el resto de los procesos que sí se incluyen (Frischknecht et al., 2007; Wittstock et al., 2012). Además, las bases de datos utilizadas no incluyen estos procesos, así que su inclusión requeriría un esfuerzo adicional fuera del alcance del estudio. Asimismo, también se excluyen los residuos generados en el mantenimiento de esta maquinaria y equipamiento debido, igualmente, al relativo bajo impacto que éstos suponen.

\subsubsection{Hipótesis realizadas}

Los datos para el inventario de la etapa de fabricación del producto han sido facilitados directamente por empresas del sector cerámico y de la cadena de valor. No obstante, se han asumido ciertas hipótesis:

Energía térmica del gas natural: Las cargas asociadas a la producción, distribución y combustión de gas natural se han obtenido de la base de datos Thinkstep, tomando como referencia datos medios europeos (EU-27) leídos por el software GaBi (PE International, 2008; Thinkstep, 2016b). Para el cálculo de la energía térmica en los procesos de combustión de la etapa de fabricación, se ha considerado el Poder Calorífico Inferior $\left(10,554 \mathrm{kWh} / \mathrm{Nm}^{3}\right)$.

Electricidad: Se ha tomado el perfil energético medio español calculado a partir de datos suministrados por Red Eléctrica de España 2013 (REE, 2014): 21,2\% nuclear; 21,2\% eólica; 14,6\% carbón; $14,2 \%$ hidráulica; $14,5 \%$ cogeneración y otras (térmica no renovable, y fuel/gas); 9,5\% ciclo combinado; $3,1 \%$ solar fotovoltaica; $2 \%$ térmicas renovables y $1,2 \%$ solar termoeléctrica.

Transportes: Para el cálculo de las cargas asociadas al transporte de materias primas del soporte y de los esmaltes, se ha sumado la cantidad total de materias primas y se ha asignado la tipología de transporte de acuerdo con su procedencia. En la tabla 12 de la Aportación $n^{\circ} 1$ se especifican las distancias promedio y vehículos escogidos para el transporte de todos los materiales, productos y residuos considerados a lo largo del ciclo de vida del producto.

Palés: Se contemplan dos tipos de palés: los Europalés (normalizados en dimensiones) que permiten su reutilización, considerando hasta 5 usos como media de veces que puede ser utilizado dicho palé dentro de los límites del sistema de estudio y, los palés denominados "de un solo uso" 
y a los cuales, se les ha asignado la totalidad de la carga ambiental asociada. De esta manera se quiere remarcar la responsabilidad del primer usuario del palé sobre el desecho creado, aun si existe un tercer sujeto, ajeno a este estudio, que vaya a utilizar dicho palé.

\subsubsection{Calidad de los datos}

Los datos utilizados en el estudio de ACV deben cumplir una serie de requisitos en cuanto a precisión, integridad, coherencia y representatividad que aseguren una buena calidad. En la Tabla 3.1 se resume el análisis de la calidad de los datos empleados en este estudio.

Tabla 3.1 Calidad de los datos utilizados en el estudio

\begin{tabular}{|c|c|}
\hline Exactitud & $\begin{array}{l}\text { La precisión y exactitud de los datos procedentes de las bases de datos del } \\
\text { software GaBi ya han sido evaluadas por sus autores. Por otra parte, cuando se } \\
\text { ha detectado una dispersión significativa en los datos calculados o recogidos, se } \\
\text { ha calculado la desviación típica (Aportación } n^{\circ} 1 \text { ) y se han incluido en el análisis } \\
\text { de sensibilidad (Aportación } n^{\circ} \text { 5). }\end{array}$ \\
\hline Alcance & $\begin{array}{l}\text { Se han utilizado principalmente datos directos facilitados por las empresas para } \\
\text { la obtención de DAPs de gres porcelánico. La veracidad de los datos y su } \\
\text { representatividad quedan asegurados, ya que los valores utilizados corresponden } \\
\text { a datos de producción estable recogidos durante los años } 2010-2015 \text {, que } \\
\text { abarcan un período mínimo de } 1 \text { año de producción, y cuya trazabilidad ha sido } \\
\text { verificada por terceras partes independientes durante el proceso de obtención de } \\
\text { las DAPs. }\end{array}$ \\
\hline Homogeneidad & $\begin{array}{l}\text { Se ha asegurado la homogeneidad de la metodología, desarrollando un único } \\
\text { modelo de ACV en el software GaBi, cuya flexibilidad ha permitido incorporar } \\
\text { todas las casuísticas tecnológicas y de proceso definidas a lo largo de la tesis. }\end{array}$ \\
\hline Reproducibilidad & $\begin{array}{l}\text { En este apartado de metodología de la tesis, así como en la sección de } \\
\text { metodología de la Aportación } n^{\circ} 1 \text {, se han descrito los métodos y datos utilizados, } \\
\text { de modo que un profesional independiente, que contara con las mismas bases de } \\
\text { datos, podría reproducir los mismos resultados. }\end{array}$ \\
\hline Coherencia & $\begin{array}{l}\text { Sólo se han utilizado datos con el mismo nivel de detalle y desarrollados bajo las } \\
\text { mismas consideraciones metodológicas. }\end{array}$ \\
\hline $\begin{array}{l}\text { Representatividad } \\
\text { temporal, geográfica } \\
\text { y tecnológica }\end{array}$ & $\begin{array}{l}\text { Los datos primarios facilitados por las empresas corresponden a un periodo } \\
\text { comprendido entre los años } 2010-2015 \text {; los datos de las bases de datos no tenían } \\
\text { una antigüedad superior a } 10 \text { años en el momento de la ejecución del estudio. } \\
\text { La cobertura geográfica abarca desde las zonas de extracción de las materias } \\
\text { primas (España, Europa o Asia), hasta la gestión del fin de vida (España), } \\
\text { incluyendo las zonas de producción del gres porcelánico (España) y el transporte } \\
\text { de las baldosas (España, Europa, resto del Mundo) y su uso (España). Para la } \\
\text { gestión de los residuos del embalaje se han estudiado los escenarios } \\
\text { correspondientes a las zonas de recepción de las baldosas España, Europa y resto } \\
\text { del mundo. } \\
\text { Para los datos correspondientes a la producción de las baldosas, se han utilizado } \\
\text { los valores de las tecnologías actualmente empleadas }\end{array}$ \\
\hline
\end{tabular}


Tabla 3.1. Calidad de los datos utilizados en el estudio (continuación)

\begin{tabular}{|c|c|}
\hline $\begin{array}{l}\text { Integridad de los } \\
\text { datos }\end{array}$ & $\begin{array}{l}\text { Se han incluido todos los procesos relevantes de los diferentes tipos de baldosas } \\
\text { cerámicas y que representen la situación específica de cada uno de ellos } \\
\text { - El } 75 \% \text { han sido facilitados directamente de los fabricantes de baldosas } \\
\text { cerámicas, y se ha realizado un promedio ponderado por la producción para } \\
\text { obtener los valores del gres porcelánico promedio } \\
\text { - El } 24 \% \text { de los datos se han obtenido a partir de la literatura y de medias } \\
\text { sectoriales (ACV-Tile, 2008; Benveniste et al., } 2011,2010 \text {; EIPPCB, 2012, 2007a) } \\
\text { - Muy pocos datos (1\%), se han tomado de los supuestos recogidos por las RCP } \\
\text { para recubrimientos cerámicos dentro de los programas españoles de DAPs: } \\
\text { (GlobalEPD, 2018; Programa DAPconstrucción } \circledast, 2015 \text { ) }\end{array}$ \\
\hline
\end{tabular}

\subsubsection{Análisis del inventario}

\subsubsection{Recopilación de datos}

Los datos cualitativos y cuantitativos incluidos en el inventario han sido mayoritariamente proporcionados directamente por 26 empresas españolas fabricantes de gránulos, fritas y esmaltes y baldosas cerámicas, para obtener 14 DAPs de gres porcelánico durante el periodo 2010 - 2015. Estos datos han sido obtenidos en algunas ocasiones de procesos unitarios y en otros, agregados de varios procesos, dependiendo de su disponibilidad o accesibilidad; en otros casos, se ha tenido que recurrir a medias bibliográficas o a la extrapolación de procesos similares.

Para la compilación de la información ambiental se han diseñado tres cuestionarios específicos para la fabricación del gránulo atomizado, de baldosas cerámicas y de fritas y esmaltes cerámicos. Estos cuestionarios se presentan en el Anexo 1.

\subsubsection{Tratamiento de la información por empresa de forma individual}

El tratamiento de la información ambiental consiste básicamente en validar los datos mediante balances de materia y energía para, posteriormente, referir los datos a la Unidad Funcional.

\section{Asignación de las entradas y salidas en la fabricación de baldosas cerámicas}

En el caso de la producción de baldosas cerámicas, se han detectado varios procesos que conllevan problemas de asignación de cargas, y cuya solución es crítica porque puede afectar directamente a los resultados del estudio. Estos problemas de asignación se han resuelto como se describe a continuación.

Siempre que ha sido posible, se ha aplicado el principio de causalidad a la hora de asignar las entradas y salidas de materia y energía, intentando establecer la relación física existente entre las entradas y salidas del sistema y sus diferentes productos. Cuando esto no ha sido posible, se ha recurrido al criterio de la masa (en $\mathrm{kg}$ ) y al volumen de producción (en $\mathrm{m}^{2}$ ). En la Tabla 3.2 se sugiere una relación de las consideraciones asumidas en la fabricación de las baldosas cerámicas, desde la etapa de conformado hasta la etapa de embalado. Se ha considerado que las etapas de 
preparación de las materias primas y la fabricación de fritas y esmaltes cerámicos no muestran diferencias ambientales entre las diferentes composiciones fabricadas y por tanto, no ha sido necesario realizar ninguna asignación de cargas.

Tabla 3.2 Métodos de asignación de cargas en las entradas y salidas de materia y energía de la etapa de fabricación de las baldosas cerámicas

\begin{tabular}{|c|c|}
\hline Asignaciones aplicadas por criterio de masa & $\begin{array}{c}\text { Asignaciones aplicadas por criterio de } \\
\text { producción }\end{array}$ \\
\hline $\begin{array}{l}\text { Energía térmica } \\
\text { Emisiones de partículas generadas en los procesos } \\
\text { previos al conformado } \\
\text { Emisiones de contaminantes gaseosos } \\
\text { Residuos de piezas cerámicas cocidas y sin cocer } \\
\text { Carga transportada en las distintas etapas }\end{array}$ & $\begin{array}{l}\text { Energía eléctrica } \\
\text { Cantidad de esmaltes } \\
\text { Cantidad de material de embalaje } \\
\text { Residuos no cerámicos }\end{array}$ \\
\hline
\end{tabular}

\section{Reciclaje en bucle abierto}

Durante el ciclo de vida de las baldosas cerámicas se generan una serie de residuos que sufren uno o varios procesos de reciclaje, como los residuos de envases y embalajes o los residuos de las baldosas al finalizar su vida útil. Por otra parte, el sistema incluye una serie de productos que contienen material reciclado.

Los beneficios generados por el material secundario en otros sistemas de producto recibe el nombre de "créditos" ambientales (Ekvall and Tillman, 1997; Wolf et al., 2010). En la Figura 3.2 se representa, de forma esquemática, el modelo de asignación utilizado en el estudio relativo a la valorización de los residuos.

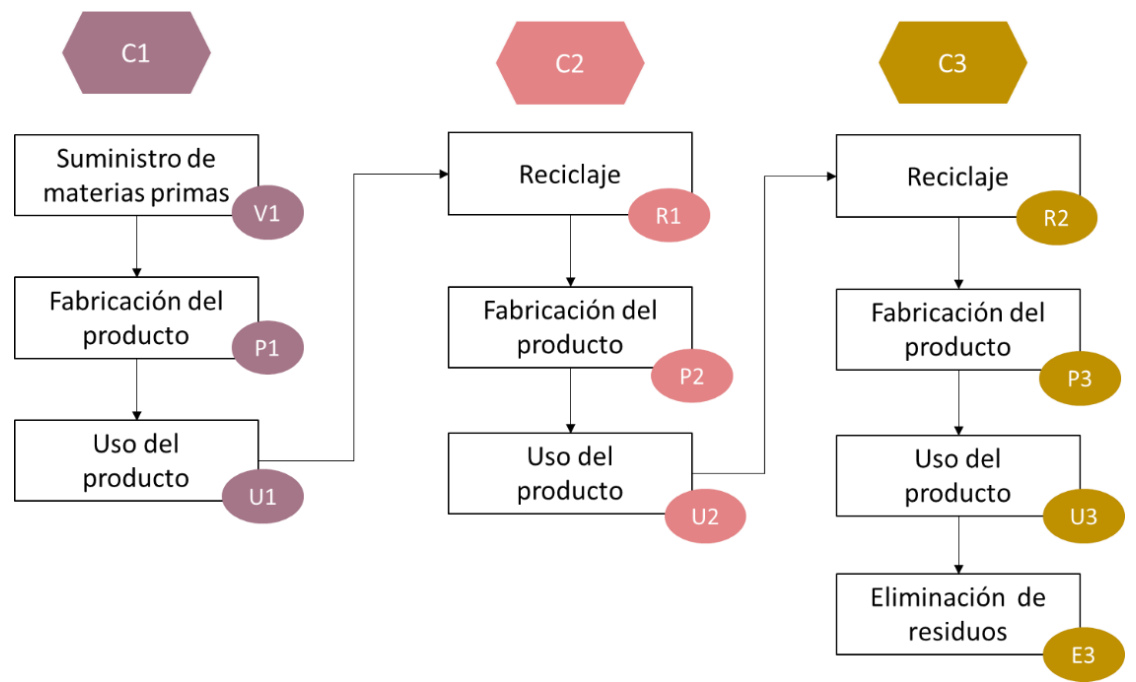

Figura 3.2 Modelo de asignación en la valorización de los residuos utilizado en el estudio (basado en Wolf et al., 2010 
Existen diferentes métodos para asignar las cargas de los procesos comunes a los distintos sistemas (producción de materias primas V1, reciclaje R1 y R2, eliminación de residuos E3). Se ha optado por aplicar el conocido como "cut-off", de manera que el reciclaje de residuos se asigna al ciclo del segundo producto (Baumann and Tillman, 2004). Este método penaliza en mayor grado a los productos no reciclables, es decir, aquellos productos que son incapaces de reintroducir el material secundario en un nuevo sistema productivo. Así, según este método, las cargas ambientales $(C)$ se reparten entre los tres productos de la siguiente manera:

$\mathrm{C} 1=\mathrm{V} 1+\mathrm{P} 1+\mathrm{U} 1$

$\mathrm{C} 2=\mathrm{R} 2+\mathrm{P} 2+\mathrm{U} 2$

$\mathrm{C} 3=\mathrm{R} 2+\mathrm{P} 3+\mathrm{U} 3+\mathrm{E} 3$

Por lo tanto, los residuos generados en el sistema de estudio que son reciclables en otros sistemas incluyen las cargas ambientales (C1) de los siguientes procesos:

- Retirada selectiva de los residuos

- Transporte hasta la planta de separación y clasificación

Del mismo modo, los materiales que contienen en su composición material reciclado incluyen las cargas ambientales (C2) de los siguientes procesos:

- Operaciones de clasificación de materiales reciclables

- Transporte hasta la planta de reciclaje

- Tratamiento y transformación del residuo hasta la obtención del material secundario.

Asimismo, los residuos generados en el ciclo de vida de los productos de estudio que no son reciclables (E3), incluyen las cargas ambientales (C3) de los siguientes procesos:

- Retirada selectiva de los residuos

- Transporte de los residuos hasta la planta incineradora o vertedero

- Impactos de la incineración o vertedero

No obstante, cabe decir que, en el presente trabajo se declara, en un módulo independiente del ciclo de vida (Módulo D según norma EN 15804+A1, 2013), la existencia de créditos ambientales debido a la reutilización, recuperación o reciclaje de la gestión de los residuos de envases y embalajes generados en la etapa de fabricación, así como en la etapa de instalación y construcción y en la etapa de fin de vida. Concretamente, se declaran los impactos netos resultantes de contabilizar los impactos de producción de los materiales o combustibles primarios desplazados o sustituidos (considerando las eficiencias de reciclaje correspondientes en cada caso) menos las cargas ambientales de las operaciones de reutilización, recuperación y reciclaje. 


\section{Cogeneración}

En el sector de las baldosas cerámicas es habitual el uso de sistemas de cogeneración en el secadero por atomización y en menor medida en hornos, con el fin de reducir los requerimientos energéticos en otros procesos (Monfort et al., 2014).

La cogeneración es la producción conjunta, en proceso secuencial, de electricidad (o energía mecánica) y energía térmica útil, a partir de una única fuente de energía primaria. Los sistemas de cogeneración más utilizados en el sector cerámico son de turbinas de gas utilizando como combustible gas natural, cuya combustión proporciona gases calientes de forma directa a la etapa demandante de energía térmica. La energía eléctrica generada se aprovecha en parte en la planta industrial, reduciendo así los requerimientos eléctricos de la red y el resto, se vuelca a la red para su venta y posterior distribución (Monfort et al., 2011b, 2010).

En el modelo de ACV, se han considerado las cargas del gas natural utilizado en la cogeneración y postcombustión, así como la energía eléctrica comprada y vendida. Esta última supone un ahorro de cargas ambientales evitadas, y desplaza la producción de energía eléctrica en la red, modelizándolo como una expansión del sistema, puesto que no es posible establecer una relación física ni aplicar una asignación por criterio energético ni económico, ya que, en este último caso, únicamente la electricidad vendida a la red tiene valor económico. Una expansión del sistema consiste en sustraer las cargas ambientales de la función no objeto de estudio (Wolf et al., 2010). En la Figura 3.3 se representa un esquema de la expansión del sistema.

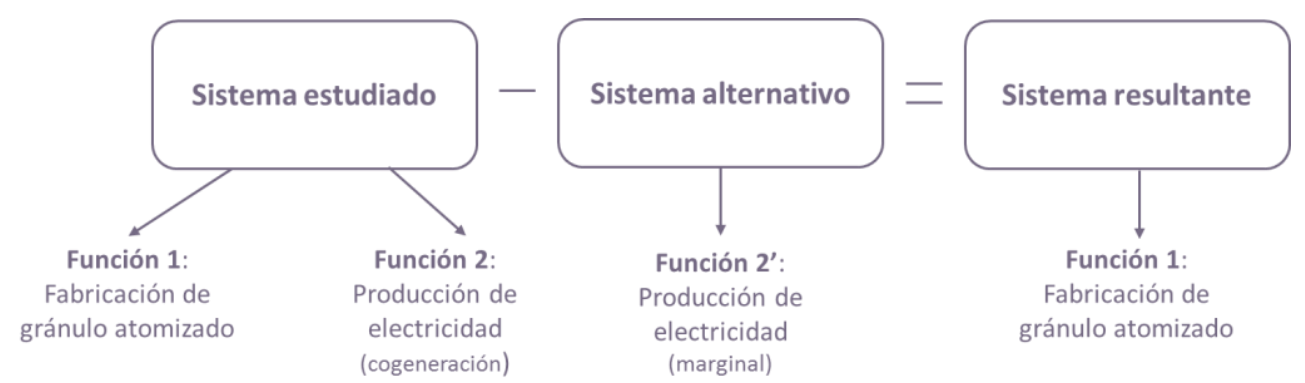

Figura 3.3 Esquema de expansión del sistema (basado en Wolf et al., 2010)

Hay dos consideraciones a tener en cuenta en este caso. Por un lado, la electricidad suministrada por la Red Eléctrica Española se genera mediante diferentes tecnologías que generan impactos ambientales muy distintos, y por otro lado, el perfil energético nacional de producción de electricidad no es representativo de los cambios marginales que se puedan producir en la demanda. Por ello, en la expansión del sistema únicamente se verán afectadas aquellas tecnologías que sean elásticas a los cambios en la demanda (Weidema, 2000, 2003). En España, en base a los datos proporcionados por estudios realizados (Arnedillo, 2007; Eid et al., 2016), se ha considerado que la tecnología marginal, es decir, la desplazada del sistema, es la procedente de las centrales térmicas de fuel o gas. 


\subsubsection{Tratamiento de la información de forma colectiva}

Con objeto de obtener valores ambientales representativos del gres porcelánico, se ha calculado un promedio ponderado por la producción de los datos facilitados por las empresas, ya referidos a la unidad funcional.

Cabe citar la especial atención que se presta en el tratamiento conjunto de la información asociada a los consumos energéticos y de agua en función de las diferentes configuraciones de empresas: ciclo completo (fabricantes de gránulo atomizado y baldosas cerámicas), ciclo parcial (fabricantes de baldosas) y fabricantes de gránulo atomizado, puesto suponen distinto reparto de los recursos entre los procesos que cada tipo de empresa posee.

Los datos de entrada y salida de materia y energía a cada uno de los procesos y etapas del ciclo de vida se resumen en el Anexo 2 en forma de tablas.

\subsubsection{Diseño del modelo de ACV en el software GaBi}

La modelización del inventario del escenario de referencia se ha realizado con el software GaBi 4 (PE International, 2008a) y su posterior migración y actualización a GaBi 6 (Thinkstep, 2016b) y a Gabi 8 (Thinkstep AG, 2018a), con las bases de datos GaBi professional y la específica de materiales de la construcción de GaBi (PE International, 2008b; Thinkstep, 2016a), así como ELCD 3.2. (JRC-IES, 2015). Se trata de un modelo altamente flexible que permite realizar, con relativa simplicidad, diferentes escenarios gracias al elevado número de parámetros programados (194 parámetros), que, a pesar de la dificultad inicial en su programación, posteriormente, permite simular y analizar los diferentes escenarios propuestos de una forma totalmente consistente a lo largo de todo el proceso de investigación de la tesis.

En el Anexo 3, se describe el modelo desarrollado y se presentan capturas de pantalla de los principales planos diseñados.

\subsubsection{Evaluación e interpretación de los impactos ambientales}

En este escenario de referencia se han aplicado los métodos basados en indicadores intermedios (mid-point) propuestos por la norma EN15084+A1,2013 Reglas de Categoría de Productos básicas para productos de la construcción:

- Potencial de agotamiento de los recursos abióticos para recursos fósiles, expresado en MJ

- Potencial de agotamiento de los recursos abióticos para recursos no fósiles (elementos), expresado en $\mathrm{kg} \mathrm{Sb}$ equivalentes

- Potencial de acidificación del suelo y de los recursos de agua, expresado en $\mathrm{kg}$ de $\mathrm{SO}_{2}$ equivalentes 
- Potencial de eutrofización, expresado en $\mathrm{kg}$ de $\mathrm{PO}_{4}{ }^{3-}$ equivalentes

- Potencial de calentamiento global, expresado en $\mathrm{kg}$ de $\mathrm{CO}_{2}$ equivalentes

- Potencial de agotamiento de la capa de ozono estratosférico, expresado en kg de CFC11 equivalentes

- Potencial de formación de ozono troposférico, expresado en $\mathrm{kg} \mathrm{de} \mathrm{C}_{2} \mathrm{H}_{4}$ equivalentes

Una vez obtenidos los resultados de la evaluación de impacto, se ha realizado un análisis de contribución de las entradas y salidas para identificar los parámetros que serán clave en la definición de las estrategias y en el desarrollo de las herramientas asociadas a cada reto planteado en este trabajo. La identificación y evaluación de estos parámetros clave permite identificar los potenciales de mejora del producto, modificando los valores de dichos parámetros y analizando las consecuencias ambientales resultantes. Cabe decir que, estos parámetros clave han sido confirmados mediante un análisis de sensibilidad llevado a cabo sobre este escenario de referencia en la Aportación $n^{\circ} 5$.

\subsection{Metodología para el desarrollo de estrategias y herramientas del ciclo de vida}

A partir de la evaluación del escenario de referencia, se han llevado a cabo diversos escenarios para acometer las estrategias planteadas. Cabe recordar que, en todas las aplicaciones de ACV de este trabajo, se ha seguido la metodología definida por ISO 14020, 2000; ISO 14044, 2006, se han tomado en consideración las normas asociadas a construcción sostenible EN 15804+A1, 2013; EN 15978, 2011; ISO 21930, 2017 y se han seguido las recomendaciones del ILCD handbook (Wolf et al., 2010).

En los estudios de ACV que sustentan las estrategias abordadas en esta tesis, se definen una serie de elementos comunes que aseguran la consistencia de la metodología y de los resultados obtenidos. Estos elementos comunes son:

- Tipo de baldosa cerámica y función: se toma como caso de estudio las baldosas de gres porcelánico instaladas como pavimento de suelos en el interior de un edificio residencial

- Unidad Funcional: definida como el recubrimiento de $1 \mathrm{~m}^{2}$ de suelo en el interior de una vivienda durante 50 años.

- Límites del sistema: se incluyen todas las etapas del ciclo de vida, es decir, la obtención y transporte de las materias primas, fabricación de los recubrimientos, distribución, instalación, uso y fin de vida.

- Hipótesis, criterios de exclusión: se asumen las mismas hipótesis y criterios de exclusión que las descritas para el escenario de referencia. 
- Modelo de ACV de recubrimientos cerámicos: se aplica un único modelo diseñado mediante el software GaBi capaz de analizar diferentes escenarios de forma consistente.

- Datos de inventario del escenario de referencia: en todos los casos, se parte del escenario de referencia del gres porcelánico descrito en el apartado anterior, a partir del cual, se actualizan y se modifican los valores de los procesos afectados por las estrategias y por las herramientas.

- Método de evaluación del impacto ambiental y categorías de impacto: se aplica el método de evaluación CML 2001 (Guinée et al., 2002) con las últimas actualizaciones disponibles en el momento de elaboración de cada una de las estrategias, y se evalúan las categorías de impacto sugeridas por la norma EN 15804+A1, 2013.

A continuación, se resume la metodología aplicada en cada estrategia y herramienta; el detalle de éstas se presenta en las publicaciones (capítulo 4).

\subsubsection{Reto de una comunicación ambiental eficiente}

\subsubsection{Estrategia de evaluación ambiental}

En la Aportación $n^{\circ} 1$, se presenta la estrategia para abordar el reto de una comunicación ambiental eficiente mediante la evaluación ambiental del ciclo de vida del gres porcelánico y de sus variantes presentes en el mercado.

\section{Descripción de escenarios e inventario del ciclo de vida}

Se han identificado 15 variantes de gres porcelánico, en base a tres parámetros clave: espesor de las piezas, cantidad de esmalte y tratamientos mecánicos superficiales.

Para el desarrollo del inventario de cada variante, en primer lugar se han identificado y cuantificado los parámetros clave y los parámetros vinculados mediante relaciones causa-efecto, y posteriormente, se han aplicado al inventario del escenario de referencia del gres porcelánico. En la Tabla 3.3, se destacan los parámetros afectados por cada uno de los parámetros clave que determinan las variantes. 
Tabla 3.3 Relación de parámetros clave en las variantes del gres porcelánico

\begin{tabular}{|c|l|}
\hline $\begin{array}{c}\text { Parámetros clave de las } \\
\text { variantes }\end{array}$ & \multicolumn{1}{c|}{ Parámetros afectados } \\
\hline \multirow{5}{*}{ Espesor de las piezas } & $\begin{array}{l}\text { Cantidad de materia prima procesada } \\
\text { Todas las entradas y salidas de la preparación de materias primas } \\
\text { Energía térmica del secado y cocción } \\
\text { Emisiones de partículas en etapas previas al conformado } \\
\text { Emisiones de contaminantes gaseosos } \\
\text { Residuos de piezas cerámicas cocidas y sin cocer } \\
\text { Carga transportada en las distintas etapas }\end{array}$ \\
\hline \multirow{3}{*}{ Cantidad de esmalte } & $\begin{array}{l}\text { Parámetros asociados a su fabricación y transporte } \\
\text { Consumo de agua } \\
\text { Generación de aguas residuales } \\
\text { Emisiones de partículas durante la etapa de esmaltado }\end{array}$ \\
\hline & $\begin{array}{l}\text { Electricidad consumida en el mecanizado } \\
\text { Consumo de agua } \\
\text { Generación de residuos y aguas residuales }\end{array}$ \\
\hline
\end{tabular}

\section{Evaluación ambiental de los escenarios e interpretación}

Una vez completado el análisis del inventario del ciclo de vida de cada una de las variantes de gres porcelánico, se ha aplicado el modelo flexible desarrollado en el software de ACV GaBi (Thinkstep, 2016b) y sus bases de datos asociadas (JRC-IES, 2015; Thinkstep, 2016a).

En primer lugar, se han evaluado los impactos del ciclo de vida de los tres parámetros clave descritos en la Tabla 3.3, de forma aislada y sus posibles variaciones con el fin de determinar la significancia ambiental de cada uno de estos parámetros clave. Posteriormente, se ha realizado la evaluación conjunta de las 15 variantes de gres porcelánico, para comprobar si las diferencias superan el $10 \%$ en alguna de las categorías de impacto ambiental consideradas y, por tanto, comprobar de qué modo es posible su agrupación bajo una misma DAP, dependiendo de los programas y de sus criterios de agrupamiento.

Esta evaluación se ha llevado a cabo aplicando el método de evaluación CML 2001 (Guinée, et al., 2002) y las categorías de impacto recomendadas por la norma EN 15804+A1, 2013. 


\subsubsection{Herramientas estratégicas de comunicación ambiental: DAPCER, CoverLEED y CoverBREEAM by ITC}

Las herramientas desarrolladas para afrontar el reto de la Comunicación Ambiental Eficiente se recogen en la Aportación n².

La herramienta DAPCER ha sido diseñada para la elaboración de estudios de ACV y DAPs de recubrimientos cerámicos. Se ha desarrollado con el soporte del software $\mathrm{GaBi}$, a partir del modelo desarrollado para la evaluación del escenario de referencia, y con la extensión GaBi i-Report.

En el anexo 3 se describe el modelo desarrollado, el cual consta de 30 planos, conectados entre sí, compuestos por diagramas de procesos unitarios conectados por flujos de materia y energía. Parte de estos flujos han sido parametrizados de forma que, su valor puede ser modificado desde un único lugar sin necesidad de modificar los procesos ni los planos.

Para la elaboración de esta herramienta, se ha vinculado el listado de flujos parametrizados con un informe tipo de ACV y un borrador de DAP, cuyo contenido y forma cumplen las normas EN 15804+A1, 2013; ISO 14025, 2006; ISO 14040, 2006; ISO 14044, 2006. Este vínculo se ha establecido bien directamente, bien a través de ecuaciones definidas específicamente, o bien con los resultados de la evaluación de impactos, según proceda en cada caso. Asimismo, se han habilitado campos donde poder incluir variables de texto para personalizar los documentos, como son el nombre de la empresa peticionaria del estudio, tipo de baldosa cerámica sometida a estudio o lugar de fabricación, entre otros.

Para su ejecución, se deben insertar los datos de inventario, que han sido previamente parametrizados y las variables de texto y la herramienta reporta los borradores del informe de ACV y DAP. Cabe indicar que ciertos campos del informe no pueden ser automatizados, como es la interpretación de resultados, o la descripción en detalle del escenario tecnológico de la empresa peticionaria del estudio o de su cadena de valor.

En la Figura 3.4., se expone una captura de pantalla de parte del listado de parámetros definidos para la ejecución de esta herramienta y en la Figura 3.5., una captura de pantalla de la extensión $\mathrm{GaBi}$ i-Report mostrando una de las hojas de la plantilla del informe de ACV.

Esta herramienta ha sido testeada en 14 empresas fabricantes de diferentes tipos de baldosas cerámicas, y cuya conformidad con las normas de referencia (EN 15804+A1, 2013; ISO 14025, 2006; ISO 14040, 2006; ISO 14044, 2006) ha sido verificada por AENOR, entidad administradora del programa GlobalEPD para agilizar el proceso de verificación de las DAPs elaboradas para empresas para este programa. No obstante, esta herramienta ha sido posteriormente empleada para elaborar 32 DAPs en este y en otros programas europeos. 


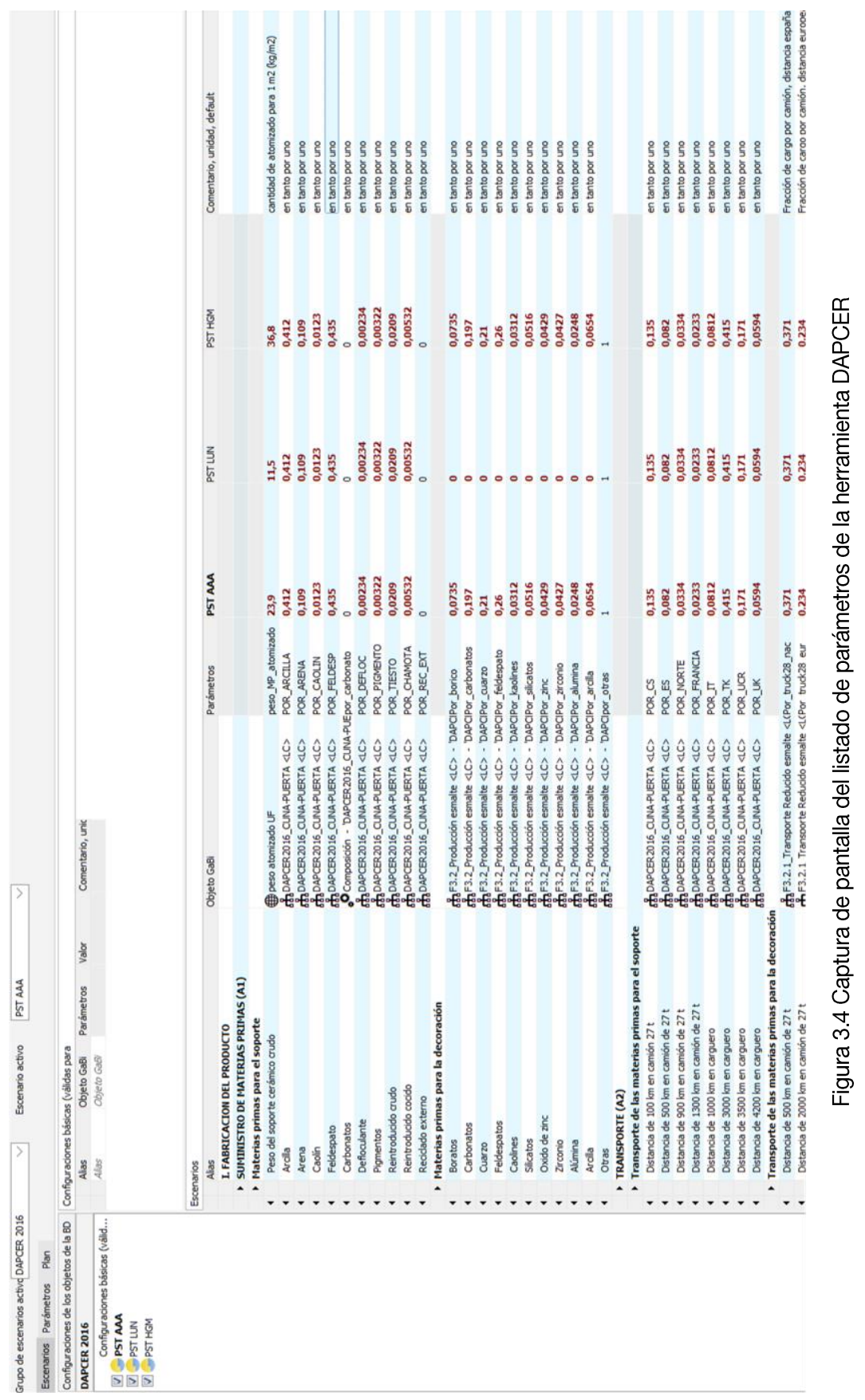




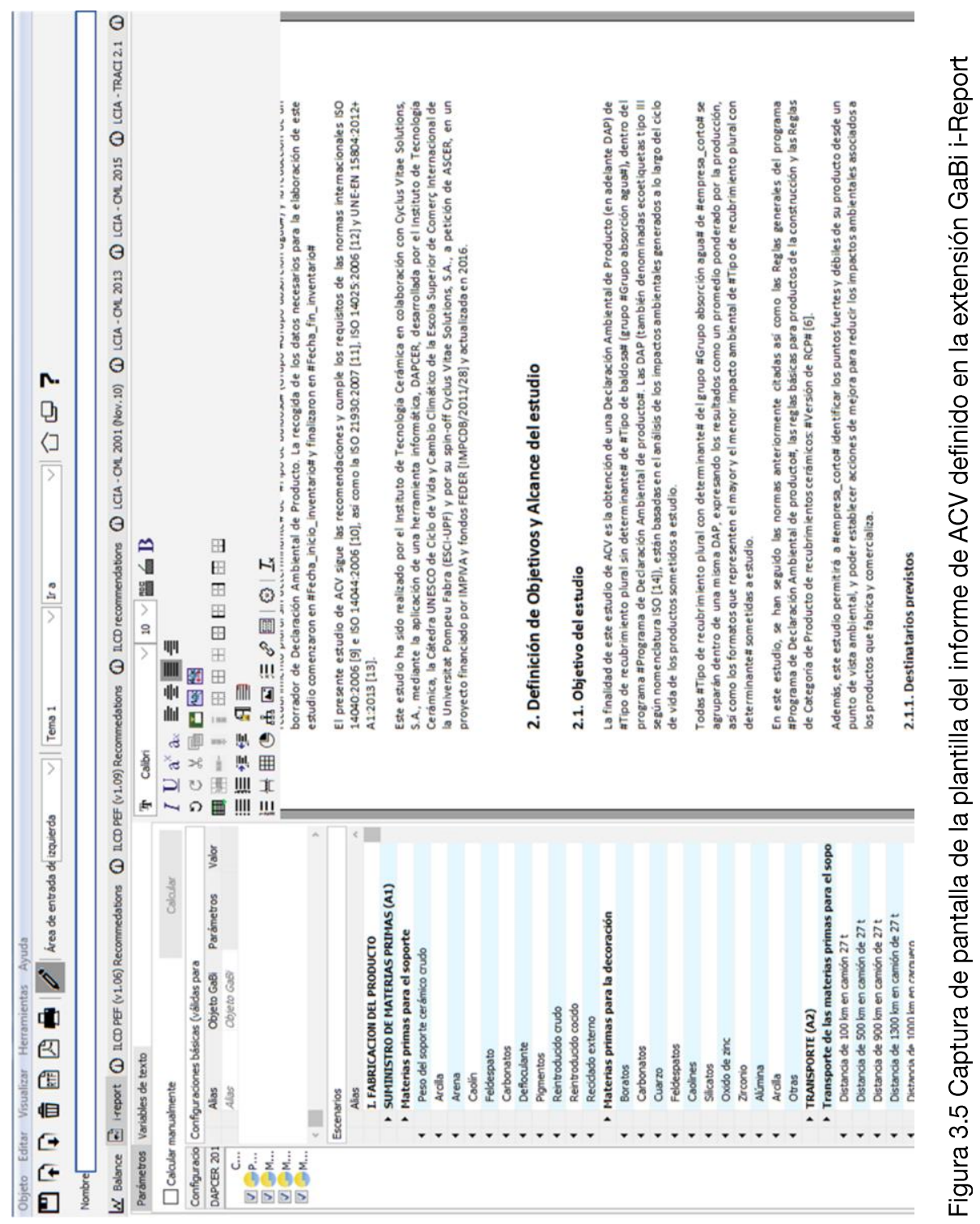


Las herramientas CoverLEED y CoverBREEAM by ITC han sido creadas específicamente para el sector de las baldosas cerámicas, y tienen como objetivo, ayudar a los fabricantes del sector a demostrar la contribución que tienen sus baldosas cerámicas en los certificados de construcción sostenible LEED y BREEAM, respectivamente.

El primer paso seguido en el desarrollo de la herramienta ha sido la identificación de criterios aplicables a las baldosas cerámicas, considerando que éstas pueden ir instaladas como recubrimiento de suelos, paredes, en ambientes interiores y exteriores. El alcance de estas herramientas contempla todos los tipos de edificaciones y esquemas de puntuación (o ranking systems).

Posteriormente, se han clasificado dichos criterios en función del tipo de información solicitada y del modo de obtención de ésta: mediante cálculos a partir de información de la empresa o de sus proveedores, mediante ensayos o mediante evidencias documentales.

Estas herramientas se han diseñado de forma que puedan ejecutarse en hojas de cálculo Excel o bien, instalarse en el sistema de planificación de recursos empresariales (ERP, Enterprise Resource Planning), dependiendo del funcionamiento, modo de gestión de la información y necesidades de las empresas. Tanto en un caso como en el otro, las herramientas se nutren de información procedente de la empresa (bien introducida en las hojas de cálculo por la empresa o bien directamente desde la ERP), realizan los cálculos pertinentes o gestionan las evidencias documentales necesarias para incluirlas en un dossier que generan las herramientas de la forma específica que se requiere para la certificación LEED y BREEAM.

\subsubsection{Reto de aumentar la competitividad}

\subsubsection{Estrategia de posicionamiento de la baldosa frente a materiales competidores}

En la Aportación $n^{\circ} 3$, se presenta la estrategia para abordar el reto de aumento de la competitividad. Para ello, se han llevado a cabo estudios de ACV comparativos de diferentes sistemas de suelos para interiores con recubrimientos de distinta naturaleza, bajo diferentes escenarios de uso y con un alcance de cuna a cuna. Los tipos de recubrimientos caracterizados han sido: inorgánicos (baldosas cerámicas y piedra natural), orgánicos (PVC y moqueta) y basados en madera (laminados y parquet).

\section{Descripción de escenarios e inventario del ciclo de vida}

En primer lugar, se han definido los sistemas de suelos de interiores con los recubrimientos más comunes en España y Europa y las características de cada uno de los elementos que los conforman, empleando como referencia, documentos y normativa española, (CYPE Ingenieros, 2018; IETcc-CSIC, 2011; Ministerio de Fomento de España, 2011, 2009). Todas las etapas del ciclo de vida y escenarios considerados son comunes a todos los sistemas de suelos en un contexto del edificio, además, se han establecido diferentes escenarios para la etapa de uso en 
base a su intensidad de tránsito peatonal: bajo, medio y alto, los cuales determinan las operaciones limpieza, reparación y sustitución.

La información ambiental relativa a la etapa de producto de los recubrimientos (A1-A3, extracción, transporte de materias primas y fabricación) se han obtenido a partir de un promedio de los impactos ambientales declarados en las DAPs, previamente seleccionadas de acuerdo a los criterios de las normas EN 15804+A1, 2013 e ISO 14025, 2006 y método de gestión similar al empleado por Gelowitz and McArthur, 2017; la información del resto de componentes, se ha tomado de las bases de datos GaBi (Thinkstep AG, 2018b) y ELCD (JRC-IES, 2015). Para las etapas y escenarios posteriores (A4-C4/D) se definieron escenarios comunes en un mismo contexto de edificio residencial en base a las descripciones proporcionadas por los fabricantes en sus DAPs, sitios web y en diversas fuentes bibliográficas.

\section{Evaluación ambiental de los escenarios e interpretación}

Una vez completados los inventarios de todos los sistemas de suelos y los diferentes escenarios, se ha evaluado el impacto ambiental utilizando las bases de datos de GaBi (Thinkstep AG, 2018b) y ELCD (JRC-IES, 2015) y exportando los impactos de los procesos a hojas de cálculo Excel. Las categorías de impacto son las recomendadas por la norma EN 15804+A1, 2013.

Esta evaluación se lleva a cabo aplicando el método de evaluación CML 2001 (Guinée, et al., 2002) y categorías de impacto recomendados por la norma EN 15804+A1, 2013.

Para la interpretación de los resultados, se realizó un análisis de incertidumbre Montecarlo a todo el ciclo de vida de los sistemas de suelos, considerando todos los datos de partida de la DAPs y todos los escenarios de uso. La simulación Montecarlo se programó en hojas de cálculo Excel, distribuyendo al azar los datos medios de cada etapa del ciclo de vida y su desviación estándar de cada uno de los sistemas de suelos, los cuales están representados por una distribución normal, ejecutándose un número de 1000 iteraciones dentro de un intervalo de confianza del 95\%.

\subsubsection{Herramienta SolconCer: Caracterización de Soluciones Constructivas}

La herramienta desarrollada para afrontar el reto de la Competitividad Ambiental se incluye en la Aportación n4.

SolconCer es una herramienta informática para caracterizar soluciones constructivas desde el punto de vida ambiental, económico y prestacional. El alcance de esta tesis únicamente incluye la caracterización ambiental.

En el desarrollo de esta herramienta se ha seguido la misma metodología que la descrita en la estrategia para mitigar el Cambio Climático, con la particularidad de que, el usuario final puede personalizar determinados campos, como los impactos ambientales publicados por DAPs o ACVs, la distancia recorrida en la distribución de los recubrimientos y los escenarios de uso. 
En la elaboración de los ACV de las soluciones constructivas, los datos de inventario asociados a la etapa de producto de los recubrimientos (extracción, transporte de materias primas y transporte de los recubrimientos) se han obtenido a partir de un promedio de los impactos ambientales declarados en las DAPs, previamente seleccionadas de acuerdo a los criterios de las normas EN 15804+A1, 2013 e ISO 14025, 2006; el resto de etapas del ciclo de vida han sido calculados en hojas de cálculo EXCEL con el soporte del software GaBi 6 (Thinkstep, 2016b) y sus bases de datos profesional y específica de materiales de la construcción (Thinkstep, 2016a).

Los métodos de evaluación del impacto ambiental y factores de caracterización considerados son los reconocidos por la norma EN 15804+A1, 2013, excepto ADPE, por la inconsistencia de los datos ambientales encontrados en las DAPs en el momento del desarrollo de la herramienta. En aras de facilitar la interpretación a los usuarios de la herramienta, los resultados de la evaluación ambiental se han reducido a unidades adimensionales, comprendidas entre 1 y 10 , mediante los factores de normalización del CML2001 - 2001-2013 EU25+3.

Posteriormente, se ha contado con un equipo de técnicos informáticos para programar la herramienta SolconCer online en https://solconcer.es/.

\subsubsection{Reto de cambio climático}

\subsubsection{Estrategia de prospección tecnológica de emisiones GEI}

En la Aportación n5, se desarrolla la estrategia para abordar el reto de la mitigación del cambio climático, a partir de una prospección que evalúa los escenarios tecnológicos que permitirían al sector de la fabricación de baldosas, alcanzar los objetivos de reducción de emisiones de GEl de la EU para el 2020 y 2050 de $83-87 \%$ respecto a los niveles de 1990.

\section{Descripción de escenarios e inventario del ciclo de vida}

En este sentido, a partir de los parámetros clave y de un análisis de la bibliografía consultada, se han identificado 17 alternativas tecnológicas, cuya combinación dan como resultados 25 escenarios tecnológicos orientados a reducir las emisiones de GEI. Estas alternativas tecnológicas suponen cambios en el diseño de producto (espesor de las piezas y cantidad de esmalte), cambios en el proceso productivo (preparación de materias primas e implantación simultáneas de medidas de eficiencia energética) y cambios en las fuentes energéticas (electrificación parcial o completa de secaderos y hornos).

De manera similar a la metodología llevada a cabo en la Aportación $n^{\circ} 1$, el análisis de inventario de cada alternativa y escenario tecnológico se ha elaborado partiendo del inventario del escenario de referencia y sustituyendo los parámetros afectados por cada una de las alternativas planteadas. En la Tabla 3. 4 se expresan los parámetros afectados por cada una de las alternativas propuestas. 
Tabla 3. 4 Relación de parámetros clave en la mitigación del cambio climático

\begin{tabular}{|c|c|}
\hline Variante/alternativa & Parámetros afectados \\
\hline Espesor de las piezas & $\begin{array}{l}\text { Cantidad de materia prima procesada } \\
\text { Todas las entradas y salidas de la preparación de materias primas } \\
\text { Energía térmica del secado y cocción } \\
\text { Emisiones de partículas en etapas previas al conformado } \\
\text { Emisiones de contaminantes gaseosos } \\
\text { Residuos de piezas cerámicas cocidas y sin cocer } \\
\text { Carga transportada en las distintas etapas }\end{array}$ \\
\hline Cantidad de esmalte & $\begin{array}{l}\text { Parámetros asociados a su fabricación y transporte } \\
\text { Consumo de agua } \\
\text { Generación de aguas residuales } \\
\text { Emisiones de partículas durante la etapa de esmaltado }\end{array}$ \\
\hline $\begin{array}{l}\text { Preparación de materias } \\
\text { primas }\end{array}$ & $\begin{array}{l}\text { Energía eléctrica comprada } \\
\text { Energía eléctrica vendida } \\
\text { Consumo de gas natural } \\
\text { Consumo de agua }\end{array}$ \\
\hline $\begin{array}{l}\text { Medidas de eficiencia } \\
\text { energética en hornos y } \\
\text { secaderos }\end{array}$ & $\begin{array}{l}\text { Consumo de energía térmica } \\
\text { Emisiones asociadas al consumo de gas natural }\end{array}$ \\
\hline Fuentes de energía eléctrica & Tecnologías de producción de energía eléctrica primaria \\
\hline $\begin{array}{l}\text { Electrificación de hornos y } \\
\text { secaderos }\end{array}$ & $\begin{array}{l}\text { Consumo de gas natural } \\
\text { Consumo de electricidad } \\
\text { Emisiones asociadas al consumo de gas natural }\end{array}$ \\
\hline
\end{tabular}

Por otro lado, para definir el escenario de 1990, se han asumido datos históricos (Celades et al., 2012) de consumo de energía térmica y eléctrica, puesto que éstos suponen alrededor del $80 \%$ de la contribución al potencial del calentamiento global.

\section{Evaluación ambiental de los escenarios e interpretación}

Del mismo modo, una vez completados los inventarios de las alternativas y escenarios tecnológicos, se han evaluado los impactos ambientales mediante la aplicación del modelo flexible desarrollado en el software de ACV GaBi (Thinkstep, 2016b) y sus bases de datos asociadas (JRCIES, 2015; Thinkstep, 2016a).

En primer lugar, se han evaluado los impactos ambientales de las 17 alternativas de forma individual para conocer las mejoras que suponen cada una de ellas, respecto a los resultados de la evaluación ambiental del escenario propio de 1990. Posteriormente, se ha realizado la evaluación de los 25 escenarios que consideran la combinación de las alternativas anteriores, para cuantificar y evaluar las mejoras globales alcanzadas y comprobar si son capaces de alcanzar los 
objetivos de reducción de emisiones de $\mathrm{CO}_{2}$ equivalentes, con respecto a los resultados de la evaluación ambiental del escenario de 1990.

El método de evaluación del Potencial del Calentamiento Global (GWP) y los factores de caracterización aplicados son los del CML 2001 (Guinée et al., 2002), actualizados a 2015. Asimismo, se han tenido en consideración el resto de categorías de impacto ambiental recomendadas por la norma EN 15804+A1, 2013 para verificar posibles transferencias de cargas entre impactos o etapas del ciclo de vida.

En la interpretación de los resultados, se ha realizado un análisis de sensibilidad para identificar y corroborar los parámetros más críticos para los cuales, pequeños cambios en sus valores conducen a grandes cambios en los resultados. Específicamente, se establecieron variaciones en un rango de $\pm 99 \%$ en los datos de inventario relacionados con cada alternativa tecnológica y otros considerados de interés para determinar su efecto sobre el Potencial de Calentamiento Global. Este análisis de sensibilidad se realizó utilizando la función GaBi Analyst del software GaBi (Thinkstep, 2016b).

\subsubsection{Herramienta $\mathrm{CerCO}_{2}$ : simulación de emisiones de $\mathrm{CO}_{2}$ para el sector cerámico}

La herramienta desarrollada para la simulación de escenarios hipocarbónicos para el sector cerámico se basa en el estudio de prospección llevado a cabo como estrategia para reducir el cambio climático. Esta herramienta se ejecuta juntamente con la herramienta DAPCER para la elaboración de estudios de ACV. La herramienta $\mathrm{CerCO}_{2}$ considera las alternativas tecnológicas contempladas en la Aportación $n^{\circ} 5$ para el gres porcelánico y además, incorpora nuevas alternativas más apropiadas para otro tipo de baldosas, como por ejemplo; la sustitución de carbonatos por Wollastonita $\left(\mathrm{CaSiO}_{3}\right)$ en composiciones porosas para evitar las emisiones de $\mathrm{CO}_{2}$ generadas por la descomposición de los carbonatos durante la cocción, el aumento de la flexibilidad y personalización a la hora de definir el grado de implementación de las alternativas tecnológicas o la posibilidad de que el usuario defina la naturaleza del mix eléctrico.

Para recopilar la información de los fabricantes, se ha elaborado un cuestionario en Google Forms, donde, además de información general, las empresas deben introducir los datos específicos de su proceso y plantear las estrategias que deseen evaluar mediante campos desplegables. Este formulario está vinculado a hojas de cálculo que, de forma automática, refieren los datos introducidos a la unidad funcional definida para obtener un inventario del ciclo de vida, en combinación con datos sectoriales asociados a los procesos independientes de las alternativas tecnológicas a estudiar y, además, genera el informe como el que se muestra en la figura 3 de la aportación $n^{\circ} 6$.

Al igual que en la Aportación n5, el método de evaluación y categorías de impacto ambiental evaluadas son las recomendadas por la norma EN 15804+A1, 2013, aplicando los factores de caracterización del CML 2001 actualizados a 2015, con especial atención al Potencial de Calentamiento Global. 


\section{RESULTADOS}

En el presente capítulo se muestra el trabajo de investigación desarrollado a través de cuatro artículos científicos (aportaciones $n^{\circ} 1,3,5$ y 6) y dos comunicados a congresos internacionales (aportaciones 2 y 4). El trabajo realizado se ha dividido según los retos abordados:

- Estrategia y herramienta para una comunicación ambiental eficiente (aportaciones $n^{\circ} 1$ y 2)

- Estrategia y herramienta para aumentar la competitividad con argumentos ambientales (aportaciones $\mathrm{n}^{\circ} 3$ y 4 )

- Estrategia y herramienta para abordar el reto de la mitigación del cambio climático (aportaciones $\mathrm{n}^{\circ} 5$ y 6 ). 


\section{APORTACIÓN No 1}

\section{ENVIRONMENTAL PROFILE OF SPANISH PORCELAIN STONEWARE} TILES

Teresa Ros-Dosdá ${ }^{1,2}$, Irina Celades ${ }^{1}$, Eliseo Monfort ${ }^{1}$, Pere Fullana-i-Palmer ${ }^{2}$

\section{International Journal of Life Cycle Assessment}

Volume 23, Issue 8, 1562-1580

Enviado el 22 de Noviembre de 2016

Aceptado el 17 de Julio de 2017

Publicado online el 29 de Julio de 2017

Publicado en Agosto 2018.

DOI: https://doi.org/10.1007/s11367-017-1377-9

Factor de impacto (2018): 4,868

SCImago Journal Rank (SJR): 1,538

\footnotetext{
${ }^{1}$ Instituto de Tecnología Cerámica (ITC). Asociación de Investigación de las Industrias Cerámicas (AICE). Universidad Jaume I. Avda. Sos Baynat s/n, 12006, Castelló, Spain.

2 UNESCO Chair in Life Cycle and Climate Change (ESCI-UPF). Passeig Pujades 1, 08003 Barcelona, Spain.
} 
Int J Life Cycle Assess (2018) 23:1562-1580 DOI 10.1007/s11367-017-1377-9

LCA COMMUNICATION AND LCA FOR ISO LABELS

\section{Environmental profile of Spanish porcelain stoneware tiles}

Teresa Ros-Dosdá ${ }^{1,2}\left(\right.$ C) $\cdot$ Irina Celades ${ }^{1} \cdot$ Eliseo $_{\text {Monfort }}{ }^{1} \cdot$ Pere Fullana-i-Palmer $^{2}$ 


\title{
ENVIRONMENTAL PROFILE OF SPANISH PORCELAIN STONEWARE TILES
}

\begin{abstract}
Purpose

Porcelain stoneware tile (PST) is currently the ceramic tile of greatest commercial and innovation interest. An environmental life cycle assessment of different varieties of PST was undertaken to enable hotspots to be identified, strategies to be defined, differences between PST varieties to be evaluated, and guidance for PST manufacturers to be provided in choosing the Environmental Product Declaration (EPD) programme that best suited their needs according to grouping criteria.

\section{Methods}

Analysis of previous information allowed three main parameters (thickness, glaze content, and mechanical treatment) to be identified in order to encompass all PST variations. Fifteen varieties of PST were thus studied. The coverage of $1 \mathrm{~m}^{2}$ of household floor surface with the different PST varieties for 50 years was defined as functional unit. The study sets out environmental data whose traceability was verified by independent third parties for obtaining 14 EPDs of PST under Spanish EPD programmes.
\end{abstract}

\section{Results and discussion}

The study presents PST inventory analysis and environmental impact over the entire life cycle of the studied PST varieties. The natural gas consumed in the manufacturing stage accounted for more than 70\% Abiotic Depletion-fossil fuels and Global Warming; electricity consumption accounted for more than $60 \%$ Ozone Layer Depletion, while the electricity generated by the cogeneration systems avoided significant environmental impacts in the Spanish power grid mix.

The variations in PST thickness, amount of glaze, and mechanical treatments were evaluated. The PST variety with the lowest environmental impact was the one with the lowest thickness, was unglazed, and had no mechanical treatments. Similarly, the PST variety with the highest environmental impact was the one with the greatest thickness, was glazed, and had been mechanically treated.

\section{Conclusions}

The PST life cycle stage with the highest environmental impact was the manufacturing stage. The main hotspots found were production and consumption of energy, and raw materials extraction.

Variation in thickness was a key factor that proportionally influenced almost all studied impact categories; the quantity of glaze strongly modified Abiotic Depletion-elements and Eutrophication, while the mechanical treatments contributed mainly to Ozone Depletion. The study of all PST varieties led to the important conclusion, against the current trend, that differences among them were found to be so significant that declaring a number of PSTs within the same EPD is not directly possible and it needs preliminary verification to ensure compliance with the Product Category Rule. 


\section{Keywords}

Ceramic Tile, Porcelain Stoneware Tile, Life Cycle Assessment, Technological Variations.

\section{Introduction}

Ceramic tile manufacturing industry is classified as a potentially polluting activity on the environment, and, therefore, is affected by Directive 2008/1/EC of 15 January 2008 concerning integrated pollution prevention and control and greenhouse gas emission trading Directive 2009/29/EC.

The Spanish ceramic tile cluster has long been one of the world's leading tile industries. However, recent years have witnessed increasing competition from new ceramic tile producing countries and new alternative products in the global market.

In 2014, ceramic tile production in the European Union (EU-28) and in Spain was 1192 and 425 million $\mathrm{m} 2$, respectively. Spain was the top European and the world's fourth-largest producer of ceramic tiles (in $\mathrm{m}^{2}$ ), behind China, Brazil, and India, accounting for $3.4 \%$ of world tile production. Spain also consolidated its position as the world's second-largest exporter of ceramic tiles by volume and the third-largest tile exporter in value. The main importers of Spanish ceramic tiles in recent years have been Saudi Arabia, France, Algeria, Jordan, and the UK (Baraldi 2015).

The ceramic tile product category comprises a wide variety of products. An accepted classification (EN 14411:2012, counterpart to standard ISO 13006:2012), and the features of the most common ceramic tiles manufactured in Spain are detailed in Table 1

Table 1 Classification and features of the most common ceramic tiles manufactured in Spain (ISO 13006:2012 and ASCER 2011)

\begin{tabular}{|c|c|c|c|c|c|}
\hline \multicolumn{2}{|c|}{ ISO 13006 classification } & \multirow{2}{*}{ Glaze } & Common name & Abbreviation & $\begin{array}{c}\text { Production } \\
\left(\% \text { in } \mathbf{~ m}^{2}\right)\end{array}$ \\
\hline Bla-Ala & $\leq 0.5 \%$ & $\begin{array}{c}\text { Water absorption } \\
\left(\mathbf{E}_{\mathrm{b}}\right)\end{array}$ & $\begin{array}{c}\text { Pes } \\
\text { Stoneware tile }\end{array}$ & PST & 25 \\
\hline Blb-Blla & $0.5-10 \%$ & Yes & $\begin{array}{c}\text { Glazed } \\
\text { stoneware tile }\end{array}$ & GST & 33 \\
\hline BIII & $>10 \%$ & Yes & Earthenware tile & ET & 38 \\
\hline
\end{tabular}


In the last 15 years, the volume of PST production has grown by about $20 \%$, GST production has decreased by $15 \%$, while ET production has remained practically stable (Figure 1) (ASCER 2015).

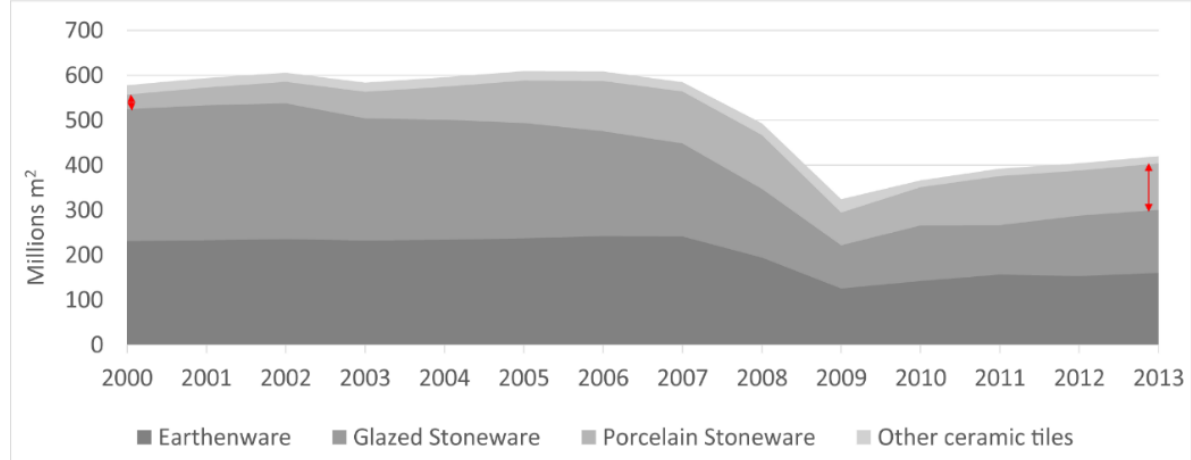

Figure 1 Evolution of Spanish ceramic tile production by types (ASCER 2015)

PST is currently the ceramic tile of greatest commercial interest, as it exhibits higher technical and functional performance and greater versatility, enabling PST to be used in different environments, both indoor and outdoor (ASCER 2011; ISO 13006:2012; Sánchez at al. 2010). Moreover, PST is considered to provide greater scope for technical and environmental improvement and innovation (da Silva et al. 2014; Martín-Márquez et al. 2010; Gabaldón-Estevan and Hekkert 2013). In fact, this type of tile encompasses a wide variety of sizes, thicknesses, different decorative designs and finishes.

In the context of environmental communication, European Standard EN 15804:2012+A1:2013 "Core rules for the product category of construction products" indicates that several products can be grouped under the same EPD when the differences in the Life Cycle Impact Assessment (LCIA) results are not significant, in this case requiring a description of the range/variability. However, the standard does not establish any limits in this regard. Therefore, EPD programmes usually fix the grouping criteria, either indicating an acceptable variation in percentage of the LCIA results or declaring the environmental profile of the products that exhibit the minimum and the maximum LCIA values. The Spanish EPD programmes establish an additional grouping criterion relating to the water absorption capacity of ceramic tiles according to standard ISO 13006:2012. The considerations made by several EPD programmes with regard to the declaration of a number of construction products are summarised in Table 2.

In order to ensure compliance with standard EN 15804:2012+A1:2013 and the criteria established by the EPD programmes, a preliminary quantification of the LCIA variations is therefore needed. 
Table 2 Summary of the considerations made in declaring the average environmental results of a number of products

\begin{tabular}{|c|c|}
\hline $\begin{array}{l}\text { Programme/standard } \\
\text { (product category) }\end{array}$ & $\begin{array}{c}\text { Considerations when an average environmental performance for a } \\
\text { number of products is declared }\end{array}$ \\
\hline $\begin{array}{l}\text { EN 15804:2012+A1:2013 } \\
\text { (Construction products) }\end{array}$ & $\begin{array}{l}\text { Grouping criteria and description of the range/variability of the LCIA } \\
\text { results if significant. }\end{array}$ \\
\hline \multirow{2}{*}{$\begin{array}{l}\text { International EPD® System } \\
\text { (Construction products and } \\
\text { construction services) }\end{array}$} & $\begin{array}{l}\text { Differences in the } L C I A \text { results below } \pm 10 \% \text { (concerning } A 1-A 3 \text { ) could be } \\
\text { presented using the impacts of a representative product. A variation range } \\
\text { description shall be presented in the declaration. }\end{array}$ \\
\hline & $\begin{array}{l}\text { Differences above } \pm 10 \% \text { (concerning } A 1-A 3 \text { ) could be presented in the } \\
\text { same } E P D \text {, but using separate columns or tables. An alternative is to } \\
\text { select a product within the product group but stating that the span } \\
\text { exceeds } 10 \% \text { or the exact figure valid for the product. }\end{array}$ \\
\hline $\begin{array}{l}\text { CET } 2014 \text { and Thurning et } \\
\text { al. } 2013 \text { (Construction clay } \\
\text { products) }\end{array}$ & $\begin{array}{l}\text { Always weighted averages. In addition, depending on the number of sites } \\
\text { and manufacturers, declaration of the maximum and minimum values. }\end{array}$ \\
\hline \multirow{2}{*}{$\begin{array}{l}\text { FDE\&S } \\
\text { (Construction products) }\end{array}$} & Idem to EN 15804:2012+A1:2013 (Standard XP P 01-064/CN) \\
\hline & The product with the highest impact (Standard XP P 01-064/CN) \\
\hline $\begin{array}{l}\text { IBU EPD programme } \\
\text { (ceramic tiles and panels) }\end{array}$ & $\begin{array}{l}\text { If averages are declared across various products, the average breakdown } \\
\text { must be explained. }\end{array}$ \\
\hline $\begin{array}{l}\text { DAPcons } ® \text { system } \\
\text { (ceramic coverings) }\end{array}$ & $\begin{array}{l}\text { Grouping criteria according to water absorption group. The average can } \\
\text { be declared only if the differences between impacts are below } \pm 10 \% \text {, } \\
\text { indicating the degree of deviation }\end{array}$ \\
\hline $\begin{array}{l}\text { GlobalEPD } \\
\text { (ceramic coverings) }\end{array}$ & $\begin{array}{l}\text { Grouping criteria according to water absorption group. Declaration of the } \\
\text { weighted average, declaring the individual product with the highest and } \\
\text { the lowest impact }\end{array}$ \\
\hline $\begin{array}{l}\text { NSF USA } \\
\text { (Flooring: carpet, resilient, } \\
\text { laminate, ceramic, wood) }\end{array}$ & $\begin{array}{l}\text { The variation shall be described and the minimum and maximum level for } \\
\text { the product group's environmental performance shall be given }\end{array}$ \\
\hline
\end{tabular}


Based on the exhaustive literature review on ceramic materials reported by Pini et al, 2014, the current study presents an update, focusing on ceramic tile (Table 3). The following may be highlighted:

- Most of the reported studies consider ceramic tile to be a generic product, without differentiating ceramic tile types according to the ISO 13006:2012 classification.

- The year of inventory data is not always reported. The study with the latest primary data is published by Almeida et al. 2016, the information dating from 2012.

- The lifespans of the studies ranged from 20 to 61 years. Moreover, in most studies, the scope and environmental impacts of the life cycle stages were declared as a total sum of the life cycle stages. These facts should be taken into account when interpreting and comparing results of different LCA studies.

- $\quad$ The studies defined the functional unit (FU) as $1 \mathrm{~m}^{2}$ of ceramic tile, with the sole exception of Tikul and Srichand 2010, who defined this as 1 ton.

- According to the available information, the most popular impact assessment method is definitively the CML2001 (Guinée et al. 2002). 


\begin{tabular}{|c|c|c|c|c|}
\hline 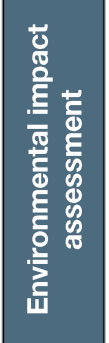 & 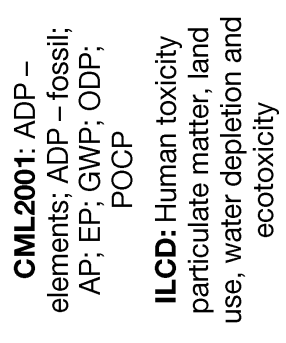 & 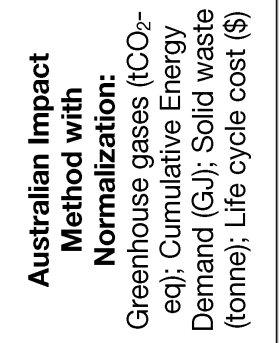 & 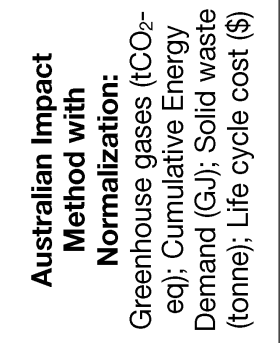 & 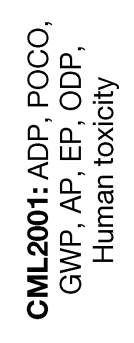 \\
\hline 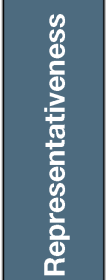 & 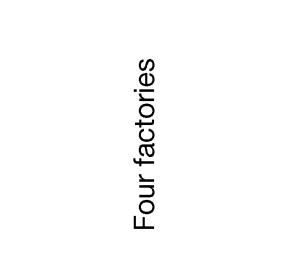 & 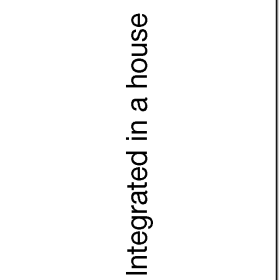 & 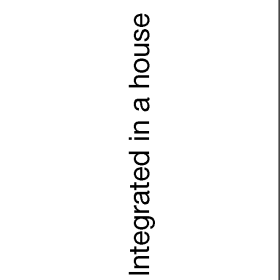 & 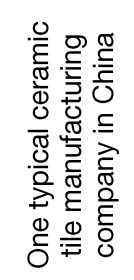 \\
\hline ¿ु & 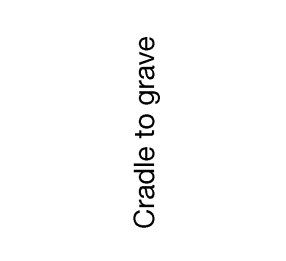 & 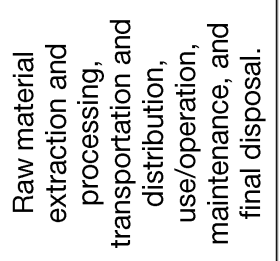 & 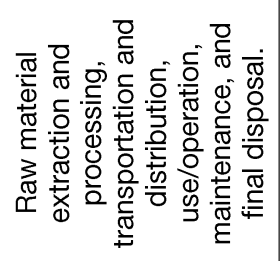 & 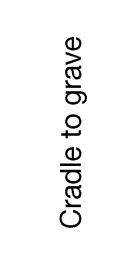 \\
\hline 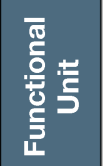 & 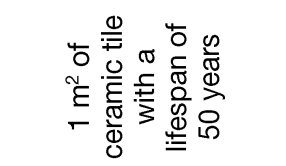 & 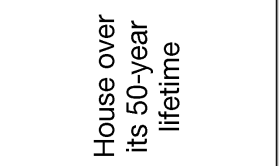 & 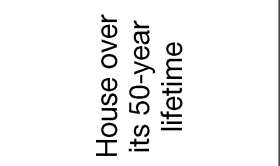 & 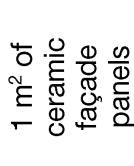 \\
\hline 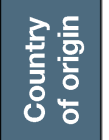 & $\begin{array}{l}\overline{\bar{g}} \\
\text { Oे } \\
\text { 힘 }\end{array}$ & 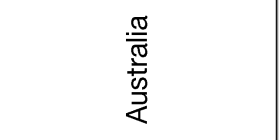 & 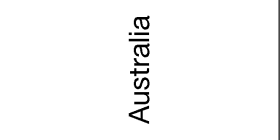 & 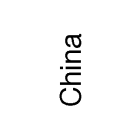 \\
\hline 중 & 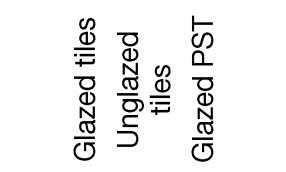 & 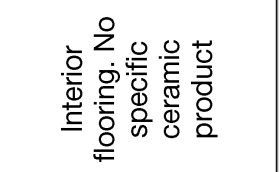 & 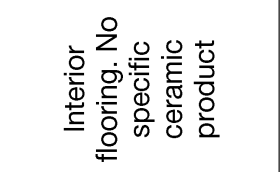 & 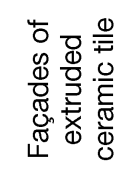 \\
\hline 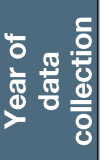 & $\stackrel{\sim}{\stackrel{N}{N}}$ & 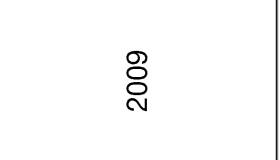 & 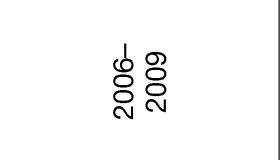 & 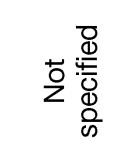 \\
\hline త్ర & 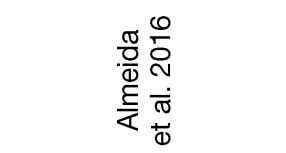 & 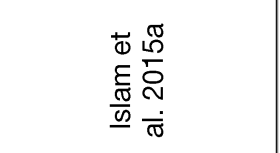 & 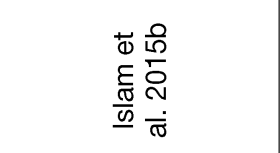 & 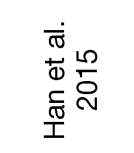 \\
\hline
\end{tabular}




\begin{tabular}{|c|c|c|c|c|}
\hline 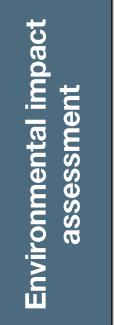 & 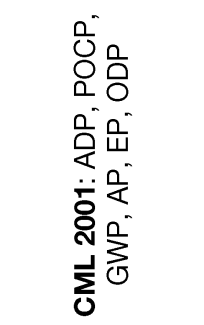 & 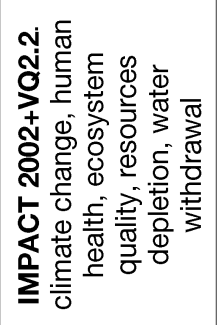 & 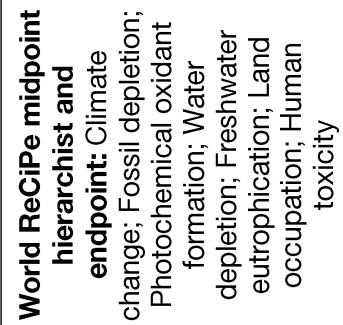 & 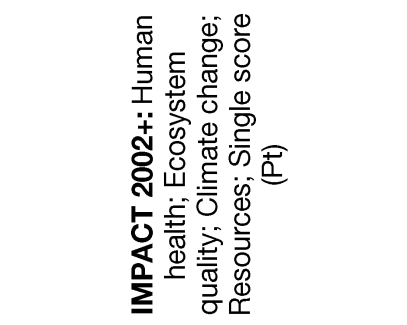 \\
\hline 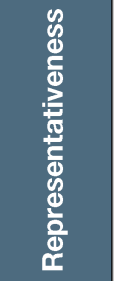 & 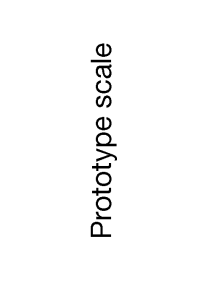 & 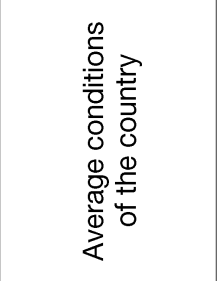 & 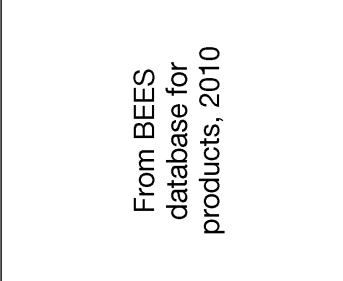 & 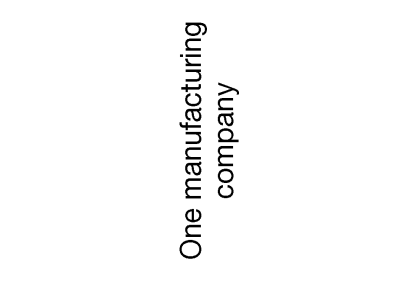 \\
\hline $\begin{array}{l}\text { ๕ } \\
\text { 유 }\end{array}$ & $\begin{array}{l}\stackrel{0}{0} \\
\frac{\pi}{0} \\
0 \\
0 \\
0 \\
\frac{0}{0} \\
\frac{\pi}{0} \\
0\end{array}$ & $\begin{array}{l}0 \\
\stackrel{0}{\pi} \\
\frac{0}{5} \\
0 \\
0 \\
\frac{0}{0} \\
\frac{\pi}{0} \\
0\end{array}$ & 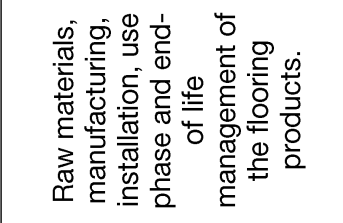 & 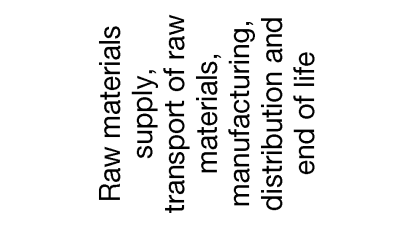 \\
\hline 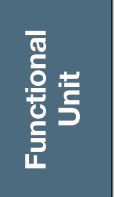 & 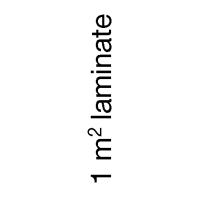 & 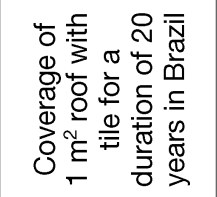 & 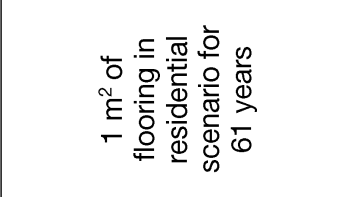 & 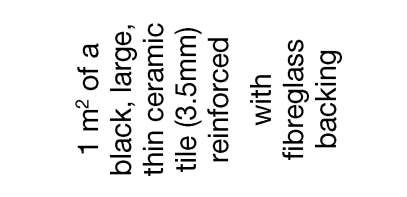 \\
\hline 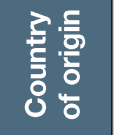 & 츂 & $\begin{array}{l}\overline{\overline{\mathbb{N}}} \\
\overline{\tilde{\omega}}\end{array}$ & 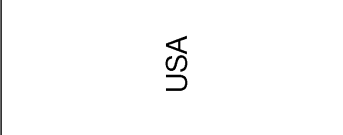 & $\begin{array}{l}\text { त्रे } \\
\text { (2) }\end{array}$ \\
\hline 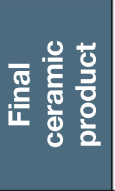 & 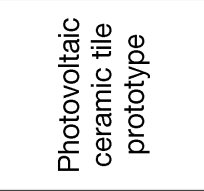 & 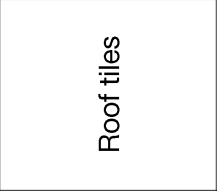 & 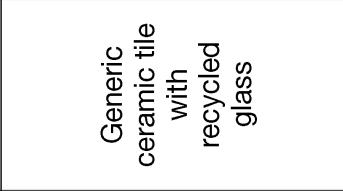 & 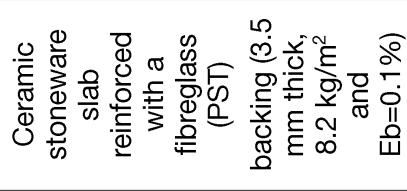 \\
\hline 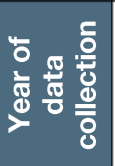 & 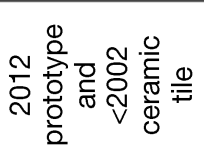 & 둥 & 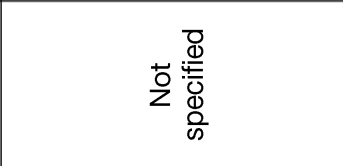 & $\stackrel{\infty}{\stackrel{\sim}{~}}$ \\
\hline 엄흘 & 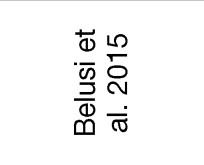 & 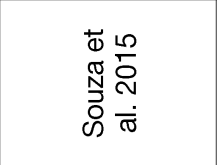 & 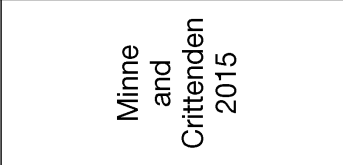 & 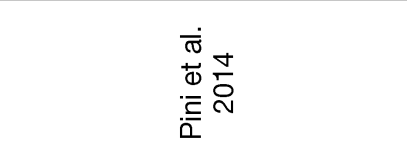 \\
\hline
\end{tabular}




\begin{tabular}{|c|c|c|c|}
\hline 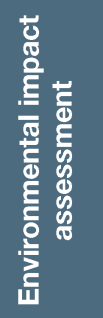 & 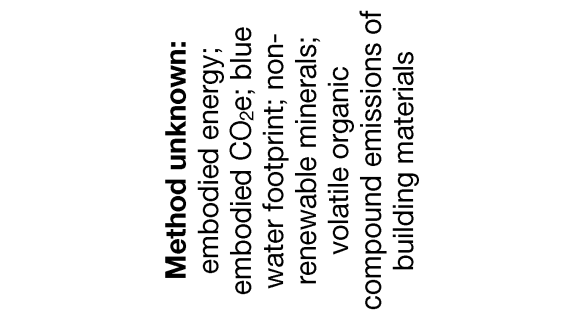 & 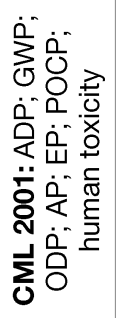 & 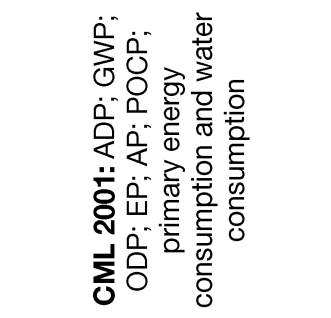 \\
\hline 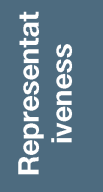 & 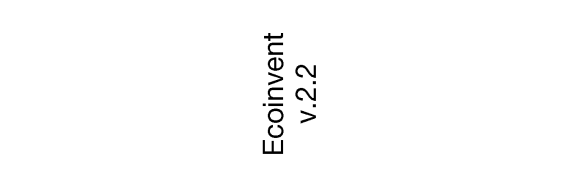 & 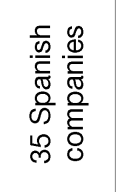 & 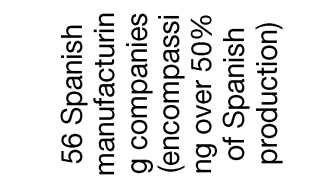 \\
\hline $\begin{array}{l}\text { ¿ } \\
\text { ¿ू } \\
\text { ¿ }\end{array}$ & 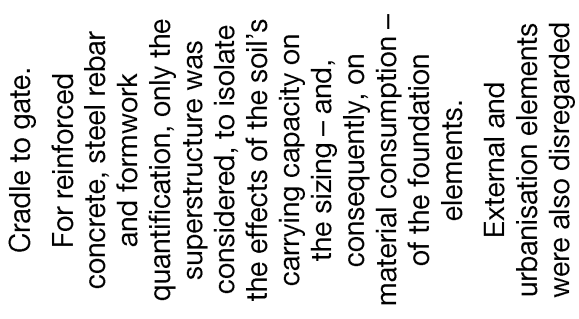 & $\begin{array}{l}\frac{1}{0} \\
\overline{0} \\
0 \\
0 \\
\frac{0}{0} \\
\frac{0}{0} \\
0\end{array}$ & 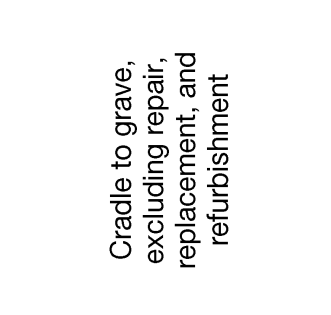 \\
\hline 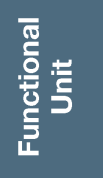 & 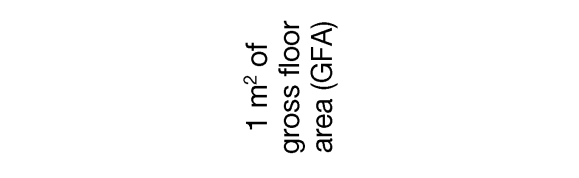 & 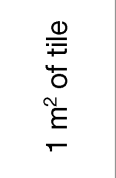 & 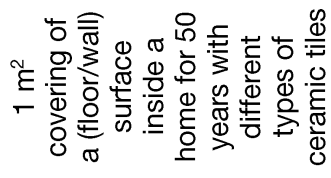 \\
\hline 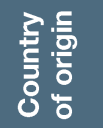 & $\begin{array}{l}\overline{\overline{\mathbb{N}}} \\
\overline{\bar{\omega}}\end{array}$ & $\begin{array}{l}\text { कू } \\
\text { के }\end{array}$ & $\begin{array}{l}\text { ज़ } \\
\text { के }\end{array}$ \\
\hline 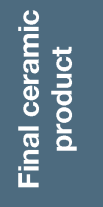 & 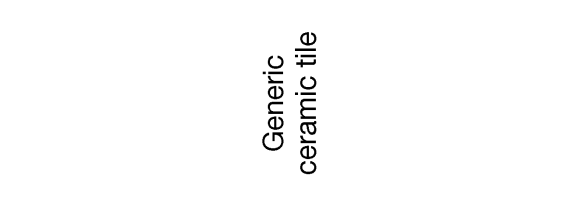 & 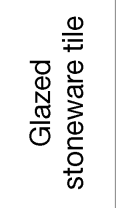 & 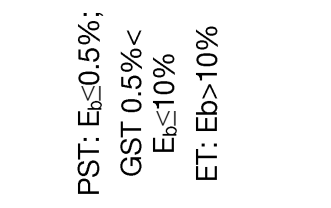 \\
\hline 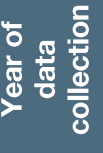 & 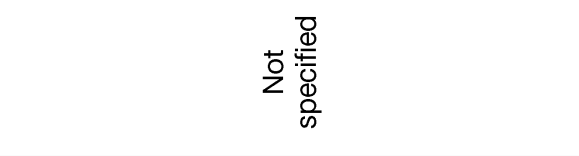 & 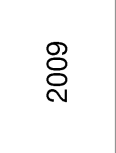 & $\stackrel{\infty}{\circ}$ \\
\hline 엉후 훟 & 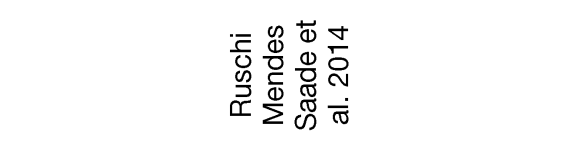 & 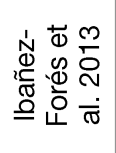 & 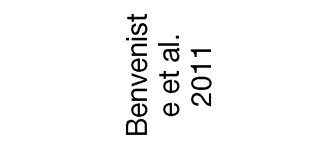 \\
\hline
\end{tabular}




\begin{tabular}{|c|c|c|c|}
\hline 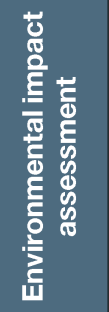 & 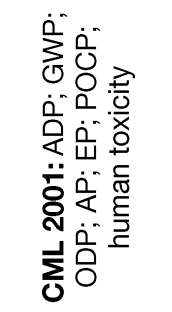 & 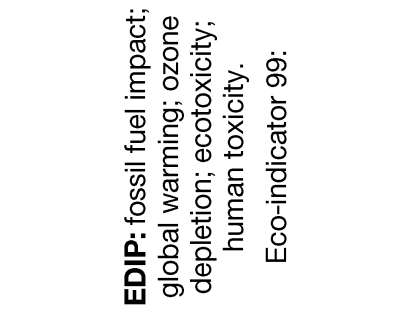 & 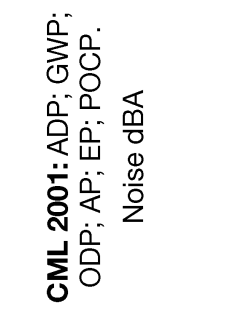 \\
\hline 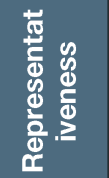 & 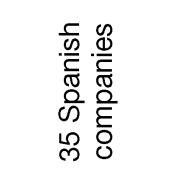 & 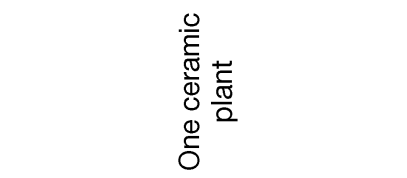 & 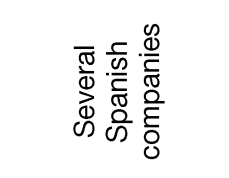 \\
\hline $\begin{array}{l}\text { \% } \\
\text { ठ․ }\end{array}$ & 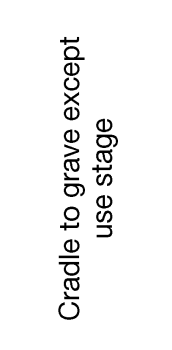 & 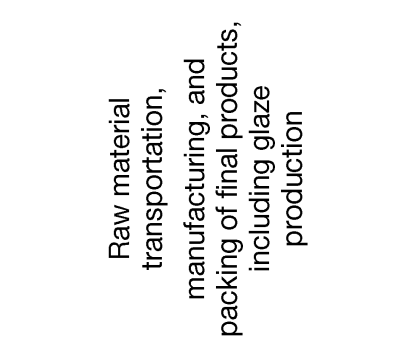 & 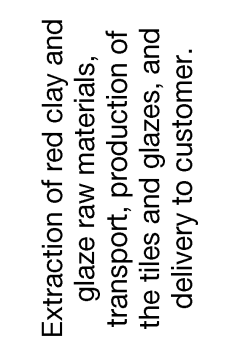 \\
\hline 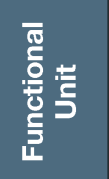 & 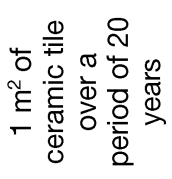 & 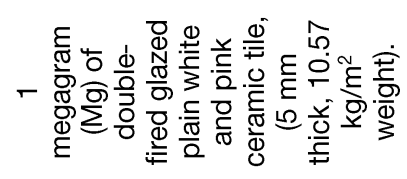 & 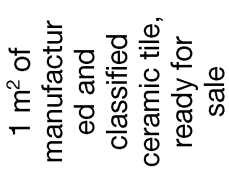 \\
\hline 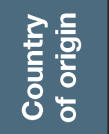 & $\begin{array}{l}\frac{.}{\bar{\pi}} \\
\text { के }\end{array}$ & 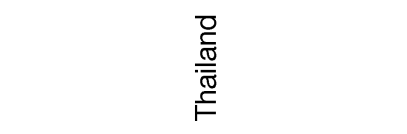 & $\begin{array}{l}\text { 言 } \\
\text { के }\end{array}$ \\
\hline 区 $\frac{0}{\frac{0}{5}}$ & 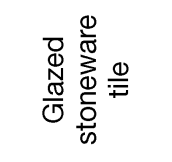 & 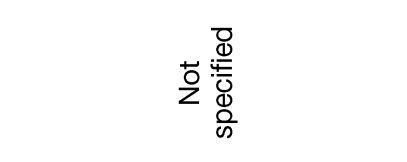 & 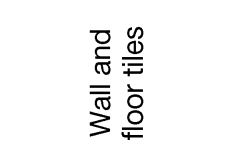 \\
\hline 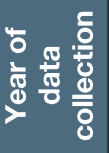 & \& & 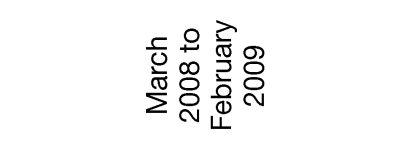 & $\begin{array}{l}1 \\
\text { ¿̊d } \\
\text { ¿ }\end{array}$ \\
\hline 엉 흥 & 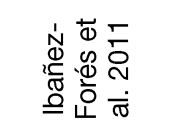 & 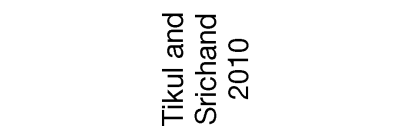 & 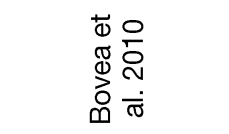 \\
\hline
\end{tabular}




\begin{tabular}{|c|c|c|}
\hline 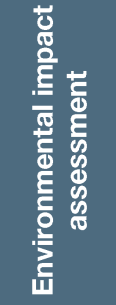 & 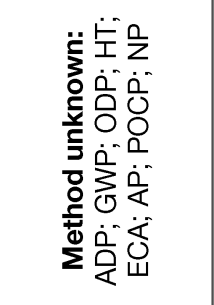 & 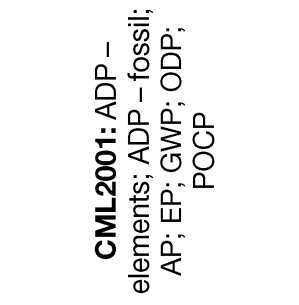 \\
\hline 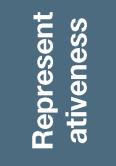 & 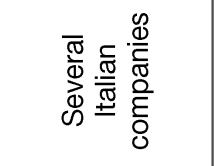 & 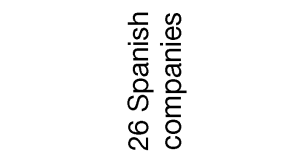 \\
\hline 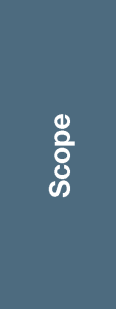 & 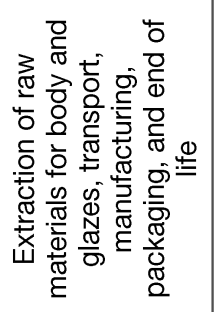 & $\begin{array}{l}\stackrel{0}{0} \\
\stackrel{0}{0} \\
0 \\
0 \\
0 \\
\frac{0}{0} \\
\frac{\pi}{0} \\
0\end{array}$ \\
\hline 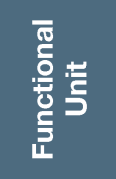 & 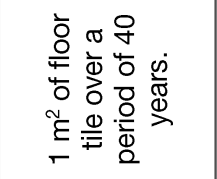 & 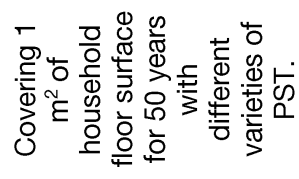 \\
\hline 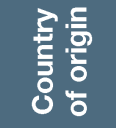 & 츨 & $\begin{array}{l}\frac{5}{\bar{\pi}} \\
\text { की }\end{array}$ \\
\hline 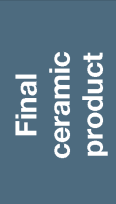 & 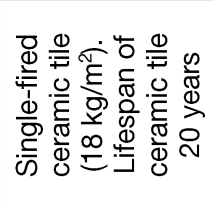 & 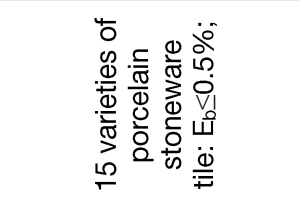 \\
\hline 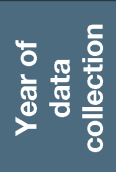 & ণิ & 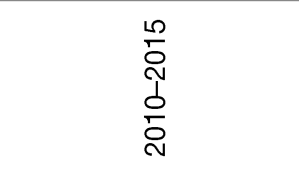 \\
\hline 엉ㅎㄹ & 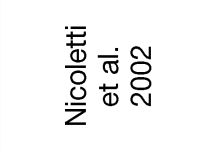 & 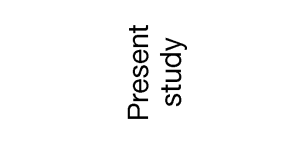 \\
\hline
\end{tabular}


The review also reveals that the most extensive LCA study on ceramic tiles was performed in the period from 2008 to 2010 in the Spanish ceramic cluster by the ITC and UNESCO Chair research groups with the cooperation of the Spanish Ceramic Tile Manufacturers' Association (ASCER). That study was carried out at cluster level with the involvement of 56 tile manufacturers and their suppliers, encompassing $48 \%$ of Spanish ceramic tile production and the three main types of ceramic tiles produced in Spain: PST, GST (red and white body), and ET (red and white body) (Benveniste et al. 2010, 2011; Ros-Dosdá et al. 2010). The study allowed obtainment of scientifically valid and objective reference values for the environmental profile of ceramic tiles, definition of sectoral technological improvements, establishment of the first Product Category Rule (PCR) for ceramic coverings in Spain, and it laid the groundwork for the development of a simplified tool for LCA studies and/or EPDs, thereby reducing implementation times and economic costs.

This tool was successfully programmed in extension i-Report GaBi after adapting the LCA model to improve its modularity and flexibility allowing all technological alternatives implemented in the Spanish ceramic sector to be included (Figure 3).

In parallel, after approval of European standard EN 15804: 2012, another PCR for ceramic coverings was developed under the Spanish Type III environmental declaration programme, GlobalEPD.

In view of the above background, a specific and updated LCA study on PST was deemed of interest for the following reasons: (1) Of the three main types of ceramic tile manufactured in Spain, PST production and demand have increased most over the last 15 years; (2) consistent, robust, thirdparty verified life cycle inventory analysis (LCI) and LCIA are available; (3) no detailed LCA studies on PST were found in the literature review; (4) owing to the high technical and functional versatility of PST, more than 15 varieties of PST are marketed worldwide; and (5) the environmental study of all PST varieties would enable EPD administrators and producers to foresee whether they could group several PST varieties under the same EPD.

The results of this study were expected to provide updated, harmonised and peer-reviewed representative $\mathrm{LCl}$ data and LCIA, which would enable changes to be envisaged at Spanish and European level in the medium or long term based on the identified hotspots, publication of this information for commercial purposes, and positioning of the product in technological, legislative, or regulatory contexts. The results would also allow PST manufacturers to establish continuous improvement strategies and efficiently choose the EPD programme that best suited their needs. 


\section{Methods}

LCA is a tool that identifies, classifies, and quantifies the environmental impacts of a product or activity throughout its life cycle. The method consists of compiling an inventory of inputs and outputs of the system; evaluating the potential impacts associated with these inputs and outputs, and interpreting the results of the LCl and LCIA in relation to the study objectives (ISO 14040: 2006).

\subsection{Goal and scope definition}

This study aimed to obtain updated, valid, objective data with regard to the environmental profile of PST throughout its life cycle in order to identify the technical aspects of the product or process that would enable companies to influence or improve the product's environmental performance. In addition, the study would allow the magnitude of the differences between PST formats, patterns, designs, and finishes to be verified, and the environmental consequences of these differences to be better understood.

In this study, the LCA of PST was developed according to international standards ISO 1404044:2006, European standard EN 15804:2012+A1:2013, and the Product Category Rules (PCRs) of two Spanish Programmes GlobalEPD 2013 and DAPcons 2015, both programmes being included in the EcoPlatform (www.eco-platform.org).

PST has an average density of $2300 \mathrm{~kg} / \mathrm{m}^{3}$ and is intended for use as surface covering in both indoor and outdoor environments. The product can be used as floor covering, wall cladding, or even in façades (ISO 13006:2012). Moreover, its versatility allows this type of ceramic tile to be used in a wide range of environments, such as homes, shops, offices, and hospitals.

Based on the information gathered in the present study, the main parameters for identifying the varieties of PST were as follows: (1) Thickness: technically there is no upper limit to thickness. However, there is a practical lower limit of about $5 \mathrm{~mm}$ to assure appropriate mechanical behaviour; when thickness is lower, it is highly recommended to reinforce the PST with a fibreglass backing (Pini et al. 2014). (2) Glaze content: the low body porosity of PST allows such tiles to be either glazed or unglazed. (3) Mechanical treatments: mechanical treatments are optional and may consist of cutting large formats into smaller sizes, bevelling, polishing, lappato, etc. Because of the mechanical properties of PST, mechanical treatments are always performed on the fired product, before the construction process stage. The combination of these options gives rise to a great range of aesthetic effects.

Table 4 shows the range of PST characteristics and designations used in this paper. Table 5 details the nomenclature used in the study to identify the different PST varieties. 
Table 4 Variations of PST characteristics according to PST thickness, glaze content, and mechanical finishes

\begin{tabular}{|c|c|c|}
\hline Parameter & Designation & Values \\
\hline Thickness & $\begin{array}{l}\text { Low }(L) \\
\text { Average }(A)^{1} \\
\text { High }(H)\end{array}$ & $\begin{array}{c}5 \mathrm{~mm} \text { (11 kg/m² weight unfired) } \\
10.4 \mathrm{~mm}\left(24.5 \mathrm{~kg} / \mathrm{m}^{2} \text { weight unfired) }\right. \\
16 \mathrm{~mm} \text { (34 kg/m² weight unfired) }\end{array}$ \\
\hline Glaze content & $\begin{array}{l}\text { Unglazed }(U) \\
\text { Average }(A)^{1} \\
\text { Glazed }(G)\end{array}$ & $\begin{array}{c}0 \mathrm{~kg} / \mathrm{m}^{2} \\
0.76 \mathrm{~kg} / \mathrm{m}^{2} \\
1 \mathrm{~kg} / \mathrm{m}^{2}\end{array}$ \\
\hline Mechanical treatment & $\begin{array}{c}\text { Non-mechanised }(\mathrm{N}) \\
\text { Average }(A)^{1} \\
\text { Mechanised }(M)\end{array}$ & $\begin{array}{c}0 \% \\
32 \% \\
100 \%\end{array}$ \\
\hline
\end{tabular}

Table 5 Nomenclature used in this study

\begin{tabular}{|c|c|c|c|c|}
\hline Letter & \multicolumn{4}{|c|}{ Parameter } \\
\hline $1^{\text {st }}$ & Thickness & $\mathrm{L}$ & $\mathrm{A}$ & $\mathrm{H}$ \\
\hline $2^{\text {nd }}$ & Glaze content & $\mathrm{U}$ & $\mathrm{A}$ & $\mathrm{M}$ \\
\hline $3^{\text {rd }}$ & Mechanical treatment & $\mathrm{N}$ & $\mathrm{A}$ & $\mathrm{M}$ \\
\hline \multicolumn{5}{|c|}{ Example: AUN $\rightarrow$ PST with Average thickness, Unglazed, and No mechanical treatments } \\
\hline
\end{tabular}

\subsubsection{System boundaries and Functional Unit}

This paper sets out environmental information on a group of PST products manufactured in Spain from 2010 to 2015. Data traceability was verified by independent third parties for 14 Environmental Product Declarations of PST under Spanish EPD programmes.

The Functional Unit (FU) was defined as $1 \mathrm{~m}^{2}$ of household floor surface covering with the different studied varieties of PST for 50 years.

The system includes the modules given in the standards for Sustainability in Construction, as illustrated in Figure 2. 


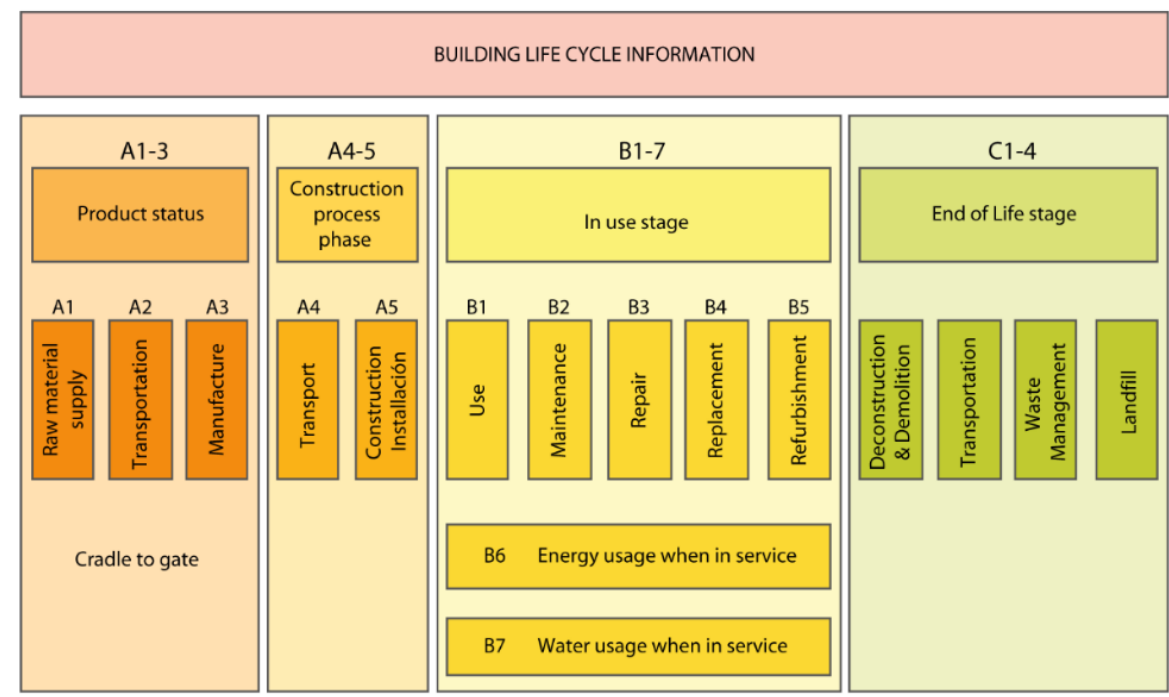

Figure 2 Life cycle information modules (EN 15978: 2011 and EN 15804:2012+A1:2013)

The following elements were left out of the system:

Modules B1, B3, B4, B5, B6, and B7, these being considered irrelevant from an environmental point of view in accordance with the PCR for ceramic coverings of the EPD programmes DAPcons $®$ system 2015, GlobalEPD 2013, International EPD® System 2012 and European PCR (CET 2014 and Thurning et al. 2013)

Industrial machinery and equipment manufacture, owing to the lack of currently available data, the cost/complexity of analysis (BSI PAS 2050:2011), and the relatively low environmental impact per FU compared to other processes in the case of building products (Frischknecht et al. 2007; Wittstock et al. 2012).

The recycling process of the packaging waste produced throughout the ceramic tile life cycle, because of the allocation method used, known as the cut-off criterion (BSI PAS 2050:2011). However, transport to the treatment facilities and the processes required to the of end-of-waste state were included.

The environmental burdens associated with ceramic pigments. These were disregarded because of wide-ranging pigment variability, lack of specific, related information, and the relatively low ceramic pigment content in the entire ceramic tile ( $<1 \%$ by weight). 


\subsubsection{Selected environmental impact categories}

The environmental impact categories analysed and characterisation factors used are those set out in EN 15804:2012+A1:2013, Table 6.

Table 6 Environmental impact categories

\begin{tabular}{|c|c|c|}
\hline Impact category & Acronym & Units \\
\hline Abiotic Depletion - elements & ADP-elements & kg Sb Equivalent \\
\hline Abiotic Depletion - fossil fuels & ADP-fossil & MJ \\
\hline Acidification Potential & AP & $\mathrm{kg} \mathrm{SO}_{2}$ Equivalent \\
\hline Eutrophication Potential & EP & $\mathrm{kg} \mathrm{PO}_{4}{ }^{3}$ Equivalent \\
\hline Global Warming Potential (100 years) & GWP & $\mathrm{kg} \mathrm{CO} 2$ Equivalent \\
\hline Ozone Layer Depletion Potential (steady state) & ODP & kg R11 Equivalent \\
\hline Photochemical. Ozone Creation Potential & POCP & $\mathrm{kg} \mathrm{C}_{2} \mathrm{H}_{4}$ Equivalent \\
\hline
\end{tabular}

Particulate matter emissions into the air have been included in this study, owing to the significant investments required and maintenance costs involved in meeting the requirements laid down in European Industrial Emissions Directive 2010/75/EU (IED).

\subsection{Life Cycle Inventory Analysis modelling}

The inventory modelling was performed with the GaBi 4 software (PE International 2008) and the bundled professional databases PE International 2008, ELCD 3.2. (Joint Research Centre 2015), and Thinkstep database 2016 run in GaBi 6 software (Thinkstep 2016) were used as the principal sources of background data.

As per foreground data: i) $75 \%$ was compiled directly from ceramic tile manufacturers; a production-weighted average of all formats yielded the FU described above; ii) $24 \%$ of the data were obtained from literature and cluster averages (Benveniste et al. 2011; EIPPCB 2007; EIPPCB 2012); and iii) very few data (1\%) were obtained from assumptions used in the Product Category Rules for ceramic coverings within the Spanish EPD programmes, DAPcons 2015 and GlobalEPD 2013.

The foreground data included primary data of both a) the PST body and b) glaze life cycles.

a) Table 7 shows the relative values (expressed as percentage by weight) of the studied PST body and glaze compositions (A1). The compositions are averages and encompass all the varieties of PST involved in this study. The body composition data were provided by 10 Spanish spray-dried granule manufacturing companies. The maximum Standard Deviation (SD) in the amount of raw materials was $3 \%$ in one of the components (clay); with regard to origin, the scatter in distances was greater, the maximum SD being $23 \%$. 
b) The glaze compositions were provided by 7 glaze manufacturers. The maximum SD in the amount of raw materials was $5 \%$, namely in the silicates; the origins of these raw materials also exhibited a maximum $5 \%$ scatter.

Table 7 Studied PST body and glaze compositions

\begin{tabular}{|c|c|}
\hline Body raw materials & Composition (wt\%) \\
\hline Feldspars & $43.53 \%$ \\
\hline Clays & $41.16 \%$ \\
\hline Sands & $10.91 \%$ \\
\hline Unfired ceramic tile scrap & $2.09 \%$ \\
\hline Kaolin & $1.23 \%$ \\
\hline Fired ceramic tile scrap & $0.53 \%$ \\
\hline Pigments & $0.32 \%$ \\
\hline Deflocculants & $0.23 \%$ \\
\hline Glaze and decorative raw materials & Composition (wt \%) \\
\hline Frit content & $33 \%$ \\
\hline Feldspars & $26.02 \%$ \\
\hline Quartz & $21.04 \%$ \\
\hline Carbonates & $19.73 \%$ \\
\hline Boron-introducing raw materials & $7.35 \%$ \\
\hline Clays & $6.54 \%$ \\
\hline Silicates & $5.16 \%$ \\
\hline Zinc oxide & $4.29 \%$ \\
\hline Zirconium & $4.27 \%$ \\
\hline Kaolin & $3.12 \%$ \\
\hline Alumina & $2.48 \%$ \\
\hline
\end{tabular}

All in all, the peer-reviewed inputs and outputs of the foreground system were provided by a total of 26 Spanish spray-dried granule, ceramic frit and glaze, and ceramic tile manufacturing companies to obtain 14 EPDs of PST. The data stem from the period 2010 to 2015 . The material and energy inputs and outputs of the PST AAA life cycle are detailed in Table 8. 
Table 8 Material and energy inputs and outputs of the PST AAA life cycle relative to the FU (including glaze life cycle from cradle to gate).

\begin{tabular}{|c|c|c|c|c|}
\hline & Product stage & $\begin{array}{l}\text { Construction } \\
\text { process stage }\end{array}$ & Use stage & $\begin{array}{l}\text { End of life } \\
\text { stage }\end{array}$ \\
\hline & A1-A3 & A4-A5 & B1-B7 & C1-C4 \\
\hline \multicolumn{5}{|l|}{ Inputs } \\
\hline Body raw materials ${ }^{(1)}\left(\mathrm{kg} / \mathrm{m}^{2}\right)$ & $2.39 \mathrm{E}+01$ & & & \\
\hline Glaze raw materials ${ }^{(1)}\left(\mathrm{kg} / \mathrm{m}^{2}\right)$ & 7.85E-01 & & & \\
\hline Auxiliary inputs $\left(\mathrm{kg} / \mathrm{m}^{2}\right)$ & & $3.50 \mathrm{E}+00$ & 4.94E-02 & \\
\hline Electric energy from the grid $\left(\mathrm{MJ} / \mathrm{m}^{2}\right)$ & $1.68 \mathrm{E}+01$ & & & negligible \\
\hline $\begin{array}{l}\text { Thermal energy from natural gas } \\
\left(\mathrm{MJ} / \mathrm{m}^{2}\right)\end{array}$ & $1.31 \mathrm{E}+02$ & & & \\
\hline Groundwater $\left(1 / \mathrm{m}^{2}\right)$ & $1.55 \mathrm{E}+01$ & & & \\
\hline Tap water $\left(1 / \mathrm{m}^{2}\right)$ & $2.36 \mathrm{E}+00$ & $8.80 \mathrm{E}-01$ & $2.60 \mathrm{E}+02$ & \\
\hline $\begin{array}{l}\text { Recycled water from other industries } \\
\left(1 / \mathrm{m}^{2}\right)\end{array}$ & $1.83 \mathrm{E}+00$ & & & \\
\hline Packaging $\left(\mathrm{kg} / \mathrm{m}^{2}\right)$ & 8.13E-01 & & & \\
\hline \multicolumn{5}{|l|}{ Outputs } \\
\hline PST $\left(\mathrm{kg} / \mathrm{m}^{2}\right)$ & $2.15 \mathrm{E}+01$ & & & \\
\hline $\begin{array}{l}\text { Electric energy sold to the grid } \\
\left(\mathrm{MJ} / \mathrm{m}^{2}\right)\end{array}$ & $1.46 \mathrm{E}+01$ & & & \\
\hline $\begin{array}{l}\text { Air emissions of particulate matter }{ }^{(2)} \\
\left(\mathrm{mg} / \mathrm{m}^{2}\right)\end{array}$ & $6.00 \mathrm{E}+03$ & & & \\
\hline $\begin{array}{l}\text { Air emissions of } \mathrm{NO}_{x} \text { from the process } \\
\left(\mathrm{mg} / \mathrm{m}^{2}\right)\end{array}$ & $3.36 \mathrm{E}+03$ & & & \\
\hline $\begin{array}{l}\text { Air emissions of } \mathrm{SO}_{2} \text { from the process } \\
\left(\mathrm{mg} / \mathrm{m}^{2}\right)\end{array}$ & $2.79 \mathrm{E}+03$ & & & \\
\hline Air emissions of $\mathrm{HF}\left(\mathrm{mg} / \mathrm{m}^{2}\right)$ & $1.36 \mathrm{E}+03$ & & & \\
\hline Air emissions of $\mathrm{HCl}\left(\mathrm{mg} / \mathrm{m}^{2}\right)$ & $1.43 \mathrm{E}+01$ & & & \\
\hline Air emissions of heavy metals $\left(\mathrm{mg} / \mathrm{m}^{2}\right)$ & $1.88 \mathrm{E}+00$ & & & \\
\hline Non-hazardous wastes $\left(\mathrm{kg} / \mathrm{m}^{2}\right)$ & $4.91 \mathrm{E}+00$ & & & $2.50 \mathrm{E}+01$ \\
\hline Hazardous wastes $\left(\mathrm{kg} / \mathrm{m}^{2}\right)$ & $1.54 \mathrm{E}-03$ & $8.13 E-01$ & & \\
\hline Wastewater discharge $\left(1 / \mathrm{m}^{2}\right)$ & 3.39E-01 & & $2.60 \mathrm{E}+02$ & \\
\hline \multicolumn{5}{|l|}{$\begin{array}{l}\text { NOTE: } \\
\text { Composition detailed in Table } 7 \\
\text { Channelled and fugitive particle }\end{array}$} \\
\hline
\end{tabular}


Primary data of each manufacturing company was compiled in questionnaires and then, treated individually to obtain data referred to the beforehand mentioned FU and allocating the environmental aspects when needed.

It is important to highlight that the individual inventory data were used to calculate a productionweighted average as a representative generic PST, hereinafter referred to as PST AAA, representing an average thickness, average quantity of decoration materials, and average application of mechanical treatments. These data were either obtained from individual unit processes or the aggregation of several processes, depending on data availability or accessibility. The results were therefore not attributable to a single manufacturer, thus safeguarding the confidentiality of individual company data.

The inventory data associated to the rest of PST varieties were obtained from PST AAA by modifying specific inputs and outputs related to each parameter as follows:

- Variation in thickness: proportional difference in the inputs and outputs in the preparation of raw materials, thermal energy consumption in the drying and firing processes, atmospheric emissions, and waste generation in the manufacturing plant.

- Variation in the glaze content: proportional variation in the inputs and outputs associated to the manufacturing of glazes and other decorative materials

- Variation in mechanical treatments: proportional variation in the associated consumption of water and electricity, as well as waste and particulate emissions generated in this process.

Once the inventories of all varieties of PST are defined, scenarios analysis were performed with the GaBi Analyst function in order to facilitate the comparison and analysis of these PSTs.

We want to give attention to some important issues. The first one is related to cogeneration. Ceramic manufacturing plants exhibit different configurations. Some include the whole manufacturing process, i.e. preparation of spray-dried granulates and ceramic tile manufacture, whereas others, which could be termed 'partial cycle' configurations, may prepare either the spraydried granulates or the actual ceramic tiles (from the pressing stage to sorting). In every case, the glazes and pigments are manufactured in specialised plants. The amount of own-consumed electricity from the cogeneration system therefore varies significantly because of the different configurations of the plants and processes involved, while factors, such as cogeneration system power and management, time distribution, and the economic regime applicable to the sale of electricity, vary highly among the companies (Monfort, et al. 2010).

The second issue is related to the optional mechanical treatments on the fired product. These could be carried out either at the manufacturing plants themselves or at specialised companies. Water and electricity consumption and waste generation varied highly depending on the treatment and equipment design. The 50th percentile (Q2) values were therefore considered. These are listed with the SD in Table 9. The data supplied did not distinguish between the different optional processes, i.e. cutting, bevelling, or polishing. 
Table 9 Specific data from mechanical treatments

\begin{tabular}{|l|l|l|}
\hline Mechanical treatments & Q2 & SD \\
\hline Electricity consumption $\left(\mathrm{MJ} / \mathrm{m}^{2}\right)$ & 3.5 & 2.5 \\
\hline Water consumption $\left(\mathrm{I} / \mathrm{m}^{2}\right)$ & 3.8 & 1.7 \\
\hline Waste generation $\left(\mathrm{kg} / \mathrm{m}^{2}\right)$ & 1.8 & 2.2 \\
\hline
\end{tabular}

Another issue is about the types of emissions. The studied emission outputs into the air included fugitive and channelled emissions. The pollutants considered in this LCA were particulate matter (PM), acid compounds ( $\mathrm{HF}, \mathrm{HCl}, \mathrm{SO}_{x}$, and $\left.\mathrm{NO}_{x}\right)$, and heavy metals. In terms of mass, the most important atmospheric pollutant was undoubtedly PM: 35\% corresponded to fugitive emissions from bulk solids handling, while the rest was emitted through stacks. Table 10 presents the direct $\mathrm{PM}$ and $\mathrm{PM}_{10}$ emissions (particles which pass through a size-selective inlet with a $50 \%$ efficiency cut-off at $10 \mu \mathrm{m}$ aerodynamic diameter (ISO 7708:1995)) in the manufacturing stage (A3).

Table 10 Direct particulate matter emissions in the manufacturing stage

\begin{tabular}{|c|c|c|c|c|}
\hline $\begin{array}{l}\text { Type of } \\
\text { emission }\end{array}$ & Manufacturing Stage & mg PM/m² & $\mathbf{P M}_{10} / \mathbf{P M}^{(1)}$ & mg PM $\mathbf{P M}_{10} / \mathbf{m}^{2}$ \\
\hline \multirow{6}{*}{ Channelled } & Milling & 399 & $74.80 \%$ & 298 \\
\hline & Spray drying & 1136 & $91.45 \%$ & 1039 \\
\hline & Drying & 768 & $84.50 \%$ & 649 \\
\hline & Glazing & 121 & $74.50 \%$ & 90 \\
\hline & Firing & 874 & $99.40 \%$ & 868 \\
\hline & General ventilation & 678 & $75.30 \%$ & 511 \\
\hline Fugitive & Bulk solids handling ${ }^{(2)}$ & & & 1850 \\
\hline \multicolumn{5}{|c|}{$\begin{array}{l}\text { (1) } \mathrm{PM}_{10} / \mathrm{PM} \text { ratio from Celades } 2013 . \\
\text { (2) Fugitive emissions factor in the ceramic industry from Monfort et al. 2011b }\end{array}$} \\
\hline
\end{tabular}

The fourth issue deals with the PST function and use, which was defined as an indoor floor covering in a residential scenario. However, porcelain stoneware tile can also be used for outdoor floor coverings and for cladding outside walls or façades in different contexts, such as commercial, hospital, and educational environments. Obviously, the more stringent the hygienic requirements, the greater the number of required cleaning cycles. Due to the near absence of porosity of PST (e.g. water absorption $\leq 0.5 \%$ ), maintenance operations are independent of the presence of glaze, but it depends entirely on the habits of the end user, place of emplacement and traffic intensity. In order to define a generic scenario, the present study considered cleaning with water and disinfectant once a week in a residential use scenario. For each cleaning cycle, 0.1 I water and 19 $\mathrm{ml}$ detergent were considered per square metre. This scenario was the considered in the Spanish EPDs of PST. 
Finally, with regard to the wastes generated during the whole PST life cycle, Table 11 lists the quantities generated and waste management operations defined in this study. In the installation stage (A5), packaging waste management depended on the geographic location of the installation site, so that management process uncertainty increased with distance.

Table 11 Management of the wastes generated by the FU of PST AAA

\begin{tabular}{|c|c|c|c|}
\hline $\begin{array}{l}\text { Life Cycle } \\
\text { Stage }\end{array}$ & Waste generated in the life cycle & Quantity (kg) & Treatment \\
\hline \multirow{3}{*}{ A3 } & \multirow{2}{*}{ Fired ceramic tile scrap } & 0.13 & Landfilling \\
\hline & & 0.38 & Recycling in other industries \\
\hline & Waste from mechanical treatments & 0.34 & Landfilling \\
\hline \multirow{9}{*}{ A5 } & \multirow{3}{*}{ Cardboard waste } & 0.01 & Incineration \\
\hline & & 0.11 & Recycling \\
\hline & & 0.04 & Landfilling \\
\hline & \multirow{3}{*}{ Plastic } & 0.002 & Incineration \\
\hline & & 0.01 & Recycling \\
\hline & & 0.01 & Landfilling \\
\hline & \multirow{3}{*}{ Wood } & 0.11 & Incineration \\
\hline & & 0.24 & Recycling \\
\hline & & 0.04 & Landfilling \\
\hline \multirow{2}{*}{ C3 } & \multirow{2}{*}{ Ceramic tiles and adhesive } & 17.50 & Recycling \\
\hline & & 7.50 & Landfilling \\
\hline
\end{tabular}

Table 12 presents the extra-plant transport data, detailing distances and means of transport used in each life cycle stage. It was generally assumed that all distances over $400 \mathrm{~km}$ involved empty returns. 
Table 12 Characteristics of the extra-plant transports associated with the life cycle of $1 \mathrm{~m}^{2}$ of PST AAA

\begin{tabular}{|c|c|c|c|c|}
\hline $\begin{array}{l}\text { Life Cycle } \\
\text { Stage }\end{array}$ & Type of load & Quantity & $\begin{array}{l}\text { Distance } \\
(\mathbf{k m})\end{array}$ & Means of transport \\
\hline \multirow{8}{*}{$\mathrm{A} 2$} & \multirow{8}{*}{ Body raw materials } & $3.22 \mathrm{~kg}$ & 150 & $27 \mathrm{t}$ truck \\
\hline & & $1.96 \mathrm{~kg}$ & 500 & $27 \mathrm{t}$ truck \\
\hline & & $0.80 \mathrm{~kg}$ & 900 & $27 \mathrm{t}$ truck \\
\hline & & $0.56 \mathrm{~kg}$ & 1300 & $27 \mathrm{t}$ truck \\
\hline & & $1.94 \mathrm{~kg}$ & 1000 & $105,000 d w t^{(2)}$ cargo ship \\
\hline & & $9.91 \mathrm{~kg}$ & 3000 & $105,000 \mathrm{dwt}^{(2)}$ cargo ship \\
\hline & & $4.10 \mathrm{~kg}$ & 3500 & $105,000 d w t^{(2)}$ cargo ship \\
\hline & & $1.42 \mathrm{~kg}$ & 4200 & $105,000 \mathrm{dwt}^{(2)}$ cargo ship \\
\hline \multirow{5}{*}{$\mathrm{A} 2$} & \multirow{4}{*}{ Decoration raw materials } & $0.28 \mathrm{~kg}$ & 500 & $27 \mathrm{t}$ truck \\
\hline & & $0.18 \mathrm{~kg}$ & 2000 & $27 \mathrm{t}$ truck \\
\hline & & $0.18 \mathrm{~kg}$ & 3500 & $105,000 d w t^{(2)}$ cargo ship \\
\hline & & $0.12 \mathrm{~kg}$ & 10000 & $105,000 \mathrm{dw}^{(2)}$ cargo ship \\
\hline & Glaze packaging & $0.25 \mathrm{~kg}$ & 140 & $27 \mathrm{t}$ truck \\
\hline \multirow{5}{*}{ A3 } & Spray-dried granulates & $23.90 \mathrm{~kg}$ & 10 & $27 \mathrm{t}$ truck \\
\hline & $\begin{array}{l}\text { Glazes and inks } \\
\text { Packages }\end{array}$ & $0.81 \mathrm{~kg}$ & 28 & $27 \mathrm{t}$ truck \\
\hline & PST packaging & $0.56 \mathrm{~kg}$ & 94 & $27 \mathrm{t}$ truck \\
\hline & Mechanical treatment ${ }^{1}$ & $37 \%$ & 3 & $27 \mathrm{t}$ truck \\
\hline & Waste management & $5.25 \mathrm{~kg}$ & 93 & $27 \mathrm{t}$ truck \\
\hline \multirow{4}{*}{ A4 } & \multirow{3}{*}{ PST for distribution } & $22 \%$ & 500 & $27 \mathrm{t}$ truck \\
\hline & & $15 \%$ & 2000 & $27 \mathrm{t}$ truck \\
\hline & & $63 \%$ & 10000 & $105,000 d w t^{(2)}$ cargo ship \\
\hline & $\begin{array}{l}\text { Packaging waste } \\
\text { management }^{(3)}\end{array}$ & $0.56 \mathrm{~kg}$ & 100 & $27 \mathrm{t}$ truck \\
\hline A5 & Fast-setting mortars ${ }^{(3)}$ & $3.50 \mathrm{~kg}$ & 100 & $27 \mathrm{t}$ truck \\
\hline $\mathrm{B} 2$ & Detergent $^{(3)}$ & $0.05 \mathrm{~kg}$ & 100 & $27 \mathrm{t}$ truck \\
\hline $\mathrm{C} 2$ & Ceramic tile end of life ${ }^{(3)}$ & $25 \mathrm{~kg}$ & 100 & $27 \mathrm{t}$ truck \\
\hline \multicolumn{5}{|c|}{$\begin{array}{l}\text { NOTES: } \\
\text { (1) } 37 \% \text { of the sample was mechanised } \\
\text { (2) dwt: dead weight tonnage } \\
\text { (3) Assuming a round trip of } 50 \mathrm{~km}\end{array}$} \\
\hline
\end{tabular}




\subsubsection{Description of the PST life cycle}

The structure of the PST life cycle stages (modules) was built up according to EN 15804:2012+A1:2013 as shown in Figure 2, including modules A1-A5, B2, and C1-C4. Figure 3 shows a detailed flow chart of the PST life cycle.

Ceramic tiles essentially consist of a ceramic body ( $97 \%$ by weight) and an optional thin layer of ceramic glaze, usually with additional decorative material ( $3 \%$ by weight). The ceramic body is mostly composed of clay, sand, feldspar, and recycled ceramic material. The most common glaze and decoration materials components are ceramic frits, inorganic pigments, other mineral raw materials, and minor organic additives (these additives being negligible).

These raw materials are transported (A2) by freighter or by truck depending on the distance from the origin. All raw materials are transported in bulk, i.e. they require no packaging.

In the PST manufacturing stage (A3), the raw materials for the ceramic body are mixed, wet milled, and then spray dried. The vast majority (about $90 \%$ ) of the spray dryers in the Spanish ceramic cluster (Gabaldón-Estevan et al. 2014; Monfort et al. 2010) are fitted with a heat and electric energy cogeneration system, in which the hot gases are recovered in the spray dryer, part of the generated electric energy being used in the production process itself, while the rest is sold to the grid, allocating the co-product electricity as an expansion of the system (Thuring et al. 2013), in which the electricity sold to the power grid is replacing the marginal technology, i.e. the technology that is most flexible to changes in demand. According to the Spanish Power Grid Mix (SPGM), this is the thermoelectric technology using coal and natural gas (REE 2014). 


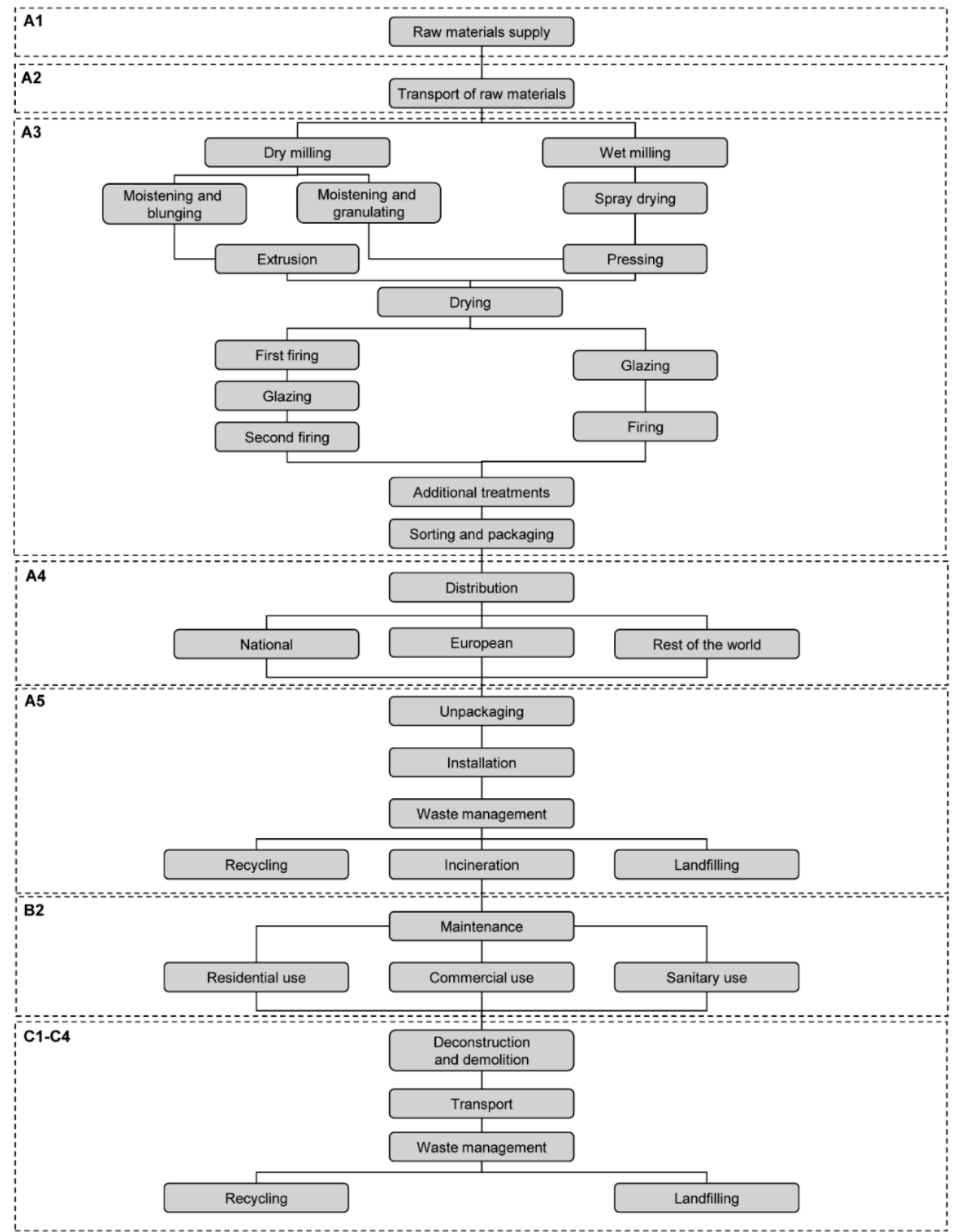

Figure 3 Boundaries of the analysed system. Modules according to EN 15804:2012+A1:2013 A1 Raw materials supply; A2 Transport of raw materials; A3 Manufacturing; A4 Transport to the building; A5 Installation into the building; B2 Maintenance; C1 Deconstruction and demolition; C2 Transport; C3 Reuse, recovery and/or recycling; C4 Disposal 
Most Spanish ceramic tiles are formed by uniaxial semi-dry pressing, the rest being mainly extruded. The freshly formed tiles are then fed into a continuous dryer. In a few cases, a first firing is performed followed by the application of one or more layers of glaze and decorative applications, and subsequent second firing. However, after drying and decorating most ceramic tiles are fired in a single cycle in single-deck roller kilns, optionally followed by mechanical treatments such as polishing and edge-grinding or rectification. Finally, ceramic tile quality is controlled, the tiles being sorted and packaged using cardboard, pallets, and polyethylene films.

The construction stage processes involve transport to the building site (A4) and installation of the product (A5). According to the latest figures from the Ceramic World Review (Baraldi 2015), Spanish ceramic tile export destinations by volume are as follows: Asian countries $29 \%$, Africa $25 \%$, the rest of the European countries 15\%, and the Americas 9\%, 22\% being sold in the Spanish domestic market.

The PST are then duly unpacked for installation, ceramic tiles typically being installed using 3.5 $\mathrm{kg} / \mathrm{m}^{2}$ of fast-setting mortars (ASCER 2011), which are mixed with water in a mortar (water ratio of $4: 1)$.

Once PST is installed, only maintenance (B2) operations are needed during the use stage. PST requires neither energy $(B 6)$ nor water $(B 7)$ input for use and produces no emissions to air, water, or soil during its use phase (B1) and, provided that it is properly installed, repair (B3), replacement (B4), or refurbishment (B5) are either not required or negligible (CET 2014; DAPcons 2015; GlobalEPD, 2013; Thurning et al. 2013).

Standard EN 14411:2012, counterpart to standard ISO 13006:2012, states that the durability ceramic tiles in interior environments may be the same as the building provided that the essential characteristics of this European standard are met. This assertion is based on practical experience of at least 50 years. Therefore, the service life defined in the article has been set at 50 years, regardless of the PST variety.

Nevertheless, it is interesting to note at this point that, in general, the lifespan depends mainly on the type of use and quality of installation. In fact, very thin PST can be used as flooring in indoor areas of high pedestrian traffic for more than 50 years avoiding cracking (the main cause of ceramic tile mortality "end use") if appropriate fixings systems over a firmly supported subflooring are used (Cerurbis project, 2013-2017).

When its service life has ended (modules $\mathrm{C} 1-\mathrm{C} 4$ ), the product is removed, either as part of building refurbishment or building demolition. In building demolition (C1), the impacts assignable to product disassembly are considered negligible (DAPcons 2015; GlobalEPD 2013). Product waste is transported (C2) by truck to the waste destination (a mean distance of $50 \mathrm{~km}$ being assumed). Based on Directive 2008/98/EC on wastes, it was assumed that $70 \%$ of the construction and demolition waste was reused, recovered, or recycled (C3), the remaining $30 \%$ being landfilled (C4). 


\section{Results and Discussion}

\subsection{Life Cycle Environmental Impact Assessment of PST AAA}

The absolute values of each environmental impact category, based on the CML 2002 method (Guinée et al. 2002) associated with $1 \mathrm{~m} 2$ of Spanish PST (AAA) installed in a home for 50 years as floor covering, are detailed in Table 13. Figure 4 shows the relative environmental contribution of each life cycle module of 1 FU of PST AAA.

Table 13 Environmental impact assessment of 1 FU of PST AAA

\begin{tabular}{|c|c|c|c|c|c|c|c|}
\hline & ADP-elements & ADP-fossil & AP & EP & GWP & ODP & POCP \\
\hline & kg Sb Eq. & MJ & $\mathrm{kg} \mathrm{SO}_{2} \mathrm{Eq}$. & $\mathrm{kg} \mathrm{PO}_{3}{ }^{4} \mathrm{Eq}$. & $\mathrm{kg} \mathrm{CO}_{2} \mathrm{Eq}$. & kg R11 Eq. & $\mathrm{kg} \mathrm{C}_{2} \mathrm{H}_{4} \mathrm{Eq}$. \\
\hline $\mathrm{A} 1$ & $9.93 \mathrm{E}-05$ & $2.82 \mathrm{E}+01$ & 1.17E-02 & $1.87 \mathrm{E}-03$ & $2.12 \mathrm{E}+00$ & $2.23 \mathrm{E}-07$ & $1.05 \mathrm{E}-03$ \\
\hline $\mathrm{A} 2$ & $6.45 \mathrm{E}-09$ & $4.19 \mathrm{E}+00$ & $5.37 \mathrm{E}-03$ & $6.94 \mathrm{E}-04$ & $3.16 \mathrm{E}-01$ & $5.93 \mathrm{E}-10$ & $3.59 \mathrm{E}-04$ \\
\hline $\mathrm{A} 3$ & $9.74 \mathrm{E}-07$ & $8.90 \mathrm{E}+01$ & $1.23 \mathrm{E}-02$ & $1.44 \mathrm{E}-03$ & $7.04 \mathrm{E}+00$ & $4.22 \mathrm{E}-07$ & 8.81E-04 \\
\hline $\mathrm{A} 4$ & $1.44 \mathrm{E}-08$ & $8.79 \mathrm{E}+00$ & $1.27 \mathrm{E}-02$ & $1.38 \mathrm{E}-03$ & $6.75 \mathrm{E}-01$ & $1.24 \mathrm{E}-09$ & $8.12 \mathrm{E}-04$ \\
\hline $\mathrm{A} 5$ & $6.60 \mathrm{E}-05$ & $4.05 \mathrm{E}+00$ & 4.82E-04 & $2.00 \mathrm{E}-04$ & 5.01E-01 & $1.06 \mathrm{E}-08$ & 5.32E-05 \\
\hline $\mathrm{B} 2$ & 2.19E-07 & $1.32 \mathrm{E}+00$ & $9.12 \mathrm{E}-04$ & $1.57 \mathrm{E}-04$ & 1.52E-01 & $5.36 \mathrm{E}-08$ & 2.64E-04 \\
\hline $\mathrm{C} 1$ & 0 & 0 & 0 & 0 & 0 & 0 & 0 \\
\hline $\mathrm{C} 2$ & 4.23E-09 & $2.45 \mathrm{E}+00$ & $9.11 \mathrm{E}-04$ & $1.84 \mathrm{E}-04$ & $1.79 \mathrm{E}-01$ & $3.63 \mathrm{E}-10$ & $1.01 \mathrm{E}-04$ \\
\hline $\mathrm{C} 3$ & 0 & 0 & 0 & 0 & 0 & 0 & 0 \\
\hline $\mathrm{C} 4$ & $9.93 \mathrm{E}-10$ & $1.13 \mathrm{E}+00$ & 5.79E-04 & 8.50E-05 & $1.56 \mathrm{E}-01$ & $1.38 \mathrm{E}-09$ & $1.02 \mathrm{E}-04$ \\
\hline D & $2.37 \mathrm{E}-08$ & $-1.70 \mathrm{E}+00$ & $-1.24 \mathrm{E}-04$ & $-3.87 E-05$ & $-1.78 \mathrm{E}-01$ & $-1.72 \mathrm{E}-08$ & $-1.61 \mathrm{E}-05$ \\
\hline
\end{tabular}




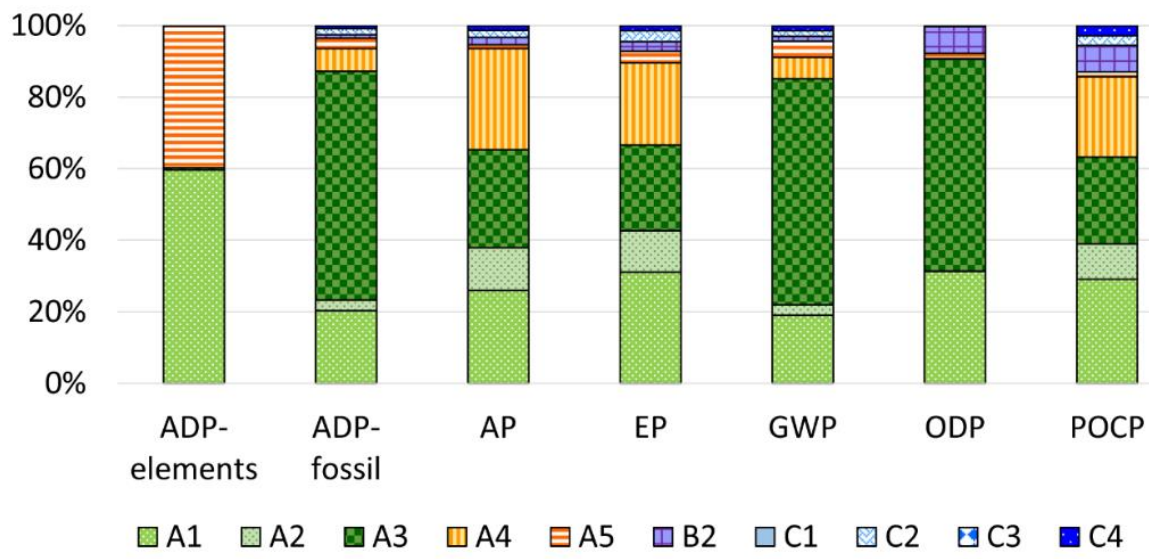

Figure $4 \mathrm{LCIA}$ results (relative units) of covering $1 \mathrm{~m}^{2}$ of household floor surface for 50 years with PST AAA

Table 13 and Figure 4 indicate that manufacturing stage A3 generated the greatest environmental impacts in every category except ADP-elements. Although this impact category needs to be included in the environmental product declarations (EN 15804:2012+A1:2013), its use is under revision since this is a much disputed impact category in LCA due to the disagreement regarding the parameters that need to be included in the characterisation model (Oers and Guinée 2016). This impact category is mainly influenced by the boron-introducing raw materials in the glaze composition and by the composition of the fast-setting mortars used in PST installation.

The main relative contributions (in \%) associated with the direct material and energy inputs and outputs in the PST AAA life cycle are presented in Table 14.

Table 14 shows that natural gas consumption in the manufacturing process (preparation of spraydried granulates and drying and firing stages) accounted for more than $70 \%$ in the ADP-fossil and GWP impact categories. Moreover, in these processes, apart from natural gas combustion emissions, there were also emissions due to raw materials decomposition, such as $\mathrm{HF}, \mathrm{SO}_{2}$, and $\mathrm{NO}_{x}$, which generated significant impacts on the AP impact category. This occurred mainly in the firing process, in which temperatures of about $120{ }^{\circ} \mathrm{C}$ are reached (Monfort et al. 2011a). $\mathrm{NO}_{x}$ generated all the nutrifying emissions, contributing to the EP impact category, while $\mathrm{SO}_{2}$ and $\mathrm{NO}_{x}$ are precursors influencing tropospheric ozone formation (POCP).

With regard to the main potential impacts associated with the consumption of electricity from the SPGM in the PST manufacturing process, its ODP was the most sensitive and accounted for over $60 \%$. This was mainly due to the refrigerant gases used in nuclear power plants, which accounted for about $21 \%$ of the SPGM in 2013 , and to fuel production. In addition, the halogenated organic compounds emissions contributed significantly to the formation of photochemical oxidant potential (POCP), while the $\mathrm{SO}_{2}$ emissions associated with coal-fired power plants $(8.5 \%$ of the SPGM in 2013) contributed to the AP. 
To be noted are the benefits of the electricity generated by the cogeneration system, which was sold to the SPGM. In the allocation process, this electricity sold to the SPGM replaced marginal technology, considered to be thermoelectric technology using coal and natural gas (REE 2014). The cogenerated electricity avoided the SPGM generating the equivalent of $28.5 \%$ ADP-fossil and $28 \%$ GWP of the PST AAA total life cycle (see Table 14). With regard to AP and POCP, the cogenerated electricity avoided more than twice the impact on the SPGM of the potential impact generated by the consumption of natural gas in the spray dryer + cogeneration system; in the case of EP, these impacts virtually offset each other (see Table 14).

Table 14 Main relative contributions (in \%) of the inputs/outputs in the FU of PST AAA to the environmental impact categories studied

\begin{tabular}{|c|c|c|c|c|c|c|c|c|}
\hline $\begin{array}{l}\text { Module life } \\
\text { cycle }\end{array}$ & Input/output & $\begin{array}{l}\text { ADP- } \\
\text { eleme } \\
\text { nts }\end{array}$ & $\begin{array}{l}\text { ADP- } \\
\text { fossil }\end{array}$ & AP & EP & GWP & ODP & POCP \\
\hline \multirow{2}{*}{ A1 } & Body raw materials & & 14.4 & 9.2 & 8.1 & 12.5 & 25.8 & 15.0 \\
\hline & Glazes (from cradle to gate) & 59.6 & 6.1 & 16.8 & 23.2 & 6.8 & 6.2 & 14.2 \\
\hline \multirow{3}{*}{$\begin{array}{c}\mathrm{A} 3 \\
\text { Granulate } \\
\text { manufacture }\end{array}$} & Electricity sold to the grid & & -28.3 & -19.0 & -9.0 & -28.1 & $<-1.0$ & -25.8 \\
\hline & $\begin{array}{l}\text { Electricity bought from the } \\
\text { grid }\end{array}$ & & 6.3 & 6.0 & 3.0 & 6.7 & 23.3 & 6.7 \\
\hline & $\begin{array}{l}\text { Thermal energy from natural } \\
\text { gas }\end{array}$ & & 32.3 & 7.6 & 9.3 & 31.1 & $<1.0$ & 11.8 \\
\hline \multirow{3}{*}{$\begin{array}{c}\text { A3 } \\
\text { PST } \\
\text { manufacture }\end{array}$} & $\begin{array}{l}\text { Thermal energy from natural } \\
\text { gas }\end{array}$ & & 44.7 & 10.5 & 12.6 & 43.1 & & 16.3 \\
\hline & $\begin{array}{l}\text { Electricity bought from the } \\
\text { grid }\end{array}$ & & 10.0 & 9.3 & 4.7 & 10.5 & 36.5 & 7.5 \\
\hline & $\begin{array}{l}\text { Emissions from raw } \\
\text { materials decomposition }\end{array}$ & & & 12.8 & 2.6 & 1.1 & & 4.6 \\
\hline $\mathrm{A} 2$ & Transport & & & 12.0 & 11.6 & 2.9 & $<1.0$ & 10.0 \\
\hline A4 & Transport & & 6.4 & 28.4 & 23.2 & 6.2 & $<1.0$ & 22.5 \\
\hline A5 & Adhesive & 40.0 & & & & & & \\
\hline B2 & Detergent & & & & & & 7.1 & 6.3 \\
\hline D & $\begin{array}{c}\text { Benefits and loads beyond } \\
\text { the product system } \\
\text { boundary }\end{array}$ & & & & & & -2.5 & \\
\hline \multicolumn{2}{|c|}{ Rest of processes } & & $\leq 3.0$ & $<2.5$ & $\leq 3.5$ & $<3.0$ & $<2.0$ & $<3.0$ \\
\hline
\end{tabular}

In relation to the potential environmental impact of ceramic glazes, the results reveal that, besides the contribution to the ADP-elements impact category, the contribution to EP was significant due to the $\mathrm{NO}_{x}$ emissions into the air generated in the fusion of ceramic frits $(33 \%$ average content in the glaze composition), accounting for more than $20 \%$ of the PST AAA total life cycle in this impact 
category. For the same reason, glazes were also significant in AP and POCP. Figure 5 presents the relative influence of the glazed ceramic tiles on each impact category.

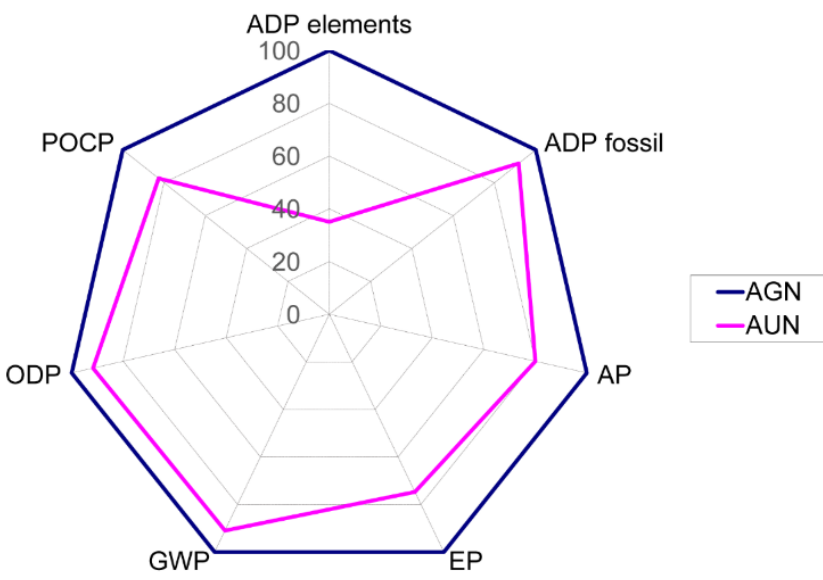

Figure 5 Influence of the glaze

In general, assuming the same material density and the same raw materials composition, a reduction in thickness entailed lower raw materials consumption, thermal energy consumption, transportation cost, and air emissions, as well as less stock in the factory and distribution depots. The influence of thickness on all impact categories can be observed in Figure 6.

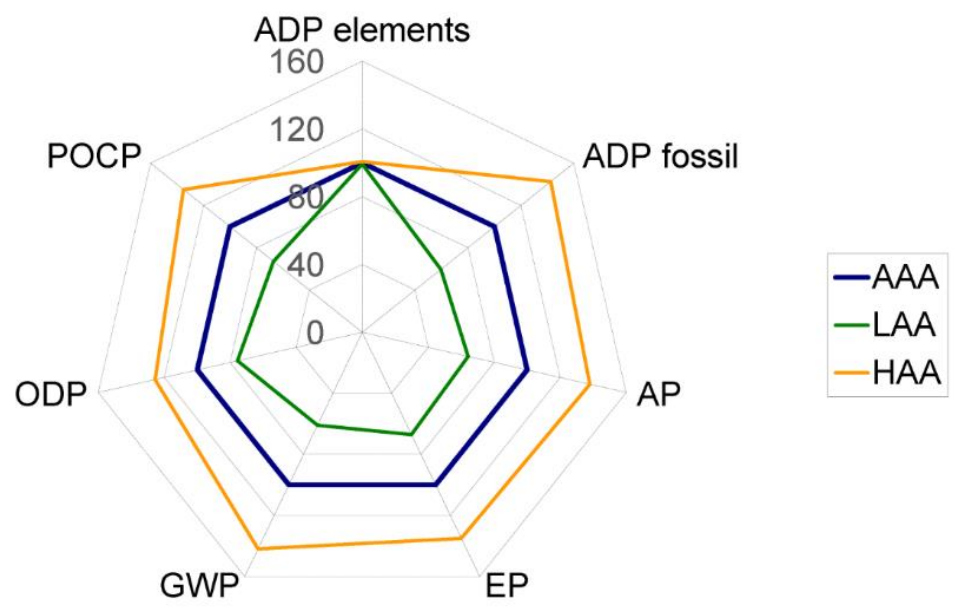

Figure 6 Influence of thickness 
The optional mechanical treatments have significant influence in ODP, owing to the high ensuing electricity consumption and to a lesser extent to the production of some body raw materials such as sand and feldspar. The relative influence of mechanical treatments on each impact category is illustrated in a spider diagram in Figure 7.

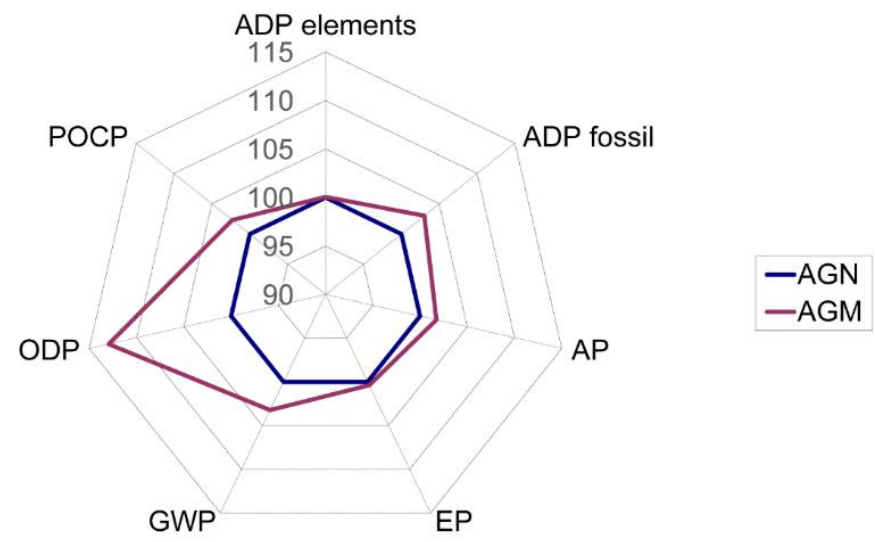

Figure 7 Influence of mechanical treatments

\subsection{Environmental impact assessment of PST varieties}

Figure 8 shows the potential environmental impacts of the different varieties of PST listed in Table 4. 


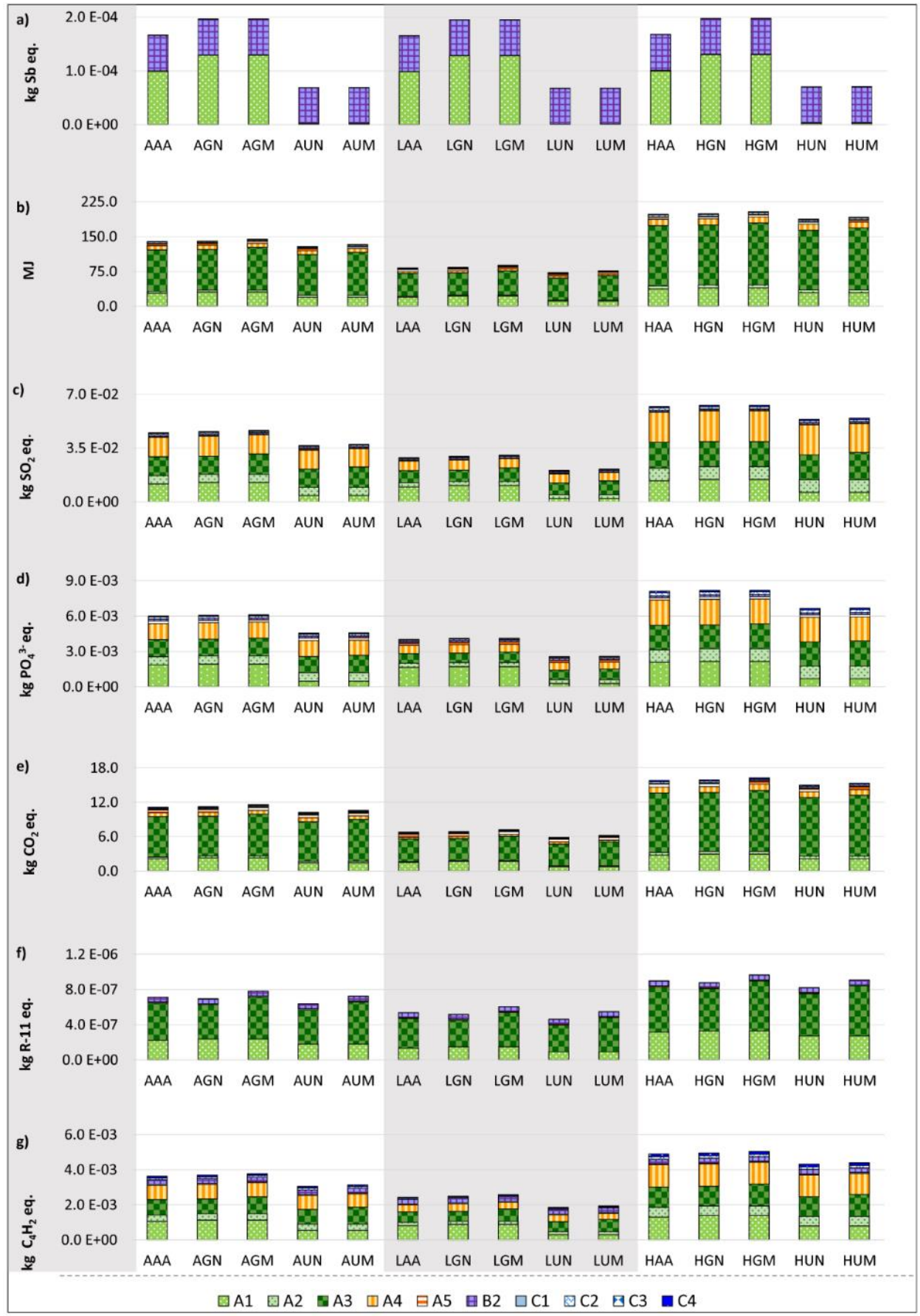

Figure 8. Environmental impacts of each PST variety 
It may be observed in Figure 8 that the graphs exhibit a similar shape and pattern in every impact category except ODP and the ADP-elements. The ADP-elements basically depended to about $60 \%$ and $40 \%$ on the glaze raw materials and the ceramic tile adhesive, respectively. Figure $8 \mathrm{a}$ shows that, since the amount of adhesive did not vary significantly with the type of PST, this impact remained constant regardless of weight and mechanical treatments, only displaying variations with the quantity of glaze. Figure 5 shows the clear relationship of the glaze and ADP-elements.

On the other hand, ODP was strongly influenced by electricity consumption from the SPGM and fuel production. Figure $8 f$ shows the increase in ODP values in the varieties of PST with mechanical treatments.

The differences between all the studied varieties of PST ranged from 31 to $37 \%$ (except ODP, which reached up to $48 \%)$. In the studied PST varieties, the value ranges were as follows: ADPelements (6.76E-05 - 1.98E-04 kg Sb eq.), ADP-fossil (1.4 - 201.3 MJ), AP (2.05E-02 - 6.26E-02 $\mathrm{kg} \mathrm{SO}_{2}$ eq.), EP (2.55E-03 - 8.15E-03 kg PO${ }_{4}^{3-}$ eq.), GWP (5.8 to $16 \mathrm{~kg} \mathrm{CO}_{2}$ eq.), ODP (4.51E-07 9.42E-07 kg R-11 eq.), POCP (1.84E-03 - 5.02E-03 kg C $4 \mathrm{H}_{2}$ eq.).

In Figure 8 all graphs show that the PST variety with the lowest environmental impact was the one that had the lowest mass (low thickness), was unglazed, and had undergone no mechanical treatment (LUN). In contrast, the PST variety with the greatest environmental impact was the one that had the highest mass (high thickness), was glazed, and had undergone mechanical treatment (HGM).

Therefore, in order to select the PST variety with the highest and the lowest impact from a diverse group, the above result may be deemed valid when the differences in mass and amount of glaze are significant and the product has or has not undergone mechanical treatment. However, when the differences are very subtle, a scenario and sensitivity analysis of the life cycle should be performed to evaluate the system holistically.

As indicated in section 2.1.2., Particulate Matter (PM) emissions were quantified for all Porcelain Stoneware Tile varieties, both, those emitted during the manufacturing process and those emitted throughout the life cycle, in addition to the environmental indicators recommended by the standard EN 15804: 201+A1: 2013.

Figure 9a and Figure 9b show that, even though some direct PM emissions depended mainly on surface area of the product (i.e. manufacturing processes after forming process), total PM emissions were closely linked to specific mass. This pattern remained similar both in the direct emissions, i.e. emitted during the manufacturing stage (A3 stage) and in the total life cycle emissions. The values between all the studied varieties of PST ranged from 2.5 to $7.6 \mathrm{~g} / \mathrm{m}^{2}$ in the case of direct emissions and from 19 to $62 \mathrm{~g} / \mathrm{m}^{2}$ the indirect emissions related to the whole life cycle of the different PST. Total PM emissions (direct and indirect emissions) had an order of magnitude higher than direct emissions generated in the manufacturing process. Indirect emissions came largely from the combustion of fossil fuels used in transport (fuel oil used on boats and diesel on trucks) and the raw material extraction activities due to the handling of powdery materials. 


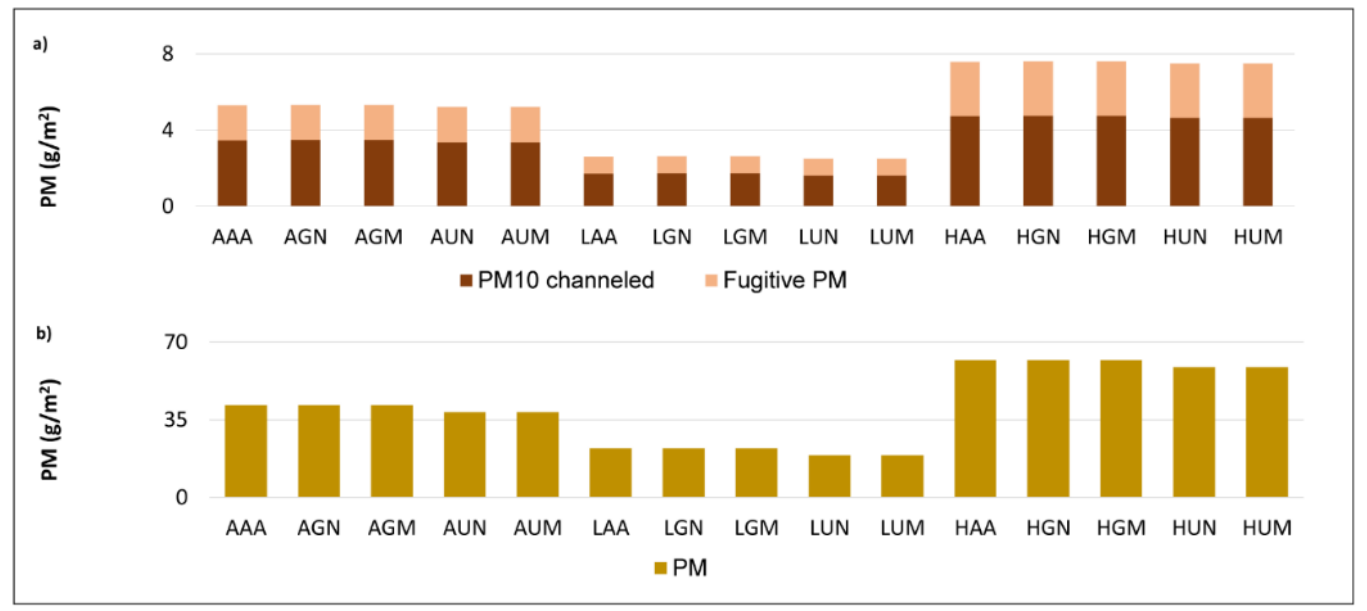

Figure 9 Emissions of particulate matter of each PST variety

In spite, direct PM emissions seem to have relatively low contribution from a life cycle perspective, the environmental and economic impact at local level is high. In fact, studies carried out by the Instituto de Tecnología Cerámica at the request of ASCER when Integrated Prevention Pollution Control Directive 96/61CE (IPPC) drove into force, estimated that the $60-70 \%$ of the total investment made by the tile manufacturing industry was addressed to mitigate PM emissions.

\section{Conclusions}

The life cycle stage with the greatest environmental impact was the manufacturing stage (A3). The main hotspots were production and consumption of natural gas in manufacturing (in A3) for ADPfossil and GWP; glazes (in A1) for ADP-elements, AP, EP, and POCP; electricity production from the SPGM and consumption (in A3) for ODP and ADP-fossil; distribution (A4) for AP and POCP; body raw materials (in A1) for ODP and adhesives used in the installation stage (A5) for ADPelements. To be noted are the great number of cogeneration systems installed in the Spanish ceramic tile cluster (an important difference from other countries production systems), which significantly reduced the impacts in the SPGM, especially in the ADP-fossil, AP, POCP, and GWP categories.

PM emissions do not have a direct contribution to the environmental impact categories required by EN 15804:2012+A1:2013 and the RCPs for ceramic products consider neither indirect nor direct emissions PM emissions as an output flow to declare in the EPD. However, PM emissions generated during the manufacturing process have an important environmental and economic significance from an industrial point of view. Therefore, the authors recommend including the mandatory declaration of PM emissions in the EPD for ceramic products as well as for those building products with a similar casuistry in the RCPs. 
The study further shows that the variation in PST thickness (i.e. specific weight) was a key factor influencing all studied impact categories except ADP-elements, as it significantly affected the materials and energy inputs and outputs in almost every life cycle stage. PST mechanical treatments particularly increased the values of the ODP impact category, mainly from increased electric energy consumption. Finally, the amount of glaze strongly modified the ADP-elements and EP values, owing to the boron-introducing raw materials in the glaze composition and $\mathrm{NO}_{x}$ emissions in ceramic frit manufacturing, respectively.

Although all studied PST varieties belonged to the same water absorption group (according to ISO 13006) and could, therefore, except in special applications, all perform the same function, the study confirmed that the differences among these commercial PST varieties were quite significant (about $35 \%$, except ODP, which was about $48 \%$ ). Consequently, the possibility of declaring a number of PST varieties in the same EPD is not as obvious as was assumed in some studies (Table 1). This suggests that a preliminary verification is required to ensure compliance with the PCR by comparing the life cycle environmental profile of the PST candidates. In this regard, the authors recommend, firstly, comparing the PST varieties that exhibit the lowest and highest environmental impact profiles, focusing in particular on thickness, amount of glaze, and mechanical surface treatment. If the results of this preliminary comparison do not comply with the grouping rules for PCRs, a new grouping process should then be performed.

\section{Acknowledgements}

This study was performed with the DAPCER tool, developed from the GaBi software package by the authors for the Spanish Ceramic Tile Manufacturers' Association (ASCER) with the financial support of the Instituto Valenciano de Competitividad Empresarial (IVACE) and the European Regional Development Fund (ERDF). The authors would also like to thank the ceramic tile manufacturing companies for their help in data collection.

The authors are responsible for the choice and presentation of the information contained in this paper as well as for the opinions expressed therein, which are not necessarily those of UNESCO and do not commit this Organization.

\section{Acronyms}

A: Average performance, weighted by the production of all thicknesses, patterns, and finishes

A1: Life cycle stage: Raw Materials Supply

A2: Life cycle stage: Transport of Raw Materials

A3: Life cycle stage: Manufacturing

A4: Life cycle stage: Transport to the building

A5: Life cycle stage: Installation into the building 
AAA: Average thickness, average quantity of glaze, and average mechanical treatments ADP elements: Abiotic Depletion-elements ADP fossil: Abiotic Depletion-fossil fuels

AGM: Average thickness, glazed, and mechanised

AGN: Average thickness, glazed, and non-mechanised

AP: Acidification Potential

ASCER: The Spanish Ceramic Tile Manufacturers' Association

AUM: Average thickness, unglazed, and mechanised

AUN: Average thickness, unglazed, and non-mechanised

B1: Life cycle stage: Use

B2: Life cycle stage: Maintenance

B3: Life cycle stage: Repair

B4: Life cycle stage: Replacement

B5: Life cycle stage: Refurbishment

B6: Life cycle stage: Operational energy use

B7: Life cycle stage: Operational water use

C1: Life cycle stage: Deconstruction and demolition

C2: Life cycle stage: Transport

C3: Life cycle stage: Reuse, recovery, and recycling

C4: Life cycle stage: Disposal

CML: The Institute of Environmental Sciences (CML), Faculty of Science of Leiden University, The Netherlands

Dwt: Dead weight tonnage

$\mathbf{E}_{\mathrm{b}}$ : Water absorption

EN: European Standard

EP: Eutrophication Potential

EPD: Environmental Product Declaration 
Eq.: Equivalent

ERDF: European Regional Development Fund

ET: Earthenware Tile

EU-28: European Union

FU: Functional Unit

G: Glazed

GST: Glazed Stoneware Tile

GWP: Global Warming Potential (100 years)

H: High thickness

HAA: High thickness, average quantity of glaze, and average mechanical treatments

HGM: High thickness, glazed, and mechanised

HGN: High thickness, glazed, and non-mechanised

HUM: High thickness, unglazed, and mechanised

HUN: High thickness, unglazed, and non-mechanised

ISO: The International Organization for Standardization

IVACE: Institut Valencià de Competitivitat Empresarial

L: Low thickness

LAA: Low thickness, average quantity of glaze, and average mechanical treatments

LCA: Life Cycle Assessment

LCI: Life Cycle Inventory Analysis

LCIA: Life Cycle Impact Assessment

LGM: Low thickness, glazed, and mechanised

LGN: Low thickness, glazed, and non-mechanised

LUM: Low thickness, unglazed, and mechanised

LUN: Low thickness, unglazed, and non-mechanised

M: Mechanised 
N: Non-mechanised

ODP: Ozone Layer Depletion Potential (steady state)

PCR: Product Category Rules

PM: Particulate matter

PM $_{10}$ : Particles which pass through a size-selective inlet with a $50 \%$ efficiency cut-off at $10 \mu \mathrm{m}$ aerodynamic diameter. PM10 corresponds to the "thoracic convention" as defined in ISO 7708:1995, Clause 6.

POCP: Photochemical Ozone Creation Potential

PST: Porcelain Stoneware Tile

Q2: $50^{\text {th }}$ percentile

SD: Standard Deviation

SPGM: Spanish Power Grid Mix

U: Unglazed

UK: United Kingdom

\section{References}

Almeida MI, Dias AC, Demertzi M, Arroja L (2016) Environmental profile of ceramic tiles and their potential for improvement. J Clean Prod 131:583-593. doi: 10.1016/j.jclepro.2016.04.131

ASCER (2011) Gúa de la baldosa cer乏́mica: el vademecum de la baldosa cer乏́mica, para su clasificacif́n, su seleccif́n, materiales de agarre y rejuntado, la redaccif́n del proyecto, el control de la obra, 6th edn. Generalitat Valenciana, Castellón (in Spanish)

ASCER (2015) El sector en datos.

http://www.ascer.es/homeinstitucional/sectorDatos.aspx?lang=es-ES. Accessed 9 Dec 2015 (in Spanish)

Baraldi L (2015) World production and consumption of ceramic tiles. Ceram world Rev 113:48-61.

Belussi L, Mariotto M, Meroni I, et al (2015) LCA study and testing of a photovoltaic ceramic tile prototype. Renew Energy 74:263-270. doi: 10.1016/j.renene.2014.07.053

Benveniste G, Gazulla C, Fullana P, Celades I, Ros T, Moliner R, Zaera V, Godes B (2010) Sectoral Life cycle assessment of ceramic tile. In: XI Global Forum of Ceramic Tile. Castellón, Spain 
Benveniste G, Gazulla C, Fullana P, Celades I, Ros T, Zaera V (2011) Life cycle assessment and product category rules for the construction sector. The floor and wall tiles sector case study. Inf de la Construcción 63:71-81. doi: 10.3989/ic.10.034 (in Spanish)

Bovea MD, Díaz-Albo E, Gallardo A, et al (2010) Environmental performance of ceramic tiles: Improvement proposals. Mater Des 31:35-41. doi: 10.1016/j.matdes.2009.07.021

BSI PAS 2050 (2011) Specification for the assessment of the life cycle greenhouse gas emissions of goods and services. UK

Celades I (2013) Caracterización física, química, mineralógica y morfológica del material particulado emitido por focos canalizados de la industria de baldosas y fritas cerámicas. Universitat Jaume I. (In Spanish)

Cerurbis project (2013-2017) Guide ceramics applications in urban space. http://www.cerurbis.eu/media/8948/guide_ceramics_applications_in_urban_space_EN_final.pdf. Accessed 17 May 2017

CET - European Ceramic Tile Manufacturer's Federation (2014) Product Category Rules for preparing an Environmental Product Declaration for Ceramic tiles. Brussels, Belgium

da Silva AL, Feltrin J, Dal Bó M, Bernardin AM, Hotza D (2014) Effect of reduction of thickness on microstructure and properties of porcelain stoneware tiles. Ceram Int 40:14693-14699. doi: 10.1016/j.ceramint.2014.05.150

DAPcons ${ }^{\circledR}$ system. http://www.csostenible.net/index.php/es/sistema_dapc. Accessed 17 Mar 2016 (in Spanish)

DAPcons (2015) RCP 002, v2. Reglas de Categoría de Producto para preparar una Declaración Ambiental de Producto (DAPcons) sobre productos de revestimiento cerámico (in Spanish)

Directive 2008/1/EC of the European Parliament and of the Council of 15 January 2008 concerning integrated pollution prevention and control. Off. J. Eur. Union L 24/8:22

Directive 2008/98/EC of the European Parliament and of the Council of 19 November 2008 on waste and repealing certain directives. Off. J. Eur. Union L 312/3:28

Directive 2009/29/EC of the European Parliament and of the Council of 23 April 2009 amending Directive 2003/87/EC so as to improve and extend the greenhouse gas emission allowance trading scheme of the Community. Off. J. Eur. Union I 140/63:25

Directive 2010/75/EU of the European Parliament and of the Council of 24 November 2010 on industrial emissions (Integrated Pollution Prevention and Control). Off. J. Eur. Union L 334/17:17

EcoPlatform. http://www.eco-platform.org/. Accessed 13 May 2016

EIPPCB Integrated Pollution Prevention and Control (2012) Reference Document on Best Available Techniques (BATs) in the Glass Manufacturing Industry. European Commission, Directorate- 
General JRC, Joint Research Centre. Institute for Prospective Technological Studies (Sevilla). Technologies for Sustainable Development. European IPPC Bureau. 2012

EIPPCB Integrated Pollution Prevention and Control (2007) Reference Document on Best Available Techniques (BATs) in the Ceramic Manufacturing Industry. European Commission, DirectorateGeneral JRC, Joint Research Centre. Institute for Prospective Technological Studies (Sevilla). Technologies for Sustainable Development. European IPPC Bureau. 2007

EN 14411 (2012) Ceramic tiles. Definitions, classification, characteristics, evaluation of conformity and marking. Brussels, Belgium

EN 15804(2012)+A1 (2013) Sustainability of construction works - Environmental product declarations - Core rules for the product category of construction products. CEN European Commission, Brussels, Belgium

EN15978 (2011) Sustainability of construction works - Assessment of environmental performance of buildings - Calculation method. CEN European Commission, Brussels, Belgium

FDE\&S. Fiches de Déclaration Environnementale et Sanitaire. http://www.inies.fr. Accessed 30 Nov 2015

Frischknecht, R., Althaus, H.-J., Bauer, C., Doka, G., Heck, T., Jungbluth, N., Kellenberger, D., Nemecek T (2007) The Environmental Relevance of Capital Goods in Life Cycle Assessments of Products and Services. In: Int J LCA (Online First). http://treeze.ch/fileadmin/user_upload/downloads/Publications/Case_Studies/Miscellaneous/Fris chknecht-2007-CapitalGoods_IntJLCA.pdf. Accessed 16 May 2016

Gabaldón-Estevan D, Hekkert MP (2013) How Does the Innovation System in the Spanish Ceramic Tile Sector Function? Bol Soc Esp Ceram Vidr 52(3):151-158. doi: 10.3989/cyv.202013

Gabaldón-Estevan D, Criado E, Monfort E (2014) The green factor in European manufacturing: a case study of the Spanish ceramic tile industry. J Clean Prod 70:242-250. doi: 10.1016/j.jclepro.2014.02.018

GlobalEPD. https://www.aenor.es/aenor/certificacion/mambiente/globalepd.asp\#.V8awe1uLRdi. Accessed 11 Nov 2015 (in Spanish)

GlobalEPD (2013) RCP 002, va. Regla de Categoría de Producto de Recubrimientos cerámicos. Madrid (in Spanish)

Guinée, J.B.; Gorrée, M.; Heijungs, R.; Huppes, G.; Kleijn, R.; Koning, A. de; Oers, L. van; Wegener Sleeswijk, A.; Suh, S.; Udo de Haes, H.A.; Bruijn, H. de; Duin, R. van; Huijbregts MAJ (2002) Handbook on life cycle assessment. Operational guide to the ISO standards. I: LCA in perspective. Ila: Guide. Ilb: Operational annex. III: Scientific background. Kluwer Academic Publishers, Dordrecht 
Han B, Wang R, Yao L, et al (2015) Life cycle assessment of ceramic façade material and its comparative analysis with three other common façade materials. J Clean Prod 99:86-93. doi: 10.1016/j.jclepro.2015.03.032

Ibáñez-Forés V, Bovea MD, Azapagic A (2013) Assessing the sustainability of Best Available Techniques (BAT): methodology and application in the ceramic tiles industry. J Clean Prod 51:162176. doi: 10.1016/j.jclepro.2013.01.020

Ibáñez-Forés V, Bovea M-D, Simó A (2011) Life cycle assessment of ceramic tiles. Environmental and statistical analysis. Int J Life Cycle Assess 16:916-928. doi: 10.1007/s11367-011-0322-6

IBU EPD programme - Institut Bauen und Umwelt e.V. http://ibu-epd.com/. Accessed 30 Nov 2015 International EPD® System. http://www.environdec.com/. Accessed 17 Mar 2016

International EPD® System (2012) Bricks, blocks, tiles, flagstone of clay and siliceous earths (suboriented PCR; appendix to PCR 2012:01; under development) - Environmental Product Declarations

Islam H, Jollands M, Setunge S, Bhuiyan MA (2015a) Optimization approach of balancing life cycle cost and environmental impacts on residential building design. Energy Build 87:282-292. doi: 10.1016/j.enbuild.2014.11.048

Islam H, Jollands $\mathrm{M}$, Setunge $\mathrm{S}$, et al (2015b) Life cycle assessment and life cycle cost implications for roofing and floor designs in residential buildings. Energy Build 104:250-263. doi: 10.1016/j.enbuild.2015.07.017

ISO 13006 (2012) Ceramic tiles - Definitions, classification, characteristics and marking, 2nd edn. International Organization for Standardization, USA

ISO 14040 (2006) Environmental management -- Life cycle assessment -- Principles and framework, 2nd edn. International Organization for Standardization, Geneva

ISO 14044 (2006) Environmental management -- Life cycle assessment -- Requirements and guidelines. International Organization for Standardization, Geneva

ISO 7708 (1995) Air quality -- Particle size fraction definitions for health-related sampling. International Organization for Standardization

Joint Research Centre (2015) European Reference Life-Cycle Database. Version 3.2. http://eplca.jrc.ec.europa.eu/ELCD3/processList.xhtml. Accessed 16 May 2016

Martín-Márquez J, Rincón JM, Romero M (2010) Effect of microstructure on mechanical properties of porcelain stoneware. J Eur Ceram Soc 30:3063-3069. doi: 10.1016/j.jeurceramsoc.2010.07.015

Minne E, Crittenden JC (2015) Impact of maintenance on life cycle impact and cost assessment for residential flooring options. Int J Life Cycle Assess 20:36-45. doi: 10.1007/s11367-014-0809-Z 
Monfort E, Celades I, Gomar S, Rueda F, Martínez J (2011) Characterisation of acid pollutant emissions in ceramic tile manufacture. Bol Soc Esp Ceram Vidr 50(4):179-184

Monfort E, Mezquita A, Granel R, Vaquer E, Escrig A, Miralles A, Zaera V (2010) Analysis of energy consumption and carbon dioxide emissions in ceramic tile manufacture. Bol Soc Esp Ceram y Vidr. 49:303-310 (in Spanish)

Monfort E, Sanfélix V, Celades I, Gomar S, Martín F, Aceña B, Pascual A (2011b) Diffuse PM10 emission factors associated with dust abatement technologies in the ceramic industry. Atmos. Environ. 45 :7286-7292

Nicoletti GM, Notarnicola B, Tassielli G (2002) Comparative Life Cycle Assessment of flooring materials: ceramic versus marble tiles. J Clean Prod 10:283-296. doi: 10.1016/S09596526(01)00028-2

NSF USA. National Center for Sustainability Standards. http://www.nsf.org/services/byindustry/sustainability-environment/product-transparency-reports/environmental-productdeclaration. Accessed 11 Nov 2015

Oers L van, Guinée J (2016) The Abiotic Depletion Potential: Background, Updates, and Future. Resources 5:16

PE International L (2008) Database for Life Cycle Engineering, copyright, TM. 1992-2008 (Compilation. 4.4.142.1, DB version 4.131)

PE International (2008) GaBi Software-system. Compilation 4.131. http://www.gabisoftware.com/software/gabi-4/. Accessed 17 May 2016

Pini M, Ferrari AM, Gamberini R, Neri P, Rimini B (2014) Life cycle assessment of a large, thin ceramic tile with advantageous technological properties. Int J Life Cycle Assess 19:1567-1580. doi: 10.1007/s11367-014-0764-8

REE Red Eléctrica de España (2014) Informe del sistema eléctrico español 2013. http://www.ree.es/sites/defhttp://www.ree.es/sites/default/files/downloadable/inf_sis_elec_ree_2 013_v1.pdf. Accessed 19 Apr 2016 (in Spanish)

Ros-Dosdá T, Celades I, Monfort E, Moliner R, Zaera V, Benveniuste G, Cerdán C (2010) Impactos ambientales del ciclo de vida de las baldosas cerámicas. Análisis sectorial, identificación de estrategias de mejora y comunicación. In: X Congreso Nacional del Medio Ambiente, CONAMA. CONAMA10, Madrid, pp 1-20 (in Spanish)

Ruschi Mendes Saade M, G. da Silva M, Gomes V, et al (2014) Material eco-efficiency indicators for Brazilian buildings. Smart Sustain Built Environ 3:54-71. doi: 10.1108/SASBE-04-2013-0024

Sánchez E, García-Ten J, Sanz V, Moreno A (2010) Porcelain tile: Almost 30 years of steady scientific-technological evolution. Ceram Int 36:831-845. doi: 10.1016/j.ceramint.2009.11.016 
Souza DM de, Lafontaine M, Charron-Doucet F, et al (2015) Comparative Life Cycle Assessment of ceramic versus concrete roof tiles in the Brazilian context. J Clean Prod 89:165-173. doi: 10.1016/j.jclepro.2014.11.029

Thinkstep (2016) Database for Life Cycle Engineering Compilation 7.2.2.28 DB version 6.115

Thinkstep (2016) GaBi Software-system. Compilation 7.2.2.28. http://www.gabisoftware.com/software/. Accessed 17 May 2016

Thuring M. Spirinckx C. Debacke W. (2013) PCR-TBE. Product Category Rules for Environmental Product Declarations for Construction Clay Products. Mol, Belgium

Tikul N, Srichandr P (2010) Assessing the environmental impact of ceramic tile production in Thailand. J Ceram Soc Japan 118:887-894. doi: 10.2109/jcersj2.118.887

Wittstock B, Gantner J, Saunders KLT, Anderson J, Carter C, Gyetvai Z, Kreißig J, Lasvaux ABS, Bosdevigie B, Bazzana M, Schiopu N, Jayr E, Nibel S, Chevalier J, Fullana-i-Palmer P, Mundy CGJ-A ST-Wc (2012) EeBGuide Guidance Document Part B: BUILDINGS. Operational guidance for life cycle assessment studies of the Energy-Efficient Buildings Initiative 1-360 



\section{APORTACIÓN N² \\ STRATEGIC ENVIRONMENTAL COMMUNICATION TOOLS}

Teresa Ros-Dosdá1, Irina Celades ${ }^{1}$, Vicenta Sanfelix ${ }^{1}$, Salvador Gomar ${ }^{1}$, Eliseo Monfort ${ }^{1}$

Publicación: Actas XIII Congreso mundial de la calidad del azulejo y del pavimento cerámico (QUALICER 2014).

www.qualicer.org

Enviado en Septiembre 2013

Aceptado en Noviembre 2013

Publicado 17 de Febrero de 2014

ISBN-13 978-84-95931-25-2

${ }^{1}$ Instituto de Tecnología Cerámica (ITC). Asociación de Investigación de las Industrias Cerámicas (AICE). Universidad Jaume I. Avda Sos Baynat s/n, 12006, Castelló, Spain. 


\section{STRATEGIC ENVIRONMENTAL COMMUNICATION TOOLS}

T. Ros-Dosdá (1), I. Celades (1), V. Sanfelix (1), S. Gomar (1), E. Monfort (1)

(1) Instituto de Tecnología Cerámica (ITC). Asociación de Investigación de las Industrias Cerámicas (AICE)

Universitat Jaume I. Castellón. Spain 


\title{
STRATEGIC ENVIRONMENTAL COMMUNICATION TOOLS
}

\begin{abstract}
The Instituto de Tecnología Cerámica (ITC), pursuing its programme of actions aimed at transferring knowledge to the ceramic industry, presents the following work to facilitate the entry of ceramic coverings to markets demanding sustainable or green products and to national and international sustainable building certification programmes.
\end{abstract}

At present, for the industry in general and for the ceramic industry in particular, companies seeking to respond to green market demands face serious difficulties owing to the vast number of existing certificates, ecolabellings, and eco-features, which adversely affect the decision-taking process in this sense.

In this context, ITC has focused on developing, adapting, and fine-tuning a series of the most demanded eco-features, currently deemed the most complete for ceramic coverings.

All tools have been developed in the frame of the ISO environmental labelling standards. The following briefly cites each of these initiatives:

- Collaboration with the Tile Council of North America (TCNA) to implement in Spain the first sustainability mark for ceramic tiles, glass tiles, and tile installation materials, GREEN SQUARED®.

- Development of the computer tools CoverLEED and CoverBREEAM by ITC, so that companies can automatically generate the requested environmental requirements for $\angle E E D \otimes$ and $B R E E A M \otimes$ sustainable construction projects.

- Development and fine-tuning of the DAPCER tool, developed at the request of the Spanish Ceramic Tile Manufacturers' Association (ASCER), which enables Life Cycle Assessment Studies and Environmental Product Declarations to be rapidly and economically obtained.

\section{Introduction}

\subsection{Sustainable marketing context}

The environmental upgrading of construction products is a clear priority in European Union policies. This has materialised in the approval of legislation such as the Construction Products Regulation No. 305/2011 which, in Article 56 and Annex I, introduces a series of changes in this sense, and the establishment of specific objectives and supporting measures to increase the level of Public Green Procurement in all Member States with a view to achieving intelligent, sustainable, and integrating growth, including in the construction and related sectors [1] and [2]. 
In addition, voluntary initiatives under the auspices of the European Commission include the EU Sustainable Development Strategy (EU SDS), the Product Environmental Footprint (PEF), and Environmental Labelling to foster consumption and sustainable production through the Sustainable Consumption and Production and Sustainable Industrial Policy (SCP/SIP) Action Plan, among others [4].

In parallel fashion, private voluntary certification schemes are pursuing their own campaigns to foster sustainable production and consumption, schemes whose green criteria do not always parallel those defined by the European Union. Finally, there are the standardisation committees of scientific and business panels for establishing sectoral sustainability criteria for certifications.

The trend is therefore clear: big private organisations, and especially public organisations, prioritise products that present environmental upgrades or that are transparent in regard to the environmental information they provide.

The above has led to the emergence of 439 eco-labels and certificates in 197 countries, corresponding to 25 industrial sectors [3]. This has not only given rise to considerable confusion among manufacturers and consumers, but it also puts obstacles in the path of free trade.

Based on an analysis of the contents of the most widespread environmental labels and certificates, the communication tools presented in this paper may be deemed the most appropriate and versatile for ceramic coverings.

\subsection{Background}

The Spanish Ceramic Tile Manufacturers' Association (hereafter ASCER) seeks to implement strategic plans with rapid, lasting actions, based on the quest for differentiation arguments, not only to foster growth, but also to survive in markets where there are competitive inequalities. Part of these competitiveness arguments must be based on R\&D\&l advances developed in the cradle of the sector, and they therefore need a high-visibility component, as it has been shown that R\&D\&l efforts focused on contributing to sustainable development are not directly cost-effective if they are not displayed.

In its approach to this strategy of disseminating and communicating the environmental performance of the ceramic tile sector and of its products, ASCER has promoted several targeted national studies [7][14], with the collaboration of panels of experts both in industrial processes and in environmental analysis techniques, such as the Instituto de Tecnología Cerámica, the UNESCO Chair in Life Cycle and Climate Change, and its spin-off Cyclus Vitae Solutions.

The most noteworthy results of this collaboration have been the writing of a Life Cycle Assessment (hereafter LCA) on a sectoral scale [7][14] and the writing of the Product Category Rules (hereafter PCR) for ceramic coverings in the frame of the DAPc programme [8] and the AENOR GlobalEPD programme [9], as well as the active participation in writing the PCR being developed on a European level, promoted by the European Ceramic Industry Association CERAME-UNIE, so that companies can obtain Environmental Product Declarations (hereafter EPD). 
In this line, an important achievement of the above consortium has been the design and development of a computer tool called DAPCER for obtaining the LCA and EPD of ceramic coverings, with a considerable reduction in execution times and costs [6].

In addition, in view of the growing importance of building certification systems and their role as major drivers of the enhancement of the communication and environmental profile of construction materials, ITC has developed computer tools adaptable to the companies that manufacture construction materials for calculating, quantifying, and communicating environmental aspects in order to demonstrate a company's contribution in LEED $^{\circledR}$ [20] and BREEAM ${ }^{\circledR}$ [21]-certified sustainable buildings. The tools are called CoverLEED and CoverBREEAM by ITC.

In this same line, ITC has collaborated with the Tile Council of North America (TCNA) to implement in Spain the first sustainability mark exclusively envisaged for ceramic tiles, glass tiles, and tile installation materials, Green Squared ${ }^{\circledR}$ [18]. A multi-attribute label is involved that addresses environmental and social requirements, whose objective is to identify the ceramic materials that exhibit a more responsible profile and to make it easier for this type of product to access, simply, sustainable construction certification programmes and green procurement tenders in the USA [17].

\section{Objectives}

The work presented here had the following general objectives:

- To enhance the importance of technical and environmental communication both of the product and the process among the ceramic companies, as sales argument.

- To raise ceramic tile competitiveness with relation to other competing materials and markets.

- To promote improved environmental performance of ceramic tiles based on knowledge of the impacts.

In addition, the proposed tasks entailed the attainment of the following specific objectives aimed at enabling different eco-features to be efficiently and economically obtained:

- $\quad$ To promote the obtainment of Environmental Product Declarations (EPD) by the ceramic tile manufacturing companies associated in ASCER.

- To expedite the preparation of the documentation required to demonstrate compliance with specific materials requirements included in sustainable construction certificates.

- To facilitate the implementation in Spain of the only sustainability mark for ceramic tiles available in the market. 


\section{Methodology}

The steps followed in developing and adapting the three tools presented in this document may be summed up as follows:

- Identification of key parameters. These parameters were either directly provided by the companies or had a sectoral origin and/or came from commercial LCA databases.

- Tool design and programming. The tools DAPCER, CoverLEED, and CoverBREEAM by ITC consist of two types of computer media. One is a macro that operates when specific environmental data of the company and sectoral data are entered, while the second is a calculation engine that obtains the environmental information to be communicated.

- Development of the documentation. When the tools had been programmed, they generated valid documentation for the Environmental Product Declaration programmes and for the Sustainable Construction Certificates.

- Verification of the generated information. The conformity of the calculation engines and of the documentation with the reference standards was verified in each case, as was the traceability of the information provided by the company.

\subsection{DAPCER}

At the request of ASCER, ITC, together with the UNESCO Chair in Life Cycle and Climate Change and its spin-off Cyclus Vitae Solutions, has developed a computer tool that is able rapidly and economically to obtain Life Cycle Assessment studies and Environmental Product Declarations for ceramic tiles [6]. This project was developed thanks to funding by IMPIVA through the II Sectoral Competitiveness Plans 2011 Action 4: Development of Markets (European Regional Development Fund, ERDF).

\section{Writing of the Product Category Rules}

The EPD are voluntary declarations based on LCA studies, which allow dissemination of quantified environmental information on the life cycle of a product. The Product Category Rules (PCR) are a set of guidelines that steer the development of the EPD and the corresponding LCA for a product category. In addition, the PCR enable the EPD made by different manufacturers to be compared with each other [7].

The development of these PCR was based on the sectoral study of LCA of ceramic tiles ([6] and [14]), and the international requirements set out in standards UNE-EN 15804:2012, UNE EN ISO 14025:2010, and ISO 21930:2010, as well as other existing PCR, were followed.

The PCR for ceramic coverings in this project were approved by the Spanish Association for Standardisation and Certification (AENOR) on 6 September 2013, after submission to public review for 1 month by the manufacturing companies and business associations, and they have a validity of 5 years. 
The significant aspects generally subject to debate were as follows: (i) grouping of several products under a single EPD, (ii) definition of the Functional Unit, and (iii) life cycle stages and corresponding information modules to be included.

If a company wished to include several products in the same EPD of the AENOR GlobalEPD programme, in the group and expression of results, it was considered that the same classification criteria should be applied as in standard UNE EN 14411:2012 (ISO 13006): that is, type of forming and water absorption. The results should be expressed by means of a production-weighted average, this value being delimited by the environmental data on the products having the greatest and the smallest environmental impact.

With relation to the life cycle stages and corresponding information modules, standard UNE EN 15804:2012 on the basic Product Category Rules for construction products [10] establishes that the EPD can be either cradle-to-gate (modules A1-A3) or cradle-to-grave, it being possible optionally to include the remaining life cycle modules.

Module D, stating the benefits and loads beyond the system boundary, can also be included.

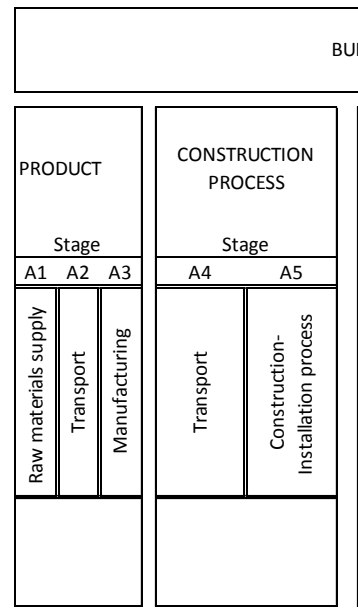

BUILDING LIFE CYCLE INFORMATION

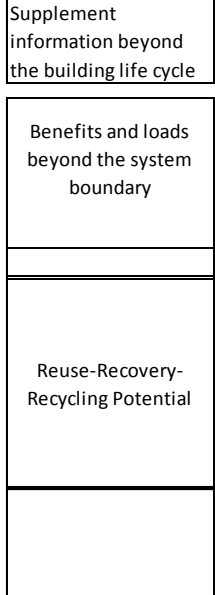

Figure 1 Types of EPD based on the life cycle stages for roofs, and life cycle stages and modules for building assessment [10]

In this case, the sectoral panel decided not to provide the possibility of developing the cradle-togate alternative with options to select the modules to be declared, thus avoiding inconsistencies between ASCER associates; the modules of use, repair, replacement, refurbishment, and deconstruction and demolition are not relevant from an environmental viewpoint.

In relation to the definition of the Functional Unit, this must be clearly defined and shall be measurable and appropriate for the product(s) at issue and for the product life cycle [12][13]. In the case of ceramic tiles, this is an issue of debate because the versatility of ceramic tiles allows tiles, 
particularly those with lower water absorption, to be installed in floors or walls, indoors or outdoors, and in different types of building constructions, such as homes, hospitals, shops, etc.

The Functional Unit must refer to the entire life cycle, specifying the specific function of the product, the surface to be covered, and the service life span. Therefore, a valid example would be: "1 $\mathrm{m}^{2}$ covering of a (floor) surface inside a home for 50 years, considering a geographical and technological context of Spain in the year 2012".

The sectoral panel, again avoiding inconsistencies among the manufacturers, decided that, when the EPD scope was cradle-to-grave, at least the following maintenance scenario should be declared:

- Tiles for wall covering: internal residential use. Washing frequency twice/year

- Tiles for floor covering: use in residential flooring with moderate pedestrian traffic. Washing frequency once/week.

The manufacturer shall establish one or more scenarios to assess cleaning products, disinfectants and/or water consumption as a function of the washing frequency throughout the tile service life.

\section{Improvement of LCA model representativeness and adaptation to the PCR}

On the other hand, the representativeness of the sectoral LCA model made in the LCA software, $\mathrm{GaBi}$ [15], was also improved in order to encompass all types of ceramic coverings and all technological scenarios present in the Spanish ceramic tile sector. In addition, the most significant aspects were identified, a sensitivity and scenarios analysis being performed to define the data that needed to be provided by the companies to obtain the EPD.

The most important changes were the updating and incorporation of certain flows and processes to improve the flexibility of the flow charts developed with the GaBi software [15 and to enhance the model's exhaustiveness by the parameterisation of indicators that had previously been considered fixed.

In addition, it was also necessary to adapt this model to the requirements of the PCR for ceramic coverings in the AENOR GlobalEPD programme.

In regard to the analyses performed to define the significant parameters, the results highlighted the importance of tile mass and energy, as well as the presence or absence of optional processes such as polishing. Consequently, the precision of these parameters was critical to the precision of the results.

\section{Design of the DAPCER tool}

Once these tasks had been performed, the computer tool was designed and programmed. Entering the characteristic values of each product and company thus enabled a LCA report and an EPD draft to be simply and efficiently obtained.

The steps were as follows: 
a. Preparation of a questionnaire for data collection from the manufacturers and a calculation matrix to be collated using individually drawn up mass and energy balances and to allocate loads.

b. Design of the calculation models in the LCA software as a function of the decision taken by the company regarding the "cradle-to-gate" or "cradle-to-grave" scope, which were then "locked" to assure consistency and compliance with the requirements of the reference standards.

c. Development of LCA and draft EPD types of reports according to the possible production alternatives for ceramic tiles made in Spain.

d. Programming of the tool with the LCA software.

\section{Tool validation and EPD verification}

Fourteen companies that manufacture different ceramic tiles, using different process technologies, participated in the tool validation and verification process as pilot trials; 12 of the companies decided to verify the EPD, these being the first in the AENOR GlobalEPD programme [9].

The pilot trials to validate the EPD tool were aimed at:

- testing the tool

- $\quad$ obtaining reports on the LCA of the selected products and the EPD.

The verification was carried out by a team of verifiers appointed by the verifying organisation. The steps in the EPD verifications were as follows:

1. Sending the LCA and EPD studies of each company that had chosen to obtain the EPD to the certifying organisation.

2. Verification of conformity of the EPD and the LCA study with the general AENOR PCR and the PCR for ceramic coverings.

3. Verification of the conformity of the LCA study and model with standards UNE EN ISO 14025, UNE EN ISO 14040, and UNE EN ISO 14044.

4. Verification of the acquisition and treatment methodology of all data in the LCA study and the EPD: coverage, precision, integrity, representativeness, consistency, reproducibility, sources, and data uncertainty.

The part of the process corresponding to the verification of the LCA study and the model, as well as the inventory analysis, was conducted by technicians from ITC and Cyclus Vitae Solutions. Verification of primary data acquisition and traceability was performed at the tile manufacturing company facilities.

The verification results were documented in a report that, together with the LCA study and EPD draft, was submitted to a committee for approval and publication of the EPD [9]. 


\subsection{CoverLEED and CoverBREEAM by ITC}

CoverLEED and CoverBREEAM are tools that are simple to use, which can be adapted to the company and integrated into the company's management computer system, and that allow appropriate documentation to be generated at any time to respond to demands by clients or other parties interested in sustainable construction.

The purpose of the tools is to calculate and demonstrate compliance with credits/criteria demanded for materials in the LEED ${ }^{\circledR}$ (Leadership in Energy \& Environmental Design) [20] and BREEAM $^{\circledast}[21]$ certification systems for sustainable buildings.

\section{Identification of criteria and calculation methodology}

The criteria and calculation methodology needed to demonstrate the contribution of coverings to the following building certification systems were identified:

- $\quad$ LEED ${ }^{\circledR}$ v03, for the 9 certification schemes or Ranking Systems recognised by LEED ${ }^{\circledR}$ in the 2009 version.

- $\quad$ LEED ${ }^{\circledR}$ v04 for the 21 certification schemes included in the LEED version approved in the last quarter of 2013

- $\quad$ UK BREEAM ${ }^{\circledR}$ for the 22 certification schemes that it recognises.

Note that LEED $^{\circledR}$ and BREEAM ${ }^{\circledR}$ are both designed to certify buildings and not products.

The LEED ${ }^{\circledR}$ v4 version introduces new demands for materials and products. The changes are mainly in the Building Product Disclosure and Optimization criteria, which now include the previously individual credits for materials containing recycled and/or regional materials.

Some of the main changes are as follows:

- MR Credit 1 - Building Life-Impact reduction

- $\quad$ MR Credit 2 - Building Product Disclosure and Optimization - environmental product declarations.

- $\quad$ MR Credit 3 - Building Product Disclosure and Optimization - sourcing of raw materials

- MR Credit 4 - Building Product Disclosure and Optimization - material ingredients

Most of these credits can be demonstrated from Life Cycle Assessment studies and Environmental Product Declarations.

\section{Development of the tools CoverLEED and CoverBREEAM by ITC}

Once the necessary company information had been compiled, either from the computer management system or manually, the appropriate calculations were made to demonstrate compliance with the criteria identified as applicable. 
The results of these calculations were compiled in a dossier of data sheets, each of which corresponded to a criterion identified in the previous section, so that the company could use them in the way that best suited it.

The company could thus decide how to group its products, i.e. perform the calculations for each model or for each series or collection.

Each data sheet also indicated for which certification scheme (or ranking system) the described characteristic was valid and the weight that it had in each requirement in the final building score.

In addition, this tool was accompanied with a practical guide for companies that manufacture construction materials, aimed at explaining how the construction materials work in the certified building, how scoring is performed, and the basic guidelines on environmental communication, standards and regulations, and related legislation.

\subsection{Green Squared®}

Another initiative promoted by ITC is the implementation of GREEN SQUARED ${ }^{\circledR}$ in Spain.

This is the first sustainability mark exclusively for ceramic tiles and tile installation materials. The mark enables those products to be identified that have a smaller impact on the environment and on society and that can, therefore, be candidates for sustainable construction projects [17].

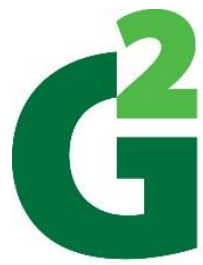

GREEN SQUARED ${ }^{\circledR}[18]$ was developed by the Tile Council of North America (TCNA), in close collaboration with the North American ceramic tile industry, in response to the needs of these products and installation materials to highlight their environmental features compared with those of their immediate competitors (carpets, laminates, etc.) in the green procurement and sustainable construction scenario.

The scope of the mark includes ceramic tiles and glass tiles, as well as cementitious adhesive, grouts, resins, insulation sheets, panel installation materials, etc.

GREEN SQUARED ${ }^{\circledR}$ was developed on a technical level as a Type I eco-label (i.e. with a voluntary, certifiable character (ISO 14024)). Consequently, a specific standard was published compiling all the requirements and specifications that could be demanded of sustainable ceramic tiles. That standard was adopted in $\mathbf{2 0 1 1}$ by the American National Standards Institute as an ANSI standard entitled: American National Standard Specifications For Sustainable Ceramic Tiles, Glass Tiles And Tile Installation Materials (ANSI A138.1-2011) [19].

Based on standard ANSI A138.1-2011, manufacturers of products detailed in this standard must demonstrate compliance with the requirements laid down in the standard in order to use the GREEN SQUARED ${ }^{\circledR}$ mark and logos. 
The system is administered by TCNA and, in addition, enjoys the collaboration of three of the world's top certifiers of product sustainability: NSF International, SCS Global Services, and UL Environment.

\section{Content of the standard}

The standard has a multi-attribute approach: that is, it is not solely focused on one environmental aspect, such as perhaps the use of recycled material or $\mathrm{CO}_{2}$ emissions, but goes beyond this and seeks to cover all sustainability vectors affected by the fabrication of tiles and tile installation materials. The standard has thus been divided into five different categories (see Figure 2).

The requirements laid down in the standard may be divided into compulsory requirements and voluntary requirements. Depending on the type of product, the number of requirements to be met differs.

Figure 2 shows the breakdown of the sustainability criteria set out in ANSI A138.1 according to the categories into which the credits are divided.

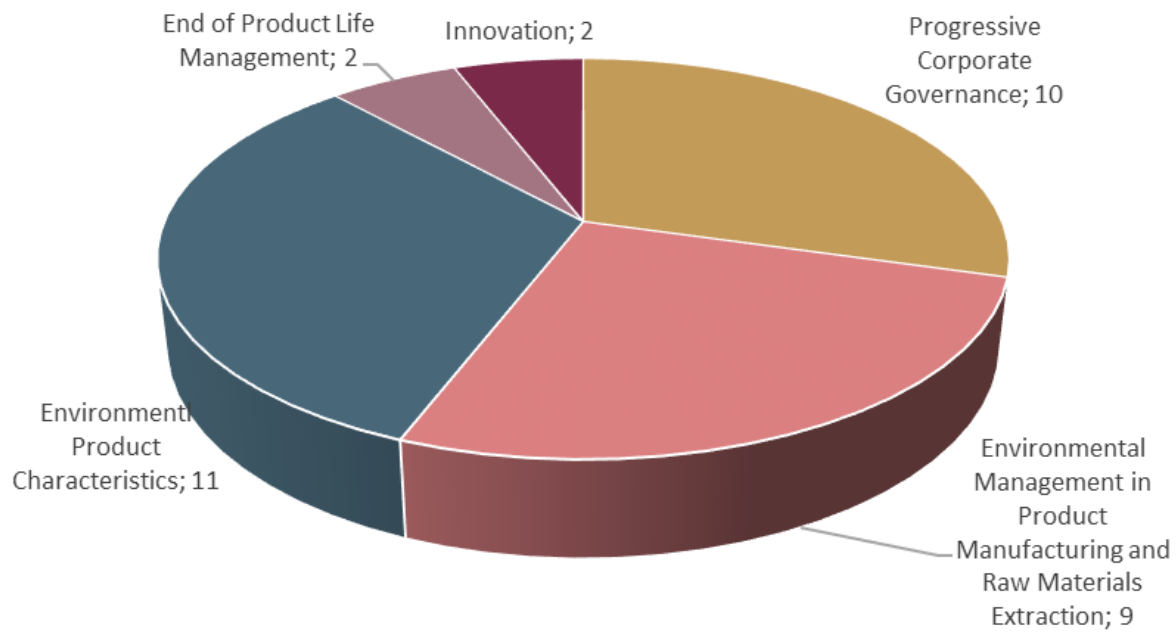

Figure 2 Breakdown of GREEN SQUARED sustainability criteria (ANSI A138.1) [19]

\section{Green Squared in Spain}

The Instituto de Tecnología Cerámica has collaborated closely with TCNA to introduce the GREEN SQUARED ${ }^{\circledR}$ mark in Spain. The requirements of ANSI A138.1 have been adapted for this purpose to the European and Spanish context and normative frame. 


\section{Conclusions}

The main conclusions drawn from the developed methodology and the obtained results are as follows:

- A tool has been developed that allows Environmental Product Declarations of ceramic coverings and Self-declared Environmental Claims for products to be simply and efficiently obtained, decreasing execution times and costs.

- The obtainment of these eco-features will help enhance the competitiveness of ceramic tile and position it with relation to other competing markets and materials that have ecofeatures, particularly in green procurement and sustainable construction scenarios.

- The methodologies developed in this study could be used in other product categories, this being simpler for sectors that are technologically mature and homogeneous.

- The tools provide valuable information for raising the environmental profile of ceramic tile, more precise information for comparing tiles with alternative products, and useful information for construction projects.

\section{Acknowledgements}

The DAPCER tool has been developed thanks to funding from the Institute of Small and Mediumsized Enterprise of the Valencia Region (IMPIVA), Spain, through the II Sectoral Competitiveness Plans 2011 Action 4: Development of Markets (European Regional Development Fund (ERDF) IMPCDB/2011/28.

\section{References}

[1] IHOBE. Manual práctico de compra y contratación pública verde: modelos y ejemplos para su implantación por la administración pública vasca. Bilbao: IHOBE, 2010.

[2] European Commission. Buying green. A handbook on green public procurement. 2nd ed. Luxembourg: Publications Office of the European Union, 2011, p. 56.

[3] Ecolabelindex http://www.ecolabelindex.com/ (last visit 23/09/2013)

[4] Communication from the Commission to the European Parliament and the Council Building the Single Market for Green Products: Facilitating better information on the environmental performance of products and organisations. /COM/2013/0196 final /

[5] Monfort Gimeno, E. ¿Que papel juegan las baldosas cerámicas en la compra verde y la edificación sostenible?. En: Qualicer 2012: XII Foro Global del Recubrimiento Cerámico. Castellón: Cámara Oficial de Comercio, Industria y Navegación, 2012. Castellón 13 - 14 febrero 2012 
[6] Ros-Dosdá, T.; Benveniste, G.; Celades, I.; Zaera, V.; Gazulla, M.F.; Sanfelix, V. Herramienta simplificada para la obtención de marcados ecológicos. [Poster] Qualicer 2012: XII Foro Global del Recubrimiento Cerámico. Castellón: Cámara Oficial de Comercio, Industria y Navegación, 2012. Castellón 13 - 14 febrero 2012

[7] Benveniste, G.; Gazulla, C.; Fullana, P.; Celades, I.; Ros, T.; Zaera. V.; Godes, B. Análisis de ciclo de vida y reglas de categoría de producto en la construcción. El caso de las baldosas cerámicas. Informes de la Construcción, 63 (522), 71-81, 2011

[8] Environmental product declarations for construction DAPc $®$ http://csostenible.net/sistema_dapc/index.php/dapc/es/inicio (last visit 24/09/2013)

[9] AENOR GlobalEPD programme http://www.aenor.es/aenor/certificacion/mambiente/globalepd.asp (last visit 25/09/2013)

[10] UNE EN 15804:2012 Sostenibilidad en la construcción. Declaraciones Ambientales de Producto. Reglas de Categoría de Productos básicas para productos de construcción.

[11] ISO 14025, 2006. Environmental labels and declarations -- Type III environmental declarations -- Principles and procedures, 1st ed. International Organization for Standardization.

[12] ISO 14040, 2006. Environmental management -- Life cycle assessment -- Principles and framework, 2nd ed. International Organization for Standardization, Geneva.

[13] ISO 14044, 2006. Environmental management -- Life cycle assessment -- Requirements and guidelines. International Organization for Standardization, Geneva.

[14] Ros, T.; Celades, I.; Monfort, E.; Moliner, R.; Zaera, V.; Benveniste, G.; Cerdán, C.; Fullana i Palmer, P. Impactos ambientales del ciclo de vida de las baldosas cerámicas. Análisis sectorial, identificación de estrategias de mejora y comunicación. In: CONAMA10 comunicaciones técnicas [Internet file]: X Congreso Nacional del Medio Ambiente. Madrid: Fundación Conama, 2011.

[15] PE International. GaBi software:

http://www.pe-international.com/international/software/ (last visit 23/09/2013)

[16] Green Building Council España: http://www.gbce.es/ (last visit 23/09/2013)

[17] Griese, B. Standards Development \& Green Initiative Manager, Tile Council of North America-United States, Canada, and Mexico. Qualicer 2012: XIlth World Congress on Ceramic Tile Quality. Castellón: Cámara Oficial de Comercio, Industria y Navegación, 2012. Castellón.

[18] Green Squared http://greensquaredcertified.com/ (last visit 23/09/2013)

[19] ANSI A138.1, 2012. Green Squared American National Standard Specifications For Sustainable Ceramic Tiles, Glass Tiles, And Tile Installation Materials. merican National Standards Institute.

[20] USGBC, 2013. US Green Building Council. Leadership in Energy \& Environmental Design https://new.usgbc.org/leed-v3 (last visit 23/09/2013).

[21] BREEAM, 2013. Building Research Establishment Environmental Assessment Methodology [https://www.breeam.com/ (last visit 23/09/2013). 


\section{APORTACIÓN Nº 3}

\section{ENVIRONMENTAL COMPARISON OF INDOOR FLOOR COVERINGS}

Teresa Ros-Dosdá $^{1,2}$, Irina Celades ${ }^{1}$, Laura Vilalta ${ }^{1}$, Pere Fullana-i-Palmer², Eliseo Monfort ${ }^{1}$

\section{Science of the Total Environment}

Volume 693, 133519

Enviado el 28 de Febrero de 2019

Artículo revisado el 17 de Julio de 2019

Artículo aceptado el 20 de Julio de 2019

DOI: 10.1016/j.scitotenv.2019.07.325

Factor de impacto (2018): 5,589

SCImago Journal Rank (SRJ): 1,536

${ }^{1}$ Instituto de Tecnología Cerámica (ITC). Asociación de Investigación de las Industrias Cerámicas (AICE). Universidad Jaume I. Avda Sos Baynat s/n, 12006, Castelló, Spain.

2 UNESCO Chair in Life Cycle and Climate Change (ESCI-UPF). Passeig Pujades 1, 08003 Barcelona, Spain. 
Science of the Total Environment 693 (2019) 133519

Contents lists available at ScienceDirect

Science of the Total Environment

ELSEVIER

journal homepage: www.elsevier.com/locate/scitotenv

Environmental comparison of indoor floor coverings

Teresa Ros-Dosdá a,b,*, Irina Celades ${ }^{\mathrm{a}}$, Laura Vilalta ${ }^{\mathrm{a}}$, Pere Fullana-i-Palmer ${ }^{\mathrm{b}}$, Eliseo Monfort ${ }^{\mathrm{a}}$

a Instituto de Tecnología Cerámica (ITC), Asociación de Investigación de las Industrias Cerámicas (AICE), Universitat Jaume I, Avda. Sos Baynat s/n, 12006 Castellón, Spain ${ }^{\mathrm{b}}$ UNESCO Chair in Life Cycle and Climate Change (ESC-UPF), Passeig Pujades 1, 08003 Barcelona, Spain 


\section{ENVIRONMENTAL COMPARISON OF INDOOR FLOOR COVERINGS}

\section{Graphical abstract}

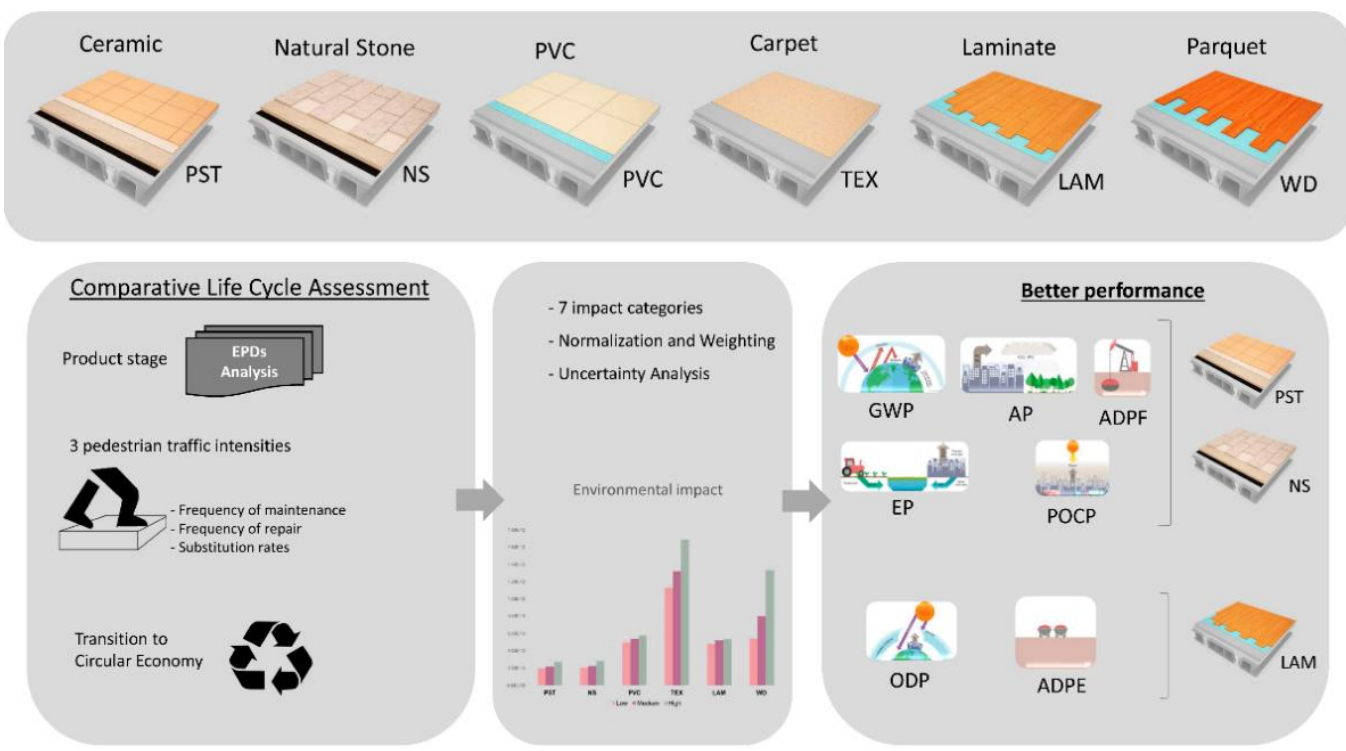

\section{Abstract}

Appropriate selection of construction materials plays a major role in a building's sustainable profile. The study sets out a comparative life cycle assessment of indoor flooring systems of different nature. The flooring systems consisted of coverings and, where required, bonding material and/or impact soundproofing material. The following coverings were assessed: inorganic (natural stone and ceramic tiles), polymer (carpeting and PVC), and wood-based (laminate and parquet) coverings. The life cycle assessment scope was defined cradle to cradle, i.e. product stage, transport to the construction site, installation of all construction elements, use, and valorisation by recycling, as end-of-life transition scenario towards a circular economy. In the use stage, three scenarios were defined as a function of pedestrian traffic intensity, which determined maintenance, repair, and replacement operations and frequencies. The environmental impacts of the coverings product stage were taken from previously assessed and selected Environmental Product Declarations (EPDs), as these are standardised public documents devised to provide environmental life cycle information. The method adopted in the study suggests that, though the use of EPDs as information source is interesting, erroneous conclusions may be drawn if the EPDs are not comparable and/or if the comparison is not made in the building context. The results 
indicate that the flooring systems with inorganic coverings performed best in the global warming, acidification, eutrophication, photochemical ozone creation, and abiotic depletion for fossil resources impact categories, whereas laminates performed best in the abiotic depletion for nonfossil resources and ozone layer depletion impact categories. The carpet flooring system performed worst in every impact category except photochemical ozone creation potential.

\section{Key words:}

Floor Systems; Life Cycle Assessment; Environmental Product Declaration

\section{Highlights}

- Six indoor flooring systems were compared through Life Cycle Assessment, considering three pedestrian traffic intensity scenarios in the use stage.

- 149 EPDs were analysed as starting point in the comparative study.

- The importance of considering the whole life cycle vs. just the product stage was evidenced on comparing different alternative construction solutions.

- Cradle-to-cradle scope was considered, based on a transition to the circular economy.

- Floor systems with inorganic coverings (natural stone and ceramics) performed best in most' of the environmental impact categories studied.

\section{List of abbreviations}

ADPE: abiotic depletion potential for non-fossil resources

ADPF: abiotic depletion potential for fossil resources

AP: acidification potential

EP: eutrophication potential

EPD: environmental product declaration

FU: functional unit

GWP: global warming potential (100 years)

LAM: laminate

LCA: life cycle assessment

MSL: material service life 
NS: natural stone

ODP: ozone layer depletion potential (steady state)

PA: polyamide

POCP: photochemical ozone creation potential

PST: ceramic tile, mainly porcelain stoneware tile

PVC: polyvinyl chloride

RSP: reference study period

TEX: synthetic carpet

VOC: volatile organic compound

WD: multilayer and solid parquet

\section{Introduction}

The construction sector is a major materials consumer. In fact, the European Union deems it a key sector in the attainment of the objectives in the Roadmap to a Resource Efficient Europe (RERM) (COM/2011/0571 final, 2011) and the EU Action Plan for the Circular Economy (COM/2015/0614 final, 2015), as about $50 \%$ of materials extraction, $30 \%$ of water consumption, and $30 \%$ of waste generation are associated with this sector (COM/2014/445 final, 2014). In addition, buildings account for most of the total final energy consumption in the EU (42\%) (COM/2007/0860 final), the use stage being the most noteworthy regarding energy consumption (Cuéllar-Franca and Azapagic, 2012). A literature review carried out by Iribarren et al., 2015, confirmed the enormous efforts being made to reduce the impacts of this stage, albeit often at the expense of using energyintensive materials, thus counterbalancing energy consumption. In this sense, Asif et al., 2007, identified cement, wood, and ceramic tiles as the three major energy expensive materials. Consequently, appropriate selection of construction materials plays a major role in a building's environmental profile (Akadiri, 2015; COM/2014/445 final, 2014; Häfliger et al., 2017; Zabalza et al., 2011).

Life Cycle Assessment ( $\mathrm{LCA}$ ) is unquestionably the most widely used methodology for evaluating product environmental impacts, particularly those of construction products (Basbagill et al., 2013; Iribarren et al., 2015; Zabalza Bribián et al., 2009). LCA applications in this sector include sustainability assessments of materials (Balaguera et al., 2018), construction systems (Albertí et al., 2019), building designs (Assiego de Larriva et al., 2014; Häfliger et al., 2017; Khasreen et al., 2009; Zabalza Bribián et al., 2009); as well as of cities (Albertí et al., 2017); innovation and ecodesign (Chang et al., 2014; Fazeni et al., 2014; Ortiz et al., 2009; Puig et al., 2017); and marketing, for example, through Environmental Product Declarations (EPDs) (Gazulla Santos, 2012).

In the particular case of floor covering materials, the application of LCA has consistently drawn attention in the literature (Abeysundara et al., 2009; Almeida et al., 2016a; Benveniste et al., 2011; 
Bovea et al., 2010; Gazi et al., 2012; Günther and Langowski, 1997; Ibáñez-Forés et al., 2011; Islam et al., 2015; Jönsson et al., 1997; Jönsson, 1999; Minne and Crittenden, 2015; Nebel et al., 2006; Nicoletti et al., 2002; Paulsen, 1999; Pini et al., 2014; Potting and Blok, 1995; Reza et al., 2011; Ros-Dosdá et al., 2018a, 2018b; Tikul and Srichandr, 2010; Traverso et al., 2010). Appendix 1 presents a synoptic analysis of these literature references based on the coverings, applied methods and impacts considered, as well as on the scope and boundaries of the system and functional or declared unit. Analysis of this information allows important differences to be noted, which prevent direct comparison of the results for conclusions to be drawn. Generally speaking, certain coincidences were identified, in which it was concluded that linoleum was the most interesting flooring, followed by vinyl, from an environmental viewpoint, when soft and/or resilient floorings were compared (Jönsson et al., 1997; Minne and Crittenden, 2015; Potting and Blok, 1995). However, hardly any comparative studies were found on hard floor coverings (Nicoletti et al., 2002) and no individual or comparative LCA studies were found that included laminate floorings. Finally, it may be noted that none of these studies addressed the integration of the coverings into the construction system as a whole, and only a minority considered the use stage.

On the other hand, drawing up LCAs for EPDs has mainly been driven by the increasing demand for sustainable construction certificates (Anand and Amor, 2017; Ganassali et al., 2018; Gelowitz and McArthur, 2016; Monfort, 2012) and by approval of the construction materials regulation (Regulation (EU) No 305/ 2011, 2011), which insists on using EPDs where available, for sustainability assessment in the efficient use of construction resources and impacts. In fact, EPDs are a basic and very valuable resource in the early stages of building design (Anand and Amor, 2017; Passer et al., 2015), as these are often the only information architects and planners have to compare and decide on different construction and/or component options (Bovea et al., 2014; IBUEPD programme).

However, certain precautions need to be taken into account in performing comparative analyses. Such use requires understanding EPDs contents, limitations, and the underpinning PCRs to be able to interpret EPDs properly (Gazulla Santos, 2012) and draw accurate conclusions. In the case of comparisons, these must be made considering the functionality and environmental performance either on a whole building level or on lower levels, for example for construction systems, assembled systems, components or products (construction solutions), assuring a series of principles that ensure objectivity and transparency (EN 15804+A1, 2013).

Thanks to the publication of the Basic Product Category Rules for Construction Products (EN $15804+A 1,2013)$, the European EPDs for floor coverings are relatively homogeneous with regard to the stages that must be declared (A1-A3). However, in subsequent stages, inconsistencies are to be found among EPDs of the same category with different and even with the same PCRs. This is because these stages contain more assumptions and, at present, PCRs do not always establish reference scenarios to avoid inconsistencies among EPDs of the same program (e.g. default values in waste management, bonding materials, and maintenance operations), besides the differences in the verification process of the different programs (Gelowitz and McArthur, 2017; Hunsager et al., 2014; Minkov et al., 2015). For example, the PCRs for ceramic coverings in the GlobalEPD (GlobalEPD, 2018) and IBU-EDP (Institut Bauen und Umwelt e.V., 2017a) programs are very 
detailed in these stages, whereas the PCRs for carpeting in IBU-EPD (Institut Bauen und Umwelt e.V., 2017b) allow the declarer greater freedom.

This study sets out a comparative analysis of six floor coverings, together with the respective construction system that contains each. The study was conducted on six materials deemed most representative of those used as indoor floor coverings (Table 1).

The industry and business stakeholders request information to compare construction products to make decisions and also to know the positioning of their products against the competitors, from an environmental point of view. Considering that there are no current publications that: i) include the most common types of coverings in Spain and Europe; ii) the existing publications on environmental impacts of the life cycle of coverings do not allow comparison among them; and iii) there is a lack of studies that are supported by objective, complete and available information for companies and industry (i.e. EPDs), the present work is proposed.

Table 1 Production in 2016 of the studied floor coverings.

\begin{tabular}{|l|c|c|c|}
\hline \multicolumn{1}{|c|}{ Covering } & World & Europe & US(6) \\
\hline Ceramic tile(1) & 13056.0 & 1304.0 & 321 \\
\hline Textile floor covering(2) & 12095.0 & 848.0 & 1150 \\
\hline Natural Stone(3) & 514.3 & 87.4 & 33.5 \\
\hline Laminate ${ }^{(4)}$ & 477.0 & 371.0 & 104 \\
\hline Parquet(5) & n.a. & 80.4 & 163 \\
\hline PVC & n.a. & n.a. & 447 \\
\hline n.a. Not available & \multicolumn{3}{|c|}{} \\
\hline $\begin{array}{l}\text { Sources of information: } \\
\text { World and European data: Baraldi, 2017; European Carpet and Rug Association (ECRA), 2018; Carlo Montani, } 2018 ; \\
\text { European Producers of Laminate Flooring (EPLF), 2018; European Federation of the Parquet Industry (FEP), 2017 } \\
\text { US data: Floor covering weekly, 2018 }\end{array}$ \\
\hline
\end{tabular}

In this context, the main purpose of this study was to perform a comparative LCA study of flooring systems with a cradle-to-cradle scope, using the information contained in the relevant EPDs (as these are public documents issued by the industry, which are verified and updated ( $<5$ years)) to assess the product stage (A1-A3), modelling the other life cycle stages in the same building context in terms of three scenarios in the use stage (maintenance, repair, and replacement operations) as a function of different pedestrian traffic intensities, and applying a progressive transition towards a circular economy, both in the use stage and in the end-of-life stage. 


\section{Method}

\subsection{Objective and scope}

The study sought to quantify the environmental impact of six major flooring systems (FSs) installed indoors throughout their life cycles, starting out from the information contained in their EPDs.

To do so, an LCA was performed of each FS with a cradle-to-cradle scope, also known as an endof-life recycling approach (or avoided burden approach) (Frischknecht, 2010; Häfliger et al., 2017; Silvestre et al., 2014), modelled within a building use context under the same system boundaries, scenarios, scope, and considerations for each transport, installation, use and end-of-life stage, in order to allow subsequent comparison, observing the requirements set in standard ISO 14025, 2006, Section 6.7.2.

The LCAs were carried out in accordance with the international standards (ISO 14040, 2006; ISO 14044, 2006) and the core construction PCRs (EN 15804+A1, 2013). The standards on sustainability of construction works (EN 15978, 2011) were also taken into account. The LCA software GaBi 8 (Thinkstep AG, 2018a) and related databases (Thinkstep AG, 2018b), as well as carefully selected EPDs of coverings, were used in the environmental assessment.

A Reference Study Period (RSP) of 50 years was used. The Functional Unit was defined as the quantity of construction elements required to build $1 \mathrm{~m} 2$ of indoor flooring system in Spain intended to last for 50 years. The study considered the useful life of the coatings and the number of installations needed to cover the RSL, rounded up to the next integer value, as shown in Table 2.

\subsection{Life cycle inventory analysis}

\subsubsection{Studied flooring system compositions}

Types of materials and their arrangement in construction systems vary according to types of buildings and countries (IEE Project TABULA, 2012; Ortiz et al., 2009). To define the FSs for this study, the construction solutions that contained them were first defined, using the following Spanish documents and regulations as references: Código Técnico de la Edificación (the Technical Building Code) (Ministerio de Fomento de España, 2011); Catálogo de Elementos constructivos (Catalogue of Construction Elements) (IETcC-CSIC, 2011); and Documento Básico de protección frente al ruido (Basic Document on Protection against Noise) (Ministerio de Fomento de España, 2009). The studied construction system of horizontal partitions was a Floating floor screed of cement mortar, as the authors deemed this to be the most generic alternative described in these documents. The system involved a floor made up of a layer of about 5-cm-thick cement mortar installed on a sheet of impact sound insulation material, the screed being covered with a finish. A schematic illustration of this type of floor is shown in Fig. 1. 


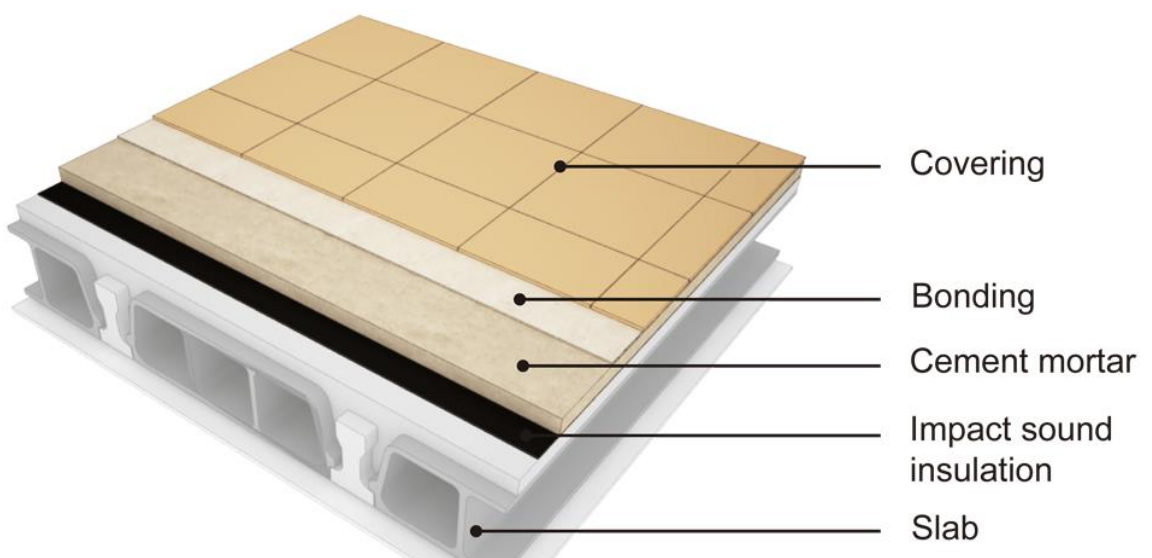

Fig. 1 Horizontal partition systems (Source: own figure from IETcC-CSIC, 2011)

Fig.1 illustrates the five layers making up a construction solution of this type, namely covering, bonding material, cement mortar screed, impact sound insulation, and slab. In this comparative study, the common components in the construction solutions, i.e. the cementitious mortar and slab, were excluded. In this study, the remaining system is designated the flooring system (FS).

The studied FSs are detailed in Table 2. The coverings properties regarding product mass, thickness, varieties and Material Service Life (MSL) were obtained from the selected EPDs (appendix 2); the arrangement and mass of the materials in the different intermediate layers were drawn from CYPE Ingenieros, 2018, databases. To facilitate discussion of the results, the coverings were divided into three groups, based on their nature: inorganic (ceramic tiles and natural stone), polymer (carpeting and PVC), and wood-based (parquet and laminate) coverings. 


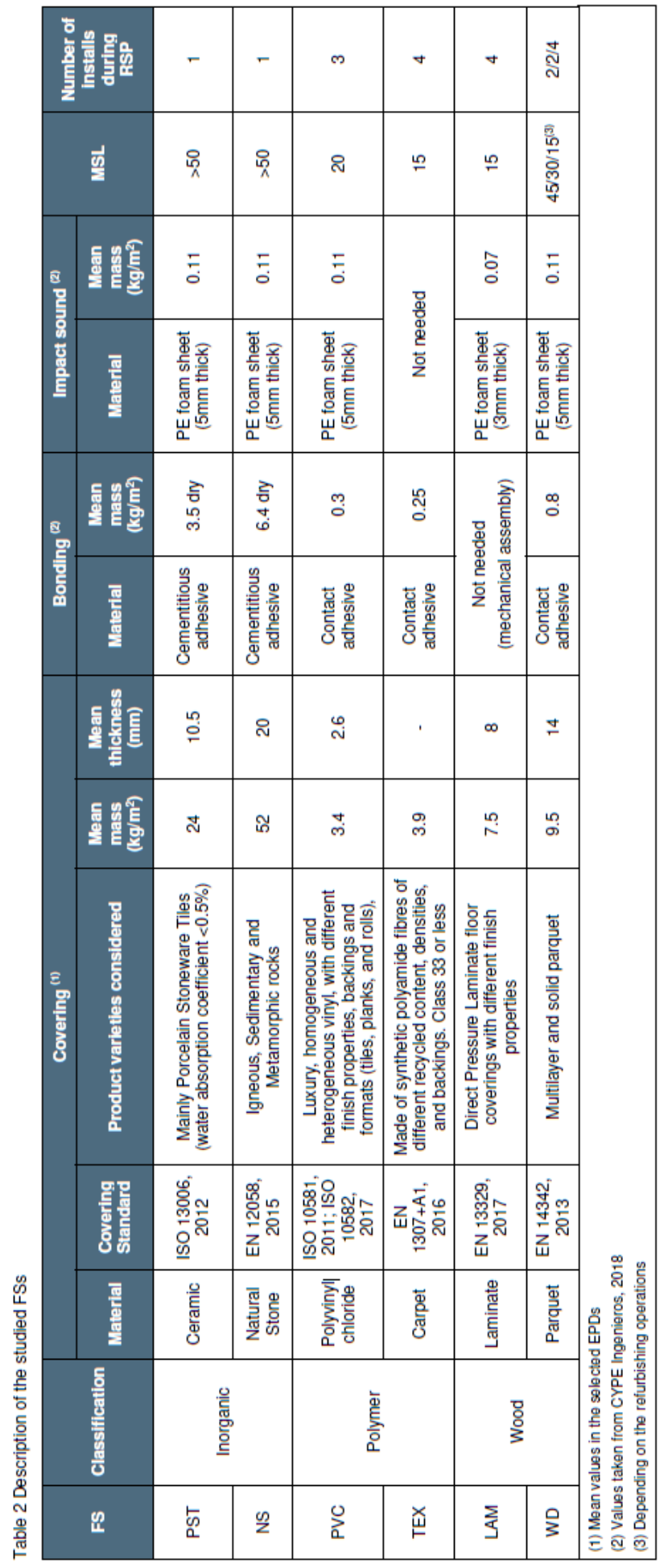




\subsubsection{Description of the FSs life cycles}

The environmental information on the FSs life cycles was organised in terms of the following stages: product, distribution, construction, use (differentiating maintenance, repair, and replacement operations), and end-of-life management.

The product stage included raw materials extraction, transport and manufacturing.

The distribution stage covered transport from the manufacturing plants to the construction site. These distances have been calculated from each EPD's company site to Madrid (Spain), obtaining a weighted average value by the number of EPDs of each type of covering (see Figure A2.1. in Appendix 2). The distances considered and means of transport applied are those shown in Table 3.

Table 3 Distance and means of transport applied in the distribution stage

\begin{tabular}{|c|c|c|c|c|c|c|}
\hline Means of transport & PST & PVC & LAM & TEX & NS & WD \\
\hline Truck & $595 \mathrm{~km}$ & $5357 \mathrm{~km}$ & $2170 \mathrm{~km}$ & $2414 \mathrm{~km}$ & $3000 \mathrm{~km}$ & $1216 \mathrm{~km}$ \\
\hline Cargo & $180 \mathrm{~km}$ & $714 \mathrm{~km}$ & $180 \mathrm{~km}$ & $184 \mathrm{~km}$ & $0 \mathrm{~km}$ & $2500 \mathrm{~km}$ \\
\hline
\end{tabular}

The construction stage included the following operations: manufacture and transport (average distance: $100 \mathrm{~km}$ ) of the bonding materials and impact-proof soundproofing sheets, where needed; managing of packaging and construction waste, $5 \%$ loss being assumed; and manual installation of each FSs element in the building. The impact caused by unloading and movement of the material at the construction site was excluded. As to waste managing, recycling of $70 \%$ and landfilling of the rest (Eurostat, 2019), except for laminate floorings were applied. Laminate flooring waste recycling at the moment of the study was estimated to be nil owing to the multicomponent nature of laminates, so that $100 \%$ of the laminate flooring waste was deemed to be landfilled (Parador $\mathrm{GmbH} \&$ Co.KG, 2013).

The FSs use stage included maintenance, repair, and replacement operations. The emissions generated during use of the coverings were excluded as, in their EPDs, most manufacturers declared that, due to known VOC-decay curves of the product, after the first year no productrelated VOC emissions were relevant, though studies are to be found that contradict this criterion (Saarela, 1999; Sollinger et al., 1993; Tuomainen et al., 2004). In comparative analysis, aspects such as comfort, visual warmth, and aesthetic versatility have been omitted owing to the subjectivity and/or difficulty involved in quantifying these, thus avoiding adding greater uncertainty to the results.

If a system lasts for a long time, values for some of the variables influencing the impact may vary and using data of the current year may consequently lead to uncertainty. The longevity of construction systems, such as flooring systems, leads to uncertainty in the use stage (Akadiri, 2015), especially because of auxiliary products and technologies involved in operations relating to this stage, such as the energy mix. To lessen this uncertainty, the evolution of the Spanish 
electricity mix over the next 50 years was considered, according to the predictions of Capros et al., 2013.

Moreover, certain data, such as those for cleaning, highly depend on user habits and installation site demands (Jönsson, 1999; Nebel et al., 2006). In order to cope with this fact, three use scenarios were considered, based on low, medium, and high pedestrian traffic intensity, consistently assuming certain cleaning, repair, and replacement operations and frequencies. To specify the maintenance operations (cleaning) and their frequencies as a function of these three scenarios, the following literature sources were consulted: EPDs that included information in this regard; Diputación de Castellón, 2018; and Minne and Crittenden, 2015.

The differences found in cleaning frequencies and intensity, which explain the different energy and cleaning product (water and detergents) consumptions, stem from the unequal cleanability of the surfaces, owing to differences in surface microstructure and properties of the materials. For example, in the case of TEX, a bed is cleaned, whereas in WD, little water is used.

The cleaning operations and pedestrian traffic intensity scenario for each floor covering are detailed in Table 4.

Table 4 FSs maintenance scenarios (cleaning operations)

\begin{tabular}{|c|c|c|c|c|c|c|c|}
\hline \multirow[b]{2}{*}{ FS } & \multirow[b]{2}{*}{ SCENARIO } & \multicolumn{6}{|c|}{ CLEANING ACTIVITIES } \\
\hline & & Wet mop & $\begin{array}{c}\text { Wet } \\
\text { mop+cleaner }\end{array}$ & $\begin{array}{l}\text { Household } \\
\text { vacuum }\end{array}$ & $\begin{array}{l}\text { Professional } \\
\text { cleaning } \\
\text { system - } \\
\text { Water }\end{array}$ & $\begin{array}{l}\text { Professional } \\
\text { cleaning } \\
\text { system - } \\
\text { Water+cleaner }\end{array}$ & $\begin{array}{l}\text { Professional } \\
\text { vacuum }\end{array}$ \\
\hline \multirow{3}{*}{ PST } & Low & 1x/week & $0.5 x /$ week & & & & \\
\hline & Medium & 7x/week & $3.5 x /$ week & & & & \\
\hline & High & & & & $14 x /$ week & 7x/week & \\
\hline \multirow{3}{*}{ NS } & Low & 1x/week & $0.5 x /$ week & & & & \\
\hline & Medium & 7x/week & 3.5x/week & & & & \\
\hline & High & & & & $14 \mathrm{x} /$ week & $7 x /$ week & \\
\hline \multirow{3}{*}{ PVC } & Low & & $1 \mathrm{x} /$ week & 2x/week & & & \\
\hline & Medium & & $7 x /$ week & $5 x /$ week & & & \\
\hline & High & & & & & $14 x /$ week & \\
\hline \multirow{3}{*}{ TEX } & Low & & 1x/year & $3 x /$ week & & & \\
\hline & Medium & & $2 x /$ year & $7 x /$ week & & & \\
\hline & High & & & & & 4x/year & $14 x /$ week \\
\hline
\end{tabular}


Table4 FSs maintenance scenarios (cleaning operations) (continued)

\begin{tabular}{|c|c|c|c|c|c|c|c|}
\hline \multirow[b]{2}{*}{ FS } & \multirow[b]{2}{*}{ SCENARIO } & \multicolumn{6}{|c|}{ CLEANING ACTIVITIES } \\
\hline & & Wet mop & $\begin{array}{c}\text { Wet } \\
\text { mop+cleaner }\end{array}$ & $\begin{array}{l}\text { Household } \\
\text { vacuum }\end{array}$ & $\begin{array}{l}\text { Professional } \\
\text { cleaning } \\
\text { system - } \\
\text { Water }\end{array}$ & $\begin{array}{l}\text { Professional } \\
\text { cleaning } \\
\text { system - } \\
\text { Water+cleaner }\end{array}$ & $\begin{array}{l}\text { Professional } \\
\text { vacuum }\end{array}$ \\
\hline \multirow{3}{*}{ LAM } & Low & & 1x/week & $3 x /$ week & & & \\
\hline & Medium & & $7 x /$ week & $7 x /$ week & & & \\
\hline & High & & & & & $7 x /$ week & $14 \mathrm{x} /$ week \\
\hline \multirow{3}{*}{ WD } & Low & $1 x /$ month & $0.5 x /$ month & $3 x /$ week & & & \\
\hline & Medium & $2 x /$ month & $1 \mathrm{x} / \mathrm{month}$ & $7 x /$ week & & & \\
\hline & High & & & & 1x/week & $0.5 x /$ week & $14 x /$ week \\
\hline
\end{tabular}

The amount of water and cleaning agent, as well as the electricity consumptions of the domestic and professional equipment in each cleaning operation, together with the information sources and FSs involved, are detailed in Table 5.

Table 5 Water, detergent, and energy consumptions for each cleaning cycle

\begin{tabular}{|c|c|c|c|}
\hline $\begin{array}{l}\text { Consumable in cleaning } \\
\text { operations }\end{array}$ & FSs involved & Amount & Sources \\
\hline \multirow{2}{*}{$\begin{array}{l}\text { Water per cleaning } \\
\left(1 / \mathrm{m}^{2}\right)\end{array}$} & All except TEX & 0.1 & \multirow{4}{*}{$\begin{array}{l}\text { Mean from EPDs, Diputación de } \\
\text { Castellón, 2018; and Minne and } \\
\text { Crittenden, 2015. }\end{array}$} \\
\hline & TEX & 2.1 & \\
\hline \multirow{2}{*}{$\begin{array}{l}\text { Cleaner per cleaning } \\
\left(\mathrm{kg} / \mathrm{m}^{2}\right)\end{array}$} & All except TEX & $1.0 \mathrm{E}-04$ & \\
\hline & TEX & 5.0E-02 & \\
\hline \multirow{2}{*}{$\begin{array}{l}\text { Energy in domestic } \\
\text { vacuuming } \\
\left(\mathrm{kWh} / \mathrm{m}^{2}\right)\end{array}$} & All except TEX & 2.3E-03 & $\begin{array}{l}\text { Power information provided by } 10 \\
\text { commercial models. Vacuum efficiency } \\
\text { from Minne and Crittenden, } 2015\end{array}$ \\
\hline & TEX & 1.4E-02 & $\begin{array}{l}\text { Power information provided by } 10 \\
\text { commercial models. Vacuum efficiency } \\
\text { from Minne and Crittenden, } 2015\end{array}$ \\
\hline \multirow{2}{*}{$\begin{array}{l}\text { Energy in professional } \\
\text { vacuuming } \\
\left(\mathrm{kWh} / \mathrm{m}^{2}\right)\end{array}$} & All except TEX & $5.4 \mathrm{E}-04$ & $\begin{array}{l}\text { Power information and vacuum efficiency } \\
\text { provided by } 4 \text { commercial models. }\end{array}$ \\
\hline & TEX & $6.6 \mathrm{E}-03$ & $\begin{array}{l}\text { Power information and vacuum efficiency } \\
\text { provided by } 4 \text { commercial models. }\end{array}$ \\
\hline \multirow{2}{*}{$\begin{array}{l}\text { Energy in professional } \\
\text { cleaning } \\
\left(\mathrm{kWh} / \mathrm{m}^{2}\right)\end{array}$} & All except TEX & $6.3 E-04$ & $\begin{array}{l}\text { Power information and vacuum efficiency } \\
\text { provided by } 7 \text { commercial models. }\end{array}$ \\
\hline & TEX & 1.6E-02 & $\begin{array}{l}\text { Power information and vacuum efficiency } \\
\text { provided by } 6 \text { commercial models. }\end{array}$ \\
\hline
\end{tabular}


The repair operations were solely applied to natural stone and parquet. Natural stone repair consisted of polishing, buffing, and waxing; parquet repair consisted of sanding or scraping followed by varnishing. The repair operations were solely applied to natural stone and parquet. Natural stone repair consisted of polishing, buffing, and waxing; parquet repair consisted of sanding or scraping followed by varnishing. The possibility of replacing accidently broken parts was not considered in the scope of this study, as any estimation would appear to be quite subjective. Table 6 details the number of repairs during RSP service life, power and efficiency of the electrical equipment, and amount of wax or varnish for surface treatment.

Table 6 Number of coverings repairs in 50 years

\begin{tabular}{|c|c|c|}
\hline & Natural Stone & Parquet \\
\hline Number of repairs: low/medium/high & $1 / 3 / 5$ & $5 / 10 / 15$ \\
\hline Equipment power & $2.2 \mathrm{~kW}^{(1)}$ & $1.5 \mathrm{~kW}^{(2)}$ \\
\hline Operation efficiency & $30 \mathrm{~s} / \mathrm{m}^{2(1)}$ & $30 \mathrm{~s} / \mathrm{m}^{2(1)}$ \\
\hline Wax/varnish & $0.02 \mathrm{~kg} / \mathrm{m}^{2(3)}$ & $0.33 \mathrm{~kg} / \mathrm{m}^{2(4)}$ \\
\hline $\begin{array}{ll}\text { (1) } & \text { Nicoletti et al., } 2002 \\
\text { (2) } & \text { Information provided by Holzmann I } \\
\text { (3) } & \text { Information provided by Fila Industr } \\
\text { (4) } & \text { Consulted EPDs }\end{array}$ & $\begin{array}{l}\text {-., } 2018 \\
., 2018\end{array}$ & \\
\hline
\end{tabular}

To define the replacement operations, the number of coverings replacements required as a function of the coverings MSL during the 50-year RSP was calculated (Table 2).

The operations involved in each replacement were as follows: disassembly of the coverings and, where applicable, of the bonding material; transport of the material removed; treatment and/or disposal of this material; manufacture of replacement material; transport to the construction site; and installation.

In the end-of-life management of the replaced materials waste, a progressive transition to $100 \%$ recycling in the course of 50 years, in a phase-in to a circular economy, was applied, as detailed in Table 7.

Table 7 Scenarios in the course of 50 years' construction and demolition waste management

\begin{tabular}{|c|c|c|c|c|}
\hline \multirow{2}{*}{$\begin{array}{l}\text { Time elapsed since } \\
\text { installation }\end{array}$} & \multicolumn{2}{|c|}{ Laminates } & \multicolumn{2}{|c|}{ Other coverings } \\
\hline & Recycling (\%) & Landfilling (\%) & Recycling (\%) & Landffilling (\%) \\
\hline $\begin{array}{l}0 \text { years (losses on } \\
\text { installation) }\end{array}$ & 0 & 100 & 70 & 30 \\
\hline $15-20$ years & 25 & 75 & 80 & 20 \\
\hline 30 years & 50 & 50 & 90 & 10 \\
\hline 40 years & 75 & 25 & 95 & 5 \\
\hline 50 years & 100 & 0 & 100 & 0 \\
\hline
\end{tabular}


The end-of-life stage considered the dismantling and demolition of all FSs elements, transport, and end-of-life management. The dismantling and demolition operations of each FSs element were assumed to be either manual or mechanised, depending on the hardness of the covering and bonding material (CYPE Ingenieros, 2018). The construction materials end-of-life stage entailed great uncertainty, as it was to take place in a distant future (Silvestre et al., 2014). In this case, applying a cradle-to-cradle approach (Häfliger et al., 2017; Silvestre et al., 2014; Wolf et al., 2010), it was assumed that within 50 years, the scenario would be $100 \%$ recycling for every type of studied covering, incineration and landfilling options being excluded. For this scenario to materialise, it will be necessary to promote changes in building design in order to facilitate dismantling of the different construction materials (Zabalza et al., 2011).

In this sense, the processes prior to the end-waste state condition for the materials exiting the system as secondary material were considered, as well as all operations beyond the system required for processing this secondary material and the benefits obtained from recycling, were included. Specifically, in this LCA comparative study, it was assumed that the impacts of these operations were those declared by modules C3 (waste treatment) and D (benefits and loads beyond system boundaries) (Silvestre et al., 2014) of the consulted EPDs that provided this information. The theoretical replacement ratios of the recovered inert and wood materials were 1:1, those of the polymer materials being 1:0.81 (Mercante et al., 2012).

In the particular case of the wood-based coverings (parquet and laminates), biogenic carbon was quantified by means of the $-1 /+1$ calculation method (method currently defined by the TC 350 and ISO 21930, 2017 standards), the stored amount of biogenic carbon thus being emitted in the endof-life stage.

All transport considered in this study occurred with a 27t truck, which conforms to the Euro 6 standard.

\subsubsection{Data sources}

The characteristics of each element making up the FSs were drawn from CYPE Ingenieros, 2018.

The environmental information relative to the coverings product stage (A1-A3) was taken from the published EPDs (Anand and Amor, 2017; Lasvaux et al., 2014; Passer et al., 2015), while the information on the other constituents was obtained from the GaBi (Thinkstep AG, 2018b) and ELCD (Joint Research Centre, 2015) databases.

For the subsequent stages (A4-C4/D), the EPD values were not used directly, owing to the inhomogeneity of the assumptions made in drawing up the scenarios (Hill et al., 2018). To reduce uncertainty and provide comparability, common scenarios based on the descriptions supplied by the manufacturers in their EPDs and on the literature sources (appendix 1) were defined. On the other hand, the inventory data of the inputs and outputs were selected from the GaBi (Thinkstep AG, 2018b) and ELCD (Joint Research Centre, 2015) databases. 


\section{EPD information processing}

To obtain representative environmental information on the product stage (A1-A3) of the different coverings, the following EPD programs were consulted: the International EPD $®$ System; Institut Bauen und Umwelt e. V. (IBU-EPD); DAPcons; GlobalEPD; Inies and EPDnorge, carrying out the following procedure:

1) EPDs selection. The following criteria were applied: suitability of the functional characteristics of the product in the building context; conformity to standard EN 15804:2012+A1:2013; verification by a third party; current validity; exclusion of EPDs not written in English, French, German, or Spanish (the authors' mother tongue).

2) EPDs comparability assessment. The criteria set out in standards ISO 14025:2006 and EN 15804:2012+A1:2013 were applied. To simplify application of these criteria, a method similar to that used by Gelowitz and McArthur, 2017, (Table 8) was adopted.

3) Data representativeness. A unit conversion process was performed where necessary, in addition to statistical processing of the impact values. In general, the 50th percentile of the sample was taken as representative value of each covering (Häfliger et al., 2017; Hill et al., 2018).

The analysis of the consulted EPDs is set out in appendix 2.

Table 8 Comparability assessment criteria

\begin{tabular}{|l|l|}
\hline \multicolumn{1}{|c|}{ Concept } & \multicolumn{1}{c|}{ Criterion } \\
\hline FU/DU & The Functional or Declared Unit must be the same or be convertible \\
\hline $\begin{array}{l}\text { Characterisation } \\
\text { factors }\end{array}$ & $\begin{array}{l}\text { The characterisation factors must be the same or their units must at least be } \\
\text { convertible, e.g. from ounces to kg or } \mathrm{m}^{3} \text { to litres }\end{array}$ \\
\hline $\begin{array}{l}\text { Mandatory content } \\
\text { for comparison } \\
\text { according to } \\
14025 / 15804\end{array}$ & $\begin{array}{l}\text { Description of the product; } \\
\text { PCR identification; } \\
\text { Listing of materials and substances to be declared; } \\
\text { The list of environmental impacts of the product stage (A1-A3) is presented } \\
\text { separately from those of the other life cycle modules }\end{array}$ \\
\hline Cut-off rules & $\begin{array}{l}\text { The cut-off rules must be identical regarding the mass, volume percentage that } \\
\text { may be excluded from the calculations }\end{array}$ \\
\hline
\end{tabular}

\subsection{Assessment of the environmental impact}

The information relative to each FS was modelled with the LCA software GaBi 8 (Thinkstep AG, 2018a), following the considerations of standards ISO 14040-44, 2006, EN 15804+A1, 2013, and EN 15978, 2011.

The studied environmental impact categories, in accordance with standard EN 15804+A1, 2013, are listed in Table 9. 
Table 9 Assessed environmental impact categories

\begin{tabular}{|l|c|c|}
\hline \multicolumn{1}{|c|}{ Impact category } & Acronym & Unit \\
\hline Global Warming Potential (100 years) & $\mathrm{GWP}$ & $\mathrm{kg} \mathrm{CO}_{2}$ Equivalent \\
\hline Acidification Potential & $\mathrm{AP}$ & $\mathrm{kg} \mathrm{SO}_{2}$ Equivalent \\
\hline Eutrophication Potential & $\mathrm{EP}$ & $\mathrm{kg} \mathrm{PO}_{4}{ }^{3-}$ Equivalent \\
\hline Ozone Layer Depletion Potential (steady state) & $\mathrm{ODP}$ & $\mathrm{kg} \mathrm{CFC}-11$ Equivalent \\
\hline Photochemical. Ozone Creation Potential & $\mathrm{POCP}$ & $\mathrm{kg} \mathrm{C}_{2} \mathrm{H}_{4}$ Equivalent \\
\hline Abiotic Depletion - elements & $\mathrm{ADPE}$ & $\mathrm{kg} \mathrm{Sb}$ Equivalent \\
\hline Abiotic Depletion - fossil fuels & $\mathrm{ADPF}$ & MJ \\
\hline
\end{tabular}

Finally, beyond the scope of standard ISO 14040-44, 2006, owing to the subjectivity of the process, to simplify comparison of the six FSs and seven impact categories and to visualise the relative magnitude of the impacts and handle the trade-offs (Laurin et al., 2016), weighting and normalisation factors were applied (Table 10). This enabled a single dimensionless value for each FS and use scenario to be obtained. The applied weighting factors were those obtained by Thinkstep "LCIA Survey 2012, Global, CML 2016, incl. biogenic carbon (global equivalents weighted)". The applied normalisation factors were taken from "CML2001 - Jan. 2016, World, year 2000 , incl. biogenic carbon (global equivalents)" (Table 10). Further information on the results for each impact category may be found in appendix 3 .

Table 10 Weighting and normalisation factors

\begin{tabular}{|c|c|c|}
\hline Environmental indicators & Weighting Factors & Normalisation Factors \\
\hline GWP & 0.193 & $4.22 \mathrm{E}+13$ \\
\hline AP & 0.127 & $2.39 \mathrm{E}+11$ \\
\hline EP & 0.137 & $1.58 \mathrm{E}+11$ \\
\hline ODP & 0.129 & $2.27 \mathrm{E}+08$ \\
\hline POCP & 0.135 & $3.68 \mathrm{E}+10$ \\
\hline ADPE & 0.133 & $3.61 \mathrm{E}+08$ \\
\hline ADPF & 0.146 & $3.80 \mathrm{E}+14$ \\
\hline
\end{tabular}

\subsection{Uncertainty analysis}

As all environmental studies, this comparative study carries a certain degree of uncertainty. In particular, the environmental impacts associated with the coverings product stage stemmed from median data, whose original sample in some cases exhibited a very scattered distribution (appendix 2), in addition to displaying differences regarding source, input data uncertainty, etc. Moreover, assumptions with a high degree of subjectivity were defined in other life cycle stages, such as cleaning or repair operations and frequencies. 
The Monte Carlo simulation was programmed, randomly distributing the median data of each life cycle stage and its standard deviation for each FS, represented by a normal distribution, performing a number of 1000 iterations.

Scenario analyses were also carried out on maintenance operations, material service life and endof-life management of the FS.

\section{Results and discussion}

Applying the above methodology yielded Fig. 2, which exhibits the contribution of each studied FS to each environmental impact category, differentiating the FS life cycle stages and representing the three use scenarios considered as a function of low, medium, and high pedestrian traffic intensity (from left to right). The results are then discussed from the viewpoint of each impact category, first indicating the results of the comparative analysis based on a cradle-to-gate scope and then on a cradle-to-cradle scope, highlighting the most noteworthy stages in each case.

\section{Limitations}

It may be noted that the impact values of the coverings associated with the product stage (cradle to gate) stemmed from previously selected EPDs. This methodology implies some considerations to be taken into account:

- The discussion of the results associated with this life stage is, therefore, limited to the generic information on floorings in scientific publications and from the interpretation of the results included in some EPDs (13.6\% of the consulted EPDs).

- The selected EPDs are registered in different programs, they have been carried out with the support of different software and databases, the data correspond to different years and come from different geographical origins (see Appendix 2). However, all EPDs were in force at the time of conducting the study and comply with EN 15804:2012+A1:2013, which means that the validity of the data and the time constrains were checked during the third party verification processes demanded by the EPD programmes. Moreover, in this study, a uncertainty and quality analysis of data has been carried out to ensure that neither this procedure nor choices lead to biased conclusions in the study.

- This approach reliably reflects the method followed by non-academic users of EPDs." 

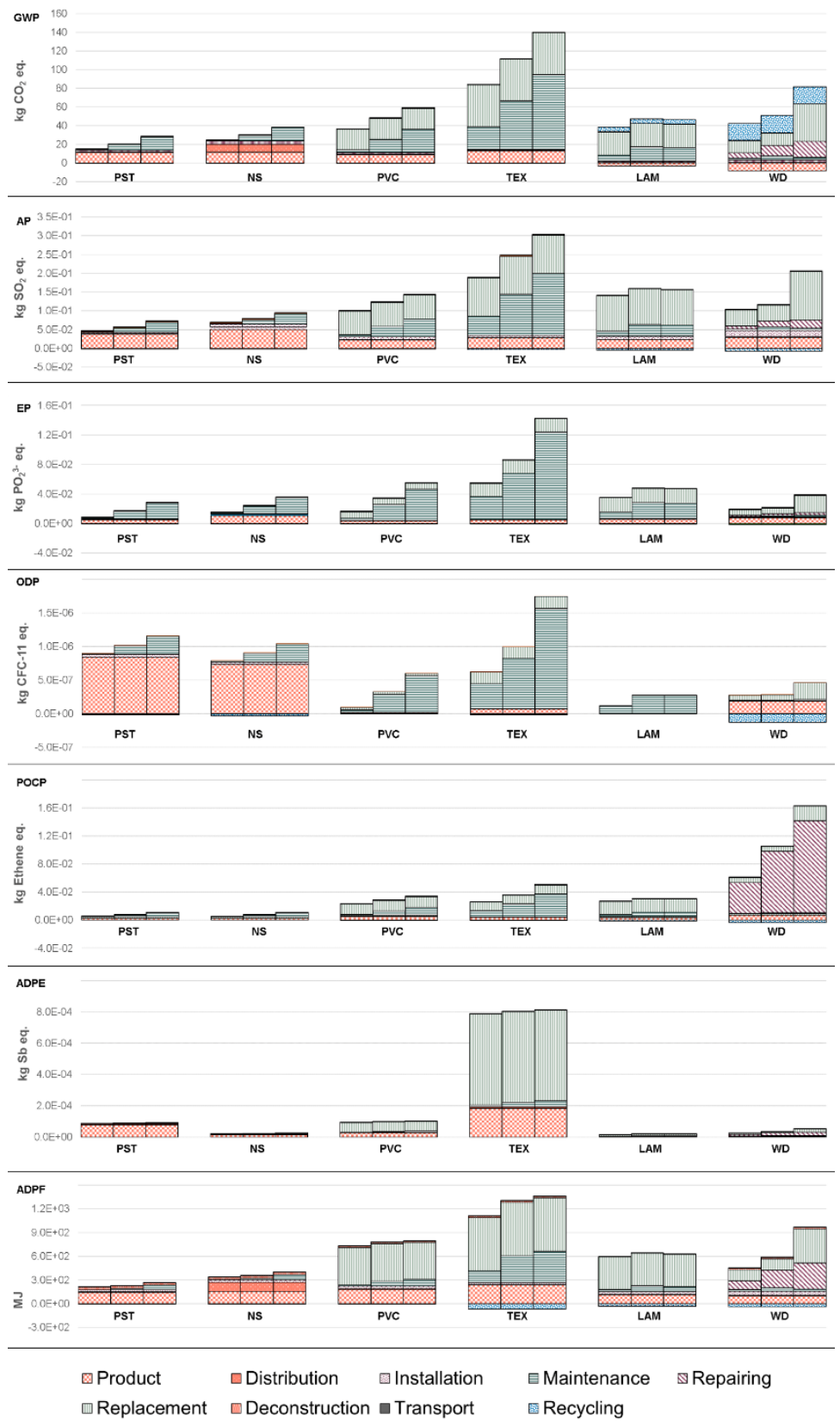

Fig. 2 Environmental impacts of the FSs studied in each defined use scenario, indicating the contribution of each life cycle stage. The values refer to the FU. For each FS, the bars represent low, medium, and high intensity pedestrian traffic, from left to right. 


\subsection{Global warming potential (GWP)}

Comparison solely of the mandatory information contained in the EPDs product stages might lead to the erroneous conclusion that the wood-based coverings performed best, as they generated positive impacts owing to the carbon sequestered by the biomass (Jungmeier et al., 2002; Nebel et al., 2006; Nebel and Cowell, 2003). However, analysis of the FSs from a life cycle perspective revealed that the FSs with inorganic coverings generated a lower environmental impact in every one of the three traffic intensity scenarios defined in the use stage. The lowest values were obtained for PST: $14.2 ; 16.7$; and $23.2 \mathrm{~kg} \mathrm{CO}_{2}$ eq./FU for low, medium, and high pedestrian traffic intensity, respectively. The order of magnitude was similar to that obtained in other studies (Almeida et al., 2016 (20.1-23.3 kg CO 2 eq./m²; lbañez-Forés et al., 2011 (18 kg CO eq./m²); RosDosdá et al., 2018a (11.14-16 kg CO 2 eq. $\left.\left./ \mathrm{m}^{2}\right)\right)$. The values determined for NS were slightly higher than those for PST, in contrast to the conclusion drawn by Nicoletti et al, 2002, though in that study different MSL and another impact assessment methodology based on eco-indicators was applied. In contrast, the most unfavourable values were obtained for TEX $(77.5,99.0$, and $141.1 \mathrm{~kg} \mathrm{CO} 2$ eq./FU) in the three studied traffic scenarios, which matched the conclusions of the study by Minne and Crittenden, 2015.

With regard to the stages that exhibited the greatest repercussion, it may be observed that, in the inorganic coverings, the product stage displayed the greatest impact in every analysed scenario, just as in other studies (Almeida et al., 2016b; Benveniste et al., 2011; Bovea et al., 2010; IbáñezForés et al., 2011; Nicoletti et al., 2002; Ros-Dosdá et al., 2018a), stemming from the great energy consumption in the manufacturing stage, combined with the ease of maintenance in the use stage and the high product lifespan (CET, 2014; DAPcons, 2015; GlobalEPD, 2018; Minne and Crittenden, 2015; Thuring et al. 2013). Conversely, in LAM and PVC, the greatest impact was found in the replacement stage, the coverings being penalised by their short lifespans: 15 and 20 years, respectively. TEX, whose origins lie in polyamide manufacture, obtained the worst results in all use scenarios, owing to high energy consumption in the manufacturing and maintenance stages, together with a relatively short lifespan ( 15 years). WD was the second most unfavourable covering, with a significantly higher impact when installed in areas with high pedestrian traffic because, on requiring more repair operations, its service life decreased, and it needed to be replaced more frequently. The WD end-of-life stage had a significant effect ( $>25 \%$ of the life cycle), as it was in this stage in which part of stored biogenic carbon was theoretically released (Jungmeier et al., 2002). To be noted is further the impact stemming from the varnish used in the WD repair operations ( $26 \%$ in an average scenario).

\subsection{Acidification potential (AP)}

In a cradle-to-gate scope, all coverings exhibited very similar impact values, those of the inorganic coverings being slightly higher. However, in a cradle-to-cradle scope, the FSs with inorganic coverings again performed best, regardless of the use stage scenario, PST performing best, with values of $0.048-0.074 \mathrm{~kg} \mathrm{SO}_{2}$ eq./FU in low and high traffic scenarios, respectively, yielding similar values to NS, whose impact was slightly greater as both its specific weight and cementitious 
adhesive consumption were twice as high. In contrast, TEX performed worst owing to maintenance, its impact stemming from electricity in vacuuming, use of detergent, and replacement operations. For the medium traffic scenario both stages accounted for $85 \%$ of the total life cycle. In low and medium traffic scenarios, PVC and WD yielded similar values, with differences in the WD cleaning frequencies, repair, and installation stages. In the installation stage, WD needed a greater amount of adhesive $\left(0.8 \mathrm{~kg} / \mathrm{m}^{2}\right)$ than PVC $\left(0.3 \mathrm{~kg} / \mathrm{m}^{2}\right)(C Y P E$ Ingenieros, 2018). In high traffic scenarios, WD required additional replacement as repair sanding diminished WD thickness. In general, the cleaning operations seemed to have no determining importance, except for TEX.

\subsection{Eutrophication potential (EP)}

In a cradle-to-gate scope, the NS covering exhibited the greatest impacts, and the PVC covering the lowest. On extending the scope, the PST FSs performed best even when installed in areas with high maintenance demands, exhibiting impact values (2.85E-02 $\mathrm{kg} \mathrm{PO}_{4}{ }^{3-}$ eq./FU) similar to those calculated by Almeida et al., 2016. PST impact was mainly caused by the product stage, specifically the NOx emissions generated during raw materials extraction and transport (Bovea et al., 2007) and by natural gas combustion in the tile drying and firing stages (Bovea et al., 2010). In this impact category, TEX again performed worst due to the ammonia emissions associated with the high detergent and chemicals demand in cleaning $\left(0.06 \mathrm{~kg} / \mathrm{m}^{2}\right.$ per annum according to the EPDs), matching the conclusions drawn by Minne and Crittenden, 2015. Although the water and detergent cleaning frequency was much lower than that of the other coverings; the amount used per cleaning operation was higher, according to the specifications provided by the manufacturers' EPDs. Solely the maintenance stage accounted for $73 \%$ of the total life cycle impact of this FS in a medium traffic intensity scenario.

\subsection{Ozone layer depletion potential (ODP)}

The surveyed EPDs exhibited a great data scatter in this impact category, both in the product category itself and among the different categories. In all coverings, differences exceeding one or more orders of magnitude were found for the same category. For example, values ranging from $3.4 \mathrm{E}-11$ to $1.5 \mathrm{E}-06 \mathrm{~kg}$ CFC-11 eq. $/ \mathrm{m}^{2}$ were found for WD, while values ranging from $7.9 \mathrm{E}-09$ to $2.8 \mathrm{E}-5 \mathrm{~kg}$ CFC-11 eq. $/ \mathrm{m}^{2}$ were found for PVC in the EPDs. This scatter meant that the results of the comparative analysis could vary if the outermost EPD values were taken. In this category, assuming a cradle-to-cradle scope, the FSs with inorganic coverings generated the greatest impact, with a difference of 2 orders of magnitude with respect to LAM, which yielded the best results. According to Bovea et al, 2010, the inorganic FS product stage by itself exhibited a higher potential impact, caused by the contribution of diesel vehicles in extraction and transport. In spite of the significant impacts exhibited by WD during the product stage, the recycling benefits obtained offset $67 \%$ of the manufacturing impacts (medium traffic scenario), thanks to its recycling ease and potential (Heisterberg-Moutsis et al., 2017). Once again, the TEX FS displayed the 
greatest impact because of the chemical agents containing chloromethane used in defoamer synthesis, applied in cleaning operations ( $76 \%$ of the total life cycle impact).

\subsection{Photochemical ozone creation potential (POCP)}

In a cradle-to-gate scenario, all coverings EPDs declared very similar impacts. In a cradle-to-cradle scope, the inorganic FSs again exhibited the lowest environmental impact in every scenario (about $1.1 \mathrm{E}-02 \mathrm{~kg}$ ethene eq./FU), followed by PCV and LAM with quite similar values (3.3E-02 and 2.9E$02 \mathrm{~kg}$ ethene eq./FU, respectively), whose impact was mainly determined by the required replacements. These results differed from those obtained by Minne and Crittenden, 2015, which positioned vinyl slightly better than the ceramic covering, albeit without considering the FSs as a whole. In this impact category, TEX was also penalised by intensive use of cleaning agents, which matched the results obtained by Minne and Crittenden, 2015. The worst-performing FS was WD, which exhibited values ranging from $5.7 \mathrm{E}-02$ to $1.6 \mathrm{E}-01 \mathrm{~kg}$ ethene eq./FU, it being penalised by the repairs required during the entire RSP owing to VOCs (56\%) as well as to $\mathrm{NO}_{x}$ and $\mathrm{SO}_{2}$ emissions $(44 \%)$ generated by the solvents contained in the varnishes. For example, in a medium traffic scenario, WD needed 10 sanding and varnishing operations (with $0.33 \mathrm{~kg} / \mathrm{m}^{2}$ varnish/repair according to the consulted EPDs), accounting for $86 \%$ of the total service life impact. In this study, two types of specific parquet varnishes (namely solvent-based and water-based varnishes) were considered, the impact of which was averaged; the choice of either one or the other could vary the contribution of this stage to the total life cycle impact by up to $\pm 7 \%$.

\subsection{Depletion potential for non-fossil resources (ADPE)}

The contribution to this impact category stemmed from raw materials extraction for the different coatings. Fig. 2 clearly evidences the high impact of TEX, for two main reasons: sulphur input in the manufacturing process (Thinkstep AG, 2018b) and the short lifespan. The former accounted for $23 \%$ of the total life cycle impact and the latter involved the need for 3 replacements in the RSP, therefore accounting for $73 \%$ (medium scenario). On the other hand, the PST product stage accounted for $93 \%$ of the total life cycle impact. These values stemmed from the use of raw materials such as borates, zinc and tin oxides in the manufacture of PST ceramic glazes (RosDosdá et al., 2018a). Wood-based and NS coverings performed best, LAM yielding the best results.

\subsection{Depletion potential for fossil resources (ADPF)}

In a cradle-to-gate scenario, the polymer coverings performed worst, matching the conclusions drawn by Jönsson et al., 1997. In this case TEX exhibited the greatest impact $\left(236 \mathrm{MJ} / \mathrm{m}^{2}\right)$ while wood-based coverings, WD and LAM, exhibited a lower impact $\left(100 \mathrm{MJ} / \mathrm{m} 2\right.$ and $113 \mathrm{MJ} / \mathrm{m}^{2}$, respectively), these values being similar to those obtained by Nebel et al., 2006. On extending the scope to the entire life cycle, inorganic FSs performed better, particularly in high traffic scenarios, with values of $290 \mathrm{MJ} / \mathrm{FU}$ and $357 \mathrm{MJ} / \mathrm{FU}$ for PST and NS, respectively. Analysis of each PST and 
NS stage revealed that the greatest differences occurred in the distribution stage. The distribution impact was basically determined by the specific weight (using the same means of transport and distance travelled), with values of $55.5 \mathrm{~kg} / \mathrm{m}^{2}$ and $24.1 \mathrm{~kg} / \mathrm{m}^{2}$ for NS and PST, respectively. The polymer coverings performed worst on extending the scope (cradle to cradle). TEX performed worst in every scenario owing to the environmental loads of raw materials supply (derived from crude oil), and manufacture (Günther and Langowski, 1997; Islam et al., 2015; Potting and Blok, 1995), thus directly affecting the 3 replacements required in the RSP. The necessary replacements and repairs involving the use of varnishes were primarily responsible for the WD impacts, WD being positioned as the second most unfavourable covering.

\subsection{Weighting and normalisation}

Fig. 3 shows the weighted and normalised environmental impacts of the FSs life cycles for each scenario defined in the use stage according to the factors detailed in Table 10.

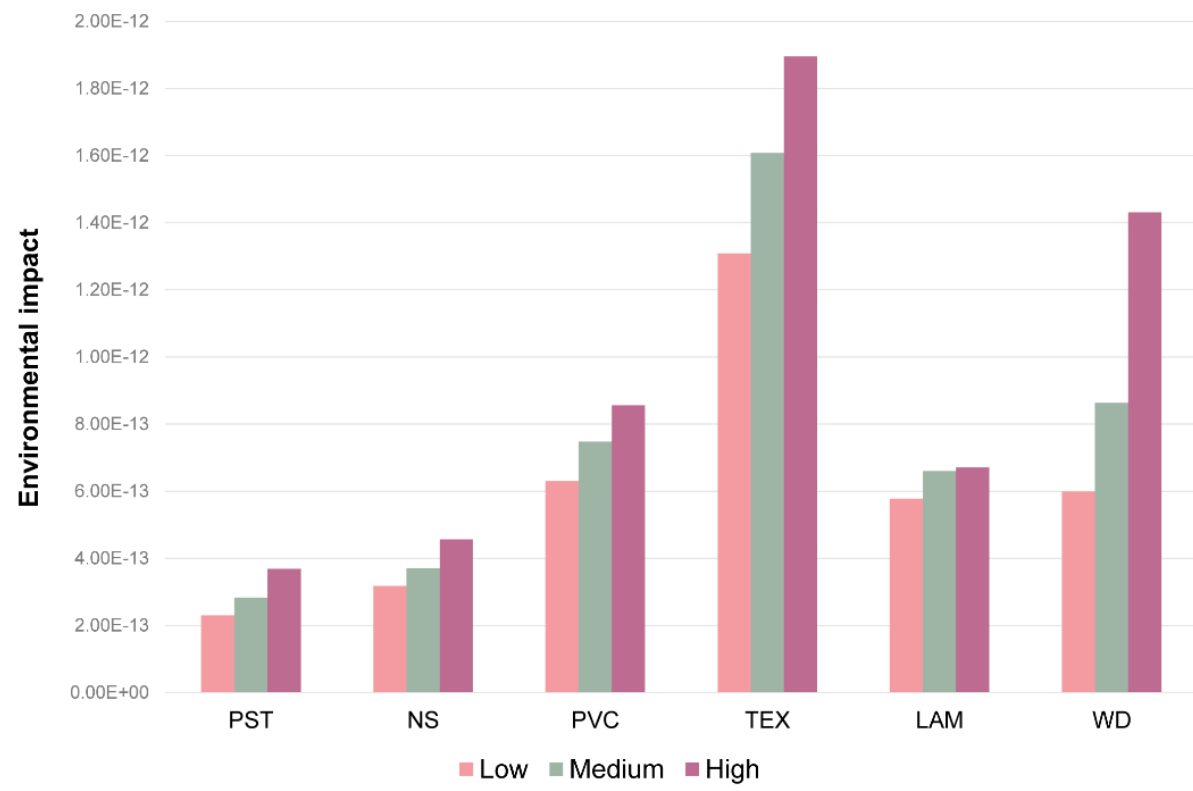

Fig. 3 Weighted and normalised values of the environmental impact results

The FSs with inorganic coverings (PST and NS) performed best, exhibiting differences of less than $5 \%$. These were followed by the FSs with LAM and PVC coverings, whose impact was $25 \%$ greater than that of the inorganic coverings, LAM and PVC exhibiting differences not exceeding $10 \%$. The FSs with WD coverings installed in low traffic areas exhibited a similar impact to that of LAM and PVC. However, the higher the traffic, the greater the impact, not just because the cleaning 
requirements increased but also because, with a greater number of repairs, WD service life decreased (Table 2).

In accordance with this methodology, TEX coverings exhibited the worst environmental performance, largely matching the results obtained in each impact category.

\subsection{Uncertainty and sensitivity analysis}

\subsubsection{Monte Carlo analysis}

A Monte Carlo analysis was applied to the entire life cycle of the FSs, using all EPDs starting data and every use scenario. Fig. 4 and Table 11 show the scatter in the results for each type of FS at $95 \%$ confidence level on performing 1000 iterations of the global warming potential values. The data are displayed in a box and whisker plot, simultaneously showing the central trend, scatter, and symmetry of the study data. The boxes represent the interquartile range between the 25 th and 75th percentile $\left(Q_{1}\right.$ and $Q_{3}$, respectively); the cross $(X)$ represents the mean value; the line represents the median value corresponding to $\left(Q_{2}\right)$; and the whiskers represent the $95 \%$ confidence interval.

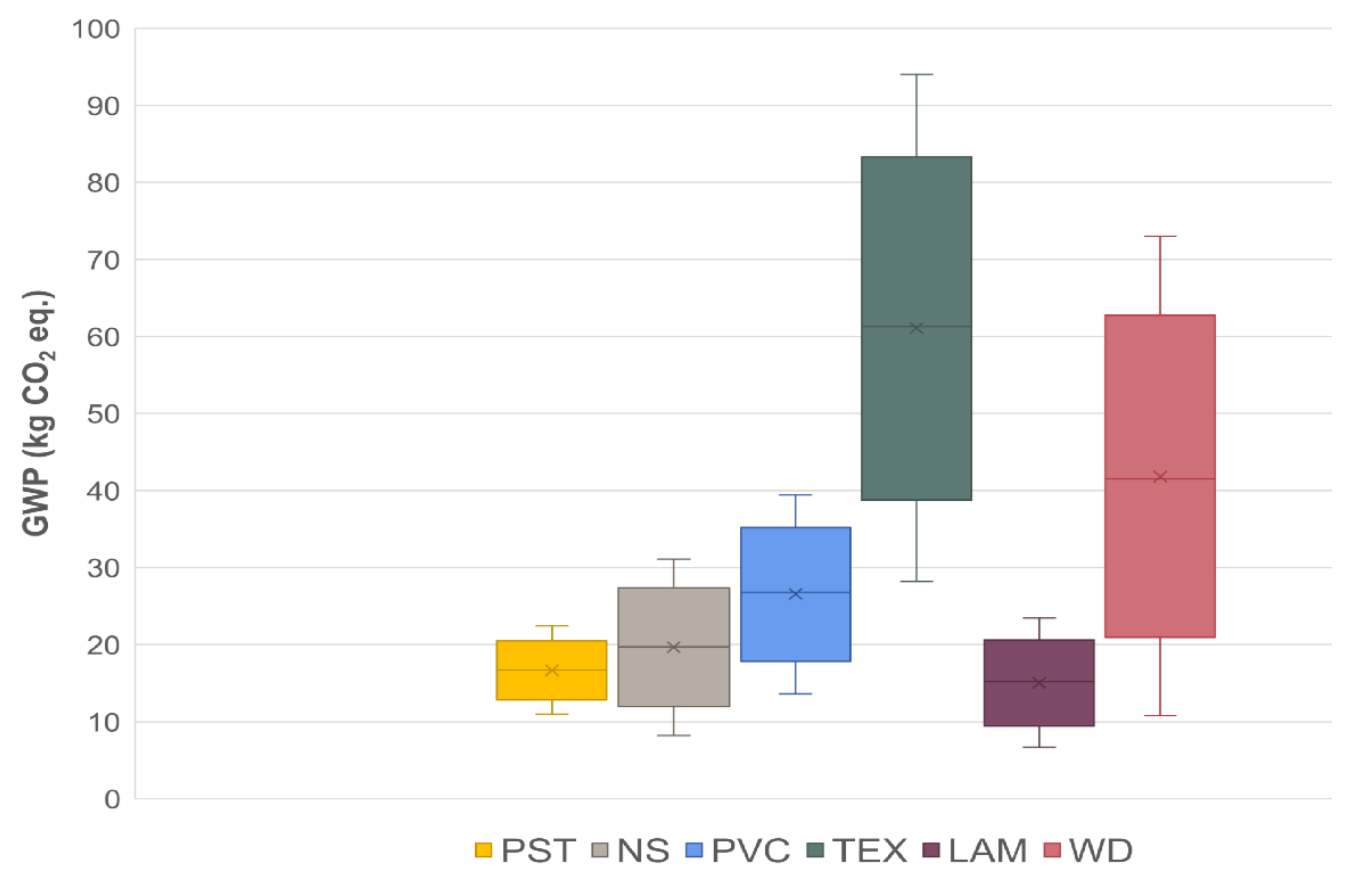

Fig. 4 Monte Carlo analysis of input/output variations in all FSs scenarios 
Table 11 shows the number of EPDs used in the study, the mean, median, standard deviation (SD), and the 2.5 and 97.5 percentiles that limit the $95 \%$ confidence interval associated to each FS.

Table 11 Uncertainties for Global Warming Potential results related to each FS

\begin{tabular}{|c|c|c|c|c|c|c|}
\hline \multirow{2}{*}{ FS } & \multirow{2}{*}{$\begin{array}{c}\text { Number of } \\
\text { EPDs }\end{array}$} & Mean & Median & SD & \multicolumn{2}{|c|}{$95 \%$ confidence interval } \\
\cline { 5 - 7 } & 20 & 16.7 & 16.7 & 2.91 & 11.0 & 22.4 \\
\hline PST & 2 & 19.6 & 19.7 & 5.8 & 8.2 & 31.1 \\
\hline NS & 14 & 26.5 & 26.8 & 6.6 & 13.6 & 39.4 \\
\hline PVC & 27 & 61.1 & 61.3 & 16.8 & 28.2 & 94 \\
\hline TEX & 5 & 15.1 & 15.2 & 4.3 & 6.7 & 23.4 \\
\hline LAM & 5 & 41.9 & 41.5 & 15.9 & 10.8 & 73.0 \\
\hline WD & & & & & & Max \\
\hline
\end{tabular}

The samples were observed to be quite symmetrical and the mean and median values, when not identical, lay quite close to each other, evidencing the normality of the data distribution obtained by the Monte Carlo analysis.

TEX and WD were the FSs with the greatest data distribution in this impact category. The interquartile difference between $Q_{3}-Q_{1}$ is 23.3 y $21.5 \mathrm{~kg} \mathrm{CO}_{2}$ eq. respectively. This distribution might be due to the different product varieties included and hypothesis in the use stage (maintenance, repair and replacement). TEX included different densities, recycled material content, backings, etc. WD included solid and multilayer parquet. In the case of TEX, the median value and the value corresponding to the upper limit of the $95 \%$ confidence level were the highest in the FSs analysed.

LAM displayed the lowest contribution in values between the $25^{\text {th }}$ and $75^{\text {th }}$ percentile. This range overlapped by $70 \%$ with the PST values. PST exhibited the FS with the least uncertainty in this impact category.

\subsubsection{Scenario analysis}

Scenario analyses were performed to evaluate the influence and significance of some of the environmental parameters that had either been defined by assumptions or entailed significant life cycle impacts. The analyses focused in particular on maintenance operations in the coverings use stage, on length of service life and end-of-life management of the FS.

The operations relating to maintenance (cleaning) were defined by type of covering and pedestrian traffic intensity, the resulting impacts being mainly determined by: i) dry cleaning: electricity consumption in air extraction; ii) wet cleaning: water and detergent consumption. 
Fig.5, shows the effect of a $99 \%$ reduction in detergent consumption in the maintenance stage of each studied FS. It was verified that the environmental impact categories most sensitive to detergent were ODP and EP. The contribution to ODP was practically determined in its entirety by the emission of chloromethane, used as a chemical intermediary in the production of silicone polymers added as antifoamers. Although the amount of chloromethane was very small $(5.0 \mathrm{E}-05$ $\mathrm{kg} / \mathrm{kg}$ detergent considered (Thinkstep AG, 2018b), it had a powerful destructive capacity on the ozone layer. The detergent's contribution to EP was principally influenced by the inorganic emissions of nitrogen compounds (mainly $\mathrm{NH}_{3}$ and $\mathrm{NO}_{x}$ ) and discharges into the water of phosphates and nitrogen compounds during their fabrication.
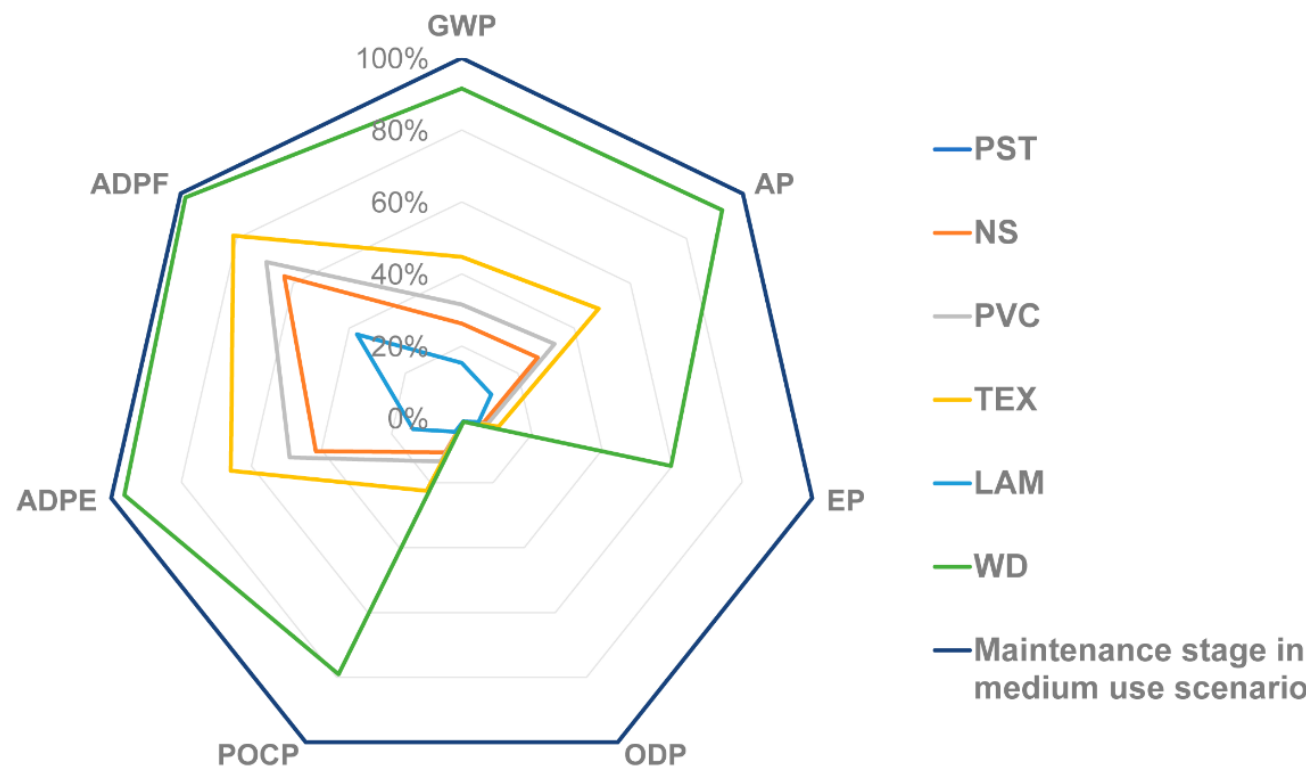

Fig. 5 Effect of $99 \%$ reduction in the amount of detergent on the environmental impacts of the maintenance stage in each type of FS

In dry cleaning, a 99\% reduction in electricity consumption in a medium use scenario notably decreased the weighted and normalised values of the TEX and WD maintenance stage by 90 and $47 \%$, respectively. The most affected impact categories were ADPF and GWP owing to the makeup of the Spanish electricity mix, with a $44 \%$ fossil energy source (REE, 2018).

On the other hand, to analyse the contribution of the maintenance stage to that of the total life cycle, an analysis was performed in which the FS life cycle with and without this stage was compared. The weighted and normalised results obtained are shown in Fig.6. Note the great importance of this stage in TEX (accounting for 33\% of the life cycle impact) because TEX cleaning required a much greater amount of detergent and energy than cleaning of the other FSs. 


\section{$1.6 \mathrm{E}-12$}

\section{$1.4 \mathrm{E}-12$}

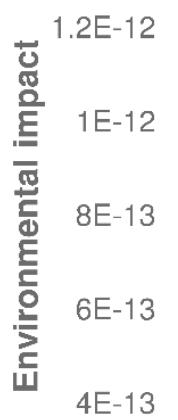

$2 \mathrm{E}-13$

0
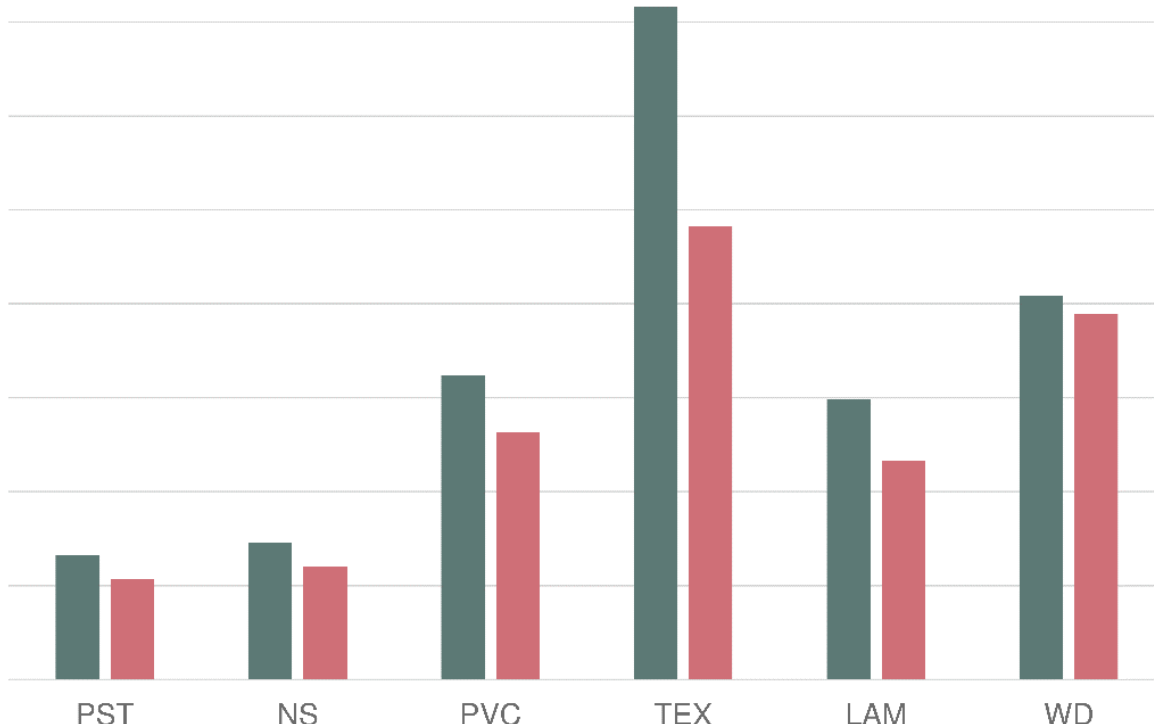

- Current scenario (medium use)

TEX

LAM

WD

No maintenance

Fig.6 Comparative analysis of the weighted and normalised impacts of the FSs life cycle, considering the maintenance stage in a medium use scenario versus the FSs life cycle without a maintenance stage.

To analyse the influence of product service life, all the coverings were assumed to have an MSL of 15 years, so that the 50-year RSP required 3 replacements (Fig.7). The analysis showed that a premature replacement of the coverings that had a longer theoretical technical (or functional) service life (NS, PST, and WD) gave rise to significant increases in environmental impact $(+247$, 187 , and $134 \%$, respectively, in a medium use maintenance scenarios). 
$1.6 \mathrm{E}-12$

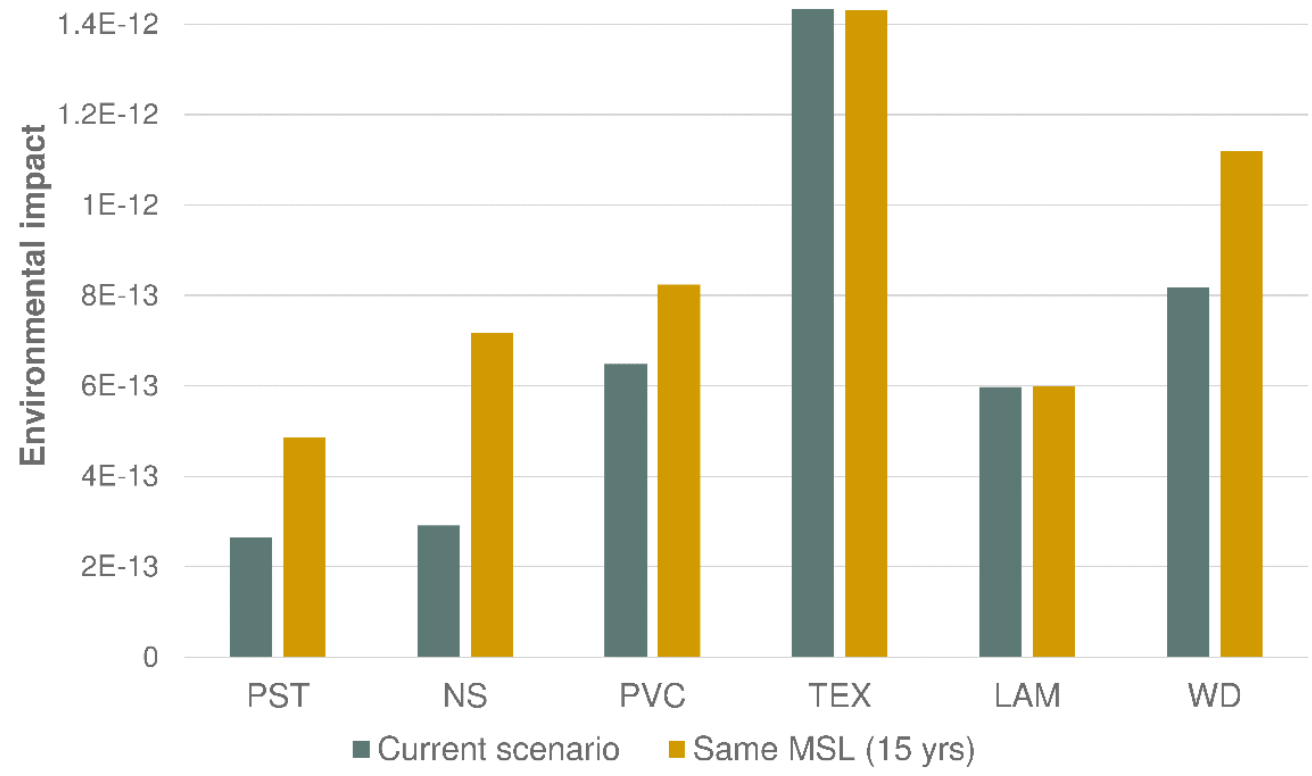

Fig.7 Environmental impacts of the studied FSs in a medium use scenario assuming a service life of 15 years.

Finally, the influence of the FS end-of-life scenarios has been analysed, considering the ideal hypothetical scenario (100\% recycling), considered in this study and the current recycling rate for the different materials according to Eurostat, $2019: 71 \%$ for PST and NS; $89 \%$ for PVC; $79 \%$ for TEX; 0\% for LAM; and $91 \%$ for WD.

Comparing both scenarios, all coverings show variations of less than $8 \%$ for all impact categories, except LAM, whose variation in GWP and POCP is $21 \%$ and $16 \%$, respectively, attributed to the methane emissions, originated in the decomposition of wood in landfills.

\section{Conclusions}

The method adopted in the study suggests that the use of EPDs as information source in comparative studies may be really useful, as was to be expected. However, their use currently requires high expertise in LCA and EPDs to avoid erroneous interpretations. To widen the use of this method for comparing materials with the same functionality, the following recommendations may be made to programs administrators: i) procedure harmonisation: verification methods, specific allocation rules, and criteria for obtaining the information provided by EPDs; and ii) scenario harmonisation beyond the gate, i.e. in the use and end-of-life stages. 
Considering the background information, the methodology applied and the results obtained, the following recommendations may be made to EPD users when selecting building materials: i) always consider all the stages of the life cycle; ii) include in the analysis the rest of the elements of the construction systems in the context of the building; iii) include in the analysis products and operations necessary for the maintenance and repair of the construction solution; and iv) establish a reference study period and consider the material service life, being aware that an intentional shortening of the theoretical material service life will always lead to increases in environmental impacts.

The inorganic floor coverings (PST, NS) behaved worst in the manufacturing stage in almost every impact category. However, they were least affected by pedestrian traffic intensity scenarios, as they required low-intensity maintenance operations and needed no replacement during the RSP. The whole life cycle of the FSs with inorganic coverings thus performed best in impact categories GWP, AP, EP, POCP, and ADPF.

The life cycle of the polymer FS, TEX, entailed the highest impacts in every impact category, except in POCP. The main contributions stemmed from the chemical agents used in wet cleaning operations (GWP, AP, EP, ODP) and the electricity consumed in vacuuming (GWP, AP, ADPF). In addition, the short lifespan played a key role.

In the wood-based FSs, WD appeared to be most affected by repair operations. The decrease in WD thickness from sanding/scraping, which shortened time between replacements and the use of varnish generated significant impacts on GWP, ADPF, and especially on POCP. LAM presented the most favourable results in ODP and ADPE.

Despite being classified in different groups in this study, LAM and PVC exhibited similar overall impacts in the rest of the impact categories, though their contribution came from different stages: while LAM had a shorter lifespan, the impacts from the PVC product stage were higher.

The application of normalisation and weighting factors allowed a simplified comparison to be made. According to this method, the inorganic FSs (PST and NS) performed best, followed by LAM and PVC whose impacts were, on average, 25\% higher. WD exhibited a similar impact to that of LAM and PVC in low traffic areas, while they clearly behaved worse in high-intensity traffic scenarios. TEX showed the worst environmental impact in all traffic scenarios.

The maintenance stage was probably the stage with the most subjective component and was one of the most influential stages in most FSs. A sensitivity analysis was therefore carried out varying the parameters that defined this stage. It was observed that detergent caused significant impacts on ODP and EP, while electricity did so on ADPF and GWP. This stage had a special relevance in TEX, as it accounted for $33 \%$ of its (normalised and weighted) impact. However, though omission of the cleaning operations reduced the absolute value in each impact category, it should be noted that it did not vary the relative position of the FSs. In this sense, a fundamental parameter in determining FSs position was service life (MSL), as it determined the number of replacements within the set time frame (RSP) and hence the magnitude of the related environmental impacts. In this study, these values were drawn from the consulted EPDs, which exhibited no significant 
scatter in this sense. A sensitivity analysis was performed matching the MSLs of all coverings, it being observed that premature substitution of coverings resulted in significant increases in environmental impact.

The Monte Carlo analysis showed that it was necessary to bear in mind that, though the comparisons were based on mean values, the same product category contained variations in product and/or impact, so that the results could not be individualised for each particular case.

\section{Acknowledgements}

This study was carried out with the financial support of the Castellón County Council through the SolconCer project https://solconcer.es, of the Valencia Institute for Business Competitiveness (IVACE) and the European Regional Development Fund [references IMAMCA/2015/1 and IMDEEA/2018/12], and of the European Commission through the LIFE+ Environment Policy and Governance programme [reference LIFE12 ENV/ES/230-LIFE CERAM].

The authors are responsible for the choice and presentation of the information contained in this paper as well as for the opinions expressed therein, which are not necessarily those of UNESCO and do not commit this Organization.

\section{Appendices}

The following complementary information is attached to the online version of this article:

- Literature review

- Analysis of the EPDs considered in this study

- Normalisation and Weighting

\section{References}

Abeysundara, U.G.Y., Babel, S., Piantanakulchai, M., 2009. A matrix for selecting sustainable floor coverings for buildings in Sri Lanka. J. Clean. Prod. 17, 231-238. https://doi.org/https://doi.org/10.1016/j.jclepro.2008.05.002

Akadiri, P.O., 2015. Understanding barriers affecting the selection of sustainable materials in $\begin{array}{lllll}\text { building } & \text { projects. } & \text { J. } & \text { Build. } & \text { Eng. }\end{array}$ https://doi.org/https://doi.org/10.1016/j.jobe.2015.08.006

Albertí, J., Balaguera, A., Brodhag, C., Fullana-i-Palmer, P., 2017. Towards life cycle sustainability assessment of cities. A review of background knowledge. Sci. Total Environ. 609, 1049-1063. https://doi.org/10.1016/j.scitotenv.2017.07.179 
Albertí, J., Civancik-Uslu, D., Contessotto, D., Balaguera, A., Fullana-i-Palmer, P., 2019. Does a life cycle assessment remain valid after 20 years? Scenario analysis with a bus stop study. Resour. Conserv. Recycl. 144, 169-179. https://doi.org/https://doi.org/10.1016/j.resconrec.2019.01.041

Almeida, M.I., Dias, A.C., Demertzi, M., Arroja, L., 2016a. Environmental profile of ceramic tiles and their potential for improvement. J. Clean. Prod. 131, 583-593. https://doi.org/10.1016/j.jclepro.2016.04.131

Almeida, M.I., Dias, A.C., Demertzi, M., Arroja, L., 2016b. Environmental profile of ceramic tiles and their potential for improvement. J. Clean. Prod. 131, 583-593. https://doi.org/10.1016/j.jclepro.2016.04.131

Anand, C.K., Amor, B., 2017. Recent developments, future challenges and new research directions in LCA of buildings: A critical review. Renew. Sustain. Energy Rev. 67, 408-416. https://doi.org/10.1016/J.RSER.2016.09.058

Asif, M., Muneer, T., Kelley, R., 2007. Life cycle assessment: A case study of a dwelling home in $\begin{array}{llll}\text { Scotland. Build. } & \text { Environ. 1391-1394. }\end{array}$ https://doi.org/https://doi.org/10.1016/j.buildenv.2005.11.023

Assiego de Larriva, R., Calleja Rodríguez, G., Cejudo López, J.M., Raugei, M., Fullana i Palmer, P., 2014. A decision-making LCA for energy refurbishment of buildings: Conditions of comfort. Energy Build. 70, 333-342. https://doi.org/10.1016/J.ENBUILD.2013.11.049

Balaguera, A., Carvajal, G.I., Albertí, J., Fullana-i-Palmer, P., 2018. Life cycle assessment of road construction alternative materials: A literature review. Resour. Conserv. Recycl. 132, 37-48. https://doi.org/https://doi.org/10.1016/j.resconrec.2018.01.003

Baraldi, L., 2017. World production and consumption of ceramic tiles. Ceram. world Rev. 123, 5870

Basbagill, J., Flager, F., Lepech, M., Fischer, M., 2013. Application of life-cycle assessment to early stage building design for reduced embodied environmental impacts. Build. Environ. 60, 81-92. https://doi.org/https://doi.org/10.1016/j.buildenv.2012.11.009

Benveniste, G., Gazulla, C., Fullana, P., Celades, I., Ros, T., Zaera, V., Godes, B., 2011. Life cycle assessment and product category rules for the construction sector. The floor and wall tiles sector case study. Inf. la Construcción 63, 71-81. https://doi.org/10.3989/ic.10.034

Bovea, M.D., Díaz-Albo, E., Gallardo, A., Colomer, F.J., Serrano, J., 2010. Environmental performance of ceramic tiles: Improvement proposals. Mater. Des. 31, 35-41. https://doi.org/10.1016/j.matdes.2009.07.021

Bovea, M.D., Ibáñez-Forés, V., Agustí-Juan, I., 2014. Environmental product declaration (EPD) labelling of construction and building materials. Eco-efficient Constr. Build. Mater. 125-150. https://doi.org/10.1533/9780857097729.1.125

Bovea, M.-D., Saura, Ú., Ferrero, J.L., Giner, J., 2007. Cradle-to-gate study of red clay for use in the ceramic industry. Int. J. Life Cycle Assess. 12, 439. https://doi.org/https://doi.org/10.1065/lca2006.06.252 
Capros, P., De Vita, A., Tasios, N., Papadopoulos, D., Siskos, P., Apostolaki, E., Zampara, M., Paroussos, L., Fragiadakis, K., Kouvaritakis, N., 2013. EU energy, transport and GHG emissions: trends to 2050, reference scenario 2013. European Commission, Directorate-General for Energy, Directorate-General for Climate Action and Directorate-General for Mobility and Transport, Luxembourg. https://doi.org/10.2833/17897

Carlo Montani, 2018. XXVIII World Marble and Stones Report 2017. Aldus Casa di Edizioni, Carrara, Italy

CET, 2014. - European Ceramic Tile Manufacturer's Federation. Product Category Rules for preparing an Environmental Product Declaration for Ceramic tiles. Brussels, Belgium

Chang, D., Lee, C.K.M., Chen, C.-H., 2014. Review of life cycle assessment towards sustainable product development. J. Clean. Prod. 83, 48-60. https://doi.org/https://doi.org/10.1016/j.jclepro.2014.07.050

COM/2011/0571 final, 2011. Roadmap to a Resource Efficient Europe. Communication from the Commission to the European Parliament, the Council, the European Economic and Social Committee and the Committee of the Regions

COM/2014/445 final, 2014. Resource Efficiency Opportunities in the Building Sector. Communication from the Commission to the European Parliament, the Council, the European Economic and Social Committee and the Committee of the Regions

COM/2015/0614 final, 2015. Closing the loop - An EU action plan for the Circular Economy. Communication from the Commission to the European Parliament, the Council, the European Economic and Social Committee and the Committee of the Regions

Cuéllar-Franca, R.M., Azapagic, A., 2012. Environmental impacts of the UK residential sector: Life cycle assessment of houses. Build. Environ. 54, 86-99. https://doi.org/https://doi.org/10.1016/j.buildenv.2012.02.005

CYPE Ingenieros, S.A., 2018. Generador de precios de la construcción. España [WWW Document]. URL http://www.generadordeprecios.info/ (accessed 10.9.18). (In Spanish)

DAPconstrucción $®, 2015$. RCP 002, v2. Reglas de Categoría de Producto para preparar una Declaración Ambiental de Producto (DAPcons) sobre productos de revestimiento cerámico (in Spanish).

Diputación de Castellón, 2018. Solconcer. Caracterización de Soluciones Constructivas [WWW Document]. URL http://solconcer.es/ (accessed 10.9.18). (In Spanish)

EN 12058, 2015. Natural stone products - Slabs for floors and stairs - Requirements. European Standards

EN 1307+A1, 2016. Textile floor coverings - Classification. European Standards

EN 13329, 2017. Laminate floor coverings - Elements with a surface layer based on aminoplastic thermosetting resins - Specifications, requirements and test methods (includes Amendment :2017). European Standards 
EN 14342, 2013. Wood flooring - Characteristics, evaluation of conformity and marking. European Standards

EN 15804+A1, 2013. Sustainability of construction works - Environmental product declarations Core rules for the product category of construction products. CEN European Commission, Brussels, Belgium

EN 15978, 2011. Sustainability of construction works - Assessment of environmental performance of buildings - Calculation method. European Standards

European Carpet and Rug Association (ECRA), 2018. The European Carpet Market [WWW Document]. URL http://www.ecra.eu/ (accessed 7.23.18)

European Federation of the Parquet Industry (FEP), 2017. The European Parquet Industries in 2016 [WWW Document]. URL http://www.parquet.net/files/2017_-_FEP_-_Market_-_June_PR.pdf (accessed 7.25.18)

European Producers of Laminate Flooring (EPLF), 2018. Market Statistics [WWW Document]. URL https://www.eplf.com/sites/default/files/downloads/elnd1802_b1-7_eplf_sales2017_press.pdf (accessed 7.25.18)

Eurostat, 2019. Treatment of waste by waste category, hazardousness and waste management operations [env_wastrt] [WWW Document]. Eur. Comm. URL http://appsso.eurostat.ec.europa.eu/nui/show.do?dataset=env_wastrt\&lang=en (Accessed 06.26.2019)

Fazeni, K., Lindorfer, J., Prammer, H., 2014. Methodological advancements in life cycle process design: a preliminary outlook. Resour. Conserv. Recycl. 92, 66-77. https://doi.org/https://doi.org/10.1016/j.resconrec.2014.08.011

Fila Industria Chimica S.p.A., 2018. Fila Industria Chimica S.p.A. [WWW Document]. URL https://www.filasolutions.com/ (accessed 1.31.19)

Floor covering weekly, 2018. Statistical Report 2017. Floor Cover. Wkly. 67

Frischknecht, R., 2010. LCl modelling approaches applied on recycling of materials in view of environmental sustainability, risk perception and eco-efficiency. Int. J. Life Cycle Assess. 15, 666671. https://doi.org/10.1007/s11367-010-0201-6

Ganassali, S., Lavagna, M., Campioli, A., Saporetti, S., 2018. Green Public Procurement and Construction Sector: EPD and LCA based benchmarks of the whole-building, in: Designing Sustainable Technologies, Products and Policies. Springer, pp. 503-513. https://doi.org/https://doi.org/10.1007/978-3-319-66981-6_5

Gazi, A., Skevis, G., Founti, M.A., 2012. Energy efficiency and environmental assessment of a typical marble quarry and processing plant. J. Clean. Prod. 32, 10-21. https://doi.org/https://doi.org/10.1016/j.jclepro.2012.03.007

Gazulla Santos, C., 2012. Declaraciones ambientales de producto instrumento para la mejora de productos. PhD thesis. UNESCO Chair Life Cycle Clim. Chang. ESCI-UPF Inst. Ciència i Tecnol. Ambient. Dr. en Ciència i Tecnol. Ambient. Univ. Autònoma Barcelona. (In Spanish) 
Gelowitz, M.D.C., McArthur, J.J., 2017. Comparison of type III environmental product declarations for construction products: Material sourcing and harmonization evaluation. J. Clean. Prod. 157, 125-133. https://doi.org/https://doi.org/10.1016/j.jclepro.2017.04.133

Gelowitz, M.D.C., McArthur, J.J., 2016. Investigating the Effect of Environmental Product Declaration Adoption in LEED $®$ on the Construction Industry: A Case Study. Procedia Eng. 145, 58-65. https://doi.org/10.1016/J.PROENG.2016.04.014

GlobalEPD, 2018. RCP 002, v2. Regla de Categoría de Producto de Recubrimientos cerámicos. Madrid. (In Spanish)

Günther, A., Langowski, H.-C., 1997. Life cycle assessment study on resilient floor coverings. Int. J. Life Cycle Assess. 2, 73-80. https://doi.org/https://doi.org/10.1007/BF02978763

Häfliger, I.-F., John, V., Passer, A., Lasvaux, S., Hoxha, E., Saade, M.R.M., Habert, G., 2017. Buildings environmental impacts' sensitivity related to LCA modelling choices of construction materials. J. Clean. Prod. 156, 805-816. https://doi.org/10.1016/J.JCLEPRO.2017.04.052

Heisterberg - Moutsis, G., Heinz, R., Wolf, T.F., Harper, D.J., James, D., Mazzur, R.P., Kettler, V., Soiné, H., Peoples, R., 2017. Floor Coverings. Ullmann' s Encycl. Ind. Chem. 1 - 26. https://doi.org/https://doi.org/10.1002/14356007.a11_263.pub2

Hill, C., Norton, A., Dibdiakova, J., 2018. A comparison of the environmental impacts of different categories of insulation materials. Energy Build. 162, 12-20. https://doi.org/https://doi.org/10.1016/j.enbuild.2017.12.009

Holzmann maschinen GmbH, 2018. Holzmann maschinen GmbH [WWW Document]. URL https://www.holzmann-maschinen.at (accessed 1.31.19)

Hunsager, E.A., Bach, M., Breuer, L., 2014. An institutional analysis of EPD programs and a global PCR registry. Int. J. Life Cycle Assess. 19, 786-795. https://doi.org/10.1007/s11367-014-0711-8

Ibáñez-Forés, V., Bovea, M.-D., Simó, A., 2011. Life cycle assessment of ceramic tiles. Environmental and statistical analysis. Int. J. Life Cycle Assess. 16, 916-928. https://doi.org/10.1007/s11367-011-0322-6

IEE Project TABULA, 2012. Typology Approach for Building Stock Energy Assessment [WWW Document]. URL http://webtool.building-typology.eu/\#bm (accessed 10.9.18)

IETcc-CSIC, 2011. Catálogo de elementos constructivos del Código Técnico de la Edificación. Ministerio de Fomento de España, Madrid. (In Spanish)

Institut Bauen und Umwelt e.V., 2017. Part B: Requirements on the EPD for Ceramic tiles and panels. Berlin.

Institut Bauen und Umwelt e.V., 2017. Part B: Requirements on the EPD for Synthetic carpet yarns. Berlin.

Iribarren, D., Marvuglia, A., Hild, P., Guiton, M., Popovici, E., Benetto, E., 2015. Life cycle assessment and data envelopment analysis approach for the selection of building components according to their environmental impact efficiency: a case study for external walls. J. Clean. Prod. 87, 707-716. https://doi.org/https://doi.org/10.1016/j.jclepro.2014.10.073 
Islam, H., Jollands, M., Setunge, S., Haque, N., Bhuiyan, M.A., 2015. Life cycle assessment and life cycle cost implications for roofing and floor designs in residential buildings. Energy Build. 104, 250-263. https://doi.org/10.1016/j.enbuild.2015.07.017

ISO 10581, 2011. Resilient floor coverings -- Homogeneous poly(vinyl chloride) floor covering -Specifications, 1st ed. International Organization for Standardization

ISO 10582, 2017. Resilient floor coverings -- Heterogeneous poly(vinyl chloride) floor covering -Specifications, 2nd ed. International Organization for Standardization

ISO 13006, 2012. Ceramic tiles - Definitions, classification, characteristics and marking, 2nd ed. International Organization for Standardization, USA

ISO 14025, 2006. Environmental labels and declarations -- Type III environmental declarations -Principles and procedures, 1st ed. International Organization for Standardization

ISO 14040, 2006. Environmental management -- Life cycle assessment -- Principles and framework, 2nd ed. International Organization for Standardization, Geneva.

ISO 14044, 2006. Environmental management -- Life cycle assessment -- Requirements and guidelines. International Organization for Standardization, Geneva

ISO 21930, 2017. Sustainability in buildings and civil engineering works -- Core rules for environmental product declarations of construction products and services, 2nd ed. International Organization for Standardization

Joint Research Centre, 2015. European Reference Life-Cycle Database. Version 3.2. [WWW Document]. URL http://eplca.jrc.ec.europa.eu/ELCD3/processList.xhtml (accessed 5.16.16)

Jönsson, A., 1999. Including the use phase in LCA of floor coverings. Int. J. Life Cycle Assess. 4, 321-328. https://doi.org/https://doi.org/10.1007/BF02978521

Jönsson, Å., Tillman, A.-M., Svensson, T., 1997. Life cycle assessment of flooring materials: case study. Build. Environ. 32, 245-255

Jungmeier, G., Werner, F., Jarnehammar, A., Hohenthal, C., Richter, K., 2002. Allocation in LCA of wood-based products experiences of cost action E9. Int. J. Life Cycle Assess. 7, 369-375. https://doi.org/10.1007/BF02978686

Khasreen, M.M., Banfill, P.F.G., Menzies, G.F., 2009. Life-cycle assessment and the environmental impact of buildings: a review. Sustainability 1, 674-701

Lasvaux, S., Gantner, J., Wittstock, B., Bazzana, M., Schiopu, N., Saunders, T., Gazulla, C., Mundy, J.A., Sjöström, C., Fullana-i-Palmer, P., 2014. Achieving consistency in life cycle assessment practice within the European construction sector: the role of the EeBGuide InfoHub. Int. J. Life Cycle Assess. 19, 1783-1793. https://doi.org/https://doi.org/10.1007/s11367-014-0786-2

Laurin, L., Amor, B., Bachmann, T.M., Bare, J., Koffler, C., Genest, S., Preiss, P., Pierce, J., Satterfield, B., Vigon, B., 2016. Life cycle assessment capacity roadmap (section 1): decisionmaking support using LCA. Int. J. Life Cycle Assess. 21, 443-447. https://doi.org/10.1007/s11367016-1031-y 
Mercante, I.T., Bovea, M.D., Ibáñez-Forés, V., Arena, A.P., 2012. Life cycle assessment of construction and demolition waste management systems: a Spanish case study. Int. J. Life Cycle Assess. 17, 232-241. https://doi.org/10.1007/s11367-011-0350-2

Ministerio de Fomento de España, 2011. Documentos básicos del Código Técnico de la Edificación [WWW Document]. URL https://www.codigotecnico.org/ (In Spanish)

Ministerio de Fomento de España, 2009. Documento Básico DB-HR Protección frente al ruido del Código Técnico de la Edificación / Apartado 3.1.2.3.5 Condiciones mínimas de los elementos de separación horizontales (In Spanish)

Minkov, N., Schneider, L., Lehmann, A., Finkbeiner, M., 2015. Type III Environmental Declaration Programmes and harmonization of product category rules: status quo and practical challenges. J. Clean. Prod. 94, 235-246. https://doi.org/https://doi.org/10.1016/j.jclepro.2015.02.012

Minne, E., Crittenden, J.C., 2015. Impact of maintenance on life cycle impact and cost assessment for residential flooring options. Int. J. Life Cycle Assess. 20, 36-45. https://doi.org/10.1007/s11367-014-0809-z

Monfort, E., 2012. What role do Ceramic Tiles play in Green Procurement and Sustainable Building?, in: World Congress on Ceramic Tile Quiality-Qualicer. Castelló, Spain

Nebel, B., Cowell, S.J., 2003. Global warming reduction potential of biomass based products: an example of wood products, in: Proceedings of the XXth SETAC-Europe Annual Meeting. p. 49

Nebel, B., Zimmer, B., Wegener, G., 2006. Life cycle assessment of wood floor coverings-a representative study for the german flooring industry. Int. J. life cycle Assess. 11, 172-182. https://doi.org/https://doi.org/10.1065/lca2004.10.187

Nicoletti, G.M., Notarnicola, B., Tassielli, G., 2002. Comparative Life Cycle Assessment of flooring materials: ceramic versus marble tiles. J. Clean. Prod. 10, 283-296. https://doi.org/10.1016/S0959-6526(01)00028-2

Ortiz, O., Castells, F., Sonnemann, G., 2009. Sustainability in the construction industry: A review of recent developments based on LCA. Constr. Build. Mater. 23, 28-39. https://doi.org/https://doi.org/10.1016/j.conbuildmat.2007.11.012

Parador GmbH \& Co.KG, 2013. Environmental Product Declaration, PD-PAR-20130290-IBC2-EN. Coesfeld, Germany

Passer, A., Lasvaux, S., Allacker, K., De Lathauwer, D., Spirinckx, C., Wittstock, B., Kellenberger, D., Gschösser, F., Wall, J., Wallbaum, H., 2015. Environmental product declarations entering the building sector: critical reflections based on 5 to 10 years experience in different European countries. Int. J. Life Cycle Assess. 20, 1199-1212. https://doi.org/10.1007/s11367-015-0926-3

Paulsen, J., 1999. Service life prediction for floor coverings. Durab. Build. Mater. components. Ottawa NRC 1467-1474

Pini, M., Ferrari, A.M., Gamberini, R., Neri, P., Rimini, B., 2014. Life cycle assessment of a large, thin ceramic tile with advantageous technological properties. Int. J. Life Cycle Assess. 19, 15671580. https://doi.org/10.1007/s11367-014-0764-8 
Potting, J., Blok, K., 1995. Life-cycle assessment of four types of floor covering. J. Clean. Prod. 3, 201-213. https://doi.org/https://doi.org/10.1016/0959-6526(95)00082-8

Puig, R., Kiliç, E., Navarro, A., Albertí, J., Chacón, L., Fullana-i-Palmer, P., 2017. Inventory analysis and carbon footprint of coastland-hotel services: A Spanish case study. Sci. Total Environ. 595, 244-254. https://doi.org/https://doi.org/10.1016/j.scitotenv.2017.03.245

REE Red Eléctrica de España, 2018. Informe del sistema eléctrico español 2017 [WWW Document].

URL https://www.ree.es/sites/default/files/11_PUBLICACIONES/Documentos/InformesSistemaElectri co/2017/inf_sis_elec_ree_2017.pdf (accessed 5.9.19).

Regulation (EU) No 305/2011, 2011. European Parliament and of the Council of 9 March 2011 laying down harmonised conditions for the marketing of construction products and repealing Council Directive 89/106/EEC

Reza, B., Sadiq, R., Hewage, K., 2011. Sustainability assessment of flooring systems in the city of Tehran: An AHP-based life cycle analysis. Constr. Build. Mater. 25, 2053-2066. https://doi.org/https://doi.org/10.1016/j.conbuildmat.2010.11.041

Ros-Dosdá, T., Celades, I., Monfort, E., Fullana-i-Palmer, P., 2018a. Environmental profile of Spanish porcelain stoneware tiles. Int. J. Life Cycle Assess. 23, 1562-1580. https://doi.org/10.1007/s11367-017-1377-9

Ros-Dosdá, T., Fullana-i-Palmer, P., Mezquita, A., Masoni, P., Monfort, E., 2018b. How can the European ceramic tile industry meet the EU's low-carbon targets? A life cycle perspective. J. Clean. Prod. 199, 554-564. https://doi.org/https://doi.org/10.1016/j.jclepro.2018.07.176

Saarela, K., 1999. Emission from floor coverings. Org. Indoor Air Pollut. Occur. 185-202. https://doi.org/https://doi.org/10.1002/9783527613663.ch14

Silvestre, J.D., De Brito, J., Pinheiro, M.D., 2014. Environmental impacts and benefits of the endof-life of building materials-calculation rules, results and contribution to a "cradle to cradle" life cycle. J. Clean. Prod. 66, 37-45. https://doi.org/https://doi.org/10.1016/j.jclepro.2013.10.028

Sollinger, S., Levsen, K., Wünsch, G., 1993. Indoor air pollution by organic emissions from textile floor coverings. Climate chamber studies under dynamic conditions. Atmos. Environ. Part B. Urban Atmos. 27, 183-192. https://doi.org/10.1016/0957-1272(93)90004-P

Thinkstep AG, 2018a. GaBi Software-system. Compilation 8.0.718 [WWW Document]. URL http://www.gabi-software.com/software/ (accessed 5.17.16)

Thinkstep AG, 2018b. Database for Life Cycle Engineering. Professional + Construction materials extension (version 8007)

Thuring M.; Spirinckx C.; Debacke W., 2013. PCR-TBE. Product Category Rules for Environmental Product Declarations for Construction Clay Products. Mol, Belgium

Tikul, N., Srichandr, P., 2010. Assessing the environmental impact of ceramic tile production in Thailand. J. Ceram. Soc. Japan 118, 887-894. https://doi.org/10.2109/jcersj2.118.887 
Traverso, M., Rizzo, G., Finkbeiner, M., 2010. Environmental performance of building materials: life cycle assessment of a typical Sicilian marble. Int. J. Life Cycle Assess. 15, 104. https://doi.org/10.1007/s11367-009-0135-z

Tuomainen, A., Seuri, M., Sieppi, A., 2004. Indoor air quality and health problems associated with damp floor coverings. Int. Arch. Occup. Environ. Health 77, 222-226. https://doi.org/10.1007/s00420-003-0481-2

Wolf, M.-A., Chomkhamsri, K., Brandao, M., Pant, R., Ardente, F., Pennington, D.W., Manfredi, S., de Camillis, C., Goralczyk, M., 2010. ILCD Handbook-General Guide for Life Cycle AssessmentDetailed Guidance. https://doi.org/10.2788/38479

Zabalza Bribián, I., Aranda Usón, A., Scarpellini, S., 2009. Life cycle assessment in buildings: Stateof-the-art and simplified LCA methodology as a complement for building certification. Build. Environ. 44, 2510-2520. https://doi.org/10.1016/J.BUILDENV.2009.05.001

Zabalza, I., Valero, A., Aranda, A., 2011. Life cycle assessment of building materials: Comparative analysis of energy and environmental impacts and evaluation of the eco-efficiency improvement $\begin{array}{llll}\text { potential. Build. } & \text { Environ. 1133-1140. }\end{array}$ https://doi.org/https://doi.org/10.1016/j.buildenv.2010.12.002 


\section{Appendix 1:}

Literature review 


\begin{tabular}{|c|c|c|c|c|}
\hline 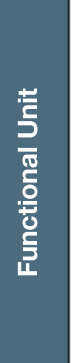 & 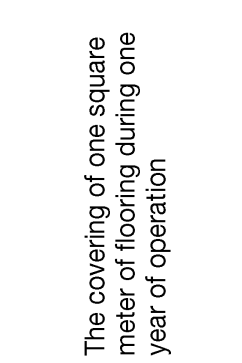 & 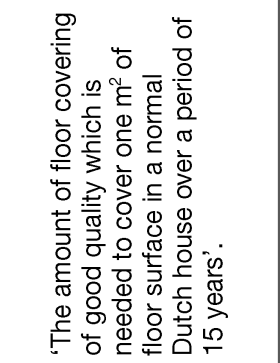 & 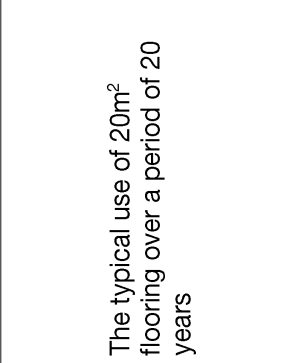 & 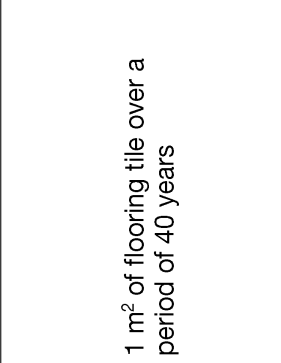 \\
\hline 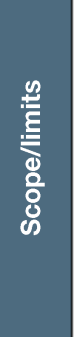 & $\begin{array}{l}0 \\
\frac{1}{0} \\
\frac{0}{5} \\
0 \\
0 \\
\frac{1}{0} \\
\frac{\pi}{0} \\
0\end{array}$ & 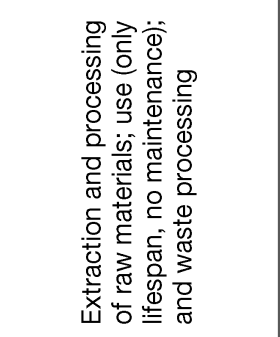 & $\begin{array}{l}\stackrel{0}{\pi} \\
\stackrel{0}{0} \\
0 \\
0 \\
\frac{0}{0} \\
\frac{0}{0} \\
0 \\
0\end{array}$ & 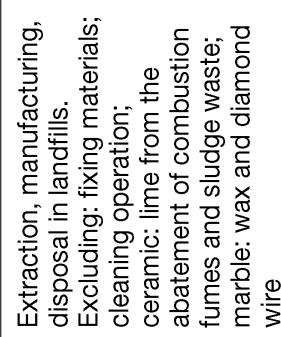 \\
\hline 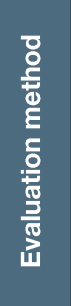 & 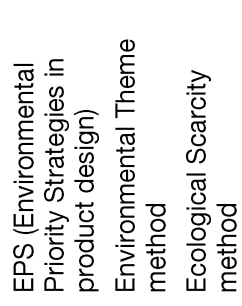 & 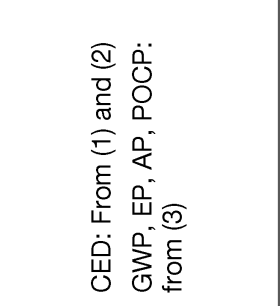 & 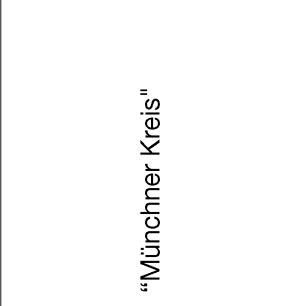 & 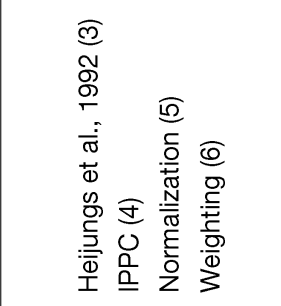 \\
\hline 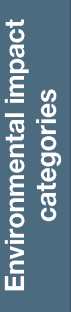 & 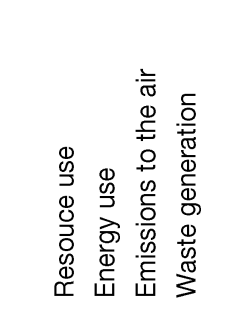 & 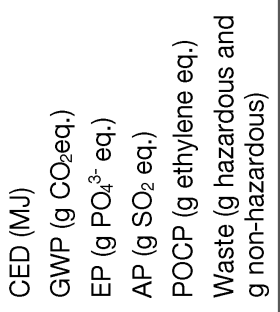 & 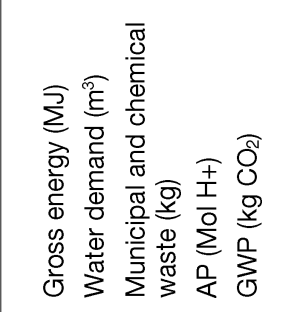 & 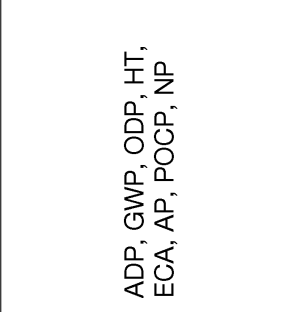 \\
\hline 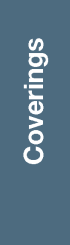 & 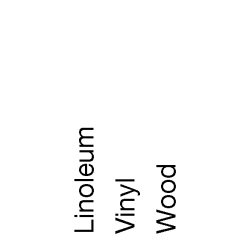 & 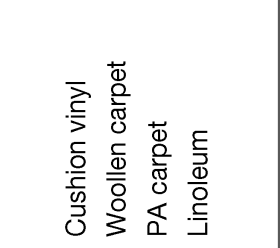 & 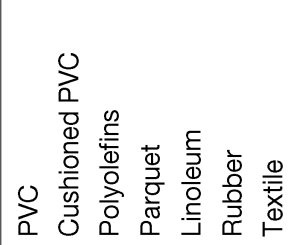 & 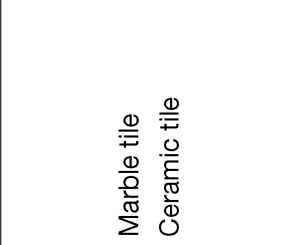 \\
\hline 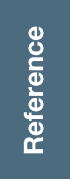 & 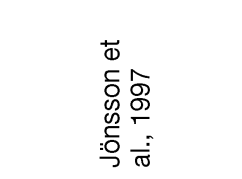 & 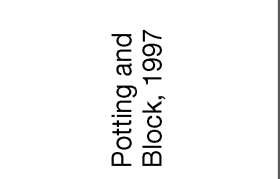 & 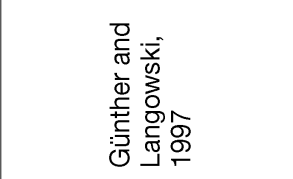 & 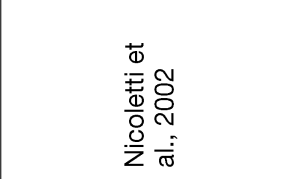 \\
\hline
\end{tabular}




\begin{tabular}{|c|c|c|c|c|}
\hline 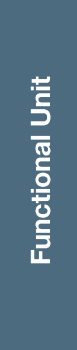 & 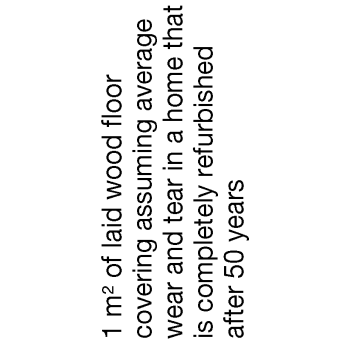 & 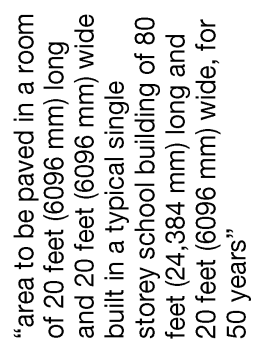 & 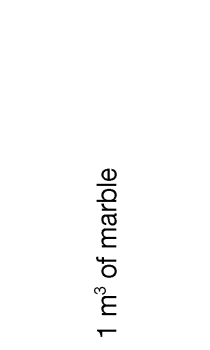 & 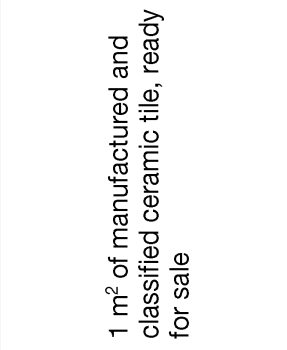 \\
\hline 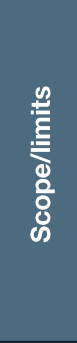 & 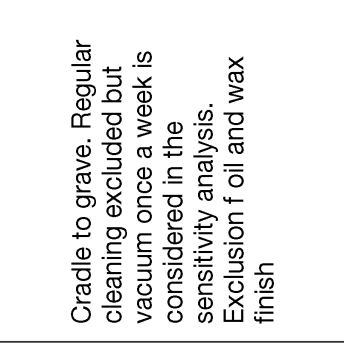 & 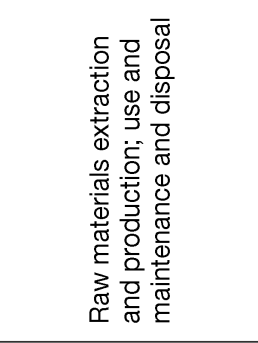 & 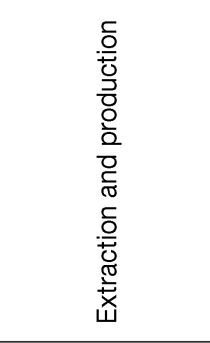 & 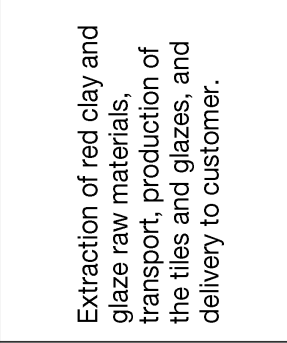 \\
\hline 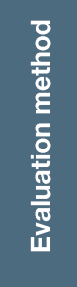 & 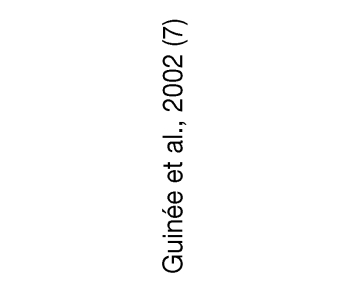 & 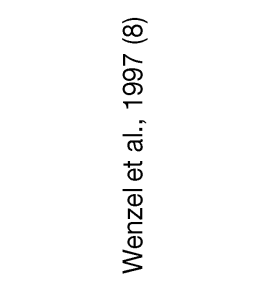 & 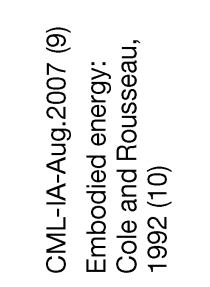 & 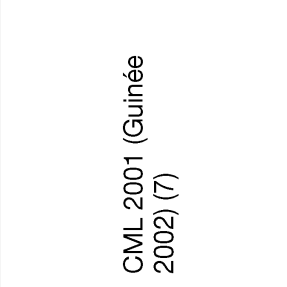 \\
\hline 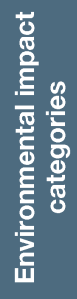 & 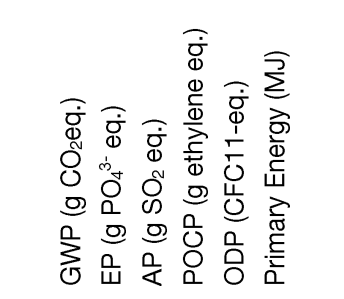 & 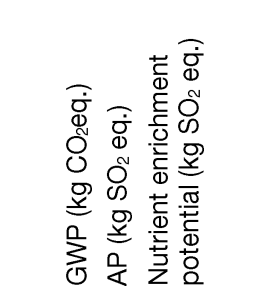 & 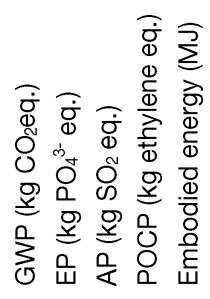 & 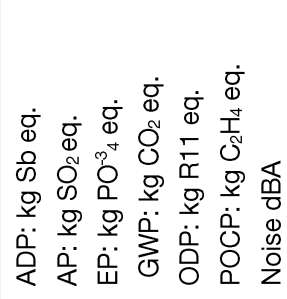 \\
\hline 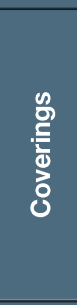 & 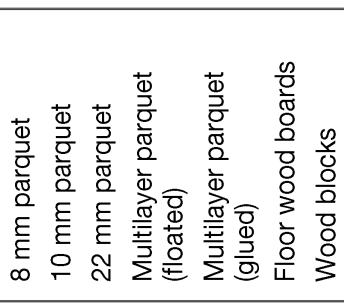 & 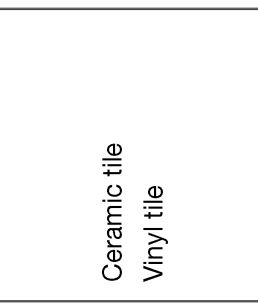 & 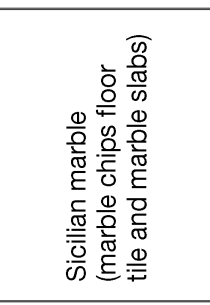 & 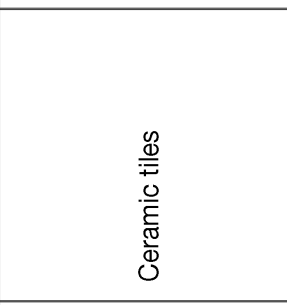 \\
\hline 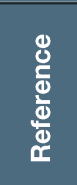 & 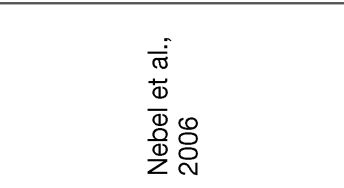 & 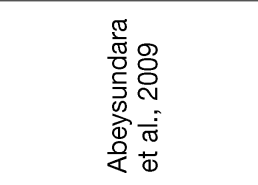 & 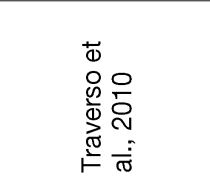 & 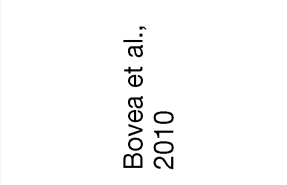 \\
\hline
\end{tabular}




\begin{tabular}{|c|c|c|c|c|}
\hline 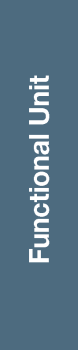 & 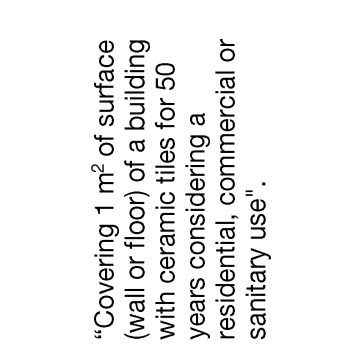 & 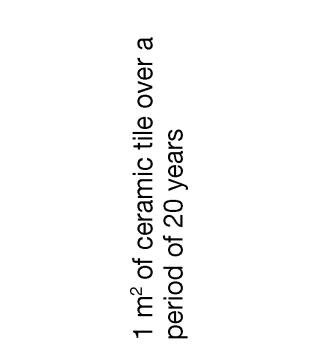 & 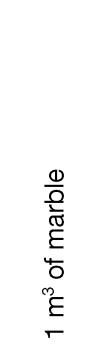 & 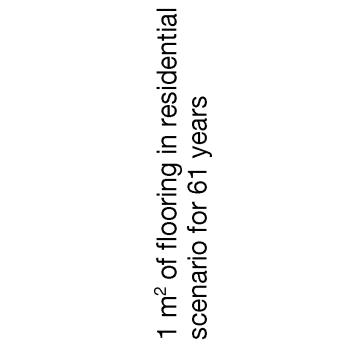 \\
\hline 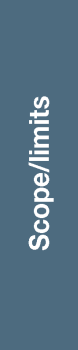 & 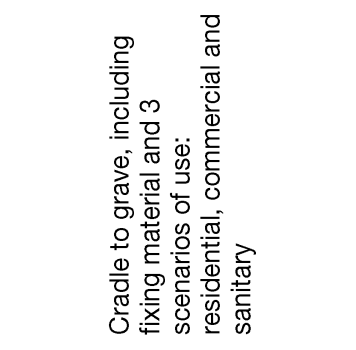 & 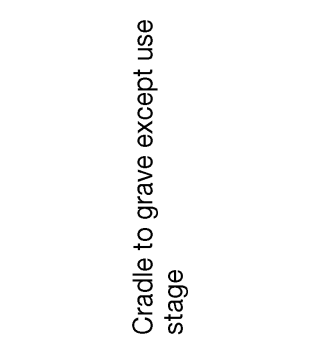 & 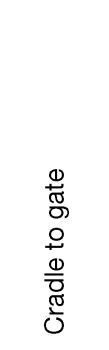 & 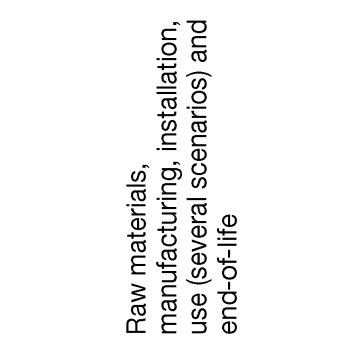 \\
\hline 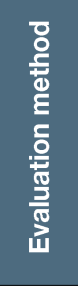 & 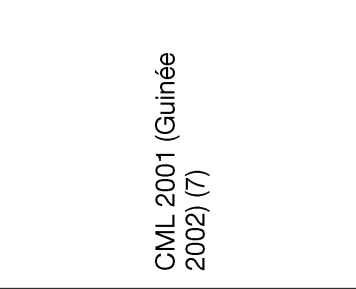 & 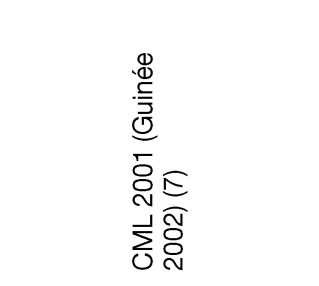 & 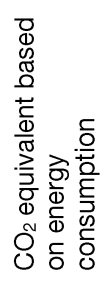 & 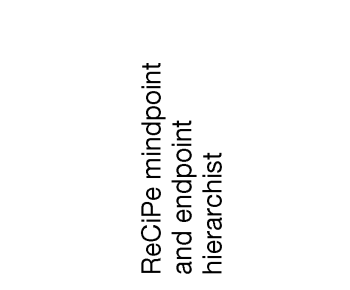 \\
\hline 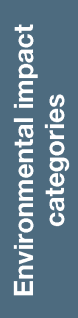 & 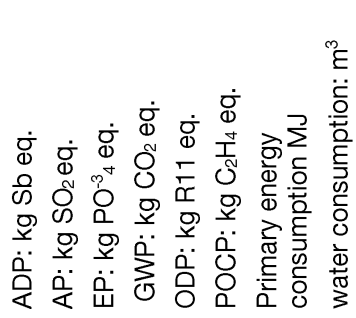 & 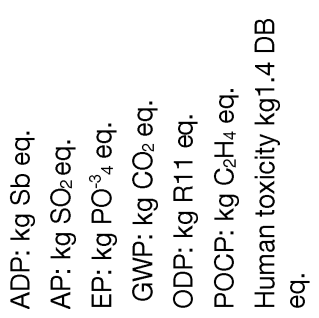 & $\begin{array}{l}\dot{\Phi} \\
\delta^{N} \\
\tilde{O}^{N}\end{array}$ & 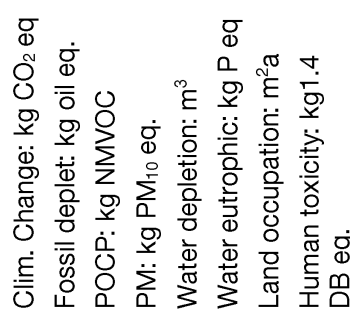 \\
\hline 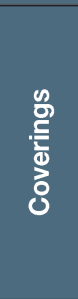 & 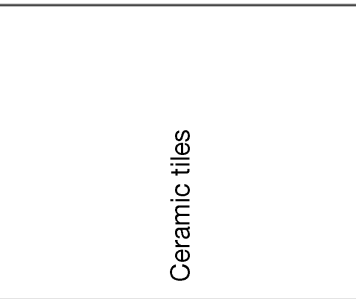 & 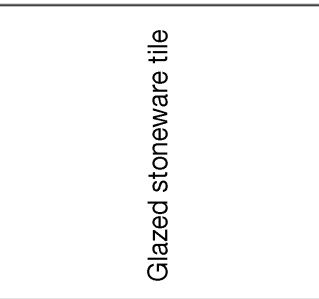 & $\begin{array}{l}\frac{0}{0} \\
\frac{0}{20}\end{array}$ & 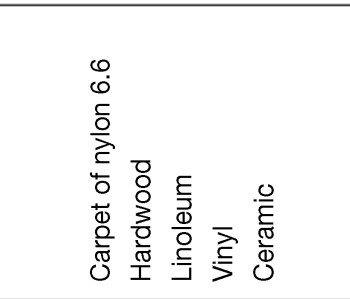 \\
\hline 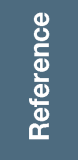 & 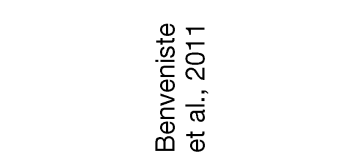 & 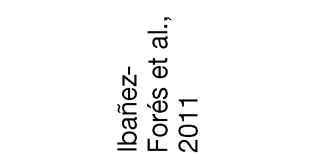 & 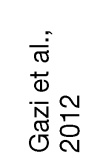 & 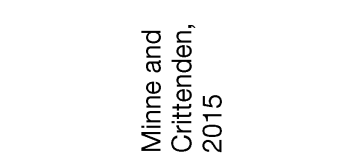 \\
\hline
\end{tabular}




\begin{tabular}{|c|c|c|c|}
\hline 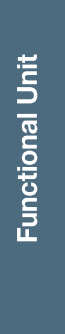 & 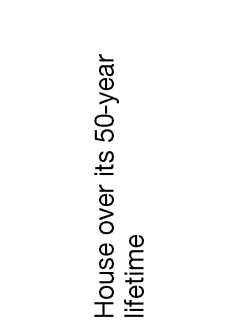 & 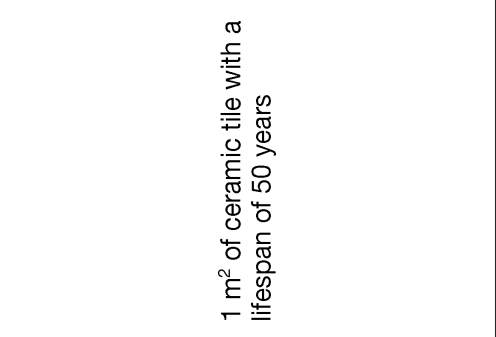 & 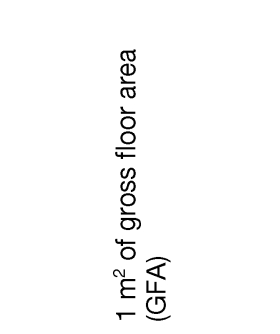 \\
\hline 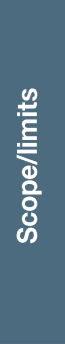 & 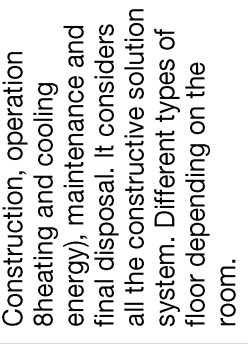 & \begin{tabular}{l}
$\frac{0}{0}$ \\
\multirow{0}{0}{} \\
0 \\
+ \\
$\frac{0}{0}$ \\
$\frac{0}{0}$ \\
0
\end{tabular} & $\begin{array}{l}\frac{1}{0} \\
\mathbb{0} \\
0 \\
0 \\
\frac{0}{0} \\
\overline{0} \\
0 \\
0\end{array}$ \\
\hline 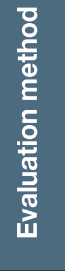 & 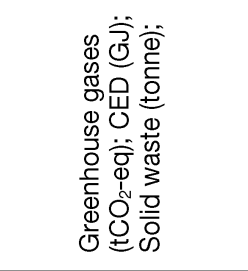 & 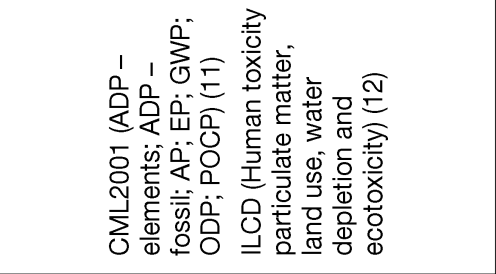 & $\begin{array}{l}\frac{5}{3} \\
0 \\
\frac{1}{5} \\
\frac{1}{5} \\
\frac{0}{0} \\
\frac{5}{ \pm} \\
\sum\end{array}$ \\
\hline 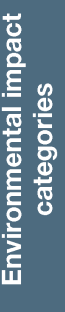 & 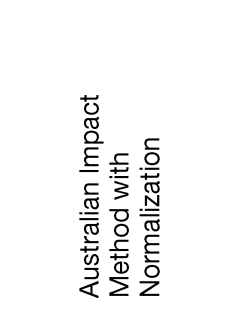 & 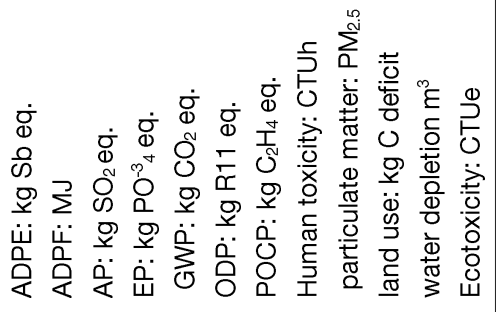 & 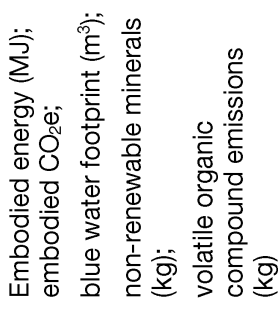 \\
\hline$\frac{\mathrm{g}}{\mathrm{E}}$ & 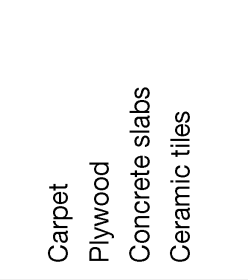 & 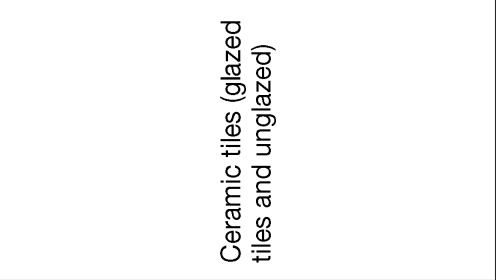 & 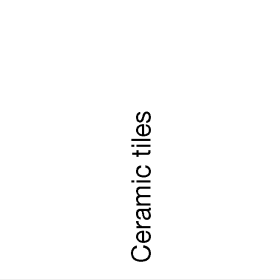 \\
\hline 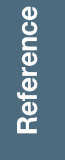 & 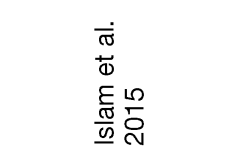 & 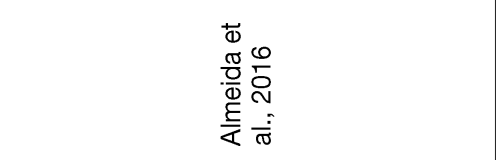 & 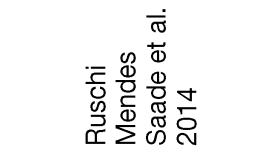 \\
\hline
\end{tabular}




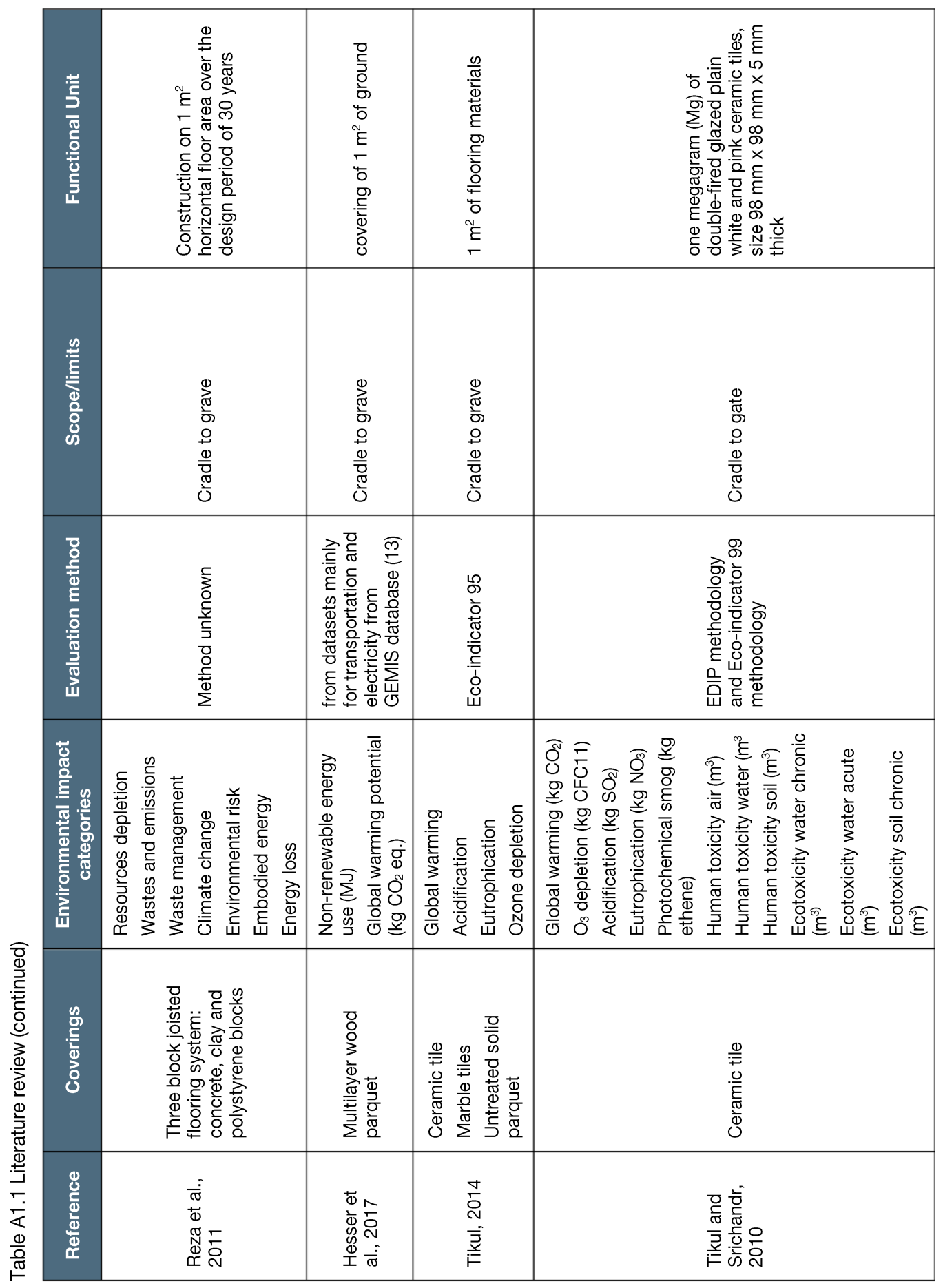




\begin{tabular}{|c|c|c|c|}
\hline 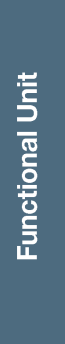 & 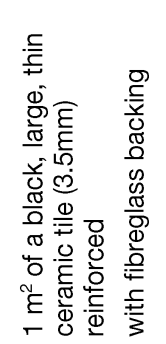 & 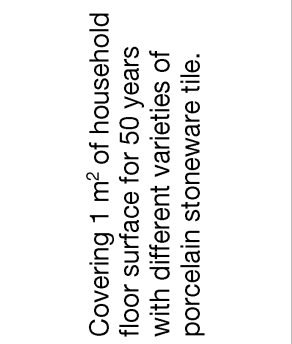 & 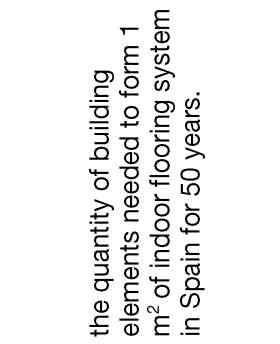 \\
\hline 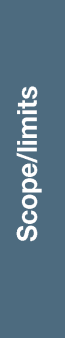 & 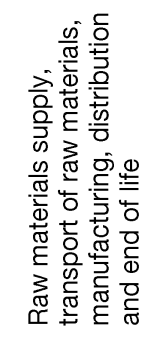 & $\begin{array}{l}0 \\
\stackrel{0}{\pi} \\
\frac{\pi}{5} \\
0 \\
+0 \\
\frac{0}{0} \\
\frac{\pi}{0} \\
0\end{array}$ & 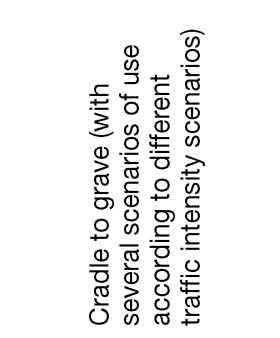 \\
\hline 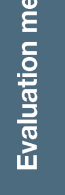 & 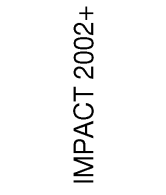 & 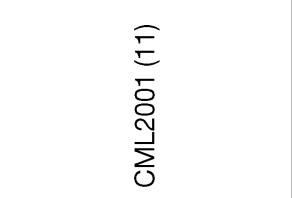 & 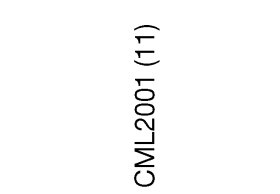 \\
\hline 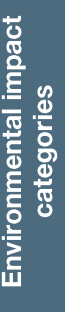 & 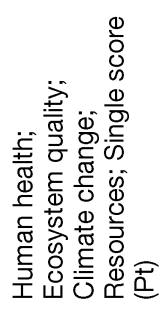 & 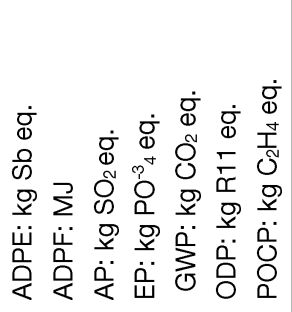 & 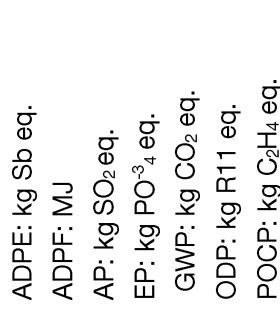 \\
\hline 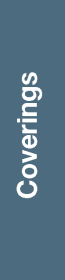 & 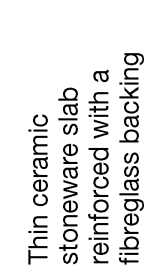 & 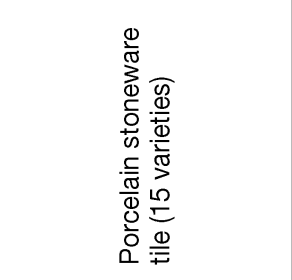 & 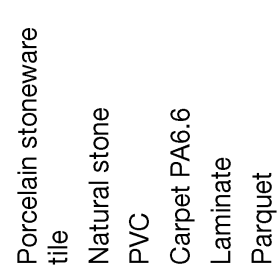 \\
\hline 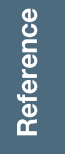 & 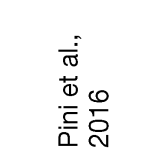 & 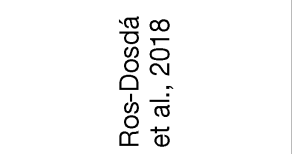 & 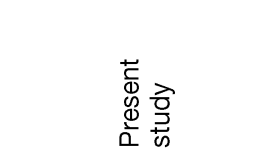 \\
\hline
\end{tabular}




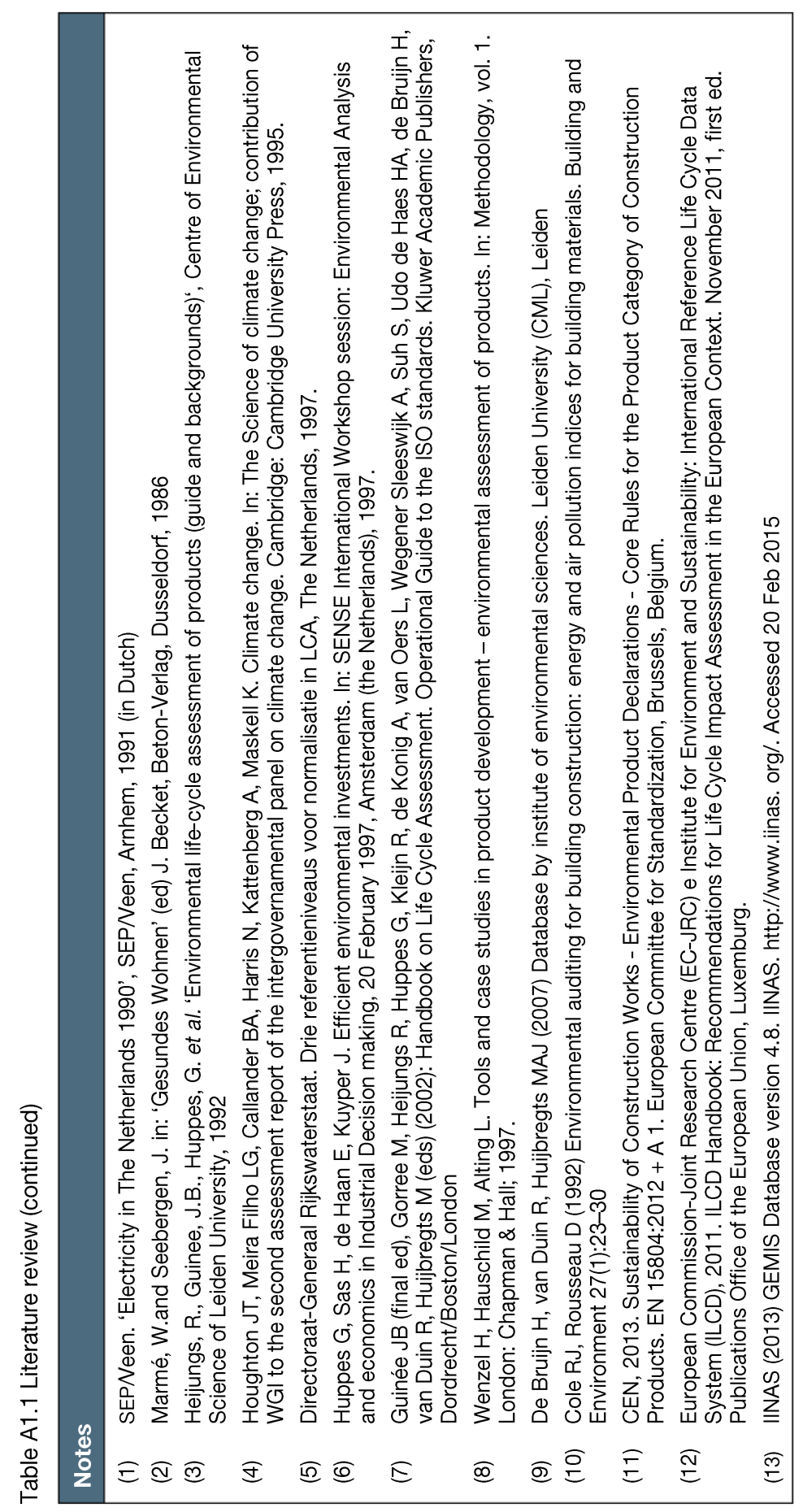




\section{References}

Abeysundara, U.G.Y., Babel, S., Piantanakulchai, M., 2009. A matrix for selecting sustainable floor coverings for buildings in Sri Lanka. J. Clean. Prod. 17, 231-238. https://doi.org/https://doi.org/10.1016/j.jclepro.2008.05.002

Almeida, M.I., Dias, A.C., Demertzi, M., Arroja, L., 2016. Environmental profile of ceramic tiles and their potential for improvement. J. Clean. Prod. 131, 583-593. https://doi.org/10.1016/j.jclepro.2016.04.131

Benveniste, G., Gazulla, C., Fullana, P., Celades, I., Ros, T., Moliner, R., Zaera, V., Godes, B., 2010. Sectoral Life cycle assessment of ceramic tile, in: XI Global Forum of Ceramic Tile. Castellón, Spain.

Bovea, M.D., Díaz-Albo, E., Gallardo, A., Colomer, F.J., Serrano, J., 2010. Environmental performance of ceramic tiles: Improvement proposals. Mater. Des. 31, 35-41. https://doi.org/10.1016/j.matdes.2009.07.021

Gazi, A., Skevis, G., Founti, M.A., 2012. Energy efficiency and environmental assessment of a typical marble quarry and processing plant. J. Clean. Prod. 32, 10-21. https://doi.org/https://doi.org/10.1016/j.jclepro.2012.03.007

Günther, A., Langowski, H.-C., 1997. Life cycle assessment study on resilient floor coverings. Int. J. Life Cycle Assess. 2, 73-80. https://doi.org/https://doi.org/10.1007/BF02978763

Hesser, F., Wohner, B., Meints, T., Stern, T., Windsperger, A., 2017. Integration of LCA in R\&D by applying the concept of payback period: case study of a modified multilayer wood parquet. Int. J. Life Cycle Assess. 22, 307-316. https://doi.org/https://doi.org/10.1007/s11367-016-1173-y

Ibáñez-Forés, V., Bovea, M.-D., Simó, A., 2011. Life cycle assessment of ceramic tiles. Environmental and statistical analysis. Int. J. Life Cycle Assess. 16, 916-928. https://doi.org/10.1007/s11367-011-0322-6

Islam, H., Jollands, M., Setunge, S., Haque, N., Bhuiyan, M.A., 2015. Life cycle assessment and life cycle cost implications for roofing and floor designs in residential buildings. Energy Build. 104, 250-263. https://doi.org/10.1016/j.enbuild.2015.07.017

Jönsson, Å., Tillman, A.-M., Svensson, T., 1997. Life cycle assessment of flooring materials: case study. Build. Environ. 32, 245-255.

Minne, E., Crittenden, J.C., 2015. Impact of maintenance on life cycle impact and cost assessment for residential flooring options. Int. J. Life Cycle Assess. 20, 36-45. https://doi.org/10.1007/s11367-014-0809-z

Nebel, B., Zimmer, B., Wegener, G., 2006. Life cycle assessment of wood floor coverings-a representative study for the german flooring industry. Int. J. life cycle Assess. 11, 172-182. https://doi.org/https://doi.org/10.1065/lca2004.10.187 
Nicoletti, G.M., Notarnicola, B., Tassielli, G., 2002. Comparative Life Cycle Assessment of flooring materials: ceramic versus marble tiles. J. Clean. Prod. 10, 283-296. https://doi.org/10.1016/S0959-6526(01)00028-2

Pini, M., Ferrari, A.M., Gamberini, R., Neri, P., Rimini, B., 2014. Life cycle assessment of a large, thin ceramic tile with advantageous technological properties. Int. J. Life Cycle Assess. 19, 15671580. https://doi.org/10.1007/s11367-014-0764-8

Potting, J., Blok, K., 1995. Life-cycle assessment of four types of floor covering. J. Clean. Prod. 3 , 201-213. https://doi.org/https://doi.org/10.1016/0959-6526(95)00082-8

Reza, B., Sadiq, R., Hewage, K., 2011. Sustainability assessment of flooring systems in the city of Tehran: An AHP-based life cycle analysis. Constr. Build. Mater. 25, 2053-2066. https://doi.org/https://doi.org/10.1016/j.conbuildmat.2010.11.041

Ros-Dosdá, T., Celades, I., Monfort, E., Fullana-i-Palmer, P., 2018. Environmental profile of Spanish porcelain stoneware tiles. Int. J. Life Cycle Assess. 23, 1562-1580. https://doi.org/10.1007/s11367-017-1377-9

Ruschi Mendes Saade, M., G. da Silva, M., Gomes, V., Gumez Franco, H., Schwamback, D., Lavor, B., 2014. Material eco-efficiency indicators for Brazilian buildings. Smart Sustain. Built Environ. 3, 54-71. https://doi.org/10.1108/SASBE-04-2013-0024

Tikul, N., 2014. Assessing environmental impact of small and medium ceramic tile manufacturing enterprises in Thailand. J. Manuf. Syst. 33, 1-6. https://doi.org/https://doi.org/10.1016/j.jmsy.2013.12.002

Tikul, N., Srichandr, P., 2010. Assessing the environmental impact of ceramic tile production in Thailand. J. Ceram. Soc. Japan 118, 887-894. https://doi.org/10.2109/jcersj2.118.887

Traverso, M., Rizzo, G., Finkbeiner, M., 2010. Environmental performance of building materials: life cycle assessment of a typical Sicilian marble. Int. J. Life Cycle Assess. 15, 104. 


\section{Appendix 2:}

\section{Use of EPDs as information source}

Using the methodology set out in Section 2.4.1. of the paper, several EPDs were selected and processed to obtain information on environmental impacts relating to the product stage (life cycle modules A1-A3) and other additional information relative to the description of subsequent life cycle stages.

A total of 149 EPDs of indoor floor coverings registered in the following programs were consulted: the International EPD® System; Institut Bauen und Umwelt e. V. (IBU-EPD); DAPcons; GlobalEPD; Inies and EPDnorge.

Table A2.1 details the EPDs consulted in this study. 


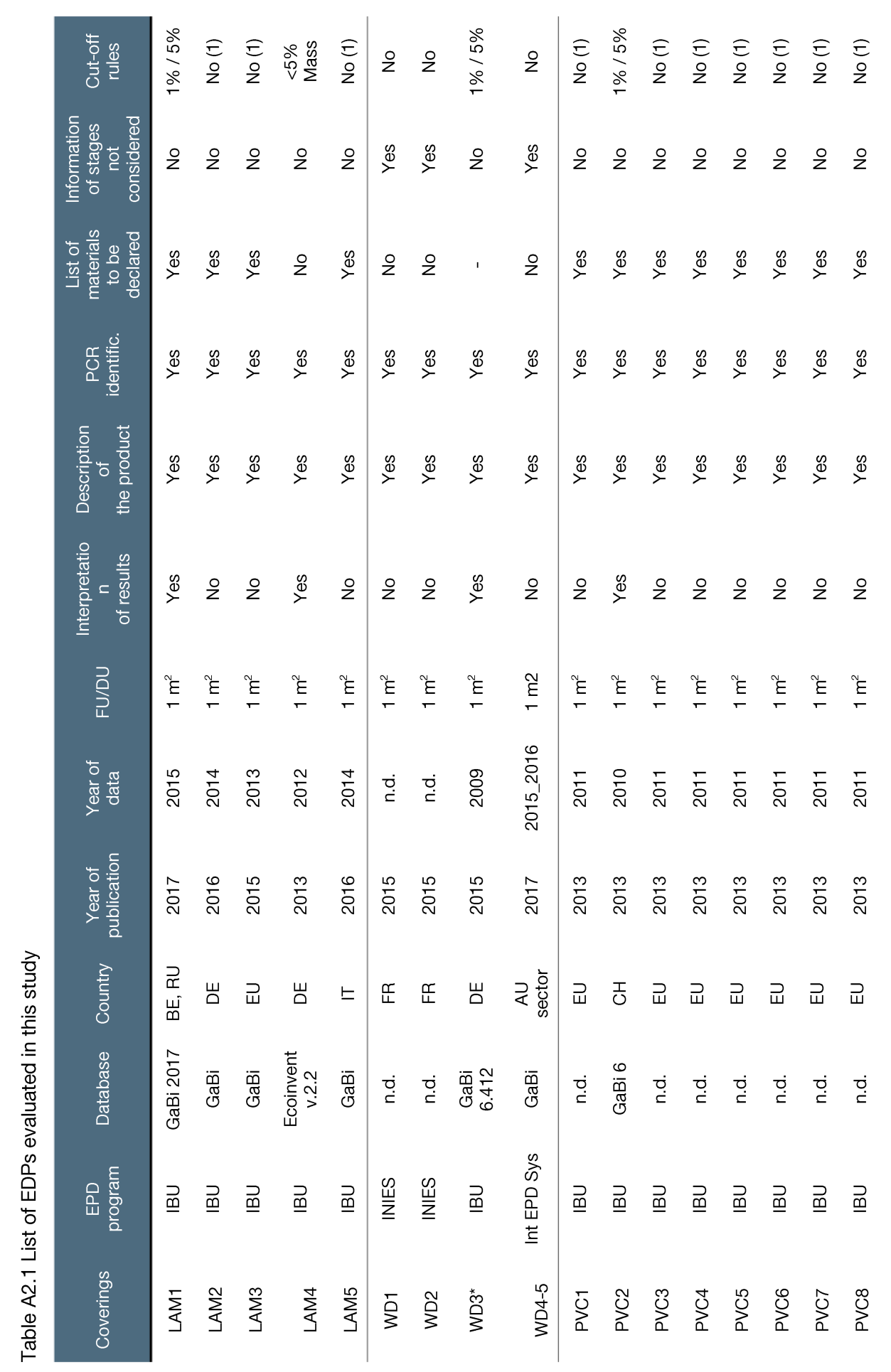




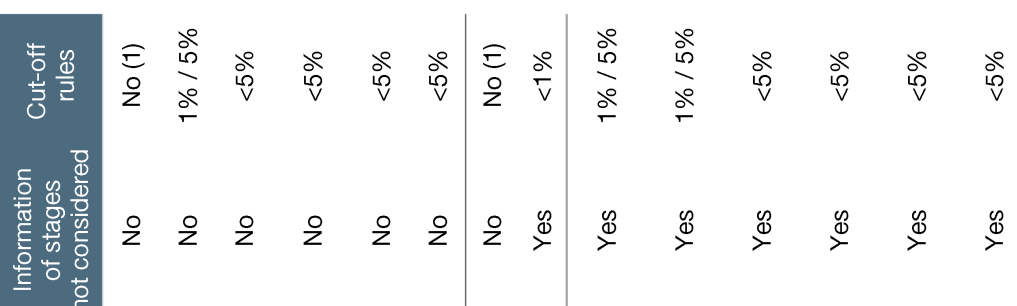

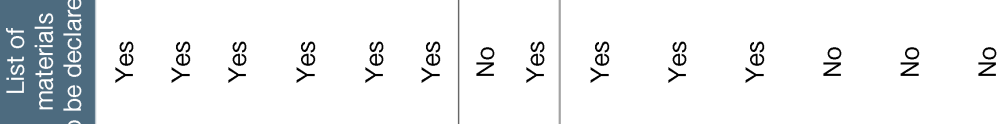

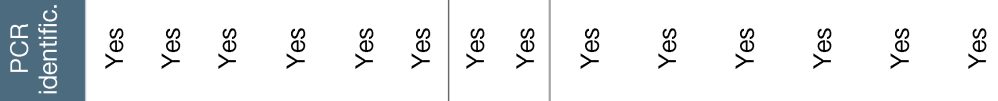

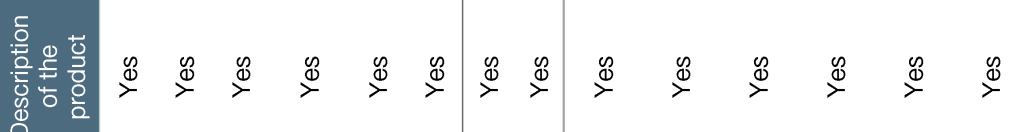

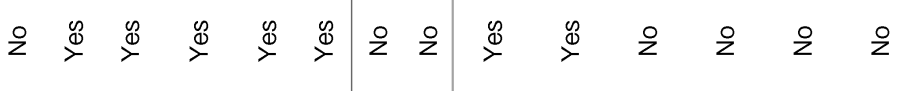

马े

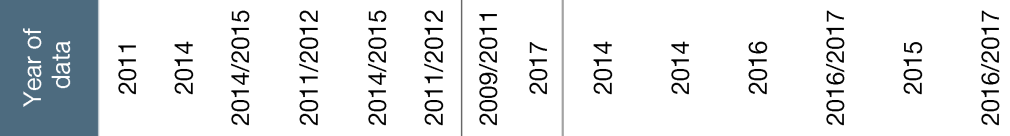

จ

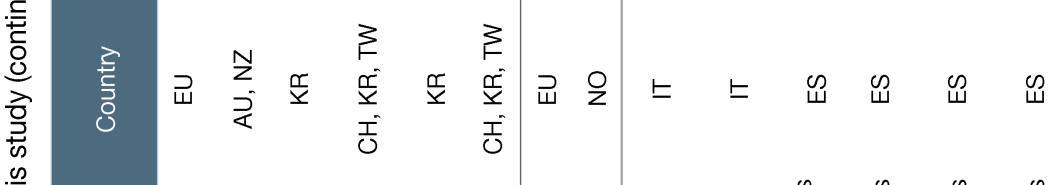

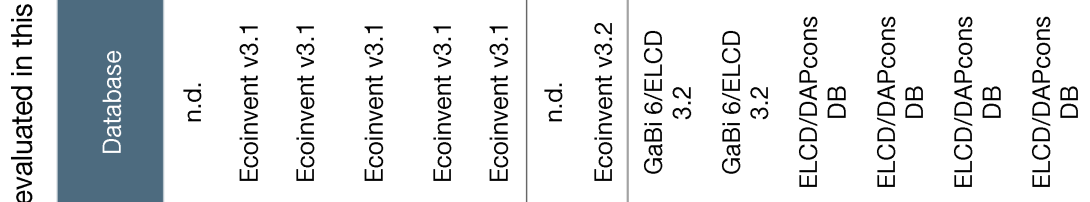

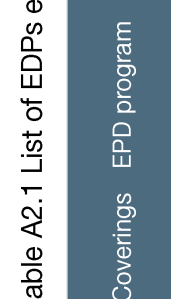

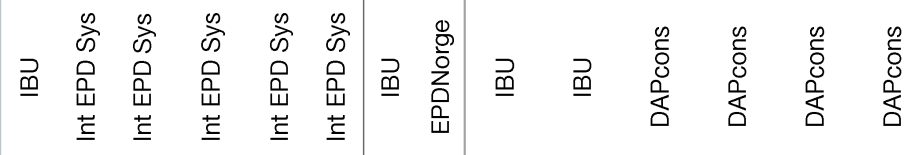

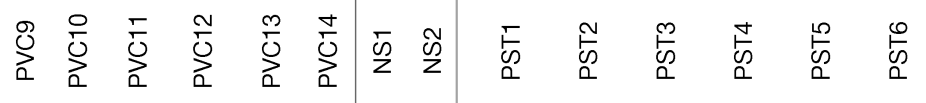




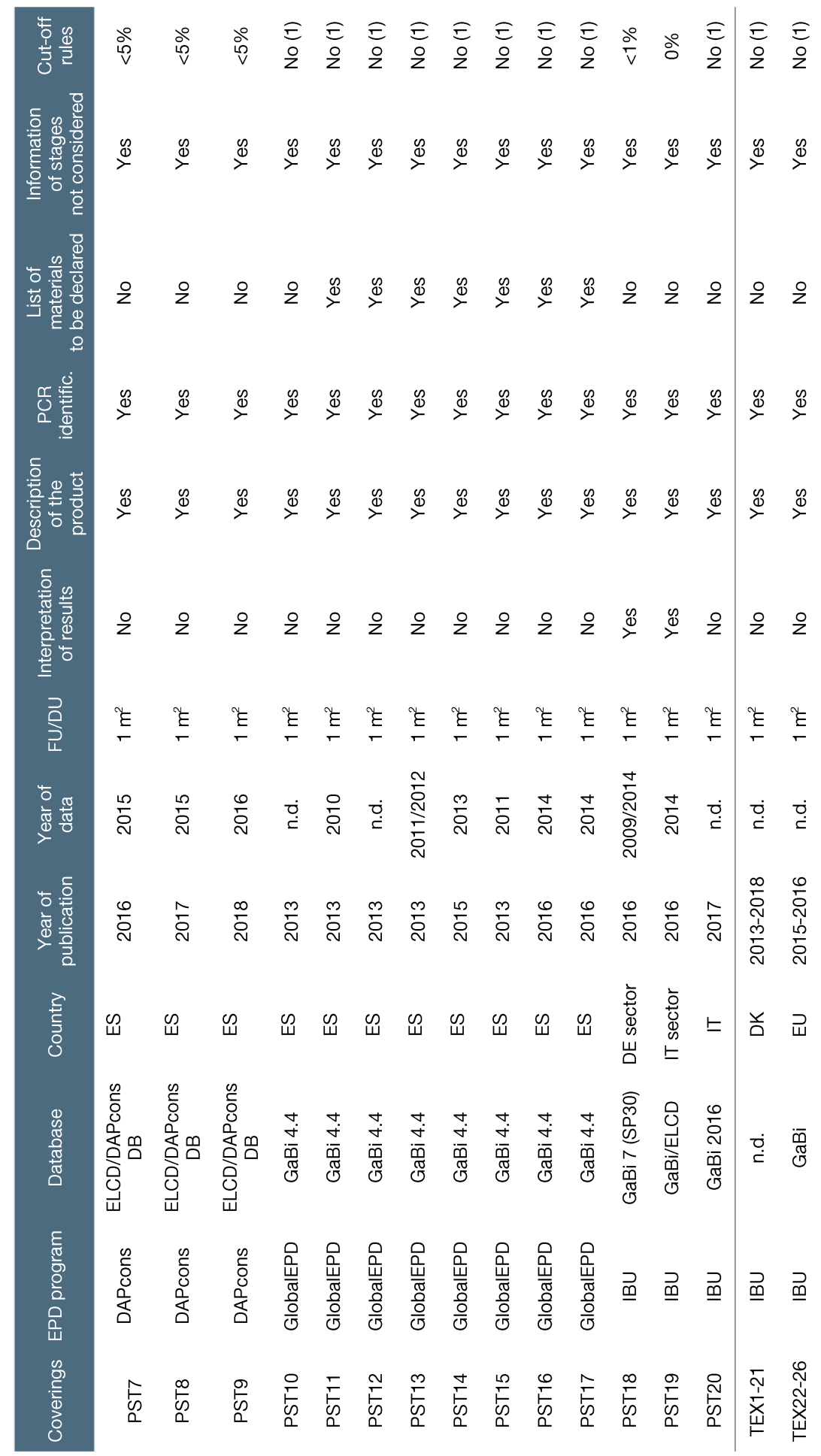




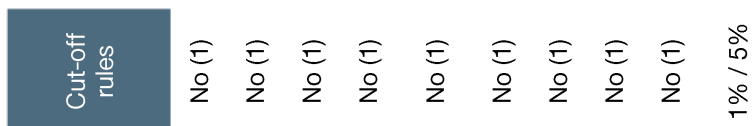

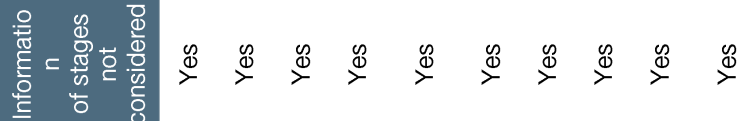

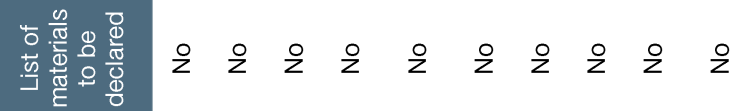

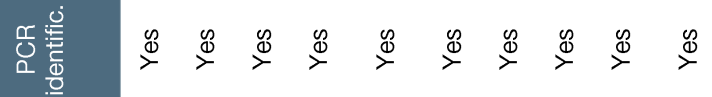

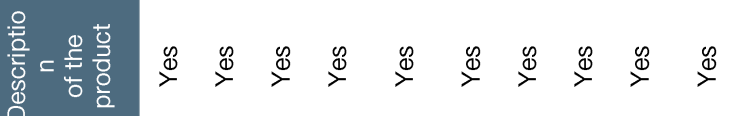

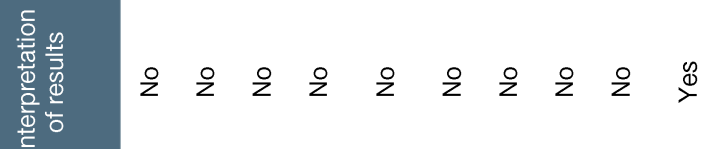
ગ્ટ 就

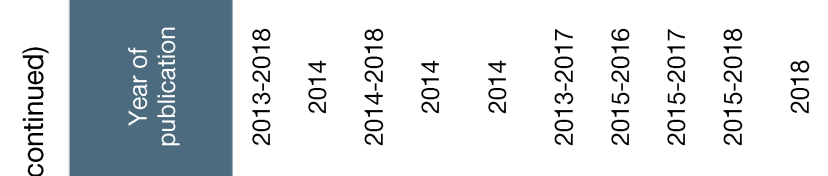

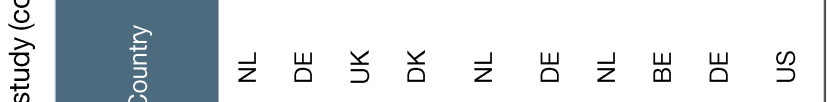
क

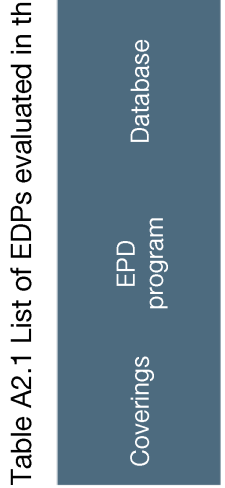

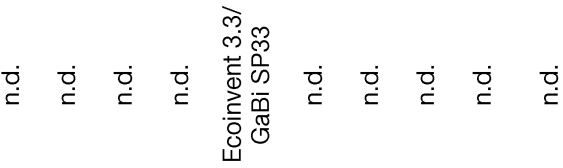

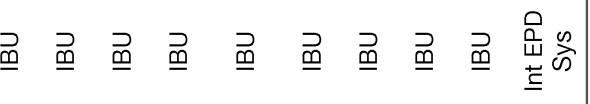

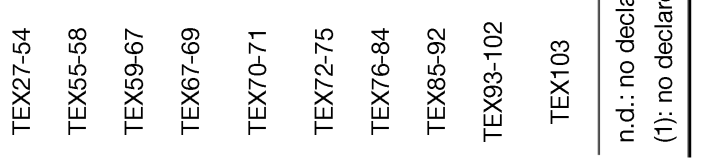


Fig. A2.1. shows the geographic distribution of the consulted EPDs.

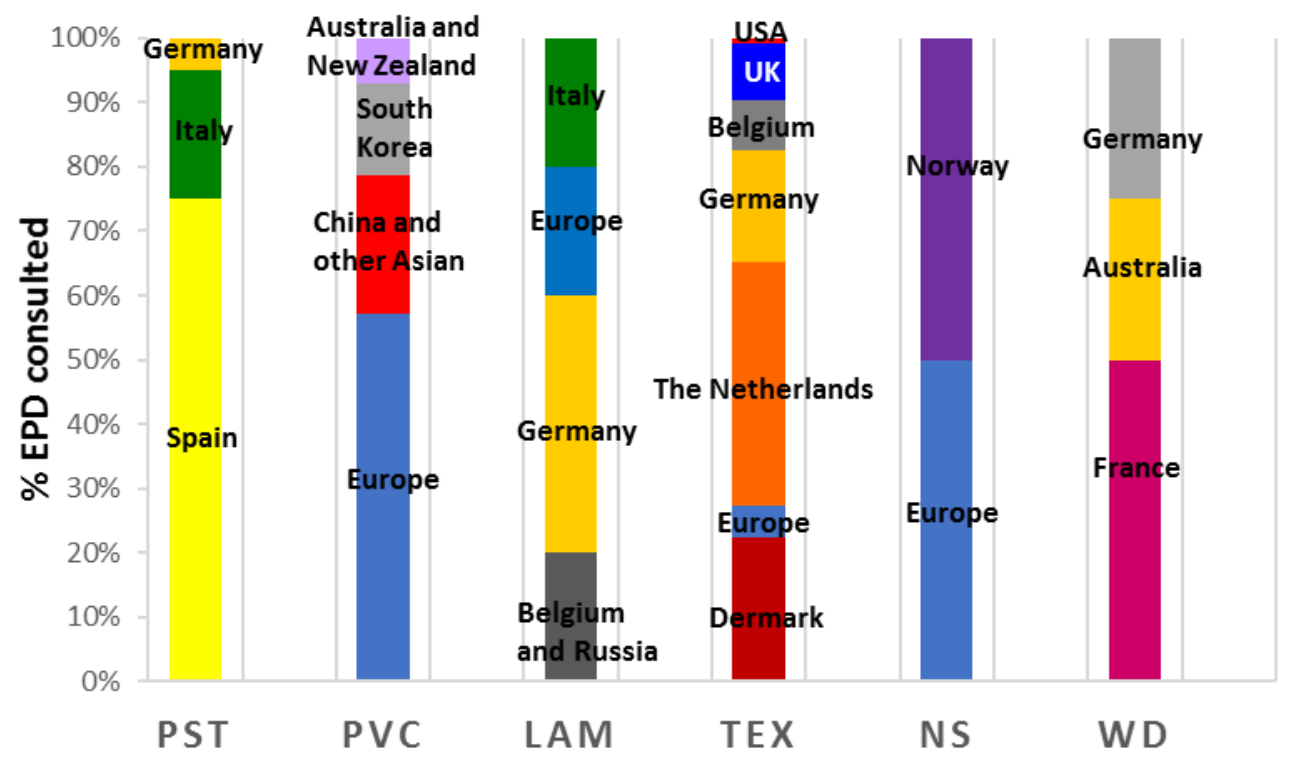

Fig. A2.1 Distribution of the consulted EPDs

Fig A.2.2 shows a box and whisker plot of the data published in the EPDs on the product stage (A1-A3), which includes raw materials extraction and transport and manufacture. At the same time, the graph provides information on the central trend, scatter, and symmetry of the study data. The boxes represent the interquartile range from the 25th to the 75 th percentile $\left(Q_{1}\right.$ and $Q_{3}$, respectively); the cross $(X)$ represents the mean value and the line represents the value corresponding to the median $\left(Q_{2}\right)$. The whiskers represent the standard deviation and the circles the atypical values calculated from the interquartile range $\left(R l=Q_{3}-Q_{1}\right)$, the lower atypical values being the values below $f_{\min }=Q_{1}-1.5 R I$ and the upper atypical values being the values above $f_{\max }=Q_{3}+1.5 \mathrm{Rl}$

Note that the justification of the data in Fig. A.2.2 is limited to product description, the scarce interpretation included in some EPDs (only $13.6 \%$ of the consulted EPDs provided some type of information in this regard), and the literature surveyed that could provide comparable values in relation to scope, calculation methodology, and impact assessment methods. However, the study's main objective was not detailed interpretation of the values published in the EPDs or comparative analysis with own environmental data of a cradle-gate scope. Consequently, only simple comments of a statistical nature are made. 


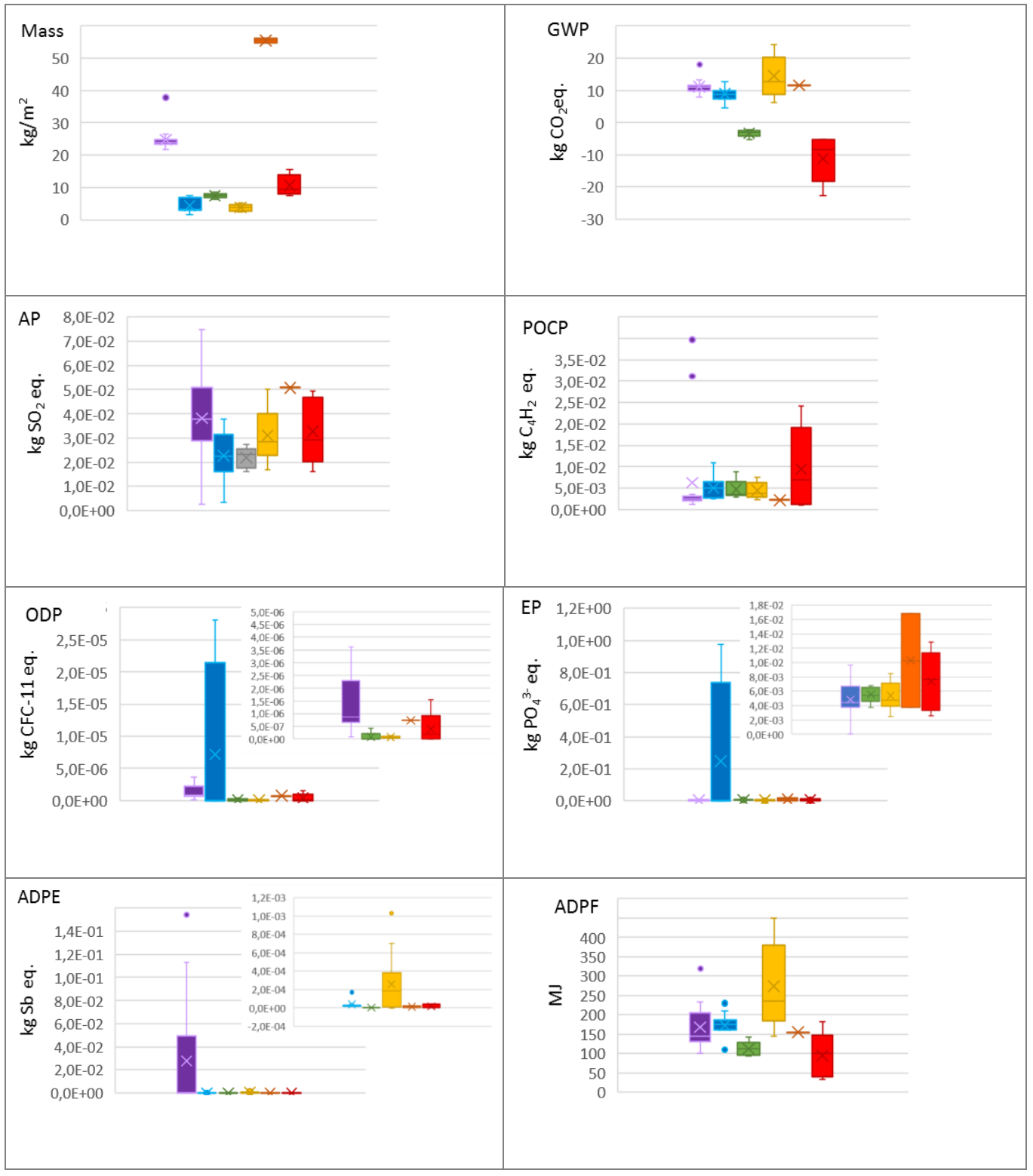

$\square$ PST $\square$ PVC $\square$ LAM $\square$ TEX $\square$ NS $\square$ WD

Fig. A2.2 Environmental impacts of the studied coverings. Cradle-to-gate scope from the consulted EDPs (Table A1) 
The inorganic coverings were the heaviest, whereas the polymer coverings were the lightest. NS was by far the heaviest covering: $52.1 \mathrm{~kg} / \mathrm{m}^{2}$, with densities ranging from 2600 to $2800 \mathrm{~kg} / \mathrm{m}^{3}$, and 20-mm thickness. This was followed by PST: $24.1 \mathrm{~kg} / \mathrm{m}^{2}$, with a density of $2300 \mathrm{~kg} / \mathrm{m}^{3}$, and $10.5-$ $\mathrm{mm}$ average thickness. The other floor coverings weighed less than $10 \mathrm{~kg} / \mathrm{m}^{2}$.

The studied coverings exhibited similar contributions (of the same order of magnitude) in the AP, POCP, and ADPF impact categories. In the GWP impact category, the wood-based coverings (laminates and parquet) provided negative values owing to stored biogenic carbon, whereas the other coverings exhibited similar behaviours. In the other categories there was a data scatter of at least two orders of magnitude. 


\section{Appendix 3:}

\section{Normalization and Weighting}

Normalization expresses the values of each impact category with respect to a reference situation (ISO 14044:2006; Laurin et al., 2016). The applied normalization factors were taken from "CML2001 - Jan. 2016, World, year 2000 , incl biogenic carbon (global equivalents)" (Table S3.1).

Weighting is a subjective process aiming to rank the results based on the relative importance of each impact category given from factors based on value-choices (ISO 14040-44:2006; Huppes et al. 2012; Cortés-Borda et al. 2013). The weighting factors applied were those obtained by Thinkstep "LCIA Survey 2012, Global, CML 2016, incl biogenic carbon (global equivalents weighted" (Table S3.1).

Table S3.1 Weighting and normalization factors

\begin{tabular}{|c|c|c|}
\hline Environmental indicators & Weighting Factors & Normalization Factors \\
\hline GWP & 0.193 & $4.22 \mathrm{E}+13$ \\
\hline AP & 0.127 & $2.39 \mathrm{E}+11$ \\
\hline EP & 0.137 & $1.58 \mathrm{E}+11$ \\
\hline ODP & 0.129 & $2.27 \mathrm{E}+08$ \\
\hline POCP & 0.135 & $3.68 \mathrm{E}+10$ \\
\hline ADPE & 0.133 & $3.61 \mathrm{E}+08$ \\
\hline ADPF & 0.146 & $3.80 \mathrm{E}+14$ \\
\hline
\end{tabular}

The tables S3.2, table S3.3. and table S3.4 show the absolute, normalized and weighted values of the FS evaluation, respectively, considering the three use scenarios.

Table S3.2 Results of the life cycle analysis of each FS. Absolute values

\begin{tabular}{|c|c|c|c|c|c|c|c|c|}
\hline \multirow{2}{*}{\multicolumn{2}{|c|}{$\begin{array}{l}\text { Impact } \\
\text { categories }\end{array}$}} & GWP & AP & EP & ODP & РОСР & ADPE & ADPF \\
\hline & & $\begin{array}{c}\mathrm{kg} \mathrm{CO}_{2} \\
\mathrm{Eq} .\end{array}$ & $\begin{array}{c}\mathrm{kg} \mathrm{SO}_{2} \\
\mathrm{Eq} .\end{array}$ & $\begin{array}{c}\mathrm{kg} \mathrm{PO}_{4}^{3-} \\
\mathrm{Eq} .\end{array}$ & $\begin{array}{c}\text { kg CFC- } \\
11 \text { Eq. }\end{array}$ & $\begin{array}{c}\mathrm{kg} \mathrm{C}_{2} \mathrm{H}_{4} \\
\text { Eq. }\end{array}$ & kg Sb Eq. & $\mathrm{MJ}$ \\
\hline \multirow{3}{*}{ PST } & Low & 14.8 & 4.7E-02 & 7.8E-03 & $8.9 \mathrm{E}-07$ & $5.2 \mathrm{E}-03$ & 8.6E-05 & 205.6 \\
\hline & Medium & 20.1 & $5.6 \mathrm{E}-02$ & 1.7E-02 & $1.0 \mathrm{E}-06$ & 7.6E-03 & $8.8 \mathrm{E}-05$ & 221.6 \\
\hline & High & 28.3 & 7.3E-02 & $2.8 \mathrm{E}-02$ & $1.1 \mathrm{E}-06$ & $1.1 \mathrm{E}-02$ & $9.2 \mathrm{E}-05$ & 265.7 \\
\hline \multirow{3}{*}{ NS } & Low & 24.5 & $6.8 \mathrm{E}-02$ & $1.5 \mathrm{E}-02$ & $7.5 \mathrm{E}-07$ & $5.1 \mathrm{E}-03$ & $1.9 \mathrm{E}-05$ & 336.9 \\
\hline & Medium & 29.8 & $7.8 \mathrm{E}-02$ & $2.4 \mathrm{E}-02$ & 8.7E-07 & 7.5E-03 & 2.1E-05 & 353.0 \\
\hline & High & 38.1 & $9.5 \mathrm{E}-02$ & 3.5E-02 & $1.0 \mathrm{E}-06$ & $1.1 \mathrm{E}-02$ & $2.5 \mathrm{E}-05$ & 397.3 \\
\hline
\end{tabular}


Table S3.2 Results of the life cycle analysis of each FS. Absolute values (continued)

\begin{tabular}{|c|c|c|c|c|c|c|c|c|}
\hline \multirow{2}{*}{\multicolumn{2}{|c|}{$\begin{array}{l}\text { Impact } \\
\text { categories }\end{array}$}} & GWP & AP & EP & ODP & POCP & ADPE & ADPF \\
\hline & & $\mathrm{kg} \mathrm{CO} 2$ & $\mathrm{~kg} \mathrm{SO}_{2}$ & $\mathrm{~kg} \mathrm{PO}_{4}^{3-}$ & kg CFC & $\mathrm{kg} \mathrm{C}_{2} \mathrm{H}_{4}$ & kg Sb Eq. & MJ \\
\hline \multirow{3}{*}{ PVC } & Low & 36.3 & 1.0E-01 & 1.6E-02 & 9.6E-08 & 2.3E-02 & 9.3E-05 & 724.5 \\
\hline & Medium & 47.7 & $1.2 \mathrm{E}-01$ & 3.4E-02 & 3.3E-07 & 2.8E-02 & 9.8E-05 & 770.3 \\
\hline & High & 58.5 & $1.4 \mathrm{E}-01$ & 5.5E-02 & $6.0 \mathrm{E}-07$ & 3.3E-02 & 1.0E-04 & 793.3 \\
\hline \multirow{3}{*}{ TEX } & Low & 83.1 & 1.9E-01 & 5.4E-02 & $6.1 \mathrm{E}-07$ & $2.5 \mathrm{E}-02$ & 7.9E-04 & 1042.0 \\
\hline & Medium & 110.6 & $2.4 \mathrm{E}-01$ & 8.5E-02 & $9.8 \mathrm{E}-07$ & $3.5 \mathrm{E}-02$ & 8.0E-04 & 1232.4 \\
\hline & High & 139.1 & 3.0E-01 & 1.4E-01 & 1.7E-06 & 5.0E-02 & 8.1E-04 & 1290.3 \\
\hline \multirow{3}{*}{ LAM } & Low & 35.3 & $1.4 \mathrm{E}-01$ & 3.4E-02 & $1.2 \mathrm{E}-07$ & 2.6E-02 & 1.5E-05 & 559.9 \\
\hline & Medium & 44.3 & $1.5 \mathrm{E}-01$ & 4.6E-02 & 2.8E-07 & 2.9E-02 & 1.9E-05 & 605.5 \\
\hline & High & 43.4 & $1.5 \mathrm{E}-01$ & 4.6E-02 & $2.8 \mathrm{E}-07$ & 2.9E-02 & 1.8E-05 & 594.2 \\
\hline \multirow{3}{*}{ WD } & Low & 34.2 & 9.6E-02 & 1.7E-02 & $1.5 \mathrm{E}-07$ & 5.7E-02 & 2.3E-05 & 412.1 \\
\hline & Medium & 42.3 & 1.1E-01 & 1.9E-02 & 1.6E-07 & 1.0E-01 & 3.3E-05 & 550.2 \\
\hline & High & 73.1 & 2.0E-01 & 3.6E-02 & 3.3E-07 & 1.6E-01 & 5.3E-05 & 926.8 \\
\hline
\end{tabular}

Table S3.3 Results of the life cycle analysis of each FS. Normalized values

\begin{tabular}{|c|c|c|c|c|c|c|c|c|}
\hline \multicolumn{2}{|c|}{$\begin{array}{c}\text { Impact } \\
\text { categories }\end{array}$} & GWP & AP & EP & ODP & POCP & ADPE & ADPF \\
\hline \multirow{3}{*}{ PST } & Low & $3.5 \mathrm{E}-13$ & $2.0 \mathrm{E}-13$ & $5.0 \mathrm{E}-14$ & $3.9 \mathrm{E}-15$ & $1.4 \mathrm{E}-13$ & $2.4 \mathrm{E}-13$ & $5.4 \mathrm{E}-13$ \\
\hline & Medium & $4.8 \mathrm{E}-13$ & $2.4 \mathrm{E}-13$ & $1.1 \mathrm{E}-13$ & 4.4E-15 & $2.1 \mathrm{E}-13$ & $2.4 \mathrm{E}-13$ & $5.8 \mathrm{E}-13$ \\
\hline & High & $6.7 \mathrm{E}-13$ & $3.0 \mathrm{E}-13$ & $1.8 \mathrm{E}-13$ & $5.0 \mathrm{E}-15$ & $2.9 \mathrm{E}-13$ & $2.5 \mathrm{E}-13$ & $7.0 \mathrm{E}-13$ \\
\hline \multirow{3}{*}{ NS } & Low & $5.8 \mathrm{E}-13$ & $2.9 \mathrm{E}-13$ & $9.5 \mathrm{E}-14$ & $3.3 E-15$ & $1.4 \mathrm{E}-13$ & $5.4 \mathrm{E}-14$ & $8.9 \mathrm{E}-13$ \\
\hline & Medium & $7.1 \mathrm{E}-13$ & 3.3E-13 & $1.5 \mathrm{E}-13$ & $3.8 \mathrm{E}-15$ & $2.0 \mathrm{E}-13$ & $5.9 \mathrm{E}-14$ & $9.3 E-13$ \\
\hline & High & $9.0 \mathrm{E}-13$ & $4.0 \mathrm{E}-13$ & $2.2 \mathrm{E}-13$ & $4.4 \mathrm{E}-15$ & $2.9 \mathrm{E}-13$ & $6.9 \mathrm{E}-14$ & $1.0 \mathrm{E}-12$ \\
\hline \multirow{3}{*}{ PVC } & Low & 8.6E-13 & $4.2 \mathrm{E}-13$ & $1.0 \mathrm{E}-13$ & $4.2 \mathrm{E}-16$ & $6.3 \mathrm{E}-13$ & $2.6 \mathrm{E}-13$ & $1.9 \mathrm{E}-12$ \\
\hline & Medium & 1.1E-12 & $5.1 \mathrm{E}-13$ & $2.2 \mathrm{E}-13$ & $1.4 \mathrm{E}-15$ & 7.6E-13 & $2.7 \mathrm{E}-13$ & $2.0 \mathrm{E}-12$ \\
\hline & High & $1.4 \mathrm{E}-12$ & $6.0 \mathrm{E}-13$ & $3.5 \mathrm{E}-13$ & $2.6 \mathrm{E}-15$ & $9.1 \mathrm{E}-13$ & $2.8 \mathrm{E}-13$ & $2.1 \mathrm{E}-12$ \\
\hline \multirow{3}{*}{ TEX } & Low & $2.0 \mathrm{E}-12$ & $7.8 \mathrm{E}-13$ & $3.4 \mathrm{E}-13$ & 2.7E-15 & $6.9 \mathrm{E}-13$ & $2.2 \mathrm{E}-12$ & 2.7E-12 \\
\hline & Medium & $2.6 \mathrm{E}-12$ & 1.0E-12 & $5.4 \mathrm{E}-13$ & 4.3E-15 & $9.5 \mathrm{E}-13$ & 2.2E-12 & $3.2 \mathrm{E}-12$ \\
\hline & High & 3.3E-12 & $1.3 \mathrm{E}-12$ & $9.0 \mathrm{E}-13$ & 7.6E-15 & 1.3E-12 & 2.2E-12 & $3.4 \mathrm{E}-12$ \\
\hline
\end{tabular}


Table S3.3 Results of the life cycle analysis of each FS. Normalized values (continued)

\begin{tabular}{|c|c|c|c|c|c|c|c|c|}
\hline \multicolumn{2}{|c|}{$\begin{array}{c}\text { Impact } \\
\text { categories }\end{array}$} & GWP & AP & EP & ODP & POCP & ADPE & ADPF \\
\hline \multirow{3}{*}{ LAM } & Low & $8.4 \mathrm{E}-13$ & $5.7 \mathrm{E}-13$ & $2.1 \mathrm{E}-13$ & $5.3 \mathrm{E}-16$ & $7.0 \mathrm{E}-13$ & $4.2 \mathrm{E}-14$ & $1.5 \mathrm{E}-12$ \\
\cline { 2 - 9 } & Medium & $1.0 \mathrm{E}-12$ & $6.4 \mathrm{E}-13$ & $2.9 \mathrm{E}-13$ & $1.2 \mathrm{E}-15$ & $7.9 \mathrm{E}-13$ & $5.2 \mathrm{E}-14$ & $1.6 \mathrm{E}-12$ \\
\cline { 2 - 9 } & High & $1.0 \mathrm{E}-12$ & $6.4 \mathrm{E}-13$ & $2.9 \mathrm{E}-13$ & $1.2 \mathrm{E}-15$ & $7.9 \mathrm{E}-13$ & $5.0 \mathrm{E}-14$ & $1.6 \mathrm{E}-12$ \\
\hline \multirow{3}{*}{ WD } & Low & $8.1 \mathrm{E}-13$ & $4.0 \mathrm{E}-13$ & $1.1 \mathrm{E}-13$ & $6.8 \mathrm{E}-16$ & $1.6 \mathrm{E}-12$ & $6.4 \mathrm{E}-14$ & $1.1 \mathrm{E}-12$ \\
\cline { 2 - 9 } & Medium & $1.0 \mathrm{E}-12$ & $4.5 \mathrm{E}-13$ & $1.2 \mathrm{E}-13$ & $7.0 \mathrm{E}-16$ & $2.8 \mathrm{E}-12$ & $9.1 \mathrm{E}-14$ & $1.4 \mathrm{E}-12$ \\
\cline { 2 - 9 } & High & $3.5 \mathrm{E}-13$ & $2.0 \mathrm{E}-13$ & $5.0 \mathrm{E}-14$ & $3.9 \mathrm{E}-15$ & $1.4 \mathrm{E}-13$ & $2.4 \mathrm{E}-13$ & $5.4 \mathrm{E}-13$ \\
\hline
\end{tabular}

Table S3.4 Results of the life cycle analysis of each FS. Weighting of normalized values

\begin{tabular}{|c|c|c|c|c|c|c|c|c|}
\hline \multicolumn{2}{|c|}{$\begin{array}{c}\text { Impact } \\
\text { categories }\end{array}$} & GWP & AP & EP & ODP & POCP & ADPE & ADPF \\
\hline \multirow{3}{*}{ PST } & Low & $6.8 \mathrm{E}-14$ & $2.5 \mathrm{E}-14$ & $6.8 \mathrm{E}-15$ & $5.0 \mathrm{E}-16$ & $1.9 \mathrm{E}-14$ & $3.2 \mathrm{E}-14$ & 7.9E-14 \\
\hline & Medium & $9.2 \mathrm{E}-14$ & $3.0 \mathrm{E}-14$ & $1.5 \mathrm{E}-14$ & 5.7E-16 & $2.8 \mathrm{E}-14$ & $3.2 \mathrm{E}-14$ & 8.5E-14 \\
\hline & High & $1.3 \mathrm{E}-13$ & $3.9 \mathrm{E}-14$ & $2.4 \mathrm{E}-14$ & $6.5 \mathrm{E}-16$ & $3.9 \mathrm{E}-14$ & $3.4 \mathrm{E}-14$ & $1.0 \mathrm{E}-13$ \\
\hline \multirow{3}{*}{ NS } & Low & $1.1 \mathrm{E}-13$ & $3.6 \mathrm{E}-14$ & $1.3 \mathrm{E}-14$ & 4.3E-16 & $1.9 \mathrm{E}-14$ & $7.2 \mathrm{E}-15$ & $1.3 \mathrm{E}-13$ \\
\hline & Medium & $1.4 \mathrm{E}-13$ & $4.2 \mathrm{E}-14$ & $2.1 \mathrm{E}-14$ & $4.9 \mathrm{E}-16$ & $2.8 \mathrm{E}-14$ & $7.8 \mathrm{E}-15$ & $1.4 \mathrm{E}-13$ \\
\hline & High & $1.7 \mathrm{E}-13$ & $5.0 \mathrm{E}-14$ & $3.1 \mathrm{E}-14$ & 5.7E-16 & $3.9 \mathrm{E}-14$ & $9.2 \mathrm{E}-15$ & $1.5 \mathrm{E}-13$ \\
\hline \multirow{3}{*}{ PVC } & Low & $1.7 \mathrm{E}-13$ & 5.3E-14 & $1.4 \mathrm{E}-14$ & $5.4 \mathrm{E}-17$ & $8.5 \mathrm{E}-14$ & $3.4 \mathrm{E}-14$ & $2.8 \mathrm{E}-13$ \\
\hline & Medium & $2.2 \mathrm{E}-13$ & $6.5 \mathrm{E}-14$ & $3.0 \mathrm{E}-14$ & $1.9 \mathrm{E}-16$ & $1.0 \mathrm{E}-13$ & $3.6 \mathrm{E}-14$ & $2.9 \mathrm{E}-13$ \\
\hline & High & 2.7E-13 & $7.6 \mathrm{E}-14$ & $4.8 \mathrm{E}-14$ & $3.4 \mathrm{E}-16$ & $1.2 \mathrm{E}-13$ & 3.7E-14 & $3.0 \mathrm{E}-13$ \\
\hline \multirow{3}{*}{ TEX } & Low & $3.8 \mathrm{E}-13$ & $9.9 \mathrm{E}-14$ & 4.7E-14 & $3.4 \mathrm{E}-16$ & $9.4 \mathrm{E}-14$ & $2.9 \mathrm{E}-13$ & $4.0 \mathrm{E}-13$ \\
\hline & Medium & $5.1 \mathrm{E}-13$ & 1.3E-13 & $7.4 \mathrm{E}-14$ & $5.6 \mathrm{E}-16$ & 1.3E-13 & $3.0 \mathrm{E}-13$ & 4.7E-13 \\
\hline & High & $6.4 \mathrm{E}-13$ & $1.6 \mathrm{E}-13$ & $1.2 \mathrm{E}-13$ & $9.8 \mathrm{E}-16$ & $1.8 \mathrm{E}-13$ & $3.0 \mathrm{E}-13$ & $4.9 \mathrm{E}-13$ \\
\hline \multirow{3}{*}{ LAM } & Low & 1.6E-13 & $7.2 \mathrm{E}-14$ & $2.9 \mathrm{E}-14$ & $6.9 \mathrm{E}-17$ & $9.4 \mathrm{E}-14$ & $5.5 \mathrm{E}-15$ & $2.1 \mathrm{E}-13$ \\
\hline & Medium & $2.0 \mathrm{E}-13$ & $8.2 \mathrm{E}-14$ & $4.0 \mathrm{E}-14$ & $1.6 \mathrm{E}-16$ & 1.1E-13 & 7.0E-15 & $2.3 \mathrm{E}-13$ \\
\hline & High & $2.0 \mathrm{E}-13$ & 8.1E-14 & 4.0E-14 & $1.6 \mathrm{E}-16$ & 1.1E-13 & 6.7E-15 & $2.3 \mathrm{E}-13$ \\
\hline \multirow{3}{*}{ WD } & Low & 1.6E-13 & 5.1E-14 & $1.5 \mathrm{E}-14$ & 8.7E-17 & $2.1 \mathrm{E}-13$ & 8.5E-15 & $1.6 \mathrm{E}-13$ \\
\hline & Medium & $1.9 \mathrm{E}-13$ & $5.8 \mathrm{E}-14$ & 1.7E-14 & $9.0 \mathrm{E}-17$ & $3.7 \mathrm{E}-13$ & $1.2 \mathrm{E}-14$ & $2.1 \mathrm{E}-13$ \\
\hline & High & $3.4 \mathrm{E}-13$ & $1.1 \mathrm{E}-13$ & $3.2 \mathrm{E}-14$ & $1.9 \mathrm{E}-16$ & $5.8 \mathrm{E}-13$ & $2.0 \mathrm{E}-14$ & $3.5 \mathrm{E}-13$ \\
\hline
\end{tabular}




\section{References}

ISO 14044, 2006. Environmental management -- Life cycle assessment -- Requirements and guidelines. International Organization for Standardization, Geneva.

Laurin, L., Amor, B., Bachmann, T.M., Bare, J., Koffler, C., Genest, S., Preiss, P., Pierce, J., Satterfield, B., Vigon, B., 2016. Life cycle assessment capacity roadmap (section 1): decisionmaking support using LCA. Int. J. Life Cycle Assess. 21, 443-447. https://doi.org/10.1007/s11367016-1031-y 


\section{APORTACIÓN Nº 4 \\ SOLCONCER, A HELPFUL TOOL FOR CHARACTERISING CONSTRUCTION SOLUTIONS}

Alfredo Beltrán', Irina Celades', Jorge Corrales', Javier Mira', Adoración Muñoz ${ }^{1}$, Ana Rioja', Teresa Ros ${ }^{1}$, Vicente Agost ${ }^{2}$.

Publicación: Actas XIV Congreso mundial de la calidad del azulejo y del pavimento cerámico (QUALICER 2016).

www.qualicer.org

Enviado en Septiembre 2015

Aceptado en Noviembre 2015

Publicado 8 de Febrero de 2014

ISBN-13 978-84-95931-25-2

${ }^{1}$ Instituto de Tecnología Cerámica (ITC). Asociación de Investigación de las Industrias Cerámicas (AICE). Universidad Jaume I. Avda Sos Baynat s/n, 12006, Castelló, Spain.

2 SiG-O gestión. Avda. Capuchinos, $55-4^{\circ} \mathrm{C}, 12004$, Castelló, Spain 


\title{
SOLCONCER, A HELPFUL TOOL FOR CHARACTERISING CONSTRUCTION SOLUTIONS
}

\author{
A. Beltrán(1), I. Celades (1), J. Corrales ${ }^{(1)}$, J. Mira ${ }^{(1)}$, A. Muñoz ${ }^{(1)}$, A. \\ Rioja $^{(1)}$, T. Ros, ${ }^{(1)}$ V. Agost ${ }^{(2)}$. \\ (1) Instituto de Tecnología Cerámica (ITC). Asociación de Investigación de las \\ Industrias Cerámicas (AICE) \\ Universitat Jaume I. Castellón. España. \\ ${ }^{(2)}$ Sig-o gestión
}




\title{
SOLCONCER, A HELPFUL TOOL FOR CHARACTERISING CONSTRUCTION SOLUTIONS
}

\begin{abstract}
This paper presents the methodology and IT program used to accurately characterise numerous construction products or building solutions in terms of their environmental, economic and social benefits, so that specifications writers, cladding manufacturers, and the public at large may be able to evaluate different surface cladding materials. To make that assessment, a number of indicators related to the three aspects at issue are specified. Furthermore, a series of scenarios (usage, traffic intensity, type of premises, etc.) are defined, which allow for closer fine tuning of the initial assumptions that affect how these construction solutions are calculated.
\end{abstract}

Characterisation of Performance stems from a methodology based on the requirements of the EOTA's[1] Technical Guidelines (ETAGs) for construction solutions, in turn based on six of the seven essential requirements contained in the EU Construction Products Directive, but includes an eighth requirement that considers durability and its finish (i.e. technical obsolescence and/or aesthetic obsolescence with regard to 'impaired appearance'). Based on this set of requirements, a series of indicators are considered that determine the quality of construction solution performance.

Characterisation of environmental impact and associated costs for the construction solutions under consideration has been organised into different life cycle stages, in accordance with the system of modules set out in the UNE-EN 15804 and 15978 standards on Sustainability in construction. The construction solution is thus assessed in its entirety, including the costs and impacts associated with extracting its raw materials and with its installation, usage and end of life process.

The indicators for each of the three aspects under assessment can be viewed or modified by the user, which adds great flexibility to the program. This feature allows manufacturers to foresee how a change in material characteristics (price, environmental impacts or performance) affects the way a construction system is perceived. 


\section{Introduction}

This paper presents the SolconCer software tool, the main objective of which is to assess the performance of construction elements that use ceramic tiles and other alternative materials, in order to select, on the basis of certain criteria of choice, which solution is the most suitable of the various options under analysis.

To carry out that assessment, various construction elements are examined from different viewpoints, namely their environmental impact, cost in economic terms, and their technical performance, hereinafter referred to as 'sets of indicators'. Each of these three sets comprises a series of indicators, which, in the case of environmental impact and economic cost, are always the same, regardless of the type of construction solution being assessed (horizontal partitions, vertical partitions, etc.), for example, potential contribution to climate change or cost in Euros, whereas in the case of performance, the indicators vary according to the technical requirements to be met by each type of construction solution, for example Slipperiness or Continuity of flooring.

At the end of the assessment of the various construction systems, the user of the computer tool, hereinafter referred to as program, is given a triad of scores on a scale of between 1 and 10 that correspond to each set of indicators. However, the user can see the value assigned to each indicator in order to evaluate the influence it has had on the final assessment score.

The user first has to define the conditions and features of the construction solution under assessment in order to assign the indicators. Thus, for instance, environmental impact or economic cost will vary depending on the distance from the point of supply, maintenance, or other conditions. The particular circumstances of each construction solution are hereinafter called 'scenarios' and are defined by the different assumptions that apply to each. Figure 1 shows an overview of the program: 


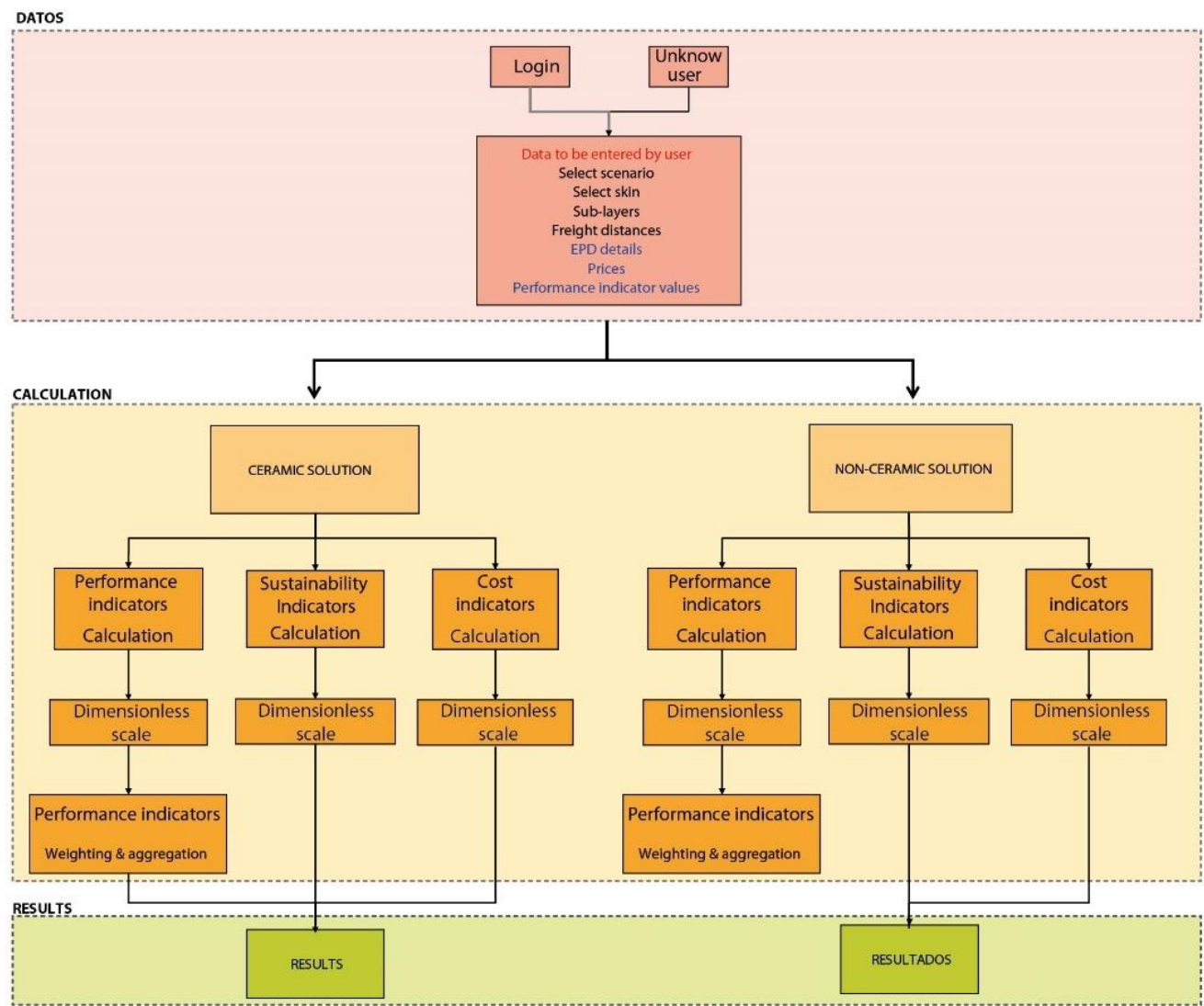

Figure 1 Overview of the SolconCer program

The sources of information used are opinions from construction sector professionals, different technical standards and the EOTA Technical Guidelines (ETAGs) and reference documents ([2][3][4][5]) in order to cover both the most common construction techniques and the recommendations proposed by different guides and manuals.

Let us now explain the assumptions used, the relevant scenarios, the construction solutions assessed, materials, groups of indicators, calculation procedures used and the characteristics of the software. 


\section{Considerations affecting all construction solutions}

A number of assumptions have been established for all construction solutions that primarily affect the environmental and economic sets of indicators, since the third set of indicators - performance - is directly related to the specific nature of each construction solution.

A construction solution includes all the various layers that comprise it (Figure 2).

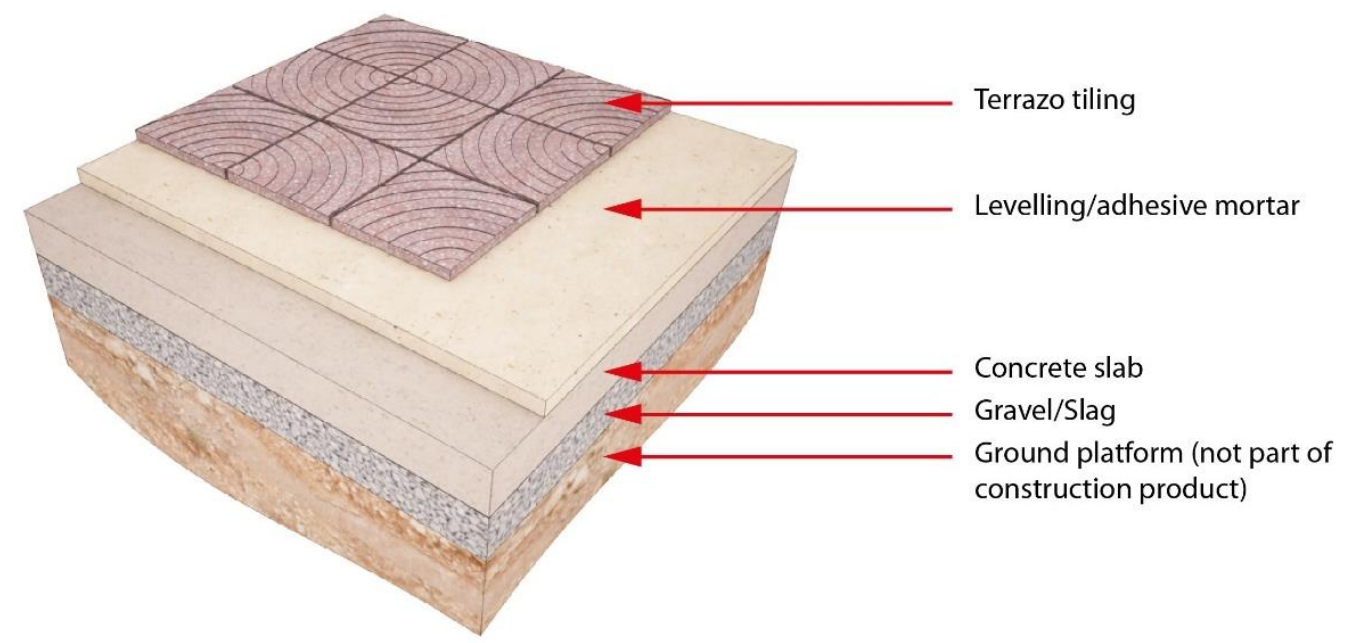

Figure 2 Example of a construction solution. Street paving

\subsection{Life cycle}

In all cases, the Functional Unit represents the function of the construction solution with a surface area of $1 \mathrm{~m}^{2}$ over a time span of 50 [6] years, in the case of indoor vertical and horizontal partition walls, and 40 [7] years, in the case of urban street paving within the geographical and technological context of Spain. The various life cycle stages have been taken from the model proposed in the Sustainability in Construction standards [10][11] (Figure 3). 

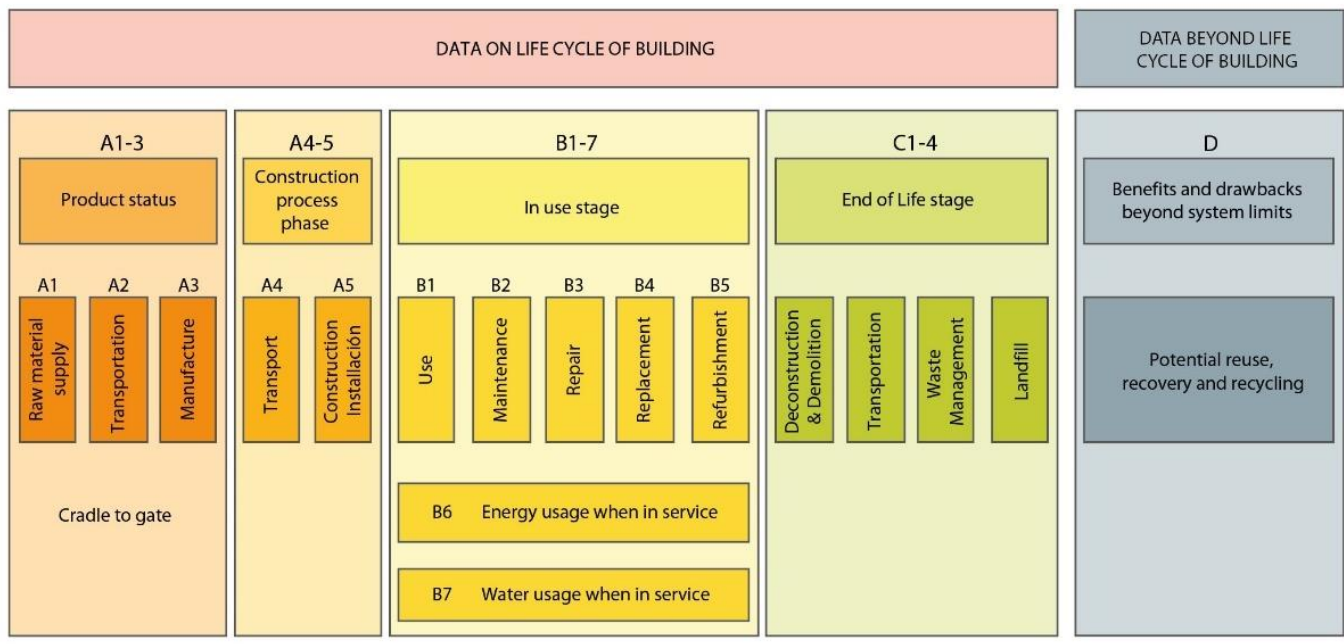

Figure 3. Life cycle stages

The software in this tool takes modules A1-A3 together. Furthermore, module B5-Refurbishment, which comprises the scheduled replacement of the item, would be practically tantamount to Replacement B4. Similarly, modules B6 and B7 on Operating Energy and Water are not applicable.

\subsection{Transport of construction products (A4)}

This variable has a bearing on environmental and economic impacts. In order to track its significant variability, two options have been proposed that allow for flexibility and reasonable accuracy. In the case of the cladding material, if the user knows the exact place where it was manufactured, the user has the option of entering the distance in kilometres. In this case, the program assigns road haulage for short distances and sea freight when that distance is exceeded, with an amount of road haulage to cover transfer to/from port.

The alternative is that the user does not know where the cladding was manufactured and so simply chooses its origin between national, European (overland haulage along default routes), or rest of the world (sea freight plus pre-set road haulage).

For the remaining layers, regional road haulage is allocated, as all components are supposed to have been delivered by a local supplier.

With regard to costing out road haulage $(€ / \mathrm{kg} / \mathrm{km})$, the costs are calculated using data from the Ministry of Public Works' Observatory of Goods Freight Costs [8], whereas sea freighting costs $(€ / \mathrm{kg} / \mathrm{km})$ are calculated on the basis of data contained in the Observatory for Intermodal Land and Sea Freigh [9]. 


\subsection{Replacement frequencies}

The operations involved in any replacement are:

- Dismantling of the cladding

- Transport of dismantling rubble / waste

- Treatment and/or disposal of that waste

- Manufacture of the new material

- Transport of the new material

- Installation of the new material

The assumptions and environmental and economic impacts associated with each of these operations are:

- Demolition or dismantling of the cladding and transport of the waste generated during dismantling, the same waste as is defined in the End of Life stage discussed below.

- For all operations involving the new materials to be fitted: manufacture, transportation and installation, where the values obtained the first time it was built shall be used.

A reference number or frequency of operations during the estimated service life of the construction solution is taken into consideration. Figure 4 shows the number and type of operations required on the assumption that the cladding has a service life of 20 years. 
Service life of construction product: 50 years

Service life of skin: 20 years

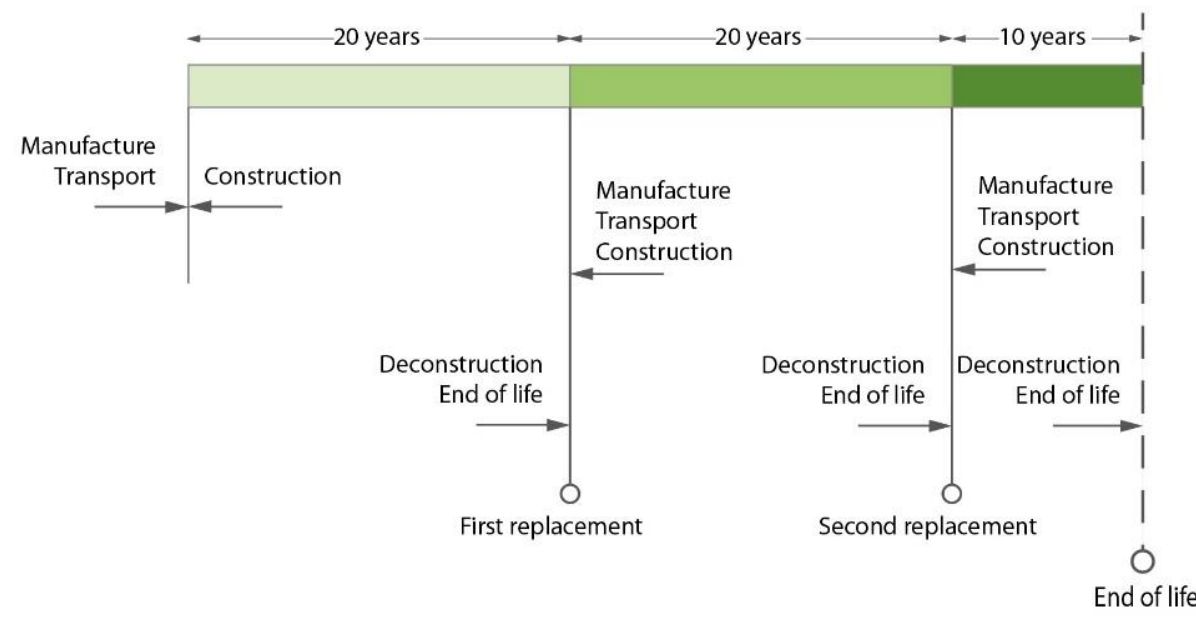

Figure 4 Example of operations required throughout a life cycle

\subsection{Impacts on End of Life operations}

In order to assess the environmental and economic impacts likely to arise in each construction solution, each component's end of life stage is evaluated:

- Dismantling and demolition (C1): This includes disassembling and tearing down the construction product and its components. At the end of its service life, the product will be removed either to be replaced or finally dismantled. This aspect takes into consideration the use of suitable ancillary equipment for demolition of the cladding and other components that make up the construction solution.

- Transport of Waste (C2): This includes removing and transporting waste from dismantling and demolition within a waste management programme, whether to landfill or for subsequent re-use.

- Reuse, recovery and recycling (C3): This includes the treatment of waste materials up to the end of their waste status, through reuse, recycling and energy recovery processes. The assumption is that $70 \%$ of construction and demolition waste is destined for re-use, recovery and recycling.

- Disposal: this includes the physical pre-treatment and disposal management on-site at the landfill. $30 \%$ of the product is estimated to be landfilled.

SolconCer does not calculate module D, which states the loads and potential benefits of secondary materials, secondary fuel or energy recovered when the construction product exits the system. 


\subsection{Environmental impacts}

The environmental impacts relating to the cladding materials and part of the materials that form the other layers, are taken from Environmental Product Declarations (EPDs) registered in European programmes complying with UNE-EN standard 15804. Data for all other materials have been taken from commercial Life Cycle Assessment databases, namely the GaBi (PE International) [15] and ELCD databases [16].

For each construction product, the program provides the values corresponding to the environmental impact recognised in the Sustainability in Construction standards [10][11] as shown in Table 1.

The concept of Abiotic Resource Depletion has been removed from the set of indicators recommended by these standards, due to the range of different methods used to assess this impact in EPDs, so that they are no longer comparable. Furthermore, according to standard UNEEN 15804: 2012 [10], this indicator is subject to further scientific development and it is foreseen that the use of that indicator will be reviewed when the standard is revised.

Table 1 Environmental impact categories

\begin{tabular}{|c|c|}
\hline Parameters in the environmental impact category & Unit( \\
\hline Global warming potential & $\mathrm{kg} \mathrm{CO} 2$ equivalent \\
\hline Acidification potential of land and water & $\mathrm{kg} \mathrm{SO}_{2}$ equivalent, \\
\hline Eutrophication potential & $\mathrm{kg} \mathrm{PO}{ }_{4}{ }^{3-}$ equivalent \\
\hline Stratospheric ozone depletion potential & kg CFC 11 equivalent \\
\hline Tropospheric ozone formation potential & $\mathrm{kg} \mathrm{C}_{2} \mathrm{H}_{4}$ equivalent \\
\hline Abiotic resource depletion potential of fossil fuels & MJ, net calorific value \\
\hline
\end{tabular}

\subsection{Standardisation of environmental impacts}

The standardisation process is an optional element in life-cycle assessment. The main objective of standardising the results of impact category indicators is to convey the relative significance and magnitude of these values for the system being studied and to reveal the most environmentally friendly building systems more easily.

Our standardisation method is the one proposed by CML2001 - 2001-2013, EU25+3 [12], which provides data about the environmental situation over the period 2001-2013 from the 25 countries 
of the European Union in 2006, plus Iceland, Norway and Switzerland (EU 25+3). Table 2 shows the standardisation values used.

Table 2 Standardisation factors used

\begin{tabular}{|l|c|}
\hline \multicolumn{2}{|c|}{ Standardisation factors: CML2001 - 2001-2013, EU25+3 } \\
\hline Global warming potential (kg CO 2 equivalent) & $5,21 \mathrm{E}+12$ \\
\hline Acidification potential (kg SO 2 equivalent) & $1,68 \mathrm{E}+10$ \\
\hline Eutrophication potential (kg PO $4{ }^{3-}$ equivalent) & $1,85 \mathrm{E}+10$ \\
\hline Ozone depletion potential (kg R11 equivalent) & $1,02 \mathrm{E}+07$ \\
\hline Photochemical ozone creation potential (kg C $\mathrm{H}_{4}$ equivalent) & $1,73 \mathrm{E}+09$ \\
\hline Abiotic depletion potential of fossil energy (MJ) & $3,51 \mathrm{E}+13$ \\
\hline
\end{tabular}

\subsection{Economic cost assessment}

Total cost is given for each construction product, sorted into 7 life cycle stages, made up of the various costs applicable to each item comprising the overall construction product or solution (Table 3).

Table 3 Economic indicators

\begin{tabular}{|l|c|}
\hline \multicolumn{1}{|c|}{ Cost indicators } & Unit \\
\hline Manufacturing costs (A1-A3) & $€ / \mathrm{m}^{2}$ \\
\hline Freight costs (A4) & $€ / \mathrm{m}^{2}$ \\
\hline Construction and Installation costs (A5) & $€ / \mathrm{m}^{2}$ \\
\hline Maintenance costs (B2) & $€ / \mathrm{m}^{2}$ \\
\hline Repair costs (B3) & $€ / \mathrm{m}^{2}$ \\
\hline Replacement costs (B4) & $€ / \mathrm{m}^{2}$ \\
\hline End of Life costs (dismantling and waste removal) (C1-C4) & $€ / \mathrm{m}^{2}$ \\
\hline
\end{tabular}

The costs of all components comprising the construction product or solution are considered, including any material likely to form part of the installation of $1 \mathrm{~m}^{2}$ of the construction solution. Many of the prices were taken from the "Construction Price Generator" database developed by CYPE, except for ceramic materials, for which average market price is used; freight costs, for which the method has already been explained above; Maintenance, for which the reference are the most common conditions stated in EPDs and manufacturers' recommendations; and the costs of disposing of the waste generated during construction and installation. 


\subsection{Performance indicators}

Performance characterisation using the SolconCer tool is based on the requirements made in the EOTA Technical Guide to construction products, based in turn on six of the seven essential requirements of the Construction Product Regulations (CPR), plus an eighth requirement that concerns durability and finish (technical and/or aesthetic obsolescence, so-called 'impaired appearance'). This set of requirements leads to a number of indicators that characterise performance on the basis of:

- The set of standards (harmonised standards, product standards and trials) and regulations (Technical Building Code (TBC), et alia) applicable to construction products or to their components

- EU Regulation No 305/2011 [17], which replaces the former Construction Products Directive.

- The set of EOTA ETAG[1] guidelines, adapted to meet the Regulations.

Having obtained the baseline data, scenarios (use, traffic intensity, type of premises, etc.) have to be defined in order to continue with the assessment and evaluation of the indicators.

The indicators are individually converted to a dimensionless scale one by one, in some cases by linear distribution but in most cases by direct allocation. Another particular decision that arises with this method also needs to be considered: the way it penalises those parameters that have no associated magnitude. In this case, the intention is to reward manufacturers' efforts to benchmark their products through their characteristics (especially standardised characteristics).

Some indicators are expressed by more than one magnitude. In such cases, the arithmetic mean of the values of the different magnitudes is taken once conversion to the dimensionless scale has taken place.

Apart from these series of magnitudes that represent one indicator, there is one other group of basic or essential indicators (the first six in EU Regulation No. 305/2011 plus the eighth indicator on durability). According to the project, the User of the SolconCer method can assess indicators some more than others.

This differing assessment of indicator sets is known as Weighting in the project. The SolconCer weighting methodology adopts a default weighting rate for all aggregations. This weighting was agreed by a workshop team of Architects, Surveyors and Managers from the ceramic tile industrial sector, who by survey provided their particular appreciation of each set of indicators. With that as the basis, the User can modify the weighting in the program. Having defined the weighting, an end dimensionless value is obtained that defines the construction product under assessment from the performance point of view.

Table 4 shows the essential requirements and the weighting used, a detailed description of which is summarised further below. 
Table 4 Basic requirements

\begin{tabular}{|l|c|}
\hline \multicolumn{1}{|c|}{ Essential requirement } & Weighting \\
\hline ER1 Mechanical strength and stability & $14 \%$ \\
\hline ER2 Safety in the event of fire & $20 \%$ \\
\hline ER3 Hygiene, health and environment & $13 \%$ \\
\hline ER4 Security and user accessibility & $19 \%$ \\
\hline ER5 Noise protection & $10 \%$ \\
\hline ER6 Energy saving and heat insulation & $12 \%$ \\
\hline ER7 Energy saving and heat insulation & $\mathrm{N} / \mathrm{A}$ \\
\hline ER8 Durability and service & $12 \%$ \\
\hline
\end{tabular}

\subsection{Final scaling}

In order to provide a quick overview of the assessment, SolconCer runs a scaling exercise on each set of indicators to adapt the results to a $0-10$ scale, where 0 is the worst situation (highest cost/environmental impacts or worst performance) and 10 the best.

\section{Factors affecting horizontal partitions}

At present, SolconCer assesses three types of construction solutions: horizontal partitions, wet vertical partitions and urban flooring. Given its limited scope, this paper will only discuss horizontal partitions, and refer the reader to the actual software (http://solconcer.es/) and help files for further information about this and other solutions.

\subsection{Structure and materials}

The top layer materials chosen for assessment are: ceramic tiles, PVC, laminate flooring, carpeting, natural stone, terrazzo and plywood parquet flooring. Each material uses different materials for its installation, such as Glue and Adhesive, Mortar, Sheeting, etc. and this assembly is known in SolconCer as the Skin.

Under the skin come the intermediate layers, composed of the sound insulation layer and levelling mortar, which in the case of ceramic tiles and stone have two options: Low Compressibility and High/Medium Compressibility; a single option: Self-levelling, in the case of laminate flooring, plywood parquet, carpeting and PVC; and High Compressibility in the case of terrazzo.

All the above components are laid on a deck, which may comprise beams and arches (residential background) or prefabricated slabs (background in public thoroughfares). This deck will then have two possible finishes on its underside: pre-fab suspended ceiling or a roughcast. 
Figure 5 shows a variant of this type of construction solution.

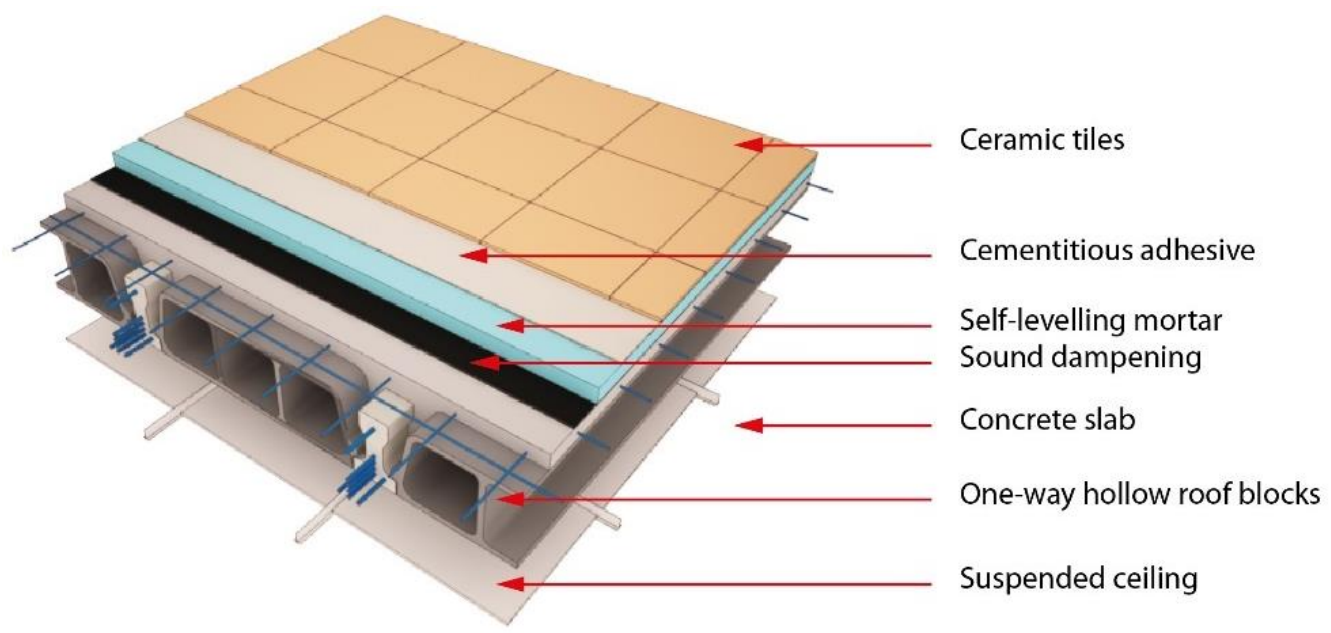

Figure 5 Example of a construction solution in a horizontal partition

\subsection{Scenarios}

Figure 6 shows the different scenarios that have been considered for this type of construction solution. Most of these scenarios have already been discussed or are sufficiently clear; nevertheless, some of them need further explanation. 


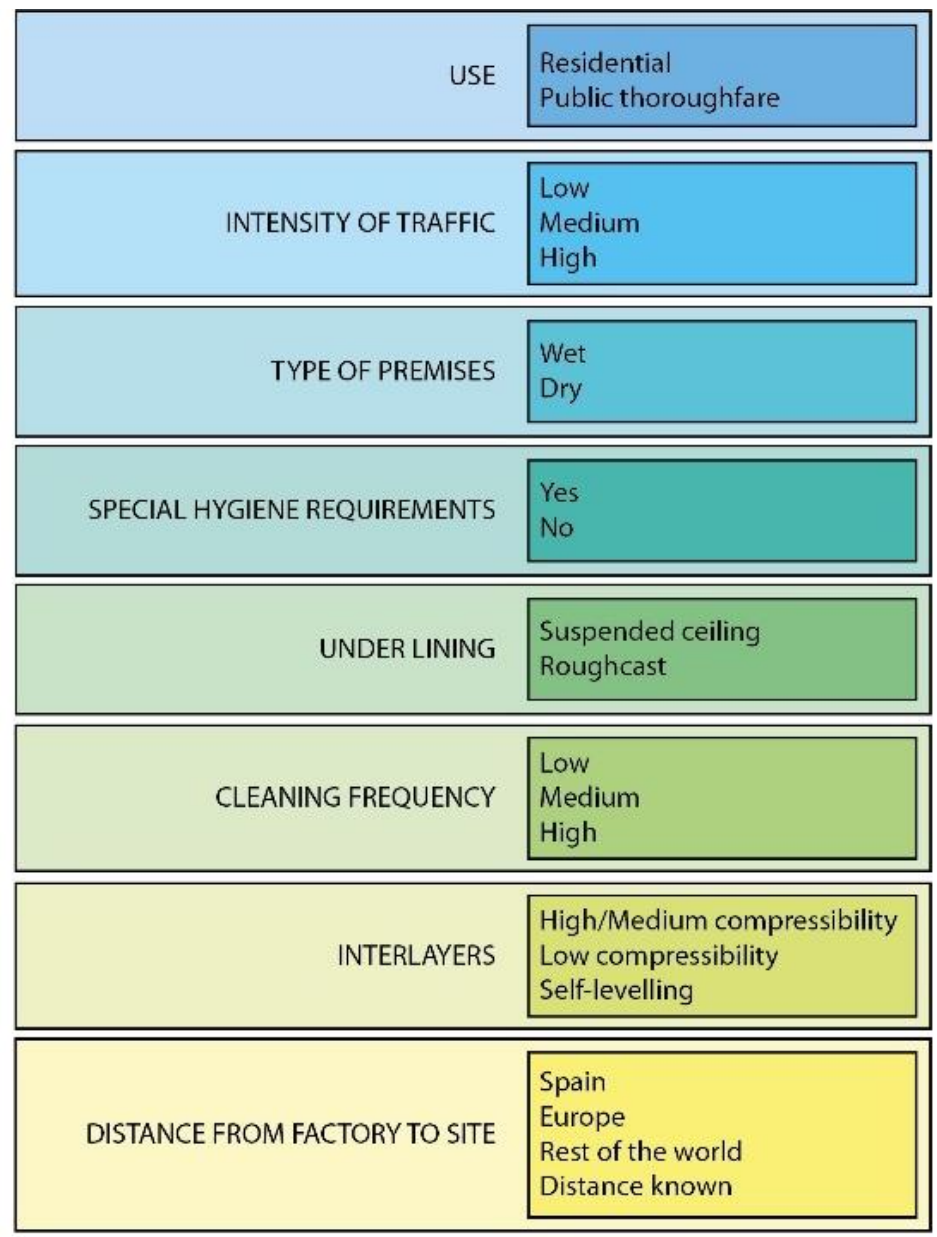

Figure 6. Scenarios in a horizontal partition

Three levels of traffic intensity have been established: Low, corresponding to traffic in a residential dwelling; Medium, which refers to traffic in a retail outlet or places with average public presence; and High, which corresponds to publicly-trafficked premises and shopping centres. This scenario impacts on the ER8-Durability performance indicator and on the selection between the different quality grades of the materials.

As far as Type of Premises is concerned, two options have been defined - damp and dry - which have a bearing on indicators ER3 - Hygiene, Health and Environment and ER4 - Security and User Accessibility.

The scenario Special Hygiene Requirements affects performance indicators ER8.4 (stain resistance) and ER8.5 (chemical resistance). 
Table 5 shows the different scenarios in terms of Cleaning Frequency with its parameters taken from EPDs and manufacturers' recommendations, which influence environmental and economic impacts.

Table 5 Skin maintenance scenarios

\begin{tabular}{|c|c|c|c|}
\hline Skin & Low maintenance & Medium maintenance & High maintenance \\
\hline $\begin{array}{l}\text { Laminate and } \\
\text { PVC flooring }\end{array}$ & $\begin{array}{c}\text { Washed with soap and } \\
\text { water once a week. } \\
\text { Vacuum cleaned twice a } \\
\text { month. }\end{array}$ & $\begin{array}{c}\text { Washed with soap and } \\
\text { water once a day. } \\
\text { Vacuum cleaned once a } \\
\text { week. }\end{array}$ & $\begin{array}{l}\text { Washed with soap and } \\
\text { water. Vacuum cleaned } \\
\text { twice a day with heavy- } \\
\text { duty equipment. }\end{array}$ \\
\hline $\begin{array}{l}\text { Ceramic tiling, } \\
\text { natural stone and } \\
\text { Terrazzo }\end{array}$ & $\begin{array}{l}\text { Washed with soap and } \\
\text { water once a week. }\end{array}$ & $\begin{array}{l}\text { Washed with soap and } \\
\text { water once a day. }\end{array}$ & $\begin{array}{l}\text { Washed with soap and } \\
\text { water and vacuum } \\
\text { cleaned twice a day } \\
\text { with heavy-duty } \\
\text { equipment. }\end{array}$ \\
\hline $\begin{array}{l}\text { Carpets and } \\
\text { parquet }\end{array}$ & $\begin{array}{l}\text { Vacuum cleaned } 3 \text { times a } \\
\text { week. } \\
\text { Wet cleaned once a year. }\end{array}$ & $\begin{array}{l}\text { Vacuum cleaned } 5 \text { times } \\
\quad \text { a week. } \\
\text { Wet cleaned once a year. }\end{array}$ & $\begin{array}{c}\text { Vacuum cleaned } 7 \text { times } \\
\text { a week with heavy-duty } \\
\text { equipment. } \\
\text { Wet cleaned } 4 \text { times a } \\
\text { year with heavy-duty } \\
\text { equipment. }\end{array}$ \\
\hline
\end{tabular}

\section{IT Tool}

The result of the whole methodology outlined above is the online program http://solconcer.es/, fully available for free use and where the User can register in order to save the data calculated with the software. The program displays the results in clearly depicted groups (Figure 7), although it also provides a detailed breakdown of each indicator to see what influence it has (Figure 8).

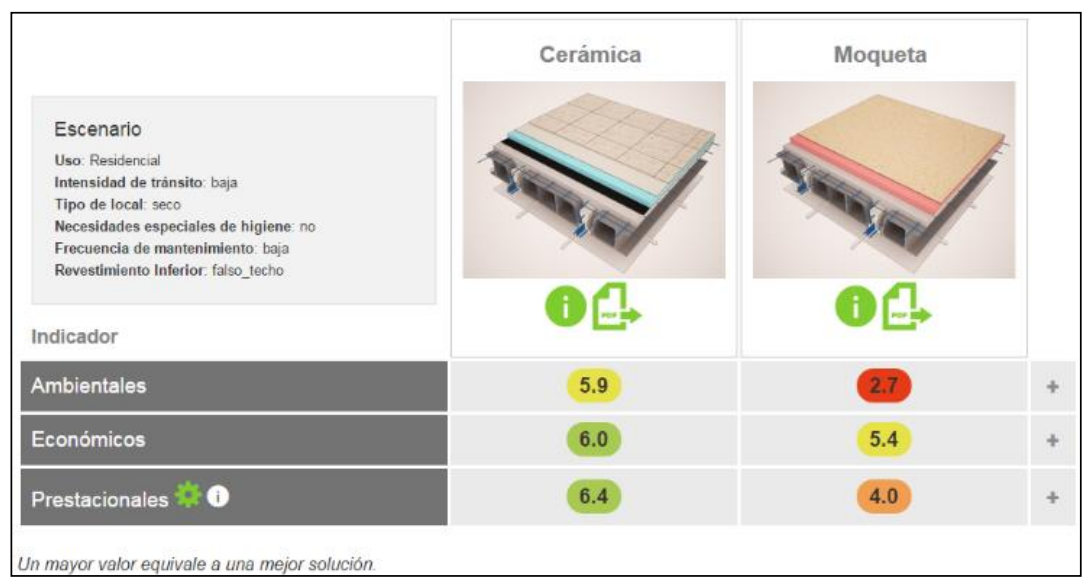

Figure 7 Grouped results 


\begin{tabular}{|c|c|c|c|}
\hline & Cerámica & Moqueta & \\
\hline \multicolumn{3}{|l|}{$\begin{array}{l}\text { Escenario } \\
\text { Uso: Residencial } \\
\text { Intensidad de tránsito: baja } \\
\text { Tipo de local: seco } \\
\text { Necesidades especiales de higiene: no } \\
\text { Frecuencia de mantenimiento: baja } \\
\text { Revestimiento Inferior: falso_techo }\end{array}$} & \\
\hline Indicador & & & \\
\hline Ambientales & 5.9 & 7 & - \\
\hline Indic adores de solución completa & 5.9 & 2.7 & - \\
\hline Potencial de calentamiento global (GWP) & 1.07 E2 kg CO2-Equiv. & 1.56 E2 kg CO2-Equiv. & \\
\hline $\begin{array}{l}\text { Potencial de agotamiento de la capa de ozono } \\
\text { estratosférico (ODP) }\end{array}$ & 1.53 E-4 kg R11-Equiv. & 1.92 E-3 kg R11-Equiv. & \\
\hline Potencial de acidificación del suelo (AP) & 3.16 E-1 kg SO2-Equiv. & 4.62 E-1 kg SO2-Equiv. & \\
\hline Potencial de eutrofización (EP) & 5.76 E-2 kg Phosphate-Equiv. & 8.31 E-2 kg Phosphate-Equiv. & \\
\hline Potencial de formación de ozono troposférico (POCP) & $3.12 \mathrm{E}-2 \mathrm{~kg}$ Ethene-Equiv. & $5.61 \mathrm{E}-2 \mathrm{~kg}$ Ethene-Equiv. & \\
\hline $\begin{array}{l}\text { Potencial de agotamiento de recursos abióticos para } \\
\text { recursos fósiles (ADP-combustibles fósiles) }\end{array}$ & $9.31 \mathrm{E} 2 \mathrm{MJ}$ & $1.76 \mathrm{E} 3 \mathrm{MJ}$ & \\
\hline Indic adores de dermis $\mathbf{C}$ & 6.0 & 2.5 & + \\
\hline Económicos & 6.0 & 5.4 & - \\
\hline Indic adores de solución completa & $193.6 € / \mathrm{m}^{2}$ & $284.4 € / \mathrm{m}^{2}$ & + \\
\hline Indic adores de dermis $\mathbf{C}$ & $41.1 € / \mathrm{m}^{2}$ & $134.9 € / \mathrm{m}^{2}$ & + \\
\hline Prestacionales $: 0$ & 6.4 & 4.0 & - \\
\hline Resistencia mecánica y estabilidad & 5.0 & 5.0 & + \\
\hline Seguridad en caso de incendio & 7.5 & 5.5 & + \\
\hline Higiene, salud y medio ambiente & 10.0 & 2.2 & + \\
\hline Seguridad y accesibilidad de utilización & 5.0 & 5.8 & + \\
\hline Protección contra el ruido & 5.3 & 6.5 & + \\
\hline Ahorro energético y aislamiento térmico & 5.0 & 1.0 & + \\
\hline Durabilidad y servicio & 6.5 & 0.6 & + \\
\hline
\end{tabular}

Figure 8 Results with detail of environmental indicators 


\section{Conclusions}

This paper presents the methodology behind the SolconCer software program that enables:

- Different construction products and solutions to be objectively assessed through contrasting indicators that evaluate their environmental, economic and performance levels.

- Enhancement of environmental protection in the context of a strategy of sustainable development based on redirecting the construction sector towards sustainable building.

- The use of ceramic systems to be disseminated and their inherent features to be publicised;

- Manufacturers to foresee how a modification in the characteristics of a material (cost, environmental impacts or performance) will affect the assessment of the construction system as a whole.

\section{Funding}

This project has been funded by the Castellon County Council, Spain.

\section{References}

[1] The European Technical Approval Guidelines (ETAGs) were established by the European Organisation for Technical Assessment (EOTA) under the Construction Products Directive 89/106/EEC - (CPD).Guía de la baldosa cerámica. Generalitat Valenciana. Instituto Valenciano de la Edificación

[2] Guía de la piedra natural. Generalitat Valenciana. Valencian Institute of Construction.

[3] Guía de la baldosa de terrazo. Generalitat Valenciana. Valencian Institute of Construction.

[4] Guía de la baldosa de terrazo. Generalitat Valenciana. Valencian Institute of Construction.

[5] Manuales de actualización en materiales y técnicas de colocación de recubrimientos cerámicos. PROALSO.

[6] CTE DB-SE. Generalidades.

[7] ANNEX III of Royal Decree 1492 of 24 October 2011.

[8] http://www.fomento.gob.es/mfom/lang_castellano/direcciones_generales/transporte_terrestr e/servicios_transportista/observatorio_costes/observatorios.htm

[9] http://www.fomento.gob.es/NR/rdonlyres/0E8318C5-2563-47B1-8FA6F0D11D196AFD/103643/OBSERVATORIO_Documento_Final.pdf 
[10] EN 15804, 2012. Sustainability of construction works - Environmental product declarations Core rules for the product category of construction products. CEN European Commission, Brussels, Belgium.

[11] EN 15978, 2011. Sustainability of construction works - Assessment of environmental performance of buildings - Calculation method. European Standards.

[12] CML 2001, 2015 - Jan. 2015, 2001-2013 EU25+3, incl biogenic carbon (global equivalents).http://cml.leiden.edu/software/data-cmlia.html

[13] EU Regulation No 305/2011 of the European Parliament and the Council of 09/03/2011, establishing harmonized conditions for the marketing of construction products and repealing Directive 89/106/EEC. Came into full effective force on 01/07/2013. Available in Spanish from the Official Journal of the European Union of 04/04/2011, pp.L88/5 - L88/41.

[14] PE International, 2008. GaBi Software-system. Compilation 4.131 [WWW Document]. URL http://www.gabi-software.com/software/gabi-4/

[15] PE International, 2008. Database for life cycle engineering, copyright, TM. 1992-2008 (compilation. 4.4.142.1, DB version 4.131)

[16] JRC-IES, 2015. Joint Research Centre, Institute for Environment and Sustainability. European $\begin{array}{lllll}\text { Reference Life-Cycle } & \text { Database. } & \text { Version }\end{array}$ http://eplca.jrc.ec.europa.eu/ELCD3/processList.xhtml

[17] Regulation (EU) No 305/2011, 2011. European Parliament and of the Council of 9 March 2011 laying down harmonised conditions for the marketing of construction products and repealing Council Directive 89/106/EEC. 



\section{APORTACIÓN No 5}

\section{HOW CAN THE EUROPEAN CERAMIC TILE INDUSTRY MEET THE EU'S LOW-CARBON TARGETS? A LIFE CYCLE PERSPECTIVE}

Teresa Ros-Dosdá ${ }^{1,2}$, Pere Fullana-i-Palmer²; Ana Mezquita'; Paolo Masoni³; Eliseo Monfort ${ }^{1}$

\section{Journal of Cleaner Production}

Volume 199, 554-564

Enviado: 22 de Febrero de 2018

Aceptado: 17 de Julio de 2018

Publicado online: 23 de Julio de 2017

Publicado el 20 de Octubre de 2018

DOI: https://doi.org/10.1007/s11367-017-1377-9

Factor de impacto 2018: 7,32

SCImago Journal Rank (SJR): 1,620

\footnotetext{
${ }^{1}$ Instituto de Tecnología Cerámica (ITC). Asociación de Investigación de las Industrias Cerámicas (AICE). Universidad Jaume I. Avda Sos Baynat s/n, 12006, Castelló, Spain.

2 UNESCO Chair in Life Cycle and Climate Change (ESCI-UPF). Passeig Pujades 1, 08003 Barcelona, Spain.

${ }^{3}$ Italian National Agency for New Technologies, Energy and Sustainable Economic Development (ENEA); Via Martiri di Monte Sole 4, 40129 Bologna, Italy. Presently, Ecoinnovazione srl; via D’Azeglio 52, 40123 Bologna, Italy
} 
Journal of Cleaner Production 199 (2018) 554-564

How can the European ceramic tile industry meet the EU's low-carbon targets? A life cycle perspective

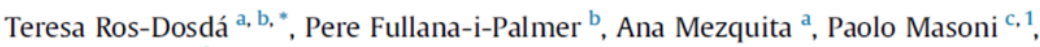
Eliseo Monfort ${ }^{\mathrm{a}}$

a Instituto de Tecnología Cerámica (ITC), Asociación de Investigación de las Industrias Cerámicas (AICE), Universidad Jaume I, Avda. Sos Baynat s/n, 12006 Castellón, Spain

${ }^{b}$ UNESCO Chair in Life Cyde and Climate Change (ESCl-UPF), Passeig Pujades 1, 08003 Barcelona, Spain

'Italian National Agency for New Technologies, Energy and Sustainable Economic Development (ENEA), Via Martiri di Monte Sole 4, 40129 Bologna, Italy

\section{A R T I C L E I N F O}

\section{Article history:}

Received 22 February 2018

Received in revised form

26 June 2018

Accepted 17 July 2018

Available online 23 July 2018 


\title{
HOW CAN THE EUROPEAN CERAMIC TILE INDUSTRY MEET THE EU'S LOW-CARBON TARGETS? A LIFE CYCLE PERSPECTIVE
}

\begin{abstract}
Ceramic tile manufacturing is deemed to be an energy intensive industry, mainly based on combustion processes and, therefore, subject to European policies aiming at reducing greenhouse gas emissions. The "Roadmap for moving to a competitive low-carbon economy in 2050", approved by the European Commission, calls for sectoral strategies to reduce $\mathrm{CO}_{2}$ emissions by $20 \%$ by 2020 and by $83-87 \%$ by 2050 , compared to $1990 \mathrm{CO}_{2}$ emissions. This study included up to 17 technological alternatives and their combination, resulting in 25 technological scenarios associated to the life cycle of porcelain stoneware tiles. In this regard, a high parametrized LCA model was developed to allow for the required flexibility. The scenario analysis can be used: a) to estimate the degree of technological innovation required; b) to define and to focus strategies and; c) to devise the lines of technological development that need to be implemented in the ceramic tile manufacturing sector in the coming years. The alternatives consisted of endogenous and exogenous sectoral technologies. The technologic alternatives involved changes in product design (thickness and decoration), changes in the manufacturing process (preparation of raw material by dry or wet route, and simultaneous implementation of thermal energy efficiency techniques), and changes in the energy sources (hybrid and/or electric driers, and kilns and decarbonization of the power grid mix). It was clearly proven that the wider the scope of the Life Cycle Assessment study is, the greater eco-innovations are necessary. In all the studied scenarios, the manufacturing stage was always the most significant from the global warming point of view. Finally, regarding the achievability of EU objectives, the results of this study show that the implementation of widespread technologies suffice for fulfilling 2020 targets; nevertheless, only some limited combinations of both widespread and ambitious breakthrough technologies may achieve the 2050 reduction targets.
\end{abstract}

\section{Keywords}

Low-Carbon Economy; Ceramic Tiles; Life Cycle Assessment; Technological Scenarios. 


\section{Highlights}

- EU $2020 \mathrm{CO}_{2}$ reduction target for the ceramic tile industry can be met through current technologies.

- The ceramic tile industry will not meet $\mathrm{EU} \mathrm{CO}_{2}$ reduction target for 2050 unless they combine several measures along the life cycle.

- Twenty-five technological scenarios have been found and assessed.

- Endogenous and exogenous breakthrough techniques are required to attain the $2050 \mathrm{EU}$ low-carbon targets.

\section{Introduction}

The most important ceramic subsector (in turnover) is the floor and wall ceramic tiles. According to European data, production is around 1304 million $\mathrm{m}^{2}$, consumption amounts to 964 million $\mathrm{m}^{2}$ and total sales were close to $€ 9$ billion in 2016. (Baraldi, 2017; Cerame Unie, 2017). Spain and Italy are the largest EU ceramic tile producers, together accounting for around $80-90 \%$ of European production. (Baraldi, 2017, Cerame Unie, 2017).

Europe produces different types of ceramic tiles. The most common ones are earthenware tiles, glazed stoneware tiles and porcelain stoneware tiles (PST) (ASCER, 2011). Their manufacturing processes are quite similar irrespective of the type of tile, and mainly consist of the reception and storage of raw materials, their granulation, tile forming, drying, glazing and decorating, and firing (EIPPBC, 2007). Some of these stages can be carried out by means of alternative technologies or routes. For instance: raw material milling may be performed through a wet or dry route; tile forming through pressing or extrusion; firing in one or two stages, etc. (Ros-Dosdá, et al., 2017). The most popular manufacturing process in Europe (raw material wet milling and single-firing) is schematically illustrated in Figure 1.

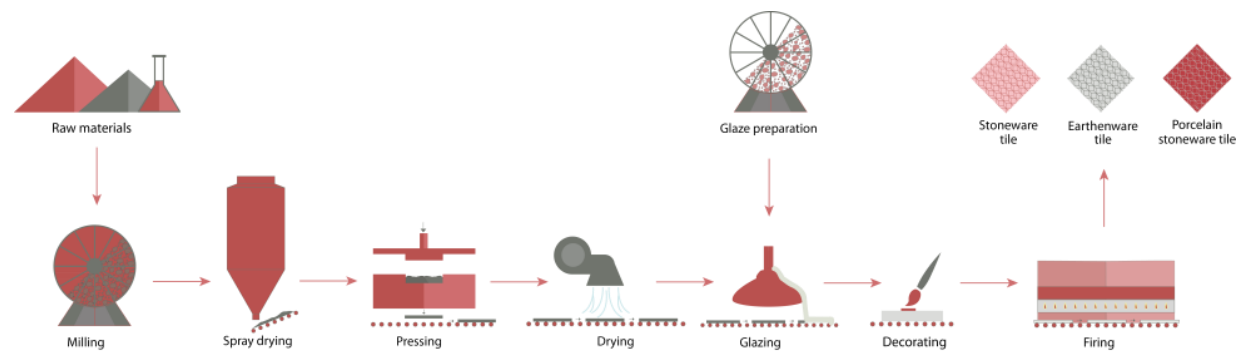

Figure 1 Schematic illustration of the single-fired ceramic tile manufacturing process 
Ceramic tile manufacturing is an energy-intensive process $\left(30-40 \mathrm{kWh} / \mathrm{m}^{2}\right.$ for an average specific weight of $22 \pm 1 \mathrm{~kg} / \mathrm{m}^{2}$ ) (lbáñez-Forés et al.,2011; Mezquita et al., 2017; Monfort et al., 2010; RosDosdá et al., 2017), being thermal energy the most important demand. This energy is mainly obtained by combustion of natural gas, which represents $90 \%$ of the overall direct energy consumption. Thermal energy consumption mainly takes place in three process stages: spray drying of ceramic slurries (36\%), drying of the formed ceramic tile bodies (9\%), and ceramic tile firing (55\%) (EIPPBC 2007, Monfort et al., 2010).

Ceramic tile manufacturers are concerned about the carbon dioxide emissions (Gabaldón-Estevan et al., 2014), since they are subject to control pursuant to the EU Climate Change and Energy Sustainability policies and laws, such as Directive 2003/87/EC, Directive 2009/29/EC, and Directive $2012 / 27 / E U$, which establish specific targets on this topic. Additionally, in 2011, the European Commission published the "Roadmap for moving to a competitive low-carbon economy in 2050" and, for the industrial sectors, the objective is to reduce $\mathrm{CO}_{2}$ emissions from $83 \%$ to $87 \%$ by 2050 (COM (2011) 112 final).

Since solutions are sector specific, the EU recommends that each industrial sector prepare a specific roadmap in order to identify the best available techniques (BAT) to reach the mentioned objectives. The European ceramic industry has prepared, through Cerame-Unie, its own roadmap. The document considers alternative energy sources and current and future production of technologies (Cerame Unie, 2012), and urges to consider the complete lifecycle of ceramics, arguing that the contribution of durable products to resource and energy efficiency can only be appreciated with a holistic approach, including its durability and impact over the use phase.

Several studies on how to improve the energy efficiency in the manufacturing sector of ceramic tiles have been published (Mezquita et al. 2014a, 2014b; Shu et al., 2012a, 2012b;) as well as Life Cycle Assessment (LCA) studies that identify hotspots and make proposals for improvement (Almeida et al. 2016; Bovea et al. 2010; Ibáñez-Forés et al. 2013).

Previous studies (Cerame Unie, 2012; Gabaldon-Estevan et al.2014, 2016) show that these objectives for the European ceramic sector are extremely demanding, and unreachable with current technologies and policies. Therefore, its application implies implementing breakthrough technology to dramatically reduce carbon dioxide emissions. Moreover, Bocken et al, 2014 stated that fundamental changes, such as an integrated approach that goes beyond eco-efficiency initiatives and rethinking the way that businesses work are required to deliver long-term sustainability to reach the scenario for 2050 , including new perceptions of values and new business models aligned in a route to a sustainable and circular economy.

On the other hand, several studies have been published with the aim of evaluating long term $\mathrm{CO}_{2}$ emissions in several industrial sectors (Ajanovic, 2013; García-Gusano et al., 2015; Griffin et al., 2017; Selvakkumaran et al., 2014; $\mathrm{Xu}$ et al., 2014). However, none of them assess the $\mathrm{CO}_{2}$ emissions from a life-cycle perspective. If this life-cycle perspective is not applied, for example, it may erroneously be concluded that the installation of electric kilns and driers would suffice to reach the established industrial targets on $\mathrm{CO}_{2}$ emissions. Therefore, a holistic approach, such as the one provided by a life cycle perspective, is necessary to avoid environmental loads shifting to 
exogenous entities. This is especially important in the case of energy studies. In fact, some authors (Streimikiene and Šivickas, 2008) have identified contradictory impacts in the implementation of changes required to meet EU Directives targeting specific sustainable objectives. Consequently, assessment from a life cycle perspective is essential to find a trade-off and to avoid environmental burden shifting. Indeed, many studies consider that the LCA methodology is the most appropriate for scientific basis to assist decision-making processes in the development of truly effective environmental policies and strategies (Tan and Culaba, 2002). LCA is a standardized and widely used methodology and is accepted for analyzing the interactions of a technological system with the environment (Guinée et al., 2002; Klöpffer et al., 2009; Tan and Culaba, 2002).

In this regard, the aim of this study is to compare different technological options to reach the EU 2020 and 2050 Greenhouse Gas (GHG) emissions objectives, applying an attributional LCA approach.

To this end, the current study was developed using real and verified data obtained by the authors from the Spanish ceramic tile industry (Ros-Dosdá et al., 2017), which is considered to be sufficiently representative of the European ceramic tile industry, (it accounts for around $50 \%$ of the European production) (Baraldi, 2017). From the global warming point of view, there are major similarities, such as the process technologies, product manufactured, legal framework based on European Directives, etc. (Gabaldon-Estevan et a., 2016). Nevertheless, there are differences to be considered in other countries, such as the degree of cogeneration systems implementation (Confindustria Ceramica, 2018; Pardo 2018) or the raw material origin. The study is focused on PST, since it is the type of ceramic tile with the greatest commercial and innovation interest due to its high technical, functional and aesthetic versatility (ASCER, 2011; Sánchez et al., 2010).

\section{Research method}

\subsection{Goal definition}

On the account of the introduction above, the aim of this study was to determine whether and how it is possible to achieve the emission reduction objectives set by the European Commission through a roadmap for moving to (and surviving in) a competitive low carbon economy in 2020 and 2050, using the LCA methodology on different technological scenarios of the PST life cycle.

When performing LCA, several standards (EN 15804:2012+A1:2013, ISO 14040:2006, ISO 14044:2006) and the ILCD handbook (Wolf et al., 2010) recommendations were followed. The EeBGuide was consulted as well (Lasvaux et a., 2014). In addition, scenario analyses were used: a) to estimate the degree of technological innovation required; b) to define and to outline the strategies and; c) to devise the lines of technological development which need to be implemented in the ceramic tile manufacturing sector in the coming years. 


\subsection{System definition and functional unit}

The analyses considered the entire life cycle, i.e. from cradle to grave, although other scopes were used in the discussion of results. Life cycle modules were those used in CEN/TC 350 standards. The system boundary included the raw materials supplied for the body and glaze manufacturing, the raw materials transport means and distances, and each stage of the ceramic tile manufacturing process. Once the tiles are packaged, they are worldwide distributed; then, the tiles are duly unpacked for installation with fast-setting mortars. In this paper, a residential scenario was considered with a lifespan of 50 years. Afterwards, $70 \%$ of the removed tiles are deemed to be recovered as a filler, and $30 \%$ landfilled.

The Functional Unit (FU) was defined as "covering $1 \mathrm{~m}^{2}$ of household floor surface for 50 years with an average PST". The characteristics of an average fired PST were defined as: water absorption <0.5\%; $23.2 \mathrm{~kg} / \mathrm{m}^{2}$ weight; and $10.4 \mathrm{~mm}$ thickness with $0.76 \mathrm{~kg} / \mathrm{m}^{2}$ of glazes (RosDosdá et al., 2017).

\subsection{Baseline scenario and latest scenario}

The study was built on a compilation of environmental information from 26 Spanish companies to obtain 14 Environmental Product Declarations (EPD) of PST. Therefore, inventory data, which corresponded to the period 2010-2015, were verified by independent third parties. The study includes companies from the whole value chain: elaborated raw material producers (both spraydried granulated and glazes) and ceramic tile manufacturers. Moreover, some generic data, such as the type of means of transport or the type of waste management processes, were taken from a Spanish sectoral LCA study, carried out in 2007-2009 (Ros-Dosdá et al. 2017).

In order to define the reference scenario, i.e. 1990, inputs and outputs of energy (thermal and electrical) for that year were taken from sectoral historical data (Celades et al.2012), as they constitute more than $80 \%$ of the GHG emitted throughout the manufacturing process of the PST (Almeida et al., 2016; Benveniste et al., 2011; Bovea et al., 2010; Ibáñez-Forés et al., 2011; RosDosdá et al. 2017). Table 1 compares the PST manufacturing energy data of 1990 and 2010-2015.

Table 1 Main changes in the energy data inventory from 1990 to 2010-15.

\begin{tabular}{|c|c|c|}
\hline PST manufacturing process & 1990 & $2010-2015$ \\
\hline \multicolumn{3}{|l|}{ Inputs } \\
\hline Electrical energy taken from the grid $\left(\mathrm{MJ} / \mathrm{m}^{2}\right)$ & 19.21 & 16.50 \\
\hline Thermal energy from natural gas $\left(\mathrm{MJ} / \mathrm{m}^{2}\right)$ & 108.0 & $128.3^{(1)}$ \\
\hline \multicolumn{3}{|l|}{ Outputs } \\
\hline Electrical energy sold to the grid $\left(\mathrm{MJ} / \mathrm{m}^{2}\right)$ & 0 & 14.6 \\
\hline
\end{tabular}




\subsection{Limitations}

No reference to the technical or economic viability of the proposals is discussed in this paper. In fact, the authors recognize that, in some cases, the development and implementation of the breakthrough technology will still be required (e.g. 100\% of renewable energy used in kilns and driers), and they are aware that some studies (Wesselling et al. 2017) claimed that the integration of breakthrough innovations in traditional industries (as the studied ones) is typically slower than in high-tech industries for different reasons, such as the need for long-term investments, low risk managerial decisions or lack of market incentives. Nevertheless, the results of this study provide an idea of the level of theoretical demand set by the European Union and the technological trends to fulfil the required targets.

\subsection{Selection of environmental impact categories}

The life cycle impact assessment was carried out applying the CML 2001 impact assessment method (Guinée et al., 2002), as suggested in EN 15804:2012+A1:2013, updated to 2015. Although special attention was given to the Global Warming Potential (GWP), other environmental categories were also analyzed under the CML 2001 method (Guinée et al. 2002), as shown in Table 2, to study potential environmental burden shifting.

Table 2 Environmental impact categories

\begin{tabular}{|c|c|c|}
\hline Impact category & Acronym & Units \\
\hline Abiotic Depletion - elements & ADP-elements & kg Sb Equivalent \\
\hline Abiotic Depletion - fossil fuels & ADP-fossil & MJ \\
\hline Acidification Potential & AP & $\mathrm{kg} \mathrm{SO}_{2}$ Equivalent \\
\hline Eutrophication Potential & EP & $\mathrm{kg} \mathrm{PO}_{4}{ }^{3-}$ Equivalent \\
\hline Global Warming Potential (100 years) & GWP & $\mathrm{kg} \mathrm{CO} 2$ Equivalent \\
\hline Ozone Layer Depletion Potential (steady state) & ODP & kg R11 Equivalent \\
\hline Photochemical Ozone Creation Potential & POCP & $\mathrm{kg} \mathrm{C}_{2} \mathrm{H}_{4}$ Equivalent \\
\hline
\end{tabular}

\subsection{LCA model}

The LCA model was developed in GaBi software (PE International 2008b and Thinkstep 2016b) and the bundled professional databases PE International 2008a, Thinkstep 2016a and ELCD 3.2. (JRC-IES, 2015) in order to obtain the background data. A total of 194 variables were parameterized to allow for the scenario analyses. Some parameters served to define the technological route when multiple alternatives were possible (e.g. dry milling vs. wet milling) and some others were used to input process values (e.g. thermal energy needed in the firing stage). The latter parameters could be grouped into different categories: consumption of raw and auxiliary materials; water and energy consumption; emissions to air; waste generated; distances and types 
of transport between the different life cycle stages; etc. Table 3 presents a summary of the different parameter categories applied in this study.

Table 3 Parameters included in the LCA model

\begin{tabular}{|c|c|c|}
\hline \multicolumn{3}{|c|}{ Parameters to define the technological route } \\
\hline Processes & Technological route & Features \\
\hline $\begin{array}{l}\text { Body raw materials } \\
\text { preparation }\end{array}$ & $\begin{array}{l}\text { Wet milling } \\
\text { Dry milling }\end{array}$ & \multirow{3}{*}{$\begin{array}{l}\text { It is possible to define an } \\
\text { application rate for each route }\end{array}$} \\
\hline Forming & $\begin{array}{l}\text { Pressing } \\
\text { Extrusion }\end{array}$ & \\
\hline Waste management & $\begin{array}{l}\text { Incineration } \\
\text { Recycling } \\
\text { Disposal }\end{array}$ & \\
\hline Firing & $\begin{array}{l}\text { Single firing } \\
\text { Double firing }\end{array}$ & \multirow[b]{2}{*}{$\begin{array}{c}\text { One of the possible routes must be } \\
\text { chosen }\end{array}$} \\
\hline Use scenario & $\begin{array}{l}\text { Residential use } \\
\text { Commercial use } \\
\text { Sanitary use }\end{array}$ & \\
\hline \multicolumn{3}{|c|}{ Parameters to define the process values (quantification of inputs/outputs) } \\
\hline Type of parameters & Life cycle processes & Features \\
\hline $\begin{array}{l}\text { Types and quantities of } \\
\text { raw materials }\end{array}$ & $\begin{array}{l}\text { Body composition } \\
\text { Glaze composition }\end{array}$ & Mineralogical composition \\
\hline $\begin{array}{l}\text { Types and distances in } \\
\text { transports }\end{array}$ & $\begin{array}{l}\text { Raw materials to the granulates } \\
\text { factory } \\
\text { Granulates to the tile factory } \\
\text { Glazes to the tile factory } \\
\text { Packaging to the tile factory and to } \\
\text { the glazes factory } \\
\text { Auxiliary materials: } \\
\text { to the tile factory } \\
\text { to the installation site } \\
\text { to the building } \\
\text { Tiles to the buildings }\end{array}$ & $\begin{array}{l}\text { Type of vehicle (truck, trailer, cargo), } \\
\text { load capacity }\end{array}$ \\
\hline Energy consumption & $\begin{array}{l}\text { Granulate production } \\
\text { Glaze production } \\
\text { Tile production }\end{array}$ & Thermal and electrical energy \\
\hline Water consumption & $\begin{array}{l}\text { Granulate production } \\
\text { Glaze production } \\
\text { Tile production } \\
\text { Tile installation }\end{array}$ & $\begin{array}{l}\text { Source of water: tap water; } \\
\text { groundwater; recycled water }\end{array}$ \\
\hline
\end{tabular}


Table 3 Parameters included in the LCA model (continued)

\begin{tabular}{|c|c|c|}
\hline \multicolumn{3}{|c|}{ Parameters to define the process values (quantification of inputs/outputs) } \\
\hline Type of parameters & Life cycle processes & Features \\
\hline $\begin{array}{l}\text { Quantity and type of } \\
\text { emissions to the air }\end{array}$ & $\begin{array}{l}\text { Granulate production } \\
\text { Glaze production } \\
\text { Tile production }\end{array}$ & Channeled emissions (cold and hot) \\
\hline $\begin{array}{l}\text { Quantity and quality of } \\
\text { waste water }\end{array}$ & $\begin{array}{l}\text { Granulate production } \\
\text { Glaze production } \\
\text { Tile production }\end{array}$ & $\begin{array}{l}\text { Destination, pollutants and } \\
\text { management processes }\end{array}$ \\
\hline Solid waste & $\begin{array}{l}\text { Granulate production } \\
\text { Glaze production } \\
\text { Tile production } \\
\text { Tile installation } \\
\text { Tile maintenance } \\
\text { End-of-life }\end{array}$ & $\begin{array}{l}\text { Hazardous and non-hazardous } \\
\text { wastes } \\
\text { Destination and management } \\
\text { processes }\end{array}$ \\
\hline
\end{tabular}

This high parameterization of the model made programming more difficult at the beginning, but it gave much more flexibility to build scenarios in the long run. The modelling applied a modular approach, i.e. each process was modelled separately to facilitate the definition of process routes and technological and managerial options, providing high flexibility in the scenario simulation process.

\subsection{Technological alternatives}

A literature review of the technological alternatives and innovation trends allowed us to identify a set of the technologies which are the most likely to be applied in the horizon 2020 and 2050 . They may be classified as: widespread (ready to be implemented) or breakthrough (further research is needed) and exogenous (outside the scope of the ceramic tile industry) or endogenous (sector specific) technologies. In Table 4, the characteristics of each technological alternative are summarized, as well as the reference source used to identify these technological alternatives and their representative values for energy and material.

A sensitivity analysis was carried out to identify the most critical parameters from the point of view of global warming. This material is attached as supplementary information. 
Table 4 Summary of technological alternatives

\begin{tabular}{|c|c|c|c|c|}
\hline \multirow{2}{*}{\multicolumn{2}{|c|}{ Technological alternatives }} & \multicolumn{2}{|r|}{ Options } & \multirow{2}{*}{ References sources } \\
\hline & & Reference & Description & \\
\hline \multirow{5}{*}{$\begin{array}{l}\text { Product } \\
\text { design }\end{array}$} & \multirow{3}{*}{$\begin{array}{l}\text { Quantity of } \\
\text { glaze }\end{array}$} & GL100 & $\begin{array}{l}\text { Current average amount of } \\
\text { glaze decorative materials. For } \\
\text { PST is estimated as } 0.76 \\
\mathrm{~kg} / \mathrm{m}^{2} \text { solid, with } 33 \% \text { frit } \\
\text { content }\end{array}$ & \multirow{3}{*}{$\begin{array}{l}\text { ASCER 2011; Nicoletti } \\
2002 \text {; Ros Dosdá et al., } \\
2017\end{array}$} \\
\hline & & GL50 & $\begin{array}{l}\text { Reduction in the amount of } \\
\text { glaze in } 50 \%\end{array}$ & \\
\hline & & GLO & $\begin{array}{l}\text { No glaze coating or decoration } \\
\text { is applied }\end{array}$ & \\
\hline & \multirow{2}{*}{$\begin{array}{l}\text { Thickness of } \\
\text { the tile }\end{array}$} & TH100 & $\begin{array}{l}\text { Current PST average } \\
\text { thickness. } 10.4 \mathrm{~mm} \text {, weighing } \\
24.2 \mathrm{~kg} / \mathrm{m}^{2} \text { unfired }\end{array}$ & \multirow{2}{*}{$\begin{array}{l}\text { ASCER 2011; Da Silva } \\
\text { et al., 2014a, 2014b; } \\
\text { Girao et al., 2009; Pini } \\
\text { et al., 2014; Raimondo } \\
\text { et al., 2010; Ros Dosdá } \\
\text { et al., } 2017\end{array}$} \\
\hline & & TH50 & $\begin{array}{l}\text { Reduction of } 50 \% \text { of PST } \\
\text { thickness, thus reducing its } \\
\text { mass. }\end{array}$ & \\
\hline \multirow{4}{*}{$\begin{array}{l}\text { Manufacturing } \\
\text { process }\end{array}$} & \multirow{2}{*}{$\begin{array}{l}\text { Body raw } \\
\text { material } \\
\text { preparation } \\
\text { process }\end{array}$} & WCS & $\begin{array}{l}\text { Wet milling of body raw } \\
\text { materials using cogeneration } \\
\text { systems }\end{array}$ & \multirow{2}{*}{$\begin{array}{l}\text { Mezquita et al., 2017; } \\
\text { Bonucchi, 2012; } \\
\text { Melchiades et al., 2010; } \\
\text { Schianchi, 2012; Shu et } \\
\text { al., 2012a, 2012b }\end{array}$} \\
\hline & & DRY & $\begin{array}{l}\text { Dry milling of body raw } \\
\text { materials }\end{array}$ & \\
\hline & \multirow{2}{*}{$\begin{array}{c}\text { Energy } \\
\text { efficiency } \\
\text { technologies } \\
\text { in driers and } \\
\text { kilns }\end{array}$} & $\mathrm{CT}$ & $\begin{array}{l}\text { Current Thermal Technology } \\
\text { scenario in driers and kilns }\end{array}$ & \multirow{2}{*}{$\begin{array}{l}\text { Almeida et al., 2016; } \\
\text { Bovea et al., 2010; } \\
\text { lbáñez-Forés et al., } \\
\text { 2013; Mezquita et al., } \\
\text { 2014a, 2014b }\end{array}$} \\
\hline & & WDS & $\begin{array}{l}\text { Simultaneous implementation } \\
\text { of widespread technologies to } \\
\text { increase the overall efficiency } \\
\text { up to } 45 \% \text { (driers + kilns) }\end{array}$ & \\
\hline \multirow{5}{*}{$\begin{array}{l}\text { Energy } \\
\text { sources }\end{array}$} & \multirow{2}{*}{$\begin{array}{l}\text { Electric } \\
\text { energy } \\
\text { source }\end{array}$} & $\begin{array}{l}\text { SGM90 } \\
\text { SGM15 } \\
\text { SGM20 } \\
\text { SGM50 }\end{array}$ & $\begin{array}{l}\text { Electricity from the Spanish } \\
\text { Power Grid Mix (SGM) of } \\
\text { different years (1990, 2015, } \\
2020,2050)\end{array}$ & \multirow{2}{*}{$\begin{array}{l}\text { Cerame Unie 2012; } \\
\text { Capros et al., 2013; } \\
\text { Gabaldón-Estevan et } \\
\text { al., 2014, 2016; REE, } \\
2016\end{array}$} \\
\hline & & REN50 & $\begin{array}{l}\text { Electricity in } 2050 \text { came from a } \\
\text { mix of } 100 \% \text { renewable } \\
\text { sources }\end{array}$ & \\
\hline & \multirow{3}{*}{$\begin{array}{l}\text { Thermal } \\
\text { energy } \\
\text { source }\end{array}$} & NG100 & Combustion: $100 \%$ natural gas & \multirow{3}{*}{$\begin{array}{l}\text { Cerame Unie 2012; Ros } \\
\text { Dosdá et al. } 2017\end{array}$} \\
\hline & & NG50 & $\begin{array}{l}\text { Hybrid: } 50 \% \text { natural gas }+ \\
50 \% \text { electric sources }\end{array}$ & \\
\hline & & NGO & Electric: $100 \%$ electric sources & \\
\hline
\end{tabular}




\subsection{Technological scenarios}

From the combination of the different technological alternatives identified in the previous chapter, a total of 25 technological scenarios were formulated. Inventory data for each scenario was adapted from the average PST inventory (Ros-Dosdá et al., 2017) to the technological alternatives applied in each case.

In Table 5, the scenarios are listed from A to Z, showing the different technological alternatives chosen from the ones listed in the columns, grouped in three major classes: product design, manufacturing processes, and energy sources. In the scenario simulation, it should be considered that reference scenario A compiles technological alternatives which are the most likely to be applied in 1990, taken as a baseline by the Kyoto protocol and EU Directives, and scenario C represents the most likely technological situation in the ceramic tile industry in 2015. 


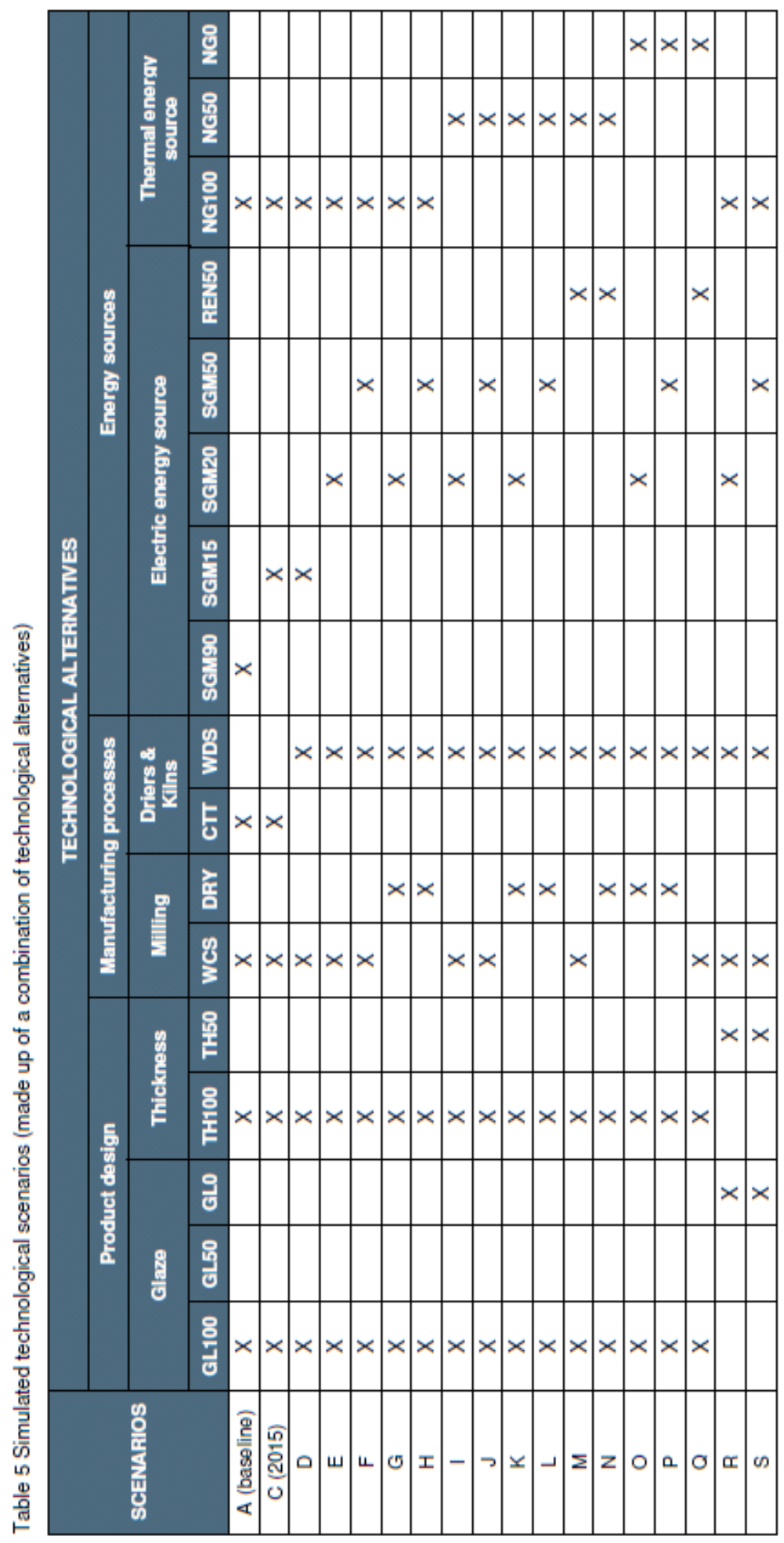




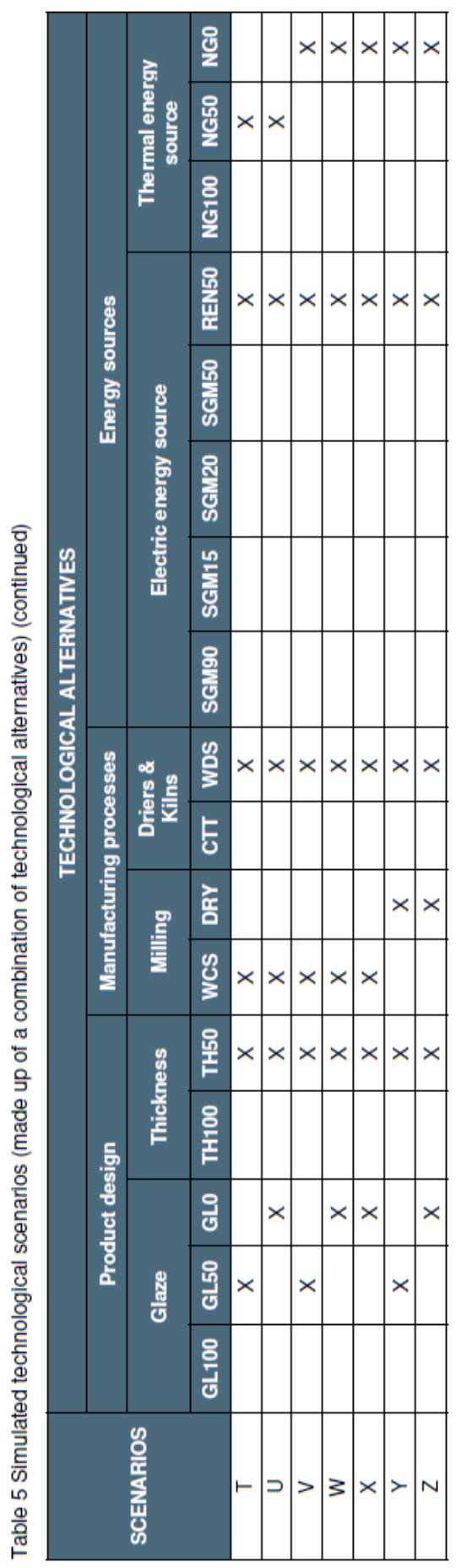




\section{Results and discussion}

The emissions of $\mathrm{CO}_{2}$ equivalent $\left(\mathrm{CO}_{2}\right.$ eq.) associated to all technological alternatives and constructed technological scenarios in the lifecycle of PST were quantified and analyzed with the support of $\mathrm{GaBi}$ Analyst (Thinkstep, 2016b). It should be noted that the same distribution destinations, maintenance operations and end-of-life management were considered in all technological alternatives and scenarios. Furthermore, other environmental impact categories were evaluated to identify possible burden shifting. In the figures, both the potential $\mathrm{CO}_{2}$ eq. emitted in 1990 (A, baseline scenario) and the reduction considered by the EU objective for 2020 and 2050 are especially highlighted.

The sensitivity analysis performed assessed the influence of inventory data related to technology alternatives on the Global Warming Potential impact category. The results showed that the parameters related to the use of energy (directly or indirectly) were the most critical ones; these parameters included the consumption of thermal and electrical energy, cogeneration systems and the thickness of the tiles, but also the quantity of glazes and frits. The results of the sensitivity analysis are presented as supplementary information

\subsection{Potential reduction by technological alternatives}

\subsubsection{Product design alternatives}

In the product design, two major factors were considered: quantity of glaze (GL100/GL50/GL0) and thickness of the tile (TH100/TH50). Regarding decoration materials, the extraction and transport of raw materials and the manufacturing of $1 \mathrm{~kg}$ of solid glaze with $33 \%$ of frit content applied on PST involved the emission of $0.8 \mathrm{~kg} \mathrm{CO}$ eq. In this regard, it should be pointed out that the frit is the glaze component with a higher carbon footprint, since its manufacturing process includes the fusion of the raw materials at around $1500^{\circ} \mathrm{C}$ (Gómez-Tena et al, 2009). Consequently, the reduction in the amount of glaze or frit content would entail an almost proportional reduction of $\mathrm{CO}_{2}$ eq. emissions.

On the other hand, lightening the tile by reducing the thickness of the ceramic body is possible as long as the technical and functional performance of the final product are not compromised (Da Silva et al., 2014a; Girao et al., 2009). Figure 2 (left) shows a potential reduction of $36 \%$ of $\mathrm{CO}_{2}$ eq. emissions corresponding to a 50\% thickness reduction (C-TH50) when compared to the latest scenario (C-TH100). This high dependence was due to the influence of thickness along the life cycle through the reduction of raw materials extraction, transportation, energy demand, etc. (Da Silva et al., 2014a; Pini et al., 2014; Ros-Dosdá et al., 2017). No burden shifting in other impact categories were identified, as shown in Figure 2 (right) where both technological alternatives are compared with relative values in 7 environmental impact categories. Indeed, the only impact category that exhibited a non-proportional reduction was the ADP element category, which is much more influenced by glaze components than by body thickness. 

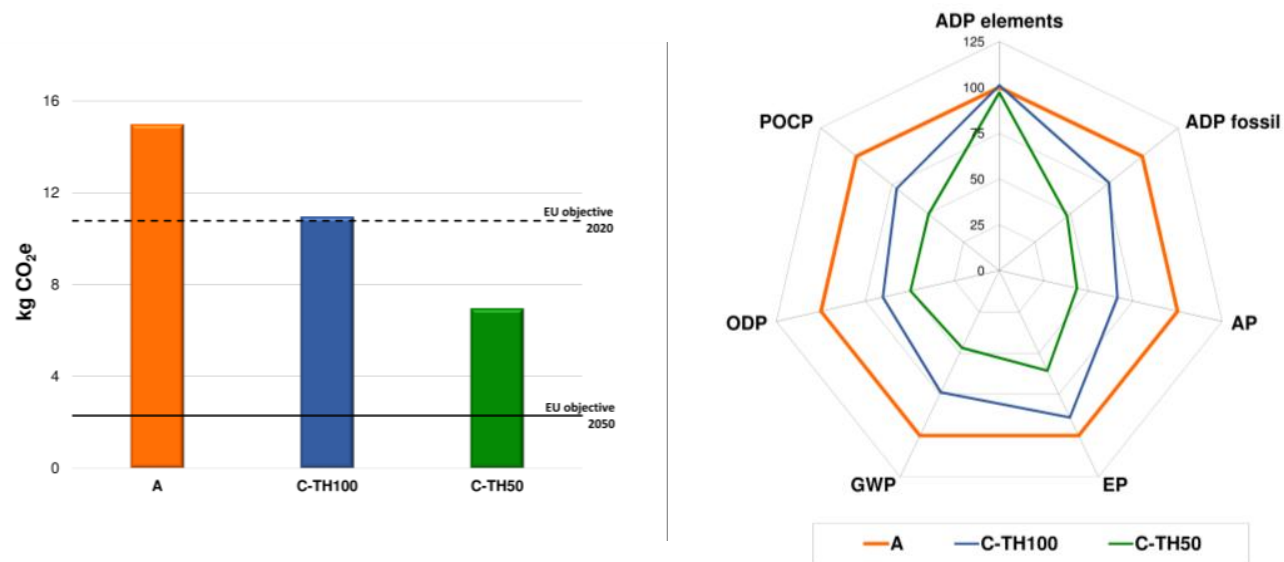

Figure 2 Effect of the thickness reduction on the associated $\mathrm{CO}_{2}$ eq. emissions of PST life cycle (left) and relative contribution in each impact category (right)

\subsubsection{Manufacturing process alternatives}

Two main process alternatives were analyzed: body raw materials preparation process (WCS/DRY) and energy efficiency technologies implemented in driers and kilns (CTT/WDS).

In the European ceramic tile industry, body raw materials are commonly prepared following a wet route (EIPPCB, 2007), because it facilitates the production of higher quality ceramic tiles in larger sizes. However, some studies claim that the new dry route developments may allow similar results to be obtained in a more sustainable way (Bonucchi, 2012; Mezquita et al., 2017; Shu et al., 2012a, 2012b). Nevertheless, these studies have not taken a life cycle approach. Consequently, a specific analysis has been included in this work. To perform the comparison in this section, three alternatives were considered: wet route (WET); wet route using combined heat and power cogeneration systems (WCS); and dry route (DRY).

The WCS is very popular in the Spanish ceramic tile industry. A combined heat and power cogeneration system (CS) installed in the spray-drier allows for the simultaneous production of electric and thermal energy with high efficiency, but it entails more natural gas consumption than the thermal process itself (Caglayan and Caliskan, 2018; Mezquita et al., 2017; Monfort at al., 2010). The surplus of electricity cogenerated was usually sent to the power grid. To analyze this co-product from a life-cycle perspective, an expansion of the system was applied instead of an allocation method, due to the lack of data and high level of uncertainties to represent the physical causalities of this process (Azapagic and Clift, 1999) and the difficulty to apply economic allocation since only the electricity which is sold to the grid has an economic value. Then, it was considered that only flexible technologies of the SGM would be displaced by the system (Weidema, 2000).

Figure 3 (left) shows a comparison of $\mathrm{CO}_{2}$ eq. emissions associated to the preparation of body raw materials following different routes and considering the implementation of CS. Figure 3 (right) shows the relative contribution to other environmental impact categories and provides the 
evidence that potential transferring of environmental loads occurs when these processes were assessed from a life cycle perspective. Thus, the achievement of a slightly reduction of $2 \%$ of $\mathrm{CO}_{2}$ eq. with the total implementation of DRY milling instead of the WCS would imply increasing the emissions of acidification substances and photochemical oxidants by $9 \%$ and $12 \%$, respectively.
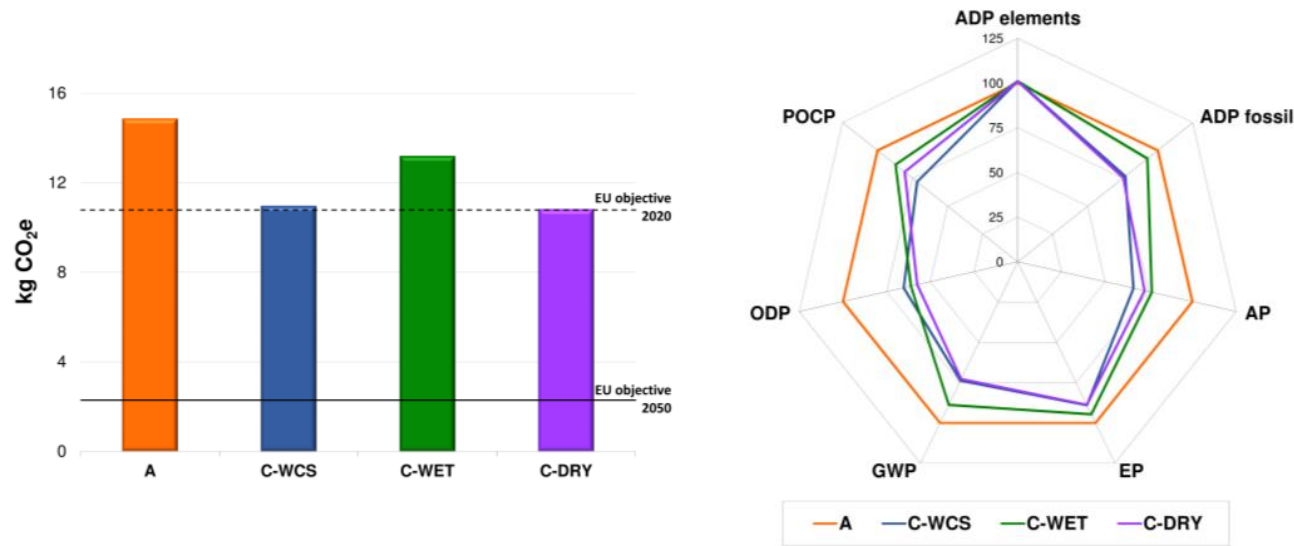

Figure 3 Effect of the preparation of raw material on the associated $\mathrm{CO}_{2}$ eq. emissions of PST life cycle (left) and relative contribution in each impact category (right)

Regarding the energy efficiency technologies in thermal processes (driers and kilns), Figure 4 reveals that the current scenario (scenario $C$ ) with an average thermal efficiency of $15 \%$, almost fulfils the EU's objectives for 2020. Mezquita et al., 2014a, 2014b showed that the simultaneous implementation of the available widespread technologies allows for a maximum thermal efficiency of around $45 \%$ to be achieved (scenario D). Figure 4 indicates that this does not suffice to attain the EU's objectives for 2050; therefore, these outcomes suggest that the combination of widespread and breakthrough technologies will be needed. 


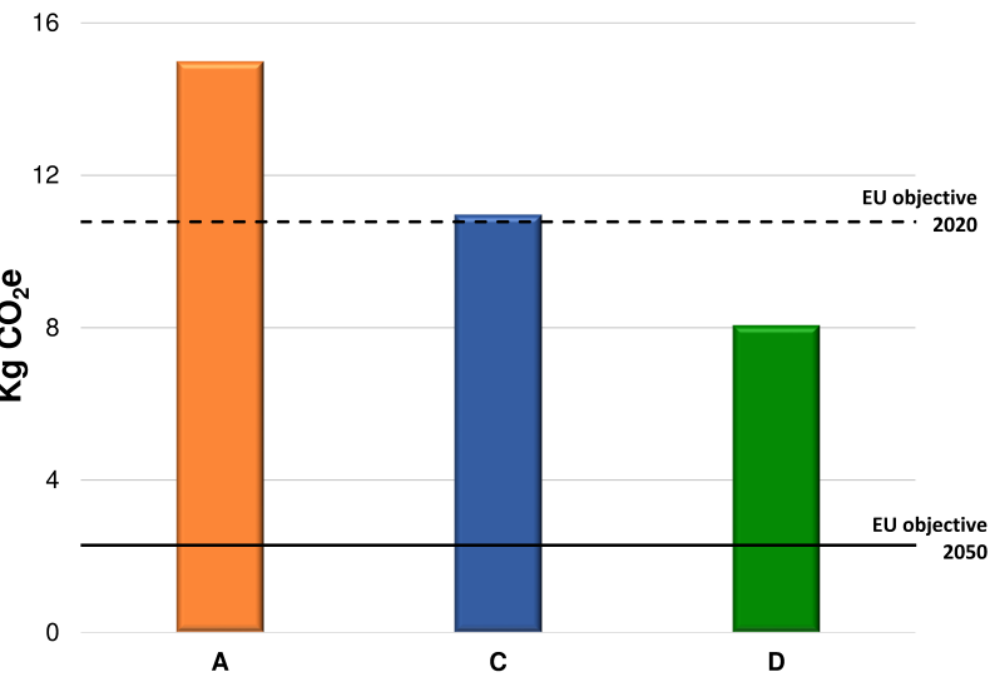

Figure 4 Effect of the energy efficiency of thermal processes on the associated $\mathrm{CO}_{2}$ eq. emissions of PST life cycle

\subsubsection{Energy source alternatives}

The effect of the evolution of the Spanish power grid mix (SGM) until 2050 was based on Capros, et al., 2013 who forecasted, in a study for the European Commission, the power and transport evolution with considerations regarding to market, economics, industry structure, demography and energy/environmental policies and regulations. The relation between the evolution of the SGM and its GHG emissions was obtained by programming the different mixes using the GaBi software (Thinkstep 2016b)

Figure 5 shows the environmental performance of the PST life cycle over the years, considering both that the technology implementation and design of the product remains as in scenario $C$ (2015), and that the SGM evolves according to the forecast made by Capros et al., 2013. Moreover, an additional alternative is presented in this figure: scenario $C$ with a $100 \%$ renewable scenario in the SGM for 2050 (C-REN50). The figure also shows the content of energetic renewable sources and the GHG reduction targets set by the EU. REN50 was built on the percentage of renewable sources foreseen for 2050 and calculating an extrapolation to cover $100 \%$, thereby maintaining the proportions of the different technologies. REN50 was composed then by $54 \%$ wind power, $24 \%$ solar power, $15 \%$ hydropower, $6.5 \%$ biomass and $0.5 \%$ geothermal and other renewable energies. 
16

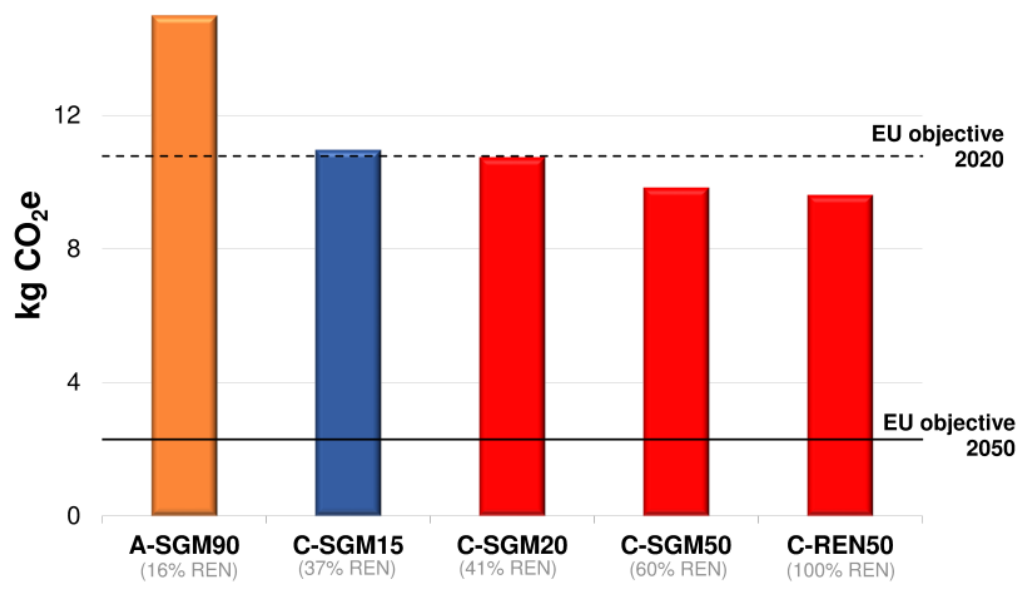

Figure 5 Effect of the SGM on the associated $\mathrm{CO}_{2}$ eq. emissions of PST life cycle

In Figure 5, a very slight decrease in $\mathrm{CO}_{2}$ eq. emissions can be observed; consequently, it may be concluded that the accomplishment of the EU target in 2050 relying solely on the evolution of the SGM (exogenous factor) was not realistically affordable, supporting Gabaldón-Estevan, 2016.

Figure 6 shows the $\mathrm{CO}_{2}$ eq. emissions associated with the life cycle of the scenario $\mathrm{C}$ when electric driers and kilns were used in the manufacturing process. An increase in emissions was detected due to the nature of the SGM. Figure 6 evidences that SGM 2015 has a bigger carbon footprint than natural gas, i.e. 0.09 and $0.07 \mathrm{~kg} \mathrm{CO}$ eq./MJ, respectively and, therefore, from the global warming impact point of view, it does not make sense to devote efforts to develop electrification technologies, if electricity from renewable energy sources is not assured. It means that ceramic industry "per se" cannot meet the $\mathrm{EU} \mathrm{CO}_{2}$ emissions objectives, if exogenous technologies are not implemented in reducing the SGM carbon footprint. The implementation of renewable sources at sector or plant scale does not seem to be sufficient to supply the required energy, hence this option has not been considered in this study. 


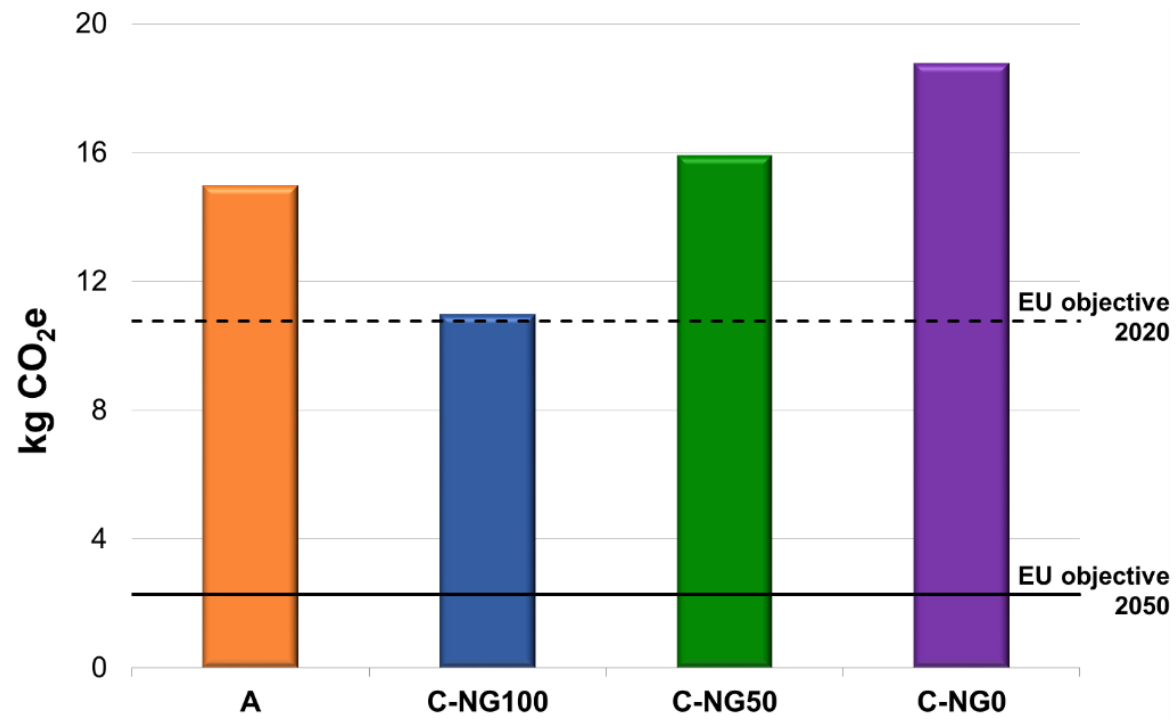

Figure 6 Effect of the thermal process electrification on the associated $\mathrm{CO}_{2}$ eq. emissions of PST life cycle

\subsection{Potential reduction by technological scenarios}

This section presents the results of the LCA of 25 technological scenarios. These 25 technological scenarios were obtained by the combination of those previous technological alternatives (see Table 5) which delivered substantial improvements in reducing $\mathrm{CO}_{2}$ eq. emissions.

Figure 7 depicts the results of $\mathrm{CO}_{2}$ eq. emissions of each PST technological scenario, differentiating each module of the life cycle of PST, from the raw material supply (stage A1) to the end-of-life (stage C4). In Figure 8 a gate-to-gate scope (life cycle stage A3) is shown. In each scope, the $\mathrm{CO}_{2}$ eq. emissions of the reference scenario and the correspondent $\mathrm{EU}$ objective reductions for 2020 and 2050 are marked. 


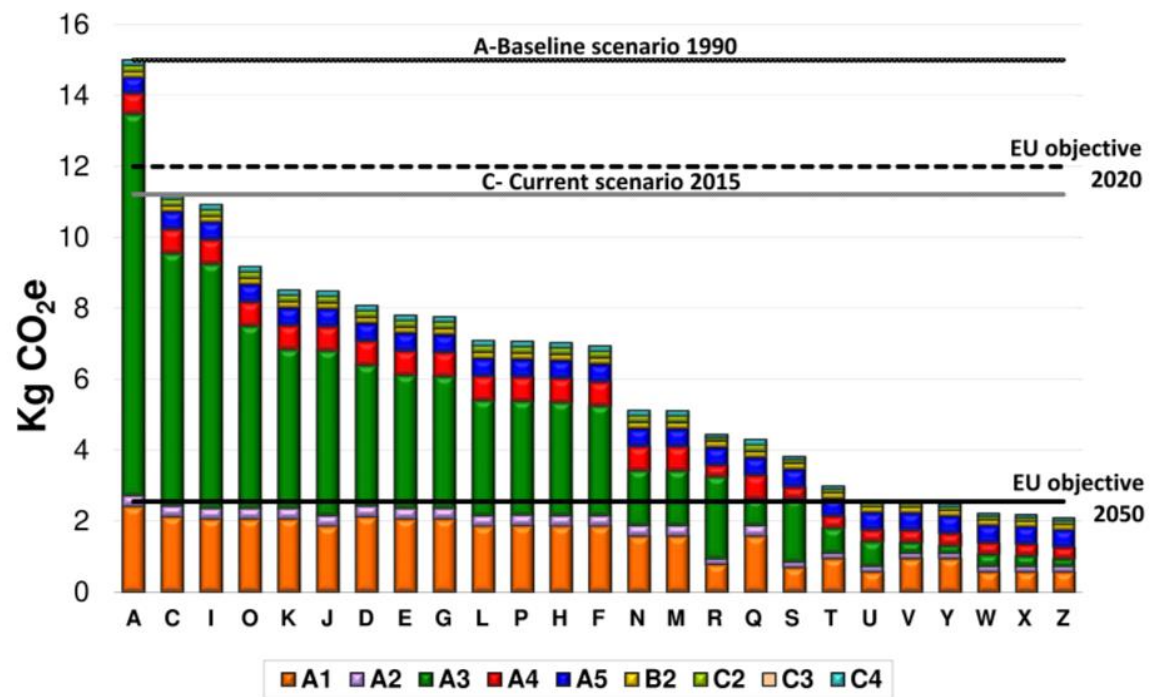

Figure $7 \mathrm{CO}_{2}$ eq. emissions of PST technological scenarios and the contribution of each lifecycle module. Cradle to grave scope

A1 raw materials supply; A2 transport; A3 manufacturing; A4 transport; A5 installation; B2 maintenance; C2 transport; C3 waste processing; C4 disposal. Codification used in EN 15804.

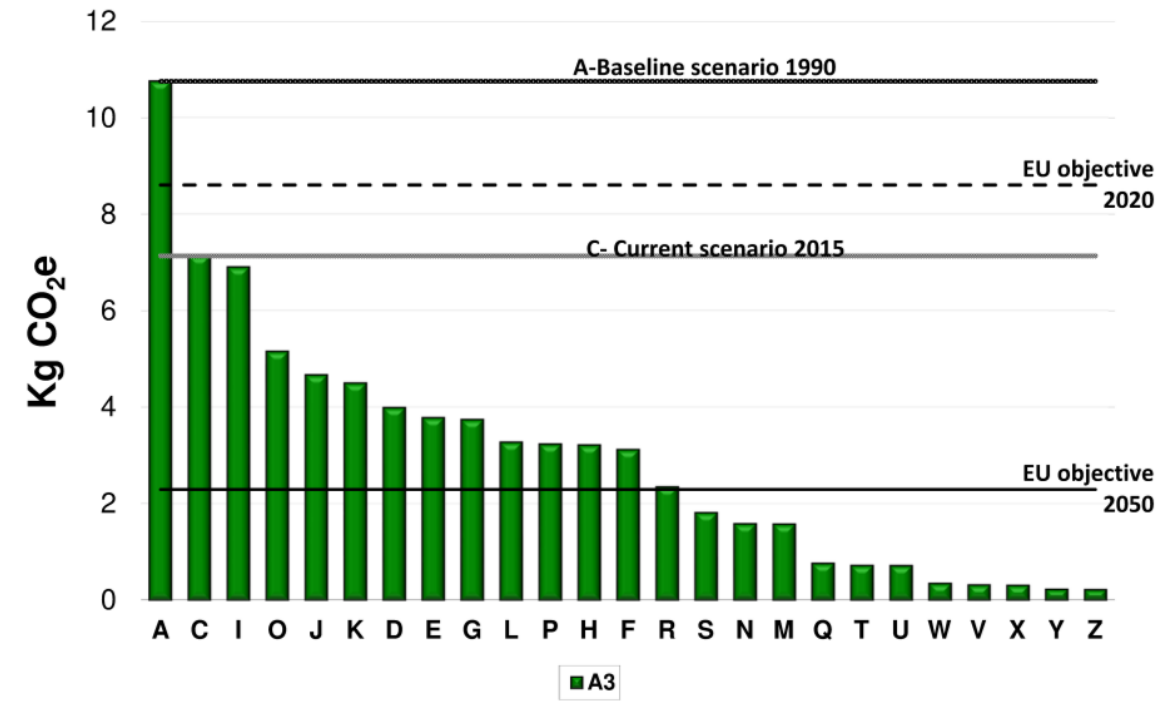

Figure $8 \mathrm{CO}_{2}$ eq. emissions of PST technological scenarios with a gate to gate scope 
Figure 7 shows that, according to the proposed simulation, the $\mathrm{CO}_{2}$ eq. emissions associated with $A 1$ and $A 2$ stages (extraction and transport of raw materials, respectively) are mostly affected by the body thickness (tile weight), being the latter much less significant in absolute value. In this regard, it should be pointed out that the effect of the thickness on the emissions beyond the manufacturing process, from A4 (tile distribution) to C4 (end-of-life), also shows slight differences in absolute values among the studied scenarios. Even some of them (specifically A5 and B2, installation and maintenance respectively) are practically independent of the studied technological scenarios.

The main effect of technological scenarios on $\mathrm{CO}_{2}$ eq. emissions can be clearly observed in stage A3 (manufacturing process). To highlight this, an explicit figure (Figure 8) with a gate-to-gate scope (i.e. manufacturing stage) has been produced.

For the sake of simplicity, in both Figure 7 and Figure 8 , the $\mathrm{CO}_{2}$ eq. emissions associated with the studied scenarios are presented in a decreasing series of data. This allows for a better comparison with the EU objectives, and how the scope of the LCA influences the emission values. The comparison of Figure 7 and Figure 8 points out the need to clearly refer the targets and emission values to a specific scope to avoid misun derstandings and unfair comparisons among products and sectors.

\subsubsection{Technological scenarios fulfilling EU's targets for 2020}

Figure 7 and Figure 8 clearly show that all the simulated technological scenarios fulfilled the EU's targets for 2020, i.e. a 20\% reduction in $\mathrm{CO}_{2}$ eq. emissions by 2020 compared to 1990 .

The current scenario (scenario C) fulfilled the 2020 targets owing to the technological changes experienced in recent years (Celades et al. 2012), but it was slightly lower than the EU's target, therefore any eco-innovation that could be included would ensure compliance with a greater margin.

The technological scenarios with an electric energy source defined for 2020 according to Capros et al., 2013 are the following ones: E; G; I; K; O; and R.

It is worth noting the results obtained with scenario $\mathrm{E}$, which allowed for a significant reduction of the $\mathrm{CO}_{2}$ eq. emissions with a relatively low innovation effort. This scenario consisted of the simultaneous implementation of the widespread technologies in the drying and firing stages (increasing the thermal energy efficiency), while the rest of the alternatives remained unchanged.

Scenario $\mathrm{R}$, the one with the greatest reductions, using the electric energy sources for 2020 (SGM20) required greater effort and more limitations, because it consisted of manufacturing unglazed lightened tiles (GLO, TH50) with the simultaneous implementation of widespread technologies in the drying and firing stage (WDS), but it was really close to the EU 'targets for 2050, particularly when a gate-to-gate approach was applied. 


\subsubsection{Technological scenarios fulfilling EU's targets for 2050}

Figure 7 and Figure 8 show that few simulated scenarios fulfilled the EU 's targets for 2050, i.e. an $85 \%$ reduction in $\mathrm{CO}_{2}$ eq. emissions by 2050 compared to 1990 , especially when a cradle-to-grave approach was employed.

Effectively, when reduction targets were applied to the entire product life cycle, only four scenarios $(\mathrm{W}, \mathrm{X}, \mathrm{Y}$, and $\mathrm{Z}$ ) could fulfil the requirements of the Commission (Figure 7). The common characteristics of these technological scenarios are: changes in product design (reductions of the thickness of the body (TH50) and reduction to half the quantity of glaze (GL50)); implementation of widespread technologies in thermal energy efficiency (WDS). Furthermore, full electrification of thermal processes (NG0) from renewable sources (REN50) would be jointly needed. It is interesting to point out that the route to prepare the body raw materials did not seem to have a significant effect on the carbon footprint, as explained in 3.1.2.

If the objectives were only focused on the ceramic tile manufacturing stage (A3), a less demanding implementation of technological alternatives would be needed to achieve the objectives of the European Commission. The technological scenarios that met the requirements of the roadmap were eleven: M; N; Q; S; T; U; V; W; X; Y; and Z (see Figure 8) These objectives could be achieved either by modifying the product design (removal of the glaze (GLO) and reduction of the thickness of the ceramic body (TH50)) or by electrifying $50 \%$ of the thermal processes (NG50) through renewable sources (REN50). In all these cases, the implementation of widespread technologies in thermal energy efficiency (WDS) was considered.

\section{Conclusions}

It has been proven that the greater the scope of the LCA study is, the greater eco-innovations are needed. The main environmental advantages appear in the use and end-of-life stages of the PST. This happens thanks to their long lifespan, easy cleaning and maintenance, the inert nature of the end-of-life waste flows, and their simplicity or open loop recycling. It is necessary then to clarify the targets and emission values to a specific scope, in order to avoid misunderstandings and unfair comparisons with products or sectors (wood floorings, carpets, etc.), which may have fewer production impacts but higher ones when it comes to use or disposal.

From the studied technological alternatives, the incorporation of widespread technologies to increase energy efficiency of the thermal processes up to $45 \%$ (WDS) and the thickness reduction of the ceramic body (TH50) were the alternatives that implied the higher reductions of $\mathrm{CO}_{2} \mathrm{eq}$. emissions. It has been ensured that none of the alternatives implied burden shifting among the different environmental impact categories. On the other hand, the increase of renewable energies in the SGM entailed relevant improvements.

Neither the electrification of thermal processes (NG50 / NG0) nor the preparation of raw materials following the dry route (DRY) seemed to be interesting measures when an overall life cycle 
approach was used, unless the electric generation was dramatically decarbonized using renewable sources of energy, since the environmental burdens would shift to other categories and processes.

In the evaluation of the different technological scenarios, the objectives for 2020 were found to be almost fulfilled thanks to the technological advances already being implemented in the European sector of ceramic tile manufacturing. However, the objectives for 2050 are far from being met, and the implementation of endogenous widespread technology will not be enough. Therefore, a combination of endogenous and exogeneous breakthrough technologies must be applied. These breakthrough technologies mainly lie on a decrease in the dependence on non-renewable fuels, the implementation of highly efficient energy measures and the application of product eco-design innovations.

Consequently, to support the ceramic tile industry in this context, it is necessary to find realistic solutions without jeopardizing its survival in a low-carbon economy. In this regard, further research is needed to evaluate technical and economic feasibility of the studied scenarios. In addition, other technical alternatives could be studied, such as using new glaze compositions or evaluating measures to promote the transition of the ceramic tile sector to a circular economy, among others.

\section{Acknowledgements}

This study was performed with the financial support from the Instituto Valenciano de Competitividad Empresarial (IVACE) and the European Regional Development Fund (ERDF) [grant numbers IMDEEA/2014/12 and IMDEEA/2015/11] as well as from Climate KIC (Knowledge and Innovation Community) through the Pioneer into Practice Program [grant number AREP0047_2014-3.4-174_P062-01].

The authors are responsible for the choice and presentation of information contained in this paper as well as for the opinions expressed therein, which are not necessarily those of UNESCO and do not commit this Organization.

\section{Supplementary material}

Supplementary material associated with this article can be found in the online version:

- Sensitivity analysis

- List of abbreviations 


\section{References}

Ajanovic, A., 2013. Renewable fuels - A comparative assessment from economic, energetic and ecological point-of-view up to 2050 in EU-countries. Renew. Energy 60, 733-738. http://dx.doi.org/10.1016/j.renene.2013.06.012

Almeida, M.I., Dias, A.C., Demertzi, M., Arroja, L., 2016. Environmental profile of ceramic tiles and their potential for improvement. J. Clean. Prod. 131, 583-593. https://doi.org/10.1016/j.jclepro.2016.04.131

ASCER, 2011. Gúa de la baldosa cer乏́mica: el vademecum de la baldosa cer乏́mica, para su clasificacif́n, su seleccif́n, materiales de agarre y rejuntado, la redaccif́n del proyecto, el control de la obra, 6th ed. Generalitat Valenciana, Spain. Available: http://library.tileofspain.com/manuales-tecnicos/guia-de-la-baldosa-ceramica/\#8 (accessed 3 January 2018) (In Spanish)

Azapagic, A., Clift, R., 1999. Allocation of environmental burdens in co-product systems: Productrelated burdens (Part 1). Int. J. life cycle Assess. 4, 357.

Baraldi, L., 2017. World production and consumption of ceramic tiles. Ceram. world Rev. 123, 5870. Available: https://issuu.com/tiledizioni/docs/cwr_123 (accessed 11 May 2018)

Benveniste, G., Gazulla, C., Fullana, P., Celades, I., Ros, T., Zaera, V., Godes, B., 2011. Life cycle assessment and product category rules for the construction sector. The floor and wall tiles sector case study. Inf. la Construcción 63, 71-81. https://doi.org/10.3989/ic.10.034

Bocken, N.M.P., Short, S.W., Rana, P., Evans, S., 2014. A literature and practice review to develop sustainable business model archetypes. J. Clean. Prod. 65, 42-56. http://dx.doi.org/10.1016/j.jclepro.2013.11.039

Bonucchi, R., 2012. Dry preparation: quality and care for the environment. Ceramic World Review, 22, 86-89.

Bovea, M.D., Díaz-Albo, E., Gallardo, A., Colomer, F.J., Serrano, J., 2010. Environmental performance of ceramic tiles: Improvement proposals. Mater. Des. 31, 35-41. https://doi.org/10.1016/j.matdes.2009.07.021

Caglayan, H., Caliskan, H., 2018. Energy, exergy and sustainability assessments of a cogeneration system for ceramic industry. Appl. Therm. Eng. 136, 504-515. https://doi.org/https://doi.org/10.1016/j.applthermaleng.2018.02.064

Capros, P., De Vita, A., Tasios, N., Papadopoulos, D., Siskos, P., Apostolaki, E., Zampara, M., Paroussos, L., Fragiadakis, K., Kouvaritakis, N., 2013. EU energy, transport and GHG emissions: trends to 2050, reference scenario 2013. European Commission Directorate-General for Energy, Directorate-General for Climate Action and Directorate-General for Mobility and Transport, Luxembourg. https://doi.org/10.2833/17897 
Celades, I., Moliner-Salvador, R., Ros-Dosdá, T., Monfort, E., Zaera, V., 2012. Environmental development of the Spanish ceramic tile manufacturing sector over the period 1992-2007. Boletín de la Soc. Española Cerámica y Vidr. 51, 111-118. https://doi.org/10.3989/cyv.162012

Cellura, M., Longo, S., Mistretta, M., 2011. Sensitivity analysis to quantify uncertainty in Life Cycle Assessment: The case study of an Italian tile. Renew. Sustain. Energy Rev. 15, 4697-4705. https://doi.org/https://doi.org/10.1016/j.rser.2011.07.082

Cerame Unie, 2012. The Ceramic Industry Roadmap: paving the way to 2050. [www Document]. URL http://cerameunie.eu/topics/cerame-unie-sectors/cerame-unie/ceramic-industry-roadmappaving-the-way-to-2050/ (accessed 3 January 2018).

Cerame Unie, 2017. Statistics, figures and facts [www Document]. http://cerameunie.eu/ceramicindustry/facts-figures/ (accessed 11 May 2018).

Cofindustria Ceramica, 2018. Consumi Energetici. [www Document] http://www.confindustriaceramica.it/site/home/aree-e-servizi/energia/consumi-energetici.html (accessed 12 June 2018) (In Italian)

COM (2011) 112 final. (2011). A Roadmap for moving to a competitive low carbon economy in 2050. Brussels, Belgium: European Commission. Retrieved November 09, 2017 from http://eurlex.europa.eu/legal-content/EN/ALL/?uri=CELEX:52011DC0112

da Silva, A.L., Feltrin, J., Dal Bó, M., Bernardin, A.M., Hotza, D., 2014a. Effect of reduction of thickness on microstructure and properties of porcelain stoneware tiles. Ceram. Int. 40(9), 1469314699. https://doi.org/10.1016/j.ceramint.2014.05.150

da Silva, A.L., Bernardin, A.M., Hotza, D., 2014b. Forming of thin porcelain tiles: A comparison between tape casting and dry pressing. Ceram. Int. 40(2), 3761-3767. https://doi.org/http://dx.doi.org/10.1016/j.ceramint.2013.09.044

Directive 2003/87/EC of the European Parliament and of the Council of 13 October 2003 establishing a scheme for greenhouse gas emission allowance trading within the Community and amending Council Directive 96/61/EC. L 275/32, 25.10.2003. Retrieved November 09, 2017 from http://eur-lex.europa.eu/legal-content/EN/TXT/PDF/?uri=CELEX:32003L0087\&from=EN

Directive 2009/29/EC of the European Parliament and of the Council of 23 April 2009 amending Directive 2003/87/EC so as to improve and extend the greenhouse gas emission allowance trading scheme of the Community. L 140/63, 05.06.2009. Retrieved November 09, 2017 from https://doi.org/10.3000/17252555.L_2009.140.eng

Directive 2012/27/EU of the European Parliament and of the Council of 25 October 2012 on energy efficiency, amending Directives 2009/125/EC and 2010/30/EU and repealing Directives 2004/8/EC and 2006/32/EC. L 315/1, 14.11.2012. Retrieved November 09, 2017 from https://doi.org/10.3000/19770677.L_2012.315.eng

EIPPCB, 2007. Integrated Pollution Prevention and Control (IPPC). Reference Document on Best Available Techniques (BATs) in the Ceramic Manufacturing Industry. European Commission, 
Directorate-General JRC, Joint Research Centre. Institute for Prospective Technological Studies (Sevilla). Technologies for Sustainable Development. European IPPC Bureau.

EN 15804:2012+A1:2013. Sustainability of construction works - Environmental product declarations - Core rules for the product category of construction products. CEN European Commission, Brussels, Belgium.

Gabaldón-Estevan, D., Criado, E., Monfort, E., 2014. The green factor in European manufacturing: a case study of the Spanish ceramic tile industry. J. Clean. Prod. 70, 242-250. https://doi.org/10.1016/j.jclepro.2014.02.018

Gabaldón-Estevan, D., Mezquita, A., Ferrer, S., Monfort, E., 2016. Unwanted effects of European Union environmental policy to promote a post-carbon industry. The case of energy in the European ceramic tile sector. J. Clean. Prod. 117, 41-49. https://doi.org/10.1016/j.jclepro.2016.01.021

García-Gusano, D., Cabal, H., Lechón, Y., 2015. Long-term behaviour of $\mathrm{CO}_{2}$ emissions from cement production in Spain: scenario analysis using an energy optimisation model. J. Clean. Prod. 99, 101-111. http://dx.doi.org/10.1016/j.jclepro.2015.03.027

Girao, J., Amaro, N., Carvalho, J., Piquer, J., 2009. Decreased thickness porcelain tiles. Revigres Light. Boletín la Soc. Española Cerámica y Vidr. 48(2), 99-101. (In Spanish).

Gómez-Tena, M.P., Bou, E., Moreno, A., Cook, S., Galindo, M., 2009. Fritless glaze compositions for single fast fired tiles. Interceram Int. Ceram. Rev. 58, 78-84.

Griffin, P.W., Hammond, G.P., Norman, J.B., 2017. Industrial energy use and carbon emissions reduction in the chemicals sector: A UK perspective. Appl. Energy. https://doi.org/10.1016/j.apenergy.2017.08.010

Guinée, J.B.; Gorrée, M.; Heijungs, R.; Huppes, G.; Kleijn, R.; Koning, A. de; Oers, L. van; Wegener Sleeswijk, A.; Suh, S.; Udo de Haes, H.A.; Bruijn, H. de; Duin, R. van; Huijbregts, M.A.J., 2002. Handbook on life cycle assessment. Operational guide to the ISO standards. I: LCA in perspective. Ila: Guide. Ilb: Operational annex. III: Scientific background. Kluwer Academic Publishers, Dordrecht.

Ibáñez-Forés, V., Bovea, M.D., Azapagic, A., 2013. Assessing the sustainability of Best Available Techniques (BAT): methodology and application in the ceramic tiles industry. J. Clean. Prod. 51, 162-176. https://doi.org/10.1016/j.jclepro.2013.01.020

Ibáñez-Forés, V., Bovea, M.-D., Simó, A., 2011. Life cycle assessment of ceramic tiles. Environmental and statistical analysis. Int. J. Life Cycle Assess. 16, 916-928. https://doi.org/10.1007/s11367-011-0322-6

ISO 14040:2006. Environmental management -- Life cycle assessment -- Principles and framework, 2nd ed. International Organization for Standardization, Geneva.

ISO 14044:2006. Environmental management -- Life cycle assessment -- Requirements and guidelines. International Organization for Standardization, Geneva. 
JRC-IES Joint Research Centre, I. for E. and S., 2015. European Reference Life-Cycle Database. Version 3.2. URL http://eplca.jrc.ec.europa.eu/ELCD3/processList.xhtml (accessed 16 May 2016).

Klöpffer, W., Grahl, B., 2009. Ökobilanz (Ica): Ein leitfaden für ausbildung und beruf. John Wiley \& Sons. (In German).

Lasvaux, S., Gantner, J., Wittstock, B., Bazzana, M., Schiopu, N., Saunders, T., Gazulla, C., Mundy, J.A., Sjöström, C., Fullana-i-Palmer, P., Barrow-Williams, T., Braune, A., Anderson, J., Lenz, K., Takacs, Z., Hans, J., Chevalier, J. 2014. Achieving consistency in life cycle assessment practice within the European construction sector: the role of the EeBGuide InfoHub. Int. J. Life Cycle Assess. 19, 1783-1793. https://doi.org/10.1007/s11367-014-0786-2

Melchiades, F.G., Daros, M.T., Boschi, A.O., 2010. Porcelain tiles by the dry route. Boletín la Soc. Española Cerámica y Vidr. 49(4), 221-226. (In Spanish).

Mezquita, A., Monfort, E., Ferrer, S., Gabaldón-Estevan, D., 2017. How to reduce energy and water consumption in the preparation of raw materials for ceramic tile manufacturing: Dry versus wet route. J. Clean. Prod. https://doi.org/10.1016/j.jclepro.2017.04.082

Mezquita, A., Boix, J., Monfort, E., Mallol, G., 2014a. Energy saving in ceramic tile kilns: Cooling gas heat recovery. Appl. Therm. Eng. 65, 102-110. http://dx.doi.org/10.1016/j.applthermaleng.2014.01.002

Mezquita, A., Monfort, E., Vaquer, E., Ferrer, S., Pitarch, J.M., Arnal, M.A., Cobo, F., 2014b. Reduction of $\mathrm{CO}_{2}$-emissions in ceramic tiles manufacture by combining energy-saving measures. CFI-Ceramic Forum Int. 5(91).

Monfort, E., Mezquita, A., Granel, R., Vaquer, E., Escrig, A., Miralles, A., Zaera, V., 2010. Analysis of energy consumption and carbon dioxide emissions in ceramic tile manufacture (in Spanish). Boletín la Soc. Española Cerámica y Vidr. 49, 303-310.

Nicoletti, G.M., Notarnicola, B., Tassielli, G., 2002. Comparative Life Cycle Assessment of flooring materials: ceramic versus marble tiles. J. Clean. Prod. 10, 283-296. https://doi.org/10.1016/S0959-6526(01)00028-2

Pardo, R. ASCER traslada al Consell la necesidad de mantener y apoyar la cogeneración. Economia3, 11/06/2018. URL https://economia3.com/2018/06/11/147288-ascer-traslada-alconsell-la-necesidad-de-mantener-y-apoyar-la-cogeneracion/ (accessed 12 June 2018). (In Spanish)

PE International, 2008. Database for life cycle engineering, copyright, TM. 1992-2008 (compilation. 4.4.142.1, DB version 4.131)

PE International, 2008. GaBi Software-system. Compilation 4.131 URL http://www.gabisoftware.com/software/gabi-4/ (accessed 16 May 2017).

Pini, M., Ferrari, A.M., Gamberini, R., Neri, P., Rimini, B., 2014. Life cycle assessment of a large, thin ceramic tile with advantageous technological properties. Int. J. Life Cycle Assess. 19, 15671580. https://doi.org/10.1007/s11367-014-0764-8 
Raimondo, M., 2010. Processing and properties of large-sized ceramic slabs. Boletín la Soc. Española Cerámica y Vidr. 49, 289-295.

REE Red Eléctrica de España, 2016. Informe del sistema eléctrico español 2015 [www Document]. URL http://www.ree.es/sites/default/files/downloadable/inf_sis_elec_ree_2015.pdf (accessed 11 November 2017). (In Spanish)

Ros-Dosdá, T., Celades, I., Monfort, E., Fullana-i-Palmer, P., 2017. Environmental profile of Spanish porcelain stoneware tiles. Int. J. Life Cycle Assess. 1-19. https://doi.org/10.1007/s11367017-1377-9

Sánchez, E., García-Ten, J., Sanz, V., Moreno, A., 2010. Porcelain tile: Almost 30 years of steady scientific-technological evolution. Ceram. Int. 36, 831-845. https://doi.org/10.1016/j.ceramint.2009.11.016

Schianchi, S., 2012. Quality in low-consumption granulation. Ceram. world Rev. 116-118.

Selvakkumaran, S., Limmeechokchai, B., Masui, T., Hanaoka, T., Matsuoka, Y., 2014. Low carbon society scenario 2050 in Thai industrial sector. Energy Convers. Manag. 85, 663-674. http://dx.doi.org/10.1016/j.enconman.2014.03.040

Shu, Z., Garcia-Ten, J., Monfort, E., Amoros, J.L., Zhou, J., Wang, Y.X., 2012a. Cleaner production of porcelain tile powders. Fired compact properties. Ceram. Int. 38, 1479-1487. http://dx.doi.org/10.1016/j.ceramint.2011.09.031

Shu, Z., Garcia-Ten, J., Monfort, E., Amorós, J.L., Zhou, J., Wang, Y.X., 2012b. Cleaner production of porcelain tile powders. Granule and green compact characterization. Ceram. Int. 38, 517-526. http://dx.doi.org/10.1016/j.ceramint.2011.07.037

Streimikiene, D., Šivickas, G., 2008. The EU sustainable energy policy indicators framework. Environ. Int. 34, 1227-1240. http://dx.doi.org/10.1016/j.envint.2008.04.008

Tan, R.R., Culaba, A., 2002. Environmental life-cycle assessment: a tool for public and corporate policy development. La Salle Univ. Manila. [www Document] URL: www.Icacenter.org (accessed 16 May 2016).

Thinkstep, 2016a. Database for Life Cycle Engineering, copyrignt Thinkstep AG. 1992-2016 (Compilation 7.2.2.28, DB version 6.115).

Thinkstep, 2016b. GaBi Software-system. Compilation 7.2.2.28. http://www.gabisoftware.com/software/ (accessed 17 May 2016).

Weidema, B., 2000. Avoiding co-product allocation in life-cycle assessment. J. Ind. Ecol. 4, 11-33. http://dx.doi.org/10.1162/108819800300106366

Wesseling, J.H., Lechtenböhmer, S., Ånman, M., Nilsson, L.J., Worrell, E., Coenen, L., 2017. The transition of energy intensive processing industries towards deep decarbonization: characteristics 
and implications for future research. Renew. Sustain. Energy Rev. 79, 1303-1313. https://doi.org/10.1016/j.rser.2017.05.156

Wolf, M.-A., Chomkhamsri, K., Brandao, M., Pant, R., Ardente, F., Pennington, D.W., Manfredi, S., de Camillis, C., Goralczyk, M., 2010. ILCD Handbook-General Guide for Life Cycle AssessmentDetailed Guidance. https://doi.org/10.2788/38479

Xu, J.-H., Fleiter, T., Fan, Y., Eichhammer, W., 2014. $\mathrm{CO}_{2}$ emissions reduction potential in China's cement industry compared to IEA's Cement Technology Roadmap up to 2050. Appl. Energy 130, 592-602. http://dx.doi.org/10.1016/j.apenergy.2014.03.004 


\section{Supplementary Material 1:}

\section{Sensitivity analysis}

The sensitivity analysis assesses the influence of a parameter (independent variable) on the value of another variable (dependent variable) (Cellura et al., 2011). This analysis identifies the most critical parameters for which small changes lead to result reversal. Specifically, variations with a range of $\pm 99 \%$ on inventory data related to each technological alternative and others considered of interest were set to determine their effect on the Global Warming Potential. This sensitivity analysis was carried out using GaBi Analyst function of the GaBi software (Thinkstep 2016b) on the latest scenario (scenario C). Table S1.1 summarizes those parameters whose variation $\pm 99 \%$ over the value associated with the last scenario (scenario $\mathrm{C}$ ) would modify the value of the selected impact indicator by more than $1 \%$.

Table S1.1Results of variation in global warming potential when $\pm 99 \%$ standard deviation applied on inventory data

\begin{tabular}{|l|c|}
\hline \multicolumn{1}{|c|}{ Parameter } & $\begin{array}{c}\text { Variation in the } \\
\text { GWP (100 years) }\end{array}$ \\
\hline Thermal energy of dryers and kilns (excluding spray dryers) & $\pm 36.5 \%$ \\
\hline Weight of the unfired body tile & $\pm 28.9 \%$ \\
\hline Thermal energy consumed in the spray dryer and cogeneration system & $\pm 26.4 \%$ \\
\hline Cogenerated electricity sold to the SGM & $\pm 11.1 \%$ \\
\hline Electricity from the SGM consumed in the manufacture of the tiles & $\pm 6.9 \%$ \\
\hline Quantity of glaze & $\pm 5.3 \%$ \\
\hline Electricity from the grid consumed in the preparation of body raw materials & $\pm 5.1 \%$ \\
\hline Transports by 27 t truck, at distances up to 3000 km (raw materials and end tiles) & $\pm 2.4 \%$ \\
\hline Decarbonation of body raw materials & $\pm 1.5 \%$ \\
\hline Frit content in the glazes & $\pm 1.5 \%$ \\
\hline Lifespan & $\pm 1.3 \%$ \\
\hline Frequency of cleaning & $\pm 1.3 \%$ \\
\hline
\end{tabular}

As Table S1.1 shows, the parameters that most affect the results of the global impact of climate change are those related to both direct and indirect use of energy in the process. The thermal energy consumed during tile drying and firing and that consumed in the spray dryer (where cogeneration system is installed) come in the first and the third place, with values of $\pm 36.5 \%$ and $\pm 26.4 \%$ in GWP when a variation in these parameters of $\pm 99 \%$ is applied. The weight of the ceramic tile comes second, with a sensitivity close to $\pm 30 \%$. This is due to the fact that the variation 
in weight of the tile has side effects in a practically proportional way in other parameters, such as energy consumption, water, emissions, transport and waste generation and in almost all the stages of the life cycle (Ros-Dosdá et al., 2017). The parameters related to electricity, both the cogenerated electricity sold to the grid and the electricity supplied by the SGM in the raw material preparation and tile manufacturing processes come in fourth, fifth and seventh place. The quantity of glazes and the quantity of frits are also significant parameters from the climate change point of view.

Decarbonation of body raw materials, which accounts for less than $1 \%$ in PST, involves direct $\mathrm{CO}_{2}$ emissions, but when this value is modified by $\pm 99 \%$, the GWP varies $\pm 1.5 \%$. In ceramic tiles belonging to group BIII/AIII, according to ISO 13006 classification, the decarbonization value can exceed $10 \%$ when $\mathrm{CaCO}_{3}$ is added as a raw material in the body composition and, therefore, may become a key factor from the $\mathrm{CO}_{2}$ eq. emission point of view. A relevant parameter which is not considered in the definition of technological alternatives is the distribution of tiles to European countries in module $\mathrm{A} 4$, as well as lifespan and frequency of cleaning regulations.

It should be highlighted that the organization's ability to change life cycle parameters for the sake of environmental improvement is restricted to those under its control.

\section{References}

Cellura, M., Longo, S., Mistretta, M., 2011. Sensitivity analysis to quantify uncertainty in Life Cycle Assessment: The case study of an Italian tile. Renew. Sustain. Energy Rev. 15, 4697-4705. https://doi.org/https://doi.org/10.1016/j.rser.2011.07.082

Thinkstep, 2016b. GaBi Software-system. Compilation 7.2.2.28. http://www.gabisoftware.com/software/ (accessed 17 May 2016). 


\section{Supplementary Material 2:}

\section{List of abbreviations}

ADP elements: Abiotic Depletion-elements

ADP fossil: Abiotic Depletion-fossil fuels

AP: Acidification Potential

CML: The Institute of Environmental Sciences (CML), Faculty of Science of Leiden University, The Netherlands

$\mathrm{CO}_{2} \mathrm{e}:$ Carbon dioxide equivalent

CS: Combined Heat and Electric Cogeneration System

CTT: Current Technologies for Thermal energy efficiency

DRY: Dry milling of body raw materials

EP: Eutrophication Potential

EPD: Environmental Product Declaration

FU: Functional Unit

GHG: Greenhouse Gases

GL: Describes the quantity of glaze: $100 \%$ (average quantity), $50 \%$ (half the average quantity) or $0 \%$ (unglazed)

GWP: Global Warming Potential (100 years)

LCA: Life Cycle Assessment

NG: Describes the thermal energy sources: Natural Gas $100 \%, 50 \%$ or $0 \%$

ODP: Ozone Layer Depletion Potential (steady state)

POCP: Photochemical Ozone Creation Potential

PST: Porcelain Stoneware Tile

REN: Electric energy from Renewable Resources

SGM: Spanish Power Grid Mix

TH: Describes the thickness of the body tile: 100\% (average thickness) and 50\% (thickness reduction by half) 
WCS: Wet milling of body raw materials with cogeneration system associated WDS: Widespread technologies in thermal energy efficiency

WET: Wet milling of body raw materials without cogeneration system associated 


\section{APORTACIÓN Nº 6}

\section{$\mathrm{CerCO}_{2}, \mathrm{CO}_{2}$ EMISSION SIMULATION TOOL FOR THE CERAMIC INDUSTRY}

Teresa Ros-Dosdá1, Irina Celades ${ }^{1}$, Jaume Adrià Alberola', Eliseo Monfort ${ }^{1}$

\section{Ceramic Forum International}

Volume $96, n^{\circ} 1-2,29-35$

Enviado el 14 de Mayo de 2018

Aceptado en Mayo 2018

Publicado en Enero 2019.

ISSN: 01739913

Factor de impacto (2018): 0,12

SCImago Journal Rank (SJR): 0,15

${ }^{1}$ Instituto de Tecnología Cerámica (ITC). Asociación de Investigación de las Industrias Cerámicas (AICE). Universidad Jaume I. Avda Sos Baynat s/n, 12006, Castelló, Spain. 


\section{PRORESS ENGINERING}

$\mathrm{CerCO}_{2}$ - the $\mathrm{CO}_{2}$ Emission Simulation Tool

for the Ceramic Industry

T. Ros-Dosdá, I. Celades, J. A. Alberola, E. Monfort 


\title{
$\mathrm{CerCO}_{2}, \mathrm{CO}_{2}$ EMISSION SIMULATION TOOL FOR THE CERAMIC INDUSTRY
}

\begin{abstract}
Ceramics manufacturing is energy intensive and the ceramic industry is subject to regulatory policies and strong controls on greenhouse gas emissions, responsible for climate change. European policies seek to reduce these emissions by $20 \%$ and by $40 \%$ in 2020 and 2040 , respectively, and by $83 \%$ to $87 \%$ in 2050 , compared to 1990 , for all industrial sectors.

ITC-AICE has developed $\mathrm{CerCO}_{2}$, a $\mathrm{CO}_{2}$ emission simulation tool, which it places at the service of ceramic tile manufacturing companies. The tool simulates the $\mathrm{CO}_{2}$ emissions that a ceramic tile would have upon implementation of $\mathrm{CO}_{2}$ emission abatement measures. The $\mathrm{CerCO}_{2}$ tool enables ceramic tile manufacturers to conduct foresight studies to rapidly and efficiently evaluate different technology scenarios for decision making on investments and adaptation to a low-carbon economy, while concurrently complying with the objectives set by the European Commission regarding climate change.
\end{abstract}

\section{Introduction}

Just as other industrial sectors, the ceramic industry must currently observe regulatory policies and laws aimed at controlling and reducing greenhouse gas (GHG) emissions to mitigate global warming and its effects. These policies include commitment to reducing GHG emissions by $83-$ $87 \%$ in 2050 , compared to the levels emitted in 1990 , by industrial sectors in the European Union [1] [2]. As specific reduction measures are required for each sector, Cerame-Unie has drawn up its own roadmap [3], which highlights the need to apply new production technologies and to change energy models, in order to achieve such demanding goals.

To help ceramic tile manufacturers reduce $\mathrm{CO}_{2}$ emissions, ITC-AICE has developed the $\mathrm{CerCO}_{2}$ tool (see logo in Figure 1). The tool simulates the $\mathrm{CO}_{2}$ emissions that a ceramic tile would have upon implementation of $\mathrm{CO}_{2}$ emission abatement measures. It therefore enables ceramic tile manufacturers to conduct foresight studies to rapidly and efficient evaluate different technology scenarios for making decisions on investments and adaptation to a low-carbon economy, while concurrently complying with the objectives set by the European Commission regarding climate change. 

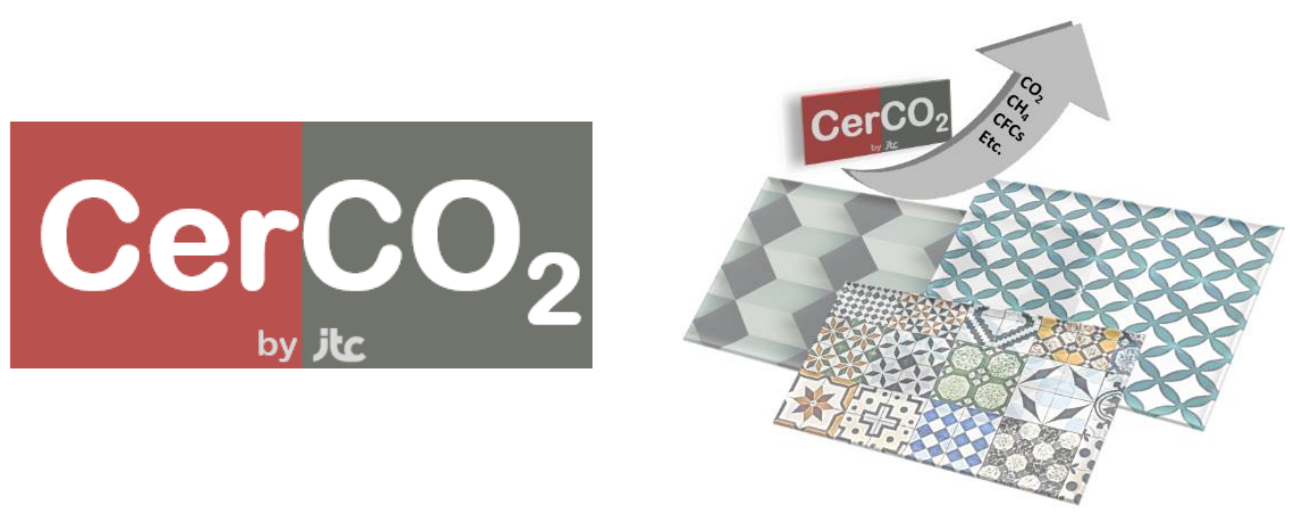

Figure $1 \mathrm{Logo}$ and representation of the $\mathrm{CerCO}_{2}$ tool

The $\mathrm{CerCO}_{2}$ tool was developed:

- To place at the service of ceramic tile manufacturers a tool to help make decisions on technology investments to meet EU objectives on climate change.

- To evaluate the most appropriate technological variants for the process or product, for each individual company, aimed at effective and efficient mitigation of greenhouse gas emissions.

Some highlights of this tool are:

- $\mathrm{CerCO}_{2}$ is a tool that allows customised identification and evaluation of the most efficient options for mitigating company $\mathrm{CO}_{2}$ emissions.

- $\mathrm{CerCO}_{2}$ helps the ceramic industry make decisions on investments and adaptation to a low-carbon economy, complying with the objectives set by the European Commission on $\mathrm{CO}_{2}$ emissions.

- $\mathrm{CerCO}_{2}$ can be used by non-experts to perform customised corporate foresight studies.

- The $\mathrm{CerCO}_{2}$ tool can help companies comply with the new approach set out in the ISO 14001:2015 Environmental Management Systems for assessing environmental aspects and impacts and for planning and operational control.

The present tool was developed in the frame of the PROMECE Environmental Challenges project by ITC-AICE (Instituto de Tecnología Cerámica-Asociación de Investigación de las Industrias Cerámicas), cofunded by the ERDF Operational Programme for the Valencia Region, 2014-2020. 


\section{Basis for the tool}

The $\mathrm{CerCO}_{2}$ tool is based on Life Cycle Assessment (LCA) techniques, in which two ceramic tile life cycle scenarios are compared. The two scenarios are the tool user's initial technology scenario and a hypothetical low-carbon scenario containing a series of improvement measures (previously selected by the tool user), which would allow mitigation of the GHG emissions associated with the products being manufactured. The company can thus evaluate, from an overall viewpoint, the expected environmental impact of possible GHG emission abatement measures before making any investments.

To use the tool, the company must complete a brief online questionnaire with information divided into two groups:

- Technologies associated with the company's current process: technological variants already implemented in the company and related data.

- Low-carbon scenario technologies to be evaluated: technological variants to be evaluated.

\subsection{Technologies associated with the current process}

To define the current scenario, the user must first enter the major technological variants of its current ceramic tile manufacturing process.

Table 1 details the process alternatives from which the user must choose to define the initial scenario.

Table 1 Characteristics of the initial scenario to be defined by the user.

\begin{tabular}{|c|c|c|c|}
\hline Technologies of the initial scenario & \multicolumn{3}{|c|}{ Options/Units } \\
\hline Scope of the LCA in the study & \multicolumn{3}{|c|}{$\begin{array}{l}\text { Cradle to gate } \\
\text { Cradle to grave }\end{array}$} \\
\hline Ceramic tile water absorption group & $\begin{array}{l}\text { Ala } \\
\text { Alla } \\
\text { Alll }\end{array}$ & $\begin{array}{l}\text { Alb } \\
\text { Allb }\end{array}$ & $\begin{array}{l}\text { Blb } \\
\text { Bllb }\end{array}$ \\
\hline Amount of granulate for manufacturing $1 \mathrm{~m}^{2}$ & \multicolumn{3}{|c|}{$\mathrm{kg} / \mathrm{m}^{2}$} \\
\hline
\end{tabular}

${ }^{2}$ Life Cycle Assessment (LCA) is the compilation and evaluation of the mass and energy inputs and outputs and the potential environmental impacts of a product system during its life cycle (EN ISO 14040:2006).

${ }^{3}$ Cradle to gate: raw materials supply and transport and product manufacture; Cradle to grave: from raw materials supply to tile end-of-life management. 
The technological variants found at the company are then indicated and the main process mass and energy inputs and outputs are quantified (Table 2 and Table 3). The remaining life cycle data correspond to representative data from the Spanish ceramic tile manufacturing sector [4].

Table 2 Key data on raw materials preparation.

\begin{tabular}{|c|c|}
\hline Data on raw materials preparation & Options/Units \\
\hline Type of milling process & Wet \\
Dry
\end{tabular}

Table 3 Key data on the manufacturing process.

\begin{tabular}{|c|c|}
\hline Data on the ceramic tile manufacturing process & Options/Units \\
\hline Water consumption & $\mathrm{I} / \mathrm{m}^{2}$ \\
\hline Electricity bought from the grid & $\mathrm{MJ} / \mathrm{m}^{2}$ \\
\hline Electricity sold to the grid & $\mathrm{MJ} / \mathrm{m}^{2}$ \\
\hline Natural gas consumption in drying & $\mathrm{MJ} / \mathrm{m}^{2}$ \\
\hline Natural gas consumption in firing & $\mathrm{MJ} / \mathrm{m}^{2}$ \\
\hline Decarbonation & $\%$ \\
\hline Does the ceramic tile have one or more layers of decoration? & $\mathrm{Yes} / \mathrm{No}$ \\
\hline Amount of decoration material on a dry basis & $\mathrm{kg} / \mathrm{m}^{2}$ \\
\hline Is any mechanical treatment applied to the ceramic tile (polishing, cutting, & $\mathrm{Yes} / \mathrm{No}$ \\
\hline lapatto, etc.)? & $\%$ \\
\hline
\end{tabular}




\subsection{Low-carbon technologies to be evaluated}

Table 4 details the technology alternatives defined to improve low-carbon performance of the ceramic tile life cycle. Each technology alternative is accompanied by the corresponding alternative options.

Table 4 Technology alternatives for the low-carbon scenario.

\begin{tabular}{|c|c|c|}
\hline \multicolumn{2}{|c|}{ Technology alternatives } & Options \\
\hline \multirow{3}{*}{$\begin{array}{l}\text { Improvements in } \\
\text { product design }\end{array}$} & Thickness & $\begin{array}{l}\text { Maintaining current product thickness } \\
\text { Reducing thickness by a percentage defined by } \\
\text { the user }\end{array}$ \\
\hline & Decoration & $\begin{array}{l}\text { Maintaining the current amount of decoration } \\
\text { Reducing the amount of decoration by } 50 \% \\
\text { Eliminating all decoration }\end{array}$ \\
\hline & $\begin{array}{l}\text { Substitution of raw } \\
\text { materials }\end{array}$ & $\begin{array}{l}\text { Using calcium carbonate in porous compositions } \\
\text { Using wollastonite in porous compositions }\end{array}$ \\
\hline \multirow{2}{*}{$\begin{array}{l}\text { Improvements in the } \\
\text { process }\end{array}$} & Raw materials milling & $\begin{array}{l}\text { Wet } \\
\text { Dry }\end{array}$ \\
\hline & $\begin{array}{l}\text { Energy efficiency in dryers } \\
\text { and kilns }\end{array}$ & $\begin{array}{l}\text { Maintaining current energy efficiency } \\
\text { Increasing energy efficiency by } 10 \%, 20 \% \text {, or } 30 \%\end{array}$ \\
\hline \multirow{2}{*}{$\begin{array}{l}\text { Energy } \\
\text { improvements }\end{array}$} & Thermal energy sources & $\begin{array}{l}\text { Obtaining } 100 \% \text { of thermal energy from natural } \\
\text { gas } \\
\text { Obtaining } 50 \% \text { of thermal energy from natural gas } \\
\text { and } 50 \% \text { from electricity } \\
\text { Obtaining } 100 \% \text { of thermal energy from electricity }\end{array}$ \\
\hline & Electric energy sources & $\begin{array}{l}\text { Direct consumption from the grid (at present) } \\
\text { Direct consumption from the grid (year } 2020 \text { or } \\
2050 \text { ) } \\
\text { Electricity consumption from various sources to be } \\
\text { defined by the user (year } 2020 \text { or } 2050 \text { ) }\end{array}$ \\
\hline
\end{tabular}

With regard to the alternative electric energy sources from which the user can choose, the options include analysing the GHG emissions of the ceramic tile life cycle when the electricity currently supplied by the Spanish Electricity Grid is used [5], when an estimated electricity is used for 2020 or 2050 [6], or when a customised electricity source is used for 2020 or 2050 . The Table 5 lists the different electric energy sources taken into account in the $\mathrm{CerCO}_{2}$ tool for the customised selection of electricity. 
Table 5 Electric energy sources

\begin{tabular}{|c|c|c|c|c|c|}
\hline $\begin{array}{c}\text { Electric energy } \\
\text { source }\end{array}$ & Type & $\begin{array}{c}\text { At } \\
\text { present } \\
(\mathbf{2 0 1 5 )}\end{array}$ & $\mathbf{2 0 2 0}$ & $\mathbf{2 0 5 0}$ & Customised \\
\hline Natural gas & Non-renewable & $21.0 \%$ & $26.9 \%$ & $21.4 \%$ & To be defined \\
\hline Nuclear & Non-renewable & $20.5 \%$ & $18.5 \%$ & $14.8 \%$ & To be defined \\
\hline Solid fossil fuels & Non-renewable & $19.7 \%$ & $10.6 \%$ & $3.5 \%$ & To be defined \\
\hline Wind & Renewable & $18.0 \%$ & $18.1 \%$ & $32.1 \%$ & To be defined \\
\hline Hydroelectric & Renewable & $11.5 \%$ & $10.1 \%$ & $9.0 \%$ & To be defined \\
\hline Solar & Renewable & $5.0 \%$ & $8.4 \%$ & $14.3 \%$ & To be defined \\
\hline Fuel oil & Non-renewable & $1.3 \%$ & $2.3 \%$ & $0.1 \%$ & To be defined \\
\hline Biomass & Renewable & $1.1 \%$ & $1.1 \%$ & $1.1 \%$ & To be defined \\
\hline Waste & Renewable & $0.8 \%$ & $3.3 \%$ & $2.8 \%$ & To be defined \\
\hline $\begin{array}{c}\text { Geothermal and } \\
\text { other renewable } \\
\text { sources }\end{array}$ & Renewable & $0.6 \%$ & $0.0 \%$ & $0.3 \%$ & To be defined \\
\hline Biogas & Renewable & $0.6 \%$ & $0.6 \%$ & $0.6 \%$ & To be defined \\
\hline
\end{tabular}




\section{Tool operation}

\subsection{General procedure}

Figure 2 shows the tool workflow diagram.

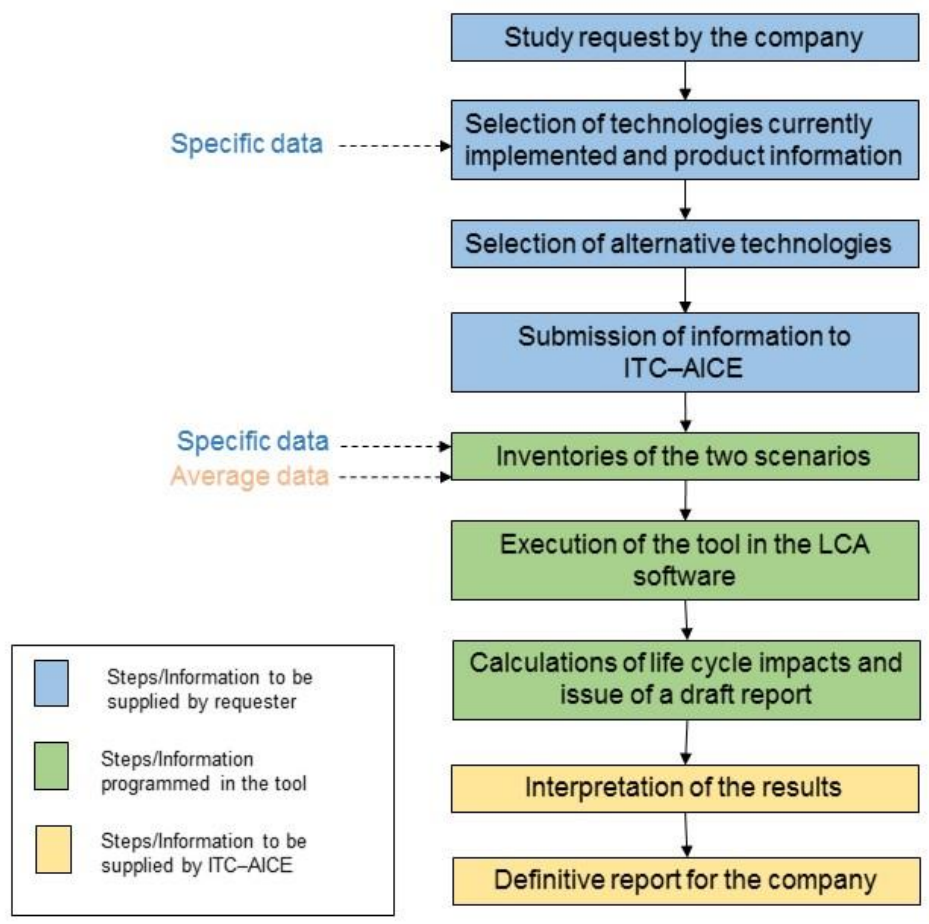

Figure 2 Tool workflow diagram

\subsection{Impact indicators}

The GHG emissions are calculated in terms of the main environmental impact category, global warming potential (expressed in $\mathrm{kg} \mathrm{CO}_{2}$ equivalent). However, the tool also calculates other environmental indicators to verify whether environmental charges are transferred in the implementation of technology alternatives. Thus, for example, sometimes ecological measures that improve certain aspects turn out not to be such important advantages as previously thought, or even to entail negative consequences in other life cycle stages or to increase other types of environmental impacts on analysis in a more integrated form, i.e. considering more life cycle stages or analysing other environmental impacts.

All the environmental indicators are calculated by the CML Baseline method, 2002 [8]. The evaluated impact categories are detailed in Table 6. 
Table 6 Environmental impact categories considered

\begin{tabular}{|c|c|c|}
\hline Environmental impact category & Acronym & Units \\
\hline Global warming potential & GWP & $\mathrm{kg} \mathrm{CO}_{2}$ equivalent \\
\hline Abiotic resource depletion potential-elements & ADP-elements & $\mathrm{kg} \mathrm{Sb}$ equivalent \\
\hline Abiotic resource depletion potential-fossil fuels & ADP-fossil & MJ \\
\hline Acidification potential of soil and water & $\mathrm{AP}$ & $\mathrm{kg} \mathrm{SO}_{2}$ equivalent \\
\hline Eutrophication potential & $\mathrm{EP}$ & $\mathrm{kg} \mathrm{PO}_{3}{ }^{4}$ equivalent \\
\hline Ozone layer depletion potential & ODP & $\mathrm{kg} \mathrm{R}_{11}$ equivalent \\
\hline Photochemical ozone creation potential & $\mathrm{POCP}$ & $\mathrm{kg} \mathrm{C} \mathrm{H}_{4}$ equivalent \\
\hline
\end{tabular}

\subsection{Tool results}

The tool generates a report that sets out the study objective and scope, evaluated measures, and results in the form of tool-generated tables and graphics (see Figure 3).

The results associated with the global warming potential (expressed in $\mathrm{kg} \mathrm{CO}_{2}$ equivalent) of the current and the potential low-carbon scenario defined by the user are displayed in a bar graph and in absolute values, accompanied by the lower quantity of $\mathrm{CO}_{2}$ (in equivalent $\mathrm{kg}$ ) and corresponding explanation and percentage $\mathrm{CO}_{2}$ reduction relative to the initial scenario.

The results of the other environmental impact indicators are displayed in a radial diagram, in which each axis represents an impact category (including global warming potential). The results are presented in relative form, as each impact is quantified by a different unit. This representation enables ready visualisation of the resulting reduction in each impact category and whether improvement in a particular environmental impact adversely affects another category. In this graphic, the current scenario always represents $100 \%$, whereas the user-defined low-carbon scenario represents the relative situation. 


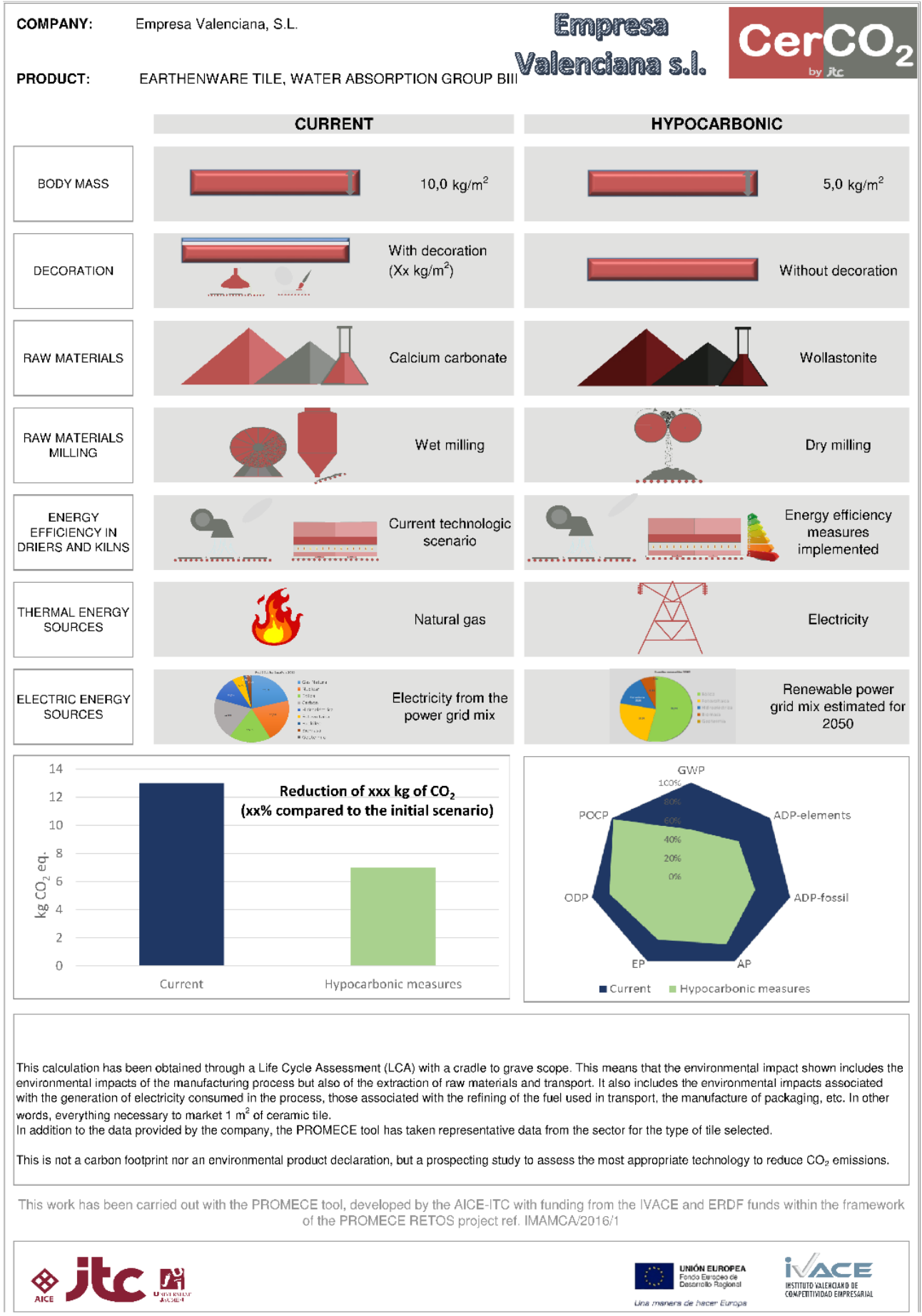

Figure 3 Example of report issued by $\mathrm{CerCO}_{2}$ 


\section{Conclusions}

The $\mathrm{CerCO}_{2}$ tool developed by ITC-AICE places at the service of ceramic tile manufacturing companies a simple, rapid, and economic method of objective, customised determination of a company's particular situation and the $\mathrm{CO}_{2}$ emission abatement to be expected in ceramic tile manufacture on implementing a given technology alternative. It is furthermore useful as a support tool in decision making on technology investments aimed at meeting EU objectives on climate change.

\section{Tool potential and future lines of work}

Besides performing technological foresight studies, the $\mathrm{CerCO}_{2}$ tool also allows internal company controls to be conducted. The tool can furthermore be used in helping to comply with the new approach of the ISO 14001:2015 environmental management systems, particularly regarding the evaluation of environmental aspects and impacts and planning and operational control.

The present, first version of the $\mathrm{CerCO}_{2}$ tool includes quantification of $\mathrm{CO}_{2}$ equivalent emissions and the relative comparison of other impact categories. However, it is intended to extend the tool in the near future to include other types of results, such as the incorporation of a Sankey diagram (which graphically visualises the energy analysis results), further technology alternatives, and $\mathrm{CO}_{2}$ capture measures.

The versatility and flexibility of the Life Cycle Assessment underpinning the $\mathrm{CerCO}_{2}$ tool enables the tool to adapt to the needs and interests of individual companies, the tool being adaptable, upon request, to other branches of ceramic industry such as structural ceramics or vitreous china sanitary ware.

For further information on the tool and its use, please contact r.medioambiente@itc.uji.es

\section{References}

[1] $\operatorname{COM(2010)~2020.~Communication~from~the~Commission.~Europe~2020.~A~strategy~for~smart,~}$ sustainable and inclusive growth. Brussels, March 2010.

[2] $\operatorname{COM}(2011)$ 112: Communication from the Commission to the European Parliament, the Council, the European Economic and Social Committee and the Committee of Regions a Roadmap for moving to a competitive low carbon economy in 2050. Brussels, March 2011.

[3] Cerame Unie, 2012. The Ceramic Industry Roadmap: paving the way to 2050. [online Document]. URL http://cerameunie.eu/topics/cerame-unie-sectors/cerame-unie/ceramicindustry-roadmap-paving-the-way-to-2050/ (retrieved 16.5.2016).

[4] Ros-Dosdá T, Celades I, Monfort E, Moliner R, Zaera V, Benveniuste G, Cerdán C (2010) Impactos ambientales del ciclo de vida de las baldosas cerámicas. Análisis sectorial, identificación de estrategias de mejora y comunicación. In: X Congreso Nacional del Medio Ambiente, CONAMA. CONAMA10, Madrid, pp 1-20 
[5] Red Eléctrica Española REE, 2015. Sistema eléctrico español 2015, síntesis. Estadísticas del sistema eléctrico. Available at: http://www.ree.es/es/estadisticas-del-sistema-electricoespanol/informe-anual/informe-del-sistema-electrico-espanol-2015 (retrieved 18.7.2016)

[6] Capros, P., De Vita, A., Tasios, N., Papadopoulos, D., Siskos, P., Apostolaki, E., Zampara, M., Paroussos, L., Fragiadakis, K., Kouvaritakis, N., 2013. EU energy, transport and GHG emissions: trends to 2050, reference scenario 2013. European Commission DirectorateGeneral for Energy, Directorate-General for Climate Action and Directorate-General for Mobility and Transport, Luxembourg. doi:10.2833/17897

[7] Thinkstep, 2016. GaBi Software-system. Compilation 7.2.2.28 [online Document]. URL http://www.gabi-software.com/software/ (retrieved 25.10.2016).

[8] Guinée, J.B.; Gorrée, M.; Heijungs, R.; Huppes, G.; Kleijn, R.; Koning, A. de; Oers, L. van; Wegener Sleeswijk, A.; Suh, S.; Udo de Haes, H.A.; Bruijn, H. de; Duin, R. van; Huijbregts, M.A.J., 2002. Handbook on life cycle assessment. Operational guide to the ISO standards. I: LCA in perspective. Ila: Guide. Ilb: Operational annex. III: Scientific background. Kluwer Academic Publishers, Dordrecht. 



\section{DISCUSIÓN GENERAL DE LOS RESULTADOS}





\section{DISCUSIÓN GENERAL DE LOS RESULTADOS}

En el presente apartado de discusión, se realiza una valoración global en torno a la hipótesis planteada: "es posible aplicar el Análisis de Ciclo de Vida en el sector de las baldosas cerámicas para abordar los retos de comunicación ambiental, competitividad y cambio climático, mediante la evaluación de tendencias y prospecciones legislativas, tecnológicas y de innovación, de una forma rigurosa, representativa y consistente". El método seguido establece estrategias y desarrolla herramientas del ciclo de vida para cada uno de los retos identificados para el sector.

La definición de estas estrategias requiere conocer la magnitud y naturaleza de los impactos ambientales que se generan. Para ello, se ha llevado a cabo un estudio de ACV de un escenario de referencia de baldosas de gres porcelánico.

A partir de la metodología aplicada y de los parámetros clave obtenidos como resultado de la evaluación del gres porcelánico de referencia, se han realizado diversos análisis de escenarios, los cuales han permitido:

- Obtener y gestionar, de un modo eficiente, instrumentos de comunicación ambiental, tomando como caso de estudio el uso de DAPs y la obtención de información apropiada para demostrar la contribución de las baldosas cerámicas en la construcción sostenible (Aportación $\mathrm{n}^{\circ} \mathbf{1}$ y $\mathrm{n}^{\circ} 2$ )

- Demostrar el uso de DAPs para comparar el comportamiento ambiental de las baldosas cerámicas con productos competidores, y valorar su integración en sistemas constructivos (Aportación $n^{\circledR} 3$ y n4) $^{\circ}$

- Determinar los escenarios tecnológicos hipocarbónicos capaces de dar cumplimiento a los objetivos de reducción de $\mathrm{CO}_{2}$ establecidos por la Unión Europea para 2020 y 2050 aplicables a los sectores industriales (Aportación $\mathbf{n}^{\circ} 5$ y $\mathbf{n}^{\circ} 6$ ).

\subsection{Evaluación del escenario de referencia}

En la Aportación $\mathrm{n}^{\circ} 1$, se desarrolla un estudio de ACV de las baldosas de gres porcelánico fabricadas en España entre los años 2010-2015, con alcance de la cuna a la tumba, a partir de los datos facilitados por 26 empresas fabricantes de gránulo atomizado, esmaltes y baldosas cerámicas, que han sido verificados por terceras partes independientes para la obtención de 14 DAPs de gres porcelánico.

Las categorías de impacto ambiental evaluadas han sido las propuestas por la norma EN15084+A1,2013 Reglas de Categoría de Productos Básicas para Productos de la Construcción, que son las que se detallan en la Tabla 5.1. 
Tabla 5.1 Categorías de impacto ambiental

\begin{tabular}{|l|c|c|}
\hline \multicolumn{1}{|c|}{ Categoría de impacto ambiental } & Acrónimo & Unidades \\
\hline $\begin{array}{l}\text { Potencial de agotamiento de los recursos abióticos } \\
\text { para recursos no fósiles }\end{array}$ & ADPE & kg Sb Equivalentes \\
\hline $\begin{array}{l}\text { Potencial de agotamiento de los recursos abióticos } \\
\text { para recursos fósiles }\end{array}$ & ADPF & MJ \\
\hline $\begin{array}{l}\text { Potencial de acidificación del suelo y de los recursos } \\
\text { de agua }\end{array}$ & AP & $\mathrm{kg} \mathrm{SO}_{2}$ Equivalentes \\
\hline Potencial de eutrofización & EP & $\mathrm{kg} \mathrm{PO}_{4}{ }^{3}$ Equivalentes \\
\hline Potencial de calentamiento global & GWP & $\mathrm{kg} \mathrm{CO}_{2}$ Equivalentes \\
\hline $\begin{array}{l}\text { Potencial de agotamiento de la capa de ozono } \\
\text { estratosférico }\end{array}$ & ODP & $\mathrm{kg} \mathrm{R}_{11}$ Equivalentes \\
\hline Potencial de formación de ozono troposférico & POCP & $\mathrm{kg} \mathrm{C}_{2} \mathrm{H}_{4}$ Equivalentes \\
\hline
\end{tabular}

\subsubsection{Cuantificación de las contribuciones a las categorías de impacto ambiental}

Los resultados obtenidos en la evaluación de impacto ambiental del escenario de referencia se presentan en la Figura 5.1, como contribuciones relativas de las entradas y salidas del ciclo de vida.

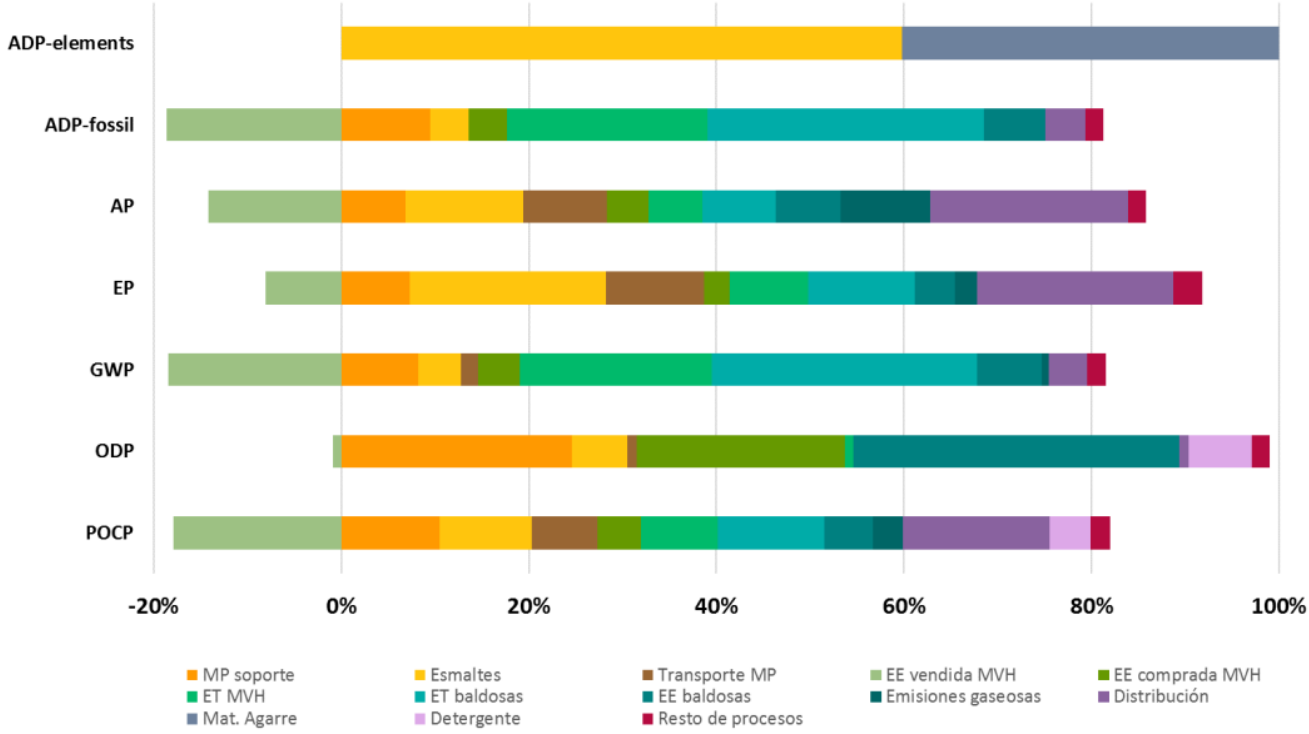

Figura 5.1 Contribución relativa de las principales entradas y salidas del ciclo de vida del gres porcelánico 
Como puede observarse en la Figura 5.1, la etapa de fabricación es la que genera impactos más elevados en 6 de las 7 categorías de impacto ambiental estudiadas: potencial de agotamiento de recursos abióticos de origen fósil, acidificación, eutrofización, calentamiento global, destrucción de la capa de ozono y formación de oxidantes fotoquímicos. Por lo tanto, es en esta etapa, donde se encuentran las principales oportunidades de mejora del comportamiento ambiental del producto.

\subsubsection{Identificación de parámetros clave}

De forma general, se puede afirmar que un parámetro clave puede afectar a una o varias categorías de impacto, y una categoría de impacto puede estar afectada por uno o varios parámetros clave.

De los resultados obtenidos en el ACV presentado en la Aportación $\mathrm{n}^{\circ} 1$, y del análisis de sensibilidad realizado sobre el escenario de referencia del gres porcelánico (presentado como material suplementario en la Aportación $n^{\circ} 5$ ), se concluye que, los parámetros que repercuten de manera más significativa en mayor número de categorías de impacto son los que se presentan en la Tabla 5.2. En ella, se detalla la contribución relativa de cada uno de los parámetros clave en las diferentes categorías de impacto estudiadas, y se hace referencia al origen de éstos.

Tabla 5.2 Contribución y principales orígenes de los parámetros clave

\begin{tabular}{|c|c|c|}
\hline Parámetro clave & Impactos & Principales orígenes \\
\hline \multirow{2}{*}{$\begin{array}{l}\text { Energía térmica en el secado de } \\
\text { las materias primas por } \\
\text { atomización y en el secado y } \\
\text { cocción de las baldosas }\end{array}$} & ADPF (77\%) & Consumo de gas natural \\
\hline & GWP (74\%) & Emisiones $\mathrm{GEI}: \mathrm{CO}_{2}$ y $\mathrm{CH}_{4}$, principalmente \\
\hline \multirow{2}{*}{ Esmaltes } & ADPE (60\%) & $\begin{array}{l}\text { Materias primas que introducen compuestos de } \\
\text { boro en la composición }\end{array}$ \\
\hline & EP $(23 \%)$ & Emisiones de $\mathrm{NO}_{x}$ durante la fusión de fritas \\
\hline \multirow{4}{*}{$\begin{array}{l}\text { Electricidad vendida a la red } \\
\text { (cogenerada no autoconsumida) }\end{array}$} & ADPF $(-28 \%)$ & \multirow{4}{*}{$\begin{array}{l}\text { Cargas evitadas de las centrales térmicas } \\
\text { fuel/gas }\end{array}$} \\
\hline & GWP $(-28 \%)$ & \\
\hline & POCP (-26\%) & \\
\hline & AP $(-19 \%)$ & \\
\hline \multirow{3}{*}{ Electricidad comprada a la red } & ODP (70\%) & $\begin{array}{l}\text { Uso de halones como refrigerantes en las } \\
\text { centrales nucleares }\end{array}$ \\
\hline & GWP (17\%) & $\begin{array}{l}\text { Emisiones de GEI por la producción de } \\
\text { electricidad, principalmente, de origen fósil }\end{array}$ \\
\hline & ADPF (16\%) & $\begin{array}{l}\text { Producción de electricidad a partir de recursos } \\
\text { fósiles }\end{array}$ \\
\hline \multirow{2}{*}{$\begin{array}{l}\text { Obtención de materias primas } \\
\text { del soporte }\end{array}$} & ODP $(26 \%)$ & \multirow{2}{*}{$\begin{array}{l}\text { Emisiones generadas por la producción y } \\
\text { consumo de electricidad, explosivos, gasoil } \\
\text { necesario para la extracción y transportes de } \\
\text { materias primas }\end{array}$} \\
\hline & POCP (15\%) & \\
\hline
\end{tabular}


Tabla 5.2 Contribución y origen de los parámetros clave (continuación)

\begin{tabular}{|c|c|c|}
\hline Parámetro clave & Impactos & Origen \\
\hline \multirow{3}{*}{ Distribución de las baldosas } & AP (28\%) & \multirow{3}{*}{$\begin{array}{l}\text { Obtención y combustión de los combustibles } \\
\text { empleados en los transportes terrestres y } \\
\text { marítimos. Su contribución depende de la carga } \\
\text { transportada y distancia recorrida }\end{array}$} \\
\hline & EP $(23 \%)$ & \\
\hline & POCP (22\%) & \\
\hline Material de agarre & ADPE (40\%) & Materias primas de los adhesivos cementosos \\
\hline
\end{tabular}

Asimismo, otros indicadores identificados como relevantes en el análisis de sensibilidad para la categoría de impacto de Potencial de Calentamiento Global son:

- el contenido en carbonatos en las composiciones del soporte

- la vida útil de las baldosas

- la frecuencia y tipo de limpieza durante su uso.

\subsection{Estrategias planteadas}

Como se ha comentado con anterioridad, estos parámetros son claves para definir los escenarios abordados en cada una de las estrategias y herramientas, y cuya variación, determinará el grado de mejora y la consecución de los objetivos planteados. En la Tabla 5.3., se expone la relación entre los parámetros considerados clave, con las estrategias y herramientas planteadas en esta tesis. 


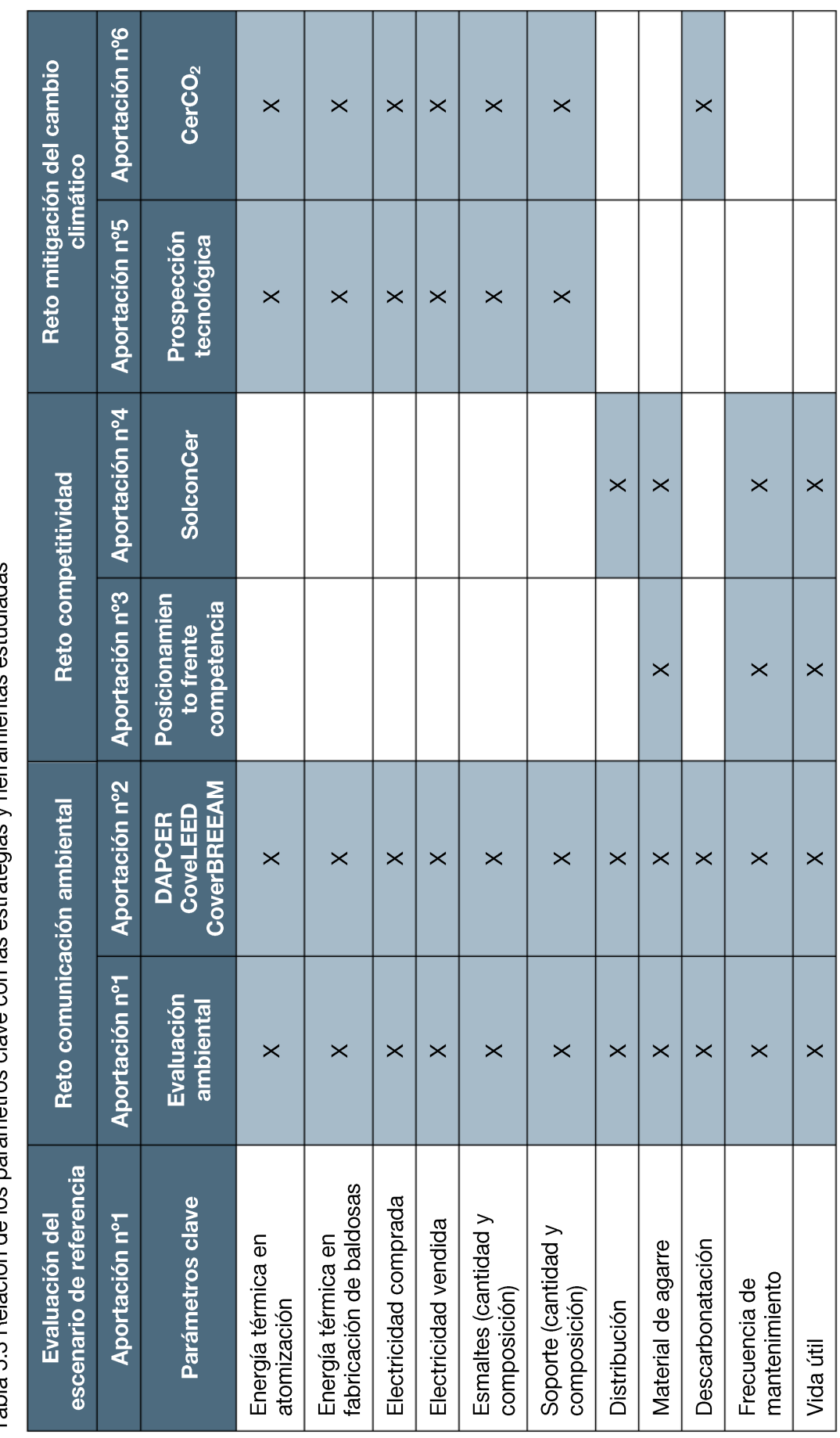


A continuación, se resumen las estrategias planteadas en esta tesis para abordar los retos identificados para el sector cerámico.

\section{Evaluación Ambiental (RETO 1)}

La evaluación ambiental, desarrollada como estrategia para el reto de comunicación ambiental eficiente (Aportación $\mathbf{n}^{\mathbf{0}} \mathbf{1}$ ), ha demostrado que la cantidad de esmalte, las operaciones de mecanizado del producto acabado, y sobre todo, el espesor de las piezas, son parámetros clave para cuantificar las diferencias ambientales de las diferentes variantes de gres porcelánico producidas por un fabricante. Se ha determinado que, las baldosas cerámicas de menor espesor, con menor cantidad de esmaltes (y/o de fritas) y menores tratamientos mecánicos son las que presentan un menor impacto ambiental. La cuantificación previa de estos parámetros permite aplicar, de manera sencilla y eficiente, los distintos criterios de agrupamiento de los diferentes programas de Declaraciones Ambientales de Producto (véase la Tabla 2 de la Aportación n¹).

\section{Posicionamiento frente a la competencia (RETO 2)}

La comparativa ambiental de recubrimientos de distinta naturaleza llevada a cabo como estrategia

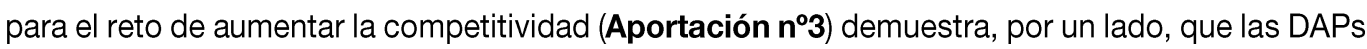
son recursos apropiados, como punto de partida (alcance cuna a puerta), para la comparabilidad de soluciones constructivas, siempre que se consideren todas las etapas del ciclo de vida en un contexto de edificio (o de solución constructiva), y se respeten los requisitos de comparabilidad recogidos por las normas EN 15804+A1, 2013 e ISO 14025, 2006. Por otro lado, del ejercicio comparativo se concluye que la vida útil de los materiales y los requerimientos de mantenimiento y reparación son aspectos clave en los resultados. Los sistemas de suelos con menor impacto ambiental son los que incorporan recubrimientos inorgánicos (gres porcelánico y piedra natural), cuando se consideran las categorías de impacto GWP, AP, EP, POCP y ADPF; mientras que los sistemas de suelos con recubrimientos laminados presentan un desempeño ambiental más favorable en las categorías de impacto ODP y ADPF. Por el contrario, los sistemas de suelos con moqueta presentan peores resultados en todas las categorías de impacto ambiental estudiadas, excepto en POCP.

\section{Prospección tecnológica (RETO 3)}

Los resultados del análisis de escenarios tecnológicos hipocarbónicos llevados a cabo para abordar el reto del cambio climático (Aportación $\mathbf{n}^{\circ} 5$ ) determinan que, para alcanzar los objetivos de la UE en materia de reducción de emisiones GEI para 2050, será necesario implementar conjuntamente medidas endógenas y exógenas que requieren tecnologías de vanguardia. Concretamente, se ha demostrado que se requerirán cambios en el diseño del producto (reducción a la mitad del espesor y de la cantidad de esmalte y/o contenido en frita), la implantación de tecnologías de elevada eficiencia energética en secaderos y hornos que funcionen, al menos, con la mitad de la energía procedente de fuentes renovables. 


\subsection{Relaciones entre retos}

\subsubsection{Variantes de productos (RETO $1 \leftrightarrow$ RETO 2)}

En la Aportación $\mathbf{n}^{\circ} \mathbf{1}$ se ha demostrado que, entre las distintas variantes de gres porcelánico pueden encontrarse diferencias en torno al $35 \%$ a lo largo de todo su ciclo de vida en todas las categorías de impacto, excepto en ODP (48\%). Cuando el alcance es de cuna a puerta (A1-A3), estas diferencias se sitúan en torno al $40 \%$ en todas las categorías, excepto en la categoría ADPE $(90 \%)$.

En el ejercicio comparativo llevado a cabo en la Aportación $\mathbf{n}^{\mathbf{3}} \mathbf{3}$, se han añadido las variantes de gres porcelánico que presentan menor impacto ambiental (PST-LUN) y mayor impacto ambiental (PST-HGM), y se han evaluado los impactos ambientales de su ciclo de vida en un escenario de bajo tránsito peatonal (uso residencial).

En la Figura 5.2, se representan los valores relativos de los recubrimientos analizados respecto al gres porcelánico promedio (PST), tomando este valor de referencia como 100\%. En lo que respecta a la etapa de producto (alcance cuna-puerta), en la figura A2.2 de la Aportación n³, puede observarse la dispersión de los impactos ambientales publicados en las DAPs.

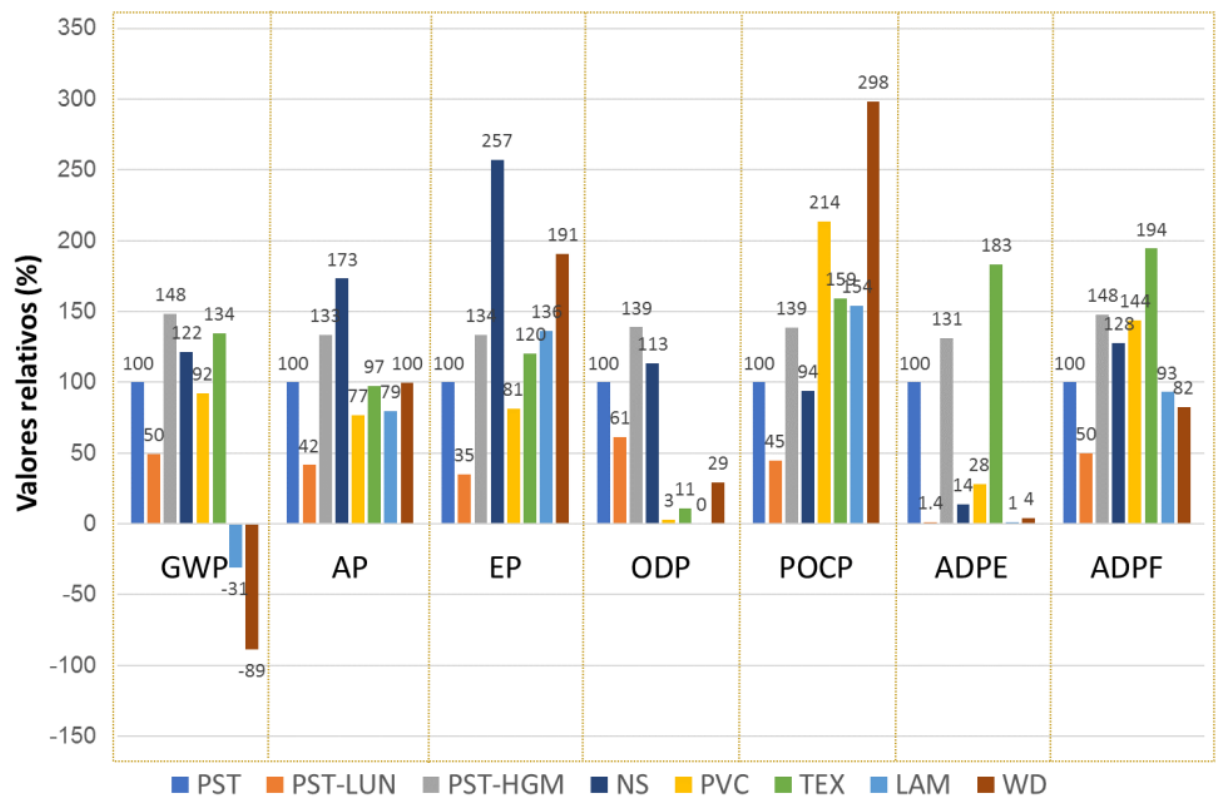

Figura 5.2 Impactos ambientales de la etapa de producto de los recubrimientos analizados (A1-A3); valores relativos al PST (100\%).

PST (gres porcelánico promedio); PST-LUN (gres porcelánico de bajo espesor sin esmaltar ni mecanizar); PSTHGM (gres porcelánico espesorado, esmaltado y mecanizado); NS (piedra natural promedio); PVC (policloruro de vinilo promedio); TEX (moquetas promedio); LAM (laminados promedio) y; WD (parquet promedio)

Tal y como se ha evidenciado en la Aportación n³, en los ejercicios comparativos deben considerarse todas las etapas del ciclo de vida de la solución constructiva. Los resultados de este 
ejercicio comparativo en un escenario de tránsito peatonal bajo se presentan en la Tabla 5.4. En esta tabla se resaltan en negrita aquellos impactos de recubrimientos no cerámicos que presentan diferencias menores con el gres porcelánico promedio (PST) que las diferencias entre algunas variantes del propio gres porcelánico (PST-LUN y PST-HGM).

Tabla 5.4 Impactos ambientales del ciclo de vida de soluciones constructivas (alcance cuna-cuna); valores absolutos

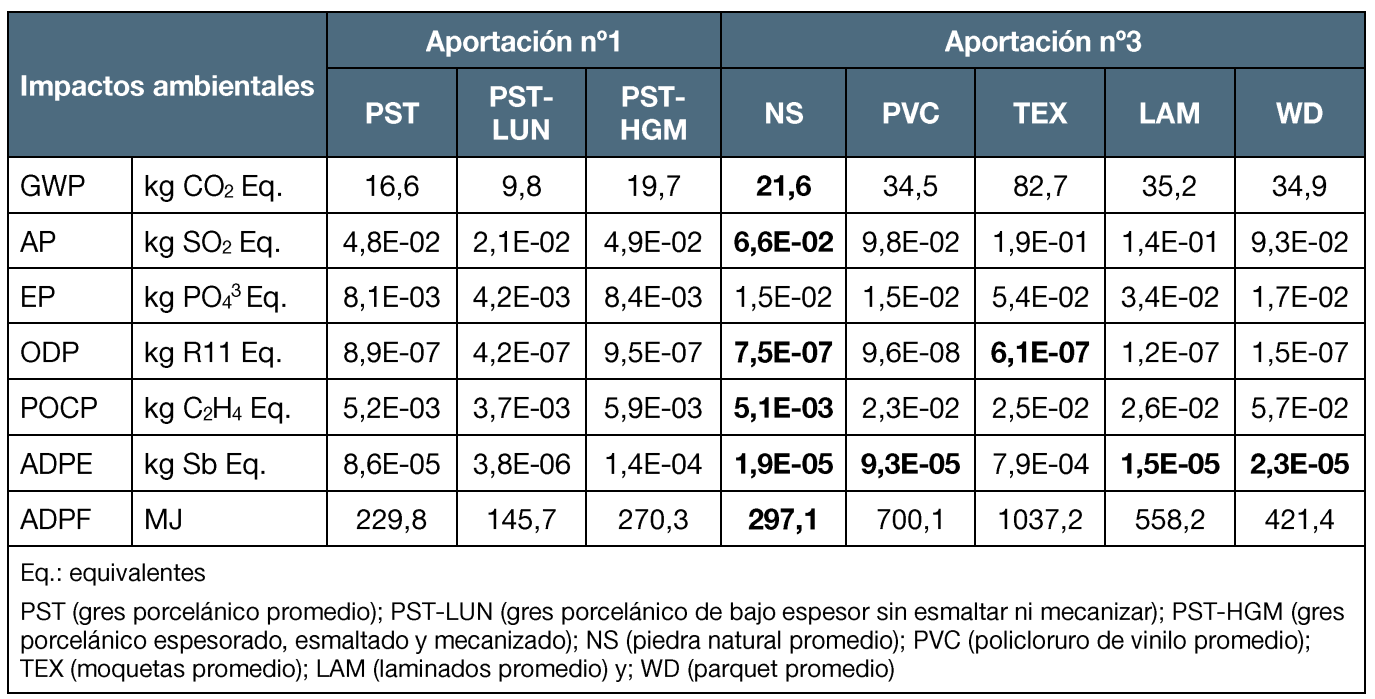

Tanto en un alcance cuna-puerta como cuna-cuna, se ha comprobado que, es posible encontrar diferencias mayores entre las variantes de gres porcelánico que entre productos de distinta naturaleza. Por ejemplo, en un alcance cuna-puerta y en las categorías de GWP, AP y ADPF, varios sistemas de suelos presentan menores diferencias con respecto al gres porcelánico medio (PST), que las diferencias entre sistemas de suelos con variantes de gres porcelánico. En un alcance cuna-cuna, las diferencias entre PST-HGM y NS son menores que algunas variantes de PST en algunas categorías de impacto.

En la Tabla 5.4, se puede observar que, en las categorías de impacto GWP, AP, EP y ADPF, cualquier variante de gres porcelánico presenta los resultados ambientales más favorables. En las categorías POCP y ADPE, sólo la variante PST-LUN presenta mejores resultados, mientras que en el caso de la categoría ODP, el PST y el PST-LUN se posicionan entre los recubrimientos más desfavorables.

Con el fin de facilitar la interpretación del análisis comparativo, los valores de impacto ambiental de cada uno de los sistemas de suelos presentados en la Tabla 5.4, se han ponderado y normalizado para obtener un único valor adimensional, cuya representación gráfica se muestra en la Figura 5.3. Concretamente, los factores de ponderación aplicados han sido los obtenidos por Thinkstep "LCIA Survey 2012, Global, CML 2016, incl biogenic carbon (global equivalents 
weighted)" y los factores de normalización "CML2001 - Jan. 2016, World, year 2000 , incl biogenic carbon (global equivalents)" (Tabla 9 de la Aportación n³).

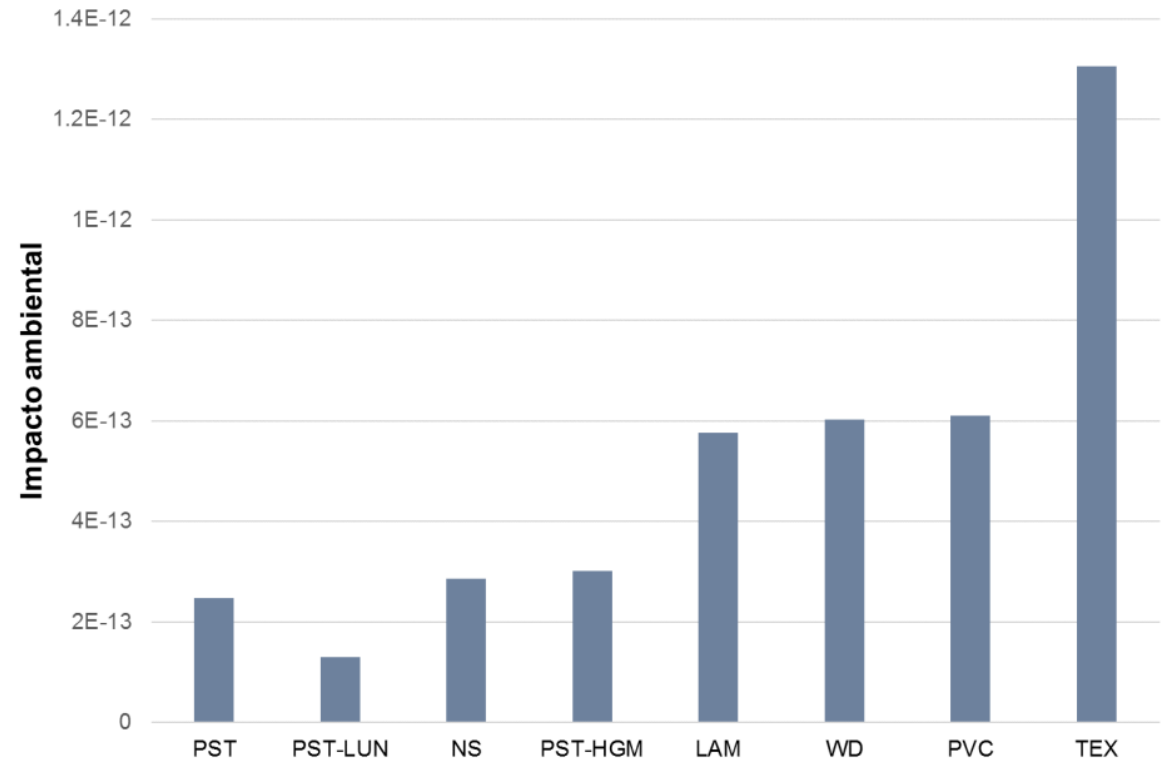

Figura 5.3 Impacto ambiental de los sistemas de suelos comparados en un escenario de tránsito peatonal bajo (valores ponderados y normalizados)

En la Figura 5.3, se demuestra que las baldosas de gres porcelánico de elevado espesor (16 mm), esmaltadas y mecanizadas (PST-HGM), conllevan impactos ambientales superiores a baldosas de piedra natural (20 mm de espesor). A partir de los datos ponderados y normalizados, se ha determinado que, el límite de espesor para el cual, una baldosa de gres porcelánico presenta mejores resultados que otro tipo de recubrimiento, es de $14 \pm 0,5 \mathrm{~mm}$, pudiendo variar ligeramente según la cantidad de esmalte e intensidad de los tratamientos mecánicos superficiales.

Del tratamiento conjunto de las Aportaciones $n^{\circ} 1$ y $n^{\circ} 3$, se confirma que, cuando se realizan ejercicios comparativos de productos hay una serie de factores a tener en cuenta:

- La comparativa debe tener en cuenta el ciclo de vida completo del producto en un mismo entorno edificatorio, bien a escala de producto o de sistemas constructivos.

- Cuando se emplean DAPs para obtener los impactos ambientales de la etapa de producto (módulos A1-A3) como punto de partida, deben aplicarse los criterios de comparabilidad recogidos por las normas EN 15804+A1, 2013 e ISO 14025, 2006.

- Las diferencias entre variantes de una misma categoría de producto pueden ser superiores a diferencias entre distintas categorías de productos. Este hecho hay que tenerlo en cuenta cuando se hacen comparaciones de productos genéricos. 
- En el caso del gres porcelánico, los parámetros más importantes que determinan el comportamiento ambiental de las baldosas y su posicionamiento frente a materiales competidores es el espesor de las piezas, su durabilidad y facilidad de limpieza.

\subsubsection{Parámetros ambientales clave (RETO $1 \leftrightarrow$ RETO 3)}

A partir de los parámetros clave del ciclo de vida identificados en la Aportación $\mathbf{n}^{\circ} \mathbf{1}$ (Tabla 5.2), se han definido una serie de alternativas tecnológicas orientadas a reducir las emisiones asociadas de GEl, cuyas características se resumen en la Tabla 5.5 (tomada de la Aportación n5).

Tabla 5.5 Resumen de las alternativas tecnológicas evaluadas en la Aportación n5

\begin{tabular}{|c|c|c|c|}
\hline \multirow{2}{*}{\multicolumn{2}{|c|}{ Procesos/parámetros }} & \multicolumn{2}{|r|}{ Alternativas } \\
\hline & & Acrónimo & Descripción \\
\hline \multirow{5}{*}{$\begin{array}{l}\text { Diseño de } \\
\text { producto }\end{array}$} & \multirow{3}{*}{$\begin{array}{l}\text { Cantidad de } \\
\text { esmalte }\end{array}$} & GL100 & $\begin{array}{l}\text { Cantidad media de esmalte. Para PST se } \\
\text { estima en } 0,76 \mathrm{~kg} / \mathrm{m}^{2} \text {, con un } 33 \% \text { de } \\
\text { contenido de fritas }\end{array}$ \\
\hline & & GL50 & $\begin{array}{l}\text { Reducción del } 50 \% \text { del contenido en } \\
\text { esmaltes y decoración }\end{array}$ \\
\hline & & GLO & No se aplica esmalte ni decoración \\
\hline & \multirow{2}{*}{$\begin{array}{l}\text { Espesor de la } \\
\text { baldosa }\end{array}$} & TH100 & $\begin{array}{l}\text { Espesor medio del PST: } 10,4 \mathrm{~mm},(24,2 \\
\mathrm{kg} / \mathrm{m}^{2} \text { peso en crudo) }\end{array}$ \\
\hline & & TH50 & $\begin{array}{l}\text { Reducción del } 50 \% \text { del espesor (reducción } \\
\text { de la masa) }\end{array}$ \\
\hline \multirow{4}{*}{$\begin{array}{l}\text { Proceso de } \\
\text { fabricación }\end{array}$} & \multirow{2}{*}{$\begin{array}{l}\text { Preparación de las } \\
\text { materias primas del } \\
\text { soporte }\end{array}$} & WCS & $\begin{array}{l}\text { Molturación por vía húmeda, con sistemas de } \\
\text { cogeneración }\end{array}$ \\
\hline & & DRY & Molturación por vía seca \\
\hline & \multirow{2}{*}{$\begin{array}{l}\text { Tecnologías de } \\
\text { eficiencia } \\
\text { energética en } \\
\text { secaderos y hornos }\end{array}$} & CTT & $\begin{array}{l}\text { Escenario actual de tecnología térmica en } \\
\text { secaderos y hornos }\end{array}$ \\
\hline & & WDS & 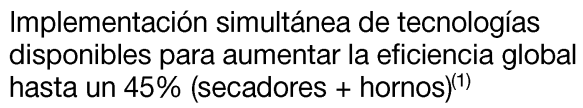 \\
\hline
\end{tabular}


Tabla 5.5 Resumen de las alternativas tecnológicas evaluadas en la Aportación n5 (continuación)

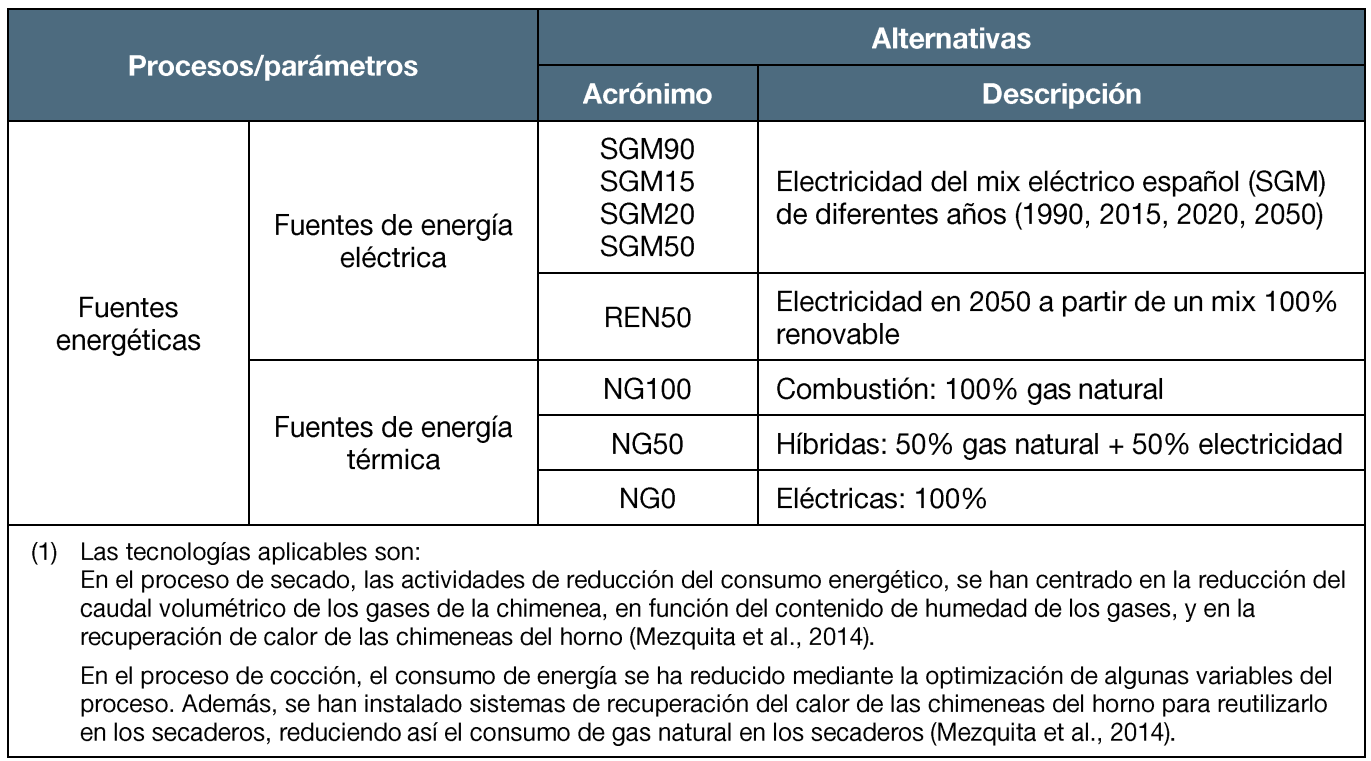

En la Tabla 5.6, se relacionan los procesos que generan mayor contribución a la categoría de impacto del potencial de calentamiento global (GWP) identificados en la Aportación $n^{\circ 1}$, con aquellos más sensibles a esta categoría de impacto, identificados mediante un análisis de sensibilidad llevado a cabo en la Aportación n5. Cabe recordar que, este análisis de sensibilidad evalúa la influencia de un parámetro cuando su valor varía con un rango de $\pm 99 \%$ en los datos de inventario. En esta tabla, únicamente se muestran aquellos parámetros cuya sensibilidad al GWP es superior al $3 \%$. Además, se identifican las alternativas tecnológicas planteadas para reducir las emisiones de $\mathrm{CO}_{2}$ equivalentes (GEI) .

Tabla 5.6 Parámetros más relevantes en el potencial al calentamiento global para los cuales se han considerado alternativas tecnológicas

\begin{tabular}{|l|c|c|c|}
\hline \multicolumn{1}{|c|}{ Parámetros clave } & Aportación n $^{\circ}$ & \multicolumn{2}{c|}{ Aportación ${ }^{\circ}$ 5 } \\
\cline { 2 - 4 } & $\begin{array}{c}\text { Contribución al } \\
\text { GWP (\%) }\end{array}$ & $\begin{array}{c}\text { Análisis } \\
\text { sensibilidad } \\
\text { al GWP (\%) }\end{array}$ & Alternativas tecnológicas ${ }^{(1)}$ \\
\hline $\begin{array}{l}\text { Energía térmica en el secado } \\
\text { y cocción de baldosas }\end{array}$ & 43,1 & $\pm 36,5$ & NG50; NG0 \\
\hline Peso del soporte & $-(2)$ & $\pm 28,9$ & TH100; TH50 \\
\hline $\begin{array}{l}\text { Energía térmica en la preparación } \\
\text { de las materias primas }\end{array}$ & 31,1 & $\pm 26,4$ & WCS; DRY \\
\hline $\begin{array}{l}\text { Electricidad cogenerada vendida } \\
\text { a la red }\end{array}$ & $-28,1$ & $\pm 11,1$ & WCS; DRY \\
\hline
\end{tabular}


Tabla 5.6 Parámetros más relevantes en el potencial al calentamiento global para los cuales se han considerado alternativas tecnológicas (continuación)

\begin{tabular}{|c|c|c|c|}
\hline \multirow[b]{2}{*}{ Parámetros clave } & \multirow{2}{*}{$\begin{array}{l}\text { Aportación n }{ }^{\circ 1} \\
\text { Contribución al } \\
\text { GWP (\%) }\end{array}$} & \multicolumn{2}{|r|}{ Aportación n5 } \\
\hline & & $\begin{array}{c}\text { Análisis } \\
\text { sensibilidad } \\
\text { al GWP (\%) }\end{array}$ & Alternativas tecnológicas ${ }^{(1)}$ \\
\hline $\begin{array}{l}\text { Electricidad en la fabricación } \\
\text { de baldosas }\end{array}$ & 10,47 & $\pm 6,9$ & SGM20; SGM50; REN50 \\
\hline Cantidad de esmaltes & 6,8 & $\pm 5,3$ & GL100; GL50; GL0 \\
\hline $\begin{array}{l}\text { Electricidad comprada en la } \\
\text { preparación de materias primas }\end{array}$ & 6,7 & $\pm 5,1$ & WCS; DRY; SGM20; SGM50; REN50 \\
\hline \multicolumn{4}{|c|}{$\begin{array}{l}\text { (1) Nomenclatura según Tabla } 5.5 \\
\text { (2) Procesos que afectan directa o indirectamente a otros procesos. Por ejemplo: } \\
\text { Peso del soporte (espesor) afecta a: la extracción de materias primas, energía térmica, transportes, etc. (Ver la tabla 3.3) } \\
\text { Frecuencia de limpieza afecta a: la cantidad de agua y detergente al finalizar la vida útil } \\
\text { Vida útil afecta a: las operaciones de mantenimiento y sustituciones, si fuera necesario }\end{array}$} \\
\hline
\end{tabular}

Con el objeto de cuantificar las emisiones de $\mathrm{CO}_{2}$ equivalente asociadas a cada alternativa tecnológica definida en la Aportación $n^{\circ} 5$, se ha realizado un ACV de cada una de ellas. En la Figura 5.4, se representa la contribución de cada alternativa tecnológica de manera individual al ciclo de vida completo del escenario de referencia del gres porcelánico, incluyendo las emisiones de $\mathrm{CO}_{2}$ equivalentes estimadas en 1990, y señalado con líneas continuas, los objetivos de reducción de la UE para 2020 y 2050.

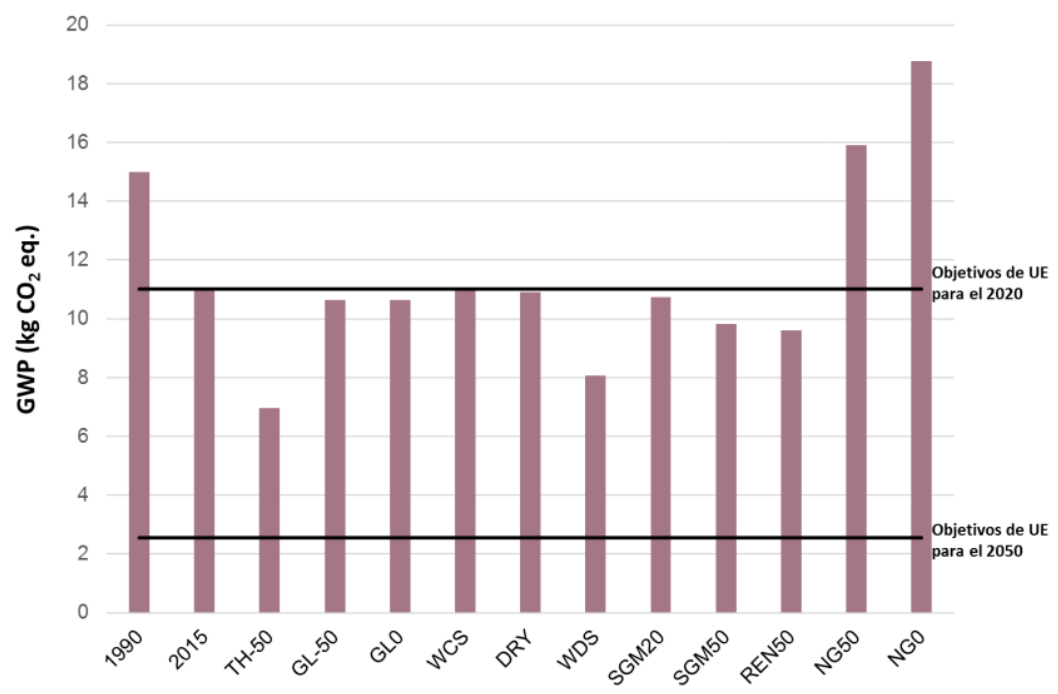

Figura 5.4 Efecto individual de las alternativas tecnológicas sobre el potencial de calentamiento global (alcance cuna-tumba) 
De los resultados se pueden obtener las siguientes afirmaciones:

- Las mejoras implementadas en el sector de la fabricación de baldosas durante el periodo 1990-2015 (BenchTile, 2017 y Ferrer, 2016) han sido suficientes para reducir las emisiones de GEl en un $20 \%$ desde 1990, pudiéndose alcanzar mejoras superiores mediante la implementación de medidas que requieren esfuerzos relativamente bajos.

- La reducción del espesor (TH50) y la implementación simultánea de tecnologías que aumentan la eficiencia energética (WDS) son las alternativas que presentan reducciones de impacto más importantes. Ambas están presentes actualmente en el sector

- Las alternativas NG50 y NG0 suponen la electrificación de secaderos y hornos a partir de la electricidad de la red, la cual genera un aumento de las emisiones de $\mathrm{CO}_{2}$ eq. debido a la naturaleza del mix eléctrico español.

- Para alcanzar los objetivos de reducción establecidos por la UE para el 2050, se requiere la implementación simultánea de varias alternativas tecnológicas.

- Se determina que, a medida que se amplía el alcance de aplicación de estos objetivos, más innovadoras y radicales deben ser las alternativas tecnológicas (de la Aportación $\left.\mathrm{n}^{\circ} 5\right)$.

Cabe mencionar que, la Aportación n³ se lleva a cabo desde una perspectiva atribucional, la cual permite describir las propiedades ambientales del ciclo de vida del sistema de producto de gres porcelánico y de sus subsistemas. Este enfoque se establece desde la base de una Unidad Funcional, apropiado para la consecución de los objetivos perseguidos en la Aportación n³: i) estimar el grado de innovación tecnológica requerido; ii) definir y perfilar estrategias de mejora, y iii) diseñar las líneas de desarrollo tecnológico que se han de implementar en el sector en los próximos años para alcanzar los objetivos de la UE en materia de una economía baja en carbono.

La aplicación de estos objetivos de reducción es sectorial. El hecho de considerar las emisiones de $\mathrm{CO}_{2}$ generadas directamente por las empresas sin una perspectiva del ciclo de vida conlleva consecuencias no deseables, como las que se citan a continuación, entre otras:

- Transferencias de cargas entre sectores: la electrificación de equipos demandantes de energía térmica (secado por atomización de las materias primas, secado y cocción de las baldosas), como única alternativa, reduciría considerablemente el problema, a costa de ceder el problema al sector eléctrico.

- Transferencia de cargas entre regiones: la deslocalización de la producción se traduciría directamente en una reducción de las emisiones en el lugar original, sin embargo, no sólo se produciría un traslado geográfico de las emisiones, sino que además, podría incluso, aumentar las emisiones globales si la producción se localizara en lugares con menores exigencias ambientales.

- Falta de coordinación con otras políticas europeas, como la Economía Circular, ya que al perder el enfoque del ciclo de vida y de la consideración de la funcionalidad como clave en la evaluación de los productos, podría poner en riesgo la valoración de características y propiedades de los productos, y sus capacidades para regenerar los sistemas de 
producto en el que se minimicen el consumo de recursos y los residuos, las emisiones y las pérdidas de energía mediante la ralentización, el cierre y el estrechamiento de los bucles de material y energía (Geissdoerfer et al., 2017; MacArthur, 2013).

Este análisis sectorial requiere una visión holística, en la que se consideren las consecuencias globales en una tecnosfera dinámica, es decir, mediante una perspectiva consecuencial. Esta perspectiva demanda análisis adicionales que quedan fuera del alcance de la presente tesis.

Para una aplicación de este enfoque sectorial consecuencial, sería necesario, en primer lugar, considerar la producción del sector de las baldosas cerámicas. En la Figura 1.2 del capítulo de la Introducción y estado del arte, se presenta la evolución de la producción de baldosas cerámicas en España: en 1990, se produjeron $225 \mathrm{Mm}^{2}$, mientras que en 2018 la producción aumentó hasta los $530 \mathrm{Mm}^{2}$. En la Tabla 5.7, se muestran las emisiones de $\mathrm{CO}_{2}$ asociadas al ciclo de vida del gres porcelánico, las cuales han sido estimadas a partir de los $\mathrm{kg} \mathrm{CO} \mathrm{CO}_{2} \mathrm{eq} . \mathrm{m}^{2}$ de gres porcelánico, calculados en las Aportaciones $n^{\circ} 1$ y $n^{\circ} 5$ y suponiendo una producción estable de baldosas desde 2018 hasta 2020 y 2050 , de $530 \mathrm{Mm}^{2}$.

Tabla 5.7 Emisiones de $\mathrm{CO}_{2}$ equivalente asociadas a la producción del sector español de baldosas cerámicas

\begin{tabular}{|c|c|c|c|c|}
\hline \multirow{2}{*}{ Producción (Mm²/año) } & \multicolumn{3}{|c|}{ Emisiones de $\mathbf{C O}_{2}$ (kton equivalente) } \\
\cline { 3 - 5 } & Alcance cuna-tumba & Alcance cuna-puerta & Alcance puerta-puerta \\
\hline Producción en 1990 & 225 & 3345 & 3032 & 2420 \\
\hline Producción en 2015 & 440 & 4853 & 4205 & 3140 \\
\hline Producción en 2018 & 530 & 7880 & 5065 & 3782 \\
\hline Reducción para el 2020 & 2676 & 2425 & 1936 \\
\hline \multicolumn{2}{|c|}{ Reducción para el 2050 } & 569 & 515 & 411 \\
\hline
\end{tabular}

Bajo estas premisas, para el 2020, se requieren cambios en el diseño del producto (espesor y cantidad de esmalte), y la implementación de medidas de elevada eficiencia energética en secaderos y hornos en todas las empresas del sector cuando los objetivos de reducción de aplican a todo el ciclo de vida (alcance cuna-tumba). Cuando los objetivos de reducción se aplican a escenarios más reducidos, se requieren medidas menos exigentes, y en este caso, sería suficiente con la implementación de medidas de eficiencia energética en secaderos y hornos.

Para el 2050, las medidas deben ser extremadamente innovadoras y, según lo comprobado en este análisis, ninguno de los escenarios tecnológicos propuestos permitiría alcanzar los objetivos de reducción para el 2050, cuando éstos se aplican a un alcance cuna-tumba. En alcances menores, el panorama no es mucho más alentador, pues se requiere la implementación simultánea de varias alternativas: cambios en el diseño del producto (en espesor y cantidad de esmalte) y la implementación de medidas de elevada eficiencia energética en hornos y secaderos híbridos o eléctricos, alimentados a partir de fuentes renovables. 
En las Tabla 5.8 y Tabla 5.9, se presentan los escenarios capaces de satisfacer los objetivos de la EU para el 2020 y para el 2050. En ambas tablas, se indica el alcance de aplicación. 

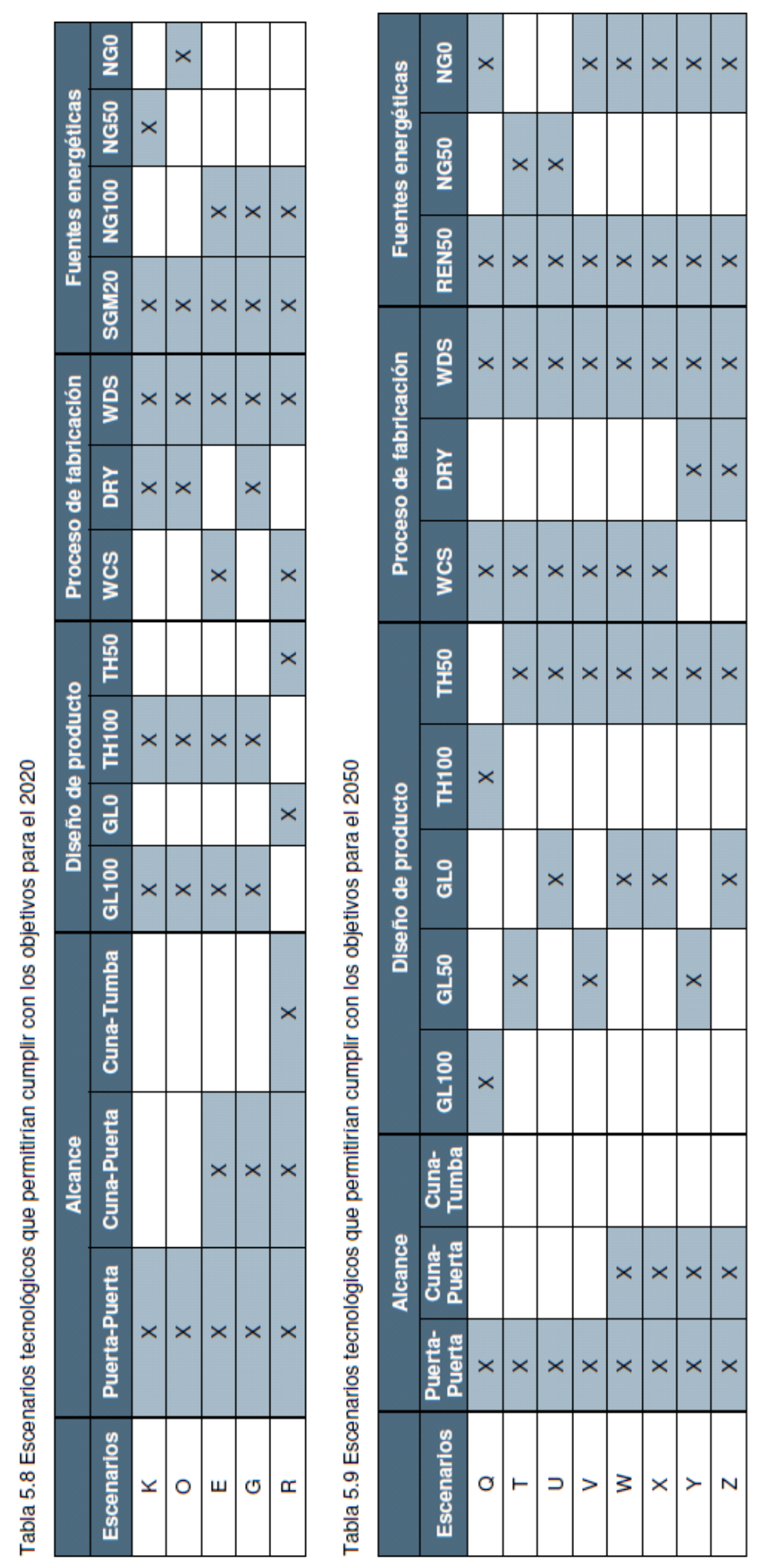

올 $\times x \times \times \times \times$

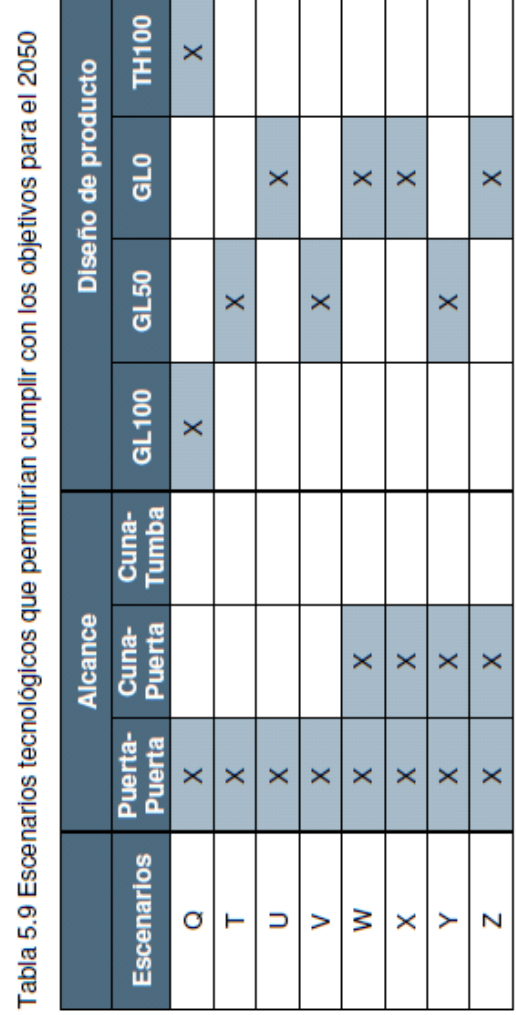




\subsubsection{Competitividad en una economía hipocarbónica (RETO $2 \leftrightarrow$ RETO 3)}

Con el objetivo de conocer el posicionamiento de las baldosas frente a materiales competidores en una economía hipocarbónica, se han aplicado los objetivos de reducción de la EU para el 2050 (Aportación $\mathbf{n}^{\circ} 5$ ) a los procesos asociados al ciclo de vida de los sistemas de suelos de distinta naturaleza estudiados en la Aportación $\mathbf{n}^{\mathbf{0}} \mathbf{3}$, y se han cuantificado las emisiones de $\mathrm{CO}_{2}$ equivalentes asociadas. Para ellos se han aplicado, de manera teórica, las reducciones expuestas en la Tabla 5.10 a través de un ACV atribucional.

Tabla 5.10 Aplicación de los objetivos hipocarbónicos en el estudio comparativo de sistemas de suelos

\begin{tabular}{|c|c|}
\hline Procesos & Objetivo de reducción ${ }^{*}$ \\
\hline Electricidad & $-93 \%$ \\
\hline Materias primas y productos industriales & $-83 \%$ \\
\hline Transporte terrestre & $-54 \%$ \\
\hline Transporte marítimo & $0 \%$ \\
\hline * Según COM(2011)112 final, 2011 & \\
\hline
\end{tabular}

En la Figura 5.5, se muestra la contribución al GWP de cada etapa del ciclo de vida de los distintos tipos de suelos instalados, en una zona de tránsito peatonal bajo (uso residencial), en un escenario tecnológico de España en 2019 (columna de la izquierda), y en un escenario tecnológico de España en 2050 (columna de la derecha), suponiendo que se alcanzan los objetivos previstos por la Unión Europea en todos los sectores expuestos en la Tabla 5.10.

Se observa que, en un escenario hipocarbónico y de economía circular, el sistema de suelos con laminados es el que genera menores contribuciones al GWP, y las baldosas de gres porcelánico se posicionan en segundo lugar.

Las ventajas ambientales del gres porcelánico, siguen derivándose de su fácil mantenimiento y su larga vida útil, aunque la etapa de producto, que incluye los procesos de extracción y transporte de las materias primas y fabricación, sigue siendo la etapa que mayor repercusión tiene sobre el cambio climático.

Cabe indicar que, estos resultados proceden de un ejercicio teórico, cuya finalidad es disponer de información para una posible previsión comercial, pudiendo considerarse, como factor motivante para la mejora. Queda fuera del alcance del estudio, conocer la capacidad de reducción de las emisiones en otros sectores y la viabilidad tecnológica y económica de las innovaciones necesarias para la consecución de dichos objetivos en todos los sectores estudiados. 
100

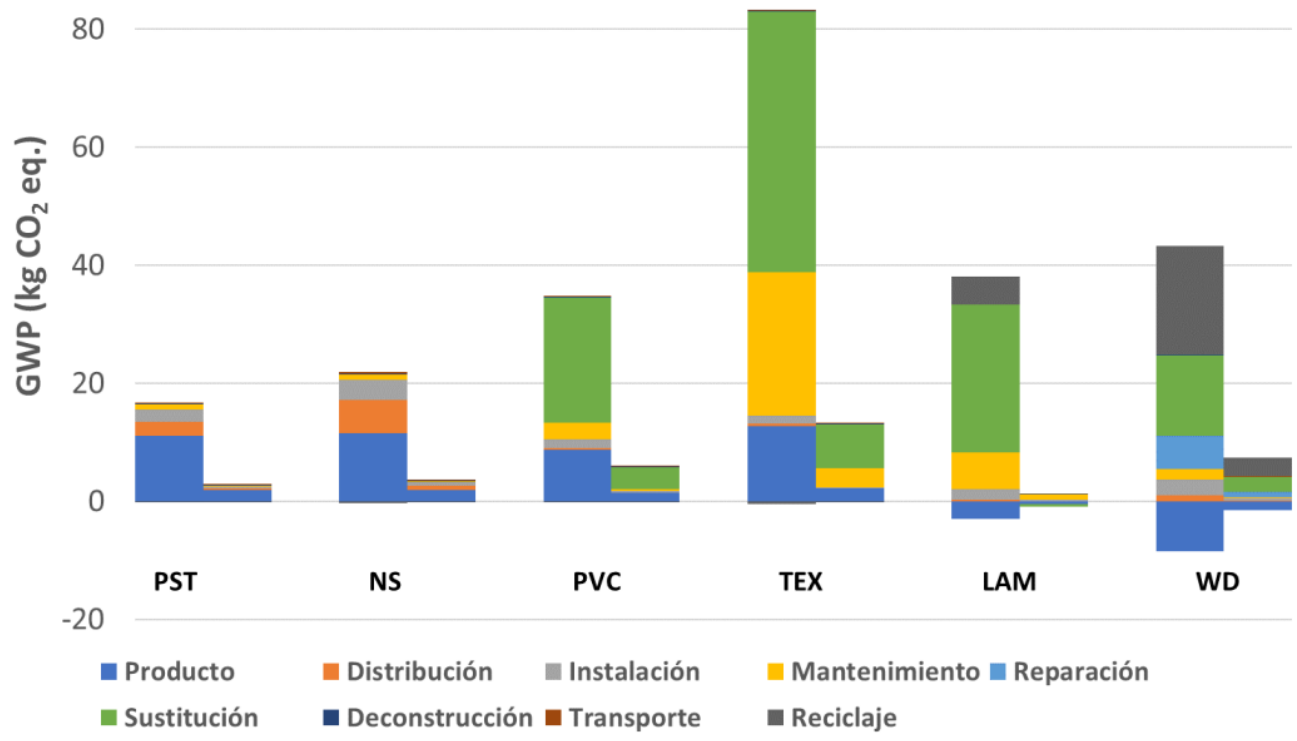

Figura 5.5 Contribución de las etapas del ciclo de vida de distintos sistemas de suelos en el escenario tecnológico actual y en un escenario tecnológico hipocarbónico (columna de la izquierda y derecha, respectivamente) instalados en una zona de tránsito peatonal bajo

\subsubsection{Herramientas (RETO $1 \leftrightarrow$ RETO $2 \leftrightarrow$ RETO 3)}

Las herramientas desarrolladas en el marco de esta tesis están diseñadas para ser aplicadas por y/o para las empresas del sector de las baldosas cerámicas. Cada herramienta está concebida para un propósito diferente, pero son complementarias a su vez. Para aportar una visión más general, en la Tabla 5.11, se muestran algunas aplicaciones comunes de las herramientas y cómo éstas intervienen en los retos abordados en la presente tesis. 
Tabla 5.11 Resumen de las aplicaciones de las herramientas

\begin{tabular}{|c|c|c|c|c|}
\hline \multirow{3}{*}{ APLICACIONES } & \multicolumn{2}{|c|}{ RETO 1} & RETO 2 & RETO 3 \\
\hline & \multicolumn{2}{|c|}{ Aportación n² } & Aportación nº & Aportación nº 6 \\
\hline & DAPCER & $\begin{array}{l}\text { CoverLEED y } \\
\text { CoverBREEAM }\end{array}$ & SolconCer & $\mathrm{CerCO}_{2}$ \\
\hline Mejora de producto & $\begin{array}{l}\text { Permite identificar } \\
\text { puntos críticos y } \\
\text { evaluar } \\
\text { potenciales de } \\
\text { mejora }\end{array}$ & $\begin{array}{l}\text { Puede inspirar } \\
\text { mejoras en el } \\
\text { producto }\end{array}$ & & $\begin{array}{l}\text { Diseñada para } \\
\text { simular } \\
\text { reducciones de } \\
\text { las emisiones de } \\
\mathrm{CO}_{2} \text { eq. }\end{array}$ \\
\hline $\begin{array}{l}\text { Comunicación } \\
\text { ambiental }\end{array}$ & $\begin{array}{c}\text { Concebida para el } \\
\text { desarrollo de } \\
\text { DAPs }\end{array}$ & $\begin{array}{c}\text { Ofrece } \\
\text { información } \\
\text { ambiental del } \\
\text { producto para su } \\
\text { difusión }\end{array}$ & $\begin{array}{l}\text { Proporciona } \\
\text { información } \\
\text { ambiental } \\
\text { interesante para } \\
\text { la promoción }\end{array}$ & $\begin{array}{c}\text { Aporta } \\
\text { información que } \\
\text { puede ser } \\
\text { comunicada al } \\
\text { consumidor }\end{array}$ \\
\hline $\begin{array}{l}\text { Construcción } \\
\text { sostenible }\end{array}$ & $\begin{array}{c}\text { Aporta } \\
\text { información } \\
\text { valorada en } \\
\text { certificados de } \\
\text { construcción } \\
\text { sostenible }\end{array}$ & $\begin{array}{l}\text { Orientada a } \\
\text { certificados de } \\
\text { construcción } \\
\text { sostenible }\end{array}$ & $\begin{array}{l}\text { Concebida para la } \\
\text { elección de } \\
\text { soluciones } \\
\text { constructivas más } \\
\text { sostenibles }\end{array}$ & \\
\hline Compra Verde & $\begin{array}{c}\text { Procura } \\
\text { información } \\
\text { solicitada en } \\
\text { licitaciones }\end{array}$ & $\begin{array}{c}\text { Procura } \\
\text { información } \\
\text { solicitada en } \\
\text { licitaciones }\end{array}$ & $\begin{array}{l}\text { Herramienta útil } \\
\text { para la toma de } \\
\text { decisiones }\end{array}$ & \\
\hline Vigilancia legislativa & $\begin{array}{c}\text { Proporciona } \\
\text { información útil } \\
\text { para el } \\
\text { posicionamiento } \\
\text { del sector ante } \\
\text { legislación } \\
\text { emergente }\end{array}$ & & & $\begin{array}{l}\text { Proporciona } \\
\text { información útil } \\
\text { para estudiar la } \\
\text { viabilidad de } \\
\text { legislación } \\
\text { emergente }\end{array}$ \\
\hline
\end{tabular}



6. CONCLUSIONES 



\section{CONCLUSIONES}

El principal objetivo de la presente tesis doctoral es determinar y evaluar, mediante análisis de ciclo de vida, diferentes estrategias y herramientas para afrontar los tres retos identificados para el sector de las baldosas cerámicas: comunicar de forma eficiente las características ambientales de las baldosas, obtener argumentos ambientales para aumentar su competitividad, y establecer medidas para mitigar su contribución y adaptarse al cambio climático.

Si bien es cierto que las conclusiones derivadas del análisis de cada estrategia y herramienta se presentan en cada una de las publicaciones incluidas en esta tesis, en el presente capítulo, se sintetizan las conclusiones generales, así como las alcanzadas en relación a cada uno de los retos identificados.

\section{En relación a la metodología}

- Se ha observado que la metodología de ACV es un instrumento adecuado para establecer y evaluar las estrategias planteadas para abordar los retos a los que el sector cerámico se enfrenta a corto, medio, y largo plazo. La perspectiva del ciclo de vida y la consideración de todas las etapas es esencial para obtener una visión holística e integradora de las estrategias ante los diferentes retos planteados.

- En este trabajo cabe destacar que, la elaboración del ACV de las baldosas de gres porcelánico se ha llevado a cabo a partir de datos directamente facilitados por empresas del sector cerámico, que han sido verificados por una tercera parte independiente. Como consecuencia, se han obtenido unos valores válidos, actualizados y representativos de todo el ciclo de vida de las baldosas.

- La elevada parametrización del modelo de ACV en el software GaBi ha otorgado la suficiente flexibilidad para realizar, con relativa simplicidad, los diferentes escenarios de forma objetiva y totalmente consistente a lo largo de todo el proceso de investigación de la tesis.

- La aplicación de la metodología ACV y la interpretación de los resultados requiere un elevado grado de especialización, por lo que es importante dotar a las empresas del sector cerámico de herramientas pragmáticas, de relativo fácil uso y acceso para posicionarse y autoevaluarse frente a los diferentes retos expuestos. Por ello, para cada uno de los retos ambientales abordados en esta tesis, se ha desarrollado una herramienta específica, siempre basada en la aplicación de la metodología de ACV.

\section{En relación a la evaluación del escenario de referencia y a los parámetros clave}

- Se ha confirmado que es fundamental elaborar un ACV de un escenario de referencia para identificar y cuantificar los parámetros clave para definir, y evaluar cada una de las estrategias y herramientas orientadas a afrontar los retos identificados.

- La aplicación de la metodología propuesta ha permitido concluir que la etapa de fabricación de las baldosas es la que contiene mayor número de parámetros clave. 
Concretamente, el consumo de gas natural (ADPF y GWP); la cantidad y tipo de esmalte (ADPE, EP, AP y POCP) y la cantidad de materias primas del soporte (todas las categorías excepto ADPE). En este sentido, cabe destacar que, aunque la instalación de sistemas de cogeneración industrial se realiza basándose puramente en criterios económicos, el estudio realizado demuestra que el volcado a la red de la electricidad cogenerada evita impactos significativos en la red eléctrica española, especialmente en las categorías de impacto ADPE, AP, POCP y GWP, por lo que la promoción de estos sistemas tiene una innegable componente ambiental, que no se debería minusvalorar al definir la política energética nacional.

\section{En relación al reto de comunicación ambiental eficiente}

- Ha sido posible identificar y evaluar 15 variantes de gres porcelánico, así como las diferencias existentes entre las mismas, a partir de la cuantificación de la significancia ambiental de los parámetros clave de diseño asociados al espesor del soporte cerámico, a la cantidad de esmalte y a los tratamientos mecánicos superficiales

- La metodología aplicada ha permitido discernir las diferencias de impacto ambiental entre las variantes de producto fabricadas por un productor, así como estimar el número de DAPs necesarias para cubrir, con rigor, toda la gama de variantes de un mismo tipo de producto, dependiendo del programa de DAPs aplicado.

- El desarrollo de la herramienta DAPCER ha permitido que se puedan obtener, de una manera sencilla y eficiente, informes de ACV y DAP para recubrimientos cerámicos, disminuyendo plazos de ejecución y costes económicos. Su validez ha sido comprobada mediante la ejecución de 32 DAPs de recubrimientos cerámicos para 4 programas europeos durante el periodo 2014-2019.

- El desarrollo de herramientas adicionales, CoverLEED y CoverBREEAM by ITC, ha permitido elaborar, de manera muy sistematizada, la documentación necesaria para demostrar la contribución de las baldosas cerámicas en edificios sostenibles certificados bajo los sistemas LEED $^{\circledR}$ y BREEAM ${ }^{\circledast}$. Se ha demostrado su aplicabilidad en 6 empresas del sector.

- La metodología empleada en el desarrollo de estas herramientas podrían ser extrapolable a otros sectores industriales, siendo este proceso más sencillo, cuando se trata de sectores homogéneos y maduros, desde el punto de vista tecnológico.

\section{En relación al reto de competitividad ambiental}

- Se ha confirmado que el método aplicado en la comparativa de sistemas de suelos (o soluciones constructivas) empleando DAPs como fuente de información de la etapa de producto, es adecuada, puesto que son documentos actualizados ( $<5$ años), industriales y verificados. Sin embargo, requieren de una previa selección y análisis para asegurar la suficiente coherencia para su ulterior comparabilidad, según requerimientos de las normas ISO 14025, 2006 y EN 15804+A1, 2013. 
- No obstante, se ha observado que los análisis comparativos partiendo de DAPs deben realizarse por especialistas en la materia. Para poder generalizar su uso, se recomienda a los administradores de programas llevar a cabo labores de armonización en lo que respecta a los procedimientos de gestión (métodos de verificación, normas específicas de asignación de cargas y criterios para obtener la información proporcionada por las DAPs). Dos puntos que se han identificado como especialmente críticos en el uso de DAPS para la misma funcionalidad son, por una parte la importancia de considerar todas las etapas del ciclo de vida, y por lo otra, la conveniencia de establecer escenarios por defecto en las etapas del ciclo de vida más allá de la puerta de fábrica.

- Los resultados obtenidos mediante la metodología aplicada permiten concluir que, los sistemas de suelos con recubrimientos inorgánicos (gres porcelánico y piedra natural) son los que presentan mejor desempeño ambiental en casi todas las categorías de impactos ambiental estudiadas; pues aunque los impactos son elevados durante la etapa de fabricación, se compensan con la elevada vida útil y fácil mantenimiento. Por contra, los sistemas de suelos con moqueta sintética son los que presentan los impactos más elevados, no sólo por su impacto en la fabricación, sino también por la corta vida útil y elevados impactos en la fase de mantenimiento (limpieza).

- Para facilitar la caracterización de soluciones constructivas por usuarios no expertos, se ha desarrollado la herramienta SolconCer. La evaluación de los impactos ambientales se han estructurado según las diferentes etapas del ciclo de vida, con alcance cuna a tumba y tomando DAPs como fuente principal de información ambiental de los materiales de construcción, y modelizando el resto de las etapas, en un entorno común del edificio. La herramienta otorga un elevado grado de libertad para definir ciertos escenarios (elementos de las soluciones constructivas, distancias de transportes y escenarios de uso) y ofreciendo valores por defecto, en caso de no disponer de datos reales. Los resultados ambientales facilitados por SolconCer muestran la contribución a 6 categorías de impacto ambiental de todo el ciclo de vida de los recubrimientos y de todo el sistema constructivo. Asimismo, los resultados se han normalizado y escalado de 0-10 con objeto de proporcionar una lectura simplificada de los mismos.

\section{En relación al reto de cambio climático}

- Los resultados muestran que, a mayor alcance considerado, mayores innovaciones se requieren para reducir las emisiones de GEl del sector. Estas innovaciones deben contemplar la implementación conjunta de medidas de vanguardia endógenas y exógenas al sector cerámico.

- Se ha demostrado, mediante un enfoque atribucional, que para alcanzar los objetivos de la EU en 2050 se requerirán cambios en el diseño del producto (reducción a la mitad del espesor, de la cantidad de esmalte y/o del contenido en frita), así como la implantación de tecnologías de elevada eficiencia energética en secaderos y hornos que funcionen, al menos, con la mitad de la energía procedente de fuentes renovables. 
- Se ha desarrollado la herramienta $\mathrm{CerCO}_{2}$, para realizar ejercicios de prospección por agentes no expertos para evaluar, de forma rápida y eficiente, diferentes escenarios tecnológicos, específicos del sector de las baldosas cerámicas, a partir de la situación actual. Los resultados obtenidos pueden servir de apoyo en la toma de decisiones a la hora de invertir y adaptarse a un escenario de economía baja en carbono, cumpliendo al mismo tiempo, los objetivos marcados por la Unión Europea en materia de cambio climático. 
7. LÍNEAS FUTURAS DE INVESTIGACIÓN 



\section{LÍNEAS FUTURAS DE INVESTIGACIÓN}

A partir de los resultados obtenidos en la presente tesis, se han planteado una serie de recomendaciones para futuras líneas de investigación que complementarían dichos resultados, y ampliarían el alcance de las estrategias del ciclo de vida desarrolladas para cada reto. A modo de ejemplo, se pueden destacar las siguientes:

\section{RETO 1. COMUNICACIÓN AMBIENTAL EFICIENTE}

Actualmente, los azulejos (baldosas del grupo BIII) y las baldosas de gres esmaltado (grupo Blb, Blla, Bllb) son los tipos de baldosas más representativos, en cuanto a producción, del sector cerámico español.

Por lo tanto, en un futuro, se propone realizar un estudio de evaluación ambiental de estos tipos de baldosas y de sus variantes para confirmar que, los parámetros clave y el método seguido para determinar la significancia ambiental de las variantes, para realizar una comunicación ambiental eficiente, son igualmente válidos.

\section{RETO 2. COMPETITIVIDAD AMBIENTAL}

La pavimentación de suelos y el revestimiento de paredes de estancias húmedas son las aplicaciones más comunes de las baldosas cerámicas, no obstante, gracias a la innovación en diseño y a los avances tecnológicos, se ha conseguido extender el uso, sobretodo del gres porcelánico, en muy diversas soluciones arquitectónicas como en fachadas, techos, o como pavimentos urbanos, entre otras.

Por ello, como futuras líneas, se propone la ampliación de este estudio para otras soluciones constructivas y con otros tipos de baldosas cerámicas: particiones verticales, tanto húmedas como secas, pavimentación de zonas urbanas, fachadas, nueva construcción, rehabilitación, etc.

Asimismo, se pueden considerar otros tipos de impactos y aspectos ambientales de carácter local o regional como por ejemplo, relacionados con el uso del suelo, toxicidad, estrés hídrico, potencial de circularidad, emisiones de compuestos orgánicos volátiles, de nanopartículas, etc. Así como, tener en cuenta otro tipo de características y prestaciones asociadas a la unidad funcional como: el confort, la higiene, la resistencia a hongos y bacterias, la versatilidad estética, etc.

\section{RETO 3. MITIGACIÓN DEL CAMBIO CLIMÁTICO}

Las alternativas planteadas para combatir este reto se han definido en base a los parámetros clave identificados en el estudio del escenario de referencia del gres porcelánico, y se han evaluado desde un punto de vista teórico.

Por lo tanto, se considera de sumo interés evaluar la viabilidad técnica y económica de las alternativas tecnológicas analizadas, así como definir alternativas tecnológicas para otros tipos de baldosas cerámicas, como por ejemplo: la sustitución de las materias primas que emiten 
$\mathrm{CO}_{2}$ en su descomposición $\left(\mathrm{CaCO}_{3}\right)$ por otras, como la wollastonita $\left(\mathrm{CaSIO}_{3}\right)$; el secado por microondas; la mejora del proceso de molturación de las materias primas por vía seca.

Por otro lado, se consdera necesaria la aplicación de una metodología de ACV consecuencial para determinar el grado de innovación requerido para cumplir los objetivos de reducción de $\mathrm{CO}_{2}$ de la Unión Europea desde un punto de vista sectorial.

\section{NUEVOS RETOS}

La aplicación de la metodología de ACV en el sector cerámico también ofrecería resultados interesantes en el estudio de estrategias relacionadas con otros retos. Sin pretender realizar una relación exhaustiva, y con la limitación obvia de que pueden existir solapamientos, a continaucón se muestras algunos de los posibles retos a abordar:

- Economía Circular, tanto en el diseño y desarrollo del producto como en los modelos de negocio.

- Estrés hídrico, desarrollar nuevos procesos y/o tecnologías que permitan un mínimo consumo de agua en todo el ciclo de vida.

- Minimizar la toxicidad, tanto en humanos como en ecosistemas.

- Nuevos procesos de fabricación con mínimo consumo de energía.

- Nuevas funcionalidades. 



\section{DIFUSIÓN DE LOS RESULTADOS}

Dado el carácter aplicado del trabajo realizado, adicionalmente a las publicaciones citadas en el capítulo 4, se ha llevado a cabo la difusión de los resultados obtenidos mediante la participación de congresos nacionales e internacionales específicos del sector. A continuación, se citan cada una de estas contribuciones:

Monfort E., Mezquita A., Vaquer E., Ferrer S., Ros-Dosda T. European ceramic industry towards and hypocarbonic economy. European Ceramic Society, Ecole Nationale Supérieure de Céramique Industrielle (ENSCI). 19-22 July 2013. Limoges (France).

Monfort E., Ros-Dosda T., Ferrer S. Life cycle assessment of ceramic products. Cp38.- Summer School "Ceramic Science and Technology for the 21th Century: Basic Principles and Modern Trends. European Ceramic Society, Ecole Nationale Supérieure de Céramique Industrielle (ENSCI). 19-22 July 2013. Limoges (France).

Ros-Dosda T., Monferrer A., Celades I., Monfort E. Estimation of Water Footprint of Porcelain Tile. LIII Congress of Spanish Society of ceramics and glass and XII congress of Ceramic Technicians Association, 24-25 October 2013, Alcora, Spain.

Ros T., Celades I., Alberola J. A., Moliner R. CERCO2: CO2 emission simulation tool for the ceramic industry. XV Global Forum of Ceramic Tile. QUALICER Castellón 12-13 February, 2018. Chamber of Commerce, Services, Navigation and Industry of Castelló, Spain. 



\section{REFERENCIAS}





\section{REFERENCIAS}

Abeysundara, U.G.Y., Babel, S., Piantanakulchai, M., 2009. A matrix for selecting sustainable floor coverings for buildings in Sri Lanka. J. Clean. Prod. 17, 231-238. https://doi.org/https://doi.org/10.1016/j.jclepro.2008.05.002

ACV-Tile, 2008. Análisis de Ciclo de Vida a nivel sectorial y Benchmarking Ambiental y Energético. Instituto de Tecnología Cerámica y Cátedra UNESCO del Ciclo de Vida y Cambio Climático para ASCER, mediante el apoyo financiero del IMPIVA (Instituto de la Mediana y Pequeña Industria Valenciana de la Generalitat Valenciana) y los Fondos FEDER. Castellón, España.

AENOR, GlobalEPD [www $\quad$ Document]. URL https://www.aenor.es/aenor/certificacion/mambiente/globalepd.asp\#.V8awe1uLRdi (accessed 12.23.18).

Albertí, J., Balaguera, A., Brodhag, C., Fullana-i-Palmer, P., 2017. Towards life cycle sustainability assessment of cities. A review of background knowledge. Sci. Total Environ. 609, 1049-1063. https://doi.org/https://doi.org/10.1016/j.scitotenv.2017.07.179

Albertí, J., Civancik-Uslu, D., Contessotto, D., Balaguera, A., Fullana-i-Palmer, P., 2019. Does a life cycle assessment remain valid after 20 years? Scenario analysis with a bus stop study. Resour. Conserv. Recycl. 144, 169-179. https://doi.org/https://doi.org/10.1016/j.resconrec.2019.01.041

Almeida, M.A., Demertzi, M., Dias, A.C., Arroja, L., 2013. Environmental product declaration: for ceramic tile. Energy Sustain. Coimbra.

Almeida, M.I., Dias, A.C., Demertzi, M., Arroja, L., 2016. Environmental profile of ceramic tiles and their potential for improvement. J. Clean. Prod. 131, 583-593. https://doi.org/10.1016/j.jclepro.2016.04.131

ANFFECC, 2019. Consulta personal, el 04.03.2019. Castellón, España

ANSI A138.1, 2012. Green Squared American National Standard Specifications For Sustainable Ceramic Tiles, Glass Tiles, And Tile Installation Materials. American National Standards Institute.

Arnedillo, Ó., 2007. Modelos de mercado eléctrico: paradigma competitivo y alternativas de diseño. Econ. Ind. 39-54.

ASCER, 2019. El sector de la fabricación de baldosas cerámicas. Visión general del sector español y datos de importación. Informe interno. Castellón, Spain.

ASCER, 2015. El sector en datos [www Document]. URL http://www.ascer.es/homeinstitucional/sectorDatos.aspx?lang=es-ES (accessed 12.9.15).

ASCER, 2011. Gúa de la baldosa cerémica: el vademecum de la baldosa cer乏́mica, para su clasificacif́n, su seleccif́n, materiales de agarre y rejuntado, la redaccif́n del proyecto, el control de la obra, 6 th ed. Generalitat Valenciana, Castellón, España. 
Asif, M., Muneer, T., Kelley, R., 2007. Life cycle assessment: A case study of a dwelling home in $\begin{array}{llll}\text { Scotland. Build. } & \text { Environ. } & \text { 1391-1394. }\end{array}$ https://doi.org/https://doi.org/10.1016/j.buildenv.2005.11.023

Assiego de Larriva, R., Calleja Rodríguez, G., Cejudo López, J.M., Raugei, M., Fullana i Palmer, P., 2014. A decision-making LCA for energy refurbishment of buildings: Conditions of comfort. Energy Build. 70, 333-342. https://doi.org/10.1016/J.ENBUILD.2013.11.049

Augustin, R., Bohnhoff, A., Finetti, C., Klingenberger, H., Vankann, E., 1997. Comparative life cycle analysis of textile floorcoverings from environmental conservation and consumer protections aspects. Melliand Textilberichte Int. Text. REPORTS 78, 526-527.

Balaguera, A., Carvajal, G.I., Albertí, J., Fullana-i-Palmer, P., 2018. Life cycle assessment of road construction alternative materials: A literature review. Resour. Conserv. Recycl. 132, 37-48. https://doi.org/https://doi.org/10.1016/j.resconrec.2018.01.003

Baldo, G.L., Rollino, S., Stimmeder, G., Fieschi, M., 2002. The use of LCA to develop eco-label criteria for hard floor coverings on behalf of the European flower. Int. J. Life Cycle Assess. 7, 269275. https://doi.org/https://doi.org/10.1007/BF02978886

Banerjee, S.B., 2017. Corporate environmentalism and the greening of strategic marketing: Implications for marketing theory and practice, in: Greener Marketing. Routledge, pp. 16-40.

Baraldi, L., 2017. World production and consumption of ceramic tiles. Ceram. world Rev. 123, 5870.

Baraldi, L., 2018. World production and consumption of ceramic tiles. Ceram. world Rev. 128, 5872.

Basbagill, J., Flager, F., Lepech, M., Fischer, M., 2013. Application of life-cycle assessment to early stage building design for reduced embodied environmental impacts. Build. Environ. 60, 81-92. https://doi.org/https://doi.org/10.1016/j.buildenv.2012.11.009

Baumann, H., Tillman, A.-M., 2004. The hitch hiker's guide to LCA, 1:3. ed. Lund, Sweden.

Belussi, L., Mariotto, M., Meroni, I., Zevi, C., Svaldi, S.D., 2015. LCA study and testing of a photovoltaic ceramic tile prototype. Renew. Energy 74, 263-270. https://doi.org/10.1016/j.renene.2014.07.053

BenchTile, 2017. Benchmarking Sectorial-Elaboración de un Benchmarking ambiental y energético para la elaboración de una Declaración Ambiental de Producto sectorial. Instituto de Tecnología Cerámica para ASCER, Castellón, España.

Benveniste, G., Gazulla, C., Fullana, P., Celades, I., Ros, T., Moliner, R., Zaera, V., Godes, B., 2010. Sectoral Life cycle assessment of ceramic tile, in: XI Global Forum of Ceramic Tile. Castellón, Spain. 
Benveniste, G., Gazulla, C., Fullana, P., Celades, I., Ros, T., Zaera, V., Godes, B., 2011. Life cycle assessment and product category rules for the construction sector. The floor and wall tiles sector case study. Inf. la Construcción 63, 71-81. https://doi.org/10.3989/ic.10.034

Blasco, A., Escardino, A., Busani, G., Monfort, E., Amorós, J.L., Enrique, J., Beltrán, V., Negre, P., 1992. Tratamiento de emisiones gaseosas, efluentes líquidos y residuos sólidos de la industria cerámica, Castellón: Instituto de Tecnología Cerámica-Asociación de Investigación de las Industrias Cerámicas.

Bou, E., 2006. Alternativas al uso del circón como materia prima para preparar recubrimientos vidriados opacos, con el fin de reducir su consumo. Tesis doctoral, Escuela Superior de Tecnología y Ciencias Experimentales. Departamento de Ingeniería Química. Universitat Jaume I de Castellón, España.

Bovea, M.D., Díaz-Albo, E., Gallardo, A., Colomer, F.J., Serrano, J., 2010. Environmental performance of ceramic tiles: Improvement proposals. Mater. Des. 31, 35-41. https://doi.org/10.1016/j.matdes.2009.07.021

Bovea, M.D., Saura, Ú., Ferrero, J.L., Giner, J., 2007. Cradle-to-gate study of red clay for use in the ceramic industry. Int. J. Life Cycle Assess. 12, 439. https://doi.org/https://doi.org/10.1065/lca2006.06.252

Bratt, C., Hallstedt, S., Robèrt, K.-H., Broman, G., Oldmark, J., 2013. Assessment of criteria development for public procurement from a strategic sustainability perspective. J. Clean. Prod. 52, 309-316. https://doi.org/https://doi.org/10.1016/j.jclepro.2013.02.007

BREEAM, 2019. Building Research Establishment Environmental Assessment Methodology [www Document]. URL https://www.breeam.com/ (accessed 3.29.19).

BSI PAS 2050, 2011. Specification for the assessment of the life cycle greenhouse gas emissions of goods and services. UK.

Carlo Montani, 2018. XXVIII World Marble and Stones Report 2017. Aldus Casa di Edizioni, Carrara, Italy.

Celades, I., 2013. Caracterización física, química, mineralógica y morfológica del material particulado emitido por focos canalizados de la industria de baldosas y fritas cerámicas. Tesis doctoral, Escuela Superior de Tecnología y Ciencias Experimentales. Departamento de Ingeniería Química. Universitat Jaume I de Castellón, España.

Celades, I., Moliner-Salvador, R., Ros-Dosdá, T., Monfort, E., Zaera, V., 2012. Environmental development of the Spanish ceramic tile manufacturing sector over the period 1992-2007. Boletín la Soc. Española Cerámica y Vidr. 51, 111-118. https://doi.org/10.3989/cyv.162012

Cerame Unie, 2019. Statistics, figures and facts [www Document]. Facts Fig. URL http://cerameunie.eu/ceramic-industry/facts-figures/ (accessed 3.13.19). 
Cerame Unie, 2012. The Ceramic Industry Roadmap: paving the way to 2050. [www Document]. URL http://cerameunie.eu/topics/cerame-unie-sectors/cerame-unie/ceramic-industry-roadmappaving-the-way-to-2050/ (accessed 5.16.16).

Chang, D., Lee, C.K.M., Chen, C.-H., 2014. Review of life cycle assessment towards sustainable product development. J. Clean. Prod. 83, 48-60. https://doi.org/https://doi.org/10.1016/j.jclepro.2014.07.050

Chen, Y., Tang, G., Jin, J., Li, J., Paillé, P., 2015. Linking market orientation and environmental performance: The influence of environmental strategy, employee's environmental involvement, and environmental product quality. J. Bus. Ethics 127, 479-500. https://doi.org/https://doi.org/10.1007/s10551-014-2059-1

COM(2010)2020 final, 2010. Europe 2020: A strategy for smart, sustainable and inclusive growth.

$\operatorname{COM}(2010) 639$ final, 2010. Communication from the Commission to the European Parliament, the Council, the European Economic and Social Committee and the Committee of the Regions. Energy 2020 A strategy for competitive, sustainable and secure energy.

COM(2011)0571 final, 2011. Roadmap to a Resource Efficient Europe. Communication from the Commission to the European Parliament, the Council, the European Economic and Social Committee and the Committee of the Regions.

$\operatorname{COM}(2011) 112$ final, 2011. A Roadmap for moving to a competitive low carbon economy in 2050.

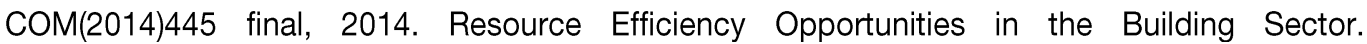
Communication from the Commission to the European Parliament, the Council, the European Economic and Social Committee and the Committee of the Regions.

COM(2015)0614 final, 2015. Closing the loop - An EU action plan for the Circular Economy. Communication from the Commission to the European Parliament, the Council, the European Economic and Social Committee and the Committee of the Regions.

Comisión Europea, n.d. Energía, Cambio Climático, Medio Ambiente [www Document]. URL https://ec.europa.eu/info/energy-climate-change-environment_es (accessed 6.4.19).

CYPE Ingenieros, S.A., 2018. Generador de precios de la construcción. España [WWW Document]. URL http://www.generadordeprecios.info/ (accessed 10.9.18).

da Silva, A.L., Bernardin, A.M., Hotza, D., 2014a. Forming of thin porcelain tiles: A comparison between tape casting and dry pressing. Ceram. Int. 40, 3761-3767. https://doi.org/http://dx.doi.org/10.1016/j.ceramint.2013.09.044

da Silva, A.L., Feltrin, J., Dal Bó, M., Bernardin, A.M., Hotza, D., 2014b. Effect of reduction of thickness on microstructure and properties of porcelain stoneware tiles. Ceram. Int. 40, 1469314699. https://doi.org/10.1016/j.ceramint.2014.05.150 
DAP sectorial, 2018. Elaboración de una DAP sectorial del proceso de fabricación de baldosas cerámicas. Instituto de Tecnología Cerámica para ASCER, a través del Programa de ayudas en materia de Industrialización para asociaciones de diferentes sectores de la Comunitat Valenciana; Plan estratégico de la industria valenciana. Ref. INENTI/2018/26, Castellón, España.

Darko, A., Chan, A.P.C., 2016. Critical analysis of green building research trend in construction journals. Habitat Int. 57, 53-63. https://doi.org/https://doi.org/10.1016/j.habitatint.2016.07.001

Decision 1600/2002/EC of the European Parliament and of the Council of 22 July 2002 laying down the Sixth Community Environment Action Programme. O.J. L 242, 10/09/2002 P. 0001-0015

Decision 2014/955/UE, 2014. Commission Decision, of 18 December 2014 amending Decision 2000/532/EC on the list of waste pursuant to Directive 2008/98/EC of the European Parliament and of the Council. O.J. L 370/44 30.12.2014.

Decision 2009/607/EC: Commission Decision of 9 July 2009 establishing the ecological criteria for the award of the Community eco-label to hard coverings. OJ L 208, 12.8.2009, p. 21-38

Decision 1386/2013/EU of the European Parliament and of the Council of 20 November 2013 on a General Union Environment Action Programme to 2020 'Living well, within the limits of our planet'. OJ L 354, 28.12.2013, p. 171-200

Directive 2009/28/EC of the European Parliament and of the Council of 23 April 2009 on the promotion of the use of energy from renewable sources and amending and subsequently repealing Directives 2001/77/EC and 2003/30/EC. OJ L 140, 5.6.2009, p. 16-62

Directive 2003/87/EC, n.d. of the European Parliament and of the Council of 13 October 2003 establishing a scheme for greenhouse gas emission allowance trading within the Community and amending Council Directive 96/61/EC. L 275/32, 25.10.2003.

Directive 2009/29/EC, n.d. of the European Parliament and of the Council of 23 April 2009 amending Directive 2003/87/EC so as to improve and extend the greenhouse gas emission allowance trading scheme of the Community. O.J. L 140/63, 05.06.2009.

Directive 2010/75/EU, 2010. of the European Parliament and of the Council of 24 November 2010 on industrial emissions (Integrated Pollution Prevention and Control). OJ L 334, 17.12.2010, p. 17119

Directive 2012/27/EU, n.d. of the European Parliament and of the Council of 25 October 2012 on energy efficiency, amending Directives 2009/125/EC and 2010/30/EU and repealing Directives 2004/8/EC and 2006/32/EC. OJ L 315, 14.11.2012, p. 1-56

Dodd, N., Cordella, M., Traverso, M., Donatello, S., 2017. Level (s)-A common EU framework of core sustainability indicators for office and residential buildings. Eur. Comm. Jt. Res. Cent. Dir. B, Growth Innov. Unit 5, 5-20. 
Eid, C., Codani, P., Perez, Y., Reneses, J., Hakvoort, R., 2016. Managing electric flexibility from Distributed Energy Resources: A review of incentives for market design. Renew. Sustain. Energy Rev. 64, 237-247.

EIPPCB, 2012. Integrated Pollution Prevention and Control. Reference Document on Best Available Techniques (BATs) in the Glass Manufacturing Industry. European Commission, Directorate-General JRC, Joint Research Centre. Institute for Prospective Technological Studies (Sevilla). Technologies for Sustainable Development. European IPPC Bureau. 2012.

EIPPCB, 2007a. Integrated Pollution Prevention and Control (IPPC). Reference Document on Best Available Techniques (BATs) in the Ceramic Manufacturing Industry. European Commission, Directorate-General JRC, Joint Research Centre. Institute for Prospective Technological Studies (Sevilla). Technologies for Sustainable Development. European IPPC Bureau.

EIPPCB, 2007b. Integrated Pollution Prevention and Control. Reference Document on Best Available Techniques (BATs) in Production of Speciality Inorganic Chemicals. European Commission, Directorate-General JRC, Joint Research Centre. Institute for Prospective Technological Studies (Sevilla). Technologies for Sustainable Development. European IPPC Bureau.

EIPPCB, 2006. Integrated Pollution Prevention and Control. Reference Document on Best Available Techniques (BATs) in Emissions from Storage. European Commission, DirectorateGeneral JRC, Joint Research Centre. Institute for Prospective Technological Studies (Sevilla). Technologies for Sustainable Development. European IPPC Bureau.

Ekvall, T., Tillman, A.-M., 1997. Open-loop recycling: criteria for allocation procedures. Int. J. life cycle Assess. 2, 155.

EN 14411, 2016. Ceramic tiles. Definitions, classification, characteristics, evaluation of conformity and marking. CEN, European Committee for Standardization. Brussels, Belgium.

EN 15804+A1, 2013. Sustainability of construction works - Environmental product declarations Core rules for the product category of construction products. CEN, European Committee for Standardization. Brussels, Belgium.

EN 15978, 2011. Sustainability of construction works - Assessment of environmental performance of buildings - Calculation method. CEN, European Committee for Standardization. Brussels, Belgium.

EPDItaly program, n.d. No Title [www Document]. URL https://www.epditaly.it/ (accessed 4.6.19).

European Carpet and Rug Association (ECRA), 2018. The European Carpet Market [www Document]. URL http://www.ecra.eu/ (accessed 7.23.18).

European Commission, 2019. EU Ecolabel [www Document]. Eur. Comm. URL http://ec.europa.eu/environment/ecolabel/ (accessed 4.6.19). 
European Federation of the Parquet Industry (FEP), 2017. The European Parquet Industries in 2016 [www Document]. URL http://www.parquet.net/files/2017_-_FEP_-_Market_-_June_PR.pdf (accessed 7.25.18).

European Producers of Laminate Flooring (EPLF), 2018. Market Statistics [www Document]. URL https://www.eplf.com/sites/default/files/downloads/elnd1802_b1-7_eplf_sales2017_press.pdf (accessed 7.25.18).

Fazeni, K., Lindorfer, J., Prammer, H., 2014. Methodological advancements in life cycle process design: a preliminary outlook. Resour. Conserv. Recycl. 92, 66-77. https://doi.org/https://doi.org/10.1016/j.resconrec.2014.08.011

Ferrer, S., 2016. Análisis energético y exergético del proceso de cocción de composiciones cerámicas. Tesis doctoral, Escuela Superior de Tecnología y Ciencias Experimentales. Departamento de Ingeniería Química. Universitat Jaume I de Castellón.

Floor covering weekly, 2018. Statistical Report 2017. Floor Cover. Wkly. 67.

Frischknecht, R., Althaus, H.-J., Bauer, C., Doka, G., Heck, T., Jungbluth, N., Kellenberger, D., Nemecek, T., 2007. The Environmental Relevance of Capital Goods in Life Cycle Assessments of Products and Services [www Document]. Int J LCA (Online First). https://doi.org/http://dx.doi.org/10.1065/lca2007.02.308

Fullana-i-Palmer, P., Puig, R., 1997. Análisis del ciclo de vida, 10 edición. ed. Rubes Editorial, Barcelona.

Gabaldón-Estevan, D., Criado, E., Monfort, E., 2014. The green factor in European manufacturing: a case study of the Spanish ceramic tile industry. J. Clean. Prod. 70, 242-250. https://doi.org/10.1016/j.jclepro.2014.02.018

Gabaldón-Estevan, D., Mezquita, A., Ferrer, S., Monfort, E., 2016. Unwanted effects of European Union environmental policy to promote a post-carbon industry. The case of energy in the European ceramic tile sector. J. Clean. Prod. 117, 41-49. https://doi.org/10.1016/j.jclepro.2016.01.021

Gabaldón Estevan, D., Hekkert, M.P., 2013. How Does the Innovation System in the Spanish Ceramic Tile Sector Function? Bol. la Soc. Española Ceram. y Vidr. 151-158. https://doi.org/10.3989/cyv.202013

Ganassali, S., Lavagna, M., Campioli, A., Saporetti, S., 2018. Green Public Procurement and Construction Sector: EPD and LCA based benchmarks of the whole-building, in: Designing Sustainable Technologies, Products and Policies. Springer, pp. 503-513. https://doi.org/https://doi.org/10.1007/978-3-319-66981-6_5

Gazi, A., Skevis, G., Founti, M.A., 2012. Energy efficiency and environmental assessment of a typical marble quarry and processing plant. J. Clean. Prod. 32, 10-21. https://doi.org/https://doi.org/10.1016/j.jclepro.2012.03.007 
Gazulla, C., 2012. Declaraciones ambientales de producto instrumento para la mejora de productos. Tesis doctiora, Cátedra UNESCO del Ciclo de Vida y Cambio Climático ESCI-UPF e Instituto de Ciencia y Tecnología Ambiental de la Universidad Autónoma de Barcelona.

GBCe, 2019. Green Building Council España. VERDE [www Document]. URL https://gbce.es/certificacion-verde/ (accessed 3.29.19).

Geissdoerfer, M., Savaget, P., Bocken, N.M.P., Hultink, E.J., 2017. The Circular Economy-A new sustainability paradigm? J. Clean. Prod. 143, 757-768.

Gelowitz, M.D.C., McArthur, J.J., 2017. Comparison of type III environmental product declarations for construction products: Material sourcing and harmonization evaluation. J. Clean. Prod. 157, 125-133. https://doi.org/https://doi.org/10.1016/j.jclepro.2017.04.133

GlobalEPD, 2018. RCP 002, v2. Regla de Categoría de Producto de Recubrimientos cerámicos. Madrid.

Gomar, S., 2016. Emisión de compuestos de flúor durante la cocción de baldosas cerámicas. Gomar, S., 2016. Emisión de compuestos de flúor durante la cocción de baldosas cerámicas. Tesis doctoral, Escuela Superior de Tecnología y Ciencias Experimentales. Departamento de Ingeniería Química. Universitat Jaume I de Castellón, España.

Gorrée, M., Guinée, J.B., Huppes, G., Van Oers, L., 2002. Environmental life cycle assessment of linoleum. Int. J. Life Cycle Assess. 7, 158-166. https://doi.org/https://doi.org/10.1007/BF02994050

Griese, B., 2012. Tile's Role in the Green Building Industry, in: XII World Congress on Ceramic Tile Quality-Qualicer. Castelló, Spain, p. 16.

Guinée, J.B.; Gorrée, M.; Heijungs, R.; Huppes, G.; Kleijn, R.; Koning, A. de; Oers, L. van; Wegener Sleeswijk, A.; Suh, S.; Udo de Haes, H.A.; Bruijn, H. de; Duin, R. van; Huijbregts, M.A.J., 2002. Handbook on life cycle assessment. Operational guide to the ISO standards. I: LCA in perspective. Ila: Guide. Ilb: Operational annex. III: Scientific background. Kluwer Academic Publishers, Dordrecht.

Günther, A., Langowski, H.-C., 1997. Life cycle assessment study on resilient floor coverings. Int. J. Life Cycle Assess. 2, 73-80. https://doi.org/https://doi.org/10.1007/BF02978763

Häfliger, I.F., John, V., Passer, A., Lasvaux, S., Hoxha, E., Saade, M.R.M., Habert, G., 2017. Buildings environmental impacts' sensitivity related to LCA modelling choices of construction materials. J. Clean. Prod. 156, 805-816. https://doi.org/10.1016/j.jclepro.2017.04.052

Han, B., Wang, R., Yao, L., Liu, H., Wang, Z., 2015. Life cycle assessment of ceramic façade material and its comparative analysis with three other common façade materials. J. Clean. Prod. 99, 86-93. https://doi.org/10.1016/j.jclepro.2015.03.032 
Hesser, F., Wohner, B., Meints, T., Stern, T., Windsperger, A., 2017. Integration of LCA in R\&D by applying the concept of payback period: case study of a modified multilayer wood parquet. Int. J. Life Cycle Assess. 22, 307-316. https://doi.org/https://doi.org/10.1007/s11367-016-1173-y

Ibáñez-Forés, V., Bovea, M.-D., Simó, A., 2011. Life cycle assessment of ceramic tiles. Environmental and statistical analysis. Int. J. Life Cycle Assess. 16, 916-928. https://doi.org/10.1007/s11367-011-0322-6

Ibáñez-Forés, V., Bovea, M.D., Azapagic, A., 2013. Assessing the sustainability of Best Available Techniques (BAT): methodology and application in the ceramic tiles industry. J. Clean. Prod. 51, 162-176. https://doi.org/10.1016/j.jclepro.2013.01.020

Ibáñez-Forés, V., Pacheco-Blanco, B., Capuz-Rizo, S.F., Bovea, M.D., 2016. Environmental Product Declarations: Exploring their evolution and the factors affecting their demand in Europe. J. Clean. Prod. 116, 157-169. https://doi.org/https://doi.org/10.1016/j.jclepro.2015.12.078

IBU-Institut Bauen und Umwelt e. V., n.d. IBU-EPD Programme [www Document]. URL http://ibuepd.com/ (accessed 12.23.18).

IETcc-CSIC, 2011. Catálogo de elementos constructivos del Código Técnico de la Edificación (in Spanish). Ministerio de Fomento de España, Madrid.

Inies, n.d. Environmental and health reference data for building [www Document]. URL http://www.inies.fr/construction-products/ (accessed 12.23.18).

Instituto de Tecnología Cerámica y Comisión de Trabajo, 2010. Guía de Mejores Técnicas Disponibles para el sector de fabricación de baldosas cerámicas en la Comunitat Valenciana. Ed. Centro de Tecnologías Limpias. Conselleria de Medio Ambiente, Agua, Urganismo y Vivienda. Generalitat Valenciana, Valencia, España.

International EPD® System, n.d. Environdec [www Document]. URL http://www.environdec.com/ (accessed 12.23.18).

IQNet SR10, 2011. Sistemas de Gestión de la Responsabilidad Social. Requisitos. The International Certification Networks.

Iribarren, D., Marvuglia, A., Hild, P., Guiton, M., Popovici, E., Benetto, E., 2015. Life cycle assessment and data envelopment analysis approach for the selection of building components according to their environmental impact efficiency: a case study for external walls. J. Clean. Prod. 87, 707-716. https://doi.org/https://doi.org/10.1016/j.jclepro.2014.10.073

Islam, H., Jollands, M., Setunge, S., Bhuiyan, M.A., 2015a. Optimization approach of balancing life cycle cost and environmental impacts on residential building design. Energy Build. 87, 282-292. https://doi.org/10.1016/j.enbuild.2014.11.048 
Islam, H., Jollands, M., Setunge, S., Haque, N., Bhuiyan, M.A., 2015b. Life cycle assessment and life cycle cost implications for roofing and floor designs in residential buildings. Energy Build. 104, 250-263. https://doi.org/10.1016/j.enbuild.2015.07.017

ISO 13006, 2012. Ceramic tiles - Definitions, classification, characteristics and marking, 2nd ed. International Organization for Standardization.

ISO 14001, 2015. Environmental management systems -- Requirements with guidance for use, 3rd ed. International Organization for Standardization.

ISO 14006, 2011. Environmental management systems -- Guidelines for incorporating ecodesign. International Organization for Standardization.

ISO 14020, 2000. Environmental labels and declarations - General principles. International Organization for Standardization.

ISO 14021, 2016. Environmental labels and declarations -- Self-declared environmental claims (Type II environmental labelling), Technical. ed. International Organization for Standardization.

ISO 14024, 2018. Environmental labels and declarations -- Type I environmental labelling -Principles and procedures, 2nd ed. International Organization for Standardization.

ISO 14025, 2006. Environmental labels and declarations -- Type III environmental declarations -Principles and procedures, 1st ed. International Organization for Standardization.

ISO 14040, 2006. Environmental management -- Life cycle assessment -- Principles and framework, 2nd ed. International Organization for Standardization.

ISO 14044, 2006. Environmental management -- Life cycle assessment -- Requirements and guidelines. International Organization for Standardization.

ISO 21930, 2017. Sustainability in buildings and civil engineering works -- Core rules for environmental product declarations of construction products and services, 2nd ed. International Organization for Standardization.

ISO 26000, 2010. Guidance on social responsibility. International Organization for Standardization.

Jönsson, A., 2000. Tools and methods for environmental assessment of building productsmethodological analysis of six selected approaches. Build. Environ. 35, 223-238. https://doi.org/https://doi.org/10.1016/S0360-1323(99)00016-5

Jönsson, $\AA$., 1999. Including the use phase in LCA of floor coverings. Int. J. Life Cycle Assess. 4, 321-328. https://doi.org/https://doi.org/10.1007/BF02978521

Jönsson, Å., Tillman, A.-M., Svensson, T., 1997. Life cycle assessment of flooring materials: case study. Build. Environ. 32, 245-255. 
Jonsson, R., 2006. Increasing the competitiveness of wood in material substitution: A method for assessing and prioritizing customer needs. J. Wood Sci. 52, 154-162. https://doi.org/https://doi.org/10.1007/s10086-005-0741-8

JRC-IES, 2015. Joint Research Centre, Institute for Environment and Sustainability. European Reference Life-Cycle Database. Version 3.2. [www Document]. URL http://eplca.jrc.ec.europa.eu/ELCD3/processList.xhtml (accessed 5.16.16).

Khasreen, M.M., Banfill, P.F.G., Menzies, G.F., 2009. Life-cycle assessment and the environmental impact of buildings: a review. Sustainability 1, 674-701.

Kibert, C.J., 1994. Establishing principles and a model for sustainable construction, in: Proceedings of the First International Conference on Sustainable Construction. Tampa Florida, November, pp. 6-9.

Kibert, C.K., 2012. Sustaination: Green building design and delivery, 3rd. ed. ed. New Jersey.

Kørnøv, L., Thissen, W.A.H., 2000. Rationality in decision-and policy-making: implications for strategic environmental assessment. Impact Assess. Proj. Apprais. 18, 191-200. https://doi.org/https://doi.org/10.3152/147154600781767402

Li, D.H.W., Yang, L., Lam, J.C., 2013. Zero energy buildings and sustainable development implications-A review. Energy $\quad 54, \quad 1-10$. https://doi.org/https://doi.org/10.1016/j.energy.2013.01.070

MacArthur, E., 2013. Towards the circular economy, economic and business rationale for an accelerated transition. Ellen MacArthur Found. Cowes, UK.

Martín-Márquez, J., Rincón, J.M., Romero, M., 2010. Effect of microstructure on mechanical properties of porcelain stoneware. J. Eur. Ceram. Soc. 30, 3063-3069. https://doi.org/10.1016/j.jeurceramsoc.2010.07.015

Mestre, S., 1997. Compuestos del sistema Fe2O3-Cr2O3. Estudio cinético y colorimétrico. Tesis doctoral, Escuela Superior de Tecnología y Ciencias Experimentales. Departamento de Ingeniería Química. Universitat Jaume I de Castellón, España.

Mezquita, A., Monfort, E., Ferrer, S., Gabaldón-Estevan, D., 2017. How to reduce energy and water consumption in the preparation of raw materials for ceramic tile manufacturing: Dry versus wet route. J. Clean. Prod. https://doi.org/https://doi.org/10.1016/j.jclepro.2017.04.082

Mezquita, A., Monfort Gimeno, E., Vaquer, E., Ferrer, S., Pitarch, J.M., Arnal, M.A., Cobo, F., 2014. Reduction of $\mathrm{CO} 2$-emissions in ceramic tiles manufacture by combining energy-saving measures.

Minguillón, M.C., 2007. Composición y fuentes del material particulado atmosférico en la zona cerámica de Castellón. Impacto de la introducción de las Mejores Técnicas Disponibles. Tesis doctoral, Escuela Superior de Tecnología y Ciencias Experimentales. Departamento de Ingeniería Química. Universitat Jaume I de Castellón, España. 
Ministerio de Fomento de España, 2011. Documentos básicos del Código Técnico de la Edificación (in Spanish) [www Document]. URL https://www.codigotecnico.org/

Ministerio de Fomento de España, 2009. Documento Básico DB-HR Protección frente al ruido del Código Técnico de la Edificación / Apartado 3.1.2.3.5 Condiciones mínimas de los elementos de separación horizontales.

Minne, E., Crittenden, J.C., 2015. Impact of maintenance on life cycle impact and cost assessment for residential flooring options. Int. J. Life Cycle Assess. 20, 36-45. https://doi.org/10.1007/s11367-014-0809-z

Moliner, R.C., 2017. Aplicaciones estratégicas de la Nanofiltración para el tratamiento de las aguas en la industria cerámica. Tesis doctoral, Escuela Superior de Tecnología y Ciencias Experimentales. Departamento de Ingeniería Química. Universitat Jaume I de Castellón.

Monfort, E., 2012. What role do Ceramic Tiles play in Green Procurement and Sustainable Building?, in: World Congress on Ceramic Tile Quality-Qualicer. Castelló, Spain.

Monfort, E., Celades, I., Gomar, S., Rueda, F., Martínez, J., 2011a. Characterisation of acid pollutant emissions in ceramic tile manufacture. Bol. Soc. Esp. Ceram. Vidr. 50(4), 179-184.

Monfort, E., Mezquita, A., Granel, R., Vaquer, E., Escrig, A., Miralles, A., Zaera, V., 2010. Análisis de consumos energéticos y emisiones de dióxido de carbono en la fabricación de baldosas cerámicas. Boletín la Soc. Española Cerámica y Vidr. 49, 303-310.

Monfort, E., Mezquita, A., Mallol, G., Granel, R., Vaquer, E., 2011b. Guía de ahorro energético en el sector de baldosas cerámicas de la Comunidad Valenciana. Agencia Valencia. la Energía-AVEN. Depósito Leg. 2078.

Monfort, E., Mezquita, A., Vaquer, E., Mallol, G., Gabaldón-Estevan, D., 2014. La evolución energética del sector español de baldosas cerámicas. Boletín la Soc. Española Cerámica y Vidr. 53, 111-120. https://doi.org/10.3989/cyv.152014

Nebel, B., Cowell, S.J., 2003. Global warming reduction potential of biomass based products: an example of wood products, in: Proceedings of the XXth SETAC-Europe Annual Meeting. p. 49.

Nicoletti, G.M., Notarnicola, B., Tassielli, G., 2002. Comparative Life Cycle Assessment of flooring materials: ceramic versus marble tiles. J. Clean. Prod. 10, 283-296. https://doi.org/10.1016/S0959-6526(01)00028-2

ONU, 2015. - Organización Mundial de las Naciones Unidas-. Agenda 2030 para el Desarrollo Sostenible [www Document]. URL https://www.un.org/sustainabledevelopment/es/sustainabledevelopment-goals/ (accessed 3.13.19).

Ortiz, O., Castells, F., Sonnemann, G., 2009. Sustainability in the construction industry: A review of recent developments based on LCA. Constr. Build. Mater. 23, 28-39. https://doi.org/https://doi.org/10.1016/j.conbuildmat.2007.11.012 
PE International, 2008a. GaBi Software-system. Compilation 4.131 [www Document]. URL http://www.gabi-software.com/software/gabi-4/ (accessed 5.17.16).

PE International, 2008b. Database for life cycle engineering, copyright, TM. 1992-2008 (compilation. 4.4.142.1, DB version 4.131) [www Document].

PE International, L., 2008. Database for Life Cycle Engineering, copyright, TM. 1992-2008 (Compilation. 4.4.142.1, DB version 4.131).

Petersen, A.K., Solberg, B., 2004. Greenhouse gas emissions and costs over the life cycle of wood and alternative flooring materials. Clim. Change 64, 143-167. https://doi.org/https://doi.org/10.1023/B:CLIM.0000024689.70143.79

Pini, M., Ferrari, A.M., Gamberini, R., Neri, P., Rimini, B., 2014. Life cycle assessment of a large, thin ceramic tile with advantageous technological properties. Int. J. Life Cycle Assess. 19, 15671580. https://doi.org/10.1007/s11367-014-0764-8

Potting, J., Blok, K., 1995. Life-cycle assessment of four types of floor covering. J. Clean. Prod. 3 , 201-213. https://doi.org/https://doi.org/10.1016/0959-6526(95)00082-8

Programa DAPconstrucción $®, 2015$. RCP 002, v2. Reglas de Categoría de Producto para preparar una Declaración Ambiental de Producto (DAPcons) sobre productos de revestimiento cerámico (in Spanish).

Programa DAPconstrucción $®$, n.d. Declaración Ambiental de Productos de Construcción [www Document]. URL http://www.csostenible.net/dapcons/documents_oficials?locale=es (accessed 12.23.18).

Puig, R., Kiliç, E., Navarro, A., Albertí, J., Chacón, L., Fullana-i-Palmer, P., 2017. Inventory analysis and carbon footprint of coastland-hotel services: A Spanish case study. Sci. Total Environ. 595, 244-254. https://doi.org/https://doi.org/10.1016/j.scitotenv.2017.03.245

REE Red Eléctrica de España, 2014. Informe del sistema eléctrico español 2013 [WWW Document]. URL http://www.ree.es/sites/defhttp://www.ree.es/sites/default/files/downloadable/inf_sis_elec_ree_2 013_v1.pdf (accessed 4.19.16).

Regulation (EC) 1221/2009 of the European Parliament and of the Council of 25 November 2009 on the voluntary participation by organisations in a Community eco-management and audit scheme (EMAS), repealing Regulation (EC) No 761/2001 and Commission Decisions 2001/681/EC and 2006/193/EC. OJ L 342, 22.12.2009, p. 1-45

Commission Regulation (EU) 2017/1505 of 28 August 2017 amending Annexes I, II and III to Regulation (EC) 1221/2009 of the European Parliament and of the Council on the voluntary participation by organisations in a Community eco-management and audit scheme (EMAS). OJ L $222,29.8 .2017$, p. $1-20$ 
Commission Regulation (EU) 2018/2026 of 19 December 2018 amending Annex IV to Regulation (EC) 1221/2009 of the European Parliament and of the Council on the voluntary participation by organisations in a Community eco-management and audit scheme (EMAS).OJ L 325, 20.12.2018, p. $18-24$

Regulation (EU) 305/2011, 2011. European Parliament and of the Council of 9 March 2011 laying down harmonised conditions for the marketing of construction products and repealing Council Directive 89/106/EEC.

Reza, B., Sadiq, R., Hewage, K., 2011. Sustainability assessment of flooring systems in the city of Tehran: An AHP-based life cycle analysis. Constr. Build. Mater. 25, 2053-2066. https://doi.org/https://doi.org/10.1016/j.conbuildmat.2010.11.041

Rivela, B., Moreira, M.T., Muñoz, I., Rieradevall, J., Feijoo, G., 2006. Life cycle assessment of wood wastes: a case study of ephemeral architecture. Sci. Total Environ. 357, 1-11. https://doi.org/https://doi.org/10.1016/j.scitotenv.2005.04.017

Ruschi Mendes Saade, M., G. da Silva, M., Gomes, V., Gumez Franco, H., Schwamback, D., Lavor, B., 2014. Material eco-efficiency indicators for Brazilian buildings. Smart Sustain. Built Environ. 3, 54-71. https://doi.org/10.1108/SASBE-04-2013-0024

Rydh, C.J., Sun, M., 2005. Life cycle inventory data for materials grouped according to environmental and material properties. J. Clean. Prod. 13, 1258-1268. https://doi.org/https://doi.org/10.1016/j.jclepro.2005.05.012

Sánchez, E., García-Ten, J., Sanz, V., Moreno, A., 2010. Porcelain tile: Almost 30 years of steady scientific-technological evolution. Ceram. Int. 36, 831-845. https://doi.org/10.1016/j.ceramint.2009.11.016

Sanfélix, V., 2017. Metodologías para la cuantificación de las emisiones difusas de material particulado en entornos industriales. Tesis doctoral, Escuela Superior de Tecnología y Ciencias Experimentales. Departamento de Ingeniería Química. Universitat Jaume I de Castellón, España.

SEC(2010)1436 final, 2010. Commission Staff Working Document State of play in the EU energy policy Accompanying document to the Communication from the Commission to the European Parliament, the Council, the European Economic and Social Committee and the Committee of the Regions. Energy 2020 A strategy for competitive, sustainable and secure energy $\{C O M(2010) 639\}$

Segars, J.W., Bradfield, S.L., Wright, J.J., Realff, M.J., 2003. EcoWorx, green engineering principles in practice. Environ. Sci. Technol. 37, 5269-5277. https://doi.org/10.1021/es034576a

Singer, F., Singer, S., 1971. Cerámica Industrial. Ediciones Urmo, Bilbao, España.

Souza, D.M. de, Lafontaine, M., Charron-Doucet, F., Bengoa, X., Chappert, B., Duarte, F., Lima, L., 2015. Comparative Life Cycle Assessment of ceramic versus concrete roof tiles in the Brazilian context. J. Clean. Prod. 89, 165-173. https://doi.org/10.1016/j.jclepro.2014.11.029 
Stamure, I., Kamola, L., Geipele, I., 2015. Practical aspects of sustainable construction in Latvia, in: 2015 International Conference on Industrial Engineering and Operations Management (IEOM). IEEE, pp. 1-8.

Thinkstep, 2016a. Database for Life Cycle Engineering, copyrignt Thinkstep AG. 1992-2016 (Compilation 7.2.2.28, DB version 6.115).

Thinkstep, 2016b. GaBi Software-system. Compilation 7.2.2.28 [www Document]. URL http://www.gabi-software.com/software/ (accessed 5.17.16).

Thinkstep AG, 2018a. GaBi Software-system. Compilation 8.0.718 [www Document]. URL http://www.gabi-software.com/software/ (accessed 5.17.16).

Thinkstep AG, 2018b. Database for Life Cycle Engineering. Professional + Construction materials extension (version 8007).

Tikul, N., 2014. Assessing environmental impact of small and medium ceramic tile manufacturing enterprises in Thailand. J. Manuf. Syst. 33, 1-6. https://doi.org/https://doi.org/10.1016/j.jmsy.2013.12.002

Tikul, N., Srichandr, P., 2010. Assessing the environmental impact of ceramic tile production in Thailand. J. Ceram. Soc. Japan 118, 887-894. https://doi.org/10.2109/jcersj2.118.887

Traverso, M., Rizzo, G., Finkbeiner, M., 2010. Environmental performance of building materials: life cycle assessment of a typical Sicilian marble. Int. J. Life Cycle Assess. 15, 104. https://doi.org/https://doi.org/10.1007/s11367-009-0135-z

USGBC, 2019. US Green Building Council. Leadership in Energy \& Environmental Design [www Document]. URL https://new.usgbc.org/leed-v41 (accessed 3.29.19).

Weidema, B., 2000. Avoiding co - product allocation in life - cycle assessment. J. Ind. Ecol. 4, 11 33. https://doi.org/http://dx.doi.org/10.1162/108819800300106366

Weidema, B.P., 2003. Market information in life cycle assessment. Miljøstyrelsen.

WGBC, 2019. World Green Building Council [www Document]. URL http://www.worldgbc.org (accessed 3.29.19).

Wittstock B, Gantner J, Saunders KLT, Anderson J, Carter C, Gyetvai Z, Kreißig J, Lasvaux ABS, Bosdevigie B, Bazzana M, Schiopu N, Jayr E, Nibel S, Chevalier J, Fullana-i-Palmer P, Mundy CGJ-A, S.T.-Wc., 2012. EeBGuide Guidance Document Part B: Buildings. Operational guidance for life cycle assessment studies of the Energy-Efficient Buildings Initiative 1-360.

Wolf, M.-A., Chomkhamsri, K., Brandao, M., Pant, R., Ardente, F., Pennington, D.W., Manfredi, S., de Camillis, C., Goralczyk, M., 2010. ILCD Handbook-General Guide for Life Cycle AssessmentDetailed Guidance. https://doi.org/10.2788/38479 
Yılmaz, M., Bakış, A., 2015. Sustainability in construction sector. Procedia-Social Behav. Sci. 195, 2253-2262. https://doi.org/10.1016/j.sbspro.2015.06.312

Yudelson, J., 2007. Green building A to Z: understanding the language of green building. New Society Publishers.

Zabalza Bribián, I., Aranda Usón, A., Scarpellini, S., 2009. Life cycle assessment in buildings: Stateof-the-art and simplified LCA methodology as a complement for building certification. Build. Environ. 44, 2510-2520. https://doi.org/10.1016/J.BUILDENV.2009.05.001 
10. ANEXOS 



\section{ANEXOS}

10.1. Anexo 1. Cuestionarios para la recogida de la información ambiental de las empresas

10.1.1. Cuestionario asociado a la fabricación de baldosas cerámicas 


\section{INFORMACIÓN GENERAL}

Empresa:

Persona de contacto:

Dirección de email:

Teléfono:

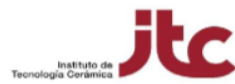

Fecha:

NOTA 1: todos los datos deben ser del mismo año, en caso de que algún dato no cumpla este requisito, consulte con el técnico del ITC. NOTA 2: añada tantas filas como sea necesario para facilitar toda la información

NOTA 3: los apartados de "responsable" y "lugar de archivo" son de cumplimentación opcional, pero recomendada. Su objetivo es ayudarles a preparar, controlar y localizar la información que les solicitarán en el proceso de verificación.

\section{Señale con una $X$ el alcance del estudio:}

\begin{tabular}{|l|l|}
\hline & De la cuna a la puerta de fábrica (desde la extracción de las materias primas hasta la puerta de fábrica) (obligatorio) \\
\hline $\begin{array}{l}\text { De la cuna a la tumba (desde la extracción de las materias primas hasta el fin de vida del producto, incluyendo } \\
\text { distribución, colocación, uso, mantenimiento y fin de vida) (opcional) }\end{array}$ \\
\hline
\end{tabular}

Responsable:

\section{Seleccione el tipo de empresa}

\begin{tabular}{|l|l|}
\hline & Empresa fabricante de gránulo atomizado \\
\hline & Empresa fabricante de baldosas (sin etapa de molienda) y conformado por prensado \\
\hline & Empresa fabricante de baldosas (sin etapa de molienda) y conformado por extrudido \\
\hline & Empresa de ciclo completo con molturación por vía seca (preparación de materias primas y fabricación de baldosas) \\
\hline & Empresa de ciclo completo con molturación por vía húmeda (preparación de materias primas y fabricación de baldosas) \\
\hline
\end{tabular}

Responsable:

\section{Señalar con un $\mathrm{X}$ el tipo de baldosas cerámicas a incluir en la DAP:}

\begin{tabular}{|l|l|}
\hline Grupo Bla & \\
\hline Grupo Blb & \\
\hline Grupo Blla & \\
\hline Grupo Bllb & \\
\hline Grupo Blll & \\
\hline Grupo Ala & \\
\hline Grupo Alb & \\
\hline Grupo Alla & \\
\hline Grupo Allb & \\
\hline Grupo Alll & \\
\hline
\end{tabular}

Responsable:

Lugar de archivo:

\section{Año de los datos de inventario:}

Responsable:

\section{Modelos/formatos comerciales de las baldosas a incluir en la DAP. Ampliar tanto como sea necesario:}

En caso de que el formato comercial se obtenga por corte y/o rectificado, indicar el formato prensa, por ejemplo:

\begin{tabular}{|l|c|l|}
\hline Formato prensa & mm de espesor & $\begin{array}{l}\text { Formatos } \\
\text { comerciales }\end{array}$ \\
\hline $60 \times 90$ & $11 \mathrm{~mm}$ & $30 \times 90$ \\
\cline { 3 - 3 } & & $60 \times 30$ \\
\hline
\end{tabular}

Responsable:

Lugar de archivo:

6. Producción anual de baldosas (por planta de producción). Hacer referencia a la producción en prensas (incluyendo bajas y mermas)

\begin{tabular}{|l|l|l|}
\hline Producción anual de baldosas: & $\mathrm{m}^{2} /$ año \\
\hline Producción anual de baldosas esmaltadas: & $\mathrm{m}^{2} /$ año \\
\hline Producción anual de baldosas con tratamientos mecánicos: & $\mathrm{m}^{2} / \mathrm{anno}$ \\
\hline Producción anual de baldosas a incluir en la DAP (especificar tipo) & $\mathrm{m}^{2} /$ año \\
\hline
\end{tabular}

Responsable:

Lugar de archivo: 
7. Producción de los formatos a incluir en la DAP [producción en prensas, incluidas las bajas y mermas], indicando si están esmaltados o sometidos a un tratamiento mecánico (corte, pulido, rectificado, etc.). Por ejemplo:

\begin{tabular}{|l|l|l|l|}
\hline Formatos comerciales & Producción $\left(\mathbf{m}^{2}\right)$ & Esmaltado & $\begin{array}{l}\text { Tratamientos } \\
\text { mecánico }\end{array}$ \\
\hline $15 \times 90$ & 100,000 & Si & $\begin{array}{c}\text { Corte y } \\
\text { rectificado }\end{array}$ \\
\hline & & & \\
\hline & & & \\
\hline
\end{tabular}

Responsable:

Lugar de archivo:

\section{En el caso de que las piezas sufran mecanizado (corte, rectificado, pulido...) indicar el lugar donde se realiza}

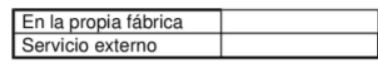

En el caso de que se realice en empresas externas indicar:

Distancia entre ambas plantas $(\mathrm{km})$

Señalar con un $\mathrm{X}$ si las piezas se envian envasadas $\mathrm{y}$ embaladas

Responsable:

Lugar de archivo:

9. Indique la cantidad de gránulo atomizado necesario para la fabricación de $1 \mathrm{~m}^{2}$ para cada formato prensa a incluir en la DAP

\begin{tabular}{|l|l|l|}
\hline Formatos prensa & $\begin{array}{l}\text { Cantidad de } \\
\text { atomizado } \\
\left(\mathrm{kg} / \mathrm{m}^{2}\right)\end{array}$ & $\begin{array}{l}\text { Peso en cocido } \\
\left(\mathrm{kg} / \mathrm{m}^{2}\right)\end{array}$ \\
\hline & & \\
\hline & & \\
\hline & & \\
\hline
\end{tabular}

Responsable:

Lugar de archivo:

\section{MATERIAS PRIMAS}

10. ¿Fabrican en su empresa el gránulo atomizado utilizado en los productos a incluir en la DAP?

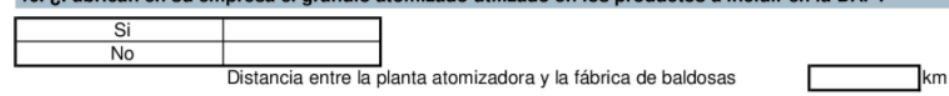

Responsable;

Lugar de archivo:

\section{1. ¿Fabrican en su empresa gránulo atomizado que NO se utiliza para la fabricación de los productos a incluir en la DAP?}

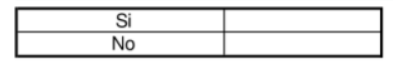

Responsable:

\section{Consumo de materias primas :}

\begin{tabular}{|l|l|}
\hline $\begin{array}{l}\text { Consumo anual de gránulo atomizado de toda la empresa } \\
\begin{array}{l}\text { Consumo anual de gránulo atomizado de los productos a } \\
\text { incluir en la DAP }\end{array}\end{array}$ & $\begin{array}{l}\text { tn/año (Diferenciar producido y comprado, si } \\
\text { procede) }\end{array}$ \\
\hline
\end{tabular}

Responsable:

Lugar de archivo: 
13. Especificar la cantidad de materiales (en seco) para la decoración de los productos a incluir en la DAP

\begin{tabular}{|l|c|}
\hline Formatos & $\begin{array}{c}\text { Cantidad de esmalte, engobe y } \\
\text { tintas en base seca }\left(\mathrm{kg} / \mathrm{m}^{2}\right)\end{array}$ \\
\hline & \\
\hline & \\
\hline & \\
\hline
\end{tabular}

Responsable:

Lugar de archivo:

\section{La molturación de engobes y esmaltes se realiza en:}

\begin{tabular}{|c|c|c|}
\hline La propia fábrica & tn/año \\
\hline Suministro externo & & tn/año \\
\hline
\end{tabular}

Responsable:

Lugar de archivo:

\section{Si se conoce, indicar las técnicas aplicadas en la empresa para la decoración de las piezas a incluir en la DAP.}

\begin{tabular}{|l|l|l|}
\hline Aplicaciones a cortina. Vela. Porcentaje de la producción & $\%$ \\
\hline Aplicaciones a cortina. Campana. Porcentaje de la producción & & $\%$ \\
\hline Aplicaciones mediante pulverización. Discos. Porcentaje de la producción & & $\%$ \\
\hline Aplicaciones mediante pulverización. Aerógrafo. Porcentaje de la producción & $\%$ \\
\hline Decoración en seco. Granillas. Porcentaje de la producción & & $\%$ \\
\hline Decoración en seco. Decoración en prensas. Porcentaje de la producción & $\%$ \\
\hline Decoración con tintas. Serigrafía. Porcentaje de la producción & $\%$ \\
\hline Decoración con tintas. Huecograbado. Porcentaje de la producción & $\%$ \\
\hline Decoración con tintas. Flexografía. Porcentaje de la producción & $\%$ \\
\hline Decoración con tintas. Inyección de tintas. Porcentaje de la producción & $\%$ \\
\hline
\end{tabular}

Responsable:

Lugar de archivo:

\section{ENERGIA}

16. Consumo total de energía eléctrica en la fabricación de baldosas cerámicas

\begin{tabular}{|c|l|l|}
\hline Electricidad total comprada a la red & $\mathrm{MJ} / \mathrm{año}$ \\
\hline Electricidad total vendida a la red & $\mathrm{MJ} / \mathrm{anno}$ \\
\hline
\end{tabular}

En caso de disponer de datos específicos para cada una de las etapas del proceso, indiquelos.

\begin{tabular}{|l|l|l|}
\hline Etapa & Consumo & $\begin{array}{l}\text { Unidad } \\
(\mathbf{k W h} / \mathbf{k g}) \\
\left(\mathbf{k W h} / \mathbf{m}^{2}\right)\end{array}$ \\
\hline Conformado & & \\
\hline Secado & & \\
\hline Esmaltado & & \\
\hline Cocción & & \\
\hline Mecanizado & & \\
\hline Otros (especificar) & & \\
\hline
\end{tabular}

Unidades Energéticas: $3,6 \mathrm{MJ}=1 \mathrm{kWh}$

Responsable:

Lugar de archivo:

\section{Consumo de energía térmica en la planta de fabricación de baldosas}

\begin{tabular}{|c|c|}
\hline Gas natural consumido en el secadero & MJ/año \\
\hline Gas natural consumido en los hornos & MJ/año \\
\hline Gas natural consumido en otras etapas (ej. Embalado) & MJ/año \\
\hline
\end{tabular}

En el caso de que no se conozca el consumo por etapas, incluir aquí el consumo total anual

$$
\text { Considerar el } \mathrm{PCl} \text { del gas natural }\left(\mathrm{KWh} / \mathrm{Nm}^{3}\right) \text { : } 10.55397534
$$

Euente: Enagás S. A. promedio del PCl suministrado en el cluster cerámico de Castellón en el año 2013

Unidades Energéticas: $\quad 3.6 \mathrm{MV}=1 \mathrm{KWh}$

Responsable:

Lugar de archivo: 


\section{AGUA}

\section{Consumo de agua en toda la planta de fabricación de baldosas}

\begin{tabular}{|l|l|l|}
\hline Consumo total de agua de pozo & & Vaño \\
\hline En caso de tratarse de un pozo externo, indicar distancia a la planta de fabricación & & $\mathrm{km}$ \\
\hline Consumo total de agua de red & & Vaño \\
\hline Consumo total de agua reciclada procedente de otras empresas & & V/año \\
\hline
\end{tabular}

En el caso de que las baldosas a incluir en la DAP estén sometidas a un tratamiento mecánico (corte, rectificado, pulido, etc.)

\begin{tabular}{|l|l|}
\hline Consumo específico de agua en el tratamiento mecánico & $1 / \mathrm{m}^{2}$ \\
\hline
\end{tabular}

$$
\text { "Considerar únicamente la producción mecanizada }
$$

Responsable:

Lugar de archivo:

\section{EMISIONES ATMOSFÉRICAS}

\section{Emisiones atmosféricas}

\begin{tabular}{|l|l|l|l|l|}
\hline Focos/Etapa & Contaminante & $\begin{array}{l}\text { Concentración al } \\
\% \mathrm{O}_{2} \text { real } \\
\left(\mathrm{mg} / \mathrm{Nm}^{3}\right)\end{array}$ & Caudal $\left(\mathrm{Nm}^{3} / \mathrm{h}\right)$ & $\begin{array}{l}\text { Horas de } \\
\text { funcionamie } \\
\text { nto }(\mathrm{h} / \mathrm{año})\end{array}$ \\
\hline & & & & \\
\hline & & & & \\
\hline & & & & \\
\hline & & & & \\
\hline
\end{tabular}

Notas:

1. Incluir ùnicamente los contaminantes contemplados por la legisiación apilicable

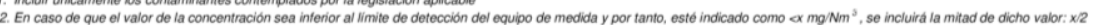

$m g / \mathrm{Nm}^{3}$.

concentración de $10 \mathrm{mgNm}^{3}$.

Responsable:

vager de ar

\section{Descarbonatación de las piezas durante la cocción (\%)}

$\%$

Responsable:

Lugar de archivo:

RESIDUOS

21. Especifique el modo de gestión y destino final de las aguas residuales

En caso de que se realice vertido a cauce público o alcantarillado, adjuntar analítica de aguas

Responsable:

Lugar de archivo: 


\section{ENVASES Y EMBALAJES}

\section{Cantidades y procedencias de productos de embalaje}

\begin{tabular}{|l|l|l|}
\hline & $\begin{array}{c}\text { Cantidades } \\
\text { (kg/año) }\end{array}$ & $\begin{array}{c}\text { Distancia desde el } \\
\text { punto de } \\
\text { fabricación hasta la } \\
\text { planta de baldosas } \\
(\mathbf{k m})\end{array}$ \\
\hline Cartón & & \\
\hline Film/retráctil & & \\
\hline Flejes & & \\
\hline Palés no reutilizables & & \\
\hline Europalés & & \\
\hline
\end{tabular}

En el caso de que los tratamientos mecánicos se realicen en una empresa externa y se envien las piezas embaladas, tener en consideración estos embalajes, asi como el embalaje de la empresa externa

Responsable:

Lugar de archivo:

\section{Indicar la cantidad promedio de baldosas por palé}

$$
\text { Capacidad promedio del palé } \mathrm{m}^{2} / \text { palé }
$$

Responsable:

Lugar de archivo:

\section{DECLARACIONES AMBIENTALES CON ALCANCE DE CUNA A TUMBA (Incluye distribución, colocación, uso/mantenimiento y gestión} final

\section{DISTRIBUCIÓN}

\section{Indicar lugares de venta del producto a incluir en la DAP}

\begin{tabular}{|l|l|l|}
\hline Distribución en España & $\%$ \\
\hline Distribución en Europa & & $\%$ \\
\hline $\begin{array}{l}\text { Distribución al resto del } \\
\text { mundo }\end{array}$ & $\%$ \\
\hline
\end{tabular}

Responsable:

Lugar de archivo:

\section{USO Y MANTENIMIENTO}

27. Señalar el escenario de uso de las baldosas a incluir en la DAP

\begin{tabular}{|l|l|l|l|}
\hline Superficie a recubrir & $\begin{array}{l}\text { Lugar de } \\
\text { colocación }\end{array}$ & $\begin{array}{l}\text { Frecuencia de } \\
\text { lavado }\end{array}$ & $\begin{array}{c}\text { Seleccionar con } \\
\mathbf{X}\end{array}$ \\
\hline Recubrimiento de pared & $\begin{array}{l}\text { uso residencial } \\
\text { interior }\end{array}$ & 2 veces al año & \\
\hline Recubrimiento de suelo & $\begin{array}{l}\text { uso residencial de } \\
\text { tránsito peatonal } \\
\text { moderado }\end{array}$ & 1 vez a la semana & \\
\hline Otro & completar & completar & \\
\hline
\end{tabular}

Responsable: 


\section{INFORMACIÓN AMBIENTAL ADICIONAL}

Información ambiental técnica adicional que se desee añadir a la DAP. La etiqueta facilita un espacio para añadir/promocionar actuaciones que se lleve en marcha en la empresa, por ejemplo, sistema de gestión ambiental/calidad/PRL, autodeclaración ambiental, resultados de alguna medición o ensayo, etc.. Es posible redactar un texto (máximo 1 hoja para facilitar la lectura). Para evidenciar esta información, adjuntar documentación. A continuación se citan las intrucciones del programa AENOR Global EPD para este apartado

Cumplimentar cuando sea pertinente. En caso de no ser pertinente se debe eliminar este punto.

En relación a los aspectos ambientales significativos, como minimo debe considerarse lo siguiente

b) Información ambiental

c) Adhesión de la organización a un sistema de gestión ambiental (con una declaración en la que una parte interesada pueda encontrar detalles del sistema)

d) Otros programas de certificación ambiental aplicados al producto (con una declaración en la que una parte interesada pueda encontrar detalles del programa de

certificación)

e) Otras actividades ambientales de la organización (por ejemplo: participación en programas de reciclaje o recuperación, información del contacto)

f) Otra información del análisis de ciclo de vida (no comunicada en ICV o ACV)

g) Instrucciones y limitaciones para una utilización eficiente

h) Análisis de peligros para la salud humana y el medio ambiente

i) Información sobre ausencia o nivel de presencia de un material en el producto que se considera ambientalmente significativo en ciertas áreas

i) Gestión de desechos de productos usados (indicar opción preferida)

k) Incidentes que puedan tener impactos en el medio ambiente

No se debe incluir información sobre seguridad de productos no relacionada con el desempeño ambiental del producto

Responsable:

Lugar de archivo: 
10.1.2. Cuestionario asociado a la preparación de las materias primas

\section{PREPARACIÓN DE MATERIAS PRIMAS}

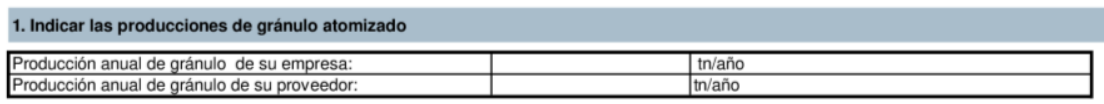

Producción anual de gránulo de su proveedor: In/año

Responsable:

Lugar de archivo:

\section{Cantidades y origen de las materias primas utilizadas en el gránulo asociado a los productos a incluir en la DAP.}

En caso de utilizar más de una composición de pastas, añadir tantas tablas como sea necesario, indicando, o bien las toneladas consumidas o el \% empleado de cada una de ellas.

\begin{tabular}{|l|l|l|l|l|}
\hline Composición & $\begin{array}{l}\text { Tipo de materias } \\
\text { mayoritarias }\end{array}$ & \% en la composición & Origen de las materias (km)* & $\begin{array}{l}\text { Tipo de } \\
\text { transporte** }\end{array}$ \\
\hline & Arcilla 1 & & & \\
\hline & Arcilla 2 & & & \\
\hline Arcilla 3 & & & & \\
\hline Arcilla 4 & & & \\
\hline Arcilla 5 & & & \\
\hline Arcilla 6 & & & \\
\hline & Feldespato 1 & & & \\
\hline Feldespato 2 & & & \\
\hline Feldespato 3 & & & \\
\hline Feldespato 4 & & & \\
\hline Caolin 1 & & & \\
\hline Caolin 2 & & & \\
\hline Caolin 3 & & & \\
\hline Arena 1 & & & \\
\hline Arena 2 & & & \\
\hline Arena 3 & & & \\
\hline Carbonato 1 & & & \\
\hline Carbonato 2 & & & \\
\hline Defloculante & & & \\
\hline Testillo crudo & & & \\
\hline $\begin{array}{l}\text { Tiesto cocido } \\
\text { chamota }\end{array}$ & & & & \\
\hline Otros & & & & \\
\hline
\end{tabular}

Indicar ciudad/pais o $\mathrm{km}$ de distancia

- Camión de 28t, camión de $17 \mathrm{t}$, barco, etc

Responsable:

Lugar de archivo:

\section{Proceso de molturación}

\begin{tabular}{|c|c|}
\hline Molturación vía húmeda & \\
\hline Molturación vía seca & \\
\hline
\end{tabular}

Responsable:

\section{Indique los consumos de los siguientes recursos}

\begin{tabular}{|l|l|l|}
\hline Molturación por via seca & \\
\hline Electricidad comprada & & $\mathrm{MJ} / \mathrm{t}$ \\
\hline Energia térmica (gas natural) consumida & $\mathrm{MJ} / \mathrm{t}$ \\
\hline Consumo de agua de pozo & & $\mathrm{V} / \mathrm{t}$ \\
\hline Consumo de agua de red & $\mathrm{Vt}$ \\
\hline
\end{tabular}

\begin{tabular}{|l|l|l|}
\hline Molturación por via húmeda & & \\
\hline Electricidad comprada a la red & & $\mathrm{MJ} / \mathrm{t}$ \\
\hline Electricidad vendida a la red obtenida en el sistema de cogeneración & $\mathrm{MJ} / \mathrm{t}$ \\
\hline Energia térmica consumida (gas natural en el sistema de cogeneración y proceso) & & $\mathrm{MJ} / \mathrm{t}$ \\
\hline Consumo de agua de pozo & & $\mathrm{ht}$ \\
\hline Consumo de agua de red & & $\mathrm{ht}$ \\
\hline Cantidad de agua reciclada recibida de otras empresas & $\mathrm{ht}$ \\
\hline
\end{tabular}

Responsable:

Lugar de archivo: 


\section{Indique la humedad del gránulo $(\%)$}

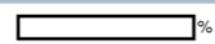

Responsable:

Lugar de archivo:

6. Emisiones atmosféricas

\begin{tabular}{|l|l|l|l|l|}
\hline Focos/Etapa & Contaminante & $\begin{array}{l}\text { Concentración al \% } \\
\mathrm{O}_{2} \text { real }\left(\mathrm{mg} / \mathrm{Nm}^{3}\right)\end{array}$ & Caudal $\left(\mathrm{Nm}^{3} / \mathrm{h}\right)$ & Horas de funcionamiento (h/año) \\
\hline & & & & \\
\hline & & & & \\
\hline & & & & \\
\hline & & & & \\
\hline & & & & \\
\hline & & & & \\
\hline & & & & \\
\hline & & & & \\
\hline
\end{tabular}

1. Incluir únicamente los contaminantes contemplados por la legislación aplicable

2. En caso de que el valor de la concentración sea inferior al límite de detección del equipo de medida y por tanto, esté indicado como <x $\mathrm{mg} / \mathrm{Nm}^{3}$, se incluirá la mitad de dicho valor: $\mathrm{x} / 2 \mathrm{mg} / \mathrm{Nm}^{3}$.

Responsable:

Lugar de archivo: 
10.1.3. Cuestionario asociado a la fabricación de fritas, esmaltes, engobes, tintas y otros materiales de decoración

\section{FABRICACIÓN DE FRITAS, ESMALTES, ENGOBES, TINTAS Y OTROS MATERIALES DE DECORACIÓN}

1. Distancia entre el colorificio y la fábrica de baldosas

$\mathrm{km}$

2. Cantidades y origen de las materias primas utilizadas en la fabricación de fritas, esmaltes, engobes, etc.

\begin{tabular}{|c|c|c|c|c|}
\hline Composición & $\begin{array}{l}\text { Tipo de materias } \\
\text { mayoritarias }\end{array}$ & \% en la composición' & $\begin{array}{l}\text { Origen de las } \\
\text { materias }(\mathbf{k m})^{2}\end{array}$ & Tipo de transporte ${ }^{3}$ \\
\hline & & & & \\
\hline & & & & \\
\hline & & & & \\
\hline & & & & \\
\hline & & & & \\
\hline & & & & \\
\hline & & & & \\
\hline & & & & \\
\hline & & & & \\
\hline & & & & \\
\hline & & & & \\
\hline & & & & \\
\hline & & & & \\
\hline & & & & \\
\hline & & & & \\
\hline & & & & \\
\hline & & & & \\
\hline & & & & \\
\hline & & & & \\
\hline & & & & \\
\hline & & & & \\
\hline 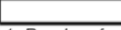 & & & & \\
\hline
\end{tabular}

1. Puede referirse al consumo total de la planta de fabricación de esmaltes y engobes

2 Indicar ciudad/pais o $\mathrm{km}$ de distancia

3 Camión de 28t, camión de $17 t$, barco, etc.

3. Cantidad promedio de material fritado que tienen los productos a incluir en la DAP

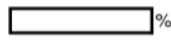

\section{Indicar los consumos de los siguientes recursos}

\begin{tabular}{|l|l|l|}
\hline Recursos & cantidades & Unidades \\
\hline Agua de pozo & & $\mathrm{V} / \mathrm{t}$ \\
\hline Agua de red & & $\mathrm{V} / \mathrm{t}$ \\
\hline Energía eléctrica comprada a la red & $\mathrm{MJ} / \mathrm{t}$ \\
\hline Electricidad vendida a la red obtenida en el sistema de cogeneración & $\mathrm{MJ} / \mathrm{t}$ \\
\hline Energía térmica consumida (gas natural en el sistema de cogeneración y proceso) & & $\mathrm{MJ} / \mathrm{t}$ \\
\hline $\mathrm{N}^{0}$ reutilizaciones de los cocios & & $\mathrm{veces}$ \\
\hline $\mathrm{N}^{0}$ reutilizaciones de los bigbags & & $\mathrm{veces}$ \\
\hline Distancia de la fábrica de BigBags & & $\mathrm{km}$ \\
\hline Distancia de la fábrica de cocios & & $\mathrm{km}$ \\
\hline Distancia de la fábrica de palés para esmaltes & $\mathrm{km}$ \\
\hline
\end{tabular}


5. Emisiones atmosféricas

\begin{tabular}{|l|l|l|l|l|}
\hline Focos/Etapa & Contaminante & $\begin{array}{l}\text { Concentración al \% } \mathrm{O}_{2} \\
\text { real }\left(\mathrm{mg} / \mathrm{Nm}^{3}\right)\end{array}$ & Caudal $\left(\mathrm{Nm}^{3} / \mathrm{h}\right)$ & $\begin{array}{l}\text { Horas de } \\
\text { funcionamiento } \\
\text { (h/año) }\end{array}$ \\
\hline & & & & \\
\hline & & & & \\
\hline & & & & \\
\hline & & & & \\
\hline & & & & \\
\hline & & & & \\
\hline & & & & \\
\hline
\end{tabular}

NOTAS:

1. Incluir únicamente los contaminantes contemplados por la legislación aplicable

2. En caso de que el valor de la concentración sea inferior al límite de detección del equipo de medida y por tanto, esté indicado como $<x \mathrm{mg} / \mathrm{Nm}^{3}$, se incluirá la mitad de dicho valor: $\mathrm{x} / 2 \mathrm{mg} / \mathrm{Nm}^{3}$.

\section{Gestión de residuos}

\begin{tabular}{|c|c|c|c|c|c|}
\hline Etapa & Tipo de residuo & Cantidad & $\begin{array}{c}\text { Ciudad de } \\
\text { destino }^{1}(\mathrm{~km})\end{array}$ & $\begin{array}{c}\text { Modo de } \\
\text { transporte }\end{array}$ & $\begin{array}{l}\text { Tratamiento del } \\
\text { residuo }^{3}\end{array}$ \\
\hline & & & & & \\
\hline & & & & & \\
\hline & & & & & \\
\hline & & & & & \\
\hline & & & & & \\
\hline & & & & & \\
\hline & & & & & \\
\hline & & & & & \\
\hline & & & & & \\
\hline & & & & & \\
\hline & & & & & \\
\hline & & & & & \\
\hline & & & & & \\
\hline
\end{tabular}

. Ciudad de destino.

2. Modos de transporte Carguero transoc

Coche privado

Furgoneta $<3.5 t$

Camión $16 t$

Camión $28 t$

Camión $40 t$

Tren eléctrico

Tren mixto electricidad/diesel

3. Indicar el tratamiento final y/o destino que tiene el residuo. Por ejemplo: depósito en vertedero, incineración, reciclaje en el mismo proceso, 


\subsection{Anexo 2. Datos de inventario del ciclo de vida del escenario de referencia de gres porcelánico}

A continuación, se presenta en forma de tablas, los datos de inventario del ciclo de vida facilitados por las empresas mediante los cuestionarios presentados en el Anexo 1, y tratados conjuntamente para obtener unos valores representativos del gres porcelánico.

En la Figura A2.1 se muestra un diagrama del ciclo de vida de las baldosas cerámicas donde se relacionan los procesos y las tablas con los datos primarios del inventario. 


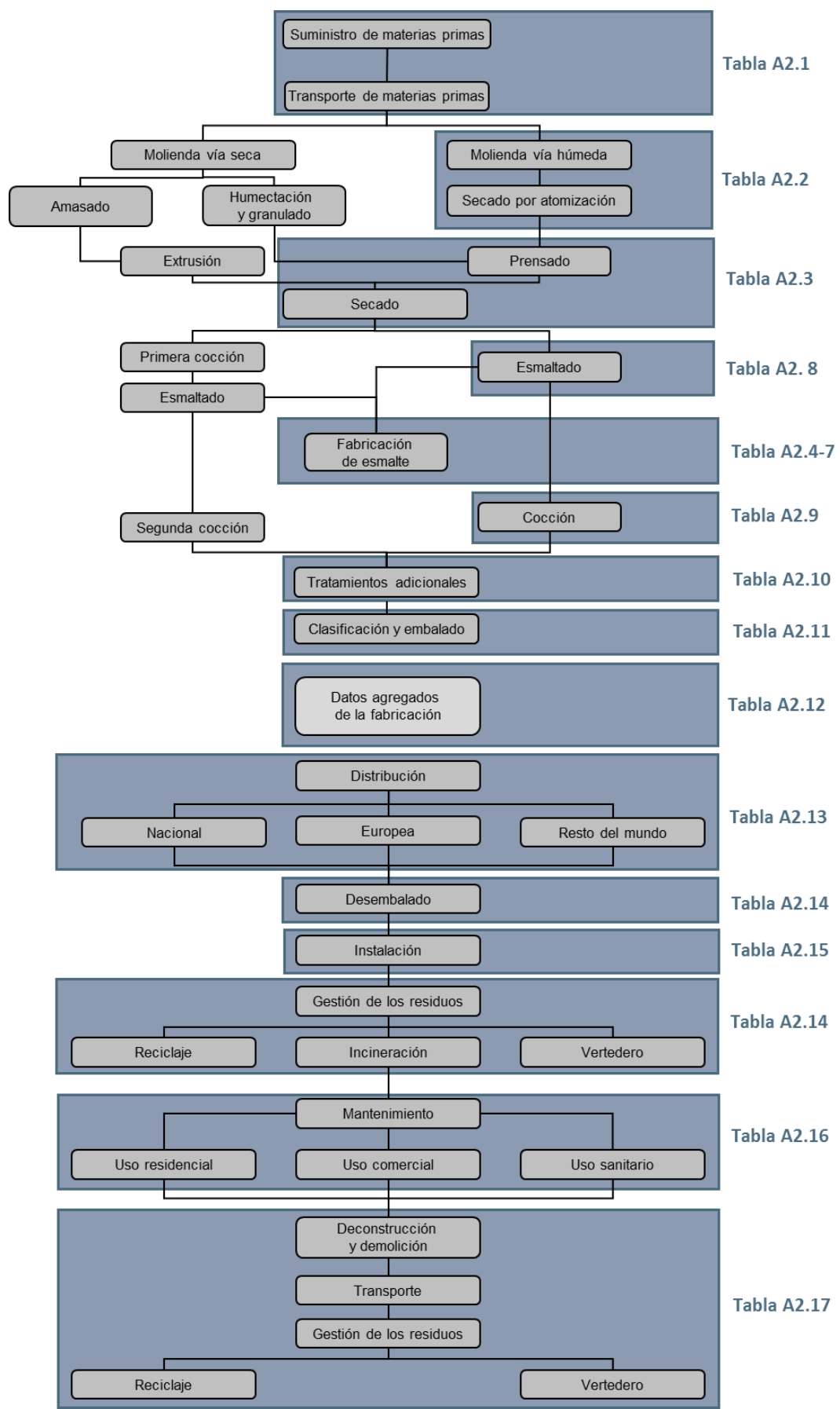

Figura A2.1 Relación de las tablas del inventario del ciclo de vida con el diagrama de procesos 
Tabla A2.1 Materias primas necesarias y distancias medias para la fabricación de $1 \mathrm{~m}^{2}$ de gres porcelánico

\begin{tabular}{|c|c|}
\hline Soporte cerámico & Gres porcelánico \\
\hline Materias primas para el soporte $\left(\mathrm{kg} / \mathrm{m}^{2}\right)$ & 23,9 \\
\hline Arcilla (\%) & 41,2 \\
\hline Arena (\%) & 10,9 \\
\hline Feldespatos (\%) & 43,5 \\
\hline Desfloculante (\%) & 0,2 \\
\hline Caolín (\%) & 1,2 \\
\hline Reintroducido sin cocer (\%) & 2,1 \\
\hline Reintroducido cocido (\%) & 0,5 \\
\hline Pigmentos (\%) & 0,3 \\
\hline TOTAL & 100 \\
\hline Tipo de transporte & Gres porcelánico \\
\hline Distancia de 150 km en camión de 27 t (\%) & 13,5 \\
\hline Distancia de 500 km en camión de 27 t (\%) & 8,2 \\
\hline Distancia de 900 km en camión de 27 t (\%) & 3,4 \\
\hline Distancia de 1300 km en camión de 27 t (\%) & 2,3 \\
\hline Distancia de 1000 km en carguero (\%) & 8,1 \\
\hline Distancia de 3000 km en carguero (\%) & 41,5 \\
\hline Distancia de 3500 km en carguero (\%) & 17,1 \\
\hline Distancia de 4200 km en carguero (\%) & 5,9 \\
\hline TOTAL & 100 \\
\hline Distancias medias para cada tipo de transporte & $\mathrm{km}$ \\
\hline Distancia media autonómica en camión de 27 t ( $\mathrm{km})$ & 150 \\
\hline Distancia media nacional en camión de $27 \mathrm{t}(\mathrm{km})$ & 500 \\
\hline Distancia media al norte de España en camión de 27 t ( $\mathrm{km})$ & 900 \\
\hline Distancia media Francia en camión de 27t $(\mathrm{km})$ & 1300 \\
\hline Distancia media Italia en carguero $(\mathrm{km})$ & 1000 \\
\hline Distancia media Turquía en carguero $(\mathrm{km})$ & 3000 \\
\hline Distancia media Ucrania en carguero $(\mathrm{km})$ & 3500 \\
\hline Distancia media Reino Unido en carguero $(\mathrm{km})$ & 4200 \\
\hline
\end{tabular}


Tabla A2.2 Entradas y salidas para la obtención de gránulo atomizado necesario para la fabricación de $1 \mathrm{~m}^{2}$ de gres porcelánico

\section{Etapa de preparación de materias primas}

\section{Entradas}

\section{Materias primas $^{(1)}$}

Arcilla $\left(\mathrm{kg} / \mathrm{m}^{2}\right)$

Arena $\left(\mathrm{kg} / \mathrm{m}^{2}\right)$

Feldespatos $\left(\mathrm{kg} / \mathrm{m}^{2}\right)$

Desfloculante $\left(\mathrm{kg} / \mathrm{m}^{2}\right)$

Caolín $\left(\mathrm{kg} / \mathrm{m}^{2}\right)$

Reintroducido sin cocer ${ }^{(1)}\left(\mathrm{kg} / \mathrm{m}^{2}\right)$

Reintroducido cocido $\left(\mathrm{kg} / \mathrm{m}^{2}\right)$

Pigmentos $\left(\mathrm{kg} / \mathrm{m}^{2}\right)$

0,5

\section{Agua}

Agua de pozo $\left(1 / \mathrm{m}^{2}\right)$

Agua de red $\left(1 / \mathrm{m}^{2}\right)$

Agua residual de otras empresas $\left(1 / \mathrm{m}^{2}\right)$

0,2

\section{Energía}

Gas natural (cogeneración + post-combustión) $\left(\mathrm{MJ} / \mathrm{m}^{2}\right)$

Energía eléctrica comprada $\left(\mathrm{MJ} / \mathrm{m}^{2}\right)$

Salidas

\section{Producto}

Gránulo atomizado $\left(\mathrm{kg} / \mathrm{m}^{2}\right)$

Emisiones atmosféricas

Partículas en aspiraciones $\left(\mathrm{mg} / \mathrm{m}^{2}\right)$

Partículas en el secadero por atomización $\left(\mathrm{mg} / \mathrm{m}^{2}\right)$

$\mathrm{NOx}\left(\mathrm{mg} / \mathrm{m}^{2}\right)$

$\mathrm{SO}_{2}\left(\mathrm{mg} / \mathrm{m}^{2}\right)$

\section{Energía}

Electricidad vendida $\left(\mathrm{MJ} / \mathrm{m}^{2}\right)$

(1) Se han calculado multiplicando el \% de cada materia prima por la cantidad de atomizado por $\mathrm{m}^{2}$.

(2) Las emisiones de $\mathrm{NO}_{x}$ y de $\mathrm{SO}_{2}$ en esta etapa se han generado por el propio proceso de combustión del gas natural y se incluyen en el proceso de combustión del gas natural 
Tabla A2.3 Entradas y salidas de los procesos de conformado y secado para obtener $1 \mathrm{~m}^{2}$ de gres porcelánico

\section{Etapas de conformado y secado}

Entradas

\section{Materias primas}

Gránulo atomizado a conformar $\left(\mathrm{kg} / \mathrm{m}^{2}\right)$

23,9

Energía

Gas natural para el secado $\left(\mathrm{MJ} / \mathrm{m}^{2}\right)$

Electricidad $\left(\mathrm{MJ} / \mathrm{m}^{2}\right)$

$\star(1)$

Salidas

\section{Materia}

Baldosa conformada y seca (bizcocho) 22,5

\section{Emisiones atmosféricas}

Partículas $\left(\mathrm{mg} / \mathrm{m}^{2}\right)$

NOx $\left(m g / m^{2}\right)$

$\mathrm{SO}_{2}\left(m g / m^{2}\right)$

$*(2)$

\section{Residuos}

Residuos de piezas sin cocer [LER 101201] $\left(\mathrm{kg} / \mathrm{m}^{2}\right)$

(1) El consumo de gas natural de este proceso está incluido conjuntamente con en el proceso de cocción (2) La energía eléctrica consumida en este proceso está contabilizada en la tabla de datos agregados de baldosas.

(3) Las emisiones de $\mathrm{NO}_{x}$ y de $\mathrm{SO}_{2}$ en esta etapa se han generado por el propio proceso de combustión del gas natural y se incluyen en el proceso de combustión del gas natural 
Tabla A2.4 Entradas y salidas para la fabricación de los esmaltes, referidos a $1 \mathrm{~kg}$ de esmalte y engobe y a la cantidad necesaria para esmaltar $1 \mathrm{~m}^{2}$ de gres porcelánico

\section{Fabricación de esmaltes}

\section{$1 \mathrm{~kg}$ esmalte}

\section{Entradas}

Materias primas esmaltes

\begin{tabular}{|l|l|l|}
\hline Boratos $(\mathrm{kg})$ & 0,07 & 0,06 \\
\hline Carbonatos $(\mathrm{kg})$ & 0,20 & 0,15 \\
\hline Cuarzo $(\mathrm{kg})$ & 0,21 & 0,16 \\
\hline Feldespatos $(\mathrm{kg})$ & 0,26 & 0,20 \\
\hline Caolines $(\mathrm{kg})$ & 0,03 & 0,02 \\
\hline Silicatos $(\mathrm{kg})$ & 0,05 & 0,04 \\
\hline Oxido de zinc $(\mathrm{kg})$ & 0,04 & 0,03 \\
\hline Óxido de zirconio $(\mathrm{kg})$ & 0,04 & 0,03 \\
\hline Alúmina $(\mathrm{kg})$ & 0,02 & 0,02 \\
\hline Arcilla $(\mathrm{kg})$ & 0,07 & 0,05 \\
\hline TOTAL $(\mathrm{kg})$ & 1 & 0,76 \\
\hline
\end{tabular}

Tipos de transportes

Carguero (3500 km) (\%)

Carguero (10000 km) (\%)

Camión 27 t (2000km) (\%)

Camión 27 t (500km) (\%)

TOTAL

37,1

23,4

23,1

16,4

100

\section{Energía}

\begin{tabular}{|l|c|c|}
\hline Electricidad $(M J)$ & 1,08 & 0,82 \\
\hline Energía térmica $(M J)$ & 10,50 & 7,98 \\
\hline Agua & & 1,41 \\
\hline Agua de red $(I)$ & 1,85 & \\
\hline
\end{tabular}


Tabla A2.4 Entradas y salidas para la fabricación de los esmaltes, referidos a $1 \mathrm{~kg}$ de esmalte y engobe y a la cantidad necesaria para esmaltar $1 \mathrm{~m} 2$ de gres porcelánico (continuación)

\section{Fabricación de esmaltes}

\section{1 kg esmalte}

$1 \mathrm{~m}^{2}$ de gres porcelánico

\section{Salidas}

\section{Materia}

\begin{tabular}{|c|c|c|}
\hline Esmalte seco $(\mathrm{kg})$ & 1 & 0,76 \\
\hline \multicolumn{3}{|l|}{ Emisiones atmosféricas ${ }^{(1)}$} \\
\hline Partículas (mg) & 230 & 175 \\
\hline $\mathrm{NOx}^{(2)}(m g)$ & 8623 & 6554 \\
\hline $\mathrm{SO}_{2}^{(2)}(m g)$ & 130 & 99 \\
\hline $\mathrm{HF}(m g)$ & 29,0 & 22,0 \\
\hline $\mathrm{HCl}(m g)$ & 57,0 & 43,3 \\
\hline Metales pesados clase I + clase II (mg) & 7,5 & 5,7 \\
\hline
\end{tabular}

(1) Valores límite de emisión permitidos por Autorización Ambiental Integrada para colorificios

(2) Se ha eliminado la parte correspondiente a la combustión del gas natural.

Tabla A2.5 Entradas y salidas en el embalaje de esmaltes cerámicos, referido a la cantidad necesaria para ensacar y embalar $1 \mathrm{~kg}$ de esmalte y la necesaria para decorar $1 \mathrm{~m}^{2}$ de gres porcelánico

\begin{tabular}{|c|c|c|}
\hline \multicolumn{3}{|l|}{ Embalaje de esmaltes y engobes } \\
\hline & $1 \mathrm{~kg}$ esmalte & $1 \mathrm{~m}^{2}$ de gres porcelánico \\
\hline \multicolumn{3}{|l|}{ Entradas } \\
\hline Esmalte seco $(\mathrm{kg})$ & 1,000 & 0,760 \\
\hline BigBag $(k g)$ & $1,51 \mathrm{E}-03$ & $1,15 \mathrm{E}-03$ \\
\hline Palé de madera $(\mathrm{kg})$ & $1,00 \mathrm{E}-03$ & $7,60 \mathrm{E}-04$ \\
\hline $\begin{array}{l}\text { Masa de } 1 \text { cocio de } 800 \text { I ( } \mathrm{kg} / \\
800 \mathrm{l} \text { de esmalte) }\end{array}$ & \multicolumn{2}{|c|}{9,10} \\
\hline $\begin{array}{l}N^{\circ} \text { de veces que se reutilizan los } \\
\text { cocios }\end{array}$ & \multicolumn{2}{|c|}{3,83} \\
\hline \multicolumn{3}{|l|}{ Salidas } \\
\hline Esmalte embalado $(\mathrm{kg})$ & 1,003 & 0,762 \\
\hline
\end{tabular}


Tabla A2.5 Entradas y salidas en el embalaje de esmaltes cerámicos, referido a la cantidad necesaria para ensacar y embalar $1 \mathrm{~kg}$ de esmalte y la necesaria para decorar $1 \mathrm{~m} 2$ de gres porcelánico (continuación)

\section{Transporte del material de embalaje de los esmaltes hasta la fábrica de esmaltes}

\begin{tabular}{|l|c|}
\hline Distancia de la fábrica de BigBags $(\mathrm{km})$ & 218,69 \\
\hline Distancia de la fábrica de cocios $(\mathrm{km})$ & 63,21 \\
\hline Distancia de la fábrica de palés para esmaltes $(\mathrm{km})$ & 140,16 \\
\hline
\end{tabular}

Tabla A2.6 Cantidad de esmaltes molturados en la misma fábrica de baldosas y externamente

\begin{tabular}{|l|l|}
\hline Esmalte que se compra molturado (\%) & 16,0 \\
\hline Esmalte que se moltura en la fábrica de baldosas (\%) & 84,0 \\
\hline
\end{tabular}

Tabla A2.7 Escenario de gestión de los residuos de envases de los esmaltes y engobes

\begin{tabular}{|c|c|c|c|}
\hline \multicolumn{4}{|c|}{ Gestión de los residuos de envases de engobes y esmaltes } \\
\hline & Incineración (\%) & Reciclaje(\%) & $\begin{array}{l}\text { Eliminación } \\
\text { vertedero (\%) }\end{array}$ \\
\hline BigBag [LER 150102] & 13 & 21 & 66 \\
\hline $\begin{array}{l}\text { Palé de madera [LER } \\
\text { 150203] }\end{array}$ & 47 & 44 & 9 \\
\hline \multicolumn{4}{|c|}{ Transporte de residuos promedio } \\
\hline \multicolumn{3}{|c|}{ Distancia entre el punto de generación y de gestión de residuos $(\mathrm{km})$} & 100 \\
\hline
\end{tabular}

Tabla A2.8 Entradas y salidas en el esmaltado de $1 \mathrm{~m}^{2}$ de gres porcelánico

Proceso de esmaltado y decorado (por $\mathrm{m}^{2}$ de gres porcelánico)

\section{Entradas}

\section{Materias}

\begin{tabular}{|l|c|}
\hline Soporte seco $\left(\mathrm{kg} / \mathrm{m}^{2}\right)$ & 21,9 \\
\hline Engobe y esmalte seco $\left(\mathrm{kg} / \mathrm{m}^{2}\right)$ & 0,76 \\
\hline Cantidad de tinta $\left(\mathrm{kg} / \mathrm{m}^{2}\right)$ & 0,025 \\
\hline Agua $^{(1)}\left(1 / \mathrm{m}^{2}\right)$ & $0^{(1)}$ \\
\hline
\end{tabular}


Tabla A2.8 Entradas y salidas en el esmaltado de $1 \mathrm{~m} 2$ de gres porcelánico (continuación)

\section{Proceso de esmaltado y decorado (por $\mathrm{m}^{2}$ de gres porcelánico)}

\section{Entradas}

\section{Energía}

Energía eléctrica $^{(1)}\left(\mathrm{MJ} / \mathrm{m}^{2}\right)$

$\mathrm{O}^{(1)}$

\section{Salidas}

\section{Producto}

Baldosa decorada cruda $\left(\mathrm{kg} / \mathrm{m}^{2}\right)$

\section{Emisiones}

Partículas $\left(\mathrm{mg} / \mathrm{m}^{2}\right)$

120,65

(1) Estos consumos se han considerado en el apartado de datos generales de la instalación, ya que no se dispone de datos desglosados.

Tabla A2.9 Entradas y salidas en la cocción de $1 \mathrm{~m}^{2}$ de gres porcelánico

\section{Proceso de cocción de gres porcelánico}

\section{Entradas}

\section{Materia}

Baldosa cruda $\left(\mathrm{kg} / \mathrm{m}^{2}\right)$

23,9

\section{Energía}

\begin{tabular}{|l}
\hline Gas natural(1) $^{(1)}\left(\mathrm{MJ} / \mathrm{m}^{2}\right)$ \\
\hline Energía eléctrica $^{(2)}\left(\mathrm{MJ} / \mathrm{m}^{2}\right)$
\end{tabular}

$74,6^{(1)}$

\section{Salidas}

\section{Producto}

Baldosa cocida $\left(\mathrm{kg} / \mathrm{m}^{2}\right)$

$$
22,5
$$

\section{Emisiones atmosféricas}

\begin{tabular}{|l|c|}
\hline $\mathrm{SO}_{2}{ }^{(3)}\left(\mathrm{mg} / \mathrm{m}^{2}\right)$ & $2758,7^{(3)}$ \\
\hline $\mathrm{NOx}^{(3)}\left(\mathrm{mg} / \mathrm{m}^{2}\right)$ & $1200,3^{(3)}$ \\
\hline $\mathrm{HF}\left(\mathrm{mg} / \mathrm{m}^{2}\right)$ & 1347,9 \\
\hline Partículas $\left(m g / m^{2}\right)$ & 873,6 \\
\hline $\mathrm{CO}_{2}$ (descarbonatación) (\%) & 0,55 \\
\hline
\end{tabular}

(1) Incluye el consumo correspondiente a la etapa de secado.

(2) Estos consumos se han considerado en el apartado de datos generales de la instalación, ya que no se dispone de datos desglosados.

(3) Se ha eliminado la parte correspondiente a la combustión del gas natural. 
Tabla A2.10 Entradas y salidas en el mecanizado en cocido de $1 \mathrm{~m}^{2}$ de gres porcelánico

\begin{tabular}{|l|l|}
\hline Procesos de tratamientos mecánicos posteriores \\
\hline Entradas & \multicolumn{2}{|l|}{} \\
\hline Materia & 22,5 \\
\hline Baldosa clasificada $\left(\mathrm{kg} / \mathrm{m}^{2}\right)$ & 0,96 \\
\hline Agua $\left(\mathrm{l} / \mathrm{m}^{2}\right)$ & \multicolumn{2}{|l|}{} \\
\hline Energía & 1,27 \\
\hline Electricidad $\left(\mathrm{MJ} / \mathrm{m}^{2}\right)$ & \\
\hline Salidas & \multicolumn{2}{|l}{} \\
\hline Producto & 21,8 \\
\hline Baldosa mecanizada $\left(\mathrm{kg} / \mathrm{m}^{2}\right)$ & \\
\hline Residuos & \\
\hline Residuos de mecanizado $\left(\mathrm{kg} / \mathrm{m}^{2}\right)[\mathrm{LER} 101213]$ & 0,34 \\
\hline
\end{tabular}

Tabla A2.11 Entradas y salidas en el envasado y embalado de $1 \mathrm{~m}^{2}$ de gres porcelánico

\section{Procesos de embalaje}

\section{Entradas}

\section{Materia}

Baldosa clasificada lista para embalar $\left(\mathrm{kg} / \mathrm{m}^{2}\right)$

Cartón $\left(\mathrm{kg} / \mathrm{m}^{2}\right)$

Film de polietileno $\left(\mathrm{kg} / \mathrm{m}^{2}\right)$

Fleje $\left(\mathrm{kg} / \mathrm{m}^{2}\right)$

Palé de un solo uso $\left(\mathrm{kg} / \mathrm{m}^{2}\right)$

Palé reutilizable ${ }^{(1)}\left(\mathrm{kg} / \mathrm{m}^{2}\right)$

\section{Energía}

\begin{tabular}{l} 
Gas natural $^{(2)}\left(\mathrm{MJ} / \mathrm{m}^{2}\right)$ \\
\hline Electricidad $^{(2)}\left(\mathrm{MJ} / \mathrm{m}^{2}\right)$
\end{tabular}

\section{Transporte hasta fábrica de baldosas}

Distancia de la fábrica de cartón, transporte en camión 27 t $(\mathrm{km})$

Distancia de la fábrica de film, transporte en camión 27 t $(\mathrm{km})$

Distancia de la fábrica de flejes, transporte en camión 27 t $(\mathrm{km})$

Distancia de la fábrica de palés, transporte en camión 27t $(\mathrm{km})$ 98,7 
Tabla A2. 11 Entradas y salidas en el envasado y embalado de 1 m2 de gres porcelánico (continuación)

\section{Procesos de embalaje}

\section{Salidas}

\section{Producto}

Baldosa embalada $\left(\mathrm{kg} / \mathrm{m}^{2}\right)$

22,1

\section{Residuos}

Residuos peligrosos $\left(\mathrm{kg} / \mathrm{m}^{2}\right)$

Residuos no peligrosos $\left(\mathrm{kg} / \mathrm{m}^{2}\right)$

Residuos de piezas cocidas depositadas en vertedero $\left(\mathrm{kg} / \mathrm{m}^{2}\right)$

Residuos de piezas crudas depositadas en vertedero $\left(\mathrm{kg} / \mathrm{m}^{2}\right)$

Residuos de piezas cerámicas cocidas que se reciclan en otro proceso $\left(\mathrm{kg} / \mathrm{m}^{2}\right)$

Residuos de papel y cartón que van a reciclaje $\left(\mathrm{kg} / \mathrm{m}^{2}\right)$

Residuos de madera que van a reciclaje $\left(\mathrm{kg} / \mathrm{m}^{2}\right)$

Residuos de plástico que van a reciclaje $\left(\mathrm{kg} / \mathrm{m}^{2}\right)$

(1) Se considera que es posible reutilizar el palé 5 veces como media.

(2) Se desconocen los datos específicos de consumo de energía térmica en este proceso. Este dato está repartido entre el consumo de gas natural en el proceso de cocción. En cuanto al dato de consumo eléctrico, se ha contabilizado en los datos generales de planta de fabricación de baldosas.

Tabla A2.12 Entradas y salidas agregadas en la fabricación de $1 \mathrm{~m}^{2}$ de gres porcelánico

\section{Datos generales de planta de fabricación de baldosas}

\section{Entradas}

\section{Materia}

Agua de red $\left(1 / \mathrm{m}^{2}\right)$

Agua de pozo $\left(l / \mathrm{m}^{2}\right)$

Lodos y fangos ${ }^{(1)}\left(1 / \mathrm{m}^{2}\right)$

5,79

\section{Energía}

Electricidad comprada $\left(\mathrm{MJ} / \mathrm{m}^{2}\right)$

Electricidad vendida $\left(\mathrm{MJ} / \mathrm{m}^{2}\right)$

8,80

0,45 
Tabla A2.12 Entradas y salidas agregadas en la fabricación de $1 \mathrm{~m}^{2}$ de gres porcelánico

\section{Datos generales de planta de fabricación de baldosas}

\section{Salidas}

\section{Emisiones atmosféricas (mg)}

Partículas de corrientes de aspiración $\left(\mathrm{mg} / \mathrm{m}^{2}\right)$ 678,21

\section{Agua}

Agua residual no reintroducida en el proceso $\left(1 / \mathrm{m}^{2}\right)$

Aguas residuales que se vierten a alcantarillado (\%)

Aguas residuales que se vierten a cauce público (\%)

\section{Analítica de aguas residuales}

\begin{tabular}{|l|c|}
\hline DBO vertidos $\left(\mathrm{mg} / \mathrm{m}^{2}\right)$ & 6,15 \\
\hline DQO vertidos $\left(\mathrm{mg} / \mathrm{m}^{2}\right)$ & 16,73 \\
\hline Sólidos en suspensión vertidos $\left(\mathrm{mg} / \mathrm{m}^{2}\right)$ & 3,04 \\
\hline Zinc vertidos $\left(\mathrm{mg} / \mathrm{m}^{2}\right)$ & $2,15 \mathrm{E}-02$ \\
\hline Fosfatos vertidos $\left(\mathrm{mg} / \mathrm{m}^{2}\right)$ & $4,40 \mathrm{E}-01$ \\
\hline Metales pesados vertidos $\left(\mathrm{mg} / \mathrm{m}^{2}\right)$ & $6,15 \mathrm{E}-03$ \\
\hline
\end{tabular}

(1) los fangos y lodos se generan en la limpieza de las líneas de esmaltado, molino de preparación de materias primas, pulido de piezas, etc. Generalmente, las aguas con suspensiones cerámicas sufren un proceso de físico-químico y tanto el agua como el rechazo se introduce como materia prima.

Tabla A2.13 Características de la fase de distribución del gres porcelánico.

\begin{tabular}{|l|l|l|l|c|}
\hline Distribución del gres porcelánico \\
\hline Destino & Distancia & Tipo Transporte & $\begin{array}{l}\text { Origen del } \\
\text { combustible* }\end{array}$ & Porcentaje \\
\hline España & $500 \mathrm{~km}$ & Camión 27t (Euro 6) & España & $22 \%$ \\
\hline Europa & $2000 \mathrm{~km}$ & Camión 27t (Euro 6) & Media Europea & $15 \%$ \\
\hline Resto del mundo & $5000 \mathrm{~km}$ & Carguero & Internacional & $63 \%$ \\
\hline
\end{tabular}


Tabla A2.14 Escenarios para la gestión de los residuos de envases y embalajes

\begin{tabular}{|c|c|c|c|}
\hline \multicolumn{4}{|c|}{ Gestión de los residuos de envases y embalajes del gres porcelánico } \\
\hline & España & Europa & Resto del mundo \\
\hline \multicolumn{4}{|l|}{ Papel y cartón } \\
\hline Incineración (\%) & 6 & 2 & 20 \\
\hline Reciclaje (\%) & 63 & 74 & 10 \\
\hline Vertedero (\%) & 31 & 24 & 70 \\
\hline \multicolumn{4}{|l|}{ Plásticos } \\
\hline Incineración (\%) & 14 & 26 & 20 \\
\hline Reciclaje (\%) & 20 & 27 & 10 \\
\hline Vertedero (\%) & 66 & 47 & 70 \\
\hline \multicolumn{4}{|l|}{ Madera } \\
\hline Incineración (\%) & 47 & 20 & 20 \\
\hline Reciclaje (\%) & 44 & 38 & 50 \\
\hline Vertedero (\%) & 9 & 42 & 30 \\
\hline
\end{tabular}

Tabla A2.15 Entradas y salidas en la colocación de $1 \mathrm{~m}^{2}$ de gres porcelánico

\begin{tabular}{|l|l|}
\hline Colocación \\
\hline Entradas \\
\hline Materia & 22,1 \\
\hline Baldosa embalada $\left(\mathrm{kg} / \mathrm{m}^{2}\right)$ & 3,5 \\
\hline Mortero adhesivo $\left(\mathrm{kg} / \mathrm{m}^{2}\right)$ & 0,88 \\
\hline Agua para el adhesivo $\left(\mathrm{kg} / \mathrm{m}^{2}\right)$ & \multicolumn{2}{|}{} \\
\hline Salidas & 26,1 \\
\hline Producto & $1,55 \mathrm{E}-01$ \\
\hline Baldosa colocada $\left(\mathrm{kg} / \mathrm{m}^{2}\right)$ & $1,52 \mathrm{E}-02$ \\
\hline Residuos & \\
\hline Cartón $\left(\mathrm{kg} / \mathrm{m}^{2}\right)$ & \\
\hline Film de polietileno $\left(\mathrm{kg} / \mathrm{m}^{2}\right)$ & \\
\hline Fleje $\left(\mathrm{kg} / \mathrm{m}^{2}\right)$ & $5,09 \mathrm{E}-03$ \\
\hline Palé de un solo uso $\left(\mathrm{kg} / \mathrm{m}^{2}\right)$ & $3,37 \mathrm{E}-01$ \\
\hline Palé reutilizable $\left(\mathrm{kg} / \mathrm{m}^{2}\right)$ &
\end{tabular}


Tabla A2.16 Escenario para el mantenimiento

\begin{tabular}{|l|c|}
\hline Mantenimiento & Uso residencial \\
\hline Agua $\left(\mathrm{l} / \mathrm{m}^{2}\right)$ & 0,1 \\
\hline Detergente $\left(\mathrm{kg} / \mathrm{m}^{2}\right)$ & $1,90 \mathrm{E}-05$ \\
\hline Distancia de la fábrica del detergente $(\mathrm{km})$ & 100 \\
\hline Frecuencia de lavado (veces/semana) & 1 \\
\hline
\end{tabular}

Tabla A2.17 Escenario de gestión del fin de vida del gres porcelánico

\begin{tabular}{|l|c|}
\hline Gestión del fin de vida & Valores \\
\hline Transporte de los residuos (km) & 50 \\
\hline Reciclaje (\%) & 70 \\
\hline Vertedero (\%) & 30 \\
\hline
\end{tabular}




\subsection{Anexo 3. Descripción del modelo de ACV de baldosas cerámicas}

En esta sección, se describe el modelo de ACV de baldosas cerámicas desarrollado con el software GaBi (Thinkstep AG, 2018a).

El ciclo de vida de las baldosas cerámicas se ha modelizado sobre un total de 30 planos, cada uno de ellos compuestos por procesos conectados mediante flujos. Estos planos están jerarquizados y contectados entre sí mediante flujos, es decir, hay planos que son utilizados como elementos dentro de otros planos (véase Figura A3.1). Los procesos que componen los planos están definidos mediante sus flujos de entrada y salida de materia y energía. Los flujos se definen mediante su magnitud y unidad de medida.

En las Figura A3.5 - A3.13 se presentan los planos principales del ciclo de vida de las baldosas cerámicas.

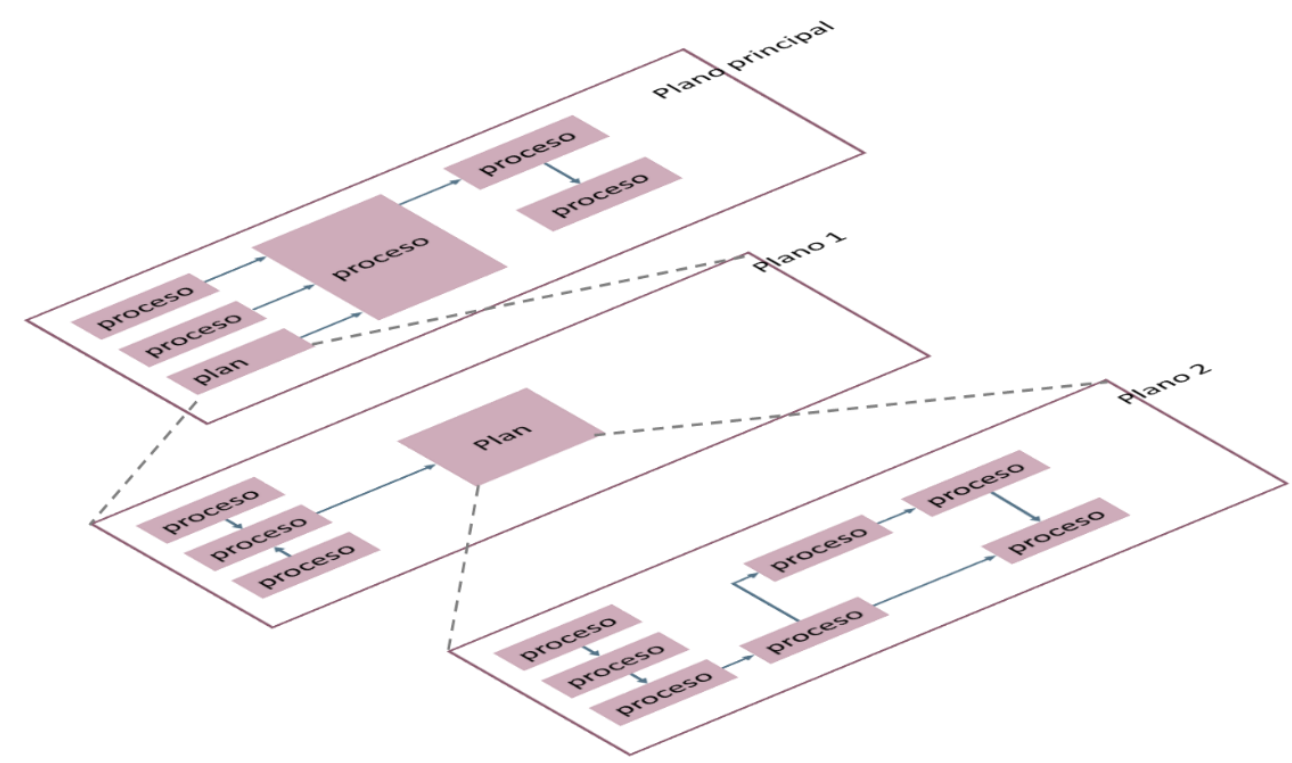

Figura A3.1 Organización jerárquica de los planos en el software de GaBi (elaboración propia a partir de GiGa$\left.\mathrm{ESCl}^{4}\right)$

\footnotetext{
${ }^{4}$ Curso de formación de GaBi impartido por GiGa-ESCl, 2010
} 
Los planos del ciclo de vida de las baldosas cerámicas se han diseñado empleando tres tipos de procesos:

- Procesos genéricos procedentes de bases de datos, los cuales contienen ya los flujos predefinidos, es decir, las entradas y salida de materia y energía desde la extracción de las materias primas hasta su uso en el sistema de estudio. Ejemplos de este tipo de proceso en el ACV de baldosas son: energía térmica procedente de gas natural (en MJ), transporte por carretera en un camión de $27 \mathrm{t}$ (en $\mathrm{kg} \cdot \mathrm{km}$ ), gasóleo (en $\mathrm{kg}$ ), depósito de residuos inertes en vertedero (en $\mathrm{kg}$ ), etc. (Véase una captura de pantalla como ejemplo en la Figura A3.2)

- Procesos definidos específicamente para el ciclo de vida de las baldosas cerámicas. En en su mayoría son procesos unitarios, en los cuales se han definido los flujos, es decir, las entradas y salida de materia y energía de dicho proceso. (Véase una captura de pantalla como ejemplo en la Figura A3.3).

- Procesos de decisión para la elección de alternativas tecnológicas y su grado de implementación, definidos específicamente para el ciclo de vida de las baldosas cerámicas. Por ejemplo: porcentaje de las materias primas preparadas por vía seca o por vía húmeda; porcentaje de los residuos que se reciclan o se depositan en vertedero, etc. (Véase una captura de pantalla como ejemplo en la Figura A3.4).

Con la finalidad de utilizar los mismos procesos y planos, pero con configuraciones diferentes para poder analizar diferentes escenarios de forma robusta y consistente a lo largo del proyecto de investigación, se recomienda el uso de parámetros. Los parámetros son flujos que pueden ser pre-escritos en el comando de GaBi parameter explorer sin tener que cambiar el proceso o el plano original y sin necesidad de modificar otras instancias del proceso.

El uso de parámetros en GaBi hace que la modelización inicial sea más complicada, pero ofrece más opciones de cambio y permite plantear diferentes escenarios para analizar, dotándolo de esta manera, de la flexibilidad suficiente para escoger las alternativas de proceso o de escenarios definidos en las estrategias planteadas, manteniendo la consistencia a lo largo del trabajo de investigación. 
EU-28: Thermal energy from natural gas ts [Thermal energy from natural gas] -- BD Procesos

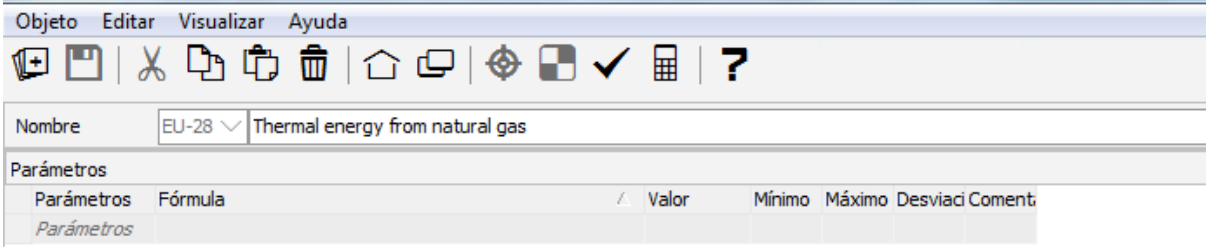

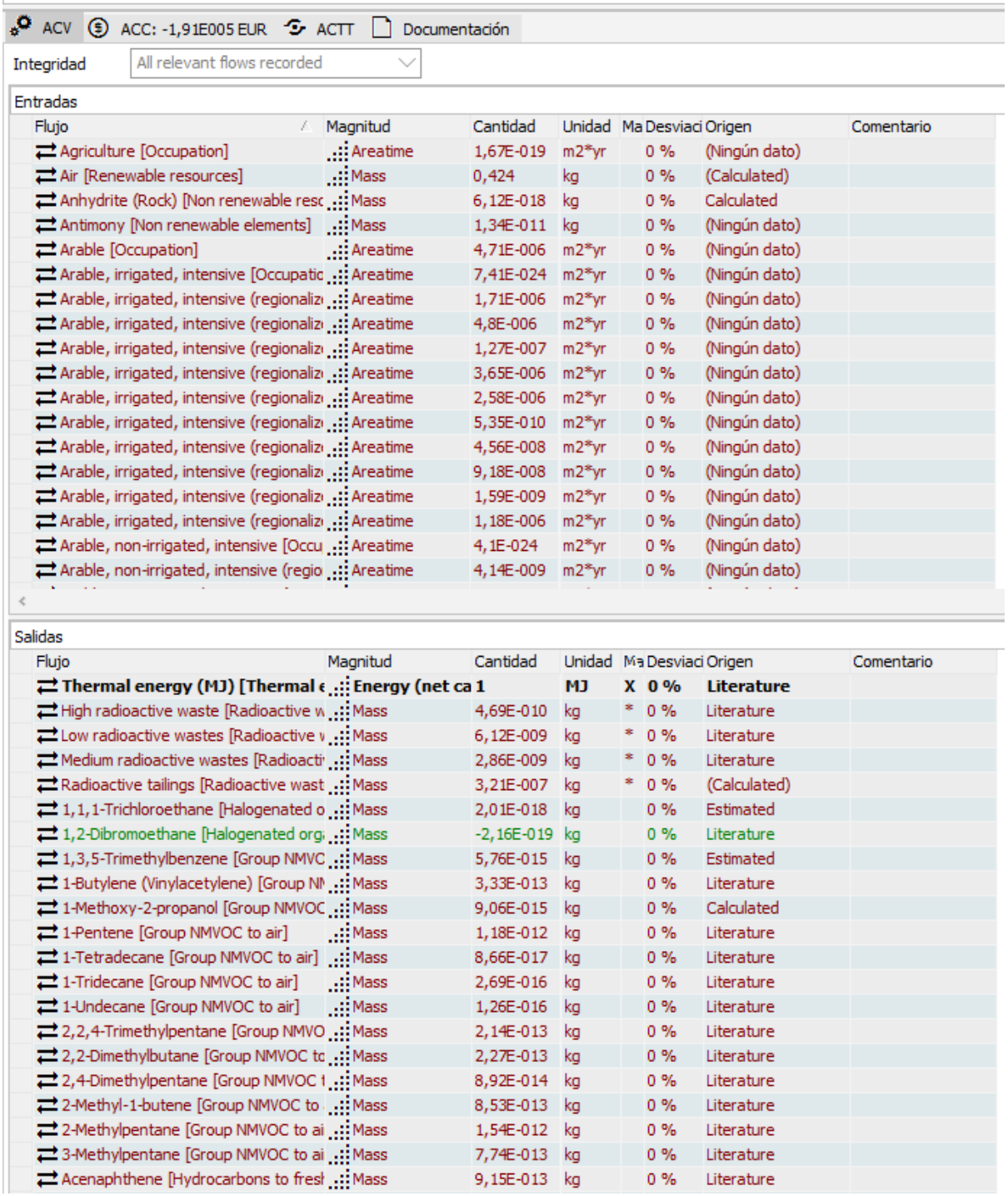

Figura A3.2 Ejemplo de proceso contenido en la Base de Datos de GaBi (Thinkstep AG, 2018b): "Thermal Energy from Natural Gas" 


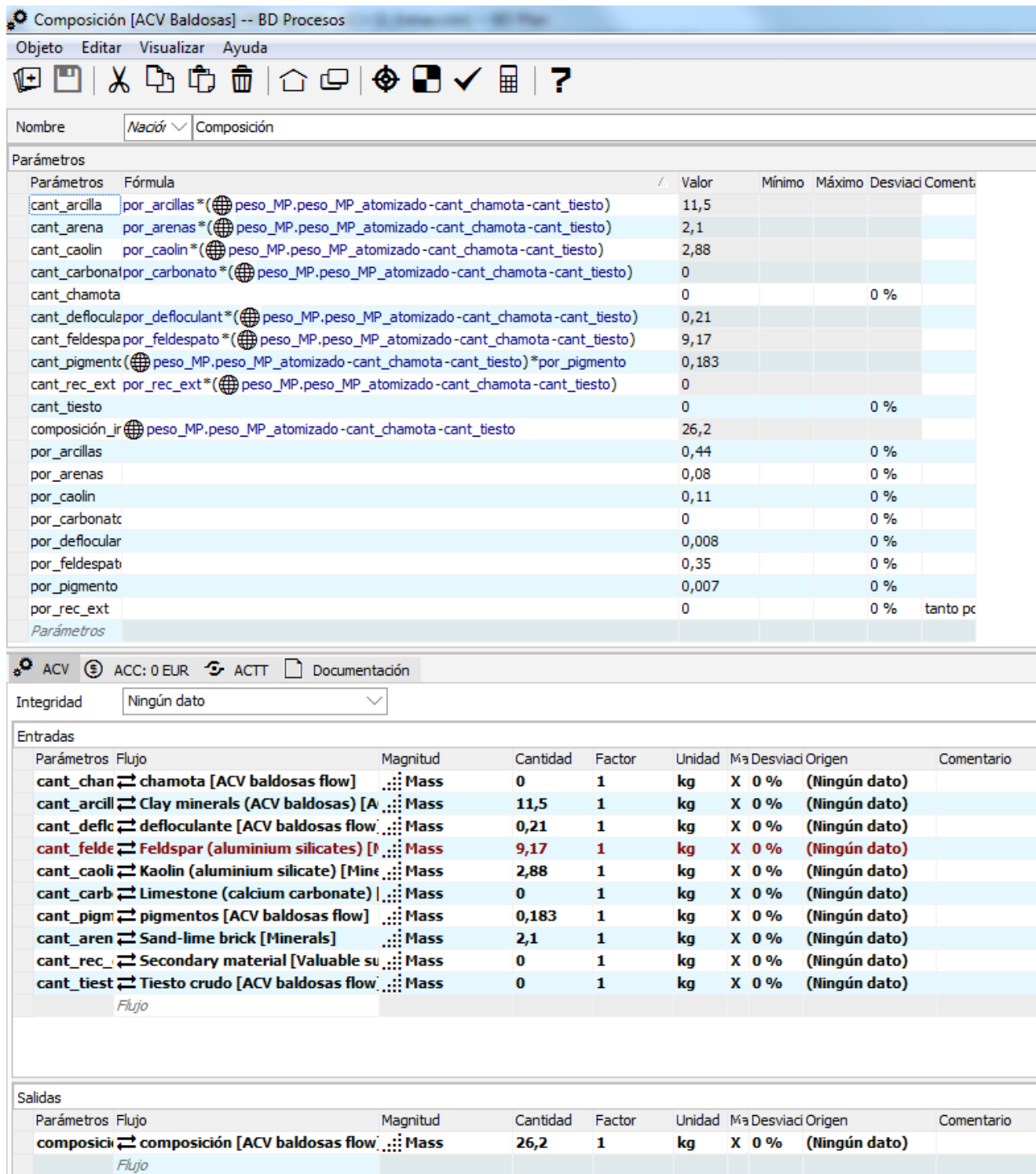

\begin{tabular}{l|l} 
System: Ninguna modificac & Ultima modificación: System01/03/2013 8:42:52 GUID: $\{5$ DFBCC94-4F7A-4A24-8458-DEBB326FEB3F\}
\end{tabular}

Figura A3.3 Ejemplo de proceso parametrizado de elaboración propia específico del ciclo de vida de las baldosas cerámicas: "Composición del soporte cerámico" 


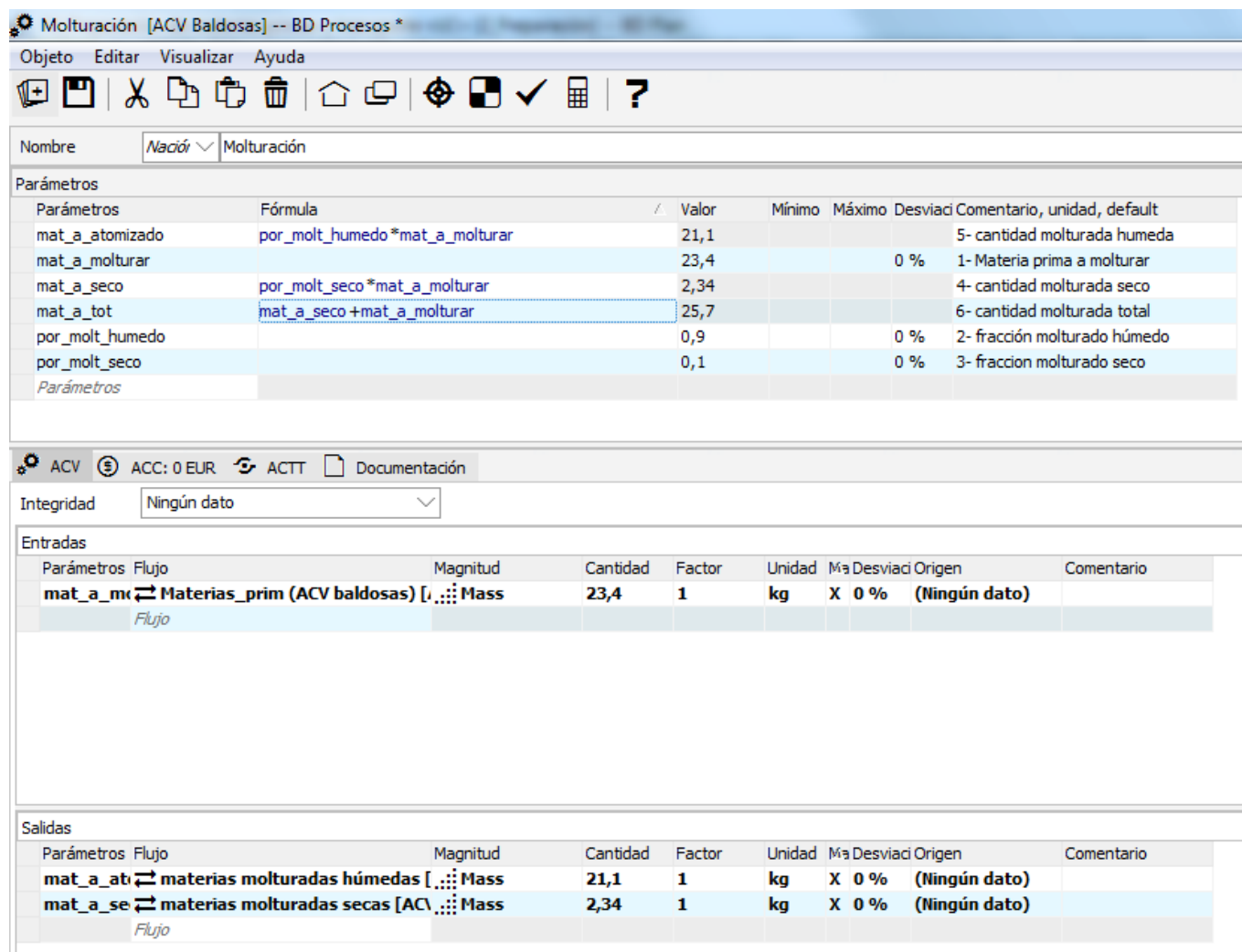

Figura A3.4 Ejemplo de proceso parametrizado de decisión para la elección de alternativas tecnológicas y su grado de implementación. Proceso de elaboración propia específico del ciclo de vida de las baldosas cerámicas 


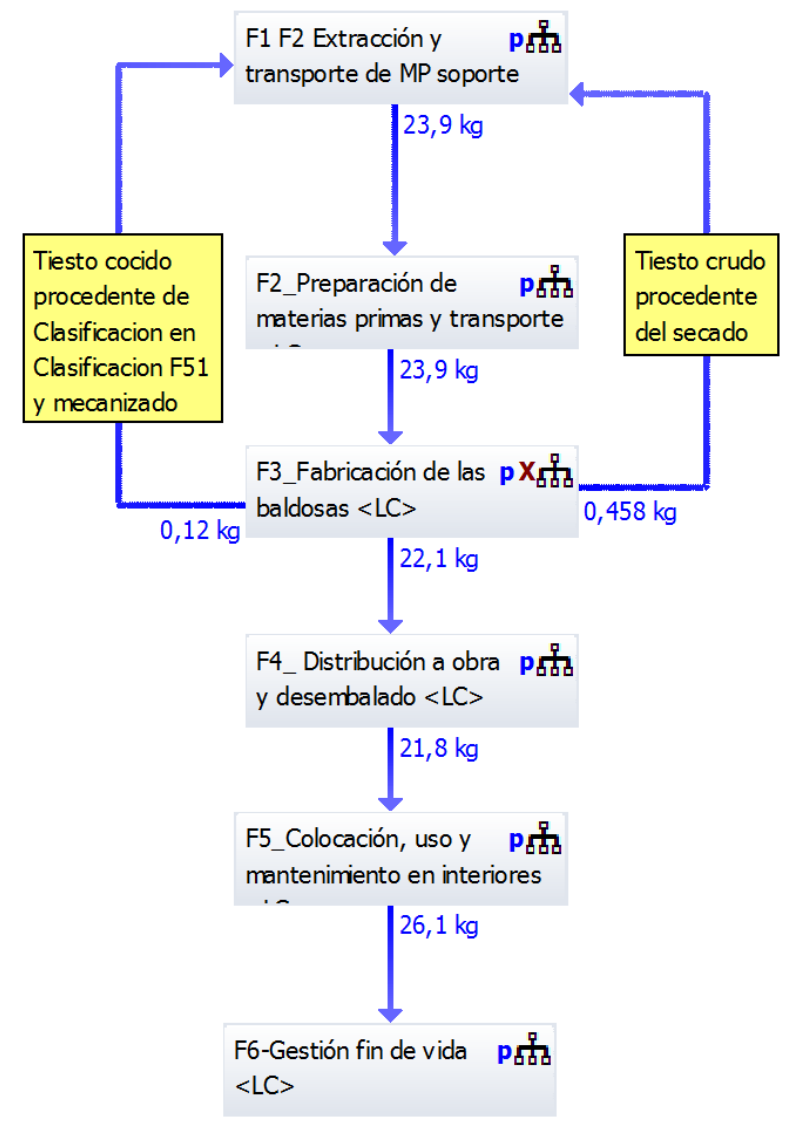

Figura A3.5 Plano principal que recoge las etapas del ciclo de vida del gres porcelánico 


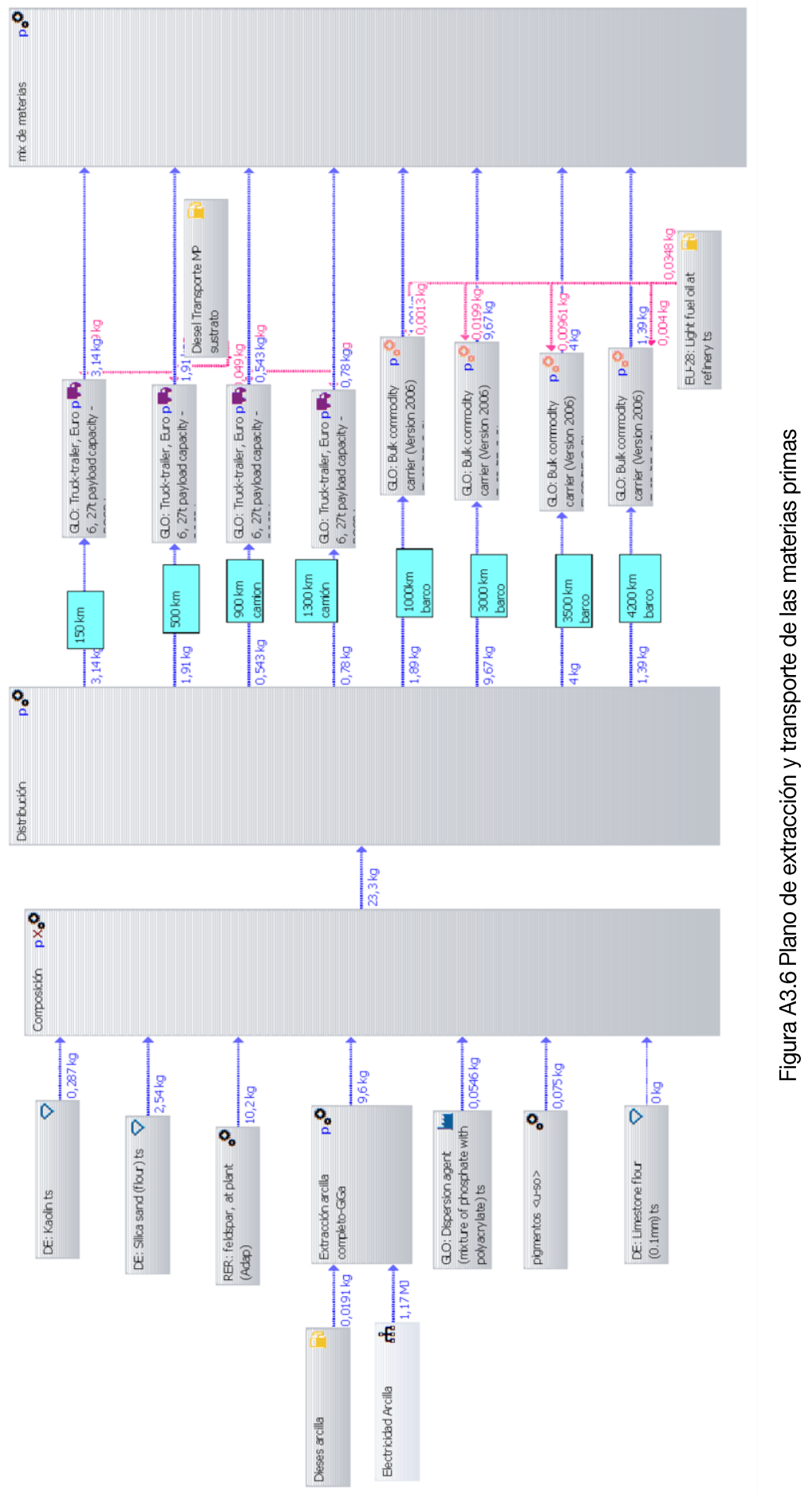




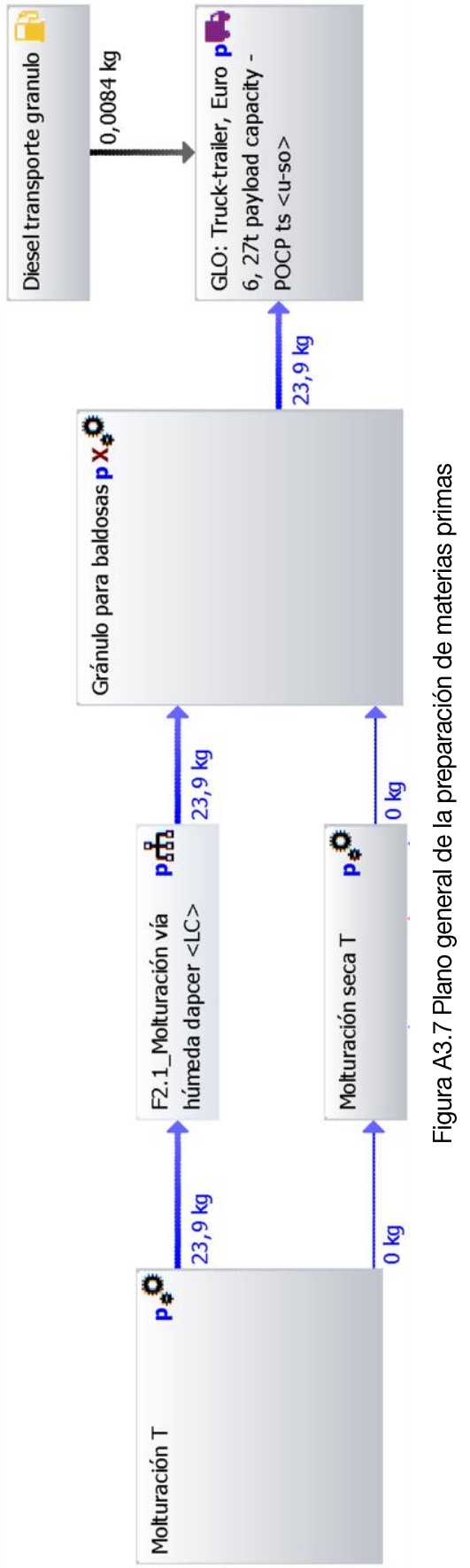




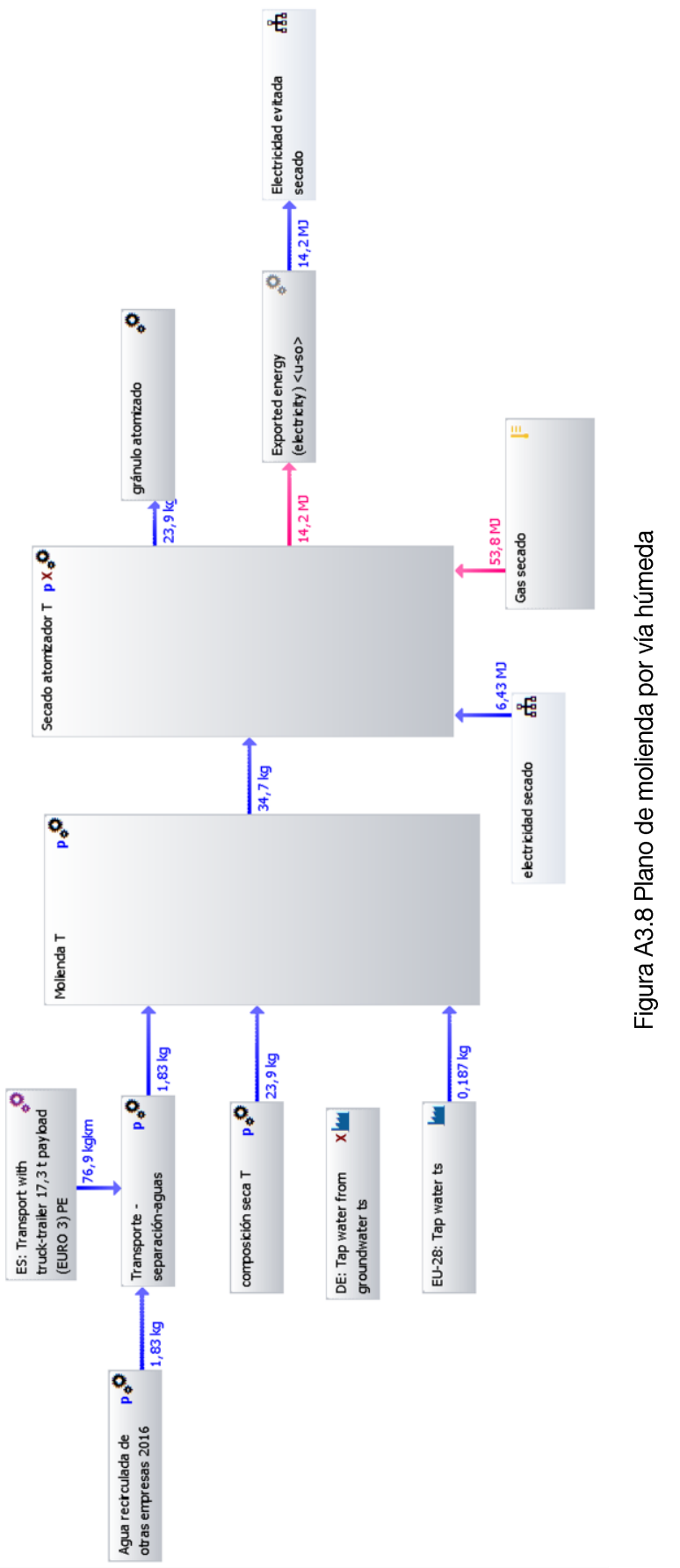




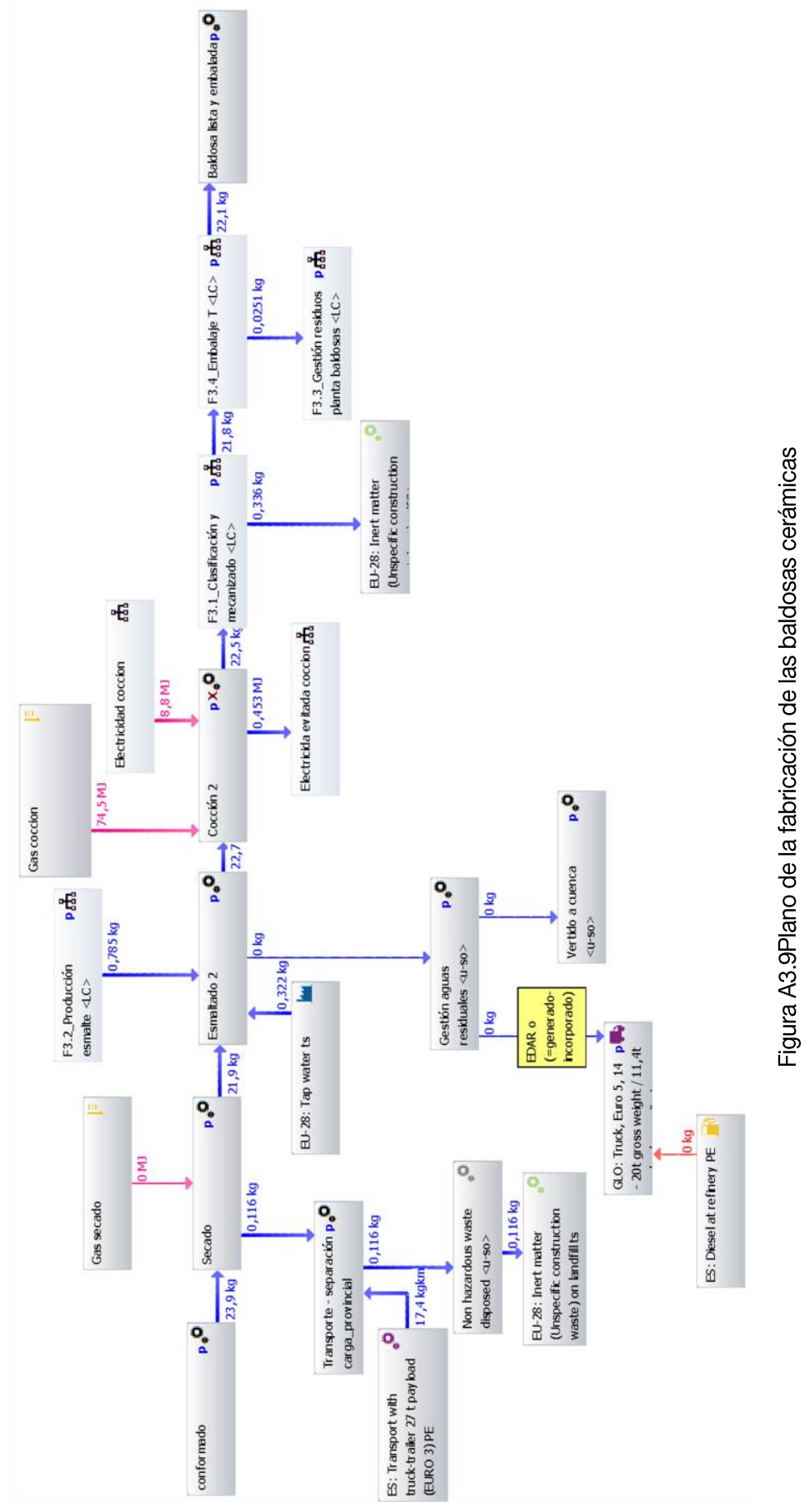




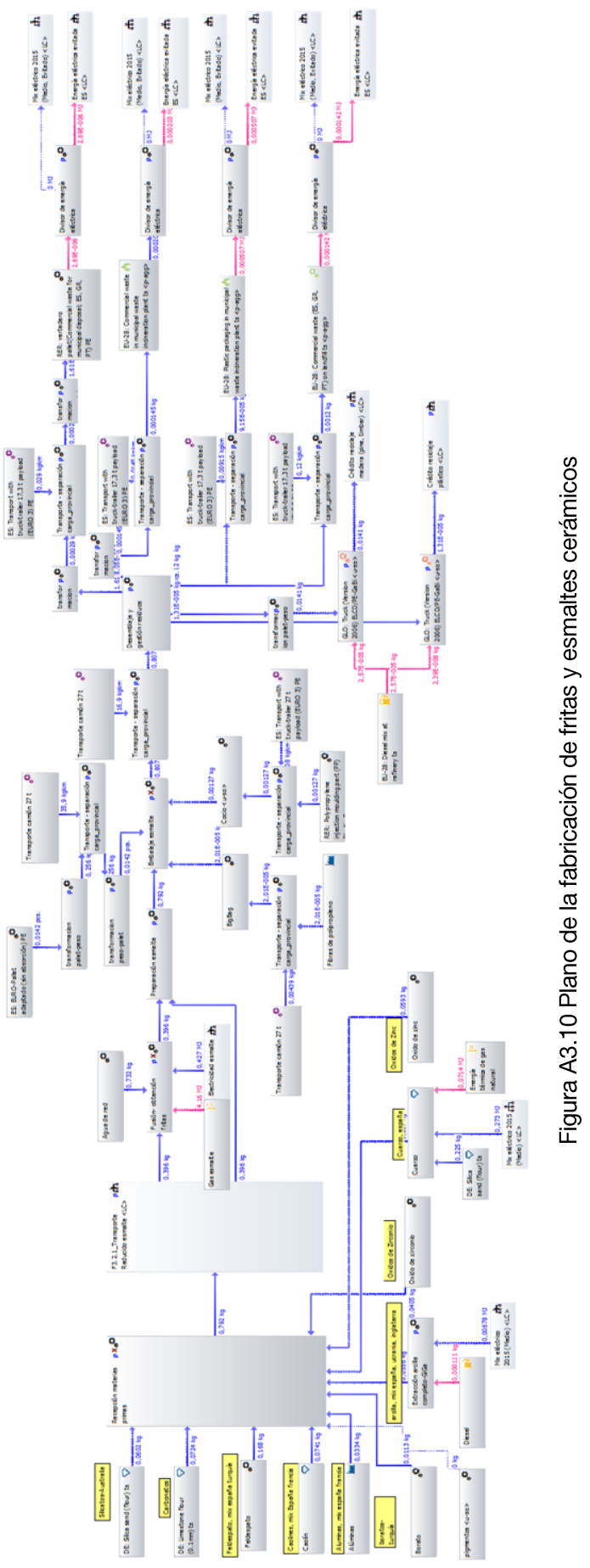




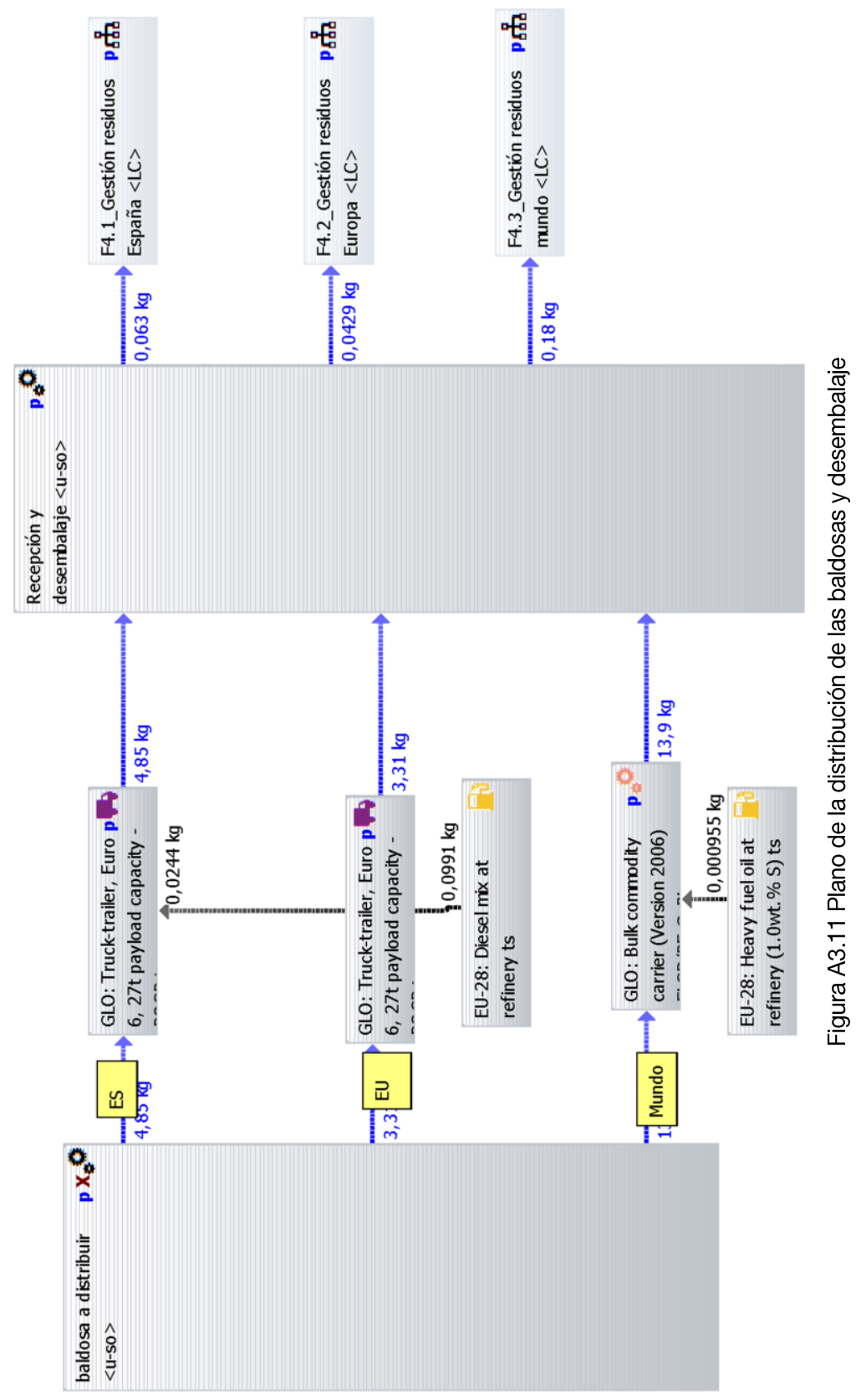




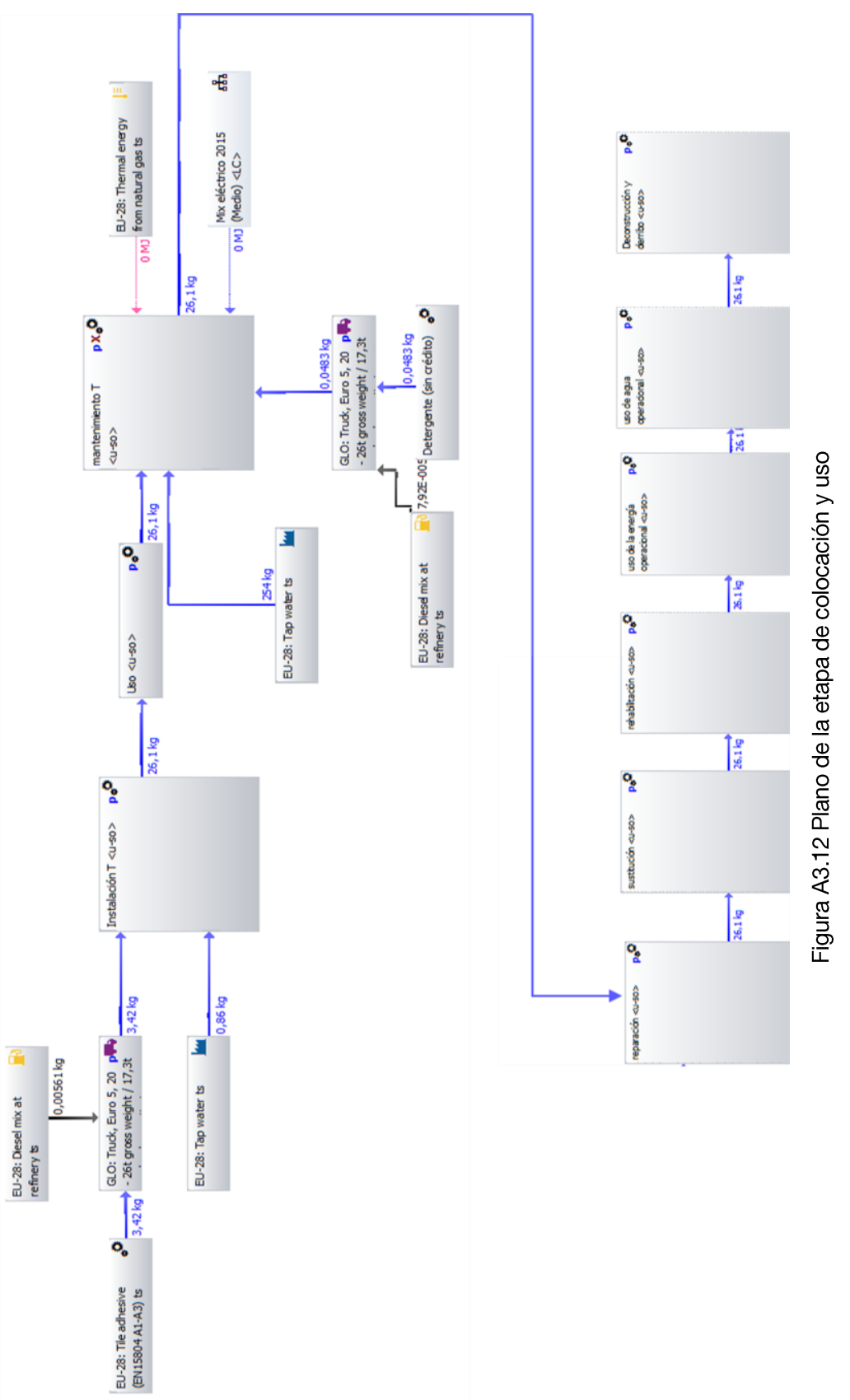




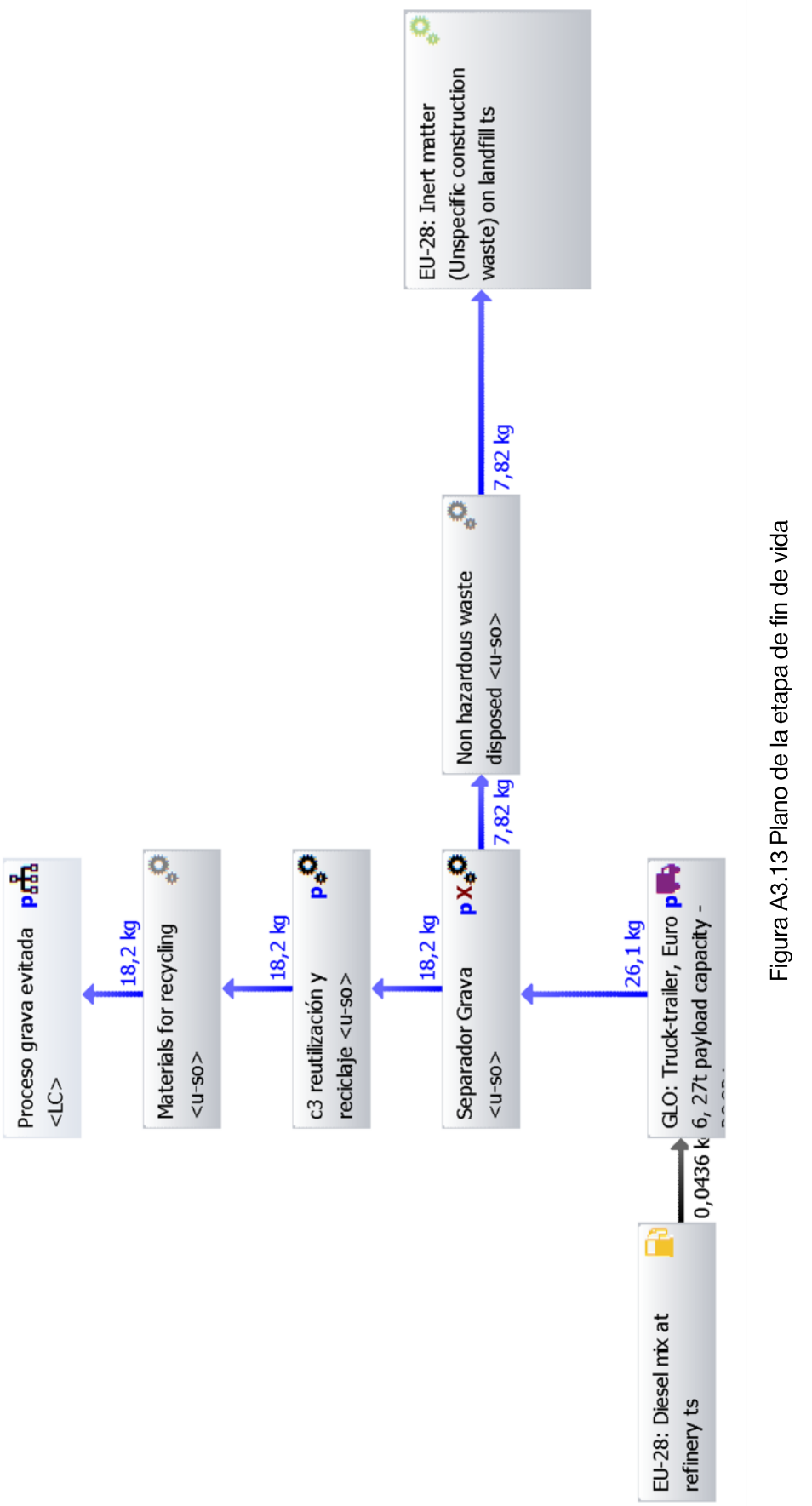


10.4. Anexo 4. Permiso de los coautores y coautoras 


\section{IINUNESTST JAUME I}

Escola de Doctorat · ED

Vicente Agost Alcón, com a coautor dono la meua autorització a Teresa Ros Dosdá per a la presentació de les següents publicacions com a part de la seua tesi doctoral.

Relació de publicacions:

- Beltrán A., Celades I., Corrales J., Mira J., Muñoz A., Rioja A., Ros, T. Agost V. SOLCONCER, a helpful tool for characterising construction solutions. XIV Global Forum of Ceramic Tile. QUALICER Castellón 8-9 February, 2016. Chamber of Commerce, Services, Navigation and Industry of Castellón, Spain.

També renuncio a poder utilitzar aquestes publicacions com a part d'una altra tesi doctoral.

I perquè conste, signe aquest document,

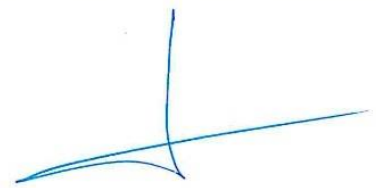

Castellón, 27 de mayo de 2019

Tot això, atenent a l'article 23 de la Normativa dels Estudis de Doctorat, regulats pel RD 99/2011, a la Universitat Jaume I (Aprovada pel Consell de Govern núm. 19 de 26 de Gener de 2012, modificada pel Consell de Govern núm. 29 de 27 de Novembre de 2012 i amb posterior modificació pel Consell de Govern núm. 37 de 25 de Juliol de 2013):

"(...)

"Aquelles tesis doctorals que opten per la incorporació d'articles (compendi de publicacions) han d'ajustar-se, en la mesura que siga possible, a l'estructura següent: Introducció / objectius - Un capitol per article incorporat - Discussió general dels resultats - Conclusions. -Acceptació dels coautors que el doctorand presenta el treball com a tesi i renúncia expressa d'aquests a presentar-lo com a part d'una altra tesi doctoral." 


\section{UNIVERSITAT \\ JAUMEI}

Escola de Doctorat . ED

(Nom) Jaume Adriả Alberola Borràs com a coautor / coautora dono la meua autorització a (Nom del doctorand/doctoranda) Teresa Ros Dosdá per a la presentació de les següents publicacions com a part de la seua tesi doctoral.

Relació de publicacions:

Ros-Dosda, T., Celades, I., Alberola, J.A., Monfort E. (2019) CerCO2 - The $\mathrm{CO}_{2}$ Emission Simulation Tool for the Ceramic Industry. Ceramic Forum International, 96, 29-35

Ros-Dosda, T., Celades, 1., Alberola, J.A. (2017). CerCO2, herramienta de simulación de emisiones de $\mathrm{CO}_{2}$ para la industria cerámica. Técnica Cerámica, 438, 170-175

També renuncio a poder utilitzar aquestes publicacions com a part d'una altra tesi doctoral.

I perquè conste, signe aquest document,

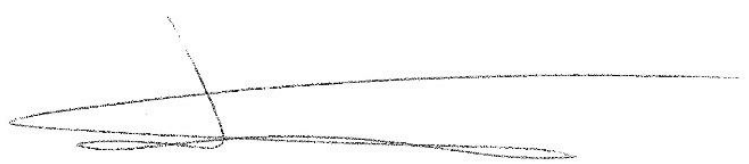

Castelló de la Plana, 15 de març de 2019

Signatura, lloc i data

Tot això, asenent a larticle 23 de la Normativa dels Estudis de Doctoras, regulats pel RD 99/2011, a la Universitat Jaume I Gaprovada pel Consell de Govern núm, 19 de 26 de Gener de 2012, modificada pel Consell de Govern num. 29 de 27 de Novembre de 20121 amb posterior modificació pel Consell de Govern núm. 37 de 25 de Juliol de 2013 )

"(...)

"Aquelies tesis doctorals que opten per la incorporació danicles (compendi de publicacions) han d'aiustar-se, en la mesura que siga possible, a l'estructura següenti introducció / objectius - Un capito per anticle incomorat - Discussio general dels resultats - Conclusions. -Acceptacio dels coautors que of doctorand presonta of troball com a tesi i renuncia exprossa d'aquests a presentar-jo com a pant dina altra tesi doctoral. " 


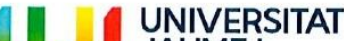 \\ JAUME I}

Escola de Doctorat $\cdot$ ED

Alfredo Beltrán González, com a coautor dono la meua autorització a Teresa Ros Dosdá per a la presentació de les següents publicacions com a part de la seua tesi doctoral.

Relació de publicacions:

Beltrán A., Celades I., Corrales J., Mira J., Muñoz A., Rioja A., Ros, T. Agost V. SOLCONCER, a helpful tool for characterising construction solutions. XIV Global Forum of Ceramic Tile.

QUALICER Castellón 8-9 February, 2016. Chamber of Commerce, Services, Navigation and Industry of Castellón, Spain.

També renuncio a poder utilitzar aquestes publicacions com a part d'una altra tesi doctoral.

I perquè conste, signe aquest document,

Castelló, 28 de Maig de 2019

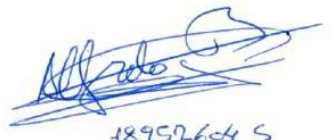

189576045

Tot això, atenent a l'article 23 de la Normativa dels Estudis de Doctorat, regulats pel RD 99/2011, a la Universitat Jaume I (Aprovada pel Consell de Govern núm. 19 de 26 de Gener de 2012, modificada pel Consell de Govern núm. 29 de 27 de Novembre de 2012 i amb posterior modificació pel Consell de Govern núm. 37 de 25 de Juliol de 2013):

"(...)

"Aquelles tesis doctorals que opten per la incorporació d'articles (compendi de publicacions) han d'ajustar-se, en la mesura que siga possible, a l'estructura següent: Introducció / objectius - Un capitol per article incorporat - Discussió general dels resultats - Conclusions. -Acceptació dels coautors que el doctorand presenta el treball com a tesi i renúncia expressa d'aquests a presentar-lo com a part d'una altra tesi doctoral." 


\section{A UNIVERSITAT JAUME I}

Escola de Doctorat - ED

Irina Celades López, com a coautora dono la meua autorització a Teresa Ros Dosdá per a la presentació de les següents publicacions com a part de la seua tesi doctoral.

Relació de publicacions:

- Ros-Dosdá, T., Celades, I., Monfort, E., Fullana-i-Palmer, P., 2018. Environmental profile of Spanish porcelain stoneware tiles. Int. J. Life Cycle Assess. 23, 1562-1580. https://doi.org/10.1007/s11367-017-1377-9

- Ros-Dosdá, T., Celades, I. Sanfelix, V., Gomar, S, Monfort E. Strategic Environmental Communication Tools. XIII Global Forum of Ceramic Tile. QUALICER14. Castellón 18 February, 2014. Chamber of Commerce, Services, Navigation and Industry of Castellón, Spain.

- Beltrán A., Celades I., Corrales J., Mira J., Muñoz A., Rioja A., Ros, T. Agost V. SOLCONCER, a helpful tool for characterising construction solutions. XIV Global Forum of Ceramic Tile. QUALICER Castellón 8-9 February, 2016. Chamber of Commerce, Services, Navigation and Industry of Castellón, Spain.

- Ros-Dosda, T., Celades I., Alberola J.A., Monfort E, 2019, $\mathrm{CerCO}_{2}$ - The $\mathrm{CO}_{2}$ Emission Simulation Tool for the Ceramic Industry. Ceramic Forum International, 96, 29-35

- Ros-Dosdá, T., Celades, I., Vilalta, L., Fullana-i-Palmer, P., \& Monfort, E. (2019). Environmental comparison of indoor floor coverings. Science of The Total Environment. 693,133519

També renuncio a poder utilitzar aquestes publicacions com a part d'una altra tesi doctoral.

I perquè conste, signe aquest document

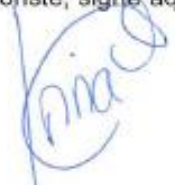

Castelló, 25 de Octubre de 2019

Tot això, atenent a larticle 23 de la Normativa dels Estudis de Doctorat, regulats pel RD 99/2011, a la Universitat Jaume I (Aprovada pel Consell de Govern núm. 19 de 26 de Gener de 2012, modificada pel Consell de Govem núm. 29 de 27 de Novembre de 2012 i amb posterior modificació pel Consell de Govern núm. 37 de 25 de Juliol de 2013).

(...)

"Aquelles tesis doctorals que opten per la incorporació d"articles (compendi de publicacions) han d'ajustar-se, on la mosura que siga possible, a l'estructura seguent: introducció / objectius - Un capitol per article incorporat - Discussió general dels resultats - Conclusions. Acceptació dels coautors que el doctorand presenta ol troball com a tesi i renúncia expressa d'aquests a presentar-to com a part duuna altra tesi doctoral. " 


\section{UNIVERSITAT}

JAUME I

Escola de Doctorat · ED

Jorge Corrales García, com a coautor dono la meua autorització a Teresa Ros Dosdá per a la presentació de les següents publicacions com a part de la seua tesi doctoral.

Relació de publicacions:

Beltrán A., Celades I., Corrales J., Mira J., Muñoz A., Rioja A., Ros, T. Agost V. SOLCONCER, a helpful tool for characterising construction solutions. XIV Global Forum of Ceramic Tile.

QUALICER Castellón 8-9 February, 2016. Chamber of Commerce, Services, Navigation and Industry of Castellón, Spain.

També renuncio a poder utilitzar aquestes publicacions com a part d'una altra tesi doctoral.

I perquè conste, signe aquest document,

Castelló, 28 de Maig de 2019

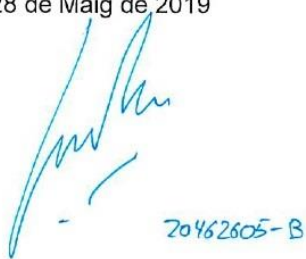

Tot això, atenent a l'article 23 de la Normativa dels Estudis de Doctorat, regulats pel RD 99/2011, a la Universitat Jaume I (Aprovada pel Consell de Govern núm. 19 de 26 de Gener de 2012, modificada pel Consell de Govern núm. 29 de 27 de Novembre de 2012 i amb posterior modificació pel Consell de Govern núm. 37 de 25 de Juliol de 2013):

"(...)

"Aquelles tesis doctorals que opten per la incorporació d'articles (compendi de publicacions) han d'ajustar-se, en la mesura que siga possible, a l'estructura següent: Introducció / objectius - Un capitol per article incorporat - Discussió general dels resultats - Conclusions. -Acceptació dels coautors que el doctorand presenta el treball com a tesi i renúncia expressa d'aquests a presentar-lo com a part d'una altra tesi doctoral. " 


\section{I UNVEESTIAT \\ JAUME I}

Escola de Doctorat · ED

Pere Fullana i Palmer, com a coautor dono la meua autorització a Teresa Ros Dosdá per a la presentació de les següents publicacions com a part de la seua tesi doctoral.

Relació de publicacions:

- Ros-Dosdá, T., Celades, I., Monfort, E., Fullana-i-Palmer, P., 2018. Environmental profile of Spanish porcelain stoneware tiles. Int. J. Life Cycle Assess. 23, 1562-1580. https://doi.org/10.1007/s11367-017-1377-9

- Ros-Dosdá, T., Fullana-i-Palmer, P., Mezquita, A., Masoni, P., Monfort, E., 2018. How can the European ceramic tile industry meet the EU's low-carbon targets? A life cycle perspective. J. Clean. Prod. 199, 554-564. https://doi.org/https://doi.org/10.1016/j.jclepro.2018.07.176

- Ros-Dosdá, T., Celades, I., Vilalta, L., Fullana-i-Palmer, P., \& Monfort, E. (2019). Environmental comparison of indoor floor coverings. Science of The Total Environment, $693,133519$.

També renuncio a poder utilitzar aquestes publicacions com a part d'una altra tesi doctoral.

I perquè conste, signe aquest document,

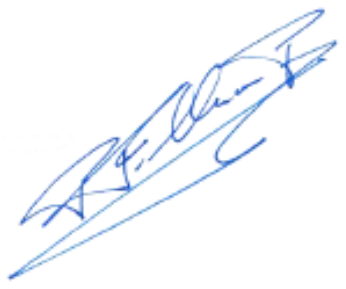

Barcelona, 25 de Octobre de 2019

Tot això, atenent a larticle 23 de la Normativa dels Estudis de Doctorat, regulats pel RD 99/2011, a la Universitat Jaume I (Aprovada pel Consell de Govern núm. 19 de 26 de Gener de 2012, modificada pel Consell de Govern núm. 29 de 27 de Novembre de 2012 i amb posterior modificació pel Consell de Govern núm. 37 de 25 de Juliol de 2013):

"(...)

"Aquelles tesis doctorals que opten per la incorporació d'articles (compendi de publicacions) han d'ajustar-se, en la mesura que siga possible, a l'estructura següent: Introducció / objectius - Un capitol per article incorporat - Discussió general dels resultats - Conclusions. -Acceptació dels coautors que el doctorand presenta el treball com a tesi i renúncia expressa d'aquests a presentar-lo com a part d'una altra tesi doctoral. " 
UNIVERSITAT

Escola de Doctorat $\cdot$ ED

Salvador Gomar Peiró, com a coautor, dono la meua autorització a Teresa Ros Dosdá per a la presentació de les següents publicacions com a part de la seua tesi doctoral.

Relació de publicacions:

Ros-Dosdá, T., Celades, I. Sanfelix, V., Gomar, S., Monfort E. Strategic Environmental Communication Tools. XIII Global Forum of Ceramic Tile. QUALICER14. Castellón 18 February, 2014. Chamber of Commerce, Services, Navigation and Industry of Castellón, Spain.

També renuncio a poder utilitzar aquestes publicacions com a part d'una altra tesi doctoral.

I perquè conste, signe aquest document,

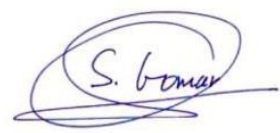

Castelló, 27 de Maig de 2019

\footnotetext{
Tot això, atenent a l'article 23 de la Normativa dels Estudis de Doctorat, regulats pel RD 99/2011, a la Universitat Jaume I (Aprovada pel Consell de Govern núm. 19 de 26 de Gener de 2012, modificada pel Consell de Govern núm. 29 de 27 de Novembre de 2012 i amb posterior modificació pel Consell de Govern núm. 37 de 25 de Juliol de 2013):

"(...)

"Aquelles tesis doctorals que opten per la incorporació d'articles (compendi de publicacions) han d'ajustar-se, en la mesura que siga possible, a l'estructura següent: Introducció / objectius - Un capitol per article incorporat - Discussió general dels resultats - Conclusions. -Acceptació dels coautors que el doctorand presenta el treball com a tesi i renúncia expressa d'aquests a presentar-lo com a part d'una altra tesi doctoral.
} 


\section{UNIVERSITAT
JAUMEI}

Escola de Doctorat · ED

Bologna, 1 October 2018

1. Paolo MASONI, hereby authorise Teresa Ros Dosdá, to include the articles listed below in her doctoral thesis. In addition, I undertake not to use those articles as part of any other doctoral thesis.

List of articles:

Ros-Dosdá, T., Fullana-i-Palmer, P., Mezquita, A., Masoni, P., \& Monfort, E. (2018). How can the Ros-Dosdá, T., Fullana-i-Palmer, P., Mezquita, A., Cleaner Production, 199, 554-564. https://doi.org/10.1016/i.jclepro.2018.07.176

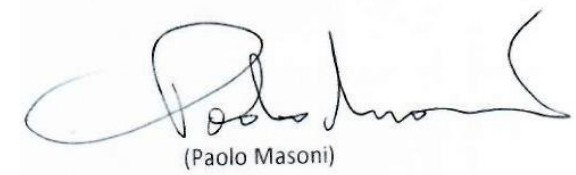

Ing. Paolo Masoni

Via A. Pertini 7

40033 Casalecchio di Reno (BO)

Italy

Paolo.masoni53.pm@gmail.com

In accordance with article 23 of the Regulation of Doctoral Studies, regulated by RD 99/2011, at the Universitat Jaume I (Approved by the Governing Council No. 19 of January 26, 2012, modified by the Governing Council no. 29 f November 27, 2012 and subsequent amendment by the Governing Council No. 37 of July 25, 2013):"(...)

"Those doctoral theses that opt for the incorporation of articles (compendium of publications) must include............ Acceptance of the co-authors that the doctoral student presents the work as a thesis and express renunciation of these to present it as part of another doctoral thesis" 


\section{UNIVERSITAT \\ JAUME I \\ Escola de Doctorat $\cdot$ ED}

Ana Mezquita Martí, com a coautora dono la meua autorització a Teresa Ros Dosdá per a la presentació de les següents publicacions com a part de la seua tesi doctoral.

Relació de publicacions:

Ros-Dosdá, T., Fullana-i-Palmer, P., Mezquita, A., Masoni, P., Monfort, E., 2018. How can the European ceramic tile industry meet the EU's low-carbon targets? A life cycle perspective. J. Clean. Prod. 199, 554-564. https://doi.org/https://doi.org/10.1016/j.jclepro.2018.07.176

També renuncio a poder utilitzar aquestes publicacions com a part d'una altra tesi doctoral.

I perquè conste, signe aquest document,

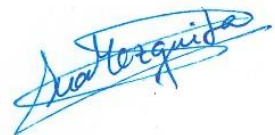

Castelló, 28 de Maig de 2019

Tot això, atenent a l'article 23 de la Normativa dels Estudis de Doctorat, regulats pel RD 99/2011, a la Universitat Jaume I (Aprovada pel Consell de Govern núm. 19 de 26 de Gener de 2012, modificada pel Consell de Govern núm. 29 de 27 de Novembre de 2012 i amb posterior modificació pel Consell de Govern núm. 37 de 25 de Juliol de 2013):

"(...)

"Aquelles tesis doctorals que opten per la incorporació d'articles (compendi de publicacions) han d'ajustar-se, en la mesura que siga possible, a l'estructura següent: Introducció / objectius - Un capitol per article incorporat - Discussió general dels resultats - Conclusions. -Acceptació dels coautors que el doctorand presenta el treball com a tesi i renúncia expressa d'aquests a presentar-lo com a part d'una altra tesi doctoral." 


\section{(1) II UNIVESSTIAT \\ JAUME}

Escola de Doctorat $\cdot$ ED

Francisco Javier Mira Peidro, com a coautor dono la meua autorització a Teresa Ros Dosdá per a la presentació de les següents publicacions com a part de la seua tesi doctoral.

Relació de publicacions:

Beltrán A., Celades I., Corrales J., Mira J., Muñoz A., Rioja A., Ros, T. Agost V. SOLCONCER, a helpful tool for characterising construction solutions. XIV Global Forum of Ceramic Tile.

QUALICER Castellón 8-9 February, 2016. Chamber of Commerce, Services, Navigation and Industry of Castellón, Spain.

També renuncio a poder $\mu$ tilitzar aquestes publicacions com a part d'una altra tesi doctoral.

I perquè conste, signe aquest document,

Castelló, 28 de Maig de 2019

$21634370-\mathrm{H}$

Tot això, atenent a l'article 23 de la Normativa dels Estudis de Doctorat, regulats pel RD 99/2011, a la Universitat Jaume I (Aprovada pel Consell de Govern núm. 19 de 26 de Gener de 2012, modificada pel Consell de Govern núm. 29 de 27 de Novembre de 2012 i amb posterior modificació pel Consell de Govern núm. 37 de 25 de Juliol de 2013):

"(...)

"Aquelles tesis doctorals que opten per la incorporació d'articles (compendi de publicacions) han d'ajustar-se, en la mesura que siga possible, a l'estructura següent: Introducció / objectius - Un capitol per article incorporat - Discussió general dels resultats - Conclusions. -Acceptació dels coautors que el doctorand presenta el treball com a tesi i renúncia expressa d'aquests a presentar-lo com a part d'una altra tesi doctoral. " 


\section{UNIVERSITAT \\ JAUME I}

Escola de Doctorat · ED

Eliseo Monfort Gimeno, com a coautor dono la meua autorització a Teresa Ros Dosdá per a la presentació de les següents publicacions com a part de la seua tesi doctoral.

Relació de publicacions:

- Ros-Dosdá, T., Celades, I., Monfort, E., Fullana-i-Palmer, P., 2018. Environmental profile of Spanish porcelain stoneware tiles. Int. J. Life Cycle Assess. 23, 1562-1580. https://doi.org/10.1007/s11367-017-1377-9

- Ros-Dosdá, T., Celades, I. Sanfelix, V., Gomar, S., Monfort E. Strategic Environmental Communication Tools. XIII Global Forum of Ceramic Tile. QUALICER14. Castellón 18 February, 2014. Chamber of Commerce, Services, Navigation and Industry of Castellón, Spain.

- Ros-Dosdá, T., Fullana-i-Palmer, P., Mezquita, A., Masoni, P., Monfort, E., 2018. How can the European ceramic tile industry meet the EU's low-carbon targets? A life cycle perspective. J. Clean. Prod. 199, 554-564.

https://doi.org/https://doi.org/10.1016/j.jclepro.2018.07.176

- Ros-Dosda, T., Celades I., Alberola J.A., Monfort E., 2019. $\mathrm{CerCO}_{2}$ - The $\mathrm{CO}_{2}$ Emission Simulation Tool for the Ceramic Industry. Ceramic Forum International, 96, 29-35

- Ros-Dosdá, T., Celades, I., Vilalta, L., Fullana-i-Palmer, P., \& Monfort, E. (2019). Environmental comparison of indoor floor coverings. Science of The Total Environment, $693,133519$.

També renuncio a poder utilitzar aquestes publicacions com a part d'una altra tesi doctoral.

I perquè conste, signe aquest document,

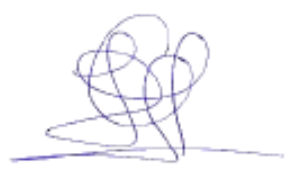

Castelló, 25 de Octobre de 2019

Tot això, atenent a larticle 23 de la Normativa dels Estudis de Doctorat, regulats pel RD 99/2011, a la Universitat Jaume I (Aprovada pel Consell de Govern núm. 19 de 26 de Gener de 2012, modificada pel Consell de Govern núm. 29 de 27 de Novembre de 2012 i amb posterior modificació pel Consell de Govern núm. 37 de 25 de Juliol de 2013):

(...)

"Aquelles tesis doctorals que opten per la incorporació d'articles (compendi de publicacions) han d'ajustar-se, en la mesura que siga possible, a l'estructura següent: Introducció / objectius - Un capitol per article incorporat - Discussió general dels resultats - Conclusions. -Acceptació dels coautors que el doctorand presenta el treball com a tesi i renúncia expressa d'aquests a presentar-lo com a part d'una altra tesi doctoral. " 
IIII UNWESTSTIT

JAUME I

Escola de Doctorat $\cdot$ ED

Adoración Muñoz Lázaro, com a coautora dono la meua autorització a Teresa Ros Dosdá per a la presentació de les següents publicacions com a part de la seua tesi doctoral.

Relació de publicacions:

Beltrán A., Celades I., Corrales J., Mira J., Muñoz A., Rioja A., Ros, T. Agost V. SOLCONCER, a helpful tool for characterising construction solutions. XIV Global Forum of Ceramic Tile.

QUALICER Castellón 8-9 February, 2016. Chamber of Commerce, Services, Navigation and Industry of Castellón, Spain.

També renuncio a poder utilitzar aquestes publicacions com a part d'una altra tesi doctoral.

I perquè conste, signe aquest document,

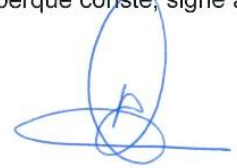

Castelló, 28 de Maig de 2019

Tot això, atenent a l'article 23 de la Normativa dels Estudis de Doctorat, regulats pel RD 99/2011, a la Universitat Jaume I (Aprovada pel Consell de Govern núm. 19 de 26 de Gener de 2012, modificada pel Consell de Govern núm. 29 de 27 de Novembre de 2012 i amb posterior modificació pel Consell de Govern núm. 37 de 25 de Juliol de 2013):

"(...)

"Aquelles tesis doctorals que opten per la incorporació d'articles (compendi de publicacions) han d'ajustar-se, en la mesura que siga possible, a l'estructura següent: Introducció / objectius - Un capito per article incorporat - Discussió general dels resultats - Conclusions. -Acceptació dels coautors que el doctorand presenta el treball com a tesi i renúncia expressa d'aquests a presentar-lo com a part d'una altra tesi doctoral. 
UNIVERSITAT

Escola de Doctorat · ED

Ana Rioja Castellano com a coautor / coautora dono la meua autorització a Teresa Ros Dosdá per a la presentació de les següents publicacions com a part de la seua tesi doctoral.

Relació de publicacions:

-Beltrán A., Celades I., Corrales J., Mira J., Muñoz A., Rioja A., Ros, T. Agost V. SOLCONCER, a helpful tool for characterising construction solutions. XIV Global Forum of Ceramic Tile. QUALICER Castellón 8-9 February, 2016. Chamber of Commerce, Services, Navigation and Industry of Castellón, Spain.

També renuncio a poder utilitzar aquestes publicacions com a part d'una altra tesi doctoral.

I perquè conste, signe aquest document,

Signatura, lloc i data

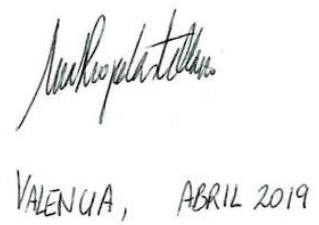

Tot això, atenent a l'article 23 de la Normativa dels Estudis de Doctorat, regulats pel RD 99/2011, a la Universitat Jaume I (Aprovada pel Consell de Govern núm. 19 de 26 de Gener de 2012, modificada pel Consell de Govern núm. 29 de 27 de Novembre de 2012 i amb posterior modificació pel Consell de Govern núm. 37 de 25 de Juliol de 2013):

"(...

"Aquelles tesis doctorals que opten per la incorporació d'articles (compendi de publicacions) han d'ajustar-se, en la mesura que siga possible, a l'estructura següent: Introducció / objectius - Un capitol per article incorporat - Discussió general dels resultats - Conclusions. -Acceptació dels coautors que el doctorand presenta el treball com a tesi i renúncia expressa d'aquests a presentar-lo com a part d'una altra tesi doctoral. 


\section{UNIVERSITAT \\ JAUME I}

Escola de Doctorat $\cdot$ ED

Vicenta Sanfélix Forner, com a coautora, dono la meua autorització a Teresa Ros Dosdá per a la presentació de les següents publicacions com a part de la seua tesi doctoral.

Relació de publicacions:

Ros-Dosdá, T., Celades, I. Sanfelix, V., Gomar, S., Monfort E. Strategic Environmental Communication Tools. XIII Global Forum of Ceramic Tile. QUALICER14. Castellón 18 February 2014. Chamber of Commerce, Services, Navigation and Industry of Castellón, Spain.

També renuncio a poder utilitzar aquestes publicacions com a part d'una altra tesi doctoral.

I perquè conste, signe aquest document,

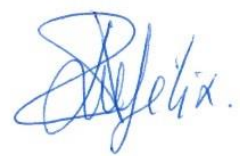

Castelló, 28 de Maig de 2019

Tot això, atenent a l'article 23 de la Normativa dels Estudis de Doctorat, regulats pel RD 99/2011, a la Universitat Jaume I (Aprovada pel Consell de Govern núm. 19 de 26 de Gener de 2012, modificada pel Consell de Govern núm. 29 de 27 de Novembre de 2012 i amb posterior modificació pel Consell de Govern núm. 37 de 25 de Juliol de 2013)

"(...)

"Aquelles tesis doctorals que opten per la incorporació d'articles (compendi de publicacions) han d'ajustar-se, en la mesura que siga possible, a l'estructura següent: Introducció / objectius - Un capitol per article incorporat - Discussió general dels resultats - Conclusions. -Acceptació dels coautors que el doctorand presenta el treball com a tesi i renúncia expressa d'aquests a presentar-lo com a part d'una altra tesi doctoral. " 


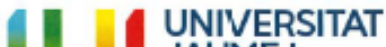 \\ JAUME I}

Escola de Doctorat ED

Laura Vilalta Ibáñez, com a coautor dono la meua autorització a Teresa Ros Dosdá per a la presentació de les segūents publicacions com a part de la seua tesi doctoral.

Relació de publicacions:

- Ros-Dosdá, T., Celades, I., Vilalta, L., Fullana-i-Palmer, P., \& Monfort, E. (2019).

Environmental comparison of indoor floor coverings. Science of The Total Environment, $693,133519$.

També renuncio a poder utilitzar aquestes publicacions com a part d'una altra tesi doctoral.

I perquè conste, signe aquest document,

Castelló, 25 de Oct.jore de 2019

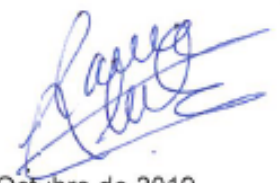

Tot aixó, atenent a l'a ticle 23 de la Normativa dels Estudis de Doctorat, regulats pel RD 99/2011, a la Universitat Jaume I (Aprovada pel Consell de Govern núm. 19 de 26 de Gener de 2012, modificada pel Consell de Govern ním. 29 de 27 de Novembre de 2012 i amb posterior modificació pel Consell de Govern núm. 37 de 25 de Juliol de 2013):

"(...)

"Aquelles tesis doctora/s que opten per la incorporació d"articles (compendi de publicacions) han d'ajustar-se, en la mesura que siga possible, a l'estructura següent: Introducció / objectius - Un capitol oer article incorporat - Discussió general dels resultats - Conclusions. -Acceptació dels coautors que ef doctorand presenta e.' treball com a tesi i renúncia expressa d'aquests a presentar-jo com a parf d'una aitra tesi doctoral." 


\subsection{Anexo 5. Listado de acrónimos}

\subsubsection{Acrónimos de los capítulos 1, 2, 3, 5, 6 y 7}

7PMA: Séptimo Programa de Acción en Materia de Medio Ambiente de la Unión Europea

AAl: Autorización Ambiental Integrada

ACV: Análisis de Ciclo de Vida

ADPE: Potencial de agotamiento de recursos abióticos para recursos no fósiles

ADPF: Potencial de agotamiento de recursos abióticos para recursos fósiles

AP: Potencial de acidificación del suelo y de los recursos de agua

BREF: Best available techniques Reference Documents

BREEAM: Building Research Establishment Environmental Assessment Method (certificado de construcción sostenible)

CCS: Captura y almacenamiento de carbono (por sus siglas en inglés Carbon Capture and Storage)

CTT: Tecnologías actuales para la eficiencia energética térmica

DAP: Declaración Ambiental de Producto

DRY: Molienda vía seca de las materias primas

EMAS: Sistema Comunitario de Gestión y Auditoría Ambiental

EP: Potencial de eutrofización

GBC: Green Building Council

GEI: Gases de Efecto Invernadero

GL: Describe la cantidad de esmalte: 100\% (cantidad promediada); 50\% (mitad de la cantidad promediada); 0\% (sin esmaltar)

GWP: Potencial de calentamiento global

LAM: Sistemas de suelos con recubrimiento de laminados

LCIA: Life Cycle Impact Assessment

LEED: Leadership in Energy \& Environmental Design (certificado de construcción sostenible)

LER: Lista Europea de Residuos 
LUN: Gres porcelánico de bajo espesor, sin esmaltar ni mecanizar

$\mathbf{M m}^{2}$; M€: Millones de m2; millones de euros

MTD: Mejores Técnicas Disponibles

NG: Describe las fuentes de energía térmica: gas natural al 100\%, 50\% ० 0\%

NS: Sistemas de suelos con recubrimientos de piedra natural

ODP: Potencial de agotamiento de la capa de ozono

ONU: Organización de las Naciones Unidas

POCP: Potencial de formación de ozono troposférico (formación de ozono fotoquímico)

PST: Baldosas cerámicas de gres porcelánico

PST-HGM: Gres porcelánico de elevado espesor, esmaltado y mecanizado

PVC: Policloruro de vinilo

PVC: Policloruro de vinilo

RCP: Reglas de Categoría de Producto

REN: Energía eléctrica a partir de fuentes renovables

SGA: Sistema de Gestión Ambiental

SGM: Mix eléctrico español

TEX: Moqueta sintética

TH: Describe el espesor del soporte de las baldosas cerámicas: 100\% (espesor medio); 50\% (mitad del espesor medio)

UE: Unión Europea

WCS: Preparación de las materias primas por vía húmeda, con sistemas de cogeneración instalados en el secadero por atomización

WD: Sistemas de suelos con recubrimientos de parquet

WDS: Tecnologías ampliamente conocidas de eficiencia energética térmica 


\subsubsection{Acrónimos del capítulo 4}

\section{Environmental Profile of Spanish Porcelain Stoneware Tiles}

A: Average performance, weighted by the production of all thicknesses, patterns, and finishes

A1: Life cycle stage: Raw Materials Supply

A2: Life cycle stage: Transport of Raw Materials

A3: Life cycle stage: Manufacturing

A4: Life cycle stage: Transport to the building

A5: Life cycle stage: Installation into the building

AAA: Average thickness, average quantity of glaze, and average mechanical treatments

ADP elements: Abiotic Depletion-elements

ADP fossil: Abiotic Depletion-fossil fuels

AGM: Average thickness, glazed, and mechanised

AGN: Average thickness, glazed, and non-mechanised

AP: Acidification Potential

ASCER: The Spanish Ceramic Tile Manufacturers' Association

AUM: Average thickness, unglazed, and mechanised

AUN: Average thickness, unglazed, and non-mechanised

B1: Life cycle stage: Use

B2: Life cycle stage: Maintenance

B3: Life cycle stage: Repair

B4: Life cycle stage: Replacement

B5: Life cycle stage: Refurbishment

B6: Life cycle stage: Operational energy use

B7: Life cycle stage: Operational water use

C1: Life cycle stage: Deconstruction and demolition

C2: Life cycle stage: Transport 
C3: Life cycle stage: Reuse, recovery, and recycling

C4: Life cycle stage: Disposal

CML: The Institute of Environmental Sciences (CML), Faculty of Science of Leiden University, The Netherlands

Dwt: Dead weight tonnage

$\mathbf{E}_{\mathbf{b}}$ : Water absorption

EN: European Standard

EP: Eutrophication Potential

EPD: Environmental Product Declaration

Eq.: Equivalent

ERDF: European Regional Development Fund

ET: Earthenware Tile

EU-28: European Union

FU: Functional Unit

G: Glazed

GST: Glazed Stoneware Tile

GWP: Global Warming Potential (100 years)

H: High thickness

HAA: High thickness, average quantity of glaze, and average mechanical treatments

HGM: High thickness, glazed, and mechanised

HGN: High thickness, glazed, and non-mechanised

HUM: High thickness, unglazed, and mechanised

HUN: High thickness, unglazed, and non-mechanised

ISO: The International Organization for Standardization

IVACE: Institut Valencià de Competitivitat Empresarial

L: Low thickness

LAA: Low thickness, average quantity of glaze, and average mechanical treatments 
LCA: Life Cycle Assessment

LCI: Life Cycle Inventory Analysis

LCIA: Life Cycle Impact Assessment

LGM: Low thickness, glazed, and mechanised

LGN: Low thickness, glazed, and non-mechanised

LUM: Low thickness, unglazed, and mechanised

LUN: Low thickness, unglazed, and non-mechanised

M: Mechanised

N: Non-mechanised

ODP: Ozone Layer Depletion Potential (steady state)

PCR: Product Category Rules

PM: Particulate matter

$\mathbf{P M}_{10}$ : Particles which pass through a size-selective inlet with a $50 \%$ efficiency cut-off at $10 \mu \mathrm{m}$ aerodynamic diameter. PM10 corresponds to the "thoracic convention" as defined in ISO 7708:1995, Clause 6

POCP: Photochemical Ozone Creation Potential

PST: Porcelain Stoneware Tile

Q2: $50^{\text {th }}$ percentile

SD: Standard Deviation

SPGM: Spanish Power Grid Mix

U: Unglazed

UK: United Kingdom 


\section{Environmental Communication Tools}

ANSI: American National Standards Institute

ASCER: Spanish Ceramic Tile Manufacturers' Association

BREEAM: Building Research Establishment Environmental Assessment Method

EPD: Environmental Product Declaration

ITC: Instituto de Tecnología Cerámica

LCA: Life Cycle Assessment

LEED: Leadership in Energy \& Environmental Design

PCR: Product Category Rules

TCNA: The Tile Council of North America 


\section{Environmental Comparison of Indoor Floor Coverings}

ADPE: Abiotic depletion potential for non-fossil resources

ADPF: Abiotic depletion potential for fossil resources

AP: Acidification potential

EP: Eutrophication potential

EPD: Environmental product declaration

FU: Functional unit

GWP: Global warming potential (100 years)

LAM: Laminate

LCA: Life cycle assessment

MSL: Material service life

NS: Natural stone

ODP: Ozone layer depletion potential (steady state)

PA: Polyamide

POCP: Photochemical ozone creation potential

PST: Ceramic tile, mainly porcelain stoneware tile

PVC: Polyvinyl chloride

RSP: Reference study period

TEX: Synthetic carpet

VOC: Volatile organic compound

WD: Multilayer and solid parquet 
SolconCer, a helpful tool for characterising Construction Solutions

CPR: Construction Product Regulations

EOTA: European Organisation for Technical Assessment

ETAG: European Technical Approval Guidelines

PVC: Polyvinyl chloride

TBC: Technical Building Code 
How Can the European Ceramic Tile Industry meet the EU's Low-Carbon Targets? A Life Cycle Perspective

ADP elements: Abiotic Depletion-elements

ADP fossil: Abiotic Depletion-fossil fuels

AP: Acidification Potential

CML: The Institute of Environmental Sciences (CML), Faculty of Science of Leiden University, The Netherlands

$\mathrm{CO}_{2} \mathrm{e}$ : Carbon dioxide equivalent

CS: Combined Heat and Electric Cogeneration System

CTT: Current Technologies for Thermal energy efficiency

DRY: Dry milling of body raw materials

EP: Eutrophication Potential

EPD: Environmental Product Declaration

FU: Functional Unit

GHG: Greenhouse Gases

GL: Describes the quantity of glaze: $100 \%$ (average quantity), $50 \%$ (half the average quantity) or $0 \%$ (unglazed)

GWP: Global Warming Potential (100 years)

LCA: Life Cycle Assessment

NG: Describes the thermal energy sources: Natural Gas 100\%, $50 \%$ or $0 \%$

ODP: Ozone Layer Depletion Potential (steady state)

POCP: Photochemical Ozone Creation Potential

PST: Porcelain Stoneware Tile

REN: Electric energy from Renewable Resources

SGM: Spanish Power Grid Mix

TH: Describes the thickness of the body tile: 100\% (average thickness) and 50\% (thickness reduction by half)

WCS: Wet milling of body raw materials with cogeneration system associated

WDS: Widespread technologies in thermal energy efficiency

WET: Wet milling of body raw materials without cogeneration system associated 


\section{$\mathrm{CerCO}_{2}, \mathrm{CO}_{2}$ Emission Simulation Tool for the Ceramic Industry}

ADP-elements: Abiotic resource depletion potential-elements

ADP-fossil: Abiotic resource depletion potential-fossil fuels

AP: Acidification potential of soil and water

EP: Eutrophication potential

ERDF: European Regional Development Fund

EU: European Union

GHG: Greenhouse gas

GWP: Global warming potential

ITC-AICE: Instituto de Tecnología Cerámica-Asociación de Investigación de las Industrias Cerámicas

LCA: Life Cycle Assessment

ODP: Ozone layer depletion potential

POCP: Photochemical ozone creation potential 